UNIVERSIDAD NACIONAL DE LA PLATA

FACULTAD DE CIENCIAS NATURALES Y MUSEO

\title{
COMPARACIÓN DE LAS DISTINTAS HISTORIAS TAFONÓMICAS EN CONJUNTOS ZOOARQUEOLÓGICOS PROVENIENTES DE LA MESETA CENTRAL DE LA PROVINCIA DE SANTA CRUZ
}

\author{
Lic. Laura Marchionni \\ Director: Dra. Laura L. Miotti \\ Co-director: Dra. María A. Gutiérrez
}

Tesis para optar por el título de Doctor en Ciencias Naturales 2012 
A mis queridos padres Isabel y Daniel

por su apoyo y confianza 


\section{AGRADECIMIENTOS}

Son muchas las personas que me acompañaron durante estos difíciles cinco años haciendo posible mi trabajo y dándome el afecto y respaldo necesario para poder realizar esta tesis.

Quiero agradecer a mi directora Laura Miotti y mi co-directora María Gutiérrez por su constante dirección y apoyo, por haber guiado y enriquecido enormemente mi formación científica y mi trabajo, por sus sugerencias y valiosos aportes a esta investigación y por permitirme crecer y aprender de sus experiencias.

Muy especialmente quiero agradecer a Laura Miotti por permitirme ser parte de su equipo de trabajo y poner las colecciones zooarqueológicas que tanto aprecia a mi entera disposición para su estudio. Quiero agradecerle además, el tiempo y esfuerzo dedicado para responder a cada consulta, pregunta, duda o mail. Pero fundamentalmente quiero agradecerle su constante afecto, apoyo y comprensión que siempre me ayudaron a continuar. Agradezco a su marido Humberto cada cena retrasada por mi presencia.

A mis compañeros y amigos del laboratorio de quienes recibí un apoyo constante durante estos años: Darío, Natalia, Lucía, Rocío, Quique, Brunito, Virginia, Eloisa, Natalia y Franca.

A Martín Vázquez y Miguel Giardina a quienes siempre les estaré agradecida por haberme ayudado descubrir el mundo de la zooarqueológía.

A todos los que participaron de los distintos trabajos de campo: Laura, Darío, Natalia, Lucía, Rocío, Quique, Bruno, Brunito, Virginia, Martín, Jimena, Antonio, Alejandra, Luciana, Mónica, Jorge, Marilén, Fernando, Julieta, Germán, Santiago, Carlita y Elo.

Quiero agradecerle a Bruno Mosquera y Eloisa García Añino quienes colaboraron con el rotulado, ordenamiento de las colecciones y análisis de los materiales faunísticos.

Mi agradecimiento a Darío Hermo por sus lecturas del manuscrito, sus consejos y sugerencias. Especialmente por siempre encontrar la manera de hacerme reír y darme ánimo cada vez que el camino se hizo pesado y duro. 
Quiero además, agradecerle a Lucía Magnín el tiempo y esfuerzo invertido en la realización de todos los mapas y por tomarse el trabajo de traducir del resumen contra reloj.

A Rocío y Quique por ser con quienes compartí cada pequeño momento y etapa de esta tesis y por tomarse el arduo trabajo de edición del manuscrito y completar y revisar toda la bibliografía e índices. En esta tarea también colaboraron Bruno y Eloisa.

Quiero agradecerle a Florencia Gordón la lectura y sugerencias para el capítulo 3 y el trabajo de edición del mismo además de su incansable apoyo en este proceso.

Agradezco el apoyo recibido por CONICET a partir de las dos becas que me fueron otorgadas y que hicieron posible mi dedicación a esta investigación doctoral. Agradezco también a la Facultad de Ciencias Naturales y Museo por haberme brindado el espacio físico de trabajo durante estos años y a los subsidios PI-UNLP N ${ }^{\circ} 550$, PICT 1552 que financiaron los trabajos de campo y análisis realizados.

Agradezco además, el apoyo brindado por la Municipalidad de Pico Truncado, especialmente por Sebastián Toledo, Cacho Alonso e Isabel Peralta, siempre dispuestos a apoyar nuestro trabajo de campo y colaborar en su logística. A nuestros anfitriones en la meseta: Chela, Carlos y Ramón, quienes todos los veranos nos agasajan con su hospitalidad y sus "manjares". A las familias Koprowski y Ferreiro por permitirnos los accesos a sus propiedades y apoyar nuestras investigaciones.

Quiero además agradecer el apoyo de mis grandes amigas con quienes comparto todo lo que no es arqueología, sin su compañía y afecto esta etapa hubiese sido intransitable: Caro, Pino, Yesi, Pau, Flora, Guille, Chizo, Tati, Micho, Vero, Mica, Mai, Mari, Ara, Mechi, Tama, Pili, Flor, Carli, Lau, Caro, Cuchi y Flor.

El gran agradecimiento para mi familia que siempre confió en mí apoyando todos mis proyectos y entendiendo mis ausencias. A mi mamá, por respaldarme siempre y ser un ejemplo constante de fortaleza y esfuerzo; a mi abuela porque con sus 90 años es un ejemplo lleno de vida; a mis hermanos por su generosidad y comprensión, por encontrar siempre la manera de sumar. A mis cuñados por su apoyo constante y a mis sobrinos porque son lo más lindo.

Un agradecimiento especial a Quique, con quién comparto además de la arqueología, un proyecto de vida y familia, sin su amor, comprensión y ayuda constante, nada de esto hubiese sido posible. 


\section{ÍNDICE GENERAL}

ÍNDICE DE FIGURAS.....................................................................................

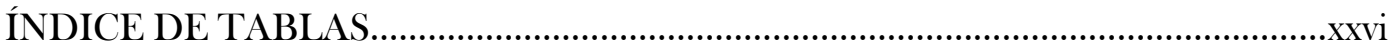

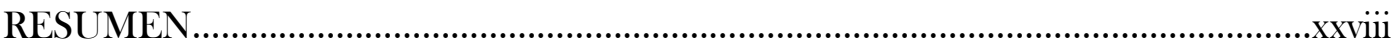

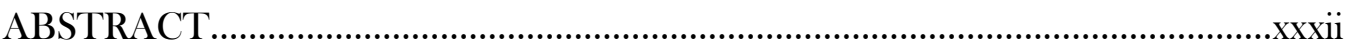

CAPÍTULO 1

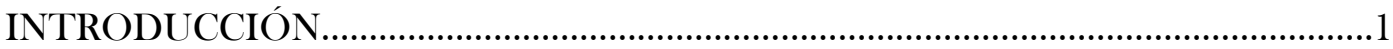

CAPÍTULO 2

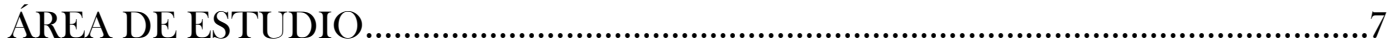

2.1. DEFINICIÓN DEL ÁREA GEOGRÁFICA.........................................................

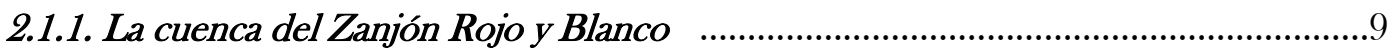

2.2. CARACTERÍSTICAS GEOLÓGICAS Y GEOMORFOLÓGICAS......................10

2.3. CARACTERÍSTICAS AMBIENTALES Y BIOGEOGRAFÍCAS..........................12

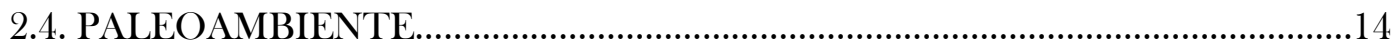

2.4.1. Transición Pleistoceno-Holoceno al Holoceno temprano....................................15

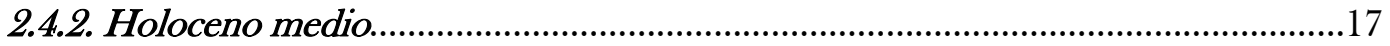

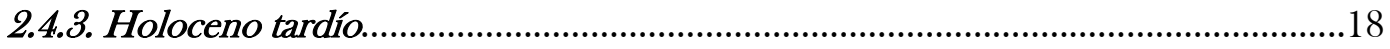

CAPITULO 3

ANTECEDENTES DE LAS INVESTIGACIONES ZOOARQUEOLÓGICAS

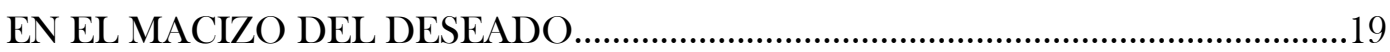

3.1. ESTUDIOS ZOOARQUEOLÓGICOS EN LA MESETA CENTRAL DE

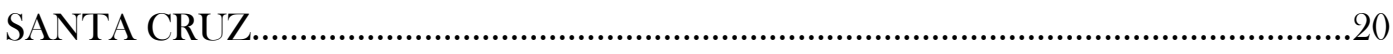

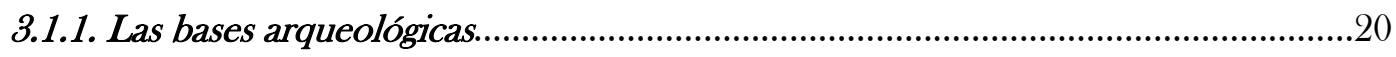

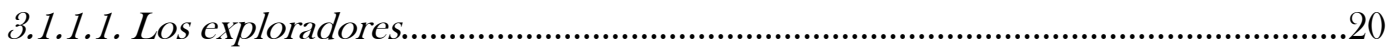

3.1.1.2. El comienzo de las excavaciones sistemáticas.........................................................21

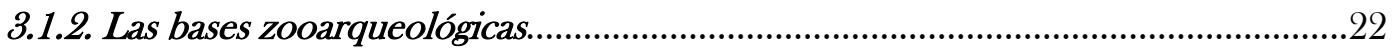

3.2. EL REGISTRO ARQUEOLÓGICO Y ZOOARQUEOLÓGICO

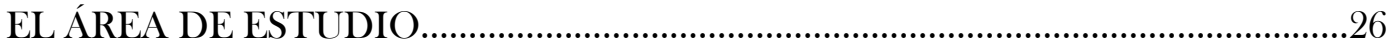

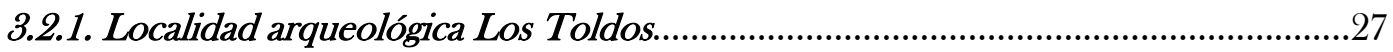


3.2.3. Localidad arqueológica El Ceibo. 31

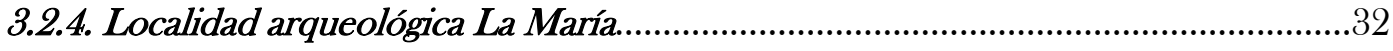

3.2.5. Localidad arqueológica Cerro Tres Tetas.................................................................36

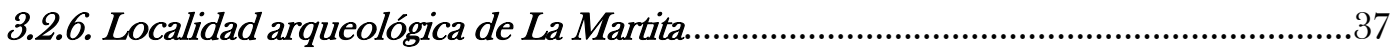

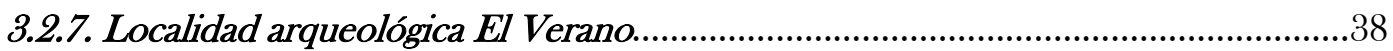

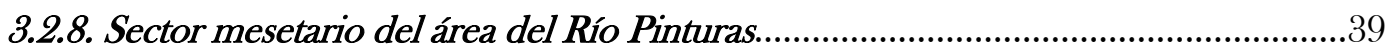

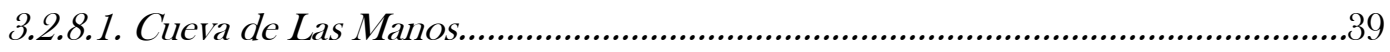

3.2.8.2. Cueva Grande de Arroyo Feo..........................................................................

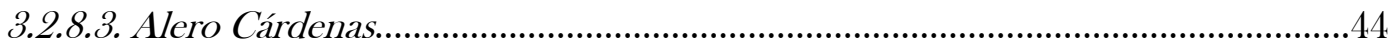

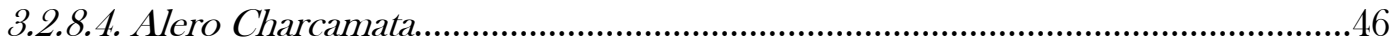

CAPÍTULO 4

ZOOARQUEOLOGÍA Y TAFONOMÍA.TENDENCIAS

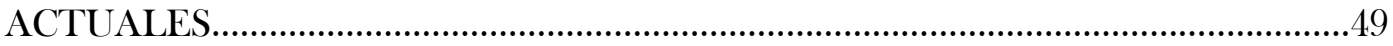

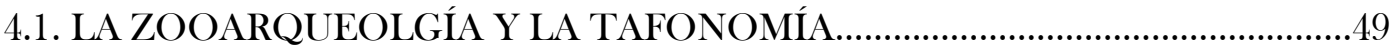

4.2. ACERCA DE LA INTERPRETACIÓN DE LOS PERFILES

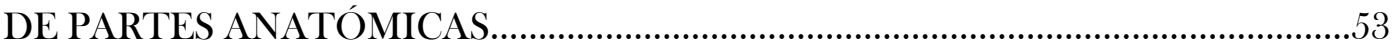

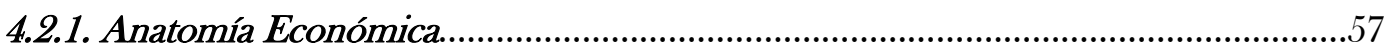

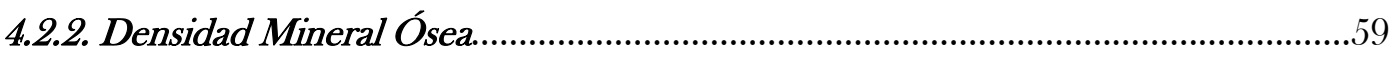

CAPÍTULO 5

LAS SOCIEDADES CAZADORAS-RECOLECTORAS DEL MACIZO DEL

DESEADO. MODELOS Y TENDENCIAS ECONÓMICAS,

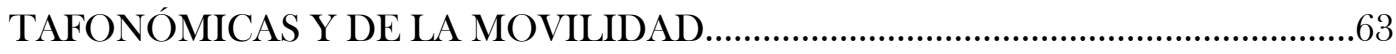

5.1. TRANSICIÓN PLEISTOCENO-HOLOCENO Y

HOLOCENO TEMPRANO (ENTRE ca.13 Y ca. 7,5 KA AP) ..................................65

5.2. HOLOCENO MEDIO (ENTRE 7,5 Y 3 KA AP) ...............................................67

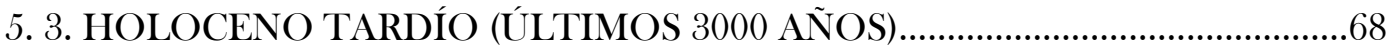

CAPÍTULO 6

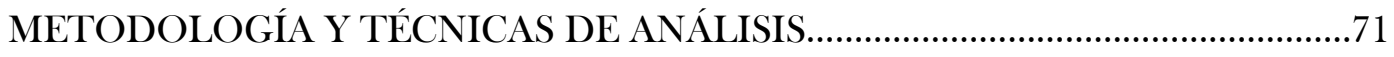

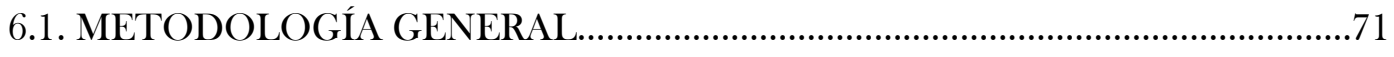

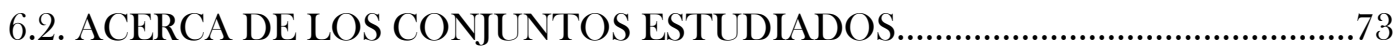


6.2.1. Alero El Puesto 1 (AEP-1), Piedra Museo............................................................73

6.2.2. Cueva Maripe (MA), La Primavera.........................................................................

6.3. ANÁLISIS ZOOARQUEOLÓGICO Y TAFONÓMICO.....................................74

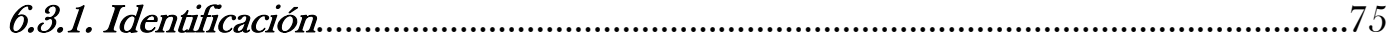

6.3.1.1. Unidades de definición anatómica.....................................................................76

6.3.2. Análisis cuantitativo de los restos óseos...................................................................77

6.3.3. Análisis de las modificaciones de las superficies óseas.........................................79

6.3.3.1. Procesos, agentes e indicadores tafonómicos......................................................79

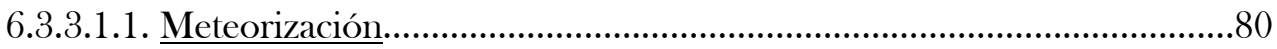

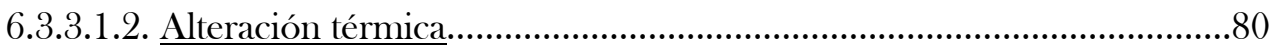

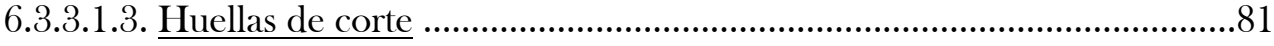

6.3.3.1.4. Marcas de machacado ….......................................................................... 82

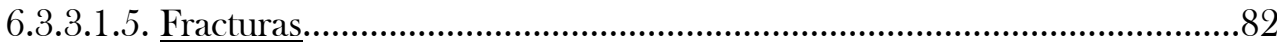

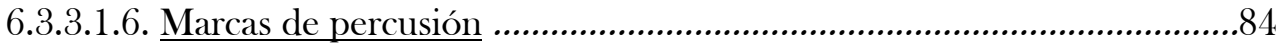

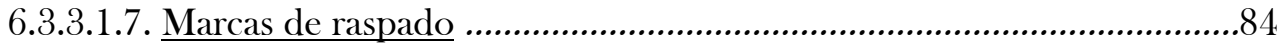

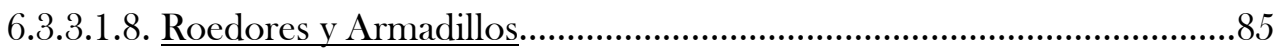

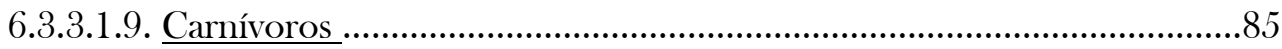

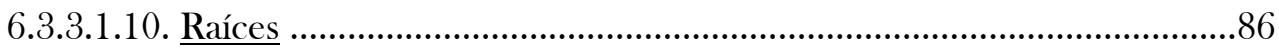

6.3.3.1.11. Depositación de manganeso...........................................................87

6.3.3.1.12. Depositación de carbonato de calcio …….............................................88

6.3.3.1.13. Disolución química..............................................................................8

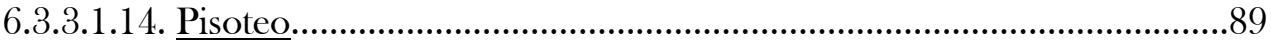

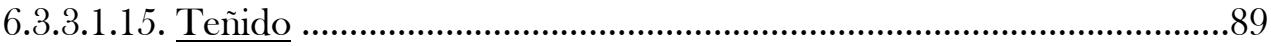

\section{CAPÍTULO 7}

ANÁLISIS DE LOS CONJUNTOS ZOOARQUEOLÓGICOS

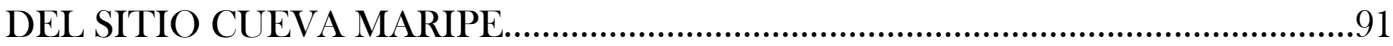

7.1. ESTADO DE CONOCIMIENTO ARQUEOLÓGICO Y

ZOOARQUEOLÓGICO EN CUEVA MARIPE..........................................................

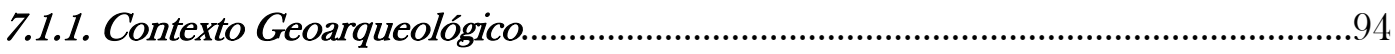

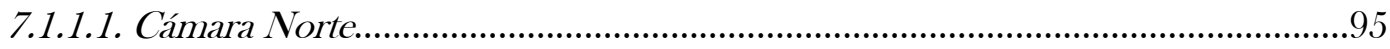

7.1.1.2. Cámara Sur ..........................................................................................................98

7.1.2. Caracterización de los conjuntos y cronología........................................................100

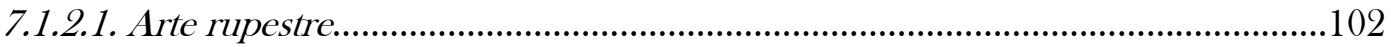




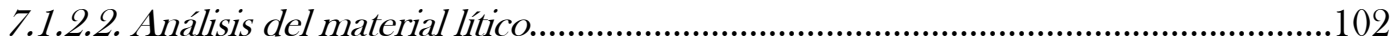

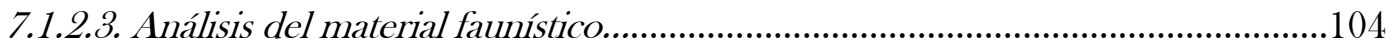

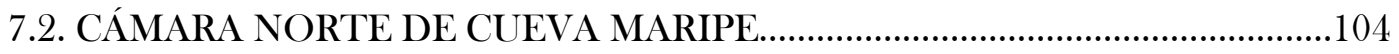

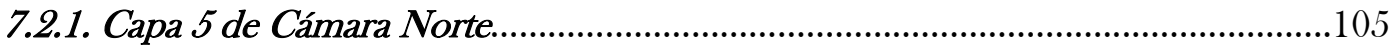

7.2.1.1. Abundancia taxonómica y anatómica..............................................................108

7.2.1.1.1. Análisis de la estrategia de transporte de partes anatómicas de

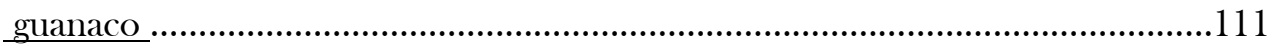

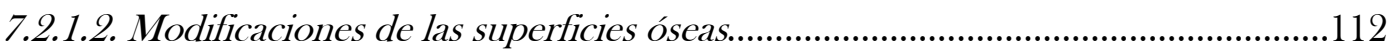

7.2.1.2.1. Patrones de modificaciones naturales.....................................................112

7.2.1.2.2. Patrones de modificación antrópica........................................................116

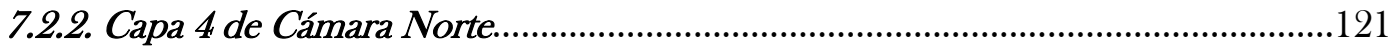

7.2.2.1. Abundancia taxonómica y anatómica...................................................................123

7.2.2.1.1. Análisis de la estrategia de transporte de

partes anatómicas de guanaco.....................................................................................128

7.2.2.2. Modificaciones de las superficies óseas..................................................................129

7.2.2.2.1. Patrones de modificaciones naturales...................................................129

7.2.2.2.2. Patrones de modificación antrópica........................................................134

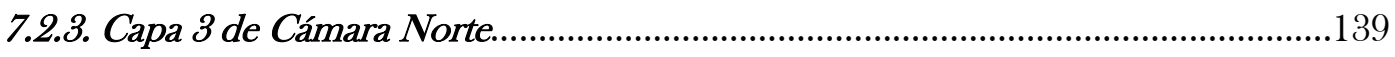

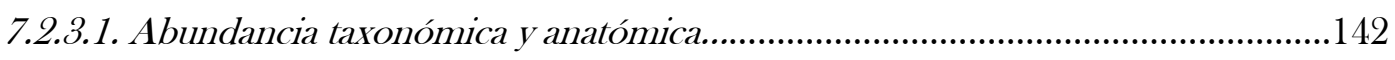

7.2.3.1.1. Análisis de la estrategia de transporte de

partes anatómicas de guanaco................................................................................146

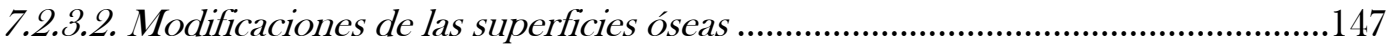

7.2.3.2.1. Patrones de modificaciones naturales........................................................147

7.2.3.2.2. Patrones de modificación antrópica.........................................................151

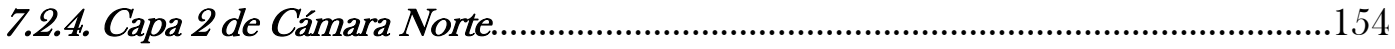

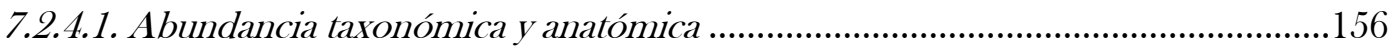

7.2.4.1.1. Análisis de la estrategia de transporte de partes anatómicas

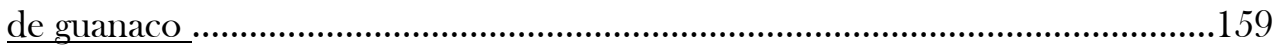

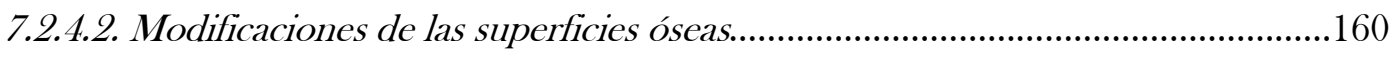

7.2.4.2.1. Patrones de modificaciones naturales .....................................................160

7.2.4.2.2. Patrones de modificación antrópica.........................................................163

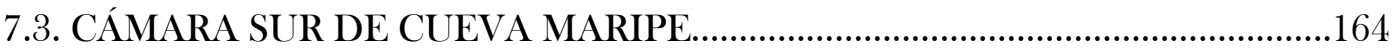

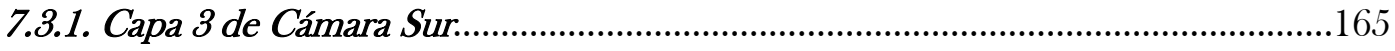

7.3.1.1. Abundancia taxonómica y anatómica...................................................................167 
7.3.1.1.1. Análisis de la estrategia de transporte de partes anatómicas

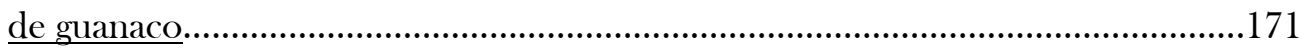

7.3.1.2. Modificaciones de las superficies óseas................................................................172

7.3.1.2.1. Patrones de modificaciones naturales.......................................................172

7.3.1.2.2. Patrones de modificación antrópica.......................................................175

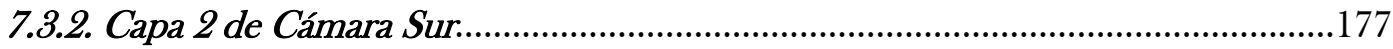

7.3.2.1. Abundancia taxonómica y anatómica................................................................178

7.3.2.1.1. Análisis de la estrategia de transporte de partes anatómicas

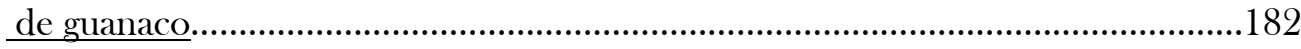

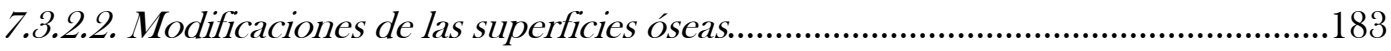

7.3.2.2.1. Patrones de modificaciones naturales............................................................183

7.3.2.2.2. Patrones de modificación antrópica.........................................................187

7.3.3. Capa 1 de Cámara Sur..........................................................................................190

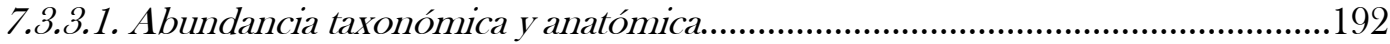

7.3.3.1.1. Análisis de la estrategia de transporte de partes anatómicas

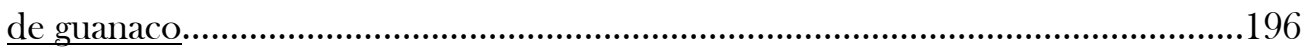

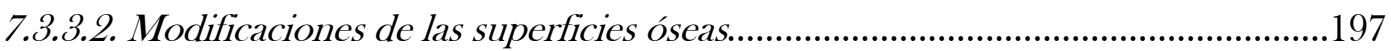

7.3.3.2.1. Patrones de modificaciones naturales.....................................................197

7.3.3.2.2. Patrones de modificación antrópica......................................................201

7.4. DISCUSIÓN DE LA VARIABILIDAD INTRASITIO........................................203

7.4.1. Transición Pleistoceno-Holoceno y Holoceno temprano en MA

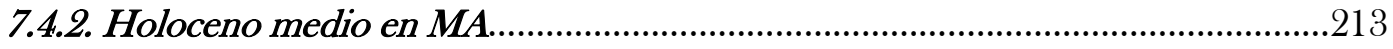

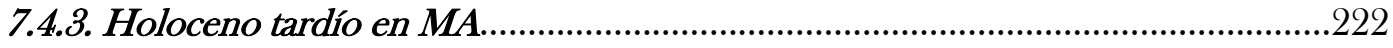

CAPÍTULO 8

ANÁLISIS DE LOS CONJUNTOS ZOOARQUEOLÓGICOS DE ALERO EL

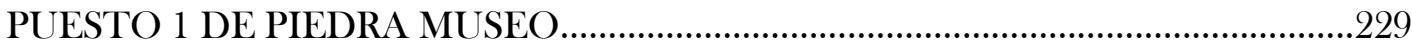

8.1. ESTADO DE CONOCIMIENTO ARQUEOLÓGICO Y

ZOOARQUEOLÓGICO EN PIEDRA MUSEO........................................................2230

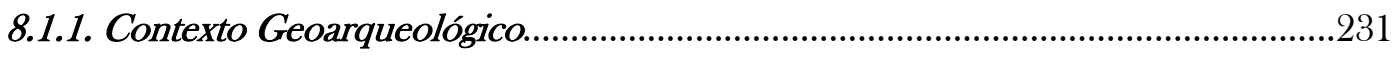

8.1.2. Caracterización de los conjuntos y cronología..........................................................233

8.1.2.1. Componente Inferior.........................................................................................224

8.1.2.2 Componente Superior.....................................................................................228 


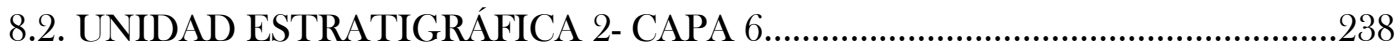

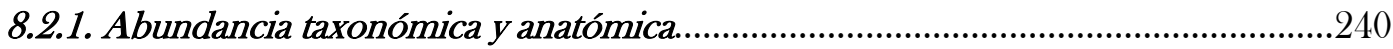

8.2.1.1. Análisis de la estrategia de transporte de partes anatómicas del guanaco...........244

8.2.2. Modificaciones de las superficies óseas...................................................................246

8.2.2.1. Patrones de modificaciones naturales ..............................................................246

8.2.2.2. Patrones de modificación antrópica...............................................................251

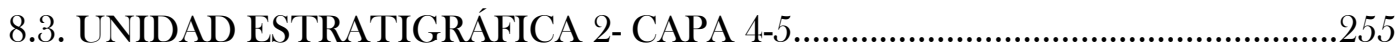

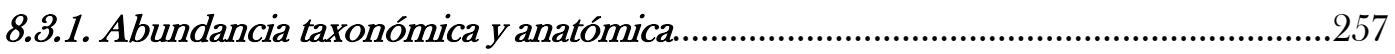

8.3.1.1. Análisis de la estrategia de transporte de partes anatómicas de guanaco.............260

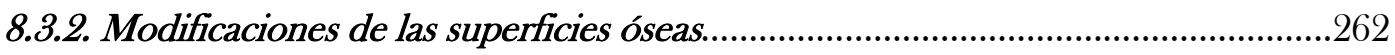

8.3.2.1. Patrones de modificaciones naturales...............................................................262

8.3.2.2. Patrones de modificación antrópica...................................................................268

8.4. UNIDAD ESTRATIGRÁFICA 2- CAPA 2........................................................272

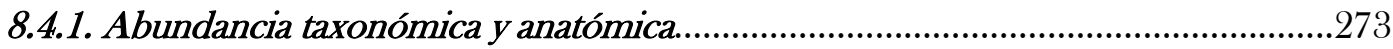

8.4.1.1. Análisis de la estrategia de transporte de partes anatómicas de guanaco.............278

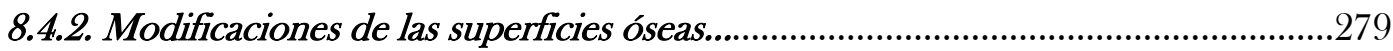

8.4.2.1. Patrones de modificaciones naturales..................................................................279

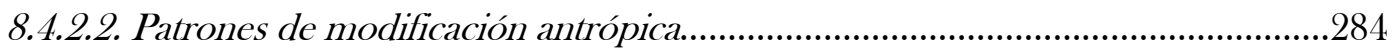

8.5. DISCUSIÓN DE LA VARIABILIDAD INTRASITIO.....................................289

CAPÍTULO 9

DISCUSIÓN DE LA VARIABILIDAD ZOOARQUEOLÓGICA Y

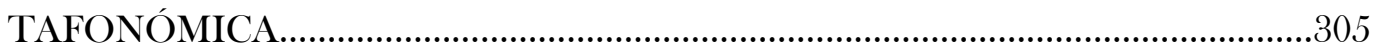

9.1. DIVERSIDAD Y RIQUEZA TAXONÓMICA. IMPLICANCIA EN LA

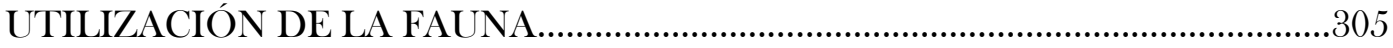

9.2. COMPARACIÓN DE LA VARIABILIDAD ZOOARQUEOLÓGICA Y

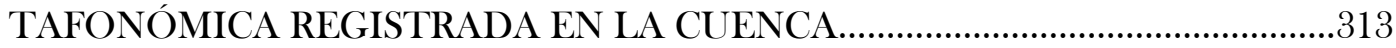

9.2.1. Transición Pleistoceno/Holoceno- Holoceno temprano....................................315

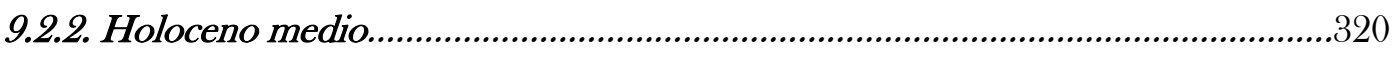

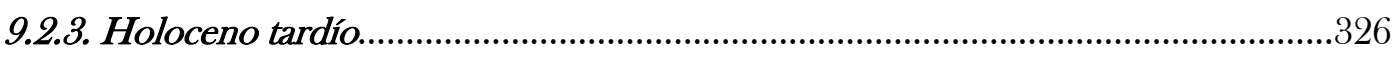


CAPÍTUlO 10

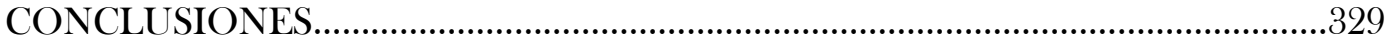

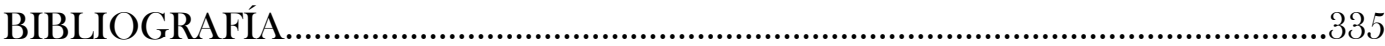




\section{ÍNDICE DE FIGURAS}

Figura 2.1: Macro-área de estudio y subregiones fisiográficas de la provincia de Santa Cruz.

Figura 2.2: Cuenca de los Zanjones Rojo y Blanco y ubicación de los sitios estudiados en

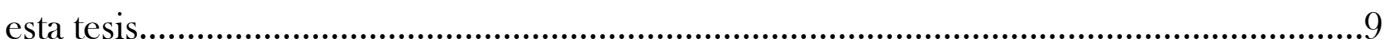

Figura 3.1: Localidades arqueológicas del Macizo del Deseado.....................................20

Figura 7.1. a) Mallín La Primavera; b) Cueva Maripe..........................................................92

Figura 7.2. Planta de excavación del sitio Cueva Maripe..................................................93

Figura 7.3. Perfil estratigráfico de Cámara Norte.............................................................96

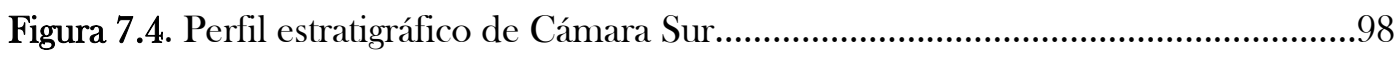

Figura 7.5. Capa 5 de CN de MA. a ) Distribución en planta de los especímenes tridimensionados; b) densidad de restos óseos por cuadrícula .106

Figura 7.6. Rasgos e indicadores de procesos y agentes tafonómicos identificados durante

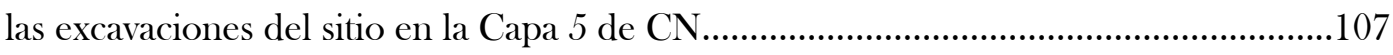

Figura 7.7. Correlaciones estadísticas de Spearman Capa 5 de CN de MA.....................111

Figura 7.8. Tendencia de la meteorización en Capa 5 de CN de MA.............................113

Figura 7.9. Frecuencia porcentual de especímenes óseos de guanaco con presencia de modificaciones en Capa 5 de $\mathrm{CN}$ de MA.......................................................................115

Figura 7.10. Modificaciones naturales en Capa 5 de $\mathrm{CN}$ de MA....................................116 
Figura 7.11. Distribución espacial de especímenes con modificaciones en Capa 5 de CN de MA. 116

Figura 7.12. Huellas de corte en Capa 5 de $\mathrm{CN}$ de MA....... 117

Figura 7.13. Frecuencia absoluta y tipos de fracturas identificadas en Capa 5 de $\mathrm{CN}$ de

MA. 118

Figura 7.14. Porción distal de tibia derecha de individuo subadulto de guanaco con restos de pigmento rojo $(\mathrm{P})$ y fractura helicoidal con punto de impacto (PI). Capa 5 de $\mathrm{CN}$ de MA

Figura 7.15. Restos de pigmento rojo y negro (a) en costilla izquierda de guanaco; (b) con huellas de corte (HC). Capa 5 de $\mathrm{CN}$ de MA.

Figura 7.16. Micro-pulido en fragmento de diáfisis de húmero de guanaco Capa 5 de CN de MA

Figura 7.17. Capa 4 de CN de MA. a) Distribución en planta de los especímenes tridimensionados; b) densidad de restos óseos por cuadrícula

Figura 7.18. Rasgos e indicadores de procesos y agentes tafonómicos identificados durante las excavaciones de Capa 4 de $\mathrm{CN}$ en MA.

Figura 7.19. Densidad de restos óseos de guanaco en la Capa 4 de CN de MA

Figura 7.20. Correlaciones estadísticas de Spearman Capa 4 de CN de MA 128

Figura 7.21. Tendencia de la meteorización en Capa 4 de CN de MA.

Figura 7.22. Frecuencia porcentual de especímenes óseos de guanaco con presencia de modificaciones en Capa 4 de $\mathrm{CN}$ de $\mathrm{MA}$ .132

Figura 7.23. Modificaciones naturales en Capa 4 de $\mathrm{CN}$ de MA. .133 
Figura 7.24. Distribución espacial de especímenes con modificaciones Capa 4 de CN de MA. 133

Figura 7.25. Modificaciones culturales en Capa 4 de $\mathrm{CN}$ de MA. 135

Figura 7.26. Frecuencia absoluta y tipos de fracturas identificadas en Capa 4 de $\mathrm{CN}$ de

MA.

Figura 7.27. Artefactos óseos formatizados por uso en Capa 4 de CN de MA.

Figura 7.28. Pigmento rojo sobre diáfisis de tibia.

Figura 7.29. Capa 3 de CN de MA. a) Distribución en planta de los especímenes tridimensionados; b) densidad de restos óseos por cuadrícula 141

Figura 7.30. Rasgos e indicadores de procesos y agentes tafonómicos identificados durante las excavaciones de Capa $3 \mathrm{CN}$ de $\mathrm{MA}$ 142

Figura 7.31. Densidad de restos óseos de guanaco por sector de cuadrícula en la Capa 3 de $\mathrm{CN}$ de MA. .146

Figura 7.32. Correlaciones estadísticas de Spearman: en Capa 3 de CN de MA.............147

Figura 7.33. Tendencia de la meteorización Capa 3 de CN de MA 148

Figura 7.34. Frecuencia porcentual de especímenes óseos de guanaco con modificaciones en Capa 3 de $\mathrm{CN}$ de MA

Figura 7.35. Modificaciones naturales en Capa 3 de $\mathrm{CN}$ de MA 150

Figura 7.36. Distribución espacial de especímenes con modificaciones en las superficies

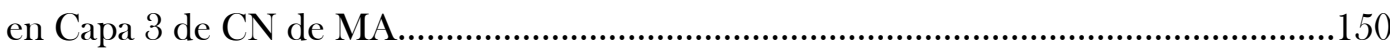

Figura 7.37. Modificaciones culturales en Capa 3 de CN de MA...................................152

Figura 7.38. Frecuencia absoluta y tipos de fracturas identificadas en Capa 3 de $\mathrm{CN}$ de

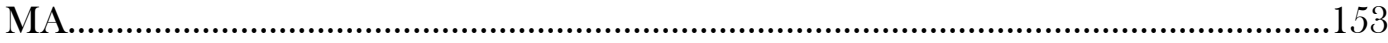


Figura 7.39. Artefactos formatizados en Capa 3 de $\mathrm{CN}$ de MA.

Figura 7.40. Capa 2 de CN de MA. a) Distribución de los especímenes tridimensionados en planta, b) frecuencia de restos óseos por cuadrícula. .155

Figura 7.41. Rasgos e indicadores de procesos y agentes tafonómicos identificados durante las excavaciones de la Capa 2 de $\mathrm{CN}$ de MA. 156

Figura 7.42. Distribución de restos óseos de guanaco por sector de cuadrícula en Capa 2 de $\mathrm{CN}$ de MA

Figura 7.43. Correlaciones estadísticas de Spearman en Capa 2 de CN de MA. 160

Figura 7.44. Tendencia de la meteorización la Capa 2 de CN de MA .161

Figura 7.45. Modificaciones naturales y culturales en Capa 2 de CN de MA 161

Figura 7.46. Frecuencia porcentual de especímenes óseos de guanaco con modificaciones en Capa 2 de $\mathrm{CN}$ de $\mathrm{MA}$.

Figura 7.47. Frecuencia absoluta y tipos de fracturas identificadas en Capa 2 de $\mathrm{CN}$ de MA. 163

Figura 7.48. Capa 3 de CS de MA. a) Distribución en planta de los especímenes tridimensionados; b) densidad de restos óseos por cuadrícula. 166

Figura 7.49. Rasgos identificados durante las excavaciones de la Capa 3 de CS de MA

Figura 7.50. Distribución de restos óseos de guanaco por sector de cuadrícula en la Capa 3 de CS

Figura 7.51. Correlaciones estadísticas de Spearman en Capa 3 de CS de MA... 171

Figura 7.52. Tendencia de la meteorización en Capa 3 de la CS de MA..... .173 
Figura 7.53. Frecuencia porcentual de especímenes óseos de guanaco con modificaciones en Capa 3 de CS de MA

Figura 7.54. Modificaciones de origen antrópico Capa 3 CS de MA..............................176

Figura 7.55. Frecuencia absoluta y tipos de fracturas identificadas en Capa 3 de CS de

MA

Figura 7.56. Capa 2 de CS de MA. a) distribución en planta de los especímenes tridimensionados; b) densidad de restos óseos por cuadrícula.

Figura 7.57. Densidad de restos óseos de guanaco por sector de cuadrícula en Capa 2 de CS de MA 182

Figura 7.58. Correlaciones estadísticas de Spearman en Capa 2 de CS de MA 182

Figura 7.59. Tendencia de la meteorización en Capa 2 de CS de MA.

Figura 7.60. Frecuencia porcentual de especímenes óseos de guanaco con modificaciones en Capa 2 de CS de MA. .185

Figura 7.61. Modificaciones naturales en Capa 2 de CS 186

Figura 7.62. Distribución espacial de especímenes con modificaciones en las superficies en Capa 2 de CS de MA. 186

Figura 7.63. Modificaciones culturales en Capa 2 de CS en MA

Figura 7.64. Frecuencia absoluta y tipos de fracturas identificadas en Capa 2 de CS de

MA. 189

Figura 7.65. Artefactos óseos formatizados en Capa 2 de CS de MA.

Figura 7.66. Capa 1 de CS de MA. a) Distribución en planta de los especímenes tridimensionados; b) densidad de restos óseos por cuadrícula

Figura 7.67. Rasgos e indicadores identificados durante las excavaciones de Capa 1 de CS de MA. 192 
Figura 7.68. Distribución de restos óseos de guanaco por sector de cuadrícula en la Capa 1 de CS 196

Figura 7.69. Correlaciones estadísticas de Spearman en Capa 1 de CS de MA 196

Figura 7.70. Tendencia de la meteorización Capa 1 de CS de MA. 198

Figura 7.71. Frecuencia porcentual de especímenes óseos de guanaco con modificaciones en Capa 1 de CS de MA. 199

Figura 7.72. Modificaciones naturales y culturales en el conjunto de Capa 1 de CS de MA. .200

Figura 7.73. Distribución espacial de especímenes con modificaciones en las superficies

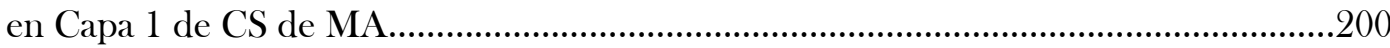

Figura 7.74. Frecuencia absoluta y tipos de fracturas identificadas en Capa 1 de CS de

MA .203

Figura 7.75. Abundancia relativa de especies aprovechadas durante la transición Pleistoceno-Holoceno y el Holoceno temprano en MA. .205

Figura 7.76. Modificaciones sobre las superficies de especímenes óseos correspondientes a los conjuntos del Pleistoceno final- Holoceno temprano en MA. .206

Figura 7.77. Representación de unidades anatómicas en los conjuntos de fines del Pleistoceno y Holoceno temprano en MA.

Figura 7.78. Abundancia relativa de especies aprovechadas durante el Holoceno medio en MA 215

Figura 7.79. Representación de unidades anatómicas en los conjuntos del Holoceno medio en MA .217

Figura 7.80. Modificaciones sobre las superficies de especímenes óseos correspondientes a los conjuntos del Holoceno medio en MA. .219 
Figura 7.81. Abundancia relativa de especies aprovechadas durante el Holoceno medio en MA

Figura 7.82. Representación de unidades anatómicas en los conjuntos del Holoceno tardío en MA .224

Figura 7.83. Modificaciones sobre las superficies de especímenes óseos correspondientes a los conjuntos del Holoceno tardío en MA.....................................................................225

Figura 8.1. a) Sitio AEP-1; b) localidad arqueológica Piedra Museo.... .230

Figura 8.2. Planta de excavación del sitio AEP-1 .231

Figura 8.3. a) Perfil estratigráfico del sitio AEP-1; b) techo de Capa 2 mostrando la discordancia erosiva

Figura 8.4. Capa 6 de AEP-1. a) Distribución en planta de los especímenes tridimensionados; b) densidad de restos óseos por $\mathrm{m}^{2}$

Figura 8.5. Correlaciones estadísticas de Spearman en Capa 6 de AEP-1 245

Figura 8.6. Tendencia de la meteorización en Capa 6 de AEP-1 .247

Figura 8.7. Frecuencia porcentual de especímenes óseos de camélidos con modificaciones en Capa 6 de AEP-1 248

Figura 8.8. Modificaciones naturales en Capa 6 de AEP-1.........................................249

Figura 8.9. Distribución de especímenes con modificaciones en Capa 6 de AEP-1.......251

Figura 8.10: Huellas de corte en Capa 6 de AEP-1 .......................................................252

Figura 8.11. Frecuencia y tipos de fracturas identificadas en Capa 6 de AEP-1.............253

Figura 8.12: Modificaciones antrópicas en especímenes óseos de cánidos en Capa 6 de

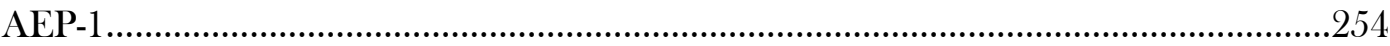


Figura 8.13. Capa 4/5 de AEP-1. a) Distribución en planta de los especímenes tridimensionados; b) densidad de restos óseos por cuadrícula

Figura 8.14. Correlaciones estadísticas de Spearman en Capa 4/5 de AEP-1 262

Figura 8.15. Tendencia de la meteorización en especímenes en Capa 4/5 de AEP-1....264

Figura 8.16. Frecuencia porcentual de especímenes óseos de guanaco con modificaciones en Capa 4/5 de AEP-1 .265

Figura 8.17. Modificaciones naturales en Capa 4/5 de AEP-1 ........................................266

Figura 8.18. Distribución de los especímenes con modificaciones en sus superficies en Capa 4/5 de AEP-1 .268

Figura 8.19. Modificaciones culturales en Capa 4/5 de AEP-1 .270

Figura 8.20. Frecuencia y tipos de fracturas identificadas en el conjunto de Capa $4 / 5$ de AEP-1 .270

Figura 8.21. Artefacto óseo formatizado en Capa 4/5 de AEP-1 270

Figura 8.22. Capa 2 de AEP-1. a) Distribución en planta de los especímenes tridimensionados; b) densidad de restos óseos por cuadrícula en Capa 2 de AEP-1......273

Figura 8.23. Densidad de restos óseos de guanaco por $\mathrm{m}^{2}$ en el conjunto de Capa 2 de AEP-1

Figura 8.24. Correlaciones estadísticas de Spearman en Capa 2 de AEP-1 .278

Figura 8.25. Tendencia de la meteorización en Capa 2 de AEP-1 280

Figura 8.26. Frecuencia porcentual de especímenes óseos de guanaco con modificaciones en el conjunto de Capa 2 de AEP-1 .282

Figura 8.27. Modificaciones naturales en los especímenes de Capa 2 de AEP-1............283

Figura 8.28. Distribución de los especímenes con modificaciones en Capa 2 de AEP-

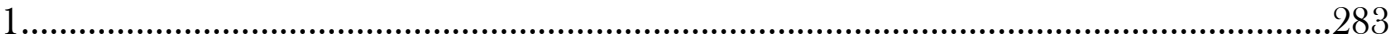


Figura 8.29. Modificaciones culturales en Capa 2 de AEP-1

Figura 8.30. Frecuencia absoluta y tipos de fracturas identificadas en el conjunto de Capa 2 de AEP-1

Figura 8. 31. Artefactos óseos formatizados en Capa 2 de AEP-1 _................................287

Figura 8.32. Diversidad taxonómica relativa en AEP-1 .................................................291

Figura 8.33. Representación de partes anatómicas de guanaco en AEP-1.....................296

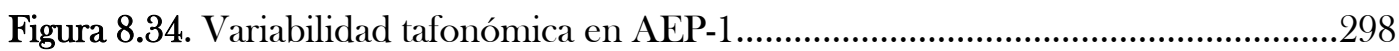

Figura 9.1. Rango cronológico de los conjuntos de AEP-1 y MA..................................306

Figura 9.2. Diversidad taxonómica de especies utilizadas en la Cuenca de los Zanjones

Blanco y Rojo en la Meseta Central de Santa Cruz......................................................307

Figura 9.3. Riqueza relativa de especies utilizadas en los sitios AEP-1 y MA...................313

Figura 9.4. Arqueotafogramas para los conjuntos del Pleistoceno final y Holoceno temprano en la cuenca de los Zanjones Rojo y Blanco en la Meseta Central de Santa Cruz 318

Figura 9.5. Arqueotafogramas para los conjuntos del Holoceno medio en la cuenca de los Zanjones Rojo y Blanco en la Meseta Central de Santa Cruz....

Figura 9.6. Arqueotafogramas para los conjuntos del Holoceno tardío en la cuenca de los Zanjones Rojo y Blanco en la Meseta Central de Santa Cruz .327 


\section{ÍNDICE DE TABLAS}

Tabla 5.1: Recursos básicos y estacionales en la economía de las sociedades cazadorasrecolectoras que habitaron Patagonia Meridional.

Tabla 6.1: Regiones en que se divide el miembro de los vertebrados Tetrápodos

Tabla 7.1. Fechados radiocarbónicos de Cueva Maripe.

Tabla 7.2. Abundancia taxonómica en la Capa 5 de CN de MA .108

Tabla 7.3. Representación de partes anatómicas de guanaco en la Capa 5 de CN de MA.

Tabla 7.4. Abundancia taxonómica en Capa 4 de CN de MA.

Tabla 7.5. Representación de partes anatómicas de guanaco en Capa 4 de $\mathrm{CN}$ de

MA.

Tabla 7.6. Abundancia taxonómica en la Capa 3 de CN de MA.

143

Tabla 7.7. Representación de partes anatómicas de guanaco en la Capa 3 de CN de MA.

Tabla 7.8. Abundancia taxonómica en la Capa 2 de CN de MA...

Tabla 7.9. Representación de partes anatómicas de guanaco en Capa 2 de CN de

MA. 158

Tabla 7.10. Abundancia taxonómica en la Capa 3 de CS de MA. 168

Tabla 7.11. Representación de partes anatómicas de guanaco en la Capa 3 de CS en MA. 169

Tabla 7.12. Abundancia taxonómica de la Capa 2 de CS de MA. 179 
Tabla 7.13. Representación de partes anatómicas de guanaco en la Capa 2 de CS de MA.

Tabla 7.14. Abundancia taxonómica en la Capa 1 de CS de MA

Tabla 7.15. Representación de partes anatómicas de guanaco en la Capa 1 de CS en

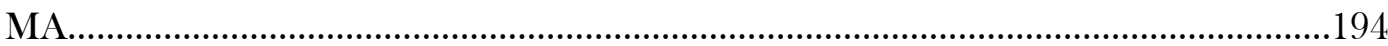

Tabla 8.1. Fechados radiocarbónicos de AEP-1 ...........................................................2.

Tabla 8.2. Abundancia taxonómica en la Capa 6 de AEP-1 ......................................... 240

Tabla 8.3. Representación de partes anatómicas de los guanacos en Capa 6 de AEP-1

Tabla 8.4. Abundancia taxonómica en Capa 4/5 de AEP-1 _.........................................257

Tabla 8.5. Representación de unidades anatómicas del guanaco en Capa 4/5 de AEP-1 259

Tabla 8.6. Abundancia taxonómica en la Capa 2 de AEP-1 ............................................274

Tabla 8.7. Abundancia anatómica de L. guanicoe en Capa 2 de AEP-1 ........................276

Tabla 9.1. Variables y escalas consideradas en los arqueotafogramas.............................314 


\section{RESUMEN}

Esta tesis aborda el estudio de las arqueofaunas, como una línea de evidencia que contribuye al conocimiento arqueológico y paleoambiental sobre el poblamiento, las formas de vida y las relaciones entre los seres humanos y su entorno en el pasado de la Meseta Central, en Patagonia austral.

El principal objetivo de esta tesis consiste en estudiar la variabilidad zooarqueológica y tafonómica en la cuenca de los Zanjones Rojo y Blanco de la Meseta Central de Santa Cruz. Para ello, se seleccionaron las localidades arqueológicas de Piedra Museo y La Primavera, teniendo en cuenta las extensas secuencias temporales que presentan sus depósitos arqueológicos y su condición de áreas arqueológicamente claves en dos sectores geomórficos diferentes de la misma cuenca (cabeceras y sector de base) para inferir la utilización de la fauna en la región y aproximar a las formas de movilidad humana. De esta manera se buscó evaluar la hipótesis principal de que la variabilidad zooarqueológica que se registra en la cuenca depende en gran medida del sector de la cuenca dentro del cual se localiza cada sitio, de las características particulares de su emplazamiento y del contexto sedimentario o matriz estratigráfica del depósito, y de las actividades culturales desarrolladas en cada uno de esos sectores. Los contextos zooarqueológicos aquí estudiados corresponden a sitios dentro de cuevas; Cueva Maripe, en el sector de cabeceras de cuenca y alero AEP-1 en el sector inferior de la misma. Sus depósitos estratigráficos presentan una alta resolución temporal, registrando ocupaciones humanas durante los distintos momentos entre la transición Pleistoceno-Holoceno y el Holoceno tardío (ca. 12,9 - 1 ka AP).

Las arqueofaunas se estudiaron desde una perspectiva zooarqueológica y tafonómica a fin de inferir las estrategias de aprovechamiento humano de los recursos faunísticos así como también para conocer los agentes y procesos de formación de los sitios. En este sentido, la zooarqueología, como el estudio de los restos faunísticos hallados en los sitios arqueológicos es la aproximación más abarcativa desarrollada en este trabajo de tesis. Entendemos, en tal sentido, que la tafonomía es una disciplina entrelazada con la zooarqueología, de esta manera es posible alcanzar una mejor inferencia acerca de las historias de formación de cada depósito y la toma de decisiones humanas respecto del uso de la fauna a lo largo del tiempo. 
En ambientes de cueva, con una dinámica heterogénea a nivel micro-espacial (decenas de $\mathrm{m}^{2}$ ) como son los del área de estudio, se diferencian múltiples procesos que modificaron los materiales arqueofaunísticos. El análisis pormenorizado de las superficies óseas nos permitió evaluar el rol jugado por los distintos agentes acumuladores y/o dispersores en la formación de cada contexto. De esta forma fue posible determinar los indicadores presentes en cada uno de los conjuntos para inferir qué pudo haber sucedido con esa fauna, qué agentes y procesos intervinieron y con qué intensidad actuaron en la formación de los registros zooarqueológicos y así poder identificar los grados de participación de los factores naturales y culturales de las acumulaciones óseas. Esta aproximación permitió evaluar la integridad y resolución del registro arqueofaunístico en distintos niveles de análisis que van desde el espécimen, pasando por la variabilidad intra e intersitio en cada microrregión. Se pudo estimar el grado de incidencia de los diferentes procesos en la formación de los depósitos arqueológicos, el papel jugado por los humanos en la formación de depósitos particulares y se determinaron los estados de preservación de los conjuntos óseos. Asimismo, se evaluó el grado de influencia de las variables cronología y tipo de fauna representada en los estados de preservación registrados.

Como resultado del análisis tafonómico y contextual intrasitio, encontramos que Cueva Maripe presenta en cada una de sus cámaras (norte y sur) historias tafonómicas diferentes. Encontramos también que la integridad arqueológica entre las cámaras difiere, registrando la mejor preservación del material y una mejor resolución arqueológica en Cámara Norte. Por su parte, en AEP-1 observamos que la mayor variabilidad interna de los contextos arqueofaunísticos del sitio responde a cuestiones cronológicas y cambios paleoambientales que incidieron en la toma de decisiones de los cazadores-recolectores que ocuparon el alero; además en este sitio, los procesos de pedogénesis que tuvieron lugar aproximadamente en el $7 \mathrm{ka} \mathrm{AP}$, afectaron particularmente a los conjuntos arqueológicos previos, generando una serie de modificaciones particulares y diferentes en las superficies de los huesos.

La comparación de las historias tafonómicas entre los conjuntos analizados se llevó adelante a través de la elaboración e interpretación de arqueotafogramas. Estos gráficos permitieron representar la historia tafonómica de cada conjunto y fueron usados como base para realizar comparaciones estandarizadas de las diferentes acumulaciones óseas, a partir de atributos tafonómicos seleccionados, y sobre la base de cronologías similares. 
En esta tesis los arqueotafogramas se construyeron para los 10 conjuntos estudiados sobre una base de más de 30 variables taxonómicas, anatómicas y tafonómicas a partir de las cuales se efectuó la comparación. De esta manera, en ellos se resume información tafonómica y de aprovechamiento humano de los recursos de cada conjunto mostrando cómo se comporta cada variable de forma individual y en relación a las otras.

Los resultados mostraron que en los dos contextos Lama guanicoe (guanaco) fue el recurso más abundante para los distintos momentos de ocupación. Esta tendencia concuerda con los modelos de aprovechamiento faunístico propuesto por otros investigadores en distintas regiones de Patagonia. La mayor variación registrada corresponde a las especies que en cada sitio jugaron un rol complementario en la dieta de los cazadores-recolectores. Una de estas diferencias corresponde a las ocupaciones más tempranas ya que en AEP-1 se reconoció la utilización de distintos mamíferos pleistocénicos, que sin duda, aun existían en la región cuando los humanos comenzaron a poblar el área hacia fines del Pleistoceno. Sin embargo, hasta el momento en Cueva Maripe, como expresión de lo que podría haber sucedido en momentos del poblamiento inicial de las cabeceras de cuenca, la explotación de la fauna comienza con el uso intensivo del guanaco. No se identificaron restos correspondientes a taxa extinguidos, sin embargo, por el momento no se puede descartar la posibilidad que esta ausencia signifique un sesgo de muestreo o que la fauna pleistocénica ya hubiera desaparecido del área para la primera ocupación de esta localidad hacia el 9,5 ka AP. Por otro lado, se confirma el rol como recurso complementario de los rheidos en la economía de estas sociedades. Los restos de estas aves con claras marcas de procesamiento en los distintos niveles de ocupación de AEP-1 avalan esa hipótesis mientras que en Cueva Maripe, el mayor interés parece estar relacionado a la utilización de los huevos de dichas aves.

Algo similar ocurre con las frecuencias de unidades anatómicas de guanaco representadas en los sitios arqueológicos, a excepción del conjunto de la Capa 4/5 de AEP-1, se registra un patrón común al observado en los sitios patagónicos, dominado por los elementos del esqueleto apendicular, y dentro del cual, las unidades anatómicas de bajo rendimiento económico y pertenecientes a los elementos del autopodio, adquieren de mediana a alta representación. En tal sentido, se está avanzando en los análisis de partes anatómicas y el uso de información etnoarqueológica y etnográfica que permite considerar que la abundancia de estas unidades en sitios residenciales puede responder a un consumo preferencial de sus grasas. 
Los resultados obtenidos reflejan la existencia de historias tafonómicas complejas y diferentes en ambos sitios. Incluso, con el resultado de integridades arqueológicas diferenciales para distintos sectores de los dos sitios. Sin embargo, el registro de una abundante y variada cantidad de modificaciones estrictamente humanas, permitió atribuir un origen antrópico a todos los conjuntos estudiados. Las diferencias observadas en ambos sitios respecto de los contexto estratigráficos, el afloramiento en el que se emplaza cada uno, y el sector de la cuenca en el que se localizan (cabecera o nivel de base), jugaron un rol importante en los procesos de formación de cada sitio, configurando patrones tafonómicos diferentes, e implicando distintos grados de participación de cada agente o proceso.

Los resultados obtenidos en este trabajo de tesis permiten realizar inferencias más detalladas sobre el uso de la fauna y la circulación de los recursos faunísticos entre los cazadores-recolectores que habitaron el noreste de Santa Cruz durante los distintos momentos del Pleistoceno final y Holoceno. 


\section{ABSTRACT}

This thesis aims to study the archaeofaunas to generate new archaeological and palaeo-environmental knowledge on human settlement, ways of life and past populationenvironment relations in the central plateau, southern Patagonia.

The main objective of this thesis is to study the zooarchaeological and taphonomic variability found at the watershed drained by the Rojo and Blanco creeks, central Santa Cruz plateau. In order to achieve it, we selected two archaeological localities: Piedra Museo and La Primavera, taking into consideration that they present long temporal sedimentary sequences and bring key archaeological information in different geomorphic sectors of the same drainage basin, and therefore provide crucial data to study faunal use and human mobility along the region. The main hypothesis tested here is that the zooarchaeological variability registered depends on the following factors: the sector of the basin where they are situated, the particular characteristics of their location, the sedimentary context of the deposit and the cultural activities developed at every locality. Both zooarchaeological contexts studied belong to cave environments: Cueva Maripe, located in the upper basin and AEP-1, in the lower basin. Their stratigraphic deposits present high temporal resolution, and show human occupations all along the sequences, from the Pleistocene-Holocene transition until the Late Holocene (ca. 12.9 - 1 ka BP).

The archaeofaunas were studied from a zooarchaeologic and taphonomic perspective, to infer human use strategies as well as site formation processes. In this sense, zooarchaeology, as the study of faunal remains found in archaeological sites, is the broader approach developed in this thesis. We understand that taphonomy is entwined with zooarcheology, and both disciplines contribute to build inferences on archaeological deposits formation history and about human decision making about faunal resources.

Multiple processes affecting archaeofaunistic materials were recognized at cave environments, with heterogeneous dynamic at the micro-spatial scale (tens of $\mathrm{m}^{2}$ ). The detailed analysis of bone surfaces allowed us to evaluate the importance of different accumulation and dispersion agents in the formation of every context. In every case we determined indicators to infer agents and processes which intervened in the formation of the archaeofaunal remains at different analysis levels: bone specimen, intra-site and intersite variability in a region. The degree of incidence of different formation processes, the role played by humans in the formation of particular deposits and preservation state of 
bone assemblages were estimated. The influence of chronology and faunal type on the preservation state were also evaluated.

As a result of the taphonomic and contextual intra-site analysis, we found that Cueva Maripe shows different taphonomic histories in each of its chambers (north and south), with better preservation and archaeological resolution in North Chamber. Meanwhile, in AEP-1 we observed that the main internal variability of archaeofaunistic contexts in the site is due to chronology issues and environmental changes that influenced the decisions taken by hunter-gatherers who occupied the rock-shelter. In addition, pedogenic processes occurred $7 \mathrm{ka} \mathrm{BP}$ affected the archaeological assemblages deposited before this date, generating particular modifications on bones surfaces.

The comparison of the taphonomic histories between the analyzed assemblages was made using taphograms. These graphs allowed us to represent the taphonomic history of every assemblage and were used to make standardized comparisons between bone accumulations, by using a selection of taphonomic attributes, in base of similar chronologies.

In this research the taphograms were constructed for 10 assemblages studied and on the base of 30 taxonomic, anatomic and taphonomic variables. They summarize information on taphonomy and faunal use for every assemblage.

The results showed that in both contexts, Lama guanicoe (guanaco) was the most abundant resource at different occupation times. This tendency accords with models of faunal use proposed by other researchers in different regions of Patagonia. The main variations registered in the species recovered in each site are interpreted as complementary resources included in the diet of hunter gatherers. One of the main differences was detected at the earliest occupations at AEP-1, where there are evidences of Pleistocene mammals' use. On the other hand, Cueva Maripe shows evidence of intense use of guanaco and absence of extinct fauna. In the current state of the research, we cannot discard that this absence could be due to sampling bias or that pleistocenic fauna was already extinguished in this area when the first human occupation took place by $9.5 \mathrm{ka}$ BP. On the other hand, rheids as complementary resource in the economy of these societies was confirmed. Remains of these birds with clear processing marks found in the different occupation levels of AEP-1 and an abundant eggshell in Cueva Maripe lends proof of this hypothesis.

Respect to the anatomic unities of guanaco represented in the archaeological sites, except for the assemblage belonging to AEP-1 Layer 4/5, a pattern which is common to 
the observed at other Patagonia sites raised. The anatomic unities of the appendicular skeleton with low economic returns belonging to the autopod are moderately to highly present. The analysis of anatomic parts and the use of etnoarchaeological and ethnographic information allow considering that the abundance of these unities in residential sites indicate a preference in the use of their fat.

The obtained results reflect the existence of complex taphonomic histories and differences in both sites. Nevertheless, the abundant and varied strictly human modifications registered allowed us to sustain an anthropic origin to the studied assemblages.

The differences observed in both sites in the stratigraphic contexts, geologic outcrops and the basin sector where they are located played an important role in the formation processes at every site, configuring different taphonomic patterns and producing different degrees of importance of every agent of process.

The results obtained in this thesis allows a better understanding of aspects related to faunal use and circulation of faunal resources between the hunter-gatherers who occupied the northwest of Santa Cruz province along the different moments of Late Pleistocene and the Holocene. 


\section{CAPÍTULO 1}

\section{INTRODUCCIÓN}

La presente tesis tiene como principal objetivo estudiar la variabilidad zooarqueológica y tafonómica en la cuenca de los Zanjones Rojo y Blanco de la Meseta Central de la provincia de Santa Cruz. En este sentido, se propone abordar a partir del estudio de las arqueofaunas, la interacción entre los humanos y la fauna a lo largo de la ocupación cazadora-recolectora de la cuenca.

El área de estudio seleccionada para realizar esta investigación corresponde a una cuenca residual (Panza 2001) de aproximadamente $140 \mathrm{~km}$ de longitud en sentido esteoeste. Cada sector de esta cuenca (nivel de base, cuenca media y cabecera) presentan características particulares de altitud, visibilidad, disponibilidad de agua y recursos faunísticos que nos llevan a suponer que en el pasado pudo existir un uso jerárquico de los recursos en relación a estos microambientes diferentes. En este sentido, durante esta tesis se buscó evaluar en que medida, la variabilidad zooarqueológica que se registra en la cuenca depende del sector dentro del cual se localiza cada sitio, de las características particulares de su emplazamiento y del contexto sedimentario o matriz estratigráfica del depósito, así como de las actividades culturales desarrolladas en cada uno de esos sectores.

Este estudio se enmarca dentro de un proyecto regional dirigido por la Dra. Laura Miotti, que considera varias líneas de evidencia y análisis a partir de las que se busca poner a prueba diferentes hipótesis relacionadas al poblamiento de la región y a la evolución temporo-espacial de las sociedades cazadoras-recolectoras que ocuparon el área entre la transición Pleistoceno-Holoceno y el Holoceno tardío (Blanco y Lynch 2011; Carden 2009; Hermo 2008; Lynch 2012; Magnin 2010; Marchionni et al. 2010; Miotti 1992, 2008; Miotti et al. 1999; Mosquera 2012, entre los principales).

El interés por el estudio de las arqueofaunas en la Meseta Central de la Provincia de Santa Cruz, comenzó sistemáticamente hacia mediados de los '80 con la tesis doctoral de la Dra. Laura Miotti (1998). Si bien los resultados obtenidos hasta el presente por los estudios zooarqueológicos han brindado abundante información (Miotti 1992, 2003, 2012; Miotti et al 1999, Miotti y Salemme 1999, 2005, entre los principales), la 
preocupación por profundizar en nuevas preguntas hace necesario para el proyecto general ahondar en la problemática tafonómica que permita afinar el grano de análisis para el estudio de las arqueofaunas. Este tipo de abordaje tafonómico ha tenido un amplio desarrollo en áreas vecinas como la Cuenca Magallánica y el sector cordillerano de la provincia de Santa Cruz (Barberena 2008; Belardi 2005; Belardi et al. 2010; Borrero 1986, 1988, 1993, 2001, 2007; Borrero y Martin 2012; Borrero et al. 1991, 2005; Martin 2008; Mengoni Goñalons 1999; entre los principales), sin embargo, en el sector de la Altiplanicie Central, estas investigaciones han sido escasas y discontinuas (Durán 1991; Miotti 1998, 2003; Miotti et al. 1999). Por tal motivo, a través de esta tesis se busca continuar de modo sistemático el desarrollo de una perspectiva tafonómica dentro de las investigaciones zooarqueológicas del área de estudio, que brinde información genuina y comparativa para comprender las dinámicas de los procesos de formación de sitios en los distintos microambientes del área, los agentes acumuladores y dispersores de los materiales zooarqueológicos, y que contribuya a una mejor comprensión de los aspectos relacionados con la economía de los grupos cazadoresrecolectores que habitaron el Macizo del Deseado.

Los restos faunísticos que los arqueólogos registramos en los sitios son resultado tanto del transporte selectivo realizado por los humanos como de otros procesos y agentes tafonómicos, culturales y naturales (Borrero 1988, 1990, 1994-95, 2011; De Nigris 2004; Gifford-González 1989a, 1993; Lyman 1994; Marean 1995; Mengoni Goñalons 1988, 1999; Salemme y Miotti 1987, entre otros). La zooarqueología, entendida como la disciplina que estudia la interacción entre la sociedad humana y los animales en el pasado (Mengoni Goñalons 2010), y cuyos objetivos trascienden el mundo animal en lugar de centrarse en él (Borrero 2011) constituye la aproximación más abarcativa en la que se enmarca la presente investigación. En este sentido, el desarrollo de una perspectiva tafonómica que nos permita explorar con mayor profundidad y detalle los procesos de formación de registro se torna fundamental para realizar interpretaciones sobre las decisiones humanas respecto del manejo y relación con las faunas en el pasado (Borrero 2011; Gutiérrez 2009). De esta manera, para el desarrollo de la presente investigación se considera a la tafonomía parte integral de la zooarqueología (Borrero 2011).

Para la realización de esta tesis se seleccionaron las localidades arqueológicas de Piedra Museo y La Primavera, teniendo en cuenta las extensas secuencias temporales que presentan sus depósitos arqueológicos y su condición de áreas arqueológicamente claves 
en dos sectores geomórficos de la cuenca (cabeceras y sector de base). Los contextos zooarqueológicos aquí estudiados corresponden a sitios dentro de cuevas; Cueva Maripe (La Primavera), en el sector de cabeceras de cuenca y Alero El Puesto 1 (Piedra Museo) en el sector inferior de la misma. Sus depósitos estratigráficos presentan una alta resolución temporal, registrando ocupaciones humanas durante la transición PleistocenoHoloceno y el Holoceno tardío (ca. 12,9 - 1 ka AP).

En ambientes de cueva, con una dinámica heterogénea a nivel micro-espacial como son los del área de estudio (Farrand 1985; Kornfeldm et al. 2008), se diferencian múltiples procesos que modificaron los materiales arqueofaunísticos. En ese sentido, los objetivos específicos de esta tesis consisten en:

-Comparar la historia tafonómica de cada uno de los conjuntos analizados.

-Evaluar la integridad y resolución del registro arqueofaunístico en cada microrregión con el fin de contribuir a las interpretaciones arqueológicas.

-Estimar el grado de incidencia de los diferentes procesos en la formación de los depósitos arqueológicos.

-Evaluar el papel jugado por los humanos en la formación de depósitos particulares y las evidencias concretas de su acción, para así diferenciarlas de aquellas correspondientes a agentes naturales.

-Determinar los estados de preservación de los conjuntos óseos.

-Evaluar el grado de influencia de ciertas geoformas del paisaje y de las variables cronología y tipo de fauna representada en los estados de preservación registrados.

Asimismo, desde una perspectiva paleoecológica se pretende brindar nuevos elementos que contribuyan a la interpretación de los sitios de los grupos cazadores-recolectores y a la diversidad ambiental patagónica durante el Pleistoceno final y el Holoceno.

Para alcanzar los objetivos propuestos en esta tesis, el análisis zooarquelógico que se desarrolla contempló las distintas etapas de procesamiento de datos cuali y cuantitativos, fundamentales para poder interpretar los conjuntos arqueofaunísticos y hacer inferencias acerca de las sociedades del pasado (Binford 1978, 1981; Borrero 2011; Gifford-González 1989b; Grayson 1984; Lyman 1994; Miotti 2008; Miotti et al. 1999; Mengoni Goñalons 1988, 1999, 2010). El reconocimiento de diferentes patrones de modificación de las superficies óseas fue la vía metodológica utilizada para inferir los agentes y procesos tafonómicos involucrados en la formación de cada conjunto (GiffordGonzalez 1991; Johnson 1985). Su análisis pormenorizado nos permitió evaluar el rol jugado por cada agente acumulador y/o dispersor, así como el grado de participación que 
tuvo en la formación de cada contexto. Para el estudio tafonómico comparativo entre los conjuntos se siguió la propuesta de un método gráfico estandarizado realizada por Behrensmeyer (1991), cuyo potencial fue demostrado por varios autores en nuestro país (Mengoni Goñalons 1999; Muñoz 2008; Rindel 2009, entre otros).

Desde esta aproximación fue posible evaluar y discutir la integridad y resolución del registro arqueofaunístico en distintos niveles de análisis que van desde el espécimen, pasando por la variabilidad intra e intersitio en cada microrregión de la cuenca.

La presente tesis se encuentra estructurada en diez capítulos cuyo contenido se describe a continuación:

Capítulo 1: es este capítulo y corresponde a la introducción, aquí se presenta el problema de investigación y los objetivos generales y específicos propuestos para esta tesis. Además, se enuncian las principales hipótesis que se someten a prueba, así como las perspectivas teórico-metodológicas desde la que se aborda el estudio.

Capítulo 2: allí se definen y caracteriza el área y la macro-área de estudio, así como los bloques temporales considerados para desarrollar las comparaciones y discusiones de esta tesis. Además, se presenta la información geológica, geomorfológica y ambiental (actual y pretérita) relevante para discutir los registros zooarqueológico y tafonómico del área de estudio y su variabilidad en los diferentes lugares y tiempos de ocupación humana con economía cazadora-recolectora.

Capítulo 3: presenta una síntesis del origen de las investigaciones zooarqueológicas en el área y reúne información relevante para comprender el estado actual del conocimiento zooarqueológico en la Meseta Central y cuál es su aporte al conocimiento arqueológico en la provincia de Santa Cruz. Hace hincapié en los avances que desde la zooarqueología y la tafonomía se desarrollaron en la Altiplanicie Central a partir a partir de otros investigadores y sitios estudiados desde los inicios de la arqueología en la región

Capítulo 4: se desarrollan los principales conceptos teórico-metodológicos seguidos en esta tesis para el estudio de las arqueofaunas. Se destaca la importancia del abordaje de una línea tafonómica dentro de la investigación zooarqueológica, en este sentido, se define la zooarqueología y tafonomía como marco de esta investigación y se presentan los modelos y marcos de referencia utilizados durante esta tesis para la interpretación de las frecuencias de taxa y partes anatómicas representadas en los sitios arqueológicos.

Capítulo 5: se presentan los modelos y tendencias propuestos por distintos autores para los grupos cazadores-recolectores que habitaron el Macizo desde fines del Pleistoceno. El énfasis principal está puesto en caracterizar las estrategias económicas y de 
movilidad desarrolladas por estos grupos humanos en las principales etapas del poblamiento del área, así como las diferentes expectativas tafonómicas que surgen a partir de ellos.

Capítulo 6: se definen las herramientas metodológicas utilizadas para efectuar el análisis de cada conjunto zooarqueológico proveniente de la cuenca del Zanjón Rojo y Blanco en la Meseta Central de la provincia de Santa Cruz, y la comparación entre ellos. Las unidades y categorías que se presentan aquí, forman la base conceptual sobre la que se discute y analiza la variabilidad tafonómica y zooarqueológica existente dentro de esta cuenca

Capítulo 7: presenta los resultados alcanzados a partir de los diferentes análisis cuali y cuantitativos realizados para los 7 conjuntos arqueofaunísticos que proceden del sitio Cueva Maripe. Asimismo, se interpreta y discute la variabilidad tafonómica y zooarqueológica existente en Cueva Maripe en distintos momentos de ocupación del sitio y las variaciones en el uso de espacio interior de la cueva.

Capítulo 8: presenta los resultados alcanzados a partir de los diferentes análisis cuali y cuantitativos realizados para los 3 conjuntos zooarqueológicos del sitio AEP-1. Aquí también se interpreta y discute la variabilidad tafonómica y zooarqueológica en los tres momentos principales de ocupación del sitio, teniendo en consideración las variaciones en el uso del espacio interior del alero.

Capítulo 9: se comparan los resultados obtenidos para los 10 conjuntos zooarqueológicos estudiados en esta tesis y que fueron presentados en los capítulos 7 y 8. Se analizan, discuten e interpretan los arqueotafogramas construidos para cada conjunto a partir de la estandarización de las variables zooarquelógicas y tafonómicas estudiadas durante esta investigación.

Capítulo 10: se presentan las principales conclusiones de este trabajo de tesis y se plantean las nuevas preguntas surgidas en el marco de las mismas, así como las perspectivas futuras de investigación. 


\section{CAPÍTULO 2}

\section{ÁREA DE ESTUDIO}

En este capítulo se definen las coordenadas espaciales y temporales dentro de las cuales se realizó el estudio zooarqueológico y tafonómico. De esta manera se caracterizarán el área y la macro-área de estudio, así como los bloques temporales considerados para abordar las distintas discusiones. En ese mismo sentido, cobra importancia presentar la información geológica y geomorfológica como así también, la caracterización del ambiente actual y pretérito del área. Esta información brinda la base ambiental y paleoambiental fundamental para interpretar y discutir el registro zooarqueológico y tafonómico, su variabilidad en los diferentes lugares y tiempos de ocupación humana con economía cazadora-recolectora que aquí se analizan.

\subsection{DEFINICIÓN DEL ÁREA GEOGRÁFICA}

La provincia de Santa Cruz está caracterizada por la existencia de tres ambientes fisiográficos principales, los cuales son descriptos como fajas longitudinales contiguas cuyos límites no son precisos pero que pueden delinearse biogeográficamente y de oeste a este son la cordillera, la meseta y la costa (Miotti 1998).

La macro-área de estudio definida para esta tesis corresponde a la meseta esteparia conocida como Nesocratón del Deseado, Macizo del Deseado o Altiplanicie Central que se ubica entre los ríos Deseado y Chico, en la provincia de Santa Cruz (Figura 2.1). Según Gradín (1980) este sector corresponde geográficamente al “área de Patagonia propiamente dicha” (Gradín 1980:178), a la cual le sobreimprime otro criterio demarcatorio, a su juicio el cultural y así la encuadra como "Patagonia Central: entre el río Chubut y el Santa Cruz, subdividida por el río Deseado en Centro Septentrional y Centro Meridional” (Gradín 1980: 179). Esta región centro-meridional de la Patagonia extra-andina se extiende desde la costa Atlántica al este y hasta el Río Pinturas, al oeste. En esta investigación el sector costero de la meseta no es considerado dentro del área 
informada debido a las diferencias ecológicas que presenta con la meseta interior. La principal diferencia que se registra entre el interior y la costa corresponde a la oferta de recursos marítimos inmediatos en la última de ellas.

Fisiográficamente, la provincia de Santa Cruz pertenece a la región Patagónica y está integrada, hacia el oeste, por la subregión de la Cordillera Patagónica Austral, y hacia el este por el área de la Meseta Patagónica (Ricciardi y Rolleri 1980). Esta última subregión, a su vez, se encuentra estructuralmente dividida en dos sectores: el Nesocratón o Macizo del Deseado y la Patagonia extra-andina que incluye la cuenca del Golfo San Jorge y la Cuenca Magallánica Austral (De Giusto et al. 1980; Ricciardi y Rolleri 1980) (Figura 2.1).

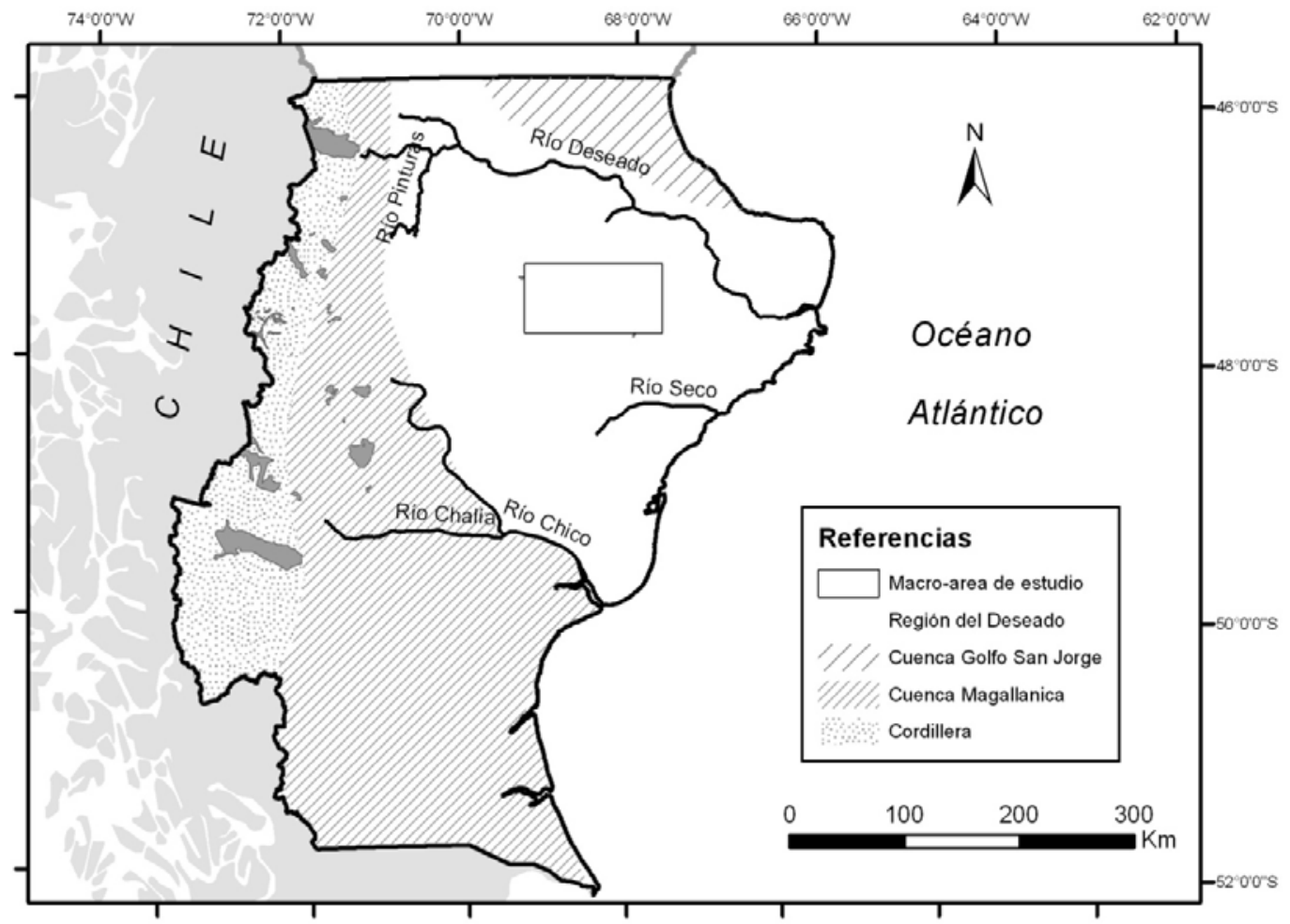

Figura 2.1: Macro-área de estudio y subregiones fisiográficas de la provincia de Santa Cruz (Tomado de Miotti 1998: Figura 4.3; modificado y digitalizado por Magnin 2010: Figura 2.4). 


\subsubsection{La cuenca del Zanjón Rojo y Blanco}

Un dominio de meso-escala en el sentido de Delcourt y Delcourt (1988) fue seleccionado como la unidad espacial y temporal de análisis y corresponde a la cuenca del Zanjón Rojo y Blanco en el sector noreste del Macizo Central del Deseado (Figura 2.2). Esta cuenca residual (Panza 2001) tiene una extensión aproximada de 140 kilómetros en sentido oeste-este y 80 kilómetros norte-sur y se localiza entre los $47^{\circ} 30^{\text {' }}$

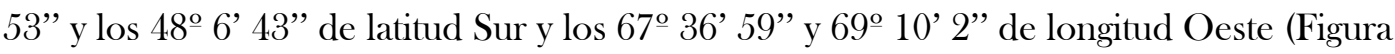
2.2). De ella proviene la base de conjuntos zooarqueológicos que se estudian en esta tesis.

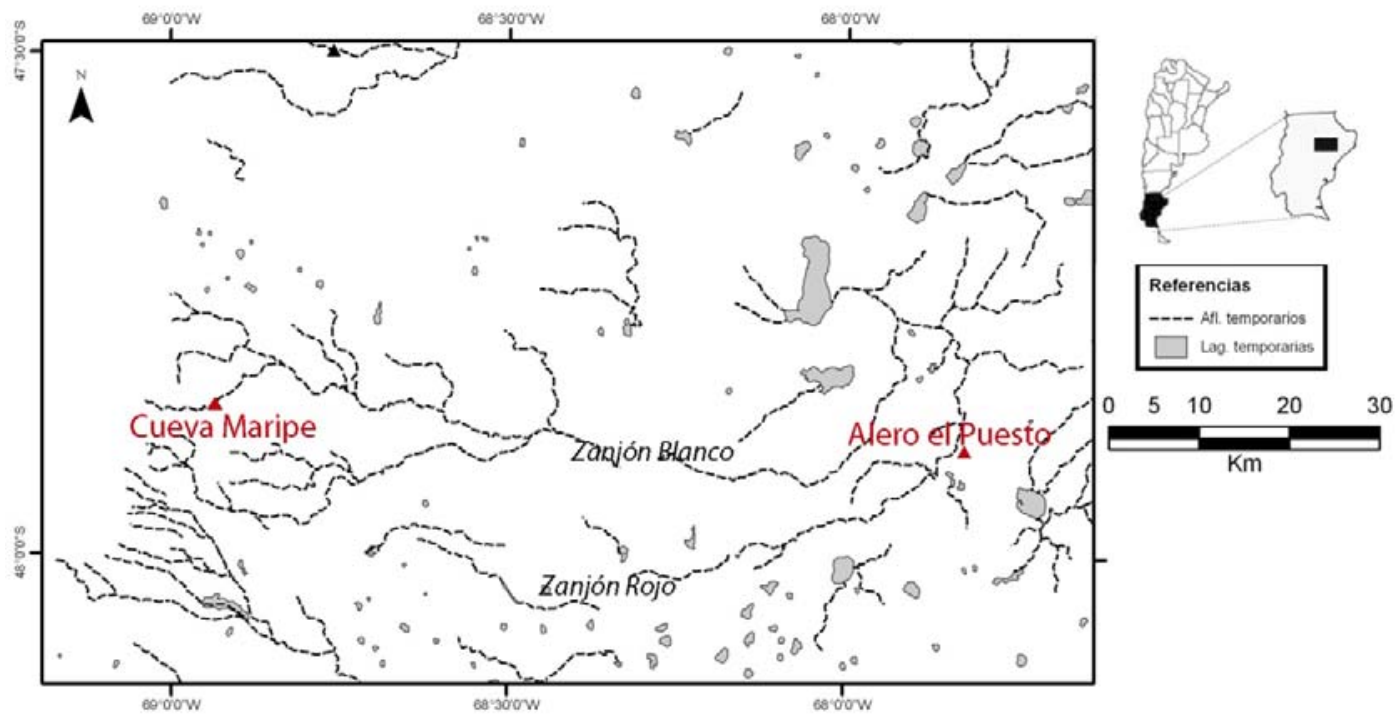

Figura 2.2: Cuenca de los Zanjones Rojo y Blanco (meso-área de estudio) y ubicación de los sitios estudiados en esta tesis.

En las cabeceras de cuenca se han registrado y excavado sitios a cielo abierto y bajo abrigo rocoso, comprendiendo las localidades de Gobernador Moyano, Aguada del Cuero (Cuevas de la Hacienda y Moreno), Tito del Valle, La Dorita, Los Ventisqueros, Las Mercedes, Sierra Blanca y La Primavera (Cueva Maripe). En el curso inferior y nivel de base de esta cuenca han sido excavados sitios entre los que se destaca Alero El Puesto 1 (AEP-1) y Chenque El Sargento de Piedra Museo y otros, que por el momento, sólo han sido posicionados y relevados en superficie, en la laguna Grande y mesetas circundantes del Monumento Natural Bosques Petrificados (MNBP). Dentro de este 
sector los contextos arqueofaunísticos que se analizaron proceden de dos depósitos estratigráficos con buena resolución temporal: la Cueva Maripe (MA) y AEP-1.

\subsection{CARACTERÍSTICAS GEOLÓGICAS Y GEOMORFOLÓGICAS}

La provincia de Santa Cruz está conformada por dos estructuras geológicas: la cordillera al oeste y la meseta al este (De Giusto et al. 1980; Ricciardi y Rolleri 1980). Los límites de esta última como una provincia geológica están dados por los ríos Deseado hacia el norte y Chico hacia el sur, por la llamada Dorsal del Río Mayo al oeste y por el océano Atlántico al este. Esta unidad ha sido caracterizada como "escudo" (Windhausen 1929 en De Giusto et al. 1980), “macizo” (Feruglio 1949 en De Giusto et al. 1980), aunque la denominación considerada como más acorde es la de Nesocratón por su comportamiento temporalmente positivo y rígido del área (De Giusto et al. 1980). Sin embargo, más recientemente se ha interpretado que la región estuvo sometida a fuerte subsidencia, donde se destacan dos episodios de rifting de gran magnitud, por lo que se ha propuesto reemplazar los términos "Macizo" y "Nesocratón" por el de "comarca" o "región del Deseado" (Sruoga et al. 2008).

Las unidades geológicas del Nesocratón son en gran parte de origen volcánico resultando en una distribución bastante abundante y homogénea de rocas con características apropiadas (fundamentalmente de la serie silícea) para la manufactura de artefactos tallados o producidos por picado y pulido, necesarias para la subsistencia de los grupos humanos que la habitaron en el pasado (Hermo 2008; Magnin 2010). Entre las rocas volcánicas que caracterizan el área, el Grupo Bahía Laura, de edad Jurásica, se caracteriza principalmente por la presencia de ignimbritas riolíticas que se disponen en mantos compactos y espesos y forman grandes paredones y crestas muy abruptas. Esta formación, conocida como Chön Aike, se reconoce en el paisaje porque forma asomos redondeados sin planos de estratificación que pueden tener disyunción columnar en su parte superior (Panza 2001). Esta formación además, se caracteriza por presentar grandes cavernas y oquedades producidas por meteorización.

Cueva Maripe, en la localidad La Primavera, es una cueva externa de grandes dimensiones cuya roca de caja corresponde a este tipo de ignimbritas características de la Fm. Chön Aike (Miotti et al. 2007). Por su parte, AEP-1 corresponde a un alero y abrigo 
rocoso contiguo que se ubica en un sector del afloramiento de sedimentitas marinas eocenas (arenisca coquinoide) de la Formación El Museo (Miotti 2000; Zárate et al. 2000). Allí además se abre la Cueva Grande (De Aparicio 1933-35; Miotti 2000).

Estos reparos naturales han sido habitados en el pasado por diferentes actores para diversos usos, y en muchos casos la ocupación humana de los mismos se dio hasta las últimas décadas del siglo XX. AEP-1 presenta una de estas situaciones ya que funcionó como lugar de cazadores-recolectores prehispánicos y luego como vivienda de puesteros de la estancia y galpón de herramientas rurales hasta 1987, cuando finalmente se abandonó el lugar y la estancia dejó de funcionar como empresa ganadera de ovinos (L. Miotti, comunicación personal 2011). Cueva Maripe en la estancia La Primavera, brinda otro ejemplo de estos usos, ya que en su Cámara Sur fue registrada una pirca, relicto de la ocupación de la familia Maripe que utilizó la cueva como espacio habitacional hasta la década de 1950 (Miotti et al. 2007). Otros ejemplos de uso de estas cuevas y aleros fueron documentados para Aguada del Cuero, Tito del Valle y los abrigos rocosos del cañadón de Los Toldos.

El paisaje geomorfológico es claramente volcánico, su altitud varía entre 1000 y 200 msnm (Miotti y Hermo 2000), y en este se pueden reconocer dos tipos diferentes. Uno conformado por extensas planicies mesetiformes, disectadas por depresiones de distintas dimensiones; las planicies elevadas se encuentran cubiertas por mantos basálticos que en sus márgenes se observan como paredones abruptos. Este paisaje es el que domina y caracteriza la cuenca alta de los Zanjones Blanco y Rojo donde se ubica la localidad arqueológica La Primavera con el sitio Cueva Maripe. El otro paisaje que se reconoce se caracteriza por un relieve irregular de zonas bajas con lomadas y cerros aislados dominantes, a esta caracterización corresponde la cuenca baja de los zanjones mencionados en donde se encuentra la localidad arqueológica Piedra museo con el sitio AEP-1.

El diseño de drenaje fluvial actual responde al curso particular de cada uno de los principales ríos que para el sector en estudio son el Deseado y el Chalía (Miotti y Hermo 2000). El sistema fluvial se encuentra parcialmente integrado, de modo que gran parte del mismo presenta un sistema endorreico múltiple. Este sistema está formado por cursos efímeros de régimen intermitente que llevan agua solamente en la estación lluviosa (durante el invierno y comienzo de la primavera) (Panza 1982). El mismo se suele caracterizar por la presencia de paleocauces de antiguas redes de drenaje. Cuando disminuye la pendiente se pueden formar lagunas de aguas semipermanente o cadenas de 
mallines (Miotti y Hermo 2000). El Zanjón Blanco (o Del Zorro) y El Zanjón Rojo (o Elornia) constituyen las cuencas hidrográficas endorreicas de mayor relevancia en la región. El primero de éstos, aunque efímero, corre en sentido oeste-este en su parte central y en su curso inferior hacia el norte para desaguar en la Laguna La Porfiada (con cotas de hasta $19 \mathrm{~m}$ por debajo del nivel del mar). El segundo de los zanjones, igualmente temporario, recorre la comarca en sentido sudoeste-noreste para desembocar en la Laguna Grande del Monumento Natural Bosque Petrificado (30 msnm) (Figura 2.2). Asimismo, se destacan colectores de menor importancia como los zanjones Cañadón Largo y Del Piche (Panza 2001; Magnin 2010).

\subsection{CARACTERÍSTICAS AMBIENTALES Y BIOGEOGRAFÍCAS}

La región patagónica extra-andina se caracteriza como un ambiente árido, riguroso y ventoso, con un clima templado frío (Paruelo et al. 2005). La variación de la temperatura está relacionada con la presencia de la cordillera de Los Andes, con la acción moderadora del océano Atlántico y con alta latitud (Jobbágy et al. 1995). Las temperaturas medias anuales varían entre $8^{\circ}$ y $10^{\circ} \mathrm{C}$. Las mínimas que corresponden al mes de julio varían, en relación con la altitud, entre $\operatorname{los} 0^{\circ}$ y $3^{\circ} \mathrm{C}$. Los fuertes vientos provenientes del oeste constituyen uno de los rasgos climáticos más característicos de la región, frecuentes en primavera-verano, aunque presentes durante el 80\% de los días del año. Se trata de vientos secos con ráfagas que pueden superar los $100 \mathrm{~km} / \mathrm{h}$. Las precipitaciones son mayores en la cordillera andina hacia el oeste, mientras que en la Patagonia extra-andina los valores promedios anuales son de alrededor de 180-300 mm anuales. Sin embargo, se pueden observar precipitaciones anuales de 100 y $400 \mathrm{~mm}$ para años muy secos o lluviosos respectivamente. Las precipitaciones níveas rondan entre las 5 y 10 nevadas anuales con un promedio de $20 \mathrm{~cm}$ cada una, se producen fundamentalmente en invierno. La disminución de las precipitaciones en sentido oesteeste se debe a la presencia de la cordillera andina, que actúa como una barrera contra los vientos que provienen del Océano Pacífico (Jobbágy et al. 1995).

Desde el punto de vista fitogeográfico, la provincia de Santa Cruz se reparte en dos regiones: la Neotropical y la Antártica (Cabrera 1976). El área de estudio definida para esta tesis corresponde al sector más árido de la Patagonia y se ubica dentro del Dominio 
de la estepa patagónica del Distrito Patagónico Central, en la Región Neotropical (Cabrera 1976). La vegetación característica del área es de tipo xerófila, representada por arbustos bajos y achaparrados, plantas en cojín o formando placas adheridas al suelo, hojas pequeñas y en muchos casos con espinas. Las zonas más húmedas y con protección del viento hay predominio de estepas graminosas (Cabrera y Willink 1980).

Zoogeográficamente, la provincia de Santa Cruz corresponde a la Subregión Patagónica de la Región Neotropical (Cabrera y Yepes 1960; Cabrera y Willink 1980). El sector del Macizo del Deseado se encuentra dentro de la Provincia Patagónica del Dominio andino-patagónico correspondiente a la Región Neotropical. Una especie característica de la región es Lama guanicoe, el ungulado silvestre de mayor talla y rango de distribución en Sud América, a diferencia de otros mamíferos patagónicos, se trata de un animal gregario que posee un peso aproximado de entre 80 y $120 \mathrm{~kg}$ (Raedecke 1978) y puede presentar elevada biomasa en determinados momentos del año (Rindel 2009). Entre los géneros y especies más comunes encontramos: la comadreja overa (Didelphis), lestodelfo patagónico (Lestodelphis), murciélagos (Lasiurus y Tadarida), la mara o liebre patagónica (Dolichotis patagonum) y la vizcacha de la sierra (Lagidium). Los tuco-tucos (Ctenomys) son muy abundantes, también los Cricetidae y menor frecuencia registran los Caviidae. Los armadillos o edentados están representados por dos especies: el piche (Zaedyus pichı) y el peludo (Chaetophractus villosus). En el área de estudio se encuentran distintos carnívoros, entre ellos especies de zorros: el colorado y el gris. El zorro colorado (Pseudalopex culpaeus) es un cánido de gran porte que pude llegar a medir 1,5 metros de largo. El zorro gris (Pseudalopex griseus) es más pequeño que el zorro colorado, con un largo total de 80 o 90 centímetros. El puma (Felis concolor) es una especie de felino que tiene una amplia distribución, es el mayor depredador de la región, netamente carnívoro, puede alcanzar una longitud de 1,5 metros y un peso de $35 \mathrm{~kg}$. En esta región también se encuentran el huroncito patagónico (Lyncodon) y el zorrino (Conepatus humboldtii).

El ave más representativa del área es el ñandú petiso o choique (Pterocnemia pennata), es un animal más pequeño que el ñandú común (Rhea), midiendo aproximadamente un metro de altura. El ñandú petiso alcanza un peso aproximado de entre 15 y $25 \mathrm{~kg}$ y su rendimiento de carne es de 8,5- $9 \mathrm{~kg}$. Igualmente, en el área se registra variedad de avifauna, la cual se encuentra integrada por patos y macaes, cauquenes o avutardas (Chloephaga), cisnes de cuello negro (Cygnus), gaviotas (Larus), martineta (Eudromia elegans); entre las rapaces más frecuentes se encuentran el águila 
escudada o mora (Geranoaetus melanoleucus), el carancho (Polyborus), el chimango (Milvago) y la lechuza del campanario (Tito alba).

\subsection{PALEOAMBIENTE}

La información paleoambiental disponible para el área procede de datos palinológicos, glaciológicos, sedimentológicos, paleontológicos y zooarqueológicos. Aquí se presenta información que corresponde con el período de ocupación humana del área entre el Pleistoceno final y los momentos en que las condiciones climáticas y biogeográficas adquieren las características actuales.

El recorte temporal se debe a que los fechados radiocarbónicos ubican a las ocupaciones humanas de los dos sitios investigados en esta tesis entre la transición Pleistoceno-Holoceno y el Holoceno tardío. En este sentido se utilizó, con fines analíticos, la división temporal propuesta por Miotti y Salemme (2004) para la ocupación humana de la región: transición Pleistoceno-Holoceno (13.000-8500 años AP), Holoceno temprano (8500-7500 años AP), Holoceno medio (7500-3000) y Holoceno tardío (3000 años AP a la actualidad).

La reconstrucción de la dinámica de la vegetación en este sector de la provincia se ha realizado fundamentalmente a partir del estudio del polen recuperado en secuencias sedimentarias de cuevas y aleros que habían sido ocupadas en el pasado por grupos humanos y que han sido o están siendo investigados por distintos arqueólogos. El polen recuperado proviene de distintas localidades y sitios arqueológicos del Macizo del Deseado como son: Alero Cárdenas y Alero Charcamata II en el área del Río Pinturas (Mancini 1998; Mancini y Trivi de Mandri 1994), Los Toldos (De Porras 2010; Prieto et al. 2002), Piedra Museo (Borromei 2003), La María (De Porras 2010) y La Martita (Mancini 1998).

En su mayor parte, los principales cambios en las comunidades vegetales registrados durante los últimos 12.000 años AP se habrían producido a escala regional. En la meseta, los mismos habrían seguido un patrón distinto al registrado en el área cordillerana donde se habría producido el reemplazo de una comunidad por otra. Comunidades vegetales relativamente similares a las actuales ya se encontraban presentes en la meseta para el 
Holoceno temprano y fueron experimentando cambios internos de composición y fisonomía (De Porras 2010).

En cuanto al registro faunístico del área de estudio, diversos trabajos han planteado que la existencia de los diferentes cambios ambientales trajeron aparejados cambios en la estructura faunística y por ende en la economía de las sociedades que habitaron esta área desde el Pleistoceno final (Miotti 1996, 1998; Miotti y Salemme 1999, 2005; Miotti et al. 1988; Paunero 2009, 2010). La tendencia registrada indica que la diversidad faunística disminuye desde el Pleistoceno final hacia el Holoceno en el sur de Patagonia (Miotti 1996, 1998; Miotti y Salemme 1999).

\subsubsection{Transición Pleistoceno-Holoceno al Holoceno temprano.}

La finalización de esta etapa hacia ca. 8500 años AP sería concordante con la presencia de los últimos ejemplares de mamíferos extinguidos tanto en la región pampeana como patagónica (Miotti y Salemme 1999; Miotti et al. 1988; Tonni 1992). Para este intervalo se registra la mayor diversidad faunística caracterizada por la presencia de megaherbívoros, mamíferos (herbívoros y carnívoros) de tamaños grande y mediano, y aves (Borrero 2001; Miotti y Salemme 1999; Mengoni Goñalons 1999)

El registro faunístico de Pampa y Patagonia muestra que para estos momentos los équidos, los camélidos, los perezosos gigantes y las aves corredoras son las especies más representadas en los sitios arqueológicos (Martínez y Gutiérrez 2004; Miotti y Salemme 1999). Sin embargo, el registro faunístico en Patagonia extra-andina, está fundamentalmente caracterizado por la asociación Lama guanicoe, Lama gracilis, Hippidion saldiasi, Rhea cf. americana (Miotti y Salemme 1999).

Entre los camélidos $L$. guanicoe es la especie que aparece representada en todos los sitios arqueológicos de la región. L. gracilis se registra en Patagonia únicamente en depósitos del último glacial y del Holoceno temprano (Miotti y Salemme 1999), su presencia ha sido determinada en algunos sitios arqueológicos de la región como son en la Cueva 3 de Los Toldos (Cardich et al. 1973; Miotti 1998), Cueva 7 de El Ceibo (Miotti 1998), Casa del Minero 1 (Paunero 2003; Paunero et al. 2007), Cueva Túnel (Frank 2011) y en Piedra Museo (Miotti et al. 1999, Miotti y Salemme 1999). Por su parte, los 
registros en el área de Hemiauchenia paradoxa provienen del sitio Cueva del Minero 1 (Paunero et al. 2007), Cueva Túnel y Cerro Tres Tetas (Frank 2011).

La presencia de Hippidion saldiasi está geográfica y estratigráficamente restringida a este período en la región Patagónica (Alberdi y Prado 1993; Alberdi et al. 2001), dentro del área de estudio se registraron restos de estos caballos en los sitios arqueológicos Cueva 2 (Mengoni Goñalons 1976-80) y 3 de Los Toldos (Cardich et al. 1973; Miotti 1998), en Cueva 7 de El Ceibo (Miotti 1998), en Cueva Túnel (Frank 2011) y en Piedra Museo (Miotti et al. 1999). También en el sitio paleontológico Cerro Bombero (Paunero 2010; Paunero et al. 2008).

Durante este lapso temporal en la región, ambas especies de Rheidos $(R$. americana y $P$. pennata) habrían sido recursos disponibles. $R$. americana habría estado presente hasta ca. 9000 años AP (como especies simpátricas) momento en que se da su último registro en el área. Su desplazamiento hacia el norte en busca de condiciones menos erémicas se produjo debido a cambios ambientales (Cardich y Miotti 1983; Miotti y Salemme 1999; Salemme y Miotti 1987; Tambussi y Tonni 1985). A partir de ese momento Pterocnemia pennata habría ocupado el nicho ecológico dejado por $\boldsymbol{R}$. americana. La presencia de estos rheidos fue determinada en la Cueva 3 de Los Toldos (Cardich et al. 1973; Miotti 1998), en la Cueva 7 de El Ceibo (Miotti 1998), Casa del Minero 1 (Paunero et al. 2007), Cueva Túnel (Frank 2011) y Piedra Museo (Miotti et al. 1999).

Otras categorías taxonómicas que también aparecen representadas en sitios arqueológicos del área para este momento son los cánidos, entre los que fue determinada la presencia de Pseudalopex sp. (Miotti 1998), Dusicyon sp. (Frank 2011). Mientras que félidos como el Puma (Felis concolor) (Miotti 1998) y Panthera sp. (Frank 2011) también fueron registrados en sitios del área. El registro lo completan la presencia de falcónidos, peces y pequeños roedores.

En general, los resultados de los estudios palinológicos realizados en la Meseta, han propuesto para los primeros momentos de la ocupación humana del área un ambiente árido con bajas precipitaciones y condiciones más frías que las actuales (Borromei 2003; De Porras 2010; Mancini 1998; Páez et al. 1999). A pesar de ello se registran algunas diferencias entre las localidades estudiadas.

Los análisis de polen de las localidades de Los Toldos y La María indican que las precipitaciones en estos momentos tendrían valores similares a los actuales (De Porras 2010); mientras que en el área de Piedra Museo hacia los ca. 11.000 años AP se registra 
una mayor disponibilidad relativa de humedad, quizá asociada a un incremento de las precipitaciones y que luego disminuye hacia los 9500 años AP (Borromei 2003). En cuanto a la cubierta vegetal, en Piedra Museo se registran dos cambios coincidentes con los cambios de humedad relativa, en el primero (ca. 11.000 años AP) se produce el reemplazo de una estepa arbustiva hacia una graminosa, mientras que en segundo (ca. 9500 años AP), esta última habría sido reemplazada por una estepa arbustiva, indicando una vegetación arbustiva de ambiente semidesértico (Borromei 2003). En Los Toldos y La María solamente se registra un cambio hacia ca. 10.250 AP donde se pasa de una comunidad subarbustiva-graminosa a una graminosa-subarbustiva, seguramente relacionado a un aumento progresivo de la temperatura que tiene lugar hacia ese mismo momento (De Porras 2010). Por su parte, los resultados de La Martita (Mancini 1998) indican la existencia de una comunidad graminosa con algunos arbustos medianos antes de los 8050 años AP.

\subsubsection{Holoceno medio}

Durante este período se registran aumentos del nivel del mar (Rabassa 1987; Rabassa et al. 1989), de la temperatura y la humedad (hipsitermal) pero que en la región extra andina no produjeron cambios en la estructura faunística (Miotti 1998). El único ejemplo que marca este aumento de humedad (ca. 8000 años AP) es el registro zooarqueológico de lobito de río (Lutra sp.) en el área de la altiplanicie central (Miotti 1998; Horovitz 2003). El registro zooarqueológico del área se encuentra dominado por la presencia de $L$. guanicoe y no se registra la presencia de la fauna pleistocénica que se reconoce en el período anterior. Respecto de este punto, para el Holoceno medio los índices indican menor diversidad taxonómica que para el Pleistoceno final- Holoceno temprano (Miotti y Salemme 1999).

En cuanto a las comunidades vegetales no se registran grandes cambios de las caracterizadas a fines del Holoceno temprano, el común denominador en los distintos sitios estudiados es el registro de un aumento progresivo de la temperatura (De Porras 2010). En La Martita, y a diferencia de lo que ocurre en otros sitios del área, hacia el ca. 5000 años AP se registra un cambio ambiental de corto plazo que corresponde con una 
mayor humedad (Mancini 1998). El mismo podría responder a condiciones más frías o con mayores precipitaciones que las actuales (Mancini 1998).

Hacia el ca. 7500 AP, en Piedra Museo empieza a dominar la estepa arbustiva reemplazando la estepa graminosa (Borromei 2003), en La Martita este cambio se produce entre ca. 8000 y 6000 años AP (Mancini 1998). De aquí la importancia de la presencia del lobito de río, ya que en la actualidad sólo se registra en los lagos y ríos cordilleranos con régimen de precipitaciones alto y alto porcentaje de eficiencia hídrica. Estando ausente en toda el área mesetaria.

Hacia fines del Holoceno medio en las localidades arqueológicas de La María y Los Toldos ya se habrían establecido condiciones similares a las actuales (De Porras 2010). Para estos momentos (ca. 3750 AP) en Los Toldos y La María las comunidades arbustivas experimentan un cambio que afectó principalmente a las especies dominantes, el mismo habría sido resultado de la caída de cenizas de la erupción del volcán Hudson (De Porras 2010).

\subsubsection{Holoceno tardío}

En La Martita hacia ca. 2190 años AP la comunidad graminosa-arbustiva establecida desde ca. 8000 años AP es reemplazada por una estepa arbustiva de Asteraceae subf. Asterideae constituyendo, de esa forma, condiciones paleoambientales similares a las actuales (Mancini 1998).

En las localidades de Los Toldos y La María a comienzos del siglo XX se produce un cambio que se relaciona a la explotación ovina en el área, el mismo no sería resultado directo del pastoreo sino más bien estaría relacionado al uso de las cuevas para refugio de ovejas (De Porras 2010).

El segundo cambio estructural se produjo con el ingreso del ganado ovino y consiguiente retroceso numérico de especies nativas que produjo casi la extinción de algunas de ellas. Un ejemplo lo constituye la retracción del huemul (Hippocamelus bisulcus) hacia el bosque cordillerano (Miotti 1998). 


\section{CAPITULO 3}

\section{ANTECEDENTES DE LAS INVESTIGACIONES ZOOARQUEOLÓGICAS EN EL MACIZO DEL DESEADO}

En este capítulo se reúne información relevante para comprender el estado actual del conocimiento zooarqueológico y cuál es su aporte al conocimiento arqueológico en la provincia de Santa Cruz. Se hace hincapié en los avances que desde la zooarqueología y la tafonomía se concretaron en la Altiplanicie Central. La información obtenida desde estas líneas de evidencia contribuye al conocimiento que actualmente tenemos sobre las sociedades cazadoras- recolectoras que habitaron el área durante los últimos 13.000 años.

Me referiré a la información obtenida a partir de los estudios realizados en las localidades arqueológicas ubicadas en el Nesocratón o Macizo del Deseado (De Giusto et al. 1980; Leanza 1958; Miotti 1998; Ramos 1999) y que sirvieron de base a este trabajo. Dentro del área se reconocen tres sectores principales en donde se han desarrollado intensas investigaciones arqueológicas. Uno de ellos en el NE de la Gran Altiplanicie Central, las investigaciones allí, fueron llevadas a cabo principalmente por el equipo de investigación del que formo parte y entre las principales localidades arqueológicas se destacan Los Toldos, Aguada del Cuero, el MNBP, Piedra Museo y La Primavera, estas dos últimas son las que se estudian en esta tesis. El segundo sector corresponde al sur de esta Altiplanicie, las principales localidades arqueológicas de ese sector son La Martita, El Verano, El Ceibo, Cerro Tres Tetas y La María. Finalmente, el sector NO del Macizo, el área del Río Pinturas, la cual corresponde al límite occidental del macizo y la convierte en una zona ecotonal entre los paisajes mesetarios del este y los contrafuertes cordilleranos con acceso a las altas mesetas que rodean los lagos como el Buenos Aires, con características ecológicas diferentes a las de la meseta central. En este último sector se han estudiado varios sitios entre los que se destacan Cueva de Las Manos, Arroyo Feo, Alero Charcamata y Alero Cárdenas (Figura 3.1). 


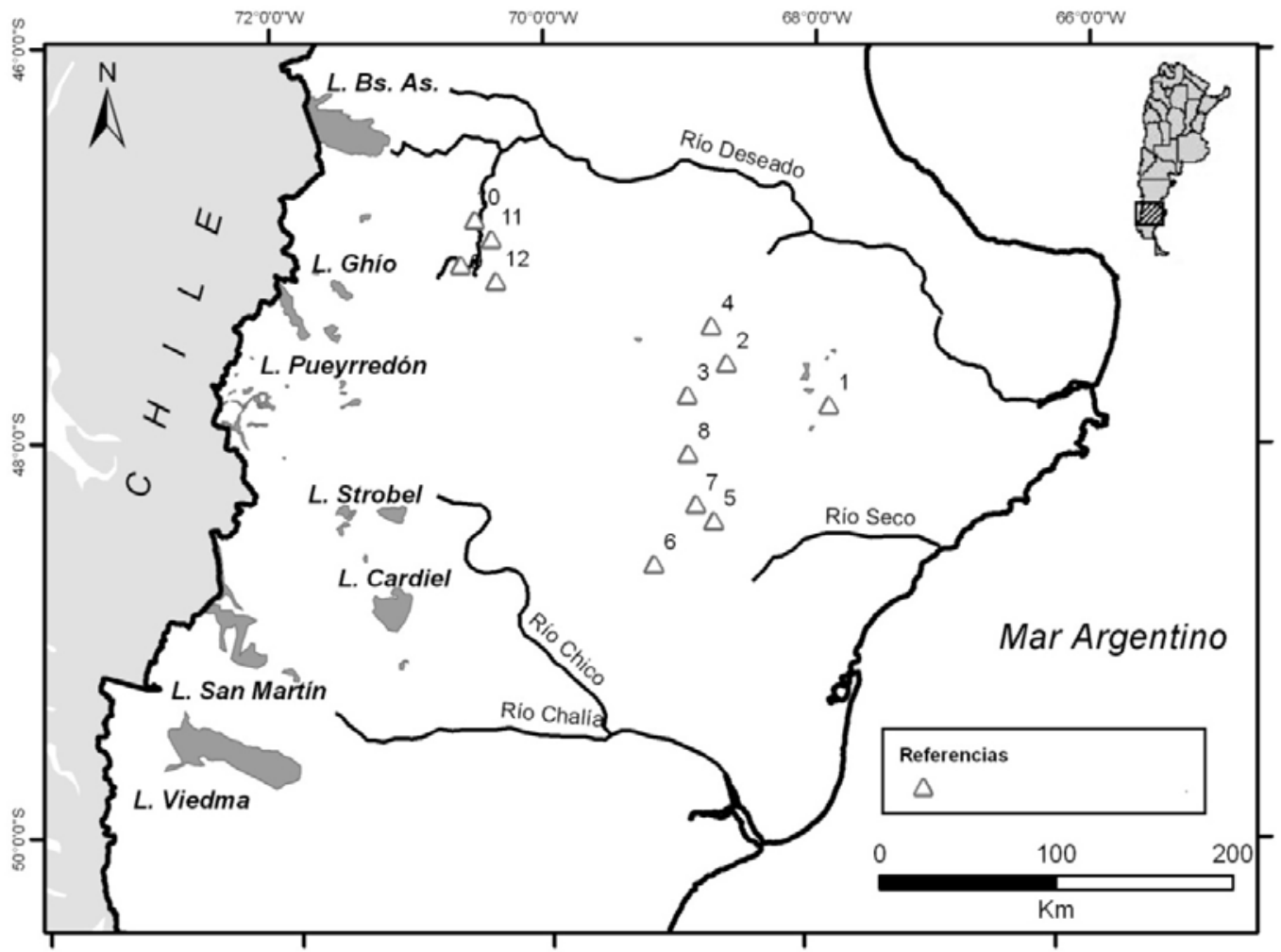

Figura 3.1: Localidades arqueológicas del Macizo del Deseado: 1) Piedra Museo; 2) Aguada del Cuero; 3) La Primavera; 4) Los Toldos; 5) El Ceibo; 6) El Verano; 7) La María; 8) Tres Tetas; 9) Cueva de Las Manos; 10) Arroyo Feo; 11) Alero Charcamata; 12) Alero Cárdenas.

3.1. ESTUDIOS ZOOARQUEOLÓGICOS EN LA MESETA CENTRAL DE SANTA CRUZ

\subsubsection{Las bases arqueológicas}

\subsubsection{Los exploradores}

El desarrollo de la arqueología en Patagonia comenzó con una etapa descriptiva hacia fines del siglo XIX. Durante la misma, distintos naturalistas, antropólogos y geólogos realizaron expediciones y trabajos de campo, localizando y describiendo sitios, 
colectando materiales, analizándolos y brindando información de mucha utilidad. Esta etapa, que se extendió hasta principio del siglo XX, estuvo representada por los trabajos de Francisco Moreno, Florentino Ameghino (Fernández 1982) y Félix Outes (1905). Como parte de esta etapa, Aparicio y Vignati realizan los primeros trabajos de campo en la provincia de Santa Cruz, los mismos se desarrollaron en un primer momento en la Meseta Central y costa (Frenguelli 1933; De Aparicio 1933-35).

La expedición arqueológica llevada a cabo en 1933 por De Aparicio, Frenguelli y Brandmayr brindó información de gran valor para el desarrollo posterior de las investigaciones en la Meseta Central ya que recorrieron y describieron varios sitios y cuevas (De Aparicio 1933-35; Frenguelli 1933). En 1949 Vignati y Rex González realizaron una expedición a la Patagonia, donde relevaron las pinturas de la cueva Charcamata en el área del Río Pinturas (Vignati 1950). A principios de 1950 Menghin realiza las primeras prospecciones y sondeos en el área del Macizo del Deseado. Además excava las cuevas 1, 2 y 3 de la estancia Los Toldos y propone, a partir de las características morfológicas y tecnológicas de los materiales, y de su ubicación estratigráfica, una secuencia cultural para Patagonia formada por dos complejos, el más antiguo llamado Toldense y el más moderno, el Casapedrense (Menghin 1952a, 1952b, 1957).

\subsubsection{El comienzo de las excavaciones sistemáticas}

Las investigaciones arqueológicas sistemáticas en la meseta comenzaron en la década de 1970 de la mano del Ing. Augusto Cardich y colaboradores (Cardich et al. 1973), y en el Pinturas con el equipo de Gradin (Gradin 1971; Gradin et al. 1976). Cardich realiza excavaciones arqueológicas en distintas cuevas de la localidad Los Toldos, las misma le permitieron corroborar la existencia de la secuencia cultural propuesta por Menghin, encontrando además, un nivel anterior al Toldense, al cual Cardich llamó industria Nivel 11 (Cardich et al. 1973; Cardich 1977; Cardich y Flegenheimer 1978).

Hacia fines de la década de 1970 empiezan a expandirse las investigaciones hacia otros sectores del área mesetaria. Por un lado, Cardich inicia sus investigaciones en la localidad arqueológica de El Ceibo con el interés puesto en comprobar la existencia de la secuencia anteriormente registrada en Los Toldos (Cardich et al. 1981-82). Esta localidad arqueológica ya había sido visitada en 1936 por Junius Bird, quién regresa en 1976 y 
realiza prospecciones arqueológicas junto con Rex González. Ellos informan a Cardich sobre la importancia arqueológica de la localidad (Miotti 1998).

En El Ceibo Cardich excavó la cueva 7, en ella registró la presencia de fauna extinguida -ie., caballo y camélidos- asociada a materiales similares a los de la Industria Nivel 11 de Los Toldos (Cardich et al. 1981-82). Para este mismo momento inicia las investigaciones arqueológicas en la localidad La María (Cardich et al. 1981-82), donde se reconoció gran cantidad de cavernas (Cardich y Paunero 2000; Cardich et al. 1981-82; Mansur-Franchomme 1983, 1987).

Los trabajos realizados por Cardich en la Meseta Central de Santa Cruz significaron un avance importante en la arqueología del área. Con ellos comenzaron las investigaciones sistemáticas en el Macizo teniendo en cuenta múltiples líneas de evidencia y se realizaron los primeros fechados radiocarbónicos (Cardich et al. 1973).

En el río Pinturas, el equipo dirigido por Gradin comienza a multiplicar la información logrando rápidamente un esquema regional. Lleva adelante la integración en temas como arte rupestre, tecnología y la nueva disciplina que se estaba instaurando en el país: la zooarqueología (Mengoni y Silveira 1976; Silveira 1979). Luego, Gradin y Aguerre comienzan a trabajar el área cercana a El Ceibo y La María (Figura 3.1). En el sector SE del Macizo, Aguerre empieza con las investigaciones en la Estancia La Martita. Sus estudios se enfocaron en la tecnología lítica de la industria Toldense (Aguerre 1979, 1982, 1987, 1997) enmarcados dentro de un proyecto regional dirigido por Gradin (Gradin et al. 1976, 1979, entre otros), cuyos intereses estaban orientados al poblamiento temprano entre otros (Aguerre 1982, 1987).

La información zooarqueológica aún era limitada, generalmente consistía en determinaciones taxonómicas sobre las especies reconocidas. A estos se sumaban los dos primeros estudios emprendidos por becarios, con objetivos que por primera vez muestran claramente los aportes zooarqueológicos dentro del equipo dirigido por Cardich (Cardich y Laguens 1984; Cardich y Miotti 1983; Miotti, 1998).

\subsubsection{Las bases zooarqueológicas}

A comienzos de los '80 la zooarquelogía como línea de investigación en la Meseta aún estaba ausente. Comenzaban a especializarse algunos jóvenes arqueólogos que 
trabajaban en otros sectores de Patagonia y del país (Borrero 1976-80, 1977, 1986; Caviglia 1976-80; Caviglia y Figuerero Torres 1976; Caviglia et al. 1986; Mengoni Goñalons 1976-80; Mengoni y Silveira 1976; Politis 1984; Sanguinetti y Borrero 1977; Silveira 1979). Dentro del área de estudio de ésta tesis (ver Capítulo 2), los materiales faunísticos procedentes de la cueva 3 de Los Toldos fueron determinados por los paleontólogos Odreman, Hoffstetter, Pascual y Tonni (Cardich et al. 1973, 1977; Miotti 1998). De esta manera, los primeros datos zooarqueológicos del Macizo aportaron a la discusión sobre la asociación de fauna pleistocénica y los primeros grupos humanos, la extinción de los megahervíboros y el paleoclima. El trabajo realizado por Mengoni Goñalons (1976-80) sobre los materiales óseos de la colección Menghin constituye el primer artículo específico sobre análisis faunístico en el área.

Algunos años después, encontramos los aportes de Cardich y Laguens (1984) quienes estudiaron la fracturación intencional del material óseo de la Cueva 3 y su posterior utilización y los trabajos de Cardich y Miotti $(1983,1988)$ sobre la economía de las sociedades cazadoras-recolectoras y el procesamiento de los recursos faunísticos. Asimismo, son de destacar dos trabajos zooarqueológicos sobre los sitios Cueva de Las Manos (Mengoni Goñalons y Silveira 1976) y Arroyo Feo (Silveira 1979).

Si bien se observa un interés creciente en esta dirección, el desarrollo metódico de esta línea en el área no comenzó hasta mediados de la década del '80. Las investigaciones zooarqueológicas que empezó a desarrollar la Dra. Laura Miotti, tenían como objetivo caracterizar los procesos adaptativos de los grupos cazadores-recolectores aborígenes en la meseta central y costa de Santa Cruz desde las ocupaciones más antiguas (ca 12.000 años AP). Para ello, Miotti analizó las muestras faunísticas procedentes de diversos sitios, estudiando además, a partir del registro zooarqueológico, la evolución del ambiente (Miotti 1998). Toda esta investigación resultó en 1989 en la primera tesis doctoral dedicada exclusivamente al estudio de restos faunísticos de sitios de Patagonia (Mengoni Goñalons 2007). En este trabajo además, se estudiaron muestras zooarqueológicas de sitios de la costa, cuya integración resultó en un estudio comparativo de las arqueofaunas de dos ámbitos ecológicos diferentes. Esto permitió establecer la variabilidad de estrategias utilizadas por los cazadores-recolectores desde el Pleistoceno final hasta el Holoceno tardío en esta región de la Patagonia extra-andina. A partir de entonces, los proyectos de investigación dirigidos por la Dra. Miotti a partir de 1990 en el sector norte de la Meseta Central de Santa Cruz tuvieron como objetivo estudiar el poblamiento humano de la región. Este estudio viene siendo abordado desde distintas 
líneas de evidencia y mediante el uso de nuevas herramientas metodológicas (Carden 2009; Cattáneo 2002; Hermo 2008; Magnín 2010; Miotti 1992, 1998; Miotti y Carden 2007; Miotti y Cattáneo 1997; Miotti y Marchionni 2009; Miotti et al. 1999a, 1999b, 2007a, 2007b; Miotti y Salemme 2005). De esta manera se profundizó el estudio de nuevos sitios arqueológicos como Piedra Museo (Giardina et al. 2000; Miotti 1992, 1995, 1996, 2003, 2006; Miotti y Carden 2007; Miotti y Salemme 1999, 2005; Miotti et al. 1999b, entre los principales), Aguada del Cuero (Miotti et al. 1999a, 2005), y más recientemente Cueva Maripe en la localidad La Primavera (Carden 2009; Hermo 2008; Hermo y Magnin 2012; Magnin 2010; Miotti et al. 2009, 2007b, 2011).

Hacia mediados de 1980 Víctor Durán, inicia sus investigaciones arqueológicas en el sector sur de la Altiplanicie Central. Tiene como objetivo contribuir con información que ayude a definir las estrategias adaptativas de los sistemas socioculturales, sin embargo sus trabajos de campo en la zona finalizan hacia fines de los '80 (Durán 1983-85, 1986-87, 1988). Como parte de sus estudios, surge un interés tafonómico al registrar, durante sus excavaciones, una importante perturbación resultado de la actividad fosorial de roedores. Por tal motivo es que lleva adelante un trabajo experimental (Durán 1991). Estos estudios tafonómicos no se continuaron en la Meseta. Varios años después, Durán y colaboradores (2003) analizan la fauna del nivel más antiguo (ca. 8900) de la Cueva 1 de la localidad El Verano.

Hacia fines de 1990, se realizaron análisis en relación con la estimación de muerte de guanacos en La Martita a partir del estudio del desgaste dental, para evaluar el uso de este recurso y la estacionalidad (Bayardo García 1983; Pagano 1996; Pagano y Aguerre 2001). Luego, se analizaron patrones de trozamiento y transporte del guanaco, registrando huellas de corte, meteorización y alteración térmica de los especímenes. Estos aspectos también son estudiados en el sitio Alero Charcamata II (área del Río Pinturas) (Aguerre 1994; Aguerre y Pagano 2003; Pagano y Aguerre 2001; Pereda 1994) y presentan información biogeográfica de interés a partir del registro de Lestoldelphys Halli en La Martita (Horovitz, 2003). En este momento se publican trabajos que analizan la estructura faunística del sitio Alero Cárdenas en el área del Río Pinturas (Aguerre y Pagano 1991; Aguerre et al. 1994a, 1994b; Horovitz 1991, 1994).

A mediados de la década de 1990 el Lic. Rafael Paunero inicia sus investigaciones en las localidades arqueológicas de Cerro Tres Tetas (Paunero 1994; Paunero y Castro 2001) y continúa con las investigaciones iniciadas en La María por Cardich (Paunero 2000a, 2000b, 2000c, 2003b). Las investigaciones que desde entonces Paunero y su 
equipo vienen realizando de forma continuada se han orientado fundamentalmente al estudio de la tecnología lítica y el arte rupestre (Frank et al. 2007; Cueto y Castro 2012; Paunero 2000a; Paunero y Castro 2001; Paunero et al. 2005; Podestá et al. 2005; Skarbun 2009; Skarbun et al. 2007). El trabajo de tesis recientemente desarrollado por Frank (2011) aborda una problemática novedosa dentro de las tradicionalmente estudiadas en la meseta. Frank estudió a partir de experimentación, el manejo del fuego por parte de las sociedades humanas del pasado, las consecuencias de la alteración térmica sobre los distintos materiales (i.e., líticos y óseos) y el rol de los fogones como estructuradores del espacio.

Como parte de las investigaciones realizadas por Paunero y colaboradores se han publicado datos sobre la abundancia taxonómica, presencia de fauna pleistocénica asociada a los niveles más tempranos de ocupación y tecnofacturas en hueso (Frank 2011; Paunero 2003a, 2003b; Paunero et al. 2007a, 2010). Sin embargo, la zooarqueología no ha sido hasta el momento, una línea de investigación desarrollada en profundidad.

Si bien las investigaciones zooarqueológicas realizadas por Miotti en el sector norte de la Meseta Central marcan el inicio de una etapa en la arqueología del área, estas investigaciones dentro del equipo de investigación estuvieron, en general, dirigidas al estudio de los paleoambientes (Alberdi et al. 2001; Miotti y Salemme 1999; Miotti et al. 1988; Salemme y Miotti 2008) y a la utilización de la fauna por parte de las sociedades del pasado (Miotti 1992, 1996, 2003, 2011; Miotti et al. 1988, 1999b; Miotti y Salemme 2004, 2005). Si bien hubo un interés en conocer la historia de la formación de sitios como Piedra Museo (Giardina et al. 2000; Miotti et al. 1999b) esa línea no se continuó, quedando los estudios tafonómico y de procesos de formación del registro pendiente de un abordaje sistemático. Si bien en algunos trabajos se percibió ese interés, era necesario tratar este tema en profundidad y a estos fines comencé mis trabajos zooarqueológicos y tafonómicos (Marchionni et al. 2010).

Esto se diferencia mucho de lo que ocurrió en sectores vecinos - eg., sur y noroestedonde se observa una falta de continuidad y desarrollo de esta línea de investigación, lo que resulta en información fragmentaria que no permite abordar con profundidad los procesos de formación del registro arqueológico, el estudio de la estrategias de subsistencia de los grupos humanos del pasado y los paleoambientes. En el área del Río Pinturas los estudios tafonómicos tampoco tuvieron un desarrollo sistemático dentro de los programas de investigación arqueológica. 
En otros sectores de Patagonia, como en la cuenca magallánica austral y el sector de los lagos cordilleranos, la zooarqueología y la tafonomía han tenido un fuerte desarrollo (Borrero 1976-80; Caviglia 1976-80; Caviglia y Figuerero Torres 1976; Caviglia et al. 1986). De suma relevancia, resultaron los aportes teórico-metodológicos realizados por Borrero $(1988,2001)$ con un fuerte desarrollo de Tafonomía Regional (Barberena 2008; Belardi 1999; Borrero 1988, 2000, 2001; Borella 2002; Cruz 2003; L’ Heureux y Borrero 2002; Martin y Borrero 1997; Martin 2008).

En el sector de los lagos cordilleranos, las investigaciones zooarqueológicas desarrolladas por Mengoni Goñalons (1999) en Cerro de los Indios han sido de gran importancia y a partir de ese momento se han formado investigadores que continúan esta línea de investigación en el área. Entre las principales investigaciones zooarqueológicas de los últimos años, se destaca la producción de tres tesis doctorales (Bourlot 2010; De Nigris 2004; Rindel 2009). Los trabajos realizados por De Nigris (2004) se propusieron estudiar las estrategias de consumo en grupos cazadores-recolectores a partir de los conjuntos arqueológicos de Cerro Casa de Piedra 7 (Parque Nacional Perito Moreno). Por su parte, Rindel (2009) abordó el estudio zooarqueológico de los materiales provenientes de aleros y sitios a cielo abierto, ubicados tanto en el Parque Nacional Perito Moreno como en Pampa del Asador, con el objetivo de conocer los patrones de subsistencia, asentamiento y movilidad de las poblaciones humanas que ocuparon el sector noroeste de Santa Cruz durante los últimos 2500 años. Bourlot (2010) tuvo como objetivo estudiar aspectos relacionados a la subsistencia de los grupos cazadores recolectores durante el Holoceno tardío. Puso un interés especial en el análisis de patrones de fractura y niveles de fragmentación ósea para conocer las estrategias de procesamiento y consumo de las presas.

\subsection{EL REGISTRO ARQUEOLÓGICO Y ZOOARQUEOLÓGICO DEL ÁREA DE ESTUDIO}

El conocimiento construido durante todos estos años de investigación en el Macizo evidencia que el área estuvo ocupada desde el Pleistoceno final (ca. 13.000 años AP) en el sector noreste y sur de la Altiplanicie, mientras que en los contrafuertes cordilleranos las primeras ocupaciones se dan a partir de ca.9500, en el área correspondiente al Río 
Pinturas (Gradin et al. 1976), y unos ca. 9700 en lago Belgrano (Civalero y Aschero 2003). El denominador común de la subsistencia de estas sociedades fue el guanaco, principal recurso económico en los distintos momentos de la ocupación del área, incluso hasta el Holoceno tardío. A continuación se sintetiza información de los sitios investigados dentro del Macizo del Deseado, con particular énfasis en los análisis zooarqueológicos y tafonómicos.

\subsubsection{Localidad arqueológica Los Toldos}

Esta localidad se ubica al sur del curso medio del río Deseado (Figura 3.1) y está compuesta por 15 cuevas y abrigos rocosos entre otros sitios arqueológicos a cielo abierto, como canteras de aprovisionamiento de materias primas y talleres (Miotti, 1998). Fue descubierta por los Dres. De Aparicio y Frengüelli (De Aparicio 1933-35). En 1951 y 1952 Menghin realiza las primeras prospecciones y sondeos arqueológicos en las Cuevas 1, 2 y 3 determinando la presencia de dos complejos culturales, el más antiguo el Toldense y el más reciente el Casapedrense (Menghin 1952a, 1952b, 1957). A partir de 1971 Cardich y colaboradores inician las investigaciones arqueológicas (Cardich 1977, 1984; Cardich y Flegenheimer 1978; Cardich y Miotti 1983, 1988; Cardich et al. 1973, 1977).

La Cueva 2, se ubica en la ladera sur del "Cañadón de las Cuevas" (Figura 3.1) al borde del cauce actual del arroyo temporario. Ella conserva la mayor cantidad de pinturas rupestres de todas las cuevas y aleros de la localidad (Carden 2009). Menghin (1952b, 1957) corroboró los dos niveles culturales identificados por Aparicio (De Aparicio 1933-35). Hacia mediados de 1980 Cardich y Paunero (2000) realizan excavaciones sistemáticas en el sitio, durante las cuales identificaron 12 capas naturales sedimentarias (para una discusión detallada ver Cardich y Paunero 2000; Mengoni Goñalons 1976-80; Miotti 1998). Para el Toldense se identificaron además de los restos óseos correspondientes a guanaco, materiales que fueron asignados a Camélidos “indeterminados que se asemejan a una vicuña" (Miotti 1998: 214), Onohippidion (Parahipparion) saldiasi (caballo fósil) y un molusco marino, cholga (Aulacomya ater). En este nivel se destaca la importancia de la asociación entre el hombre temprano y fauna fósil, en particular el caballo americano. 
Para el nivel Casapedrense, Mengoni Goñalons (1976-80) identifica restos de guanaco, cánidos y Pterocnemia pennata. La mayor frecuencia de unidades anatómicas del guanaco la registra para el esqueleto apendicular, encontrando patrones de fragmentación transversales y longitudinales. El perfil etáreo del conjunto sería similar al Toldense (adultos y juveniles). Por otra parte, para el Toldense, Cardich y Paunero en 1986 registran dientes sueltos de caballo fósil y para el Casapedrense de la misma cueva, restos de moluscos marinos, que analizados por Miotti y Castellanos fueron determinados como dos cuentas de Fisurella sp. (Miotti 1998: 215 figura 8.2).

La cueva 3, ubicada en la ladera sur del "Cañadón de las Cuevas”, es una gran cueva, protegida de los fuertes vientos del oeste por un reparo rocoso. Su interior está dividido en dos cámaras: el recinto principal o mayor y el recinto oscuro. En las paredes y techos de ambos sectores hay representaciones rupestres de negativos de manos (Cardich 1987; Cardich et al. 1973; Miotti 1998). Las excavaciones arqueológicas se realizaron por Cardich y colaboradores durante los años 1971 y 1974 (Cardich et al. 1973, 1977) y 1985 y 1986, alcanzando $93 \mathrm{~m}^{2}$ de superficie excavada (Cardich 1984; Miotti 1998: 109, Figuras 7.1.7 y 7.1.8). Se identificaron doce capas naturales en el recinto principal y 4 en el recinto oscuro. La secuencia estratigráfica registrada en esta cueva es la más completa de la localidad. En ella se identificaron cuatro componentes arqueológicos en base a sus materiales líticos, óseos, fechados radiocarbónicos y sedimentología, los mismos fueron definidos por Cardich como "complejos culturales" (Cardich et al. 1973).

La industria Nivel 11 (capa 11) es el complejo cultural más antiguo (12.600 \pm 600 años AP a ca. 11.000 años AP). Aquí fue registrada la presencia de algunos restos de megamamíferos pleistocénicos, como Hippidion sp. y elementos de los cuartos de Lama gracilis (Cardich et al. 1973; Miotti 1998). En los huesos largos de L. gracilis fue determinada la presencia de fracturas intencionales. Sin embargo, el recurso económico básico para este momento fue el guanaco, del cual se registraron fundamentalmente elementos correspondientes a los cuartos traseros y delanteros (para una discusión detallada sobre la funcionalidad del sitio ver Miotti 1998). De todas formas, dicha antigüedad para el Nivel 11 ha sido cuestionada por diferentes autores, fundamentalmente debido a la falta de información precisa y procedencia dudosa respecto de la muestra fechada (Borrero 1996; Politis 1999).

El nivel de ocupación Toldense comienza ca. 11.000 años AP y finaliza hacia el $8.750 \pm 480$ años AP (Cardich y Flegenheimer 1978; Cardich et al. 1973, 1977; Miotti 1998). Entre la fauna pleistocénica se registró el aprovechamiento de Hippidion sp. Se 
determinó la presencia de Rhea americana (especie que actualmente no habita el área). La misma fue interpretada como un recurso complementario del guanaco. En este sentido, se propuso un cambio en la estrategia, dirigido a optimizar un recurso especial: el guanaco (Miotti 1998).

En el contexto Casapedrense el conjunto faunístico está dominado por la especie Lama guanicoe aunque también se recuperaron otros especímenes correspondientes a especies autóctonas con huellas de procesamiento. En este nivel se registra la presencia de perro doméstico (Cardich et al. 1977; Miotti 1998). Este componente se ubica temporalmente entre $7.260 \pm 350$ y $4.850 \pm 50$ años AP (Cardich 1984).

La "Industria nivel 1,2 y 3" de Los Toldos (Cardich et al. 1973; Cardich y Miotti 1983; Mansur-Franchomme 1983), puede correlacionarse con el Patagoniense (Aschero 1975, 1987). Los restos faunísticos corresponden a especies autóctonas que actualmente ocupan el área, la excepción la constituye el registro de restos de un cérvido (Cardich et al. 1973; Miotti 1998).

La parte central del recinto principal, con fogones amplios, fue interpretada como un sector donde se realizaron actividades de preparación y consumo de alimentos, y confección de tecnofacturas, mientras que el recinto lateral oscuro, donde también se registraron fogones, fue considerado un área de basural (Miotti 1998). La capa 12 es arqueológicamente estéril, lo mismo ocurre con las capas 4 y 5 que corresponden a ceniza volcánica, por su parte la capa 8 es semi-estéril y fue interpretada como un momento de sequía que volvió inhóspito el lugar (Cardich et al. 1973).

La cueva 13 se encuentra ubicada sobre la margen norte del "Cañadón de las Cuevas" (Cardich et al. 1973, 1987). En 1987 comenzaron las excavaciones en la cueva (Cardich y Miotti 1988; Miotti 1998). Allí fueron definidas once capas naturales y se identificaron dos componentes culturales: el superior o Patagoniense (capas 2, 3, 4 y techo de 5), similar al de la cueva 3 y el inferior o Casapedrense (capa 6 a 9), dentro del cual se pudieron identificar dos pisos de ocupación. La capa 5 está constituida por cenizas volcánicas que se correlacionan con las capas 4 y 5 de la cueva 3.

Del análisis zooarqueológico efectuado por Miotti (1998) se desprende que durante el Casapedrense el guanaco fue el principal recurso económico siendo todas sus unidades anatómicas transportadas al sitio. El registro de elementos correspondientes a aves y cánidos es interpretado como resultado posiblemente del consumo de los mismos. Entre las modificaciones óseas se identificaron marcas de procesamiento, fracturas para la 
extracción de médula ósea, alteración térmica, manchas de manganeso, pigmento rojo y depósitos de carbonato.

\subsubsection{Localidad arqueológica Aguada del Cuero}

Se encuentra ubicada en la estancia homónima, en las cabeceras del Zanjón Blanco. Dentro de ella fueron reconocidos varios sitios arqueológicos, entre los que se encuentran bardas con pinturas rupestres y petroglifos, sitios a cielo abierto y sitios en cuevas (Miotti et al. 1999 a). Dos de estos últimos fueron excavados durante la campaña de 1999 y a continuación se describen brevemente. Los resultados indicarían lugares de habitación, refugio y procesamiento de alimentos, enfatizando el uso de estos espacios altos y mesetarios en momentos tardíos de ocupación (Miotti et al. 2005).

La Cueva de La Hacienda, conocida como "Abrigos de Aguada del Cuero” (De Aparicio 1933-35: 82), está ubicada en $47^{\circ} 41^{\prime} 20^{\prime \prime}$ 'sur y $68^{\circ} 38^{\prime} 26^{\prime}{ }^{\prime}$ oeste, en la cumbre de un afloramiento de la formación Baqueró (Miotti et al. 2005). En sus paredes y techo se describieron tres sectores con pinturas rupestres. Durante sus excavaciones se identificaron cuatro unidades estratigráficas en base a sus características de color, textura y clastos. La unidad 4 es arqueológicamente estéril y apoya sobre la roca de caja. La mayor parte de los materiales arqueológicos fueron recuperados en la unidad 3 donde también

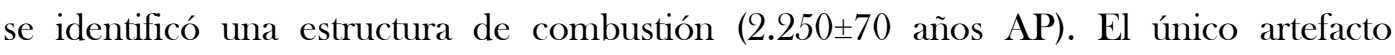
formatizado corresponde a una punta pedunculada con aletas del tipo "Patagoniense". Los restos de fauna son escasos y se encuentran en muy mal estado de conservación (Miotti et al. 2005).

Por otra parte la Cueva Moreno se emplaza sobre la margen norte de un cañadón subsidiario en las nacientes del Zanjón Blanco. La cueva se encuentra a $50 \mathrm{~m}$ sobre el "Bajo de Los Adobes" al cual desemboca este cañadón y tiene la particularidad de presentar inclusiones de troncos petrificados, cuya calidad es poco apta para la talla (Miotti et al. 2005). En ella fueron registrados cinco negativos de manos. Se excavaron dos cuadrículas de 2 × 2 m., una de ellas dentro de la cueva y la otra en el sector externo. Se identificaron tres unidades principales, desde la superficie actual hacia la roca de base. La mayor cantidad de materiales se recuperó en la unidad 2, aunque algunos también proceden de la unidad más superficial. El material lítico de este sitio está caracterizado 
por una notable frecuencia de láminas y por gran cantidad de clastos de xilópalo provenientes de la formación en la que se emplaza la cueva, entre ellos, un raspador, una muesca y una raedera elaborados sobre láminas. Los restos faunísticos, a excepción de unos pocos que proceden de la unidad 1, presentan muy mala conservación con estadios de meteorización elevados (4 y 5 sensu Behresmeyer 1978). En este nivel se identificaron estructuras de combustión, el fechado realizado sobre la más profunda de ellas indica una edad de 3.000 \pm 110 años AP (Miotti et al. 2005).

\subsubsection{Localidad arqueológica El Ceibo}

Esta localidad arqueológica se encuentra ubicada a $48^{\circ} 31^{\prime}$ sur y $68^{\circ} 45^{\prime}$ oeste, en el sector sur de la Gran Altiplanicie Central de Santa Cruz, unos $150 \mathrm{~km}$ al NO de Puerto San Julián. La localidad está integrada por 9 cuevas y sitios a cielo abierto (Cardich 1979; Cardich et al. 1981-82; Mansur-Franchomme 1983). Todas las cuevas presentan pinturas rupestres y materiales líticos en superficie, pero la mayoría no posee acumulación de sedimentos (Miotti, 1998). Las excavaciones arqueológicas efectuadas en la Cueva 7, de la cual se presenta una breve descripción a continuación, brindaron la secuencia estratigráfica más completa de la zona (Miotti 1998).

Se trata de una pequeña cueva ubicada al pie del acantilado norte de la depresión que hasta 1984 ocupaba una somera laguna, sus dimensiones habrían sido mayores cuando los primeros grupos humanos la ocuparon (Cardich et al. 1981-82; Miotti 1998). En su secuencia estratigráfica se reconocieron trece capas naturales. Los materiales recuperados en la capa 9 fueron asignados al contexto Toldense, mientras que los recuperados en la capa 12 fueron relacionados con la Industria Nivel 11 de Los Toldos. Entre los restos faunísticos recuperados en este nivel, se registraron especímenes correspondientes a megamamíferos extinguidos. En la base de la capa 11 se apoyan los pedrones desprendidos del antiguo techo del abrigo, el resto de las capas son arqueológicamente estériles o presentan escasos vestigios (Cardich et al. 1981-82; Miotti, 1998).

El análisis zooarqueológico reveló que, para el nivel correspondiente a la Industria Nivel 11, la fauna pleistocénica identificada no presentó modificaciones antrópicas y corresponde a Hippidion sp. y Lama gracilis. El guanaco fue el recurso principal y a la 
cueva se transportaron las unidades anatómicas completas de los cuartos. Las partes esqueletarias identificadas representan etapas terminales del procesamiento y utilización de las presas. El sitio fue utilizado en la estación veraniega, coincidiendo con la época de la caza de animales jóvenes (para una discusión detallada ver Miotti 1998).

\subsubsection{Localidad arqueológica La María}

Esta localidad se ubica en el sector sur del Macizo del Deseado, a unos $150 \mathrm{~km}$ de la ciudad de San Julián y $20 \mathrm{~km}$ al NO de la localidad El Ceibo (Figura 3.1). Hasta el momento en La María fueron definidos 14 sectores diferentes considerando aspectos arqueológicos, ambientales y paisajísticos (Frank 2011; Paunero 2000a; Paunero et al. 2007a; Skarbun 2009). Los estudios arqueofaunísticos consisten, principalmente, en determinaciones taxonómicas y anatómicas realizadas en el marco de investigaciones más amplias (Frank 2011; Paunero 2003a, 2003b; Paunero et al. 2007a). El conjunto zooarqueológico correspondiente a la Cueva de La Lavandería fue estudiado por Miotti (1998) en el marco de su tesis doctoral. A continuación se sintetiza la información publicada que resulta de utilidad para este trabajo.

La Mesada se localiza dentro del sector correspondiente a La María Quebrada. Consiste de una pequeña cueva compuesta por dos oquedades, una superior y una inferior, en esta última es donde entre 1996 y 2000 se practicaron excavaciones arqueológicas (Frank 2011; Paunero 2000a, 2000b; Paunero 2009b; Paunero et al. 2005).

El registro de elementos que indican cambios en el régimen hídrico, sumado a la ausencia de restos óseos en los niveles inferiores, permitieron inferir que este tipo de fenómenos pudo haber ocurrido varias veces a lo largo de la transición Pleistoceno/Holoceno (Paunero 2000b; 2009b). En la unidad 8 (ca. 9000 años AP) fueron recuperados escasos restos óseos, entre ellos un molar y una falange de Lama guanicoe, cuatro fragmentos indeterminados y un conjunto lítico integrado por 6 instrumentos y productos de talla, en este nivel no se registraron fogones (Paunero 2000b, 2009b; Paunero et al. 2005; Skarbun 2009). En una de las cuadrículas (B1) fue identificada una mancha carbonosa (Frank 2011). En cuanto al análisis de alteración térmica encuentran modificaciones de este tipo en un 15,4\% del conjunto lítico y en un sólo espécimen óseo indeterminado, lo que no fue interpretado como resultado de un 
tratamiento térmico intencional (Frank 2011). Se infirió una ocupación eventual de características exploratorias (Frank 2011; Paunero 2009b). En la unidad 5 (4500 \pm 40 años AP) y la unidad 6 fueron registrados elementos óseos, lentes de fogón y materiales líticos como raspadores, raederas, cuchillos y lascas retocadas (Paunero 2000b).

Cueva Túnel se encuentra en el sector La María Quebrada, al norte de la localidad. La cueva está conformada por dos vestíbulos que convergen en un umbral (Frank 2011; Paunero 2009b). Durante las excavaciones se reconocieron once unidades estratigráficas, y se identificó en las unidades 8, 9 y 10 un componente inferior correspondiente al Pleistoceno final (ca. 10.400 años AP) donde se registró la asociación de escasos materiales líticos con fauna extinguida y actual (Ramos y Paunero 2009; Frank 2011; Paunero 2009b). Las unidades 6 y 7 representan una discontinuidad ocupacional (Paunero 2009b) mientras que las unidades estratigráficas 4 y 5 corresponden al Holoceno medio (ca. 4100 y 5500 AP) (Frank 2011). El componente inferior ha sido interpretado como un sitio de procesamiento primario de presas cazadas a poca distancia del lugar (Paunero 2009b)

En el componente inferior se registró la presencia de especies extinguidas, como Hemiauchenia sp., Lama gracilis, Panthera sp. e Hippidion saldiasi, además de Lama guanicoe, Rhea sp., Dusicyon sp., mamíferos y felinos indeterminados, aves y roedores. Se ha indicado un mal estado de conservación en función del grado de meteorización. El análisis de la fragmentación de los huesos largos de camélidos indicó diversidad de fracturas. En este nivel fueron identificados 3 artefactos óseos formatizados: una punta roma, un punzón y un machacador (ver Frank 2011; Paunero et al. 2010).

En cuanto a los elementos correspondientes a camélidos Frank (2011) nota una distribución desigual entre aquellos del esqueleto apendicular y los del esqueleto axial. A pesar de que en este nivel no se han registrado fogones, un $13,1 \%$ del conjunto del conjunto lítico y un 7\% de los restos óseos presentan algún estadio de alteración térmica (Frank 2011).

Este componente ha sido interpretado como un sitio de procesamiento primario de presas cazadas a poca distancia del lugar, principalmente en la vega próxima, en un contexto de etapa exploratoria en el proceso de colonización del área (Paunero 2009b; Paunero et al. 2007b).

Casa del Minero 1 es un sitio multicomponente que evidencia ocupaciones desde el Pleistoceno final hasta inicio del s. XX (Frank 2011; Paunero 2000c; Paunero et al. 2007a). Se encuentra en el sector llamado Cañadón de la Mina, al sur de la localidad 
(Paunero et al. 2004). Las excavaciones se realizaron entre los años 2000 y 2004, y se registró la presencia de un sello constituído por rocas de derrumbe que delimita claramente 2 unidades de depositación correspondientes al Pleistoceno final: unidad 4 $(10.999 \pm 55$ años AP-10.967 \pm 55 años AP) y unidad 3c o inferior $(10.250 \pm 110$ años AP) (Paunero, 2000c; Paunero et al. 2007a). El componente inferior del sitio es el que se encuentra debajo del derrumbe y está constituido por, de abajo hacia arriba, una capa estéril que apoya sobre la roca de base y por encima se encuentra la Unidad 4 que corresponde a la primera ocupación del sitio. El componente superior está constituido por la Unidad 3, que presenta tres niveles de ocupación (inferior, medio y superior), el más antiguo de ellos (ca. 10.200 años AP) es la unidad 3 inferior que apoya sobre el derrumbe, sobre la lente estéril o sobre la unidad 4, el más moderno es el superior con una antigüedad de ca. 5000 años AP. Por encima, en la unidad 2 se registraron fogones y se recuperaron materiales Holocénicos. La unidad 1 contiene materiales históricos correspondientes a los mineros que habitaron la cueva a principio del s. XX; por encima de ella se encuentran las cenizas correspondientes a la erupción volcánica del Hudson en 1991 (Frank 2011; Paunero 2000c; Paunero et al. 2007a). En las dos unidades correspondientes al Pleistoceno final (unidad 4 y unidad 3 inferior) se registró fauna extinguida y actual, mientras que en las unidades más modernas solamente se registró la presencias de especímenes de fauna actual (Paunero et al. 2007a).

En la unidad 4 fueron registrados 10 fogones lenticulares (Paunero et al. 2007a). El registro zooarqueológico de la misma está constituido por camélidos extintos, determinados por el paleontólogo Mariano Bond como Hemiachenia paradoxa y Lama gracilis. Se registraron marcas intencionales. Asimismo, se relevaron cánidos y rheidos (Frank 2011; Paunero et al. 2007a, 2010). En este nivel se registraron tres instrumentos óseos, dos punzones y un retocador, elaborados sobre diáfisis de camélido. El estado de conservación de los restos óseos es bueno, no se registraron modificaciones producidas por roedores ni carnívoros, algunos especímenes presentaron manchas de manganeso (ver Frank 2011; Paunero et al. 2007a). El conjunto lítico de esta unidad está integrado por numerosos productos de talla y escasos instrumentos (ver Skarbun 2009).

En relación con la distribución de restos de camélidos, Frank (2011) encuentra sectores con mayor concentración de elementos apendiculares y otros de elementos axiales. El análisis de los conjuntos óseos ha permitido inferir, según las evidencias de fracturas helicoidales, longitudinales, lascados y marcas de corte, que en el sitio se llevaron a cabo actividades de procesamiento primario y consumo (Paunero et al. 2010). 
En unidad 3 c o inferior (ca. 10.000 años AP) se registraron 9 fogones y presenta una densidad de restos menor que la registrada en la unidad 4 (Frank 2011; Paunero et al. 2007 a). El conjunto faunístico es escaso y está integrado fundamentalmente por restos de guanaco, principalmente huesos largos con escasas evidencias de acción humana (Paunero et al. 2007a). En esta unidad fue recuperado un instrumento óseo; una punta roma confeccionada sobre hueso de Lama sp. (Paunero et al. 2010). El conjunto lítico está conformado por una importante cantidad de productos de talla en relación a la cantidad de instrumentos y a partir de su estudio se infirieron actividades centradas en la confección de soportes. Esto indicaría que, al igual que en la unidad 4, los primeros pasos de la secuencia de producción de artefactos debieron ser realizados en otros sectores del paisaje (Skarbun 2009).

Si bien hasta el momento no hay fechados radiocarbónicos para la unidad 3 b o medio, podría ser asignada al Holoceno temprano. El conjunto faunístico correspondiente a esta unidad es pequeño y está formado exclusivamente por fauna actual. Según Paunero et al (2007a) los camélidos (Lama sp. y Lama guanicoe) son los más representados y es sobre los únicos que se registró evidencia de acción humana.

El conjunto lítico está integrado por cinco artefactos, un núcleo y numerosos productos de talla (Sakarbun 2009). En este componente es notable la ausencia de fogones. Tanto en los materiales líticos como en los óseos se han registrado porcentajes muy bajos (<2\%) de alteración térmica (Frank 2011). La baja densidad de artefactos líticos y restos óseos registrada en este nivel, junto con la ausencia de fogones, indicaría una ocupación humana eventual del sitio para el Holoceno temprano (Paunero 2009b; Paunero et al. 2007a).

La Cueva de La Lavandería es una pequeña cueva que se encuentra en el Cañadón de La Lavandería, en ella se registraron escasas pinturas rupestres en la pared posterior (Franchomme 1987; Miotti 1998). Las excavaciones se llevaron a cabo en 1984 bajo la dirección de Cardich y Mansur-Franchomme (Miotti 1998). Se diferenciaron nueve capas sedimentarias, de las cuales las capas 7, 8 y 9 son arqueológicamente estériles. Debido a la imposibilidad de separación del contexto arqueológico recuperado (capa 2 a capa 6), la muestra fue tratada como un sitio unicomponente (Miotti 1998). Si bien el conjunto carece de fechados radiocarbónicos y los materiales líticos son escasos, tecno-morfológicamente, podría ser asimilado al Casapedrense de Los Toldos (sensu Cardich et al. 1973) o a la tradición Central Patagónica (sensu Aschero 1987). Los especímenes registrados corresponden a especies autóctonas que actualmente habitan el 
área, siendo Lama guanicoe $(92 \%)$ la más representada. Además, se identificaron elementos correspondientes a Pterocnemia pennata, roedores y félidos (Miotti 1998). El análisis de modificaciones de las superficies óseas indica la presencia de marcas producidas por roedores, alteración térmica, marcas de corte y lascados, superficies de fractura alisadas y regularizadas (Miotti 1998).

El sitio habría sido ocupado de forma temporaria, posiblemente durante primavera, pudiendo corresponderse con un sitio de campamento transitorio. En él se habrían desarrollado principalmente actividades relacionadas al trabajo de cueros y pieles, consumo de carne y médula de guanaco y ñandú (Miotti 1998).

La Cueva de La Ventana se encuentra en el sector denominado Cañadón de La Ventana de la localidad La María. Es una cueva oscura, cuya particularidad es la de poseer una "ventana" circular pintada con "rayos" a su alrededor (Frank 2011; Paunero 2009b, 2000d). Se reconocieron 7 unidades en su estratigrafía, identificándose dos componentes, uno correspondiente al Holoceno temprano (unidad 6), y otro correspondiente al Holoceno medio (unidad 4). Entre ambos componentes se encuentra la unidad 5 que es arqueológicamente estéril y representa una discontinuidad ocupacional entre los dos niveles (Paunero 2009b, 2000d). En el componente más antiguo (ca. 7900 años AP) se identificó un fogón y escasos restos óseos. Se propuso un uso particular del espacio, relacionado con la actividades específicas (Frank 2011; Paunero 2000d; Paunero et al. 2005).

\subsubsection{Localidad arqueológica Cerro Tres Tetas}

Esta localidad arqueológica se encuentra ubicada en la estancia San Rafael, departamento de Deseado, Santa Cruz (Cardich 1987; Paunero 1996, 2000e).

La Cueva 1 es una cueva oscura, cubierta en su techo por hollín y en sus paredes por pinturas rupestres. Se destaca por ser un sitio multicomponente, con contextos representativos y una estratigrafía muy clara (Paunero 2000e). La excavación sistemática del sitio se realizó entre 1994 y 1995, y fueron identificadas siete unidades de depositación estratigráfica ( 0 a 6 ). La primera presencia humana del sitio fue registrada en la unidad 5 (ca. 11.000 años AP), por encima de esta unidad se registró un derrumbe del techo de la cueva, el cual actúo como sello natural (Paunero 2000e). Sobre el derrumbe 
se encuentra la unidad 4, correspondiente al Holoceno medio (ca. 5200 años AP), por encima de ésta la unidad 3 donde se registraron tres niveles de ocupación, todos correspondientes al Holoceno tardío: unidad 3 b (ca. 2100 años AP), unidad 3 a inferior (ca. 1300 años AP) y unidad 3 a superior (ca. 800 años AP). Por encima de la unidad 3 se registraron materiales post hispánicos (unidad 2). La unidad 1 es arqueológicamente estéril y la unidad cero corresponde a ceniza volcánica del año 1991 (Paunero 2000 e).

En la unidad 5 se identificaron cuatro fogones y los materiales líticos y óseos se disponían a su alrededor (Paunero y Castro 2001). Paunero (2009a) considera que estos fogones representan sucesivas ocupaciones donde se habría seleccionado el mismo sector de la cueva para encender los fuegos. Se recuperaron escasos restos óseos, en los casos que pudo identificarse un taxón, éste correspondió a Lama guanicoe, no identificándose especímenes correspondientes a fauna extinguida (Frank 2011; Paunero 2000e). El conjunto se encuentra distribuido en su mayor parte en el sector que presenta las estructuras de combustión, presenta un buen estado de preservación. Se registró que un 46,2\% de los restos exhibía alteración térmica. Además se relevaron marcas de procesamiento en un metapodio y una diáfisis. Se identificó la presencia de un punzón y un instrumento sobre diáfisis con tratamiento térmico (Frank 2011; Paunero et al. 2010).

En relación con el conjunto lítico de este nivel, abundan los productos de talla y escasean los instrumentos líticos y los núcleos (para una discusión detallada ver Frank 2011; Paunero 2009a; Paunero y Castro 2001.

\subsubsection{Localidad arqueológica de La Martita}

Esta localidad se ubica en el sector sur de la gran Altiplanicie Central de Santa Cruz, a $133 \mathrm{~km}$ al NNE de Gobernador Gregores. Se trata de cuatro cuevas contiguas orientadas al este (Aguerre 1982, 1987, 2003). La cueva más grande es la Cueva 4, cuyas características generales en relación con las investigaciones allí efectuadas se presentan a continuación.

Las excavaciones comenzaron en 1979 y durante la misma fueron reconocidas siete capas (Aguerre 1982). El componente inferior (capa 7b), donde se registra el inicio de la ocupación de la cueva (ca. 8000 años AP), corresponde a un largo momento de ocupación por grupos portadores de la "Industria Toldense" (Aguerre 1982). Se trata de 
"pan de ocupaciones", un "palimpsesto", donde los materiales aparecen sin solución de continuidad, generando la impresión de un sector que fue habitado continuamente (Aguerre 2003). Se registra la presencia de escasos artefactos en huesos relacionados al trabajo de cuero (Aguerre 2003). Por encima de ese nivel se registró en las capas 5 y 6 el Componente Intermedio (ca. 4500 años AP) vinculado al Casapedrense (Aguerre 1982). Las capas 3 (ca. .600 años AP) y 4 (ca. 2100 años AP) conforman el Componente Superior. Según Aguerre (1982), la ergología de la capa 3 remite inmediatamente a la Industria Patagoniense (sensu Gradin 1980 y Aschero et al. 1988), mientras que el conjunto de la capa 4 podría asimilarse a lo definido por Gradin (1980) como "transicional". Las capas 1 y 2 constituyen el Componente Actual de la secuencia estratigráfica y cronológica del sitio (Aguerre 1982).

Aguerre y Pagano (2003) sugirieron que al componente inferior, se habrían transportado las distintas partes de guanaco. Propusieron actividades vinculadas al procesamiento y aprovechamiento intensivo de las presas. El estado general de conservación de la muestra es bueno aunque algunos especímenes registraron estadios de meteorización elevados. La humedad habría permanecido transformando el color y consistencia de los huesos. Se registran especímenes óseos quemados en mayor porcentaje en el sector externo que en el interno. En un 25,19\% de los restos se identificaron huellas de corte (Aguerre y Pagano 2003). Se relevaron escasos instrumentos óseos: retocadores, punzones de punta aguzada muy pulida y aguja muy pulida y recta con bordes romos (Aguerre 2003). El sitio habría funcionado como un campamento de año redondo con un basurero en el sector exterior. Para una discusión detallada sobre aspectos funcionales se sugiere la lectura de Aguerre (1987, 2003) y Aguerre y Pagano (2003).

\subsubsection{Localidad arqueológica El Verano}

Esta localidad se encuentra ubicada en el sector Centro Sur del Macizo del Deseado, sus investigaciones comenzaron entre 1983 y 1985 (Durán 1983-85, 1988; Durán et al. 2003). El sitio es una cueva pequeña (Cueva 1) que se ubica en un cañadón que desemboca en la depresión de la Laguna El Verano. Presenta un conjunto notable de representaciones rupestres (Durán et al. 2003) y se obtuvo una secuencia que abarca los 
últimos 9000 años (Durán 1983-85, 1986-87, 1988; Durán et al. 2003). Durante las excavaciones se identificaron cinco unidades estratigráficas, de las cuales la unidad V es la que apoya sobre la roca de base y es la única que carece de restos culturales. La unidad IV es la más espesa e incluye las ocupaciones iniciales del sitio. Fue dividida en dos subcapas: IVa y IVb, de la última provienen los fechados radiocarbónicos de $7500 \pm 250$ y $8960 \pm 140$ (Durán et al. 2003).

Las dos subunidades de la capa 4 constituyen el componente 1 de la secuencia. La heterogeneidad de artefactos líticos en esta capa hace suponer que en la cueva se efectuaron actividades múltiples, sin embargo esa funcionalidad del sitio no se ve tan claramente en los resultados del análisis de restos faunísticos (Durán et al. 2003). El conjunto zooarqueológico está integrado por taxa que actualmente habitan el área, la excepción la constituye el registro de Rhea americana. De todas la especies identificadas, los camélidos son significativamente el grupo más abundante y los guanacos representan la principal especie consumida (Durán et al. 2003). El análisis de partes anatómicas representadas para el guanaco indica que todas las unidades están presentes pero que no se destacan aquellas de alto valor económico sino que hay un predominio del esqueleto apendicular y la mandíbula.

Durán et al. (2003) sugirieron que si la cueva fue usada como base residencial, debería haber sido ocasional, vinculado entre otras causas, con períodos de desmejoramiento climático.

\subsubsection{Sector mesetario del área del Río Pinturas}

El área investigada del Río Pinturas comprende cuatro sectores topográficos: 1) la alta meseta del Lago Buenos Aires; 2) las pampas y cañadones intermedios; 3) el borde noroccidental de la Altiplanicie Central; y 4) las cuencas lacustres cordilleranas (Gradin et al. 1976). Acá nos referimos solamente a los sitios que se encuentran dentro del tercer sector, el de la altiplanicie.

\subsubsection{Cueva de Las Manos}


Esta cueva se encuentra en la estancia Alto Río Pinturas, en el sector NO de la provincia de Santa Cruz, y puede considerarse uno de los sitios más importantes de arte rupestre de Patagonia. Las excavaciones comenzaron en 1973 en la zona exterior de la cueva. Se distinguieron seis unidades estratigráficas, cada una de las cuales presenta dos o más niveles de ocupación (Gradin et al. 1976).

Las capas más superficiales (1 y 2), básicamente están constituidas por guano, son arqueológicamente estériles y se comportan como un sello de la secuencia (Gradin et al. 1976). La capa 3 se corresponde con un manto continuo de cenizas, resultado de un incendio de guano estratificado (Etchichury 1976). Se determinó un nivel inferior (3a) y uno superior (3b). El superior está asociado a un potente fogón del que procede un fechado de $430 \pm 50$ años $\mathrm{AP}$, que fue objetado por contener alto contenido de hidrógeno, los autores estiman que dicho contexto podría fecharse hacia ca. 1000 años AP (Gradin et al. 1976). La capa 4 fue subdividida en 4a, 4b y 4c. En la subcapa 4b se halló la casi totalidad de materiales recuperados, por debajo se encuentra la subcapa c $(1.610 \pm 60$ años AP), la cual presenta un aumento de la fertilidad coincidente con el hallazgo de un potente fogón (Gradin et al. 1976). Los materiales procedentes de esta capa representan el nivel Cueva de las Manos III (a, b y c). El nivel IIIa (subcapa 4c), corresponde a la ocupación más potente del área excavada. El nivel III de la Cueva de las Manos corresponden a la Industria Patagoniense sensu Menghin (1952) (Gradin et al. 1976).La capa 5 (3380 \pm 90 años AP) corresponde al nivel Cueva de las Manos II. El instrumental lítico fue vinculado al nivel Toldense de Cueva de las Manos I y al Patagoniense de las capas superiores. Se lo definió como de carácter transicional (Gradin et al. 1976). La capa 6 registra dos ocupaciones (Ia y Ib), ambas presentan similitudes que permiten asimilarlas a un mismo nivel cultural, Cuevas de las Manos I, correlacionable con la industria Toldense. Esta capa fue dividida en cumbre $(7280 \pm 60$ años AP), media $(9320 \pm 90$ años AP) y base. La cumbre y parte media tienen varios fogones vinculados a dos niveles de ocupación, la base es arqueológicamente estéril y apoya sobre la roca de base (Gradin et al. 1976). Este nivel cultural, puede considerarse una fase tardía del Toldense que se registra en el Deseado (Gradin et al. 1976).

En relación con los análisis zooarqueológicos, se determinó la presencia de guanaco Pseudalopex sp., félidos, Lagidium, Peces, Cricetidos y rehidos (Mengoni Goñalons y Silveira 1976). Al sitio habrían ingresado los cuartos traseros y delanteros de los guanacos adultos sin las pezuñas, la pelvis, la escápula proximal y la cabeza pero no el costillar ni el pecho. Estas últimas partes podrían haberse consumido en el sitio de caza (para una 
discusión de la ergología consultar Gradin y Aguerre (1994); Gradin et al. (1976); Mengoni Goñalons y Silveira (1976). Para el nivel de la capa 5, correspondiente al Holoceno medio $(3380 \pm 90$ años AP), se halló mayor representación de los cuartos y mandíbula de guanaco, siendo ésta la especie predominante en el sitio. Se determinó también la presencia de Rheidae, Ctenomys, Iguanidae y un pequeño carnívoro. El registro de fracturas intencionales plantea la posibilidad de que se haya consumido la médula y la importancia del hueso para la confección de instrumentos (Mengoni Goñalons y Silveira 1976). Este nivel fue definido como transicional; entre su instrumental lítico figuran puntas triangulares apedunculadas y bolas (Gradin et al. 1976). En los niveles de ocupación correspondientes al Holoceno tardío (1.610 \pm 60 años AP; ca. 1.000 años AP), Mengoni Goñalons y Silveira (1976) determinaron a L. guanicoe como la especie que domina el conjunto. También se registró la presencia de Duscicyion, Ctenomys y Rheidae (posiblemente Pterocnemia pennata). El conjunto lítico es relacionado con el Patagoniense (Gradin et al. 1976).

\subsubsection{Cueva Grande de Arroyo Feo}

Conocida también como Cueva de Altamirano, se ubica sobre la margen izquierda del cañadón Quesada que desemboca en el arroyo Feo, afluente del curso medio del río Pinturas (Gradin et al. 1979). El sitio consiste en una cueva abierta en la formación de tobas. Se identificaron once capas, las superiores se encuentran asociadas a camadas de residuos vegetales, numerosos restos faunísticos, artefactos y restos de cuero (Gradin et al. 1979).

En la capa 5a (290 años d.C.) que corresponde a un lente basurero, fueron recuperados 1517 fragmentos óseos (Silveira 1979), de los cuales 94 se encontraban completos. El 90\% del material que pudo identificarse corresponde a guanaco. También se encontraron restos de cérvido (Cf. Hippocamelus sp.), roedores (Ctenomys sp y Cricétidos), marsupiales (Didelphis halli), fragmentos de Rheidae, plumas de Pteronemia pennata y un molusco marino. Respecto de la estructura de edad de los guanacos se identificaron 4 chulengos ( 0 a 12 meses), 12 juveniles (12 a 36 meses) y 2 adultos (más de 36 meses). El estado de conservación de la muestra es excelente (73,7\%), un 25\% de los especímenes presenta algún principio de deterioro y 1,25\% están deteriorados (Gradin et al. 1979; Silveira 1979). El registro de modificaciones antrópicas reveló que 230 huesos 
(25\%) presentaron huellas de corte, se identificaron, además, 3 huellas que no son de corte: un lascado, un punteado y un espécimen con marcas de roedor (Silveira 1979).

La capa 5b corresponde al nivel cultural Río Pinturas III y fue fechada en $3260 \pm 50$ años AP (Alonso et al. 1984-85). En la capa 5b/6a (agrupadas) de recuperaron un total de 287 huesos fragmentados y 18 completos (Silveira 1979). Del total identificado (172), el $85,5 \%$ correspondían a guanaco. A partir de dos molares se determinó la presencia de Equus sp., aunque no se sabe si actual o extinto. También se reconoció un resto de rheido adulto y fragmentos de roedores. Se registraron fracturas transversales $(14,3 \%)$ y longitudinales (28,6\%). El 80,5\% del material está en muy buen estado, un 16,7\% tiene algún deterioro y solo el 2,7\% está en mal estado (Gradin et al. 1979; Silveira 1979).

La capa 7 base corresponde al nivel cultural Río Pinturas IIb, fue fechada en $4050 \pm$ 50 y $4480 \pm 60$ (Alonso et al. 1984-85). En ella se recuperaron 659 fragmentos óseos y 36 huesos completos (capas 7 base y 8 cumbre) (Silveira 1979). El 91\% de los restos identificados corresponden a guanaco. En este nivel se registraron especímenes de roedores (Ctenomys sp. y cricétidos) y fragmentos de ave (rheidae y falcónido). En cuanto a la estructura de edad de los guanacos se identificaron 3 chulengos, 6 juveniles y 2 adultos. La mayor parte de los materiales presentaba muy buen estado de conservación (81\%), el 37\% de los huesos presentó huellas de corte, principalmente transversales, algunas con marcado perimetral. En un 13,5\% se evidenció quemado.

La capa 8 (Río Pinturas IIb) fue fechada en su parte media-base en $5550 \pm 50$ años AP (Alonso et al. 1984-85). Se recuperaron 19 huesos completos y 329 fragmentos. El 85,2\% del material que se pudo identificar correspondía a guanaco (Silveira 1979). El resto de la muestra estuvo integrada por roedores pequeños, una vizcacha de la sierra (Lagidium sp.), Rheidae y otra familia que no pudo ser precisada. En esta capa se recuperó una pluma de falcónido. A partir de esta capa comienza a reducirse la cantidad de restos faunísticos (Gradin et al. 1979). Con respecto a la estructura de edad de los guanacos, fueron identificados dos chulengos, tres juveniles y un adulto. El 73,5\% de los materiales se encontró en muy buen estado de conservación y el 46,7\% presentó huellas de corte. Por otra parte, algunas fracturas transversales presentan marcado perimetral y en algunos casos se registraron fracturas longitudinales. El 24\% presentó algún tipo de deterioro y un 2,5\% estaban en mal estado. Se registraron especímenes quemados $(17,2 \%)$ y un 12,3\% con restos orgánicos y un fragmento con ocre. La fauna sugiere una ocupación discreta; es posible que los roedores hayan sido consumidos por el hombre, mientras que los cricétidos probablemente hayan ingresado al sitio en bolos de 
regurgitación (Silveira 1979). Las capas 8 y 7b son las que tienen mayor intensidad. Se registra actividades relacionadas al trozamiento secundario de las presas y al trabajo del cuero en la capa 7b (Gradin et al. 1979).

La capa 9 corresponde al nivel cultural Río Pinturas IIa. Se registraron dos grandes fogones, astillas de guanaco, instrumentos y lascas (Gradin et al. 1979). Esta capa en su base mostro una antigüedad de $6000 \pm 60$ años $\mathrm{AP}$, mientras que su cumbre fue fechada en $4900 \pm 50$ años AP (Aguerre 1981-82; Alonso et al. 1984-85). Del total de restos óseos, 407 eran fragmentos y 14 elementos completos. El 96\% de lo que pudo identificarse corresponde a guanaco (Silveira 1979). Fue identificada una placa de edentado y el resto de los materiales son de roedores pequeños y de Rheidae. Entre los guanacos fueron identificados un chulengo, 3 juveniles y un adulto. El 51,2\% de los especímenes presenta un muy buen estado de conservación, el 36,4\% presenta huellas de corte y fracturas transversales y longitudinales. El 16\% presenta algún tipo de deterioro y el $24,4 \%$ se encuentra en mal estado. Solamente un $2,4 \%$ presentaron rastros de tejidos orgánicos, mientras que el 9,2\% registró signos de quemado, solo un fragmento tenía restos de sulfato de calcio. Esta es la primera capa que acusa un deterioro en la conservación, sin embargo en ella se halló un tiento de cuero (Silveira 1979).

En la capa 10 se identificó un fogón y escasos artefactos, astillas de hueso largo de guanaco y restos óseos de roedores. El total de los fragmentos óseos recuperados es de 195 y 9 elementos completos (Silveira 1979). Un 87,7\% de los especímenes reconocidos correspondieron a guanaco, el resto a roedores y aves. Entre los guanacos solo se reconocieron individuos adultos y juveniles. El 71\% de los materiales presenta buena conservación y un 13,9\% registra deterioro, no habiéndose determinado la presencia de especímenes en mal estado. Algunos restos presentan material orgánico $(3,6 \%)$ y signos de alteración térmica (23,1\%). Se registraron escasas huellas de corte. Se registraron fracturas transversales y longitudinales, como así también marcado perimetral (Silveira 1979).

La capa 11 base está fechada en $9330 \pm 80$ años AP y corresponde al nivel cultural Río Pinturas I (Alonso et al. 1984-85; Gradin et al. 1979), mientras que el fechado para la parte media es de $8610 \pm 70$ años AP (Aguerre 1981-82; Alonso et al. 1984-85). Se analizaron 807 fragmentos óseos y dos huesos completos. El 70,9\% de los restos identificados, corresponden a roedores pequeños y sólo el 26,6\% a guanaco. También se registró la presencia de Rheidae y otras aves (Silveira 1979). La estructura faunística de este componente difiere de la de todos los hallados hasta el momento en sitios de Santa 
Cruz cuya especie dominante es el guanaco. El único guanaco identificado es un individuo juvenil. La muestra se encuentra en buen estado de conservación, no registrándose fragmentos con deterioro o mal conservados. Las huellas de corte son escasas. Se registra la presencia de marcado perimetral, fracturas longitudinales con muescas, transversales y longitudinales simples (Silveira 1979). Para este nivel se infirió una funcionalidad relacionada con episodios de caza (Aguerre 1981-82).

\subsubsection{Alero Cárdenas}

Se encuentra ubicado a $10 \mathrm{~km}$ de la margen derecha del Río Pinturas y fue considerado como un sitio ocupacional de invierno. Las excavaciones arqueológicas se realizaron en 1980 y 1981, durante las mismas fueron diferenciadas 8 capas (Gradin 1994).

La capa 1 integrada por guano de animales domésticos y de guanaco, contiene artefactos seguramente de la capa 2 removidos por pisoteo y elementos rurales.

La capa 2 está compuesta por guano de guanaco y se identificaron artefactos líticos. También hay clavos y herraduras. Aparece sedimento carbonoso y dos núcleos de fogones. También hay un potente basural con huesos y restos vegetales con raspadores y puntas pedunculadas (Gradin 1994). En esta capa 93 especímenes óseos fueron diagnosticados como guanaco $(\mathrm{MNI}=2)$. Entre las partes representadas se encuentra la mandíbula, especímenes del esqueleto axial (fragmentos de vértebras) y elementos de la extremidad anterior y posterior. Se registra un alto grado de fragmentación, en un 32,2\% se presenta cierto grado de meteorización y un $82,8 \%$ se encuentran quemados. Un 21,5\% de los especímenes exhibieron huellas o marcas (Aguerre et al. 1994a). Es llamativa la presencia de Rhea americana, lo que prolongaría el rango de distribución de Rhea al sur del río Negro al menos para esta época (Horovitz 1994).

En la capa 3 desaparecen las lentes de ceniza y aumenta la potencia de las ocupaciones (más fogones). Corresponde a un momento alfarero y fue adscripta al nivel cultural Río Pinturas V (Patagoniense Cerámico), fechado en $1180 \pm 85$ años AP. En esta capa se recuperaron 685 especímenes óseos de guanaco, todas las partes del esqueleto se encuentran representadas. Aparentemente, se habrían transportado todas las partes del esqueleto y es notoria la presencia de fracturas longitudinales (Aguerre et al. 1994a). En 
esta capa se registra la mayor cantidad y diversidad de restos relevándose, en relación a otras capas, una abundancia notable de restos de guanaco (Horovitz 1994).

La capa 4 es de color marrón y la 5 de color marrón oscuro grisáceo, con abundantes artefactos, fogones y restos vegetales. Se registró gran cantidad de bloques especialmente en la capa 4. Otro núcleo de fogón está en la base de capa 5 fechado en $3450 \pm 100$ años AP. El deslinde de las capas 4 y 5 también se basó en la presencia de tecnología bifacial, confección de puntas pedunculadas y apedunculadas y el índice de laminaridad. Puede asemejarse al nivel transicional (Río Pinturas III). En la capa 4 fueron recuperados 317 especímenes óseos de guanaco entre los que se registraron elementos tanto del esqueleto apendicular como así también del axial (Aguerre et al. 1994b). El 92,7\% de los especímenes presentan baja meteorización, un 18,24\% están quemados y un $36,13 \%$ registran huellas o marcas. El 50\% de las astillas corresponden a huesos largos, un $26 \%$ a huesos planos, un $21 \%$ son indeterminadas y un $1,26 \%$ pertenecen a epífisis. De ellas, el $21 \%$ están quemadas y 33,81\% presentaron huellas o marcas. En la capa 5 se recuperaron 146 especímenes óseos de guanaco y 507 astillas. Se identificaron elementos del esqueleto axial y apendicular. De las 507 astillas, 232 corresponden a huesos largos, 88 planos, 32 epífisis y 155 a indeterminados (Aguerre et al. 1994b).

Las capas 6 y 7 tienen el mismo color pero se distinguen en su textura. La capa 7 es más arenosa y junto con la 8, prácticamente estériles, fueron consideradas como un solo nivel ocupacional, con materiales arqueológicos similares (puntas triangulares e instrumentos en hueso como punzones y retocadores). Fue fechado un fogón en la parte inferior de la capa 7 base en $7750 \pm 125$ años AP y la parte superior de la capa 7 base en $7300 \pm 200$ años AP. Se registran puntas Magallanes III, vinculado al Toldense y el nivel Río Pinturas I. La capa 8 es arenosa y relativamente estéril.

Sobre la base de la concentración de artefactos y las características estratigráficas se han propuesto 4 niveles ocupacionales (Gradin 1994): el nivel I sería el más reciente (capas 1 y 2); el nivel II, subreciente (capa 3); el nivel III, intermedio (capas 4 y 5); y el nivel IV, más antiguo (capas 6 y 7). El guanaco es la única especie que está representada en todas las capas y que registra la mayor abundancia. Otras presas están representadas por zorro colorado, puma, ñandú pequeño, (Lagidium sp) chinchillón y Zaedyus pichy. Entre ellos se registró rastros de actividad humana en aproximadamente el 50\% (Horovitz 1994) 
Se encuentra ubicado en el cañadón tributario de la margen derecha del Río Pinturas. Tiene 50 metros de frente y una visera de 40 de proyección a casi $20 \mathrm{~m}$ de altura, pero solo permite su aprovechamiento por zonas. Fue excavado en dos etapas; en 1973 y en 1986 (Aguerre y Gradin 1994).

La capa 1 está constituida por guano. Se registraron astillas de hueso fresco y material lítico en superficie. La capa 2, por guano consolidado. Se hallaron clavos, herraduras, cuero, hebillas, telas y tejidos. Se recuperó abundante material lítico y restos óseos. En esta capa se recuperaron 505 especímenes óseos de guanaco. Se determinaron partes correspondientes al esqueleto axial (vértebras y costillas) y al esqueleto apendicular (paleta, húmero, fémur, radio, tibia, carpianos, metapodios). En general el estado de los huesos es fresco. Se diagnosticaron especímenes correspondientes a individuos juveniles. En las astillas predominan las de hueso largo. En general, abundan partes más ricas en médula que en carne. Una pieza destacada es un retocador de punta y aristas romas bien pulidas sobre una epífisis proximal más diáfisis media y distal de metatarso derecho (Aguerre 1994). Los especímenes de fauna no guanaco se encuentran ennegrecidos, quemados y destruidos, correspondiendo a restos de un ave indeterminada (Pereda 1994).

La capa 3 es una potente acumulación de huesos fragmentados, carbonatados, con signos de haber estado a la intemperie. Se identificaron abundantes restos vegetales. En esta capa se recuperaron 2598 especímenes óseos de guanaco, de los cuales 209 estaban enteros. Fueron recuperadas partes correspondientes a distintos sectores. Se han propuesto actividades referidas a la obtención de médula. En general abundan los huesos con valor bajo de rinde económico a excepción del metatarso con valor alto en médula más que en carne. Si bien se destacan los cuartos respecto de las paletas, el valor económico estaría dado por huesos ricos en médulas. Al sitio habrían ingresado todas las partes, las paletas y los cuartos en primer lugar. Se identificó la presencia de individuos jóvenes. Se recuperó un retocador confeccionado en diáfisis medial y distal (Aguerre 1994). El análisis de 60 especímenes de fauna "no guanaco” (Pereda 1994) revela superficies deterioradas y blanqueadas. Entre ellos se registró 1 falange de roedor, 3 especímenes correspondientes a peludos (mandíbula, tibia y fémur), 1 a un mamífero indeterminado (sesamoideo), 1 fémur de zorro gris, 8 especímenes de choique (Pterocnemia pennata), 16 de aves falconiformes, todos en buen estado de conservación. 
Se sugirió que estas aves carroñeras se encuentran por haber consumido restos del basural. Además se relevaron 4 especímenes de aves indeterminados y 26 huesos indeterminados (Pereda 1994). En la capa 3 base se obtuvieron dos fechados; uno de $5040 \pm 60$ años AP y el otro de $5290 \pm 60$ años AP. El total de especímenes correspondientes a guanaco es de 685 , de los que 52 fueron encontrados enteros. Se recuperaron fragmentos de la cabeza, mandíbula, hioides, vértebras y costillas del esqueleto axial, mientras que del apendicular se determinó la presencia de elementos de los cuartos. Se registraron pocas huellas de corte o quemado. Se ha propuesto un transporte al sitio de partes ricas en carne, como el estilopodio de paletas y cuartos. En este nivel también se registra un individuo juvenil (Aguerre 1994). Se registraron muy escasos huesos $(\mathrm{n}=7)$ correspondientes a fauna no guanaco (Pereda 1994). Los materiales recuperados en la capa 3 se encuentran muy deteriorados, blanqueados y cuarteados (Aguerre 1994).

En la capa 4 cumbre se recuperaron 341 especímenes óseos de guanaco, siendo solamente 30 los enteros. De las paletas y cuartos han sido transportadas partes del zeugopodio con más valor de médula que de carne, se registran algunos especímenes correspondientes al esqueleto axial (fragmentos de la cabeza y de las vértebras). Fue identificada la presencia de un guanaco joven (Aguerre 1994). Los restos faunísticos no guanaco provienen de un basural potente contra un bloque y corresponden 3 a roedor, 1 a chinchillón, 1 a carnívoro indeterminado, y 11 fragmentos indeterminados (Pereda 1994). A partir de la capa 4 cumbre no se hallaron más evidencias de ocupación humana.

Si bien hay variaciones en los valores de MAU de todas las capas no son tan significativas, las partes presentes en todos los casos son más ricas en médula que en carne (Aguerre 1994). Gradin y Aguerre (1994) proponen que entre el 10.000 y el 6000 AP el caudal hídrico del arroyo Charcamata esporádicamente habría alcanzado un nivel superior al piso actual del abrigo, imposibilitando su ocupación. A partir del quinto milenio se consolida una formación terrazada. Las capas 4 cumbre y 3 denotan una ocupación relativamente continua, el mayor problema se registra en la capa 3 basural, usado también por pobladores históricos. Las primeras ocupaciones podrían correlacionarse con el nivel cultural Río Pinturas IIb. 


\section{CAPÍTULO 4}

\section{ZOOARQUEOLOGÍA Y TAFONOMÍA. TENDENCIAS ACTUALES}

Los humanos explotan recursos animales por varias cuestiones, pero básicamente para la obtención de alimento como carne y grasa, y/o materiales para confección de herramientas, prendas y adornos como los huesos, las pieles, las plumas, los tendones, entre otros (Lyman 1994: 294). En este sentido, los restos faunísticos que los arqueólogos recuperamos en los sitios son el resultado tanto del transporte selectivo realizado por los humanos como de otros procesos y agentes tafonómicos, culturales y naturales, que afectan en mayor o menor grado los depósitos originales (Borrero 1988, 2001, 2011; Lyman 1994; Nash y Petraglia 1987; Mengoni Goñalons 1999, 2010; Salemme y Miotti 1987).

En este capítulo se plantean las principales posturas teórico-metodológicas desde las que se desarrolla el estudio de los conjuntos arqueofaunísticos de la cuenca de los Zanjones Rojo y Blanco en la Meseta Central de Santa Cruz.

\subsection{LA ZOOARQUEOLGÍA Y LA TAFONOMÍA}

El análisis de las arqueofaunas es una de las líneas de evidencia que hace posible la inferencia de cambios en las poblaciones de cazadores-recolectores así como también, permite obtener datos sobre las decisiones y acciones humanas respecto de los recursos locales y regionales, el cambio de estrategias económicas (de caza, recolección, distribución y procesamiento de presas) y la utilización del espacio y la función otorgada a los sitios (Barberena 2008; Belardi 2005; Binford 1978, 1980, 1981; Borrero 1986; Bourlot 2010; De Nigris 2004; Frontini 2012; Gifford-González 1989a, 1989b, 1991, 1993, 2008; Gutiérrez 2004; Lyman 1994; Martínez 1999; Massigoge 2010; Mengoni Goñalons 1988, 1999, 2010; Messineo 2008; Miotti 1998; Mondini 2002; Muñoz 2002; Politis 1984; Rindel 2009; Salemme 1987; Santiago 2010; entre muchos otros). 
Los restos faunísticos que los arqueólogos registramos en los sitios son resultado tanto del transporte selectivo realizado por los humanos como de otros procesos y agentes tafonómicos, culturales y naturales (Borrero 1988, 1990, 1994-95, 2011; De Nigris 2004; Gifford-González 1989a, 1993; Lyman 1994; Marean 1995; Mengoni Goñalons 1988, 1999; Salemme y Miotti 1987, entre otros). Siguiendo a Lyman 1994, el análisis de restos faunísticos tiene dos objetivos principales que son la reconstrucción de las condiciones paleoecológicas y los patrones de subsistencia. En ese mismo sentido, Mengoni Goñalons (2007) destaca dos variantes dentro del campo disciplinario: la arqueozoología propiamente dicha cuyo foco está puesto en la relevancia cultural de los restos óseos; y la "arqueología biológica" más interesada en la comparación de las distribuciones de la fauna en el pasado y en el presente. Ambas perspectivas son complementarias y sinérgicas (Borrero 2011; Mengoni Goñalons 2007).

En el análisis zooarqueloógico, las etapas de procesamiento de datos cuali y cuantitativos, son fundamentales para poder interpretar los conjuntos zooarqueológicos y hacer inferencias acerca de las sociedades del pasado (Binford 1978, 1981; Borrero 2011; Gifford-González 1989b; Grayson 1984; Lyman 1994; Miotti 2008; Miotti et al. 1999; Mengoni Goñalons 1988, 1999, 2010). Sin embargo, es un abordaje que se extiende más allá del análisis de la fauna ya que, su característica transdisciplinaria requiere de una fuerte interacción con otros materiales no faunísticos, como pueden ser el uso de distintas fuentes o escalas temporales y espaciales para discutir el problema (Borrero 2011). La zooarqueología y la tafonomía son ejes claves de estas líneas relacionadas entre sí, ya que su objeto de estudio se centra en el análisis de los contextos arqueofaunísticos, aunque con objetivos diferentes (Lyman 1994; Marean 1995).

La zooarqueología es la aproximación más abarcativa que le da marco a esta investigación, entendida como la disciplina que estudia la interacción entre la sociedad humana y los animales en el pasado (Mengoni Goñalons 2010); en tal sentido es considerada como transdiciplinaria, ya que sus objetivos no están exclusivamente centrados en el mundo animal y deben ir más allá del necesario análisis exhaustivo de restos faunísticos hallados en sitios arqueológicos (Borrero 2011). No obstante, aspectos teóricos y metodológicos de la tafonomía son recurrentemente utilizados en esta tesis ya que los mismos son considerados una etapa fundamental dentro del estudio de las arqueofaunas. La investigación tafonómica, entendida como el estudio de los procesos de preservación y cómo ellos afectan la información contenida en el registro (Behrensmeyer y Kidwell 1985), es un requisito necesario que permite conocer la formación del registro 
arqueofaunístico antes de realizar interpretaciones acerca de la subsistencia de los grupos humanos en el pasado (Lyman 1982a). En este sentido, coincidimos con Borrero (2011: 268) en que "La tafonomía asumió un papel crucial en el logro de estos fines [zooarqueológicos], dada su capacidad para apuntalar la construcción de conocimiento....la tafonomía se constituye en parte integral de esta disciplina.”

Los restos arqueológicos son afectados por múltiples procesos depositacionales y post-depositacionales (Nash y Petraglia 1987). En este sentido, el interés de la tafonomía, radica en entender "Ios procesos que generan, modifican y destruyen los conjuntos óseos" (O’Connor 2000: 19).

Desde el punto de vista metodológico, Marean (1995) distingue dos tipos de tafonomía: la tafonomía actualística y el método comparativo. La tafonomía actualística tiene dos componentes, el experimental y el naturalista. En el naturalista el analista observa los procesos ocurriendo y el patrón resultante (no existe duda entre la traza y el actor). En el experimental, el analista observa directamente las relaciones entre trazas y agentes. La diferencia radica en que el analista controla activamente los parámetros del proceso observado con el fin de maximizar el entendimiento de las relaciones que vinculan a las trazas con el actor. El método comparativo, por otra parte, se centra en el estudio de los efectos, es decir la relación entre el proceso y el resultado no es observada sino inferida. Aquí hay varias cadenas de razonamiento analítico que vinculan las trazas con el agente efector. Ambos métodos deben considerarse aspectos complementarios de una investigación, en la cual la identificación y análisis de los efectos por un lado, y los estudios actualísticos, por otro, permitirán obtener un mayor entendimiento de las causas y contextos en los cuales dichos efectos son producidos.

Esta investigación comparte objetivos con el enfoque de Tafonomía Regional (Borrero 1998, 2001) el cuál busca identificar rangos de variabilidad de procesos potenciales que afectan el registro arqueológico de una región. La escala de análisis es el espacio amplio y heterogéneo, y en consecuencia existe un número importante de circunstancias bajo las cuales los conjuntos arqueológicos ven afectada su integridad (Borrero 2001). No existe un patrón típico de dispersión de los huesos ni tampoco de meteorización. Hay variables que cambian de acuerdo a las condiciones locales (GiffordGonzález 1991). Los enfoques regionales requieren de investigaciones que contemplen las condiciones que crean variabilidad (Borrero 2001).

En ambientes de cuevas como los estudiados en esta tesis, donde existe una dinámica heterogénea a nivel micro-espacial, el estudio de los procesos de formación de 
sitios que configuraron historias tafonómicas particulares permitió evaluar la integridad y resolución del registro arqueofaunístico en distintos niveles de análisis que fueron desde el espécimen, pasando por la variabilidad intra e intersitio en cada microrregión de la cuenca. Dentro de esta perspectiva, las cuevas se presentan como casos excepcionales de depositación sedimentaria. Siguiendo a Waters (1992: 243), “The stratigraphic sequence in any rockshelter is unique because of differences in shelter lithology, weathering processes, hydrologic conditions, and types of depositional environments present outside the shelter", lo que sumado a la intensidad de las ocupaciones humanas, complejiza la correlación estratigráfica entre estos tipos de sitios. Incluso, dentro de una misma cueva pueden ser reconocidos ambientes con grandes diferencias sedimentarias (Farrand 1985, Kornfeldm et al. 2008). Las singularidades ambientales y estratigráficas intrínsecas a las cuevas (Farrand 1985) nos enfrentan a situaciones de estudio muy diferentes a niveles intra e intersitio, por lo que el entendimiento de las condiciones y agentes intervinientes en la formación de los conjuntos arqueológicos cobra relevancia.

Los sitios AEP-1 (Piedra Museo) y Cueva Maripe (La Primavera) que son estudiados en esta tesis, presentan características diferentes que permiten entenderlos como microambientes dentro del área de estudio y fuentes potenciales de variabilidad. De esta forma consideramos que la variabilidad arqueológica existente en los dos sectores de la cuenca en estudio es muy alta y no solo depende de factores naturales actuales o pasados. El reconocimiento de diferentes patrones de modificación de las superficies óseas permite inferir, en algunos casos, los agentes y procesos tafonómicos involucrados en la formación del conjunto (Gifford-Gonzalez 1991; Johnson 1985). Por tal motivo, este tipo de estudio constituye una vía de análisis para comprender la historia tafonómica de un sitio y discutir su integridad arqueológica (Lyman 1994). De esta forma, es posible estimar el grado de incidencia de los diferentes procesos en la formación de depósitos arqueológicos, el papel jugado por los humanos en la formación de depósitos particulares y la determinación de los estados de preservación de los conjuntos óseos.

La aplicación de tasas de sedimentación y depositación a problemas arqueológicos es una herramienta geológica, que ha demostrado ser de gran utilidad en el estudio de formación de sitios en distintos contextos (Farrand 1993; Favier Dubois 1997; Ferring 1986; Miotti 2010; Miotti et al. 2007; Stein et al. 2003;). Las mismas definen las tasas de acumulación de matriz en sitios arqueológicos, permitiendo un control en los procesos de formación de sitios. Estos ritmos de acumulación sedimentaria tienen implicancias arqueológicas muy variadas que afectan a las densidades artefactuales, los patrones 
espaciales y la preservación diferencial. Tasas sedimentarias bajas generan la expectativa de una integridad arqueológica baja, inversamente, tasas de sedimentación altas generan una expectativa de integridad arqueológica alta (Miotti 2010; Miotti et al. 2007).

\subsection{ACERCA DE LA INTERPRETACIÓN DE LOS PERFILES DE PARTES ANATÓMICAS}

El procesamiento de presas contempla varias etapas que van desde la captura del animal, hasta el consumo del mismo, y supone distintas fases de reducción de partes a unidades más pequeñas. Esa reducción, se relaciona no solo con la preparación de los alimentos sino también con el transporte y formas de consumo de los mismos (Binford 1978; Bourlot 2010; De Nigris 2004; Fernández 2010; Gifford-González 1989b, 1993; Kent 1993; Mengoni Goñalons 1999; Miotti 1998; Montón Subías 2002; Oliver 1993; Politis y Martínez 1996; Politis y Saunders 2002; Rindel 2009; Yellen 1977, entre muchos otros). En un conjunto zooarqueológico, el grado de fragmentación de los huesos puede ser considerado una medida que permite evaluar las distintas etapas de este proceso. Consideramos a este indicador como indirecto para inferir actividades de procesamiento humano debido a que existen muchos motivos por los cuales los huesos pueden fragmentarse (De Nigris 2004; Gifford-González 1989b, 1993; Lyman 1994).

Mucha de la información generada a partir de los estudios etnoarqueológicos y experimentales, ha sido integrada en modelos teóricos predictivos, acerca de las distintas estrategias que un grupo humano puede desarrollar bajo determinas condiciones y circunstancias. Estos modelos surgen del gran interés que han tenido los zooarqueólogos por interpretar la variabilidad con la que los esqueletos de taxa particulares aparecen representados en los sitios arqueológicos (Lyman 1994). De esta manera, los distintos modelos permiten evaluar la forma de obtención de los recursos (Binford 1978, 1980, 1981; Bettinger 1991; Borrero 1990, 2009; Lupo y Schmitt 2005; Stiner 1993) y las distintas estrategias vinculadas al transporte, procesamiento, reparto, preparación y consumo (Binford 1978; De Nigris 2004; Lupo 2007; Mengoni Goñalons 1999; Miotti 1998; Morin 2007; Perkins y Daly 1968).

En este sentido, los modelos de forrajeamiento óptimo (Bettinger 1991), así como los modelos de compartir y procesar los alimentos (Gifford-González 1993; Marshall 
1993) brindan un marco interpretativo para las distintas frecuencias de partes anatómicas que pueden registrarse en los sitios arqueológicos.

Los trabajos sistemáticos acerca de esta problemática comienzan en la década de 1950 con los aportes de White quién sugiere que las decisiones de selección y transporte de partes esqueletales por grupos humanos están vinculadas a la decisión de reducir los costos. Sostiene que aquellos elementos con mayor cantidad de carne utilizable (miembros proximales) tendrán más probabilidad de ser transportados desde el sitio de matanza al de consumo, mientras que aquellos que ofrezcan poca cantidad de carne utilizable, como en el caso de los miembros inferiores, es esperable que sean cortados y abandonados en el sitio de matanza para reducir la carga (White 1953).

Por su parte, Perkins y Daly (1968), para estimar la variación de la representación de partes esqueletales, propusieron el concepto de "schlepp effect". Este modelo tiene en cuenta la combinación de dos factores, el tamaño del animal cazado y la distancia entre el sitio de matanza y el sitio de residencia. El modelo supone que, cuanto mayor sea el tamaño de la presa y más lejos se encuentre el sitio de matanza del campamento, será menor la cantidad de huesos que ingresen a este último. De esta manera, el "Schlepp effect" constituye una forma de estimar la baja abundancia relativa de huesos largos asociada a una alta abundancia de huesos de las patas (Perkins y Daly 1968). Los autores sugieren que la mayor parte de los huesos sería abandonada luego del descarne en el sitio de matanza y que la carne sería transportada envuelta en el cuero, donde quedarían adheridos los huesos de las patas como "manijas" para sujetar la carga y quizá porque contiene tendones que resultan de utilidad y se lo ha llamado "el equipo de costura de los cazadores" (Lyman 1994). De esta manera, la expectativa que propone el modelo es que en sitios residenciales los animales pequeños estarían más completos que lo más grandes, estando estos últimos representados principalmente por las porciones distales de las extremidades.

En el caso de Patagonia, las crónicas etnográficas y etnohistóricas brindan información respecto de las formas de trozamiento, transporte, reparto y consumo de guanacos desarrolladas por grupos Selk'nam y Tehuelches entre el siglo XVI y principios del XX. Miotti (1998: 249-250), a partir de esa información, presenta una serie de expectativas acerca de la frecuencia y tipos de elementos anatómicos que sería esperable encontrar en los distintos tipos de sitios: matanza y/o trozamiento primario, procesamiento secundario y campamento familiar. Si bien los modelos Selk'nam pedestre y Tehuelches ecuestres comparten bastante las formas de trozamiento y 
transporte de las presas, varían como en el caso de otros grupos cazadores-recolectores (Bettinger 1991; Kelly 1995) respecto del tamaño de las partidas de caza para optimizar el acceso a los recursos. Por otro lado incide en las formas de trozamiento de las presas de gran tamaño la estación del año y el estado de gordura de los animales en el momento de la cacería. Una tercera fuente de variabilidad es la distancia que media entre el sitio de matanza (locus de actividades limitadas) y el campamento familiar (base residencial) que puede alterar, incluso, las formas de movilidad de las bandas. En algunos casos, como los registrados entre Selk'nam (Gallardo 1910), la base residencial era trasladada al lugar de matanza de los guanacos representando un clara estrategia de movilidad residencial (Binford 1980), mientras que en otros casos, los animales en forma completa eran trasladados por la partida de caza hacia las bases residenciales, y ahí se repartían y procesaban (Aguerre 2000; Bridges 1952; Gallardo 1910; Claraz 1988; Musters 1964;). Además, existen decisiones humanas de transporte de unidades esqueletarias de bajo rendimiento o preferencia alimenticia que pueden estar en las bases residenciales por su transporte ocasional relacionado con la producción de instrumentos y artefactos óseos (Aguerre 2000); esto podría verse reflejado en la presencia de elementos o fragmentos de las extremidades de las patas.

La analogía etnográfica y otros modelos etnoarqueológicos, en este aspecto constituyen una línea importante como herramienta heurística, procedimiento abductivo para la inferencia arqueológica (Gándara 2006). La misma es comprendida como analogía débil y dentro de un marco de actualismo crítico y metodológico (GiffordGonzález 1989a; Lyman 1994:50).

No obstante, la representación de partes anatómicas en un conjunto zooarqueológico es resultado de una historia tafonómica que involucra la participación tanto de procesos y agentes culturales como naturales (Behrensmeyer et al. 1989; Borrero 1988, 2011; Gifford-González 1989a, 1993; Lyman 1994; Marean 1995; Mengoni Goñalons 1999, 2010; O’Connor 2000), en ese sentido, el desarrollo de una perspectiva tafonómica dentro de las investigaciones arqueológicas se vuelve indispensable (Borrero 2007, 2011).

En las últimas décadas, los zooarqueólogos han avanzado en el desarrollo de distintos estudios actualísticos para evaluar los diferentes factores que influyen en una determinada representación de partes anatómicas observadas en un sitio arqueológico. El conocimiento generado al respecto, ha sido articulado en distintos marcos de referencia, que conforman cuerpos de conocimiento empírico obtenidos de forma independiente y 
que constituyen herramientas para explorar las distintas causas de representación anatómica en los sitios. Entre los marcos de referencias más usados en zooarqueología encontramos los estudios de anatomía económica, los modelos de transporte fluvial y los índices de densidad mineral ósea. En esta tesis, y debido a las características del área estudiada, descripta en el Capítulo 2, y a la ausencia de indicadores tanto a escala local como de sitio sobre la acción de estos procesos, los modelos de transporte fluvial no son aplicados.

En esta tesis, para la evaluación de prácticas de transporte y selección de partes de L. guanicoe, así como los procesos de destrucción/preservación de los conjuntos, se utilizaron los índices de utilidad de carne (Borrero 1990; Lyman 1992) y densidad mineral ósea (Elkin 1995). Los resultados de este cruce de información son ampliamente utilizados en zooarqueología (Durán et al. 2003; Fernández 2010; Mengoni Goñalons 1999; Miotti et al. 1999; Rindel 2009). Sin embargo, en los últimos años su potencialidad ha sido discutida a partir del desarrollo de estudios tafonómicos actualísticos sobre otros factores que estarían mediando en la variabilidad de la densidad mineral ósea (DO) como son los perfiles de edad de los guanacos (Álvarez et al. 2010; Gutiérrez y Kaufmann 2007; Gutiérrez et al. 2010; Lyman 1994). Estas discusiones sobre las potencialidades interpretativas de estos índices también han sido planteadas respecto de la equifinalidad que evidencian en función del bajo rendimiento económico de las partes más recurrentemente representadas en sitio de Patagonia (De Nigris 2008).

En este sentido, es que creemos necesario considerar otros factores que pueden estar mediando en la representación de partes esqueletales de los conjuntos zooaqueológicos. Una propuesta al respecto se relaciona con el contenido graso de los huesos, en tal sentido, un nuevo caso de equifinalidad puede aparecer entre aquellos huesos de alta densidad ósea y bajo contenido de carne y grasa que, como los autopodios, aparecen muy representados en sitios arqueológicos de Patagonia. La nueva información discutida en los trabajos de Rindel (2009) y otros autores (Binford 1978; Bourlot 2010; Miotti y Marchionni 2012; Morin 2007), también relativiza los valores de DO de las distintas unidades anatómicas. Sin embargo, y a pesar de todos los recaudos que a partir de estos estudios creemos importantes considerar, al momento de interpretar los resultados de dichas correlaciones, consideramos que tanto la DO como los índices de rendimiento económico continúan siendo herramientas útiles en cierta medida, para introducir la discusión y evaluar las causas posibles de una determinada representación de 
restos óseos en un conjunto y por otro lado, hacer de cada uno, una estimación comparable con las demás muestras (Capítulo 9).

Por tal motivo, y para aplicar los mismos parámetros en todos los conjuntos estudiados en esta tesis (Capítulos 7 y 8), estos índices estandarizados fueron utilizados. Por otro lado, si bien estos estudios sobre variabilidad ontogénica son importantes para la interpretación, cada una de las muestras analizadas presenta diferencias en cuanto al perfil etario que pudo ser inferido para el conjunto. En tal sentido, y al no contar con elementos esqueletales completos, se vuelve difícil aplicar la relativización de la densidad ósea en las distintas categorías etarias. Tema que por su importancia, quedará para una futura agenda.

\subsubsection{Anatomía Económica}

Estos estudios consideran la distribución que los distintos productos alimenticios como carne, grasa muscular, grasa ósea y médula, adquieren en el cuerpo de un animal determinado. De esta forma, permiten evaluar la utilidad alimenticia de las distintas partes anatómicas y el aprovechamiento realizado de las diferentes especies representadas en los sitios arqueológicos. Este marco de referencia, tradicionalmente ha sido utilizado para discutir la representación de partes anatómicas como resultado de decisiones de transporte, sin embargo, también permiten evaluar esas frecuencias en relación a los distintos patrones de procesamiento utilizados para la obtención y consumo de productos diferentes (De Nigris 2004; Mengoni Goñalons 1999).

El interés en los estudios de anatomía económica surge a partir de las observaciones etnoarqueológicas de Binford (1978) entre los Nunamiut. A partir de estos trabajos, Binford consideró que la utilidad alimenticia de las partes anatómicas es uno de los principales factores que influyen en las decisiones de transporte que toman los grupos de cazadores. De esta forma, entiende que cualquier variabilidad en la frecuencia relativa de partes anatómicas entre sitios arqueológicos debería derivar de las dinámicas de su uso (Binford 1978). Para proveer un conocimiento específico acerca de la variabilidad anatómica que se puede esperar del desarrollo de distintas actividades, estimó la cantidad de carne, médula y grasa asociada a cada parte anatómica de dos ovejas (Ovis aries) y un caribú (Rangifer tarandus), y elaboró distintos índices en relación al rendimiento de cada 
uno de estos productos. Luego construyó el General Utility Index (GUI) que considera a los diferentes productos nutritivos del animal y brinda valores más precisos sobre el aporte de cada unidad anatómica (Binford 1978). Finalmente modificó los valores calculados para el índice de utilidad general (GUI) y creó el Modified General Index Utility (MGUI) que refleja el hecho de que los animales no siempre son despostados en partes esqueletales discretas sino que, algunas partes con bajo GUI pueden ir unidas a partes con alto GUI. Binford (1978) desarrolló un modelo predictivo para evaluar las distintas frecuencias de elementos transportados a los sitios en función de las diferentes estrategias de aprovechamiento de los recursos que los grupos cazadores-recolectores pueden desarrollar bajo distintas circunstancias. Este modelo postula el transporte al campamento de unidades anatómicas de alto rendimiento y abandono de aquellas que poseen baja utilidad en lugares de matanza.

Desde los trabajos de Binford se ha acrecentado la cantidad de índices de utilidad económica disponibles para evaluar las decisiones de transporte y estrategias de procesamientos empleadas para el aprovechamiento de numerosas especies (Belardi y Gómez Otero 1998; Borrero 1990; Brink y Dawe 1989; De Nigris y Mengoni Goñalons 2004; Emerson 1990; Giardina 2006; Lupo 1998; Lyman 1992, 1994; Lyman et al. 1992; Madrigal y Holt 2002; Marani 2011; Mengoni Goñalons 1991, 1996; O'Connell et al. 1990; Olivera 2001; Outram y Rowley-Conwy 1998; Tívoli y Pérez 2009). En esta tesis, para evaluar si la representación de partes anatómicas de Lama guanicoe (guanaco) registradas en los conjuntos refleja una selección en términos de rendimiento económico, se utilizó el índice de utilidad de carne elaborado por Borrero (1990) y el índice de utilidad modificado propuesto por Lyman (1992). Estos valores de utilidad fueron correlacionados a través del coeficiente de correlación de Spearman con las frecuencias estimadas para las distintas unidades anatómicas de guanaco (MAU\%). De esta manera, es posible generar hipótesis acerca de las distintas estrategias de transporte y selección de partes anatómicas en relación a su rendimiento económico.

La aplicación de estos marcos de referencia, como fue dicho anteriormente, y a pesar de sus limitaciones es útil ya que constituyen medios para aproximarse a decisiones humanas medibles y nos ofrecen una base de información importante para la interpretación de los conjuntos faunísticos de sitios arqueológicos, permitiéndonos incluso, asignarles cierta funcionalidad y facilitando la comparación entre conjuntos diferentes. 
No obstante, creemos necesario considerar que difícilmente las decisiones humanas sólo hayan resultado de estimaciones acerca de las relaciones costo-beneficio sin que, en esas decisiones medien otras cuestiones más difíciles de reconocer arqueológicamente. Entre estas cuestiones consideramos la existencia de diferentes factores que pueden influir en las decisiones de transporte como son el tamaño de las presas, la distancia al campamento, la tecnología disponible para el procesamiento, la edad, el sexo y el estado nutricional de las presas, el interés en determinadas unidades anatómicas para la confección de instrumental óseo, la existencia de preferencias, o factores ideológicos como pueden ser los tabúes alimenticios (Bartram 1993; Binford 1978; Bunn 1993; Lupo 2007; Lupo y Schmitt 2005; De Nigris 2004, 2008; Metcalfe y Jones 1988; Oliver 1993; O'Connell 1995; Outram 2004; Politis 2007; Politis y Saunders 2002).

Si bien la presencia de partes de mediano a bajo rendimiento económico, muchas veces han sido explicadas como mecanismo de destrucción/transporte diferencial, trabajos recientes (Morín 2007; Rindel 2009) discuten profundamente estos modelos y ayudan a construir una nueva alternativa respecto de la presencia de falanges y metapodios en los sitios arqueológicos. Estas unidades anatómicas se caracterizan por tener grasas no saturadas a diferencia de aquellas unidades con alto contenido de masa muscular y médula (húmeros, fémures). La propuesta de Morín es importante porque observa que las grasas no saturadas son de fácil consumo humano y en general para los casos etnoarqueológicos, su recurrencia en los sitios de procesamiento y consumo, se debe a que esta grasa resulta más palatable y por lo tanto son preferidas. En base a esto y sin la mensura de Kcal. que aportarían las grasas saturadas, su consumo se privilegia por su sabor.

La ausencia de determinadas partes anatómicas también podría ser interpretada como resultado del sesgo introducido por un alto grado de fragmentación en la muestra como resultado de un procesamiento secundario y final para obtener mayor cantidad de sustancia grasa (De Nigris 2004; Gifford-González 1989a; 1993).

\subsubsection{Densidad Mineral Ósea}

La densidad mineral ósea (DO) corresponde a una propiedad intrínseca de los huesos que se refiere a la relación entre la masa y el volumen de un elemento óseo o 
porción del mismo. El grado de incidencia de determinados procesos tafonómicos sobre un conjunto óseo y la representación de partes anatómicas puede estar mediado por la DO de cada elemento particular, resultando en una supervivencia diferencial de las unidades anatómicas (Binford y Bertram 1977; Lam y Pearson 2005; Lyman 1994; Symmons 2005a, 2005b). Entre los distintos procesos que pueden afectar la preservación de un conjunto en relación a la DO de cada elemento encontramos el procesamiento humano, la acción de carnívoros, la meteorización, la diagénesis (Behrensmeyer 1975; Binford y Bertram 1977; Blumeschine y Marean 1993; Brain 1981; Haynes 1980; Massigoge et al. 2010; Marean y Spencer 1991).

La DO además, varía de manera considerable entre los distintos taxa, entre los distintos elementos de un mismo individuo e incluso, entre los mismos elementos de una misma especie en relación a la edad de los individuos y el grado de osificación que cada elemento registra (Álvarez et al. 2010; Gutiérrez et al. 2010; Ioannidou 2003; Symmons 2005a; 2005b). La mayor destrucción se produce sobre aquellos elementos con baja DO (Lyman 1994).

Los antecedentes en las investigaciones sobre la DO se remontan a los trabajos de Brain (1969; 1976), Behrensmeyer (1975), Binford y Bertram (1977), entre los principales. Lyman (1984) representa el primer esfuerzo por definir estrictamente las propiedades de la DO y documentar en forma sistemática como varía en distintos elementos y fragmentos del esqueleto. A partir de estos trabajos pioneros se aplicaron numerosos métodos y técnicas para su medición, siendo la densitometría fotónica que mide el contenido mineral en un área particular, el método más utilizado. Sin embargo, el método más preciso y recomendado para calcular la DO de un elemento es la medición del volumen a través de Tomografía Computada (Lam y Pearson 2004, 2005).

Los valores de DO de cada elemento o porción del esqueleto de un taxón son expresados en índices que, de la misma forma que con los índices de utilidad económica, en la práctica arqueológica son correlacionados estadísticamente con las frecuencias de unidades anatómicas (MAU\%). De esta manera, son utilizados para evaluar si las frecuencias de partes anatómicas representadas en un sitio arqueológico están influidas por procesos de destrucción mediados por densidad como los anteriormente mencionados (Lyman 1994).

A partir de distintos estudios actualísticos es que disponemos de estos índices para diferentes especies (Chambers 1992; Elkin 1995; Elkin y Zanchetta 1991; Kreutzer 1992; Lam et al. 2003; Lyman 1982b, 1984; Lyman et al. 1992; Stahl 1999). En este trabajo de 
tesis, para evaluar la destrucción mediada por DO en los conjuntos estudiados en la cuenca, se utiliza el índice propuesto por Elkin (1995) para camélidos sudamericanos.

Estudios recientes sobre guanaco indican que la DO de un mismo elemento varía en relación con su desarrollo ontogénico, en este sentido, la variabilidad intra-taxonómica de la DO parece ser mayor de lo que hasta el momento se conocía (Álvarez et al. 2010; Gutiérrez et al. 2010). Sin embargo, y como fue mencionado anteriormente, si bien en las interpretaciones de las correlaciones entre las frecuencias de MAU\% y la DO se considera la destrucción diferencial por la variabilidad intra-taxonómica de la DO, su evaluación forma parte de la agenda de esta investigación. 


\section{CAPÍTULO 5}

\section{LAS SOCIEDADES CAZADORAS-RECOLECTORAS DEL MACIZO DEL DESEADO. MODELOS Y TENDENCIAS ECONÓMICAS, TAFONÓMICAS Y DE LA MOVILIDAD.}

Los modelos etnográficos y arqueológicos son congruentes en cuanto a que el guanaco (L. guanicoe) fue a lo largo de toda la ocupación cazadora-recolectora de Patagonia el recurso básico de la subsistencia. Sin embargo, los matices respecto a su aprovechamiento más o menos integral, la distribución y etología de estos animales y la incidencia de las mismas en las decisiones humanas, en la tecnología, y en la movilidad, son variados. En este capítulo se presentan los modelos más importantes, a la luz de los cuales hemos interpretado la información zooarqueológica y tafonómica de la región en estudio.

Como se verá en los capítulos siguientes, la información zooarqueológica recabada avala esta idea general del dominio taxonómico de la especie por sobre todas las demás utilizadas por las poblaciones que ocuparon desde el Pleistoceno final la región del Macizo del Deseado, pero se agregará un mayor detalle al uso del recurso en una microregión como es la cuenca de los Zanjones Blanco y Rojo.

Los guanacos habrían estado disponible durante todo el año y distribuidos en forma más o menos homogénea en todo el sector extra-andino (Miotti 1998). El ñandú habría sido el recurso complementario básico del guanaco (Miotti 1998). Según Miotti (1998); esta hipótesis de recursos complementarios se fundamentaría en el estado de mayor gordura que alternativamente tendrían guanacos y ñandúes en las distintas épocas del año como se expresa en la Tabla 5.1. Esta información sintetiza los datos obtenidos de crónicas de la región de Patagonia meridional (Claraz 1988; Musters 1964) y referidos exclusivamente a los dos recursos que para el siglo XVIII y XIX eran básicos en las economías de los cazadores-recolectores del área. Aquí se destaca la alternancia estacional de caza de ambas especies, según el estado de gordura de los animales y los otros productos derivados, que aun podían obtener de animales flacos que cazarían ocasionalmente para reparar cueros de toldos o vestimentas. 


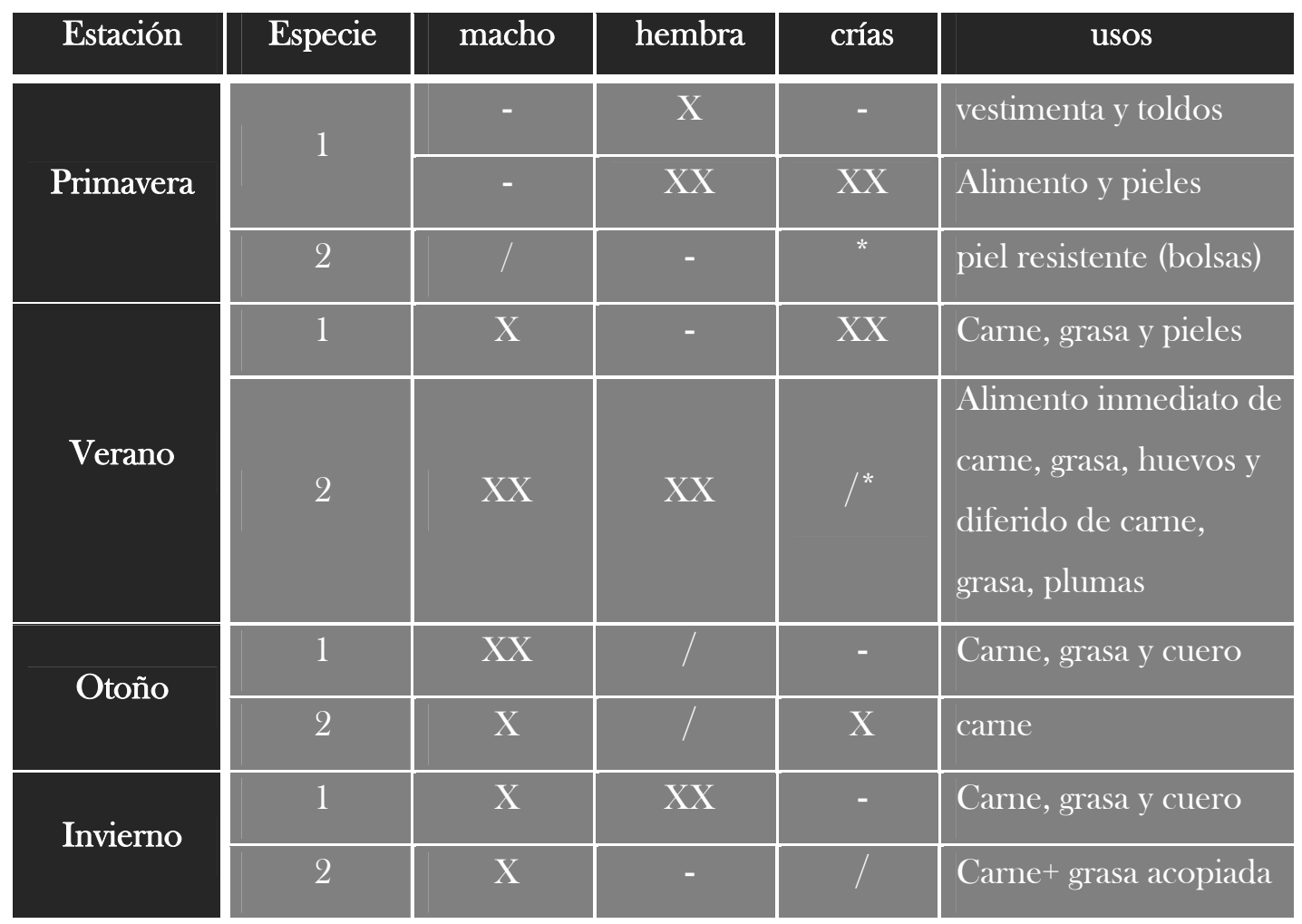

Tabla 5.1: Recursos básicos y estacionales en la economía de las sociedades cazadorasrecolectoras que habitaron Patagonia Meridional según las crónicas etnográficas y etnohistóricas del s. XVIII y XIX (tomado de Miotti 1998: 245). Referencias: XX muy abundante; X Presencia; - Ausencia; / ocasional; * cáscaras; 1 guanaco; 2 ñandú.

Los cánidos y félidos habrían sido cazados de forma ocasional, lo mismo para los zorrinos, tuco-tuco y piches. Su baja representación parece indicar incorporaciones no antrópicas al registro; sin embargo, existe un escasa frecuencia de especímenes de zorro en sitios arqueológicos donde se han registrado modificaciones antrópicas que nos hacen pensar que determinados huesos de estos carnívoros fueron utilizados como materia prima para la confección de instrumentos (Miotti 1998).

Los moluscos litorales fueron un recurso ocasional en los sitios de la meseta, su uso habría sido más recurrente desde el Holoceno medio por grupos de cazadores del interior de la Meseta (Miotti 1998; Miotti 2008); sin embargo, como también es señalado por Miotti la presencia de caracoles marinos en la Cueva 2 de Los Toldos durante la transición Pleistoceno-Holoceno, podría indicar algún tipo de comunicación de las poblaciones colonizadoras del interior con las de la zona costera, o que las primeras habrían introducido desde el litoral esos objetos en su viaje de exploración hacia el interior del continente (Miotti 2003; 2008). De todos modos, la presencia de valvas y 
conchas de moluscos marinos permite inferir que, al menos, una movilidad entre el interior y el litoral debe haber ocurrido por parte de todo el grupo social, o de pequeños grupos o individuos. En todos los casos documentados, se trata de escasos ítems por lo que esta autora plantea que los mismos habrían sido bienes de comunicación social o de intercambio.

\subsection{TRANSICIÓN PLEISTOCENO-HOLOCENO Y HOLOCENO TEMPRANO (ENTRE ca.13 Y ca. 7,5 KA AP)}

Como dijimos anteriormente, en esta tesis seguimos los criterios ambientales propuestos por Miotti y Salemme (1999, 2004) y Miotti (1998, 2003), en los cuales las faunas tienen un rol protagónico para definir los principales bloques temporales. Este intervalo fue definido como la Fase de Colonización de los cazadores recolectores por las autoras citadas, sin embargo, Borrero (1989-90) propone que la dispersión de las primeras poblaciones humanas, correspondiente a este período, corresponderían a una etapa de exploración.

Esta etapa se caracteriza por presentar la mayor diversidad de megaherbívoros y mamíferos de tamaño grande y mediano en los sitios arqueológicos durante toda la ocupación humana del área. En estos momentos se registran por última vez las especies de magamamíferos, la extinción que se habría completado hacia los 10.000 años AP según el registro de Los Toldos y El Ceibo pero que según registros en otros sitios, los

últimos representantes de fauna pleistocénica podrían haber perdurado hasta el 9000 y 8500 AP. Para este momento también se registra la desaparición en el área de la especie Rhea americana. Miotti (1998) propone que la extinción de los megamamíferos no habría sido de gran repercusión para los sistemas culturales de fines del Pleistoceno y principios del Holoceno.

Para este período se propuso que los grupos humanos que colonizaron la región tuvieron una estrategia generalista centrada en la caza del guanaco y que abarcó un amplio rango de recursos faunísticos -ie., équidos, camélidos, perezosos gigantes y aves corredoras- (Borrero 1994-95; Miotti 1998; Miotti y Salemme 1999). La hipótesis de que los mamíferos pleistocénicos fueron aprovechados en forma complementaria y ocasional al guanaco, fue propuesta por varios autores (Borrero 1984, 2009; Cardich y Miotti 1983; 
Gutierrez y Martinez 2008; Mengoni Goñalons 1983, 1988; Miotti 1998; Miotti et al. 1988; Politis 1984; Politis y Messineo 2008). El aprovechamiento pudo seguir varias vías: el carroñeo o la caza programada. Esta última alternativa, habría seguido estrategias cinegética especiales según la etología de la presa a capturar. Por ejemplo Borrero (1986) propone que para el Mylodon sp. posiblemente pudo ser la caza colectiva o por entrampamiento; para los caballos y camélidos extinguidos se proponen estrategias de caza similares a las empleadas para guanacos, es decir una caza programada, incluyendo acecho y entrampamiento de manadas, donde posiblemente el arma más utilizada habría sido la lanza con cabezales líticos (Miotti 1998).

Se sostiene para este intervalo que los grupos cazadores recolectores habrían seguido una estrategia Forager (sensu Binford 1980), inferida a partir de la recurrencia de taxa identificados en los sitios arqueológicos, desarrollando un uso jerárquico del espacio.

Habrían existido redes amplias de comunicación e intercambio con grupos de áreas vecinas (Miotti 1995, 2003; Miotti y Salemme 1999). La movilidad habría sido alta y en grupos pequeños, tal vez unas pocas familias, pero manteniendo su comunicación aún a larga distancia, esto habría permitido un conocimiento más eficiente de los lugares más aptos para la instalación humana (Miotti y Salemme 2004). Esto último difiere de lo propuesto por Borrero (1989) para el momento inicial de este intervalo al que denomina una etapa de Exploración, que implica movimientos a través de rutas naturales y la ocupación de localidades no óptimas.

Para este momento se espera discontinuidad ocupacional debida a la estructura de los recursos, la baja demografía y la posibilidad de que algunos grupos o poblaciones se hayan extinguido en este proceso, por tal motivo, la visibilidad arqueológica de esta etapa sería baja (Borrero 1994-95). Esta situación aumentaría las posibilidades de alternancia ocupacional con carnívoros o roedores, lo que puede afectar la integridad de los sitios (Borrero 1989). Durante esta etapa Borrero (1994-95) propone que los rangos de acción deberían haber sido amplios para la explotación de una biota diversificada.

Hacia la etapa final de este intervalo habría comenzado lo que Borrero (1989) llamó etapa de Colonización y que habría continuado durante el Holoceno medio con la generación de abundante variación de estrategias.

Durante el proceso de Colonización habría una mayor intensidad de ocupaciones y por ende, la expectativa sería la de una mayor visibilidad arqueológica y buena resolución. Se registraría una mayor variabilidad del material y un cambio más acelerado (Borrero 1994-95). Es esperable la presencia de grupos humanos en sectores restringidos del 
espacio y con rangos de acción específicos, implicando un uso más repetitivo de los sitios (Borrero 1989-90).

Por su parte, para estos momentos tempranos de ocupación en la región pampeana, Martínez y Gutiérrez (2004) encuentran la misma tendencia que se observa en Patagonia meridional. En Pampa, el modo de subsistencia habría estado caracterizado por una economía regional generalista, basada en la explotación de un amplio rango de recursos (Martínez y Gutiérrez 2004).

\subsection{HOLOCENO MEDIO (ENTRE 7,5 Y 3 KA AP)}

Este período fue denominado Fase de Consolidación Territorial de los cazadores recolectores (Miotti y Salemme 1999). Para este intervalo se registra una menor diversidad faunística y todas las especies identificadas corresponden a especies que actualmente viven en el área; la proporción de aves grandes y medianas disminuye respecto de la representación que adquirían en el intervalo anterior (Miotti y Salemme 1999).

Respecto del intervalo anterior, aquí la estrategia de subsistencia cambia hacia la especialización, centrada específicamente en el guanaco. Esto estaría relacionado con la desaparición de los megamamíferos; los grupos cazadores habrían pasado un proceso adaptativo hacia condiciones más áridas donde el guanaco se vuelve la especie dominante aunque las aves también fueron recursos importantes (Miotti 2012; Miotti y Salemme, 1999; Salemme y Miotti 2008). Esto mismo observan Martínez y Gutiérrez (2004) en la región pampeana y proponen una economía regional especializada, donde el guanaco sería el centro de la subsistencia. Estos conceptos fueron recientemente explorados desde una metodología más ajustada y con una base de datos más amplia para la región y dentro de este concepto de especialización aparece la discusión del de especificación (Miotti 2012).

Durante esta fase, las relaciones entre los grupos cazadores-recolectores estuvieron basadas en alianzas e intercambios; la movilidad parece que siguió siendo alta, y debido a un sensible aumento poblacional que pudo ocurrir durante este intervalo, los desplazamientos e intercambios entre la meseta, la costa y la cordillera parecen ser una constante, esto sumado a la existencia de nichos ecológicos vacantes, facilitaron y 
favorecieron el éxito de la ocupación territorial (Miotti y Salemme 2004; Miotti 2008). Durante el Holoceno medio se comienza a ver la existencia de cierta territorialidad, aún poco estructurada, de bandas uni y multifamiliares (Miotti y Salemme 2004).

Se sugirió que los factores ambientales no fueron la única razón de los cambios en el patrón espacial de recursos y asentamiento que se registraron entre los cazadores recolectores que habitaron el sur de la Patagonia, especialmente la Meseta Central, durante este período (Miotti 2008).

Para mediados de este intervalo, Borrero (1989-90; 1994-95) propone que comenzaría una etapa de Ocupación Efectiva, donde todo el espacio deseable estaría siendo utilizado. Dos estrategias distintas podrían haber tenido lugar: la Ocupación Estable y la Saturación del Espacio. La primera de ellas podría implicar una territorialidad bajo ciertas condiciones específicas, la segunda implicaría la aparición masiva de mecanismos dependientes de la densidad poblacional (Borrero 1994-95). Se espera, para este proceso, una alta visibilidad arqueológica con baja resolución debida a la superposición de rangos de acción de los distintos grupos.

\section{3. HOLOCENO TARDÍO (ÚLTIMOS 3000 AÑOS)}

Durante este período se habría producido un nuevo giro en el uso de los recursos faunísticos por parte de los cazadores-recolectores de la región, con la concomitante repercusión en la tecnología de la movilidad y re-estructuración social. La aridización sostenida que se da a lo largo de este período en Patagonia se agudizó hacia los últimos 100 años con el ingreso del ganado ovino en la región, que resultó en el retroceso numérico de especies nativas como el guanaco, y en casos más severos provocando la casi extinción de algunas de ellas - eg., la retracción del huemul hacia el bosque cordillerano(Miotti 1998). Los guanacos y ñandúes habrían tenido una alta disponibilidad durante todo el año tanto en la costa como en el interior (Miotti 1998). Durante este intervalo se registra una mayor abundancia taxonómica con respecto del Holoceno medio, si bien se produce un aumento del registro de especies de bajo retorno económico provenientes tanto de ambientes acuáticos (continentales y marítimos), como terrestres, el guanaco continúa siendo el principal recurso económico entre las sociedades de la meseta (Miotti 2012). 
Se propuso la existencia durante el Holoceno medio, de diversas estrategias de uso de los recursos las cuales presentan grandes diferencias en las distintas latitudes para Patagonia. En un trabajo reciente se propone que el cambio en la explotación de recursos faunísticos adoptaría una tendencia de intensificación en Patagonia Norte, de especificación en la región Meridional con un fuerte aprovechamiento del guanaco, aunque con dos variables: extensificación y potenciación del recurso base (Miotti 2012). El valor agregado se habría concentrado en el procesamiento integral de sus productos, lo que indica una potenciación del mismo recurso, con la complementación de ítems de otras regiones debido a las redes de intercambio a larga distancia que ya para este intervalo tendrían amplia distribución geográfica. Miotti (2012) sostiene que la hipótesis de extensificación formulada por Goñi (2010) en base a la evidencia de los contrafuertes cordilleranos, sería adecuada para ese sector, pero para la región de estudio sería más apropiado el concepto de especificación con una potenciación del recurso base.

La extensificación de los rangos de movilidad de los grupos humanas estaría estrechamente relacionada con la aridización del Holoceno tardío, aunque no debe descartarse la importancia del conocimiento que estas sociedades habrían acumulado durante todo el Holoceno acerca de los lugares y recursos disponibles. En aquellos lugares donde el recurso crítico agua lo permitía, se habría producido la agregación multifamiliar. Estos nodos habrían facilitado los procesos de intercambio de bienes (locales, regionales y supra-regionales), la potenciación de los recursos, especialmente el guanaco -ei., charque, salado, derretimiento y almacenamiento de grasas- sirvió de base para extender la movilidad de estos grupos humanos (Miotti 2012).

Por su parte, el registro arqueológico del Holoceno tardío en la región pampeana muestra una importante diversidad y riqueza taxonómica, que sugiere la existencia de economías areales de diversificación e intensificación en la explotación de recursos (Martínez y Gutiérrez 2004). 


\section{CAPÍTULO 6}

\section{METODOLOGÍA Y TÉCNICAS DE ANÁLISIS}

En este capítulo se definen las herramientas metodológicas utilizadas para efectuar el análisis de cada conjunto zooarqueológico proveniente de la cuenca del Zanjón Rojo y Blanco en la Meseta Central de la provincia de Santa Cruz, y la comparación entre ellos. Las unidades y categorías que se presentan aquí forman la base conceptual sobre la que se discute y analiza la variabilidad tafonómica y zooarqueológica existente dentro de esta cuenca. Las mismas constituyen las herramientas metodológicas que permiten articular el campo teórico y el campo empírico (Mengoni Goñalons 2010). En el sentido de O’Brien y Lyman (2002) son las entidades conceptuales que sirven de estándar para realizar nuestras observaciones.

\subsection{METODOLOGÍA GENERAL}

Se estudiaron comparativamente los conjuntos zooarqueológicos procedentes de contextos localizados en diferentes ambientes de la cuenca del zanjón Blanco y Rojo en la Meseta Central de la provincia de Santa Cruz. El objetivo fue analizar la variabilidad tafonómica y zooarqueológica dentro de la cuenca asumiendo que cada ambiente particular ya lleva implícito un grado importante de variabilidad tafonómica y zoológica que intrínsecamente afectan las calidades de las conservaciones de materiales. Para ello fueron seleccionados dos sitios arqueológicos cada uno de los cuales se encuentra en sectores distintos de la cuenca. El sitio AEP-1 de la localidad Piedra Museo se localiza en la cuenca baja del Zanjón Rojo, y a 146 msnm, mientras que el sitio Cueva Maripe de la localidad La Primavera se ubica en las cabeceras del Zanjón Blanco a 562 msnm (Figura 2.2). Los materiales arqueofaunísticos analizados provienen de contextos estratigráficos en abrigos rocosos con secuencias ocupacionales que se remontan a la transición Pleistoceno-Holoceno y llegan hasta el Holoceno tardío. 
El análisis comparativo se efectuó tanto a nivel intra sitio como intersitio. Dentro de cada secuencia se analizaron comparativamente los diferentes conjuntos mientras que la comparación entre sitios, se efectuó confrontando aquellos conjuntos cuyas cronologías son similares.

Los bloques temporales utilizados para el estudio comparativo corresponden a la transición Pleistoceno-Holoceno y Holoceno temprano, Holoceno medio y Holoceno tardío, siguiendo el esquema general propuesto por Miotti y Salemme $(1999,2004)$ y que fue caracterizado en el Capítulo 2.

El estudio de los materiales óseos recuperados en estos sitios permitió conocer la estructura faunística de cada conjunto y analizar la abundancia relativa de especies a partir de la utilización de los diferentes estimadores de abundancia anatómica y taxonómica que se detallan más adelante. De este modo, se puede obtener un primer nivel de taxones dominantes y subordinados (ver Capítulos 7, 8 y 9).

El estudio de la fauna de mamíferos terrestres fue sin duda el más detallado debido a que en general las muestras están dominadas por una especie: Lama guanicoe (guanaco), sobre la cual se profundizaron los estudios tafonómicos como zooarqueológicos.

El reconocimiento de diferentes patrones de modificación en las superficies óseas permite inferir, en algunos casos, los agentes y procesos tafonómicos responsables de las mismas (Gifford-González 1991; Johnson 1985). Por tal motivo, este tipo de estudio constituye una vía de análisis para comprender la historia tafonómica de un sitio y discutir su integridad arqueológica (Borrero 2001; Lyman 1994a).

El estudio tafonómico comparativo se realizó siguiendo la propuesta de un método gráfico estandarizado realizada por Behrensmeyer (1991), la cual fue seguida por varios autores en nuestro país, quienes con sus trabajos demostraron el potencial de la misma (De Nigris 2004; Mengoni Goñalons 1999; Muñoz 2008; Rindel 2009, entre otros). Esta técnica gráfica llamada "arqueotafograma” (Lyman 1994a; Mengoni Goñalons 1999), por un lado muestra el comportamiento de las diferentes variables tafonómicas dentro del mismo conjunto, y por otro lado, ofrece una representación estandarizada de los datos que hace posible la comparación entre conjuntos distintos (Behrensmeyer 1991; Lyman 1994a; Mengoni Goñalons 1999). 


\subsection{ACERCA DE LOS CONJUNTOS ESTUDIADOS}

En esta sección, se describe la metodología empleada durante la excavación de cada sitio, y se establecen los criterios utilizados para el registro de los restos faunísticos que de ellos proceden.

\subsubsection{Alero El Puesto 1 (AEP-1), Piedra Museo}

Las excavaciones del sitio se realizaron entre 1990 y 1999 bajo la dirección de la Dra. Laura Miotti, cubriendo una superficie total de 40,25 m². Las unidades prácticas de excavación consistieron en total de doce cuadrículas cuyas medidas varían en función de la topografía del sitio (ver Capítulo 8: Figura 8.2), ellas fueron divididas en sectores o cuadrantes. Los materiales se recuperaron a partir de la tridimensión, utilizando un eje de coordenadas horizontales establecido para el sitio y un plano cero o datum a partir del cual se registró la profundidad de los hallazgos, esta información junto a la contextual de cada hallazgo particular fue registrada en las planillas de excavación. Los sedimentos extraídos fueron pasados por tamices de entre 0,2 y $0,5 \mathrm{~cm}$, lo que permitió recuperar materiales más pequeños (generales), cuya correspondencia espacial al sitio es dada a partir de la pertenencia a un determinado sector y a la ubicación vertical en los distintos horizontes del paleosuelo y a los remontajes efectuados. La excavación del sitio se realizó siguiendo las seis unidades estratigráficas naturales identificadas (Miotti 1992; Miotti et al. 1999, 2003; Zárate et al. 2000).

\subsubsection{Cueva Maripe (MA), La Primavera}

Las excavaciones se realizaron bajo la dirección de la Dra. Laura Miotti, en cuadrículas de $2 \times 2 \mathrm{~m}$, cada una de las cuales fue dividida en cuatro cuadrantes o sectores de 1 x $1 \mathrm{~m}$. La superficie total excavada entre 2003 y 2010 es de $34 \mathrm{~m}^{2}$, aquí se analizan los restos faunísticos procedentes de 5 cuadrículas, tres de Cámara Norte (C5, 
D5 y D6) y dos de Cámara Sur (A12 y B12), cuyas excavaciones se han completado hasta el nivel de la roca de base. Los materiales arqueológicos fueron recuperados por medio de dos técnicas, la de tridimensión y la de zaranda. La tridimensión se llevó a cabo a partir de la toma de medidas desde un eje de coordenadas Sur y Este, y un plano horizontal o datum establecido para el sitio. Estos materiales fueron numerados e ingresados a las planillas de campo en las que se incorporó la información correspondiente a cada espécimen, su procedencia e información contextual tanto arqueológica como de matriz sedimentaria. Todos los sedimentos extraídos fueron tamizados con mallas de 0,2 y $0,5 \mathrm{~cm}$, los materiales recuperados de esta forma corresponden a la categoría "Generales", a diferencia de los tridimensionados, ellos tienen asignación espacial al sitio a través de su pertenencia a un determinado sector de la grilla de cuadrículas y a un nivel de excavación (Miotti et al. 2007, 2009).

Algunas técnicas de excavación entre la Cámara Norte (CN) y la Cámara Sur (CS) varían en función de las dificultades presentadas por cada una de ellas, fundamentalmente en relación a sus características estratigráficas (ver para mayor detalle Capítulo 7). En tal sentido la $\mathrm{CN}$ fue excavada siguiendo niveles naturales con control artificial, mientras que la CS se hizo por niveles artificiales de $10 \mathrm{~cm}$ cada uno.

A partir de 2010 La toma de datos tridimensionales se comenzó a realizar con Estación Total de pulso (Topcon serie GTS-3000W). Técnica que permitió no sólo agilizar y precisar el ingreso de materiales, sino que ayudó a mejorar la base de datos digitales para los sitios.

\subsection{ANÁLISIS ZOOARQUEOLÓGICO Y TAFONÓMICO}

El estudio de los restos faunísticos hallados en sitios arqueológicos constituye la línea de evidencia que se encarga de estudiar las interacciones entre los animales y las sociedades humanas del pasado (Mengoni Goñalons 2010). Este tipo de investigación aporta información valiosa para abordar temas relacionados tanto a los paleoambientes como a aspectos culturales de estas sociedades, entre los que están los netamente económicos, vinculados a las estrategias de subsistencia de los grupos humanos, como así también, aspectos sociales que contemplan el reparto y distribución de las presas cazadas, ó los ideológicos entre los que por ejemplo, estarían los tabúes alimenticios (Binford 
1978, 1981; Borrero 2011; De Nigris 2004; Gifford-González 1993; Lyman 1994a; Mengoni Goñalons 2007, 2010; Politis y Martínez 1996; Politis y Saunders 2002; Salemme y Miotti 1987).

La historia de la zooarqueología revela distintas realidades acerca de la contribución de la tafonomía a estos estudios zooarqueológicos. Como fue desarrollado en el Capítulo 4, entendemos a la tafonomía como parte de la investigación zooarqueológica ya que los objetivos de ambas disciplinas, relacionadas entre sí, están perfectamente alineados (Borrero 2011; Gifford-González 1989; Grayson 1989; Gutiérrez 2004; Lyman 1994a; Marean 1995). Abordar la perspectiva tafonómica desde el inicio de una investigación zooarqueológica, permite conocer los distintos agentes y procesos involucrados en la formación del conjunto $\mathrm{y}$, en tal sentido, realizar interpretaciones más ajustadas sobre el pasado cultural de las sociedades (Borrero 2007). Sin embargo, el avance de los análisis de otros contextos del sitio como el lítico, radiocarbónico, y los transdisciplinares como los palinológicos, diatomológicos, de fitolitos, entre otros, pueden incluso ir ajustando asimismo las hipótesis tafonómicas stricto sensu.

\subsubsection{Identificación}

Las determinaciones anatómicas y taxonómicas de los especímenes óseos se realizaron conforme los estándares de la biología, y siguiendo la propuesta metodológica realizada por Salemme y colaboradores (1988). Para realizar esta etapa del trabajo se utilizó como referente empírico, material óseo de individuos actuales recolectados en el área de estudio -que han pasado a formar parte de la colección zooarqueológica del equipo- y otros procedentes de las colecciones comparativas de las Divisiones Mastozoología y Paleontología de Vertebrados del Museo de La Plata (FCNyM- UNLP).

Los especímenes fueron asignados a las distintas categorías taxonómicas según las características morfológicas que presentaban y el nivel de diagnosticabilidad de las mismas (Salemme et al. 1988). De esta manera se alcanzaron distintos niveles de identificabilidad, los cuales además son afectados por el estado de preservación y el grado de fragmentación de los especímenes. Este punto nos presenta un desafío en cuanto a que la fragmentación puede tener origen antrópico y/o post-depositacional. La asignación 
taxonómica de los restos óseos a nivel específico fue alcanzada cuando los especímenes contenían rasgos diagnósticos característicos para dicho nivel sistemático, quedando en otras situaciones, determinados a niveles taxonómicos mayores como los de género, familia, orden y clase. Los especímenes que no pudieron ser asignados a ninguna de estas categorías taxonómicas conforman el grupo de los indeterminados.

\subsubsection{Unidades de definición anatómica}

Aquí se definen las unidades que se utilizaron en esta tesis para referirse a las distintas partes o regiones del esqueleto de los animales, el cual constituye el marco de referencia más básico dentro de la zooarqueología. Estas unidades son las siguientes:

Región o zona esqueletaria: son las zonas mayores en las que se segmenta el esqueleto, engloba un grupo de huesos que se vinculan anatómicamente con determinado sector del animal (Mengoni Goñalons 1988, 2010). Según Mengoni Goñalons (1988) estas pueden ser:

Cabeza: cráneo y mandíbula.

Segmento Axial: vértebras, costillas y esternón.

Cintura escapular: escápulas y clavículas.

Cintura pélvica: dos hemipelvis.

Miembro anterior: húmero, radio, cúbito, carpianos, metacarpianos y falanges.

Miembro posterior: fémur, tibia, peroné, rótula, trasianos, metatarsianos y falanges.

Porción: son fragmentos óseos que corresponden a un sector o parte anatómica de un elemento esqueletario - e.g., capítulo de costilla, epífisis proximal de fémur, entre otros-.

Elemento: corresponde a una unidad anatómica completa, sugiere integridad (Grayson 1984; Lyman 1994a, 1994b; Mengoni Goñalons 1988; Salemme et al. 1988)

Espécimen: unidad mínima y fundamental de observación en zooarqueología, con ello nos referimos a todo fragmento óseo de una pieza esqueletaria, sea ésta identificable o no (Grayson 1984; Lyman 1994a, 1994b; Salemme et al. 1988).

También son consideradas las distintas regiones sucesivas en que se pueden dividir los miembros pares de los vertebrados Tetrápodos (Gavrilov 1959): 


\begin{tabular}{c|c|c|c|c}
\hline Parte esquelética & \multicolumn{2}{|c|}{ Extremidad anterior } & \multicolumn{2}{c}{ Extremidad posterior } \\
\hline Estilopodio & \multicolumn{2}{|c|}{ Brazo: húmero } & \multicolumn{2}{|c}{ Muslo: fémur } \\
\hline Zeugopodio & \multicolumn{2}{|c|}{ Antebrazo: Radio y cúbito } & \multicolumn{2}{|c|}{ Pierna: tibia y peroné } \\
\hline \multirow{2}{*}{ Autopodio } & \multirow{2}{*}{ Mano } & $\begin{array}{c}\text { Basipodio: } \\
\text { carpos }\end{array}$ & & $\begin{array}{c}\text { Basipodio: } \\
\text { tarsos }\end{array}$ \\
\cline { 5 - 5 } & \multirow{2}{*}{$\begin{array}{c}\text { Metacarpo: } \\
\text { metacarpales }\end{array}$} & \multirow{2}{*}{ Pie } & $\begin{array}{c}\text { Metatarso: } \\
\text { metatarsales }\end{array}$ \\
\cline { 5 - 6 } & Acropodio: & & $\begin{array}{c}\text { Acropodio: } \\
\text { falanges }\end{array}$ \\
\hline
\end{tabular}

Tabla 6.1: regiones en que se divide el miembro de los vertebrados Tetrápodos (tomado de Gavrilov 1959)

\subsubsection{Análisis cuantitativo de los restos óseos}

En zooarqueología utilizamos categorías taxonómicas y anatómicas. Las primeras dan cuenta del rango de animales presentes en el conjunto, las segundas permiten categorizar las partes esqueletarias representadas (Mengoni Goñalons 2010), a partir de los métodos de cuantificación podemos abordar la importancia de los distintos taxones en la dieta de las sociedades cazadoras-recolectoras, la selección de sus partes para transporte, consumo, confección de instrumentos, prendas u otros usos.

Aquí se utiliza el Número de Especímenes Identificado o NSP para referirse al total de restos óseos que componen la muestra recuperada (Grayson 1991), mientras que el Número de Especímenes Identificados por Taxón o NISP se refiere solamente a aquellos especímenes óseos que, según sus características y rasgos diagnósticos, pudieron ser identificados a algún nivel taxonómico (Grayson 1984; Klein y Cruz Uribe 1984; Lyman 1994a, 1994b, 2008; Mengoni Goñalons 1988, 2010; Payne 1975). El NISP constituye una medida directa tanto de la abundancia anatómica como taxonómica, y de la cuál se derivan otras medidas como el Número Mínimo de Individuos (MNI) o el Número Mínimo de Elementos (MNE).

El Número Mínimo de Individuos (MNI), es una medida de abundancia taxonómica, que se calcula a partir del valor de MNE y equivale al número de individuos necesarios para dar cuenta de todos los huesos identificados para un determinado taxón 
(Grayson 1984; Klein y Cruz Uribe 1984; Lyman 1994a, 1994b, 2003, 2008; Mengoni Goñalons 1988, 2010; White 1953). Su cálculo en esta tesis contempló para el caso de los elementos pares, la lateralidad (derecho e izquierdo) y el estado de fusión de las epífisis (no fusionado, fusionado con metáfisis marcada y fusionado sin metáfisis marcada). Para el caso de los guanacos se siguieron los estadios de fusión propuestos por Kaufmann (2009).

Para estimar la frecuencia de partes anatómicas se utilizó el Número Mínimo de Elementos, el Número Mínimo de Unidades Anatómicas y su valor estandarizado (Binford 1978, 1984). El Número Mínimo de Elementos o MNE constituye una medida de abundancia anatómica (Binford 1978, 1984; Lyman 1994a, 1994b; Mengoni Goñalons 1988, 2010). Derivada del NISP, expresa la frecuencia mínima de elementos necesaria para dar cuenta del número total de especímenes recuperados que corresponden a un determinado elemento o región del esqueleto. Es un valor recompuesto ya que su cálculo requiere el conteo tanto de fragmentos óseos como de elementos completos (Lyman 2008), el método utilizado para realizar este cálculo está basado en las zonas diagnósticas, de esta manera, aquella zona que esté más veces representada es la que define el MNE para esa parte esqueletaria (Mengoni Goñalons 1999; Morlan 1994). Para estimar el MNE se tuvieron en cuenta, al igual que para el cálculo del MNI, la lateralidad de los elementos pares y el estado de fusión de los mismos, siendo considerados en su cuantificación los fragmentos correspondientes a diáfisis debido a que ellas son menos afectadas que las epífisis por los distintos procesos y agentes tafonómicos - eg., meteorización, carnívoros- garantizando un valor de MNE más ajustado a la realidad del conjunto original (Cleghorn y Marean 2007; Marean 1995). Sin embargo, una posición alternativa acerca de que la meteorización es más acelerada sobre las diáfisis que sobre las epífisis ha sido propuesta por Belardi et al. (2010).

Por su parte, el Número Mínimo de Unidades Anatómicas (MAU) (Binford 1978, 1984; Lyman 1994a, 1994b; Mengoni Goñalons 1988, 2010), se obtiene dividiendo el MNE obtenido para cada unidad anatómica por la cantidad de veces que la misma se encuentra en el esqueleto completo, de esta forma se logra una frecuencia normalizada respecto a un esqueleto completo. Esta medida también puede ser expresada en valores porcentuales estandarizados (MAU\%) respecto del máximo valor de MAU obtenido.

Para evaluar las posibles causas de una determinada representación de partes anatómicas en un sitio, se correlacionan los valores obtenidos de MAU\% con distintos índices. Los resultados de esas correlaciones pueden indicarnos si esas frecuencias de 
partes anatómicas coinciden con alguno de los patrones esperados según ellas sean resultado de la acción de procesos de destrucción mediados por densidad, de decisiones humanas de transporte, o una combinación de ambas (Lyman 1994a). Los distintos marcos de referencia utilizados para evaluar el aprovechamiento de las presas fueron presentados y discutidos con mayor profundidad en el Capítulo 4.

En esta investigación, se analiza la frecuencia de unidades anatómicas para la especie Lama guanicoe a partir de dos marcos de referencia como son la Densidad Mineral Ósea (Elkin 1995) y la Anatomía Económica (Borrero 1990; Lyman 1992).

\subsubsection{Análisis de las modificaciones de las superficies óseas}

El estudio de patrones de modificaciones de superficies óseas es una herramienta metodológica a partir de la cual es posible inferir los distintos procesos y agentes involucrados en la formación de un conjunto arqueológico (Binford 1981; GiffordGonzález 1981, 1991; Marean 1995, Lyman 1994a). Desde esta perspectiva, los patrones de modificaciones de las superficies óseas son indicadores de procesos y agentes, naturales y culturales, de formación de sitios arqueológicos. La importancia de su estudio radica en la validez que puedan alcanzar nuestras interpretaciones acerca del comportamiento humano a partir del estudio de un conjunto cuyos procesos de formación han sido complejos, de esta manera es posible evaluar la integridad del registro arqueológico, reconstruir contextos, y obtener información útil sobre aspectos de la subsistencia de sociedades prehistóricas.

El reconocimiento de estos patrones sobre la superficie de los especímenes procedentes tanto de AEP-1 como de MA, fue realizado tanto a ojo desnudo como a partir del uso de lupa binocular (Nikon SMZ 800) con magnificaciones entre 10 y 60 x.

\subsubsection{Procesos, agentes e indicadores tafonómicos}

La gran cantidad de estudios actualísiticos que se han desarrollado conforman el marco interpretativo para el estudio de estas traza, ya que ellos han desarrollado criterios para su identificación. A continuación se presentan los distintos aspectos tafonómicos 
considerados en este estudio y se establecen los criterios utilizados para su identificación y cuantificación.

\subsection{Meteorización}

Se define como un proceso en el cual los componentes microscópicos originales del hueso, son separados y destruidos por la acción de agentes físicos y químicos que operan sobre el hueso in situ (Behrensmeyer 1978:153). Behrensmeyer (1978) sobre la base de características macroscópicas que exhibían los huesos según el tiempo de exposición que habían tenido propuso seis estadios. Dichos estadios aquí fueron utilizados como indicadores para evaluar entre los especímenes la mayor o menor exposición relativa de cada uno, y la potencial pérdida ósea de cada conjunto, así como su integridad (Behrensmeyer 1978; Borrero 2007).

\subsection{Alteración térmica}

La exposición directa o indirecta al fuego, es un proceso que produce cambios de color y textura, además reduce el tamaño de los especimenes óseos y aumenta la capacidad de fragmentación de los mismos, pudiendo además, producir otras modificaciones como grietas, exfoliación y cuarteamiento (Bennet 1999; Cain 2005; Costamagno et al. 2005; David 1990; De Nigris 2004; Frank 2011; Gifford-González 1989; Hanson y Cain 2007; Johnson 1989; Merlo 2006; Shipman et al. 1984; Stiner et al. 1995; Taylor et al. 1995; White 1992). Las modificaciones producidas por calor adquieren características que dependen de si el hueso tenía o no carne, o si se encontraba en estado seco en el momento en que fue expuesto al fuego (Buikstra y Swegle 1989). Registrar la alteración térmica en restos óseos de un conjunto arqueológico puede ser un indicador de la preparación de alimentos (Marshall 1989; Wandsnider 1997), procesos de destrucción de basura ó uso del hueso como combustible (Frank 2011; Joly et al. 2005; Langiano 2006; Merlo 2006; Théry-Parisot 2002). Por otra parte, la frecuencia de huesos quemados también puede ser utilizada como indicador de la intensidad del uso del fuego (Mengoni Goñalons 1988). El reconocimiento de la alteración térmica en los especímenes durante este trabajo se realizó con un examen visual descriptivo que consideró los criterios de color propuestos por Cain (2005) y Johnson (1989). Estos cambios de color se consideraron como indicadores relativos de tiempo de exposición e 
intensidad del calor recibido (Buikstra y Swegle 1989; Cain 2005; Fernández-Jalvo y Perales Piquer 1990; Shipman et al. 1984). Las categorías utilizadas entonces son las siguientes: huesos no quemados (blancuzcos-amarillentos), huesos quemados (marrón); hueso carbonizado (ennegrecidos), y huesos calcinados (blancos- azulados).

\subsection{Huellas de corte}

Son indicadoras del procesamiento humano de las carcasas. Se presentan como surcos individuales o formando conjuntos de surcos, generalmente son finas, alargadas y rectilíneas de bordes paralelos y profundidad variable, en sección transversal presentan forma de V o U (Bunn 1983; Johnson 1989; Mengoni Goñalons 2010; Potts y Shipman 1981; Shipman 1981, 1983, 1986a, 1986b; Shipman y Rose 1983a, 1983b, 1984). La pared de la huella presenta múltiples finas estrías y "hombros”, estos últimos consisten en pequeñas estrías paralelas a las estrías principales (Cook 1986; Olsen y Shipman 1988; Shipman y Rose 1983a). Hay otros procesos que generan marcas similares sobre la superficie de los huesos - e.g., pisoteo, acción de carnívoros- el análisis de la orientación y ubicación topográfica de la marcas en el hueso es fundamental para distinguir en primer término y con un sentido de patrones orientativos sobre los lugares de desarticulación de unidades de trozamiento mayores (cuartos, tronco) de aquellas menores (paleta, costillar, patas) entre las huellas de corte y las provocadas por otros agentes o procesos. En función de la localización de las mismas, siguiendo a Binford (1981) es posible relacionar las huellas de corte a distintos tipos de actividades como:

1. Cuereo: generalmente se localizan en la diáfisis de los huesos distales de las extremidades, en el borde inferior de la mandíbula y en el cráneo.

2. Desarticulación: aparecen en superficies articulares de huesos largos, vértebras y cinturas escapular y pélvica, en la primera en la cavidad glenoidea, y en la última en el acetábulo.

3. Descarne: suelen registrarse tanto en huesos largos, planos y cortos (vértebras), en general se presentan paralelas al eje longitudinal del hueso.

Un trabajo actualístico llevado a cabo por Nielssen (2000) mostró que, cuando se descarna una presa se registran huellas en los sectores adyacentes a las epífisis pero ocasionalmente, también en las superficies articulares. Si bien el autor sugiere utilizar el ángulo de las huellas para determinar la actividad llevada a cabo, esta variable no se ha contemplado en este estudio. 


\subsection{Marcas de machacado}

Son consecuencia de uno o más impactos producidos por el filo activo de un artefacto pesado sobre el hueso y están caracterizadas por una sección en $\mathrm{V}$ abierta, estrías destacadas y desprendimientos de la superficie interna del surco principal (Binford 1981, 1984; Cook 1986; Gifford-González 1989). Este tipo de marcas suelen ser asociadas a la desarticulación de ciertas partes esqueletales - e.g., sínfisis púbica- o cuando las carcasas están congeladas o secas (Binford 1981, 1984).

\subsection{Fracturas}

Son el resultado de una falla mecánica localizada en el hueso, que resulta de la aplicación de una fuerza estática o dinámica, y cuyas causas pueden deberse a diferentes factores naturales y culturales (Johnson 1985). Estudiar los patrones de fracturas en los especímenes óseos permite discriminar entre las que son resultado de procesos y agentes tafonómicos, y aquellas producidas intencionalmente por el agente humano. Las fracturas tafonómicas brindan información sobre la historia depositacional y post-depositacional del conjunto, ya que ellas pueden ser producidas por diferentes agentes como los carnívoros, la meteorización, la alteración térmica, el pisoteo (Binford 1981; Johnson 1985, 1989; Lyman 1994a; Miotti 1998, 1992, Mengoni Goñalons 1988, 1999, 2010). Mientras que las fracturas intencionales, generalmente son producto de distintas actividades vinculadas al procesamiento y consumo de las presas, como la obtención de médula o grasa ósea, o el uso del hueso como materia prima para la confección de instrumentos (Bunn 1989; Church y Lyman 2003; De Nigris 2004; Enloe 1993; Johnson 1985, 1989; Lupo y Schmitt 1997; Miotti 1998, 1992; Mengoni Goñalons 1988, 1999, 2010; Outram 2002).

Los patrones de fractura que resultan de los diferente procesos y agentes fueron caracterizados y descriptos a partir de la realización de diversos estudios actualísticos (Alcántara García et al. 2006; Behresmeyer 1978; Binford 1981; Bonnichsen 1979; Bunn 1989; De Nigris 2004; Gifford-González 1989; Haynes 1983, 1986; Johnson 1985; Mengoni Goñalons 1982; Miotti 1998, 1992; Morlan 1980; Outram 2002; Yellen 1977, entre muchos otros). Hay algunos factores que condicionan el patrón de fractura resultante, uno es el tipo de fuerza ejercida sobre el hueso -e.g., estática o dinámica(Johnson 1985), el otro es el estado del hueso al momento de ser fracturado - e.g., fresco 
o seco- (Bonnichsen 1979; Johnson 1985; Miotti 1998, 1992; Morlan 1980; Shipman 1981).

Para este trabajo se siguieron los criterios establecidos por Bonnichsen (1979) y Johnson (1985: 172) para evaluar los atributos de huesos fracturados. De esta manera entendemos que un hueso que se fracturó en estado fresco presenta superficies de fractura cuyo color no se diferencia del de la superficie cortical del hueso. Además, registra una textura suave y homogénea que se distingue de la del hueso que se fractura en estado seco y que se presenta rugosa e irregular. En este último caso, el color de la superficie de fractura contrasta con el del tejido cortical del hueso (Johnson 1985: 48-49). Los tipos de fracturas fueron determinados como perpendicular o transversal cuando la fractura forma un ángulo recto con el eje longitudinal del hueso; longitudinal cuando la misma se desarrolla paralela al eje longitudinal del hueso; espiral o helicoidal cuando la fractura sigue un patrón curvado o parcialmente helicoidal, el cual acompaña la torsión de las fibras de colágeno alrededor de la circunferencia del hueso (Gifford-González 1989, 1988; Miotti 1992, 1998). Por lo expuesto, para este trabajo consideramos fracturas producidas intencionalmente por el agente humano a aquellas que resultan en un patrón helicoidal o longitudinal, su forma sigue la disposición de las fibras de colágeno del elemento en cuestión, presentan superficies suaves cuyo color no difiere del que presenta el tejido cortical y muchas veces presenta atributos tecnológicos asociados a los bordes de fracturas como pueden ser puntos de impacto, muescas, negativos de impacto u otros rasgos relacionados a la fracturación de los huesos (Johnson 1985, 1989; Miotti 1992, 1998). Consideramos además, para alcanzar este nivel de determinación, aquellas características que permiten diferenciar este tipo de fracturas de las producidas en estado fresco del hueso por otros agentes - eg., carnívoros-, estas características se registran en la superficie de la fractura y son las "hackle marks" definidas como lomos o estrías discontinuas y curvas, y "ribs" como lomos cóncavos (Johnson 1989). Además, para determinar el origen antrópico de estas fracturas, se debe considerar la ausencia de trazas vinculables a la acción de carnívoros - eg., perforaciones, hoyuelos, arrastres, surcos-.

También se consideraron como intencionales y de origen antrópico, aquellas fracturas transversales cuyas superficies no difieren en color con la superficie del hueso y presenta algún tipo de aserrado perimetral intencional para debilitar el hueso y provocar una fractura controlada. 
Todas aquellas fracturas que no presenten los atributos arriba descriptos, a los fines de este trabajo fueron contempladas como resultado de agentes tafonómicos no humano -e.g., meteorización, pisoteo, alteración térmica, carnívoros, entre muchos otros-

En los especímenes óseos se registraron tantos tipos de fracturas como las que presentaban dado que un hueso puede ser fracturado más de una vez, en momentos distintos y por diversos agentes causales.

\subsection{Marcas de percusión}

Se generan como consecuencia de golpear el hueso con un percutor o yunque con la intención de fracturarlo. Están caracterizadas por la presencia de hoyos y estrías de percusión (Blumenschine y Selvaggio 1988; Blumenschine et al. 2007). Generalmente estas marcas se localizan a lo largo de los bordes de fractura y se disponen de forma

transversal al eje longitudinal del hueso. Ambos tipos suelen presentarse asociados y se producen por golpe directo y contragolpe (Blumenschine 1995; Blumenschine y Selvaggio 1988; Blumenschine et al. 1996). Los hoyos de percusión son depresiones de forma circular u ovalada, tamaño variable, y presentan en su interior microestriaciones que pueden salir de ellos (Blumenschine y Selvaggio 1988). Las estrías de percusión se caracterizan por la presencia de microsurcos que se presentan agrupados formando un rastro, tienen forma lineal y están asociados a microestrías (Blumenschine y Selvaggio 1988). Trabajos experimentales indican que la frecuencia de marcas en los huesos no se correlaciona de forma directa con la cantidad de golpes requeridos para fracturarlo, y que, el uso de percutores o yunques con superficies ásperas produce mayor cantidad de marcas que los que tienen bordes romos (Egeland 2003; Pickering y Egeland 2006).

\subsection{Marcas de raspado}

Se presentan como microestrías, generalmente superficiales, finas y rectilíneas; se disponen aproximadamente paralelas al eje longitudinal del hueso y se producen por el movimiento perpendicular al eje mayor del hueso del filo de un artefacto lítico (Blumenschine y Selvaggio 1988; Fisher 1995; Potts y Shipman 1981; Shipman 1981). Estas marcas han sido interpretadas por Binford (1981) como resultado de la remoción del periostio. Por su parte, Olsen (1988) dice que pueden indicar el rebaje del tejido compacto durante la manufactura de instrumentos. 


\subsubsection{8. $\underline{\text { Roedores y Armadillos }}$}

Ambos agentes tienen actividad fosorial, como resultado de la misma pueden modificar la asociación primaria (sincrónica) de los materiales en un depósito arqueológico, configurando nuevas asociaciones espaciales o incorporando nuevos materiales (Bocek 1986; Durán 1991; Frontini 2012; Frontini y Deschamps 2007; Johnson 1989; Lyman 1994a; Mello Araujo y Marcellino 2003; Salemme et al. 2011). Además, cuando los roedores roen generan marcas sobre los huesos con sus incisivos. Dejan un patrón muy particular que se caracteriza por su localización sobre los bordes de fractura de los huesos (Binford 1981) y surcos paralelos con sección en U sin estrías en el interior y con base plana (Johnson 1985; Lyman 1994a; Shipman 1981).

En este trabajo se consideraron las marcas producidas por roedores en los huesos como indicadora de un área o sector potencialmente alterado por la actividad de estos organismos. Por otro lado, el registro y mapeo de cuevas o galerías durante las excavaciones de los sitios también fue considerado como indicador de posible perturbación, y los materiales cuya procedencia es dudosa por estar asociados a dichos rasgos han sido agrupados en un universo aparte. Se prevé a futuro la apertura de una agenda de tratamiento especial para estos materiales, así como su fechado, en un test de congruencia con los fechados de otros huesos de áreas no impactadas por la acción de animales cavícolas.

\subsection{Carnívoros}

El interés por estudiar las consecuencias de la acción de estos agentes sobre conjuntos arqueológicos es de larga data (Binford 1981; Blumenschine 1986; Hill 1979). Los carnívoros cazan, carroñean y consumen las carcasas de los animales para obtener nutrientes de ellas -e.g., carne, cuero, tejido óseo, médula- provocando marcas sobre la superficie cortical de los huesos, y modificando la distribución de las carcasas y/o de los conjuntos -i.e., acumulan, seleccionan y transportan partes anatómicas, provocando modificaciones en los huesos y en los conjuntos, generando patrones que pueden ser confundidos con los humanos- (Binford 1981; Blumenschine y Marean 1993; Borrero et al. 2005; Brain 1981; Cleghorn y Marean 2007; Marean y Spencer 1991; Martin 2008; Mondini 1995, 2002; Stallibrans 1984). 
En este trabajo el foco estuvo puesto en reconocer la acción de los carnívoros como agente tafonómico a partir del reconocimiento de las modificaciones que ellos generan sobre las superficies de los huesos. Estos agentes tienen preferencia por las partes anatómicas con tejido esponjoso y menor densidad ósea -e.g., epífisis de los huesos largos y vértebras-, ya que mordiendo las mismas acceden a la grasa ósea trabecular del hueso; el interés por alcanzar la médula de los huesos largos puede provocar patrones de fractura similares a los generados intencionalmente por los humanos (Haynes 1983). Por otro lado, los ácidos gástricos también dañan la superficie del hueso cuando estos son consumidos. En este sentido, para este trabajo se reconocieron los tipos de marcas definidas por Binford (1981) y vinculadas a la acción de los carnívoros:

-Perforaciones: se ven como depresiones con un centro astillado, en corte transversal forma un cono. Son provocadas por la presión ejercida por los caninos que producen el colapso del hueso. En los huesos planos o bordes resistentes puede registrarse una remoción de tejido en el área del borde provocando un cranulado.

-Hoyuelos: son producto del mordisqueo del tejido óseo más resistente, el cual no colapsa como en el caso de las partes óseas más blandas.

-Arrastres: se registran en el tejido compacto y son resultado de guiar y rotar al hueso con los dientes. Se presentan como surcos rectos, poco profundos y sin estrías en sus paredes interiores.

-Surcos: son resultado del mordisqueo intenso del tejido esponjoso, donde caninos y dientes pasan por el mismo lugar obliterando las perforaciones dejadas con anterioridad y generando un aspecto irregular y ondulado del tejido esponjoso.

\subsection{Raíces}

Las raíces pueden modificar las superficies de los especímenes óseos generando surcos poco profundos o superficiales una vez que los huesos han sido enterrados. Sin embargo, algunos musgos y líquenes pueden crecer sobre los huesos cuando todavía están en la superficie del terreno provocando modificaciones pre-depositacionales (Lyman 1994a). Macroscópicamente, estas modificaciones se presentan como surcos grabados sobre la superficie de los huesos que adquieren diseños dendríticos (Morlan 1980) o sinuosos (Andrews y Cook 1985). La coloración de los surcos grabados puede variar, a veces presenta el mismo color que la superficie que no fue afectada, a veces los 
surcos son de color más claro (Morlan 1980), y otras más oscuros (Binford 1981). Microscópicamente estos surcos son anchos, con un fondo suave, y en sección transversal tienen forma de "U" (Andrews y Cook 1985: 685). Aún no se sabe con claridad si estos grabados son resultado de la disolución de ácidos que están vinculados al crecimientos y descomposición de las raíces, o si son resultado de la acción de ácidos secretados por el hongo que se asocia a la descomposición de la planta (Behrensmeyer 1978; Grayson 1988; Morlan 1980).

Montalvo (2002) distingue dos tipos de trazas producidas por raíces a partir de las cuales se podrían interpretar momentos distintos en los que las raíces pudieron afectar los materiales. El primer tipo corresponde a marcas dendríticas pequeñas, superficiales e irregulares, que forman canales en forma de " $U$ " con bordes nítidos y que presentan ramas principales y bifurcadas, usualmente de 0,15 a $1 \mathrm{~mm}$ de ancho. El segundo tipo consiste en trazas más grandes que las anteriores (miden más de 1,5 mm de ancho), prácticamente no registra bifurcaciones y presentan contornos y superficies muy irregulares, mostrando un alto grado de corrosión, a veces se presentan asociadas a otras subcirculares y pequeñas. Las primeras se habrían desarrollado en la interfase elemento esquelético-sedimento después del enterramiento, indicaría la existencia de cobertura herbácea sobre el suelo mientras los restos fueron depositados y facilita la identificación de paleosuelos en el afloramiento. El segundo tipo sugiere que las raíces afectaron los restos en etapas más recientes.

Las raíces también pueden provocar la fractura de un hueso si ésta crece a través del mismo (Behrensmeyer 1978). Registrar marcas de raíces sobre los bordes de fractura o en la superficie interna de las diáfisis, puede aportar información acerca del tiempo relativo que el hueso fue fracturado (White 1992).

\subsection{Depositación de manganeso}

Se presentan como finos depósitos de color negro- azulado, muchas veces dicha tinción es de aspecto metálico, sobre la superficie de los huesos. Los mismos se pueden registrar en forma de motas o cubriendo completamente la superficie de los especímenes, suelen mostrar un patrón dendrítico característico. El manganeso puede provenir de la disolución de rocas carbonáticas y es transportado por el agua, precipitando cuando se registran cambios en el pH (López-González et al. 2006). También puede liberarse como 
resultado de la descomposición de materia orgánica y depositarse sobre los especímenes (Marín Arroyo et al. 2008; Shahack-Gross et al. 1997).

\subsection{Depositación de carbonato de calcio}

Es resultado de la precipitación de sales solubles que se depositan sobre la superficie de los huesos formando una película continua de color blanquecino y que cubre parcial o totalmente la superficie del mismo. Estas sales provienen de los sedimentos o rocas carbonáticas y son transportadas disueltas en el agua o precipitadas por humedad en el ambiente depositacional. Los procesos de pedogénesis favorecen la disolución de las sales que precipitan cuando alcanzan el estado de saturación (Courty et al. 1989; Gutiérrez 2004).

\subsection{Disolución química}

Es resultado de distintos procesos químicos o bioquímicos que afectan los materiales óseos cuando estos están enterrados -i.e., pedogénesis, actividad de raíces(Andrews y Cook 1985; Behrensmeyer 1991; Denys 2002; Nicholson 1996). Los depósitos sedimentarios presentan diferentes características que contribuyen al deterioro químico de los huesos como son la acidez de los sedimentos, la cantidad de sales, agua u oxígeno, el tipo de drenaje, la humedad, la acción de bacterias o microorganismos descomponedores, entre otros (Andrews y Cook 1985; Behrensmeyer 1991; Hedges 2002; Nicholson 1996).

Existen algunos procesos que producen disolución química en los huesos cuando estos aún no estuvieron enterrados -i.e., la acción de algas sobre huesos sumergidos en agua, la acción de algunos hongos o líquenes que pueden actuar antes de que el hueso sea sepultado- (Fernández-Jalvo et al. 2002; Gutiérrez 2004).

Este tipo de modificación se presenta como una disolución de los tejidos más externos del hueso, a veces formando hoyos esféricos u ovales (Gutiérrez 2004; Nicholson 1996). En este trabajo se han determinado como modificaciones de este tipo a aquellas que registran el patrón descripto y que no han podido ser interpretadas como resultado de la acción de raíces o de la digestión provocada por animales predadores o carroñeros. 


\subsection{4. $\underline{\text { Pisoteo }}$}

Es causado tanto por animales como por humanos y provoca distintos tipos de modificaciones sobre los huesos -i.e., marcas sobre las superficies, fracturación, desplazamiento espacial y abrasión (Brain 1967; Lyman 1994a)-.

Durante el pisoteo, los materiales que se encuentran justo debajo de la superficie del terreno pueden sufrir desplazamientos verticales y horizontales (Behrensmeyer et al. 1989; Borrero 1990, 2007; Gifford-González et al. 1985; Lyman 1994a; Olsen y Shipman 1988). Los huesos que aún no están enterrados tienen más chances de que la acción del pisoteo los desplace horizontalmente (Yellen 1991) o, si se encuentran en sustratos poco compactados, que esta acción favorezca su enterramiento (Behresmeyer et al. 1989; Borrero 1990, 2007). Por su parte, Olsen y Shipman (1988) sostienen que el desplazamiento vertical de los materiales está relacionado al grado de compactación y tipo de sedimentos, pudiendo, en el caso de tratarse de un sustrato duro, aumentar la probabilidad de un movimiento horizontal de los huesos.

Si el pisoteo se produce sobre elementos que están meteorizados o debilitados por la acción de otros procesos destructivos, puede provocar fragmentación y hasta destrucción de alguno de ellos (Behrensmeyer 1978; Borrero 1990, 2007; GiffordGonzález 1981; Haynes 1991), siendo los especímenes con forma plana o cilíndrica más propensos a romperse que aquellos de forma esférica (Yellen 1991).

Por otra parte, el pisoteo también provoca marcas sobre la superficies de los huesos, si bien morfológicamente son similares a las producidas por instrumental lítico, éstas son menos profundas que las marcas de procesamiento y suelen presentar una distribución azarosa en múltiples direcciones, localizándose más en las diáfisis de los huesos largos que en las epífisis (Andrews y Cook 1985; Behrensmeyer et al. 1986, 1989; Fiorillo 1989; Lyman 1994a).

\subsection{Teñido}

En esta categoría se agruparon aquellas modificaciones producidas sobre especímenes óseos que corresponden a superficies oscurecidas y cuyo agente causal (fuego, manganeso, u otro) no pudo ser identificado. La dificultad por diferenciar procesos de alteración térmica de la tinción producida por diagénesis fue planteada por varios autores (López-González et al. 2006, y bibliografía allí citada). 


\section{CAPÍTULO 7}

\section{ANÁLISIS DE LOS CONJUNTOS ZOOARQUEOLÓGICOS DEL SITIO CUEVA MARIPE}

En este capítulo se presentan los resultados obtenidos a partir del análisis de los conjuntos arqueofaunísticos provenientes de los dos sectores excavados de Cámara Norte (CN) y Cámara Sur (CS) en el sitio Cueva Maripe (MA), localidad La Primavera.

La complejidad estratigráfica que presenta el sitio, tal como se explica a continuación, no permite hasta el momento, unificar los conjuntos de CN y CS, por tal motivo en esta tesis ellos son analizados por separado. Los criterios establecidos para el estudio de cada uno de estos conjuntos fueron descriptos en los Capítulos 4 y 6 .

El capítulo se encuentra estructurado en cuatro partes principales, la primera de ellas presentan la información generada con anterioridad a esta tesis y a partir de distintas líneas de evidencia para el sitio. Las dos secciones siguienter corresponden a los distintos resultados zooarqueológicos y tafonómicos obtenidos para cada uno de los sectores excavados en MA: CN y CS. Finalmente, en la cuarta sección se analiza y discute la variabilidad intra-sitio a partir de la comparación de los resultados presentados en las secciones anteriores del capítulo.

\subsection{ESTADO DE CONOCIMIENTO ARQUEOLÓGICO Y ZOOARQUEOLÓGICO EN CUEVA MARIPE}

La localidad arqueológica La Primavera se encuentra ubicada en el sector de cabeceras del Zanjón Blanco en la estancia homónima, en el sector norte del Macizo del Deseado, a $47^{\circ} 51^{\prime} 05^{\prime \prime}$ sur y $68^{\circ} 56^{\prime} 03^{\prime \prime}$ ' oeste (Capítulo 2: Figura 2.2; Capítulo 3: Figura 3.1). Las investigaciones sistemáticas en esta localidad arqueológica comenzaron en 2003 bajo la dirección de la Dra. Laura Miotti, desde entonces en ella han sido registradas distintas fuentes de agua potable (fundamentalmente manantiales), fuentes 
primarias y secundarias de materias primas rocosas, así como de ocres y otros minerales; se han localizado y estudiado distintos sitios arqueológicos tanto a cielo abierto como en abrigos rocosos, en estos últimos además, también se ha registrado la presencia de pinturas rupestres (Carden 2009; Hermo 2008; Magnin 2010; Miotti et al. 2009, 2007).

La Cueva Maripe se ubica en el curso medio del extenso mallín La Primavera, que recorre unos $10 \mathrm{~km}$ en sentido SO-NE, por un valle muy encajonado (Figuras 7.1a y 7.1b) desde sus nacientes en la meseta de Los Ventisqueros, hasta su desembocadura en el Zanjón Blanco. Se trata de una cueva externa (Farrand 1985; Miotti 2010) de grandes dimensiones (Figura 7.1b) que se emplaza sobre la margen este del cañadón a aproximadamente $560 \mathrm{msnm}$ en un afloramiento de ingnimbritas correspondientes a la Formación Chön Aike. Cueva Maripe tiene $26 \mathrm{~m}$ de boca por $24 \mathrm{~m}$ de profundidad; la altura del techo varía entre 1 y $5 \mathrm{~m}$ de la superficie actual del suelo. La cueva abre hacia el oeste y se encuentra aproximadamente $4 \mathrm{~m}$ sobre el nivel actual del mallín; internamente está dividida en dos cámaras a partir de un tabique rocoso: Cámara Norte (CN) y Cámara Sur (CS) (Figura 7.2), cada una de las cuales fue considerada como un microambiente distinto (Miotti et al. 2007), y en sus paredes y techos se registró la presencia de pinturas rupestres (Cárden 2009; Miotti et al. 2009).

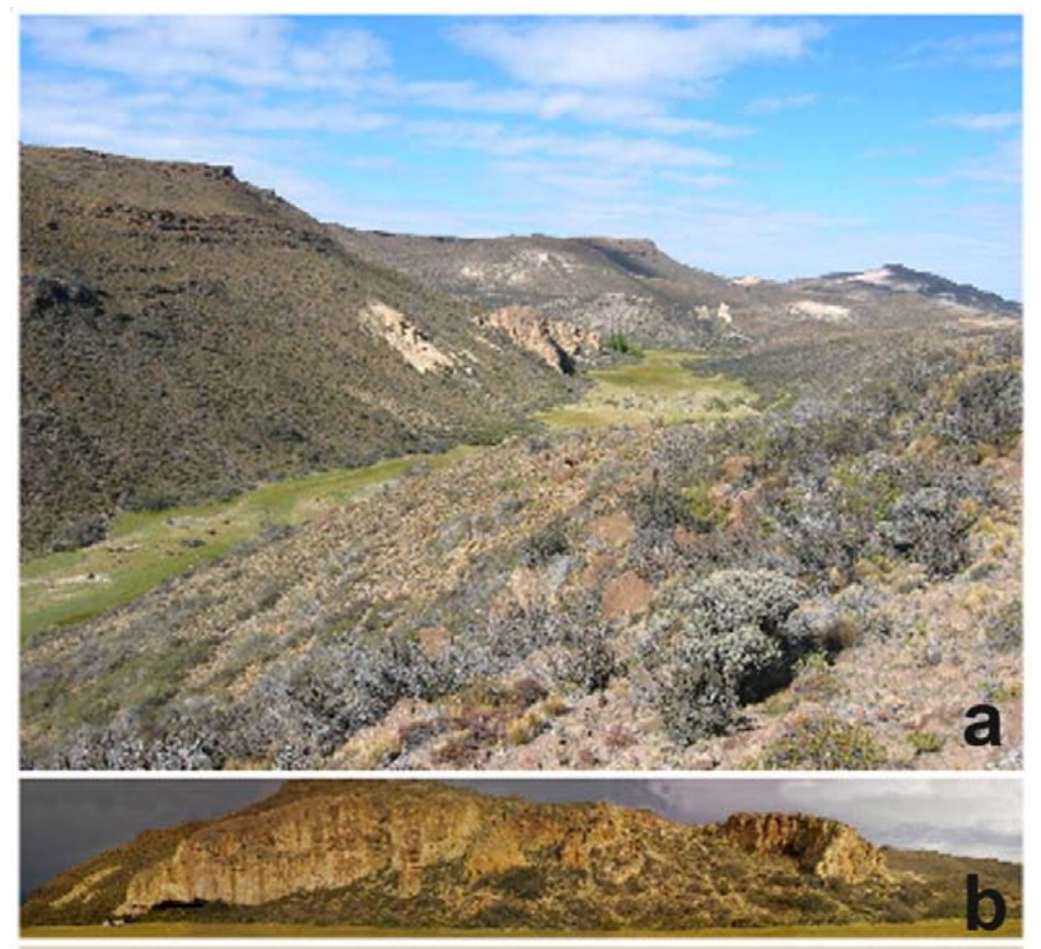

Figura 7.1. a) Mallín La Primavera (foto tomada por Pianzola en 2006); b) Cueva Maripe (composición fotográfica realizada por Pianzola en 2006). 
Desde el inicio de las investigaciones en Cueva Maripe, las excavaciones arqueológicas se realizaron en ambos sectores de la cueva (Figura 7.2) con el objetivo de contrastar la hipótesis de que "las diferencias registradas entre las cámaras pudieron jugar un papel significativo en las decisiones tomadas por las sociedades cazadoras-recolectoras y los distintos agentes biológicos que utilizaron la cueva en los distintos momentos" (Miotti 2010; Miotti et al. 2007). Esta idea, también fue abordada como parte de las investigaciones sobre arte rupestre (Carden 2009) y tecnología lítica (Hermo 2008) que se desarrollaron en el marco de dos Tesis Doctorales, en ambas se presenta evidencia que soporta la hipótesis de un uso diferencial del espacio interior de la cueva.

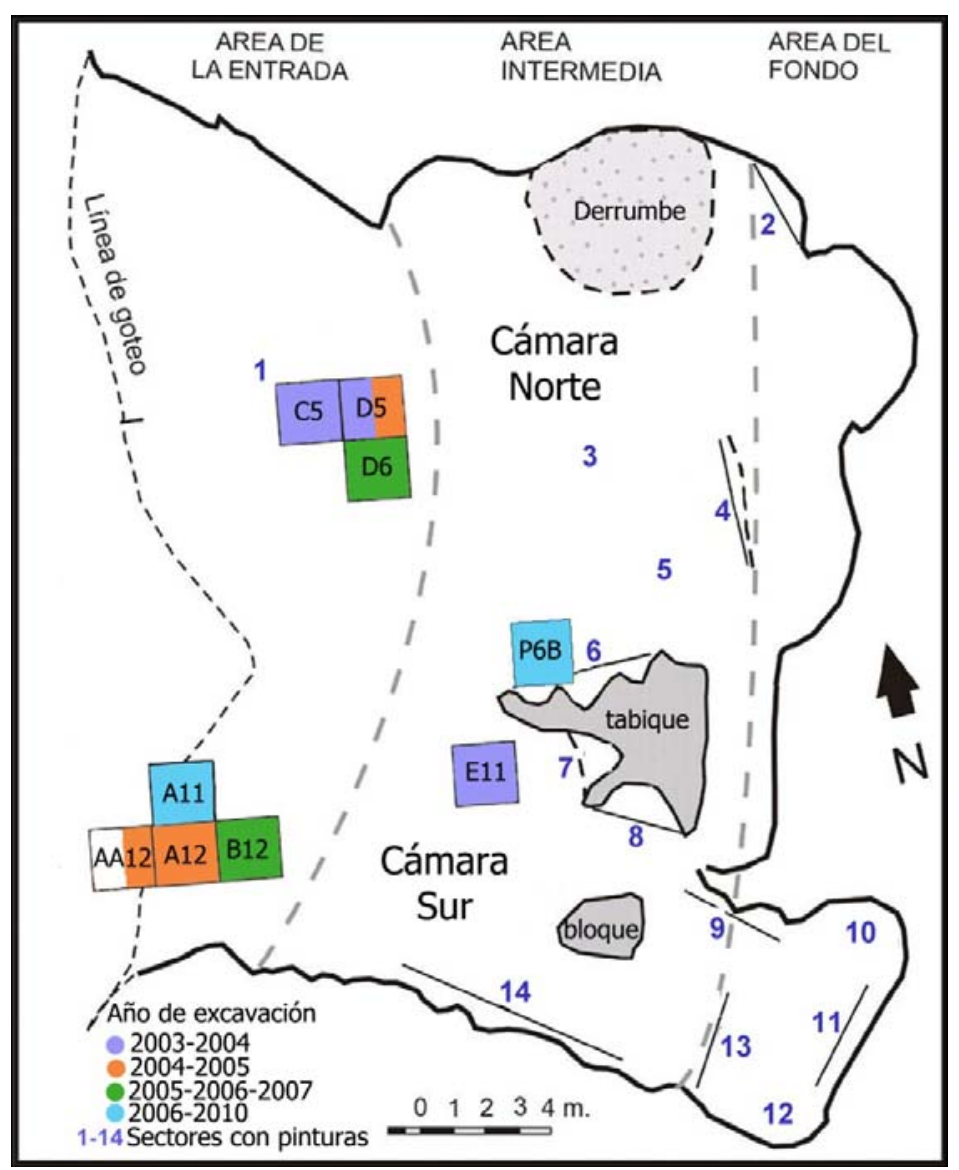

Figura 7.2. Planta de excavación del sitio Cueva Maripe.

Otra característica de este abrigo rocoso es que en la $\mathrm{CN}$ se registró la presencia de un derrumbe de un sector del techo relacionado con una vertiente de agua situada por encima y hacia el norte del afloramiento; por otro lado en la Cámara Sur se encuentra una vertiente activa en la pared del fondo. Las diferentes condiciones actuales registradas 
en cada cámara pueden sintetizarse de la siguiente manera: la CN está caracterizada por una mayor incidencia de los vientos, menor insolación, ambiente seco y mayor tasa de sedimentación; la CS está más reparada de los vientos, en verano la incidencia de la luz solar es mayor, presenta humedad como resultado de un manantial intermitente en el fondo de la misma el cual depende fundamentalmente del agua de las vertientes externas, y la tasa de sedimentación es menor que en $\mathrm{CN}$, lo que resulta en una secuencia comprimida.

Las excavaciones del sitio continúan en pos de poder resolver preguntas fundamentalmente tafonómicas y de estructuración del espacio, esto implica estudios de detalle geoarqueológico, de macro y microrestos biológicos. Estas tareas se realizan a la par de una intensiva exploración sistemática de toda la localidad, en los términos propuestos en la tesis de Magnin (2010) y con la aplicación de GIS. En Cueva Maripe hasta el momento han sido excavadas 8 cuadrículas y media, cada una de $2 \mathrm{~m}$ x $2 \mathrm{~m}$; cubriendo la excavación una superficie total de $34 \mathrm{~m}^{2}$ (Figura 7.2).

Es importante destacar que la cueva fue utilizada al menos hasta la década de 1950 por la familia Maripe, algunos indicadores superficiales de esta ocupación han sido registrados en CS como la presencia de una pequeña pirca y el ahumado de algunos sectores de las paredes que nos permiten suponer que dichas áreas pudieron ser donde se encendieron los fogones y/o correspondieron a áreas de cocina, ya que además materiales de vidrio y metal fueron hallados en la superficie y en la capa más superficial (Miotti et al. 2009).

Previo al comienzo de las excavaciones, tanto los dueños de la Ea. La Primavera (Familia Koproski), como pobladores vecinos y puesteros, le contaron a la Dra. Miotti que desde el siglo XX en la estancia se desarrolló producción alternada de la ganadería ovina y la de vacunos. Por otro lado, según los pobladores, existió un evento de quemazón de los depósitos de estiércol vacuno y de ovejas en la cueva, que duró varios días. En años posteriores a los inicios de las excavaciones, esta información fue reafirmada por el Sr. Cano quién se encontraba al cuidado de la estancia ya que la misma está desocupada desde fines de los '90.

\subsubsection{Contexto Geoarqueológico}

La estratigrafía general del sitio es compleja ya que ambas cámaras presentan 
potencias sedimentarias muy variadas (de $30 \mathrm{~cm}$ a más de $2 \mathrm{~m}$ ), diferencia que también fue observada en las tasas de sedimentación. Estas tasas muestran que la velocidad de depositación fue más rápida en $\mathrm{CN}(1 \mathrm{~cm}=103$ años $)$ que en $\mathrm{CS}(1 \mathrm{~cm}=250$ años $)$. Su utilización como metodología indirecta para evaluar la integridad del sitio avala que la misma es mayor en CN que en CS (Miotti et al. 2007). Las secuencias estratigráficas de ambas cámaras presentan rasgos geológicos y estratigráficos particulares, lo que no permite correlacionar las capas de ambas cámaras, a excepción de la matriz eólica que se apoya sobre la roca de base de todo el sitio y la capa de estiércol continua que recubre la cueva en su totalidad formando la superficie actual (Rabassa et al. 2007). Esta situación, sumada a la presencia de derrumbes, estratos lenticulares y cuevas, y a las diferencias microambientales actuales registradas entre ambos sectores (CN y CS) y mencionadas anteriormente, son la causa por la que cada una es analizada separadamente.

La descripción estratigráfica responde a criterios litoestratigráficos propios de cada sector. Esto se debe a la carencia de límites netos verticalmente y continuos en sentido lateral, que permitan definir las mismas capas o eventos estratigráficos para toda el área de la cueva -eg., niveles de ceniza volcánica, discordancias erosivas, eventos de derrumbe, gravas abiertas, etc. (Rabassa el al. 2007).

\subsubsection{Cámara Norte}

Las excavaciones arqueológicas de $\mathrm{CN}$ se realizaron siguiendo niveles artificiales y con control de las capas naturales, dado que la complejidad estratigráfica dificultaba el seguimiento de las mismas durante la excavación. Durante la caracterización de los perfiles, en ella fueron reconocidas seis capas transicionales, de las cuales, la capa 6 corresponde a la arena que apoya sobre la roca de caja. Se recuperaron materiales arqueológicos en todas las capas excepto en la Capa 1 y en la Capa 6 (Figura 7.3).

La secuencia estratigráfica fue descripta por Rabassa et al. (informe de campaña 2007) a partir del perfil norte (Figura 7.3) de las cuadrículas C5 y D5, y del perfil este de D5 y D6.

Las capas 1 y 2 corresponde a guano de ganado, cada una de ellas tiene unos $10 \mathrm{~cm}$ de espesor, la diferencia entre ellas radica en que el guano de la Capa 2 se encuentra quemado.

La Capa 3 (43 cm de espesor) corresponde a un sedimento psefítico, en matriz 
arenosa color gris claro; presenta clastos mayores muy angulosos que provienen del techo de la cueva. Los clastos de basalto tienen hasta $3 \mathrm{~cm}$ de diámetro mientras que los de ignimbrita son de hasta $6 \mathrm{~cm}$ de diámetro. Esta capa se acuña hacia el sur. Dentro de esta capa fueron diferenciadas tres subcapas en función de las variaciones de color, presencia de guano y detrito:

Subcapa 3a: $(9 \mathrm{~cm})$ por debajo del nivel de combustión el sedimento presenta color castaño y en ella se ha detectado presencia de guano.

Subcapa 3b: $(31 \mathrm{~cm})$ sedimento de un color gris más claro en los que la presencia de guano disminuye.

Subcapa 3c: $(3 \mathrm{~cm})$ nivel de detritos del techo con lavado de matriz ("open gravel"). Se registra presencia de guano, pero en menor proporción que en la capa superior. Se reconocen pequeños carbones.

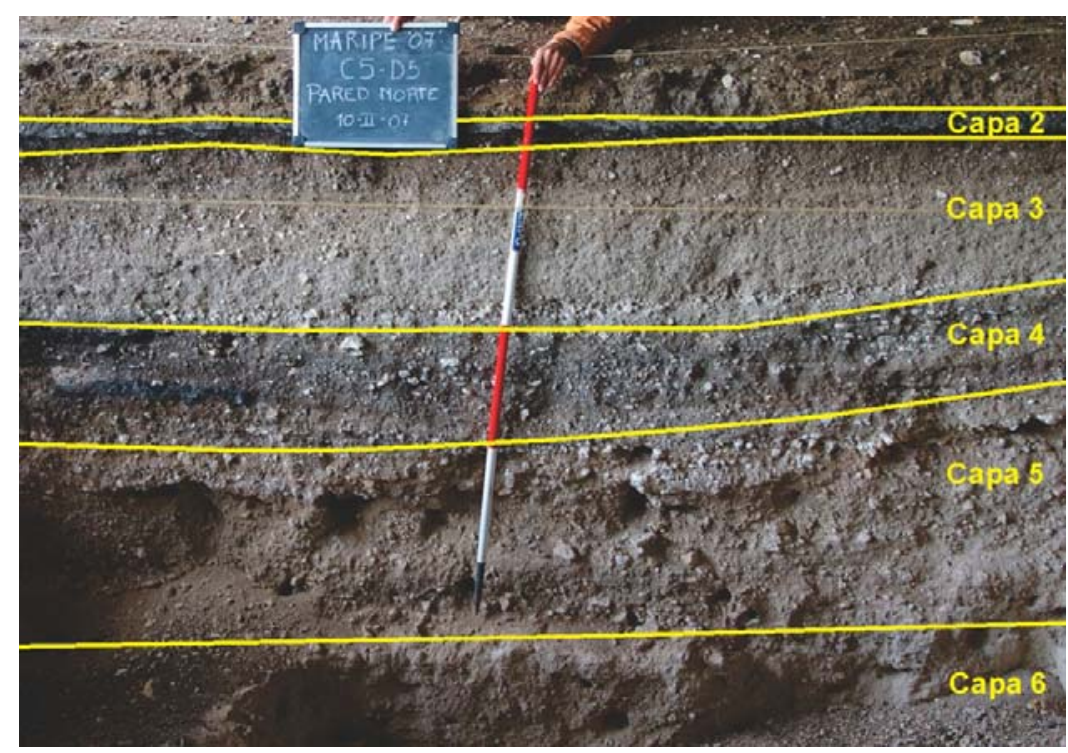

Figura 7.3. Perfil estratigráfico de Cámara Norte, pared norte de las cuadrículas C5 y D5.

La Capa 4: es similar a la 3 aunque su textura es levemente más gruesa y presenta un alto contenido de carbones. Se han diferenciado 4 subcapas (a, b, c y d):

Subcapa 4a: $(2 \mathrm{~cm})$ con clastos lajosos que presentan laminación, hay abundantes carbones diseminados y gran cantidad de materiales vegetales.

Subcapa 4b: $(12 \mathrm{~cm})$ es de color gris castaño más claro y tiene clastos de ignimbritas angulosas. Presenta abundantes carbones y se detecto un sector de grava abierta de $40 \mathrm{~cm}$ de largo por 4 de espesor conteniendo carbones de $2 \mathrm{~cm}$ de diámetro promedio. Tiene forma de un paleocanal, ya que presenta carbones lavados entre la grava abierta. 
Subcapa 4c: Solo aparece en el perfil norte de D5, tiene forma lenticular y color gris castaño oscuro. Incluye fragmentos de carbones escasos y minúsculos. En el sector norte se apoya sobre la Capa 5.

Subcapa 4d: $(6 \mathrm{~cm})$ nivel de grava arenosa, es lenticular y se apoya sobre Capa 5. tiene un espesor de $6 \mathrm{~cm}$ y $110 \mathrm{~cm}$ de largo. Muy abundantes fragmentos de carbón; la base es de arena muy fina. Hay carbones que alcanzan un tamaño de $3 \mathrm{~cm}$ de largo. Los clastos de ignimbritas son siempre muy angulosos, pero parecen estar alterados por agua.

La Capa 5 comienza a $83 \mathrm{~cm}$ de la superficie del suelo actual y en el sector este del perfil de la cuadricula D5 se apoya en la roca de base. En ella se reconocieron cuatro subcapas (a, b, c y d).

Subcapa 5a: grava abierta de ignimbrita con clastos de basaltos subordinados, abundantes carbones esparcidos lateralmente. En un sector del perfil la grava pasa a un sedimento fino que corresponde a un fogón. Se observa una fina capa de restos vegetales. La densidad de carbones aumenta hacia el sur. Es de color gris blanquecino en el sector norte de gravas, y gris castaño en la zona del fogón. En el sur del perfil apoya sobre otro fogón.

Subcapa 5b: es un fogón que se desarrolla hacia el sur en la cuadrícula D6. La microestratigrafía del fogón se compone de arriba hacia abajo por ceniza, sedimento castaño y en la base hay guano. En el sur apoya sobre gravas abiertas.

Subcapa 5c: En el sector NE se apoya sobre grava gruesa con clastos de ignimbrita de hasta $10 \mathrm{~cm}$, angulosos y escasos clastos de basalto. Hay escasos fragmentos de carbón asociados a las gravas abiertas y aparecen pequeños restos de guano en lentes de pocos cm de largo y escasos mm de espesor. El tamaño de la ignimbrita no es homogéneo y en ciertos sectores están dentro de matriz arenosa-limosa. Esto da un bandeado de $50 \mathrm{~cm}$ de capas finas y gruesas con diferencias en la proporción de matriz.

Subcapa 5d: tiene $25 \mathrm{~cm}$ basales visibles. De textura areno-limoarenosa, tiene estructura palustre, porosidad y no se observan gravas. Tiene briznas, posiblemente raicillas.

Capa 6: Arena eólica, arqueológicamente estéril. 


\subsubsection{Cámara Sur}

La CS reviste una mayor complejidad en su estratigrafía dado que presenta una secuencia estratigráfica comprimida respecto de la CN. Las excavaciones en este sector se realizaron siguiendo niveles artificiales de $10 \mathrm{~cm}$ cada uno ya que la fracción de los sedimentos es más fina que en CN (Mosquera 2011, Informe de Beca UNLP) y los límites entre las capas son transicionales por lo que hasta el momento no hemos podido separar estas capas como unidades analíticas. Actualmente estamos trabajando en esta dirección a partir de distintas líneas de evidencia como son la geoarqueología, la sedimentológía, la tecnología lítica, la zooarqueología, el estudio de diatomeas, polen y fitolitos.

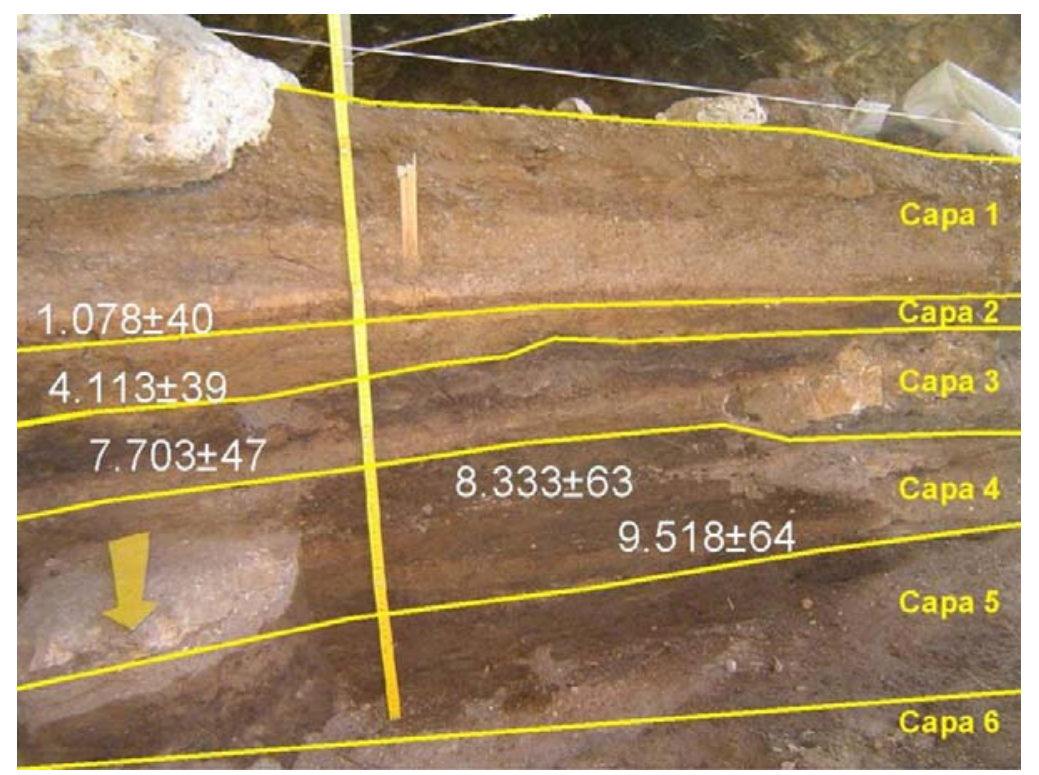

Figura 7.4. Perfil estratigráfico de Cámara Sur, pared sur de las cuadrículas A12 y B12.

La secuencia estratigráfica fue descripta por Rabassa (Rabassa et al 2007) a partir del perfil sur de las cuadrículas A12 y B12 (Figura 7.4) como sigue:

La Capa 1 está conformada por la acumulación de guano de ganado perteneciente a momentos históricos en que la cueva fue utilizada como corral, presenta dos subcapas:

Subcapa 1a: corresponde a guano superficial fresco de 10 a $15 \mathrm{~cm}$ promedio de espesor (bosta suelta de oveja y vaca).

Subcapa 1b: corresponde a guano compactado de color castaño grisáceo. En la base pierde color, lo que puede deberse a lavado. 
Capa 2: disminuye la concentración de guano siendo muy inferior a Capa 1. Hay guano quemado y con cierta laminación que puede deberse a la mayor humedad de este sector de la cueva.

Capa 3: aproximadamente de $19 \mathrm{~cm}$ de espesor, es un limo areno-arcilloso con alto contenido de moteados negros y castaño rojizo (alteración de guano y raíces). Laminación de ámbito palustre color gris verdoso a castaño amarillento a gris ocráceo decolorándose en la base. No tiene guijarros. Aparece en la base un color castaño oscuro, casi negro. Estos niveles negros húmicos se extienden hacia abajo con el aporte de guijarros de tamaño cada vez mayor. La laminación se extiende rodeando los clastos que aparecen en la base de la unidad. En el techo de la capa se observa poco guano el cual se encuentra oxidado. El sedimento amarillento en seco, se muestra con precipitación de sales, indicando condiciones de humedad local (posible pantano). Hacia la base de este nivel, en el sedimento negro, se reconocieron carbones, aunque no se detecto una estructura clara de fogón.

Capa 4: la caracteriza una matriz limo-arenosa con clastos óseos y carbones. Tiene un gran porcentaje de materia orgánica. Muestra laminación. Se reconocieron fogones en los cuales se halló material arqueológico (óseo y lítico). Apoya sobre unidad 5.

Capa 5: matriz de arena fina con gran contenido de guijarros. Es muy pulverulenta. Se detectó una cueva con restos de pelvis de oveja y guano de oveja quemado, tiene $8 \mathrm{~cm}$ de espesor por $76 \mathrm{~cm}$ de largo, y profundidad de $14 \mathrm{~cm}$. Este relleno procede de Capa 1 , que es donde arranca la cueva. Presenta dos subcapas:

Subcapa 5a: contiene fogones, es de color gris claro con presencia de clastos de roca de caja.

Subcapa 5b: de color pardo y disminuye la concentración de clastos de la roca de caja.

Capa 6: Arena eólica, arqueológicamente estéril.

Los clastos de roca de caja de CS son más redondeados que los de la $\mathrm{CN}$. Esto podría deberse a la mayor humedad de este sector de la cueva, lo que a su vez habría influido en la compactación de este sector y la formación del "pantano" representado en la Capa 3.

Como se menciona en la descripción, el aporte de agua en CS habría contribuido a la erosión de los clastos de roca de caja presentes en la estratigrafía, a la compactación del sedimento y a propiciar condiciones de humedad que permitieron generar un ambiente de tipo pantanoso en este sector. Estas características contribuyeron a conformar 
estratigrafías muy diferentes en ambas cámaras.

La distribución de los elementos arqueológicos en la estratigrafía de ambos sectores presenta cierta homogeneidad vertical, lo que complica la división de conjuntos arqueológicos en bloques temporales, sobretodo en CS donde la secuencia se encuentra comprimida.

Por las dificultades mencionadas para alcanzar la discriminación de las capas, los materiales procedentes de CS, como se verá más adelante y a diferencia de los de CN, son analizados siguiendo los niveles artificiales utilizados en la excavación.

El primer acercamiento a la reconstrucción paleoclimática y paleoambiental del área se realizó mediante el análisis de fitolitos en muestras sedimentarias extraídas de ambas cámaras. Los resultados obtenidos permitieron observar abundante cantidad de fitolitos en las distintas muestras: estiércol, sedimentos y fogones. Las determinaciones morfológicas realizadas indican que la mayor cantidad de fitolitos corresponden a vegetación de tipo herbácea, y que en todos los niveles sedimentarios se encontraron restos de epidermis de tamaño considerable, y algunos casos, del tejido subepidérmico de las hierbas (Miotti et al. 2008).

\subsubsection{Caracterización de los conjuntos y cronología}

El registro arqueológico de MA proviene tanto de $\mathrm{CN}$ como de CS y se encuentra integrado principalmente por artefactos líticos, restos óseos y arte rupestre. Ambas cámaras registran secuencias ocupacionales amplias que van desde la transición Pleistoceno-Holoceno hasta el Holoceno tardío (Tabla 7.1). A pesar de ello, hasta el momento no se registró superposición en los fechados radiocarbónicos obtenidos para cada cámara (Tabla 7.1), este hecho nos permitió proponer en un trabajo previo la hipótesis de una alternancia en el uso de la cámaras en los diferentes momentos en que los grupos cazadores-recolectores utilizaron el espacio interior de la cueva (Miotti y Marchionni 2009). 


\begin{tabular}{|c|c|c|c|c|c|c|c|c|c|c|c|c|c|c|c|c|}
\hline & \multicolumn{8}{|c|}{ Cámara Norte } & \multicolumn{8}{|c|}{ Cámara Sur } \\
\hline & Cuadricula & Sector & $z$ & Código & Material & C14 años AP & $\delta^{13} \mathrm{c}$ & Nivel/Capa & Cuadrícula & Sector & $z$ & Código & Material & C14 años AP & $\delta^{13} \mathrm{c}$ & Nivel/Capa \\
\hline \multirow{2}{*}{$\begin{array}{c}\text { Transición Pleistoceno/ } \\
\text { Holoceno }\end{array}$} & D5 & NW & -212 & AA65179 & carbón & $8992 \pm 65$ & $-22,3$ & 5 & A12 & SW & -196 & AA65175 & carbón & $9518 \pm 64$ & $-23,3$ & $180-200$ \\
\hline & $C 5$ & SE & -229 & AA65178 & carbón & $8762+50$ & $-21,9$ & 5 & & & & & & & & \\
\hline Holoceno temprano & & & & & & & & & A12 & SE & -180 & AA65174 & carbón & $8333 \pm 63$ & $-23,9$ & $180-200$ \\
\hline \multirow{2}{*}{ Holoceno medio } & D6 & SE & -138 & AA65173 & carbón & $5084 \ddagger 49$ & $-23,2$ & 3 (base) & $B 12$ & SW & -171 & AA65177 & carbón & $7703 \pm 47$ & $-21,2$ & $160-180$ \\
\hline & C5 & NE & -175 & LP.1497 & carbón & $3210 \pm 60$ & $s / d$ & 4 (techo) & A12 & SE & -164 & AA65181 & carbón & $4113 \pm 39$ & $-22,6$ & $160-180$ \\
\hline Holoceno tardio & & & & & & & & & $B 12$ & sw & -151 & AA65176 & carbón & $1078 \pm 40$ & $-22,5$ & $130-160$ \\
\hline
\end{tabular}

Tabla 7.1. Fechados radiocarbónicos de Cueva Maripe.

Un trabajo recientemente presentado en las Jornadas de Arqueología de Patagonia de Malargüe (Miotti et al. 2011) nos permitió afinar el grano de resolución temporal de los conjuntos arqueológicos correspondientes a $\mathrm{CN}$ a partir de la utilización de un modelo digital (GRASS 6.4). De esta manera fue posible dividir, al menos para CN, el conjunto arqueológico que, hasta ese entonces era tratado como un conjunto de grano grueso (Miotti et al. 2007; Hermo 2008). En un trabajo previo los materiales y estructuras tridimensionados hasta los trabajos de campo de 2005 se plotearon en gráficos de tres dimensiones, a partir de lo que se logró discriminar 2 resoluciones arqueológicas, fundamentalmente en la $\mathrm{CN}$, permitiendo la separación de un componente superior y uno inferior (Miotti et al. 2007). El nuevo programa de digitalización de los datos permitió realizar la asignación de capa a los materiales tridimensionados, mediante la ampliación y actualización de los SIG desarrollados previamente (Miotti et al. 2007). El proceso consistió en: a) la digitalización de los perfiles registrados en el campo, que fueron tabulados e ingresados dentro de un SIG; b) la interpolación de la información digitalizada, mediante la cual se modelaron las superficies de las capas utilizando algoritmos de interpolación (GRASS 6.4); y c) la asignación de los materiales tridimensionados a cada capa (superficies generadas) en función de los valores de X, Y y Z (Ceraso 2011, Informe de Beca UNLP). De esta manera, fue posible a partir de la digitalización de los perfiles y de las plantas relevadas en el campo, generar modelos tridimensionales representativos de las diferentes capas observadas en la estratigrafía de la cueva, a partir de las cuales se llevó a cabo la asignación de capa a cada uno de los registros tridimensionados, extendiendo el análisis de los materiales en relación a su contexto estratigráfico (Miotti et al. 2011). De esta manera se logró alcanzar una mejor resolución para el análisis y separación de los conjuntos que hasta entonces estaban siendo estudiados como un único conjunto de baja resolución temporal y arqueológica. En esta tesis, los conjuntos que se analizan de $\mathrm{CN}$ son los que resultan de la aplicación de este modelo digital y que corresponden a las distintas capas descriptas en la estratigrafía.

Este grado de resolución no pudo lograrse hasta el momento con la secuencia 
correspondiente a CS dada la mayor complejidad y compresión sedimentaria de la misma. Por lo tanto, en esta tesis los conjuntos analizados de CS fueron definidos en base a los niveles artificiales utilizados durante las excavaciones y agrupados en tres capas según los fechados radiocarbónicos de cada una, tal como se detalla más adelante.

\subsubsection{Arte rupestre}

En las paredes y techo de ambas cámaras de la cueva, tanto en los sectores más iluminados como en los más oscuros, fueron registradas pictografías que en su mayor parte corresponden a negativos de manos, encontrando la mayor densidad y cantidad de motivos en CS (Miotti et al. 2009). El estado de conservación de las pinturas es malo y su integridad es baja (Miotti et al. 2007).

Dentro de la compleja estructura de MA se delimitaron 14 sectores con arte rupestre (Figura 7.2), distribuidos en tres áreas distintas de acuerdo con la profundidad dentro de la cueva y la incidencia de la luz que reciben (Cárden 2009).

Dentro de un total de 225 motivos, un 91\% de ellos corresponden a negativos de manos, un 7\% a líneas, estando los zoomorfos y los círculos representados cada uno en un 1\% del total (Cárden 2009).

\subsubsection{Análisis del material lítico}

La frecuencia de artefactos líticos es notablemente mayor en CS que en CN mientras que la representación de artefactos formales entre ambas cámaras es similar (Miotti et al. 2007, 2009).

Como resultado del análisis de los materiales líticos correspondientes al Holoceno medio, Hermo (2008) encuentra diferencias entre las cámaras en los distintos tipos de artefactos formatizados (AF) y núcleos, y las materias primas en la que los mismos se presentan, siendo la CS la que registra la mayor de esas variedades. También registra que CS es la que presenta la mayor riqueza en términos de grupos tipológicos.

Los AF de MA son en amplia mayoría unifaciales, elaborados por micro-retoque ultra-marginal periférico y con una amplia y clara predominancia del Grupo Tipológico de los raspadores, principalmente de los raspadores de filo frontal corto (Hermo 2008). 
Como resultado del análisis Hermo (2008) encuentra que MA muestra ser coherente con un sitio de actividades múltiples, en el que "...se abandonaron herramientas talladas capaces de cumplir con diversas acciones sobre diferentes materias...", además, propuso la existencia de un uso diferencial del espacio interior de la cueva. En la CN se habrían realizado las etapas iniciales de reducción que serían continuadas y/o utilizadas en la CS. También registra un abandono diferencial de armas ya que en CS existe una presencia más fuerte de puntas de proyectil y en $\mathrm{CN}$ fueron hallados los únicos dos fragmentos de bolas de boleadora (Hermo 2008). De esta forma Hermo (2008) propuso que la CS habría funcionado como el espacio habitacional de MA, mientras que la CN conformaría un espacio de uso alternativo destinado a actividades especiales en momentos en que la CS estuviera siendo utilizado para otras actividades y/o cuando las condiciones de reparo no fueran necesarias.

Los resultados del análisis funcional de los filos principales de los raspadores correspondientes al Holoceno medio permitieron observar una baja frecuencia de artefactos con alteraciones post-depositacionales intensas, a pesar de ello, un $31 \%$ de los materiales correspondientes a CS y un $6 \%$ de los de $\mathrm{CN}$ presentaron algún tipo de alteración que impidió realizar la determinación del uso (Lynch 2012).

Los rastros de uso permitieron reconocer en ambas cámaras raspadores con trabajo sobre cuero $(\mathrm{CS}=15 \% ; \mathrm{CN}=8 \%)$, material duro vegetal $(\mathrm{CS}=25 \%$; $\mathrm{CN}=34 \%)$ y material duro no diferenciado (ca. 20\% en ambas cámaras); rastros de uso de material duro animal (10\%) solo fueron determinas en dos raspadores de la CS (Lynch 2012).

Lynch (2012) sostiene que los recursos vegetales deben haber tenido un rol fundamental en la economía de los grupos cazadores-recolectores que habitaron el área, no solo como recursos alimenticios sino también para la confección de diversas tecnologías, esto es congruente con los resultados obtenidos en un trabajo previo donde se presenta evidencia sobre la determinación de rastros de enmangue en raspadores del Holoceno medio en MA (Lynch y Hermo 2011). Propone además, que es altamente posible que en la cueva se hayan realizado todas las actividades resultantes del tratamiento de los cueros (Lynch 2012). 


\subsubsection{Análisis del material faunístico}

Los análisis realizados con anterioridad a esta tesis involucraron solamente los materiales con asignación tridimensional correspondientes a los primeros años de la excavación del sitio, por lo tanto, a los niveles más superficiales de ambas cámaras (Miotti y Marchionni 2009; Miotti et al. 2007). Como fue expresado anteriormente, estos trabajos previos contemplaron los materiales como un mismo conjunto y por lo tanto la resolución arqueológica y temporal es menor a la alcanzada en esta tesis. Aquí, se incorporan al análisis todos los materiales zooarqueológicos (tridimensionados y generales) de las 5 cuadrículas excavadas hasta la roca de caja (CN: C5, D5 y D6; CS: A12 y B12) y separados en conjuntos distintos según la asignación de capa realizada recientemente (Miotti et al. 2011) y los fechados radiocarbónicos de cada una (Tabla 7.1).

Las tendencias obtenidas indican que el guanaco es la especie mayormente representada en ambas cámaras (Miotti y Marchionni 2009; Miotti et al. 2007). Los perfiles de meteorización indicaron tendencias diferentes, con una meteorización más marcada hacia los estadios más bajos en la $\mathrm{CN}$ que en $\mathrm{CS}$. El análisis de las tendencias de fragmentación, permitieron observar que la misma, ha sido mayor en CS que en CN; lo mismo ocurre con las frecuencias de especímenes con signos de alteración térmica (Miotti y Marchionni 2009).

Fue sugerido que los guanacos habrían ingresado enteros al sitios como resultado de cacerías en la zona; que en el sitio se habrían realizado actividades de procesamiento secundario y consumo con un uso heterogéneo del espacio interior, de esta manera el sitio habría funcionado como una base residencial donde el mayor procesamiento de las presas habría tenido lugar en la CS (Miotti y Marchionni 2009).

\subsection{CÁMARA NORTE DE CUEVA MARIPE}

Los restos faunísticos de esta cámara proceden de las cuadrículas C5, D5 y D6, excavadas hasta la roca de base, totalizando una superficie de $12 \mathrm{~m}^{2}$ (Figura 7.2). En total en esta cámara fueron recuperados, a partir de los métodos de tridimensión y zaranda, un total de 4592 especímenes entre los que están incluidas pequeñas astillas óseas y fragmentos de cáscara de huevo. Los mismos se encuentran distribuidos verticalmente en 
4 de las 6 capas estratigráficas identificadas y descriptas en la sección anterior, ellas son:

Capa 5: contiene los materiales arqueológicos más profundos de la secuencia, su techo fue fechado entre ca. 8700 y 8900 años AP (Tabla 7.1), lo que permitiría ubicarla, al menos, hacia fines del intervalo correspondiente al Pleistoceno final-Holoceno temprano (ver Capítulo 2). En ella fueron recuperados el 8,27\% del total de los especímenes $(\mathrm{NSP}=380)$.

Capa 4: de donde procede la mayor parte de los restos zooarqueológicos de la secuencia, en ella se recuperó el 57,27\% del total de $\mathrm{CN}(\mathrm{NSP}=2630)$. Se fecharon carbones procedentes del techo de esta capa arrojando una antigüedad de $3210 \pm 60$ años AP (Tabla 7.1). Esto indicaría que el conjunto se habría generado en el lapso del Holoceno temprano y Holoceno medio ca. 8500 y 3200 años AP.

Capa 3: de aquí procede el 28,74\% del conjunto arqueofaunístico totalizando un $\mathrm{NSP}=1319$. Para esta capa se obtuvo un fechado radiocarbónico de $5084 \pm 49$ años AP (Tabla 7.1) a partir del cual sería posible asignar este nivel de ocupación al Holoceno medio aunque no descartamos que parte de este conjunto pueda corresponder a ocupaciones del Holoceno tardío.

La relativa superposición de edades entre la Capa 3 y 4, deberá ser evaluada con mayor detalle y a la luz de nueva información radiocarbónica -que se encuentra en procesamiento-. Sin embargo, en la discusión de este capítulo y como resultado de los análisis aquí presentados, se ofrecen y discuten algunas hipótesis acerca de las posibles causas en esas diferencias.

Capa 2: aún no se obtuvieron fechados radiocarbónicos para estos niveles, sin embargo, en base a los análisis de tecnología lítica (Hermo et al. 2012) consideramos que la misma estaría reflejando el uso de la CN de MA durante el Holoceno tardío y previo al contacto europeo. Esto se debe a que la misma asienta sobre la Capa 3, con fechados radiocarbónicos correspondientes al Holoceno medio y a que no fueron detectados materiales europeos que avalen dicha ocupación. En ella se recuperaron un total de 262 especímenes los cuales representan el 5,7\% del total de la muestra de $\mathrm{CN}$.

\subsubsection{Capa 5 de Cámara Norte}

El conjunto procedente de esta capa está constituido por 380 especímenes (NSP), 
de ellos, 246 corresponden al NISP (64,73\%) ya que pudieron ser determinados a algún nivel taxonómico o anatómico, mientras que 134 restos $(35,26 \%)$ quedaron en la categoría indeterminados. Los especímenes indeterminados corresponden a pequeños fragmentos de diáfisis de hueso largo o fragmentos de hueso plano carentes de rasgos diagnósticos.

El análisis de la distribución espacial de los especímenes tridimensionados (Figura 7.5a) permite observar que los mismos se encuentran en toda la superficie excavada, mostrando una mayor concentración en el sector SW de la cuadrícula D6.

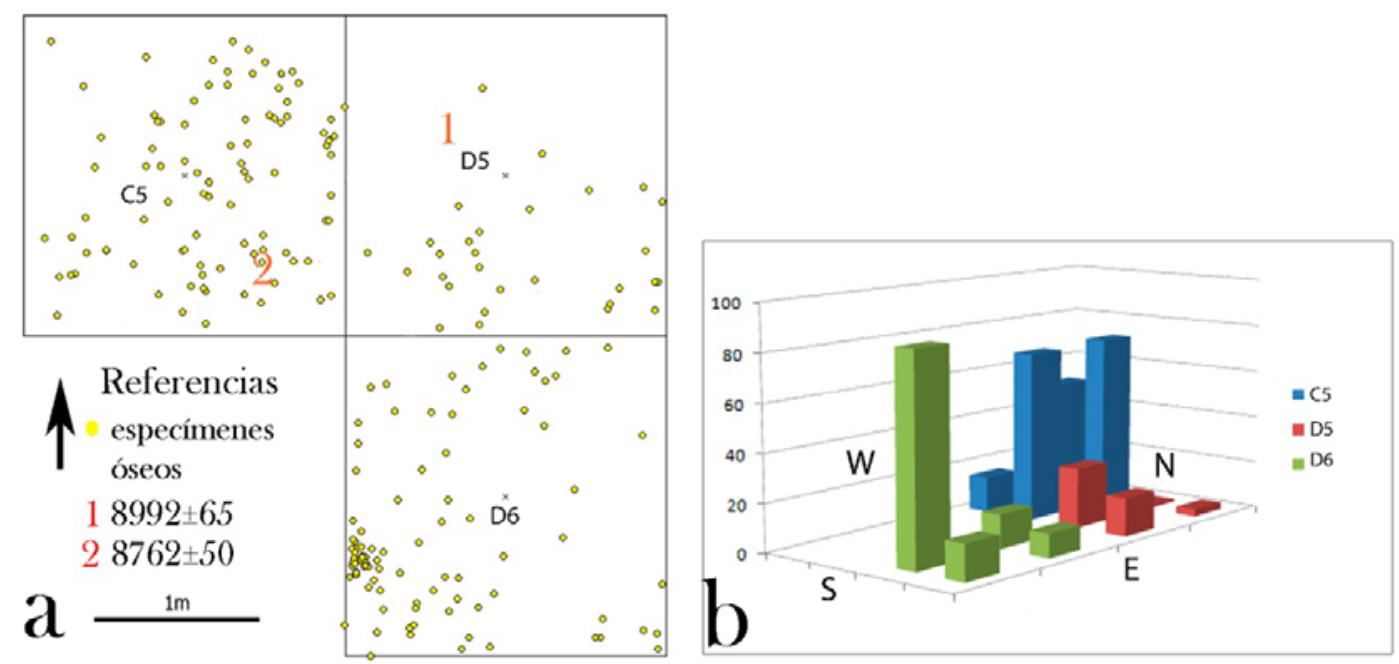

Figura 7.5. a) Distribución en planta de los especímenes tridimensionados y ubicación de los fechados radiocarbónicos; b) densidad de restos óseos por cuadrícula (C5, D5 y D6) y sector de excavación (NE, NW, SE y SW). Valores expresados en frecuencia de NISP por $\mathrm{m}^{2}$.

El análisis de distribución de restos óseos, incluyendo los tridimensionados y los recuperados a través de zaranda, permitió observar que la cuadrícula C5 concentra el 55\% de los mismos, mientras que en D6 se recuperó el 33\%, siendo el menor porcentaje el brindado por la cuadrícula D5 (12\%). Sin embargo, el análisis de densidad de restos óseos por $\mathrm{m}^{2}$ (Figura 7.5b), en este caso coincidente con los sectores de cada cuadrícula, muestra que el sector SW de D6 registra la mayor densidad con 86 especímenes por $\mathrm{m}^{2}$. Sin embargo, los sectores NE, SE (ca. 70 especímenes por $\mathrm{m}^{2}$ ) y NW (50 especímenes por $\mathrm{m}^{2}$ ) de la cuadrícula C5 también registran densidades importantes (Figura 7.5b). Los restantes sectores presentan densidades menores a 25 especímenes por $\mathrm{m}^{2}$ (Figura $7.5 \mathrm{~b}$ ). 
Estos resultados nos permiten observar dos áreas con mayor densidad de restos en Capa 5: una correspondiente al sector SW de D6, la otra integrada principalmente por los sectores NE y SE de C5 (Figura 7.5b).

Dentro de Capa 5 fueron identificadas diferentes áreas de combustión (Figura 7.6), tanto en la cuadrícula C5 como en la D6. Además, durante la excavación se reconocieron tres oquedades que contenían sedimento removido y que posiblemente correspondan a cuevas (Figura 7.6). Dos de ellas fueron identificadas en el sector SW de C5 y por sus dimensiones posiblemente correspondan con las realizadas por Dasipodidae como el piche (Zaedyus sp.); el tercer sector con estas características, localizado en el NE de la cuadrícula D6, de tamaño más pequeño posiblemente sea resultado de la actividad de algún animal cavador pequeño, a juzgar por al diámetro que presenta la abertura. Se mapearon, además, tres sectores con sedimentos removidos o perturbados (Figura 7.6) que debido a la forma que presentaban podrían corresponder con posibles galerías de roedores.

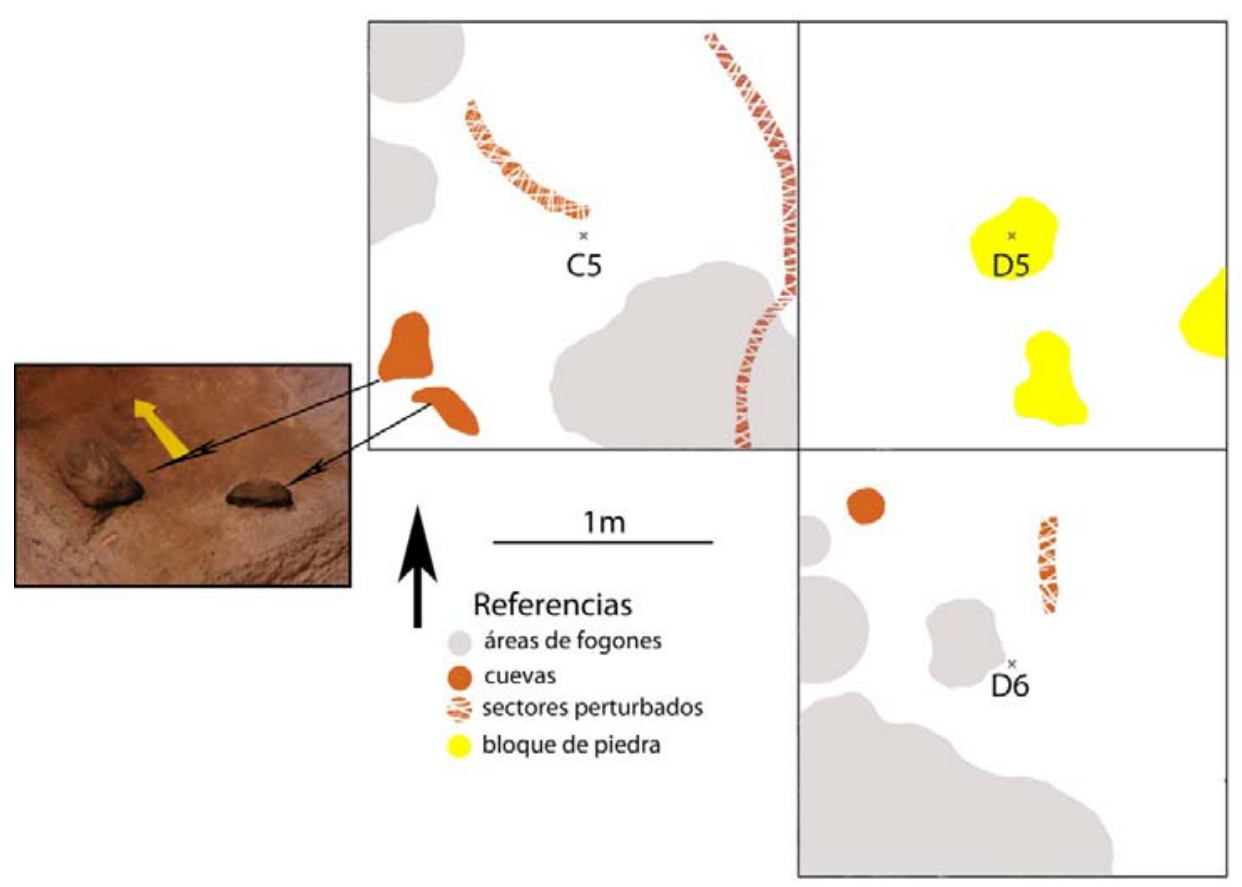

Figura 7.6. Esquema de rasgos e indicadores de procesos y agentes tafonómicos identificados durante las excavaciones del sitio en la Capa 5 de $\mathrm{CN}$. 


\subsubsection{Abundancia taxonómica y anatómica}

Los resultados indican que Lama guanicoe (guanaco) es la especie más representada en el conjunto (Tabla 7.2), correspondiendo a ella el 46,34\% del NISP $(\mathrm{NISP}=114)$. En segundo lugar se posicionan los Mamíferos de tamaño grande $(31,71 \%)$ y de tamaño indeterminado $(17,89 \%)$. Otras categorías taxonómicas se encuentran presentes aunque en frecuencias muy bajas que varían entre uno y cuatro especímenes cada una (Tabla 7.2). Entre ellas encontramos la presencia de restos de aves $(\mathrm{NISP}=4)$, de los cuales solamente uno pudo ser asignado a nivel de familia Rheidae (Tabla 7.2).

\begin{tabular}{|l|c|c|c|}
\hline & NISP & $\%$ NISP & M NI \\
\hline Ave indet. & 4 & $1,63 \%$ & 1 \\
\hline Rheidae & 1 & $0,41 \%$ & 1 \\
\hline Mamifero Indet. & 44 & $17,89 \%$ & - \\
\hline Mamífero Grande & 78 & $31,71 \%$ & - \\
\hline Dasipodidae & 1 & $0,41 \%$ & 1 \\
\hline Rodentia indet. & 1 & $0,41 \%$ & 1 \\
\hline Artiodactyla & 1 & $0,41 \%$ & 1 \\
\hline Camelidae & 1 & $0,41 \%$ & 1 \\
\hline Lama sp. & 1 & $0,41 \%$ & 1 \\
\hline Lama guanicoe & 114 & $46,34 \%$ & 3 \\
\hline
\end{tabular}

Tabla 7.2. Abundancia taxonómica en la Capa 5 de $\mathrm{CN}$ de MA.

En cuanto a la representación de partes anatómicas del guanaco se determinó la presencia tanto de elementos del esqueleto apendicular como del esqueleto axial (Tabla 7.3). Para dar cuenta de dichas frecuencias, al menos fueron necesarios tres individuos $(\mathrm{MNI}=3)$. Considerando los criterios de edad relacionados a la fusión de las epífisis (Capítulo 6), al menos uno de los guanacos correspondería con un ejemplar subadulto.

La relación entre MNE/NISP de guanaco indica una fragmentación moderada del conjunto dando por resultado un valor de 0,6. Esta fragmentación podría ser una de las causas de que una cantidad importante de especímenes (48\%) no hayan podido ser asignados a categorías más ajustadas que la de Clase.

El análisis de las unidades anatómicas del guanaco muestra que las partes más representadas $(\mathrm{MAU} \%=100 \%)$ son el cráneo y el radio-cúbito proximal (Tabla 7.3). Dentro del esqueleto axial, la mandíbula y el atlas corresponden a elementos que están bien representados $(\mathrm{MAU}=50 \%)$; otras partes correspondientes al tronco del animal como las vértebras cervicales $(30 \%)$ y torácicas $(16,6 \%)$, las costillas $(16,6 \%)$ y esternebras 
$(8,35)$ adquieren frecuencias más bajas. En el conjunto no se registraron vértebras lumbares, caudales ni elementos del sacro. Con respecto al esqueleto apendicular, las frecuencias más elevadas se expresan para los elementos del miembro anterior, destacándose entre ellos, las porciones proximal y diafisiaria del radio-cúbito y la diáfisis del húmero $(\mathrm{MAU} \%=75 \%$ ), seguidas en importancia por los elementos escapulares $(\mathrm{MAU}=50 \%)$. Las porciones distales de estos elementos -i.e., radio-cúbito distal y húmero distal- se registraron en menor frecuencia (MAU\%=25\%), esos mismos valores adquieren algunos elementos distales como el escafoides y el lunar (Tabla 7.3). No se identificaron otros elementos del autopodio a excepción de las falanges y metapodios indiferenciados, en los cuales no pudo determinarse su correspondencia con el miembro anterior o posterior.

Con respecto al miembro posterior, los elementos que adquieren mayor frecuencia pertenecen al autopodio (Tabla 7.3), entre ellos se destacan el metatarso (MAU\% $=75 \%$ ) y el astrágalo $(\mathrm{MAU} \%=50 \%)$, los restantes elementos como las porciones proximal y diafisiaria del fémur, la pelvis, la tibia y el navicular se encuentran en bajos valores $(25 \%$ del MAU\%).

De este análisis se desprende que todas las unidades de trozamiento estarían representadas aunque en frecuencias distintas. El hecho de que partes como la cabeza o el miembro anterior alcancen frecuencias más elevadas permite suponer, de no mediar procesos tafonómicos que hayan modificado o destruido parte del conjunto, que una selección de partes pudo haber tenido lugar durante estas ocupaciones de la CN.

Respecto de los restos óseos de guanaco, estos se distribuyen con el mismo patrón que se registró para el conjunto completo (Figura 7.5b). Sin embargo, se observaron algunas variaciones en las densidades de la cuadrícula C5. Mientras que el análisis efectuado con el conjunto entero muestra una mayor densidad en los sectores NE y SE, los restos de guanaco alcanzan una mayor concentración en el sector NW de dicha cuadrícula (34 especímenes por $\mathrm{m}^{2}$ ). En ese mismo sector, y a diferencia de lo que se observa en los restantes, se encuentran invertidas las proporciones entre esqueleto axial $(\mathrm{NISP}=20)$ y apendicular $(\mathrm{NISP}=14)$.

El gran número de especímenes de mamíferos de tamaño grande corresponde, en su mayoría, a fragmentos de hueso largo. Estos fragmentos no han preservado, o por el grado de fragmentación que tienen o por la acción de procesos tafonómicos, rasgos o características diagnósticas que permitan asignarlos a una categoría taxonómica más específica. Sin embargo, dichos restos tendrían amplias posibilidades de corresponder a 
L. guanicoe. La evaluación de si las partes anatómicas registradas en esta clase podrían estar complementando las ausentes entre los guanacos mostró que solamente se podrían incrementar los valores de NISP para porciones medias de costillas $(\mathrm{NISP}=19)$ ya que la gran mayoría de estos restos corresponden a fragmentos de diáfisis de hueso largo $(\mathrm{NISP}=45)$.

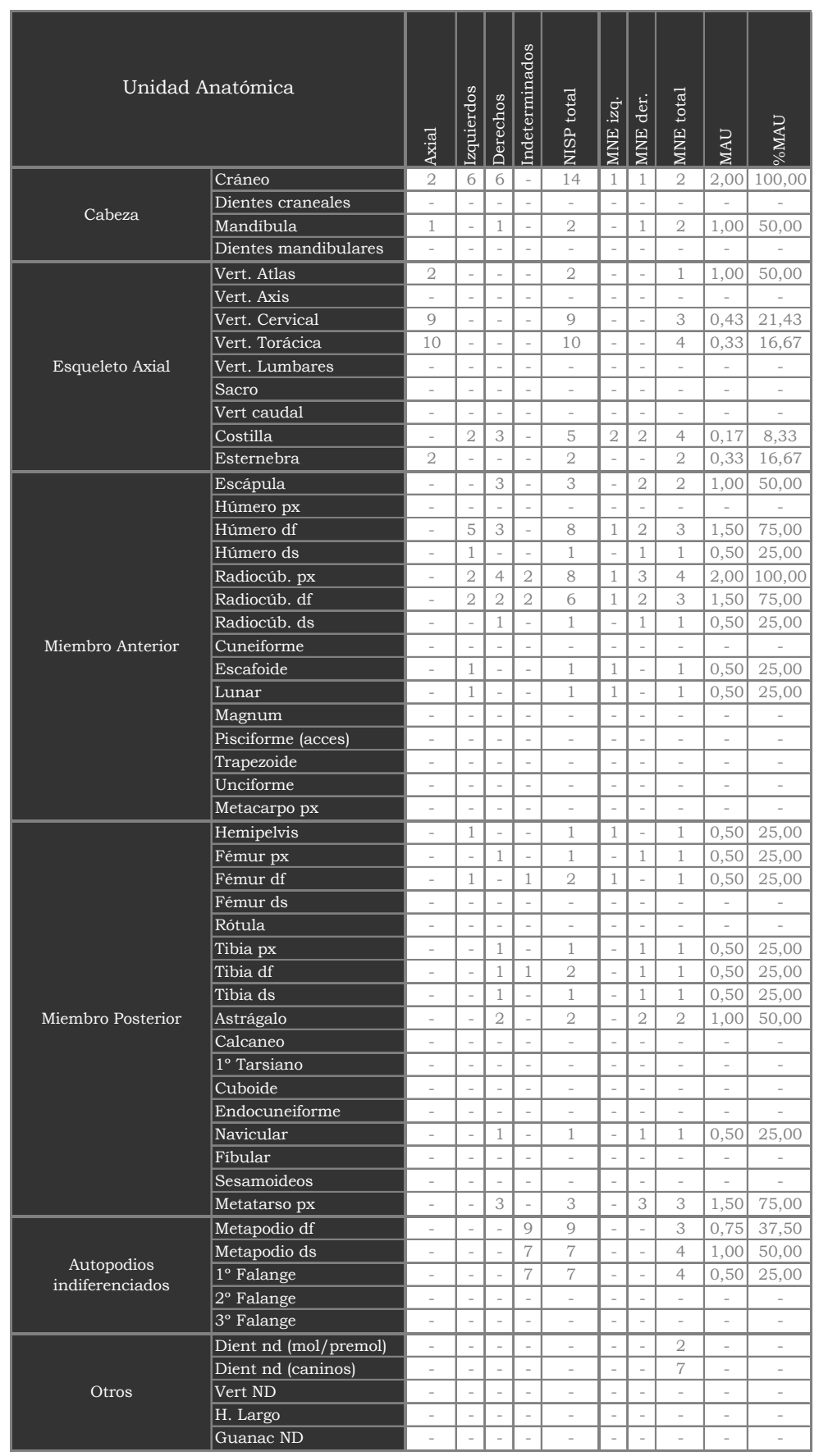

Tabla 7.3. Representación de partes anatómicas del guanaco en la Capa 5 de CN de MA. 
El único espécimen determinado como rheido corresponde a una diáfisis de tibiotarso. Los otros restos de aves corresponden a pequeños fragmentos de diáfisis y a un tibio tarso de Tyto alba (A. Alcaraz comunicación personal 2007).

\subsection{Análisis de la estrategia de transporte de partes anatómicas de guanaco}

Para evaluar las posibles causas de la representación de partes anatómicas del guanaco -i.e., estrategias de transporte vinculadas al rendimiento económico, procesos de destrucción mediados por densidad, o una combinación de ambas- se correlacionaron los valores de MAU\% obtenidos para el conjunto de la Capa 5 con los índices de utilidad del guanaco (Borrero 1990; Lyman 1992) y de densidad ósea (DO) (Elkin 1995).

Los resultados obtenidos indican que la frecuencia de partes anatómicas representadas se correlaciona de forma moderada y positiva con la DO $(\mathrm{r}=0,54 ; \mathrm{p}=$ $0,0004)$ mostrando una tendencia en la cual los elementos más representados son los que tienen DO más alta (Figura 7.7a). Por otro lado, los resultados obtenidos al correlacionar las frecuencias de MAU\% con los dos índices de utilidad muestran ausencia completa de correlación (Figura 7.7b y 7.7c). Esta última situación no referiría a una estrategia clara de selección humana de las partes en función de su alto o bajo rendimiento económico.

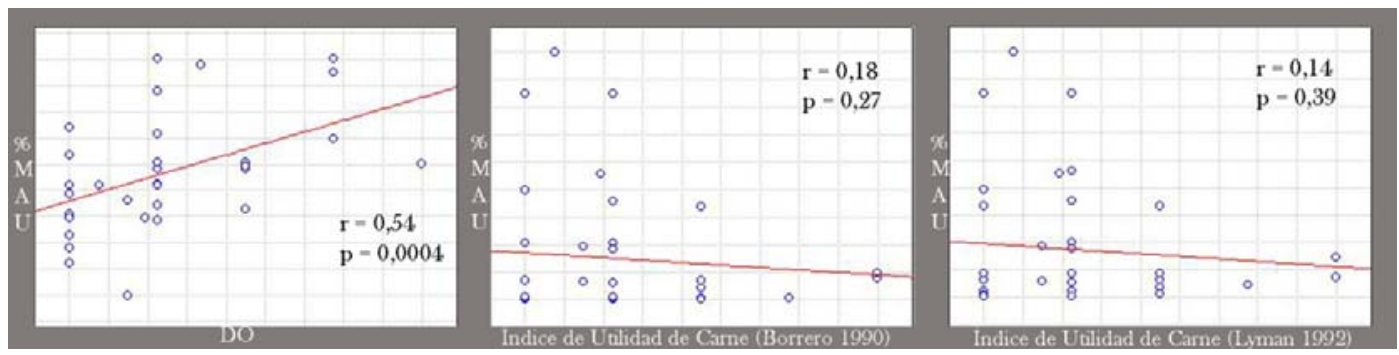

Figura 7.7. Correlaciones estadísticas de Spearman a) MAU\%-DO; b) MAU\%-Índice de

Utilidad (sensu Borrero 1990); c) MAU\%-Índice de Utilidad (sensu Lyman 1992).

El análisis de estos resultados a partir de las clases propuestas por Lyman (1994) permite observar que el conjunto estudiado correspondería a la Clase 4 "lag or ravaged". Esta situación, a priori, indicaría la posibilidad de que el mismo haya estado expuesto a la acción de procesos o agentes tafonómicos no antrópicos - e.g., meteorización diferencial, carnívoros- cuya acción puede ser más intensa sobre los huesos cuando la DO de los mismos es baja. Sin embargo, y como fue presentado en el Capítulo 4, trabajos experimentales acerca de la variabilidad intra-taxonómica de guanacos han demostrado 
que la destrucción por DO puede estar mediada por el desarrollo ontogénico de los individuos (Gutiérrez et al. 2010) de la misma manera que la meteorización (Massigoge et al. 2010).

Es importante destacar que en este conjunto fueron identificadas 2 esternebras de guanaco ya que son elementos que presentan una muy baja DO. Entendemos que si los procesos de destrucción mediados por densidad que afectaron al conjunto habrían sido importantes, elementos óseos con estas características tendrían que haber desaparecido o exhibir niveles avanzados de meteorización. Por el contrario, en estas esternebras, además de registrarse un excelente estado de preservación, fue determinada la presencia de claras huellas de corte (ver más adelante). A pesar de tal preservación, no podemos descartar que elementos como estos correspondientes a individuos juveniles, hayan desaparecido por tener menor DO que los mismos en individuos adultos.

En cuanto a la destrucción que puedan haber generado los carnívoros, y como se verá más adelante, la misma es una hipótesis de baja probabilidad ya que no se registró daño producido por estos agentes sobre el conjunto.

\subsubsection{Modificaciones de las superficies óseas}

El análisis de las modificaciones óseas efectuado sobre el conjunto comprendió tanto la observación a ojo desnudo como a lupa binocular con amplificaciones de entre 10x y 60x. Se destaca que si bien los mayores resultados fueron obtenidos en especímenes de guanaco, debido a que es la especie más representada en el depósito, también se registraron modificaciones en restos óseos de otras especies representadas en el conjunto y que nos permiten discutir su incorporación al mismo por decisiones humanas.

\subsection{Patrones de modificaciones naturales}

El análisis de las superficies de los especímenes correspondientes a guanaco muestra que la mayor cantidad de restos óseos (ca.96\%) se encuentran entre los estadios

0 y 2 de Behrensmeyer (1978). Esta tendencia (Figura 7.8) estaría indicando que el conjunto óseo tuvo un tiempo relativamente corto de exposición en superficie con un rápido proceso de enterramiento. Esto estaría en parte, avalado por la alta tasa de 
sedimentación estimada para esta cámara (Miotti et al. 2007). De todas formas, la presencia de escasos especímenes en el estadio 3 (Behrensmeyer 1978) podría indicar un mayor deterioro de las superficies en algunos pocos restos, o la influencia de una meteorización diferencial en relación a la madurez osteológica de los especímenes (Massigoge et al. 2010) y a condiciones microambientales de depositación (Miotti et al. 2007).

El análisis de la meteorización exhibida entre los restos óseos del esqueleto apendicular y los del esqueleto axial (Figura 7.8) muestra diferencias. Si bien es altamente probable que parte de esta variación responda a las características particulares de estos elementos (Behrensmeyer 1978), otros factores como la DO, la variabilidad intrataxonómica (Massigoge et al. 2010) y la fragmentación también son considerados. De todas formas, el 95\% del conjunto registra un buen estado de preservación que avala el enterramiento sincrónico. Pensamos que ese mayor deterioro por meteorización que se observa en algunos especímenes pudo, al menos en parte, estar vinculado con el alto grado de astillamiento que algunos restos presentan.

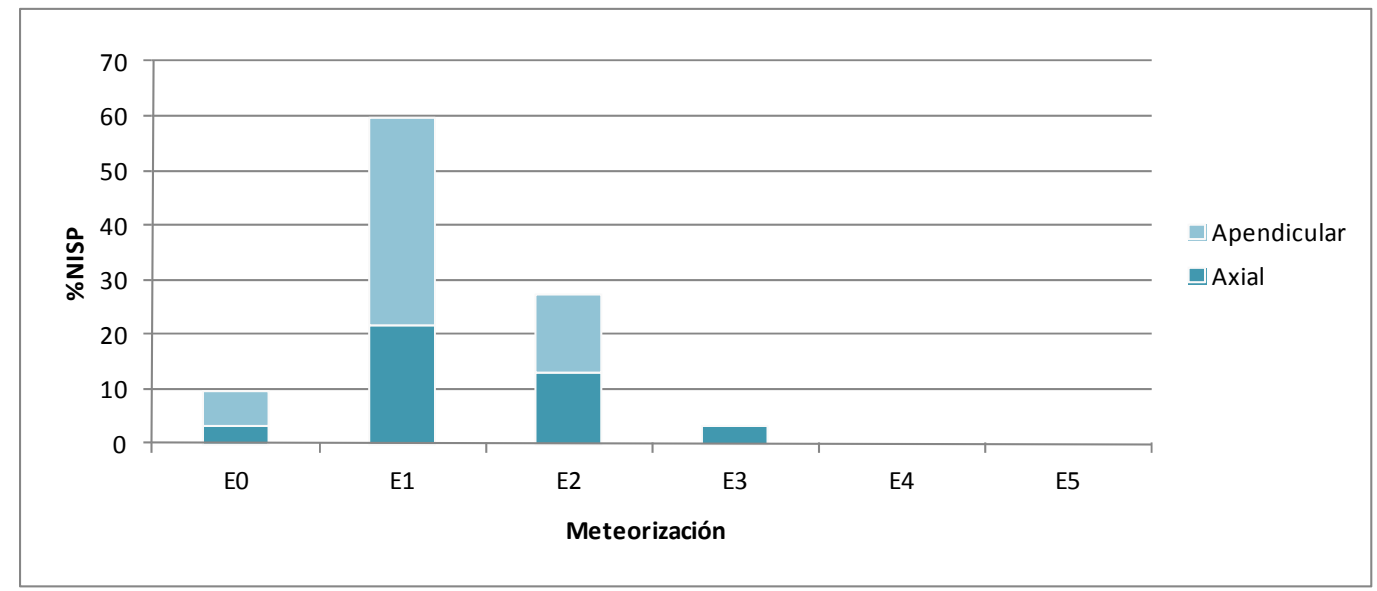

Figura 7.8. Tendencia de la meteorización en especímenes asignados a $L$. guanicoe en el conjunto de Capa 5 de CN. Los valores son expresados en NISP\%.

Otras modificaciones naturales identificadas en las superficies óseas de los especímenes de guanaco corresponden a las producidas por roedores, raíces, depósitos de manganeso y carbonatos (Figura 7.9a). No fue posible determinar la presencia de patrones de daño que se relacionen con la acción de carnívoros, la disolución química ó los distintos tipos de abrasión, como tampoco especímenes teñidos. Entre estas alteraciones, los depósitos de manganeso (Figura 7.10a y 7.10b) son los que aparecen en 
mayor frecuencia (28\%). Generalmente se presentan en forma de grandes manchas o motas dispersas sobre la superficie cortical y/o medular del hueso sin llegar a cubrir la misma en su totalidad (Figura 7.10a y 7.10b).

El segundo lugar de importancia lo ocupan los depósitos de carbonato $(4,9 \%)$, los mismos aparecen como capas de espesor muy delgado que solo cubren algunos sectores de las superficies óseas; en general, aquellos donde hay irregularidades. Las marcas producidas por la acción de las raíces (Figura 7.10c) se determinaron en escasos especímenes $(1,7 \%)$. Las mismas corresponden con finos surcos que adquieren diseños dendríticos y superficies suaves. Los surcos suelen presentar la misma coloración que la superficie del hueso en que se localizan (Figura 7.10c) y se habrían producido en la interfase elemento esquelético-sedimento después del enterramiento (Montalvo 2002).

A pesar de que en este nivel de excavación se identificaron galerías y sectores perturbados por roedores (Figura 7.6), la acción de ellos sobre los huesos ha sido extremadamente escasa $(0,8 \%)$, la misma fue identificada sobre un único resto óseo correspondiente a un astrágalo derecho de guanaco.

Los especímenes con manchas de manganeso, si bien se hallan distribuidos en toda el área excavada, alcanzan frecuencias más elevadas en los sectores NE de C5 y SE de D6 (Figura 7.11a). La presencia de manganeso indica la existencia de humedad en algún momento mientras los restos estuvieron enterrados. Esto se debe a que el manganeso puede ser transportado por el agua y cuando se registran cambios en el pH precipitan sobre los huesos (López-González et al. 2006). Que los especímenes con manchas de manganeso aparezcan más concentrados en dos sectores de la excavación (Figura 7.11a) podría indicar la existencia de humedad diferencial en los mismos. Algo similar ocurre con los depósitos de carbonato ya que estos restos, aunque en frecuencias muy bajas, se presentan localizados en los sectores del sur de D6. La presencia de estos depósitos sobre los huesos se puede relacionar con la disolución de roca base de la cueva. Tanto el manganesos como el carbonato pueden liberarse a partir de rocas carbonáticas (LópezGonzález et al. 2006; Marín Arroyo et al. 2008; Shahack-Gross et al. 1997). Sin embargo, para producir un depósito de carbonato es necesaria la presencia de humedad efectiva, que disuelva a la roca. En tal sentido, este proceso podría estar relacionado con la presencia de sedimentos de "escurrimiento" como son los detritos del techo con lavado de matriz (“open gravel”) registrados en Capa 3b y Capa 5a, y descriptos en la primera sección de este capítulo. Pero la mayor carbonatación de especímenes óseos en D6 podría indicar que este sector estuvo, asimismo, sometido a condiciones de humedad 
retenida y que serían propicias para la disolución de roca de base y depositación de carbonatos en los huesos.

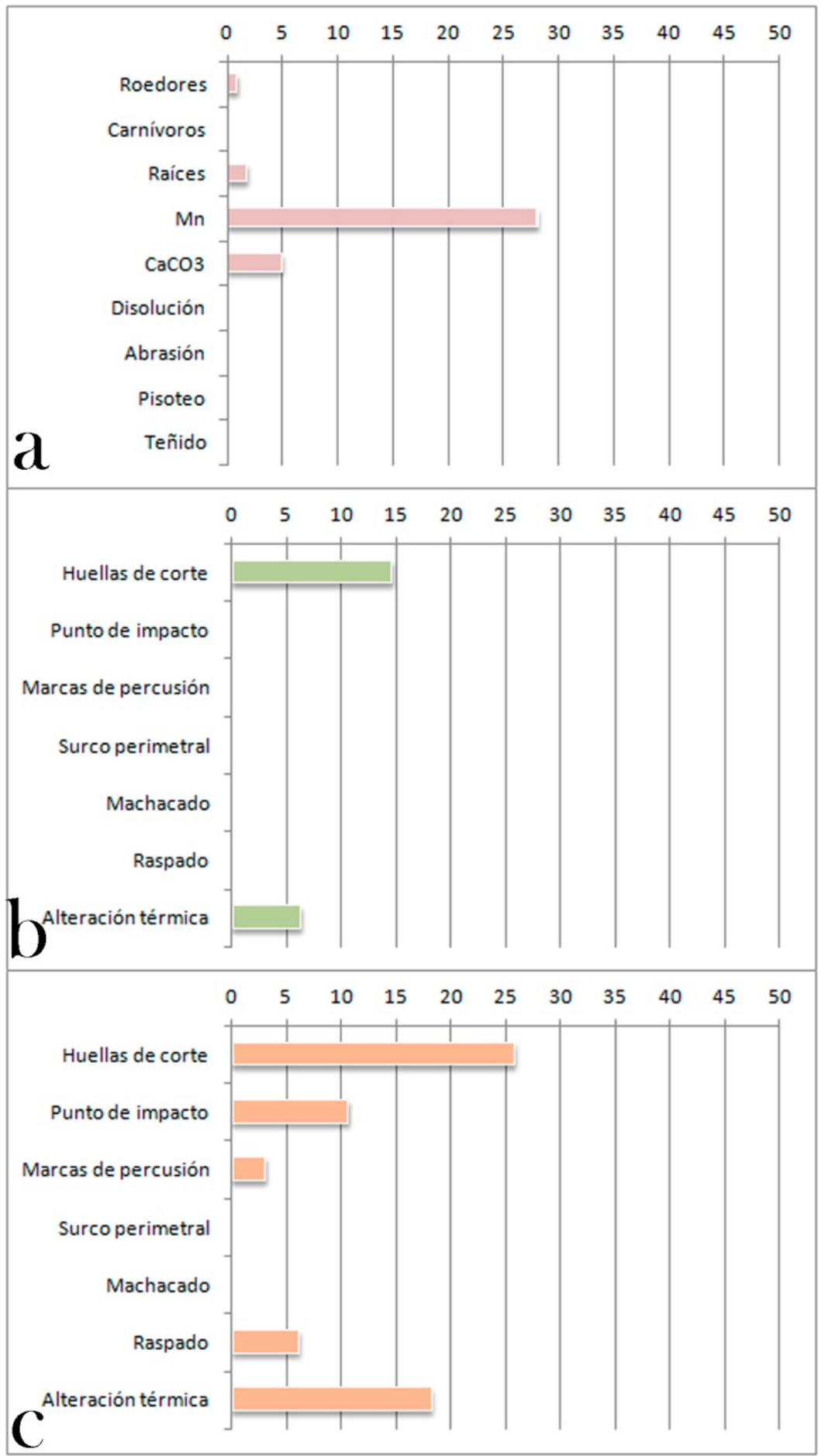

Figura 7.9. Frecuencia porcentual de especímenes óseos de guanaco con presencia de modificaciones: a) naturales; b) modificaciones antrópicas en especímenes del esqueleto axial; c) modificaciones antrópicas en el esqueleto apendicular. 


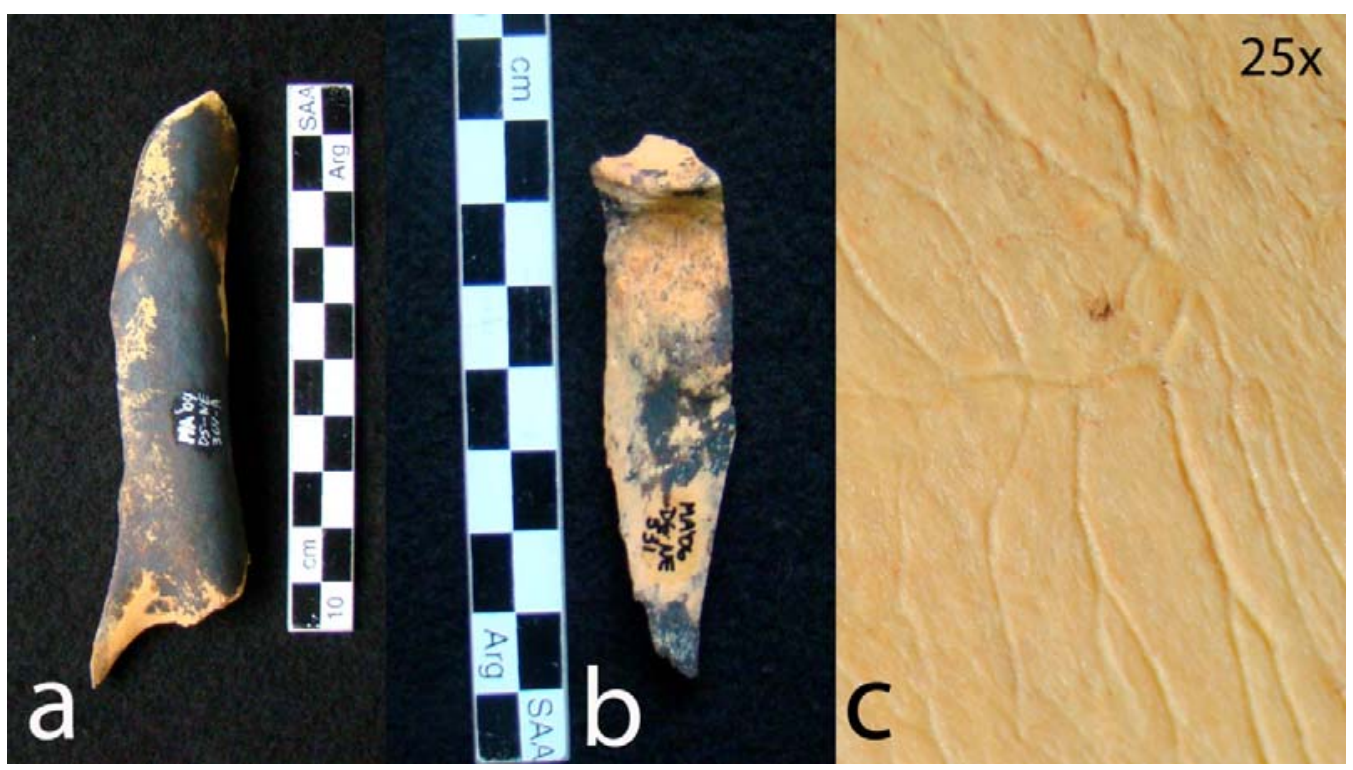

Figura 7.10. Modificaciones naturales: a) manganeso en porción distal de diáfisis de húmero derecho; b) manganeso en porción proximal anterior de radio-cúbito; c) impronta de raíces sobre costilla.

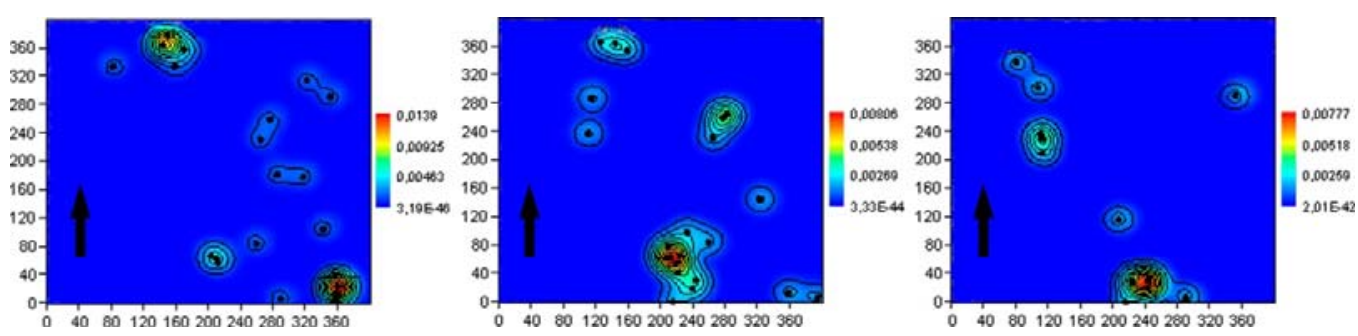

Figura 7.11. Distribución espacial de especímenes con modificaciones en las cuadrículas excavadas de CN (C5, D5 y D6): a) especímenes con manganeso; b) especímenes con huellas de corte; c) especímenes con alteración térmica.

\subsection{Patrones de modificación antrópica}

El estudio de modificaciones culturales de las superficies óseas permitió observar que las mismas estaban presentes tanto en restos correspondientes al esqueleto axial como apendicular de los guanacos (Figura $7.9 \mathrm{~b}$ y 7.9c). Sin embargo, el esqueleto apendicular es el que presenta la mayor variabilidad en cuanto a tipos de huellas, alcanzando además, las frecuencias más elevadas (Figura 7.9c). 

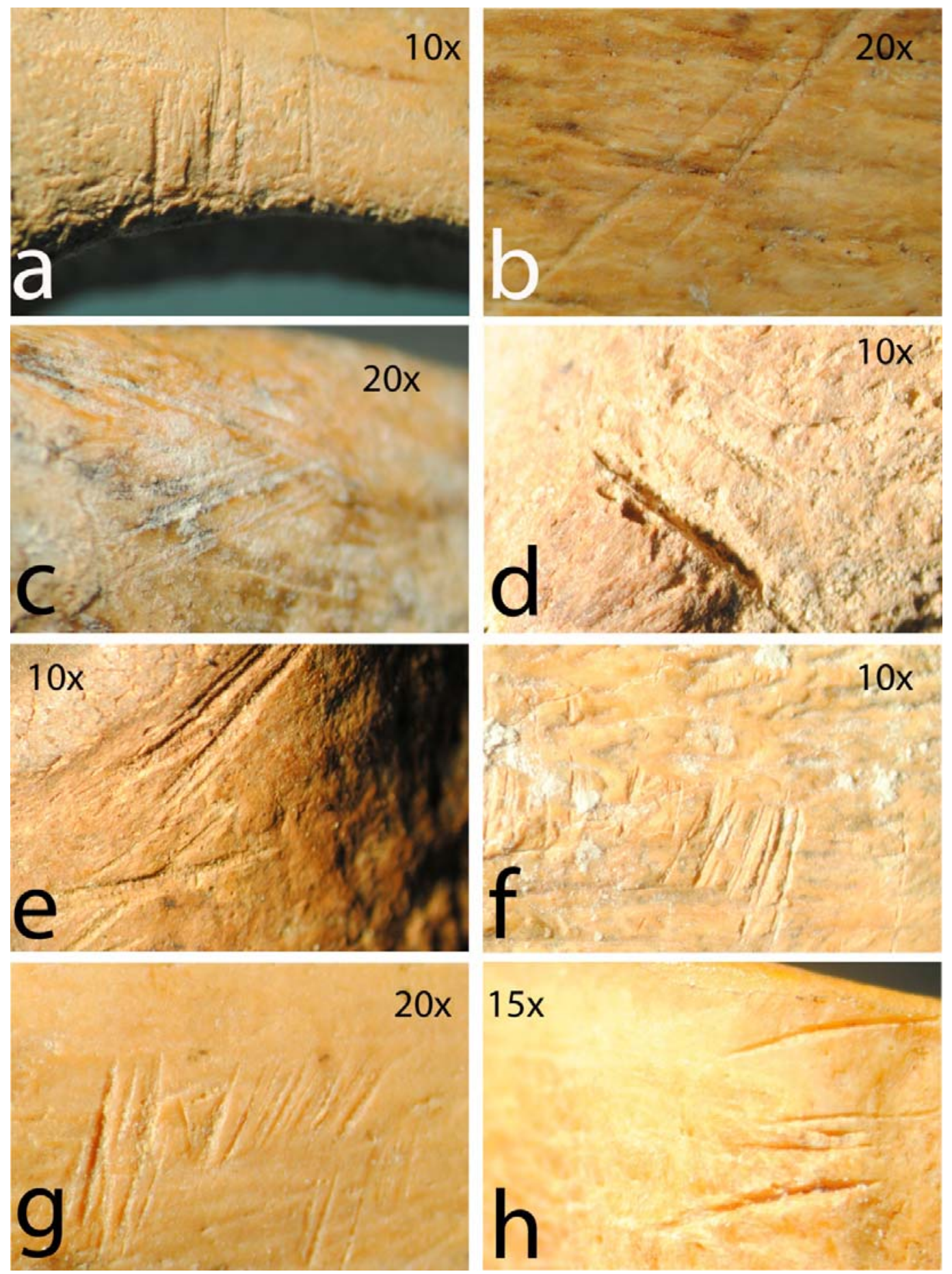

Figura 7.12. Huellas de corte con destacada morfología fusiforme longitudinal y en $\mathrm{V}$ en vista transversal: a) en vértebra torácica; b) en esternebra; c) en maxilar; d) en esternebra; e) en radio-cúbito proximal derecho; f) en escápula derecha; g) en diáfisis de húmero derecho; h) en epífisis proximal de metatarso derecho. 
Entre las modificaciones vinculadas al procesamiento de las presas en el esqueleto axial (Figura 7.9b), solamente se determinó la presencia de huellas de corte (Figura 7.12a, $7.12 \mathrm{~b}$ y $7.12 \mathrm{c}$ ) en un $14,5 \%$ de los especímenes. Por su parte, en el esqueleto apendicular (Figura 7.9c) estas huellas fueron identificadas en un 25,7\% de los especímenes (Figura 7.12d, 7.12e y 7.12f), en los cuales además se determinó la presencia de puntos de impacto $(10,6 \%)$, marcas de raspado $(6 \%)$ y marcas de percusión (3\%). Las huellas de corte reflejan actividades que podrían estar vinculadas al procesamiento primario y secundario de los guanacos (Binford 1981). Sin embargo, las restantes marcas presentes en el esqueleto apendicular podrían relacionarse con la etapa final de la reducción de las carcasas, ya que reflejan la intencionalidad de fracturar los huesos, sea para cocción, consumo de médula, o para manufactura de instrumentos óseos (Binford 1978; De Nigris 2004; Gifford-González 1993; Mengoni Goñalons 1999).

Los especímenes con huellas de corte muestran una distribución más o menos homogénea en la superficie excavada (Figura 7.11b), donde los sectores con mayor frecuencia coinciden con los que registraron mayor cantidad de restos óseos (Figura 7.5b), pudiendo de esta manera, sugerir áreas específicas de actividades.

El análisis de fracturas realizado sobre los 57 especímenes de huesos largos de guanaco $(\mathrm{NISP} \%=50 \%)$ nos permitió identificar un total de 95 fracturas entre las que fueron reconocidos tanto patrones de tipo antrópico como otros de tipo tafonómico (Figura 7.13).

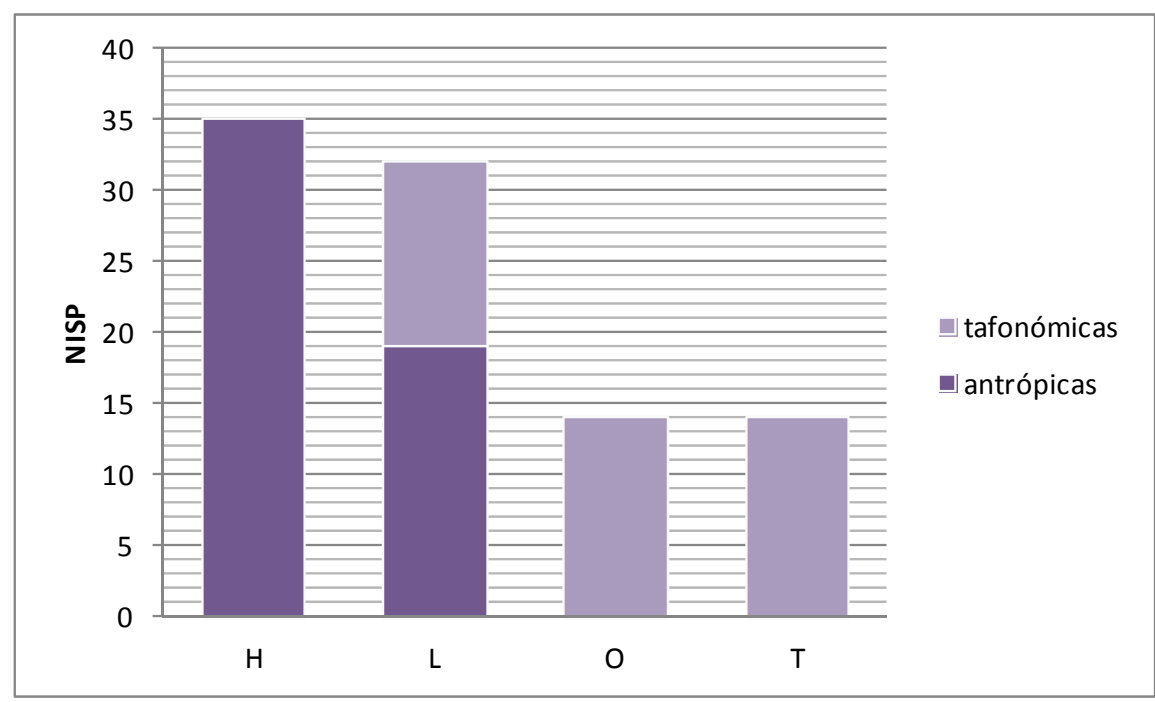

Figura 7.13. Frecuencia absoluta y tipos de fracturas identificadas: H) helicoidal; L) longitudinal; O) oblicua; T) transversal. 
$\mathrm{El}$ análisis realizado muestra que mayoritariamente se determinaron fracturas de tipo helicoidal, las cuales representan el $36 \%$ del total. La presencia de distintos atributos tecnológicos asociados como puntos de impacto y huellas de corte, sumado a la ausencia de modificaciones atribuibles a carnívoros, nos permiten interpretar este patrón como resultado de la aplicación de una fuerza dinámica sobre el hueso en estado fresco y, en este sentido, producto de la intencionalidad humana.

El número de fracturas de tipo longitudinal también es elevado (33\%); sin embargo, su totalidad no puede ser atribuida al agente humano. Un número de 19 (59,4\%) fracturas longitudinales presentaron características que concuerdan con un patrón de fractura del hueso en estado fresco y presencia de atributos como puntos de impacto y marcas de raspado. Las restantes $13(40,6 \%)$ fracturas exhibieron un patrón irregular el cual se podría atribuir a causas tafonómicas. Este patrón tafonómico también se registra en las fracturas oblicuas $(\mathrm{n}=14)$ y transversales $(\mathrm{n}=14)$ (Figura 7.13).

En todos los casos atribuidos a la acción humana, las superficies de fractura son suaves, regulares y con claros frentes de fracturación, lo que avala que la fractura fue producida en el estado fresco del hueso.

Más de un 18\% de los especímenes presentan signos de alteración térmica. En su totalidad corresponden a especímenes carbonizados ya que sus superficies se encuentran completamente ennegrecidas (Capítulo 6). Entre ellos, la mayoría de los restos (NISP= 12) pertenecen al esqueleto apendicular del guanaco, aunque algunos pocos $(\mathrm{NISP}=3)$ correspondena unidades axiales del esqueleto. El análisis de la distribución espacial de los restos óseos quemados (Figura 7.11c) muestra que la principal concentración de los mismos (58\%) se produce en el sector SW de D6. Una segunda concentración importante (33\%) se observa en el sector SE de C5. Estas dos acumulaciones de restos óseos quemados (ca. 90\%) coinciden con los sectores en los que fueron mapeadas las principales áreas de fogones (Figura 7.6).

La presencia de alteración térmica también fue observada en un tibio-tarso de rheido y placas dérmicas de Dasipódidos.

Se determinó la presencia de sustancias rojas y negras depositadas sobre los especímenes óseos tanto de guanaco como de rheidos. Posiblemente estas manchas correspondan a restos de pigmentos o pintura ya preparada para producción de imágenes rupestres, pintura de cueros o corporal, las cuales podrían guardar relación con la producción de arte rupestre en la cueva. Estas sustancias fueron identificadas en los siguientes tres especímenes de guanaco: una porción distal posterior de húmero 
izquierdo, una porción distal de tibia subadulta derecha (Figura 7.14) y en una costilla izquierda (Figura 7.15a y 7.15b). En los tres casos se registró sustancia de color rojo, excepto en la costilla que además, presenta manchas de pigmento negro (Figura 7.15a y 7.15b). La tibia y la costilla provienen del sector SW de la cuadrícula D5 mientras que el húmero fue recuperado en el sector SE de C5. Manchas rojas que también pueden corresponder con pigmento fueron identificadas sobre un fragmento quemado de diáfisis de tibio-tarso de rheido.

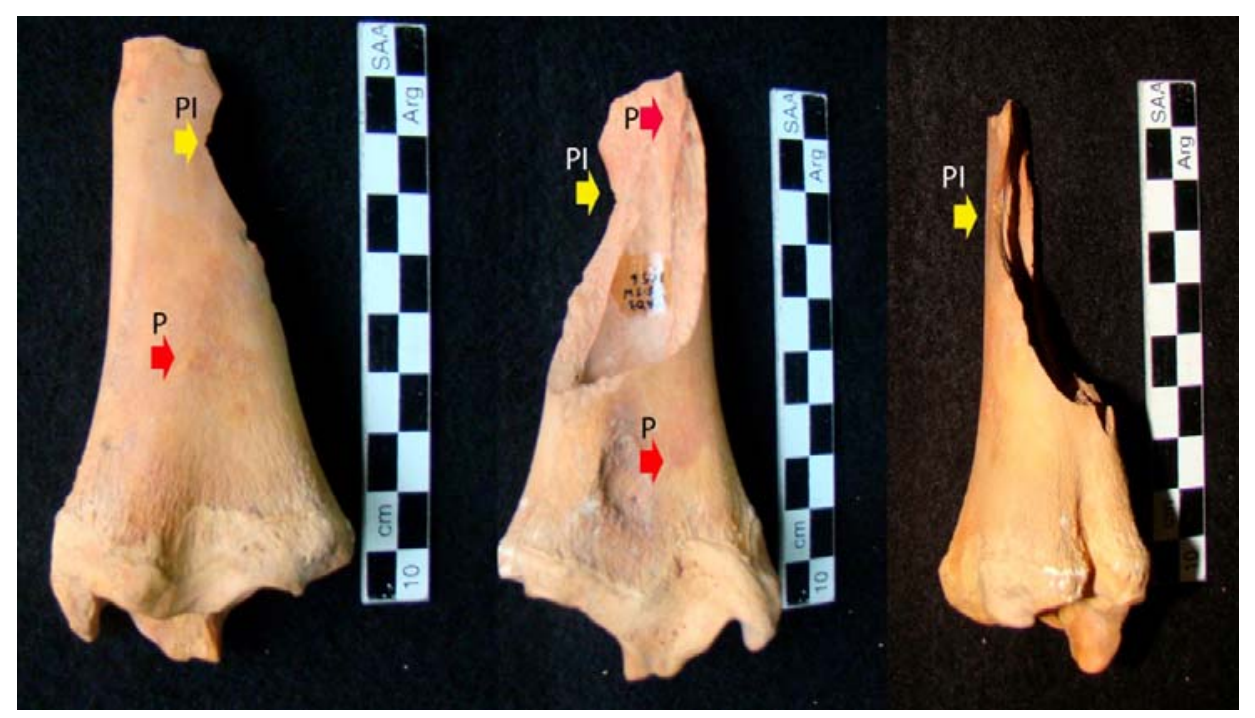

Figura 7.14. Porción distal de tibia derecha de individuo subadulto de guanaco con restos de pigmento rojo $(\mathrm{P})$ y fractura helicoidal con punto de impacto (PI).

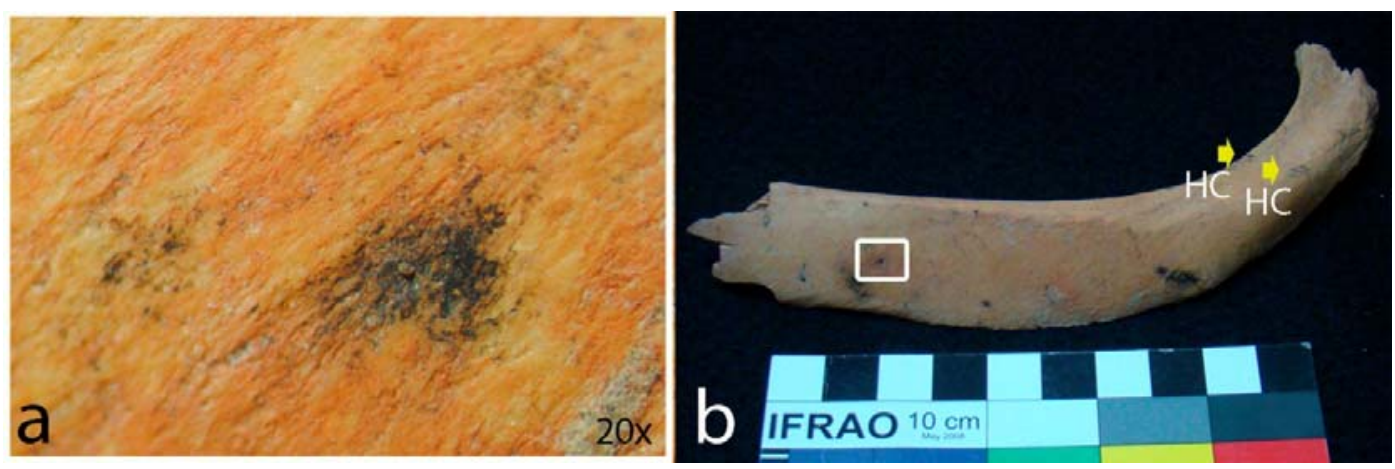

Figura 7.15. Restos de pigmento rojo y negro (a) en costilla izquierda de guanaco; (b) con huellas de corte (HC).

Por otro lado, en un fragmento diafisiario de húmero derecho fue registrado un borde de fractura con un alto nivel de micro-pulido (Figura 7.16), que pondría en 
evidencia la utilización del mismo como instrumento óseo.

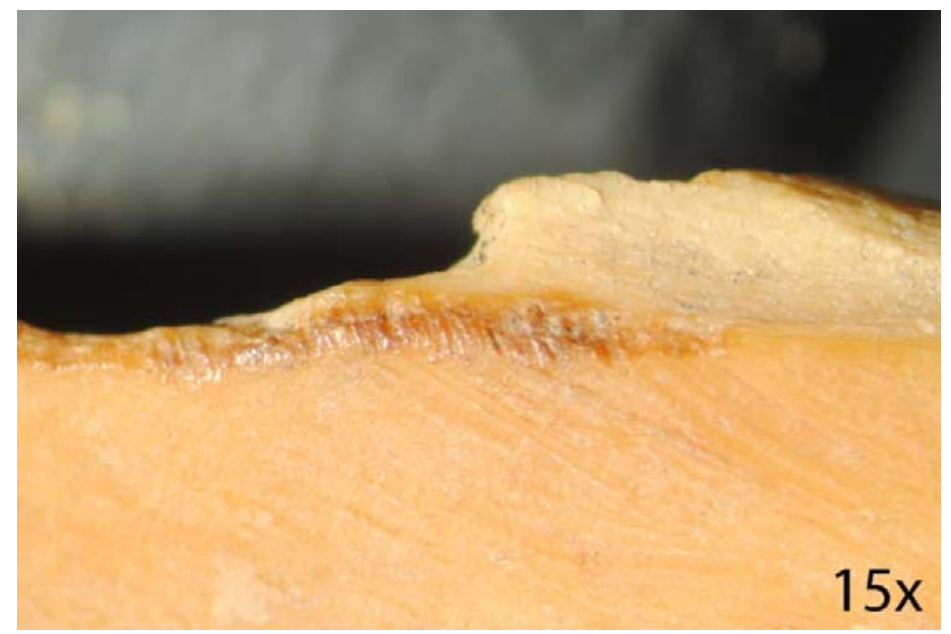

Figura 7.16. Borde con micro-pulido en fragmento de diáfisis de húmero de guanaco.

\subsubsection{Capa 4 de Cámara Norte}

El conjunto correspondiente a esta capa está integrado por un total de 2630 (NSP). De los cuales un 30,38\% (NISP= 799) pudieron ser determinados a algún nivel taxonómico y/o anatómico. Por su parte, el 69,61\% del total del conjunto (NSP=1831) corresponden a pequeños fragmentos de diáfisis de hueso largo o fragmentos de hueso plano carentes de rasgos diagnósticos para su determinación más ajustada y por lo tanto integran la categoría indeterminados.

El análisis de la distribución espacial a partir de los especímenes óseos tridimensionados (Figura 7.17a) permite observar que los restos se distribuyen en toda la superficie excavada y que en el sector SW de D6 registran una mayor concentración.

Por otro lado, se realizó el análisis de la densidad de restos óseos por $\mathrm{m}^{2}$ (Figura 7.17b), coincidente con los subsectores de cada cuadrícula, para este análisis se consideró al conjunto completo (tridis y generales). De esta manera, la figura $7.17 \mathrm{~b}$ permite observar que las densidades más altas se encuentran en el sector NE de C5 (551 especímenes por $\left.\mathrm{m}^{2}\right)$. Sin embargo, el sector SE de C5 (388 especímenes por m²) y NW de D5 (313 especímenes por $\mathrm{m}^{2}$ ) también registran densidades elevadas. Como se puede observar, al comparar las figuras 7.17 a y $7.17 \mathrm{~b}$, no hay coincidencia en los sectores de 
mayor densidad entre el análisis de distribución de los tridis (Figura 7.17a) y el de densidades para el conjunto completo (Figura 7.17 b). Esta diferencia podría estar relacionada al nivel de fragmentación de los restos óseos y a la mayor probabilidad de que los fragmentos más pequeños sean los que se recuperaron a través de zaranda.

Durante las excavaciones de la Capa 4 fueron identificadas diferentes áreas de combustión en las tres cuadrículas (Figura 7.18). En su mayoría corresponden a fogones bien delimitados, espesos e internamente estructurados en una capa superior que contiene cenizas, una intermedia con carbones y restos de macro vegetales, y una inferior en la que se registran rocas alteradas térmicamente o sedimento rojizo. En el sector NE de C5, en el centro de una de las áreas se describió un sector removido que podría corresponder con una cueva de roedor (Figura 7.18).

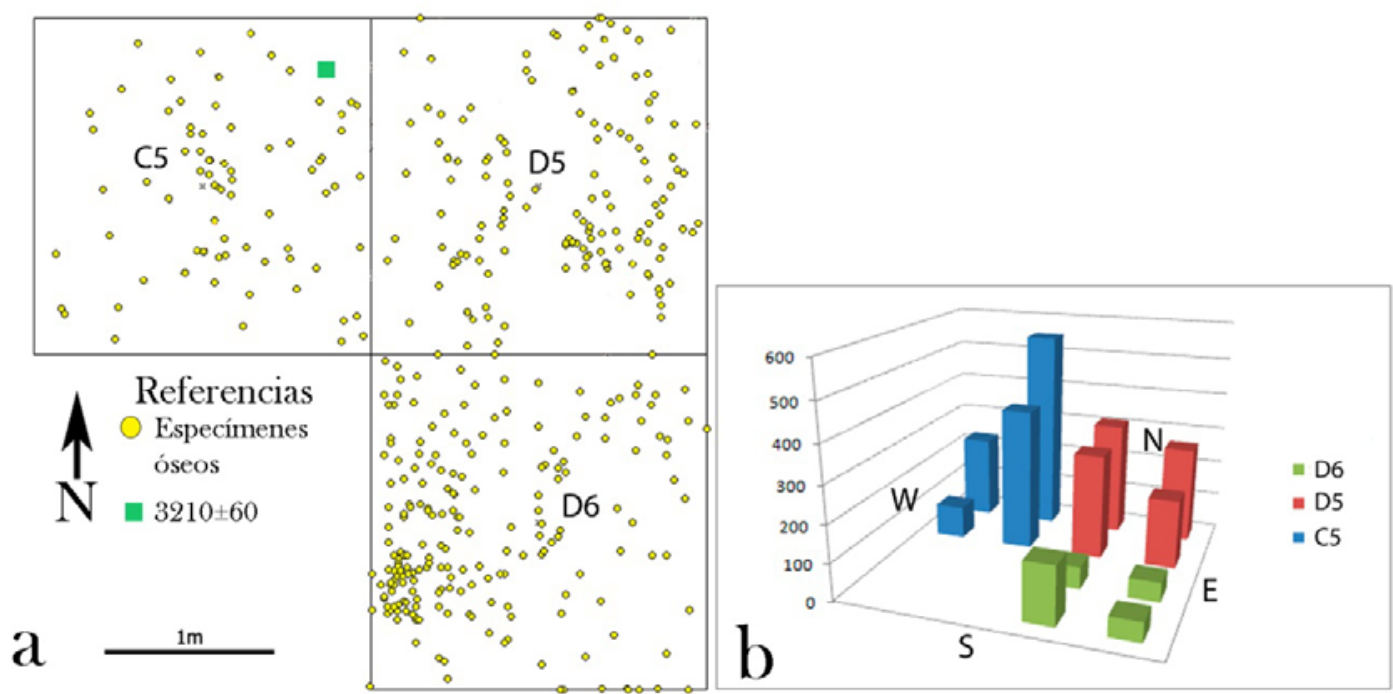

Figura 7.17. a) Distribución en planta de los especímenes tridimensionados en Capa 4 de CN de MA; b) densidad de restos óseos por cuadrícula (C5, D5 y D6) y sector de excavación (NE, NW, SE y SW). Valores expresados en frecuencia de NISP por m². 


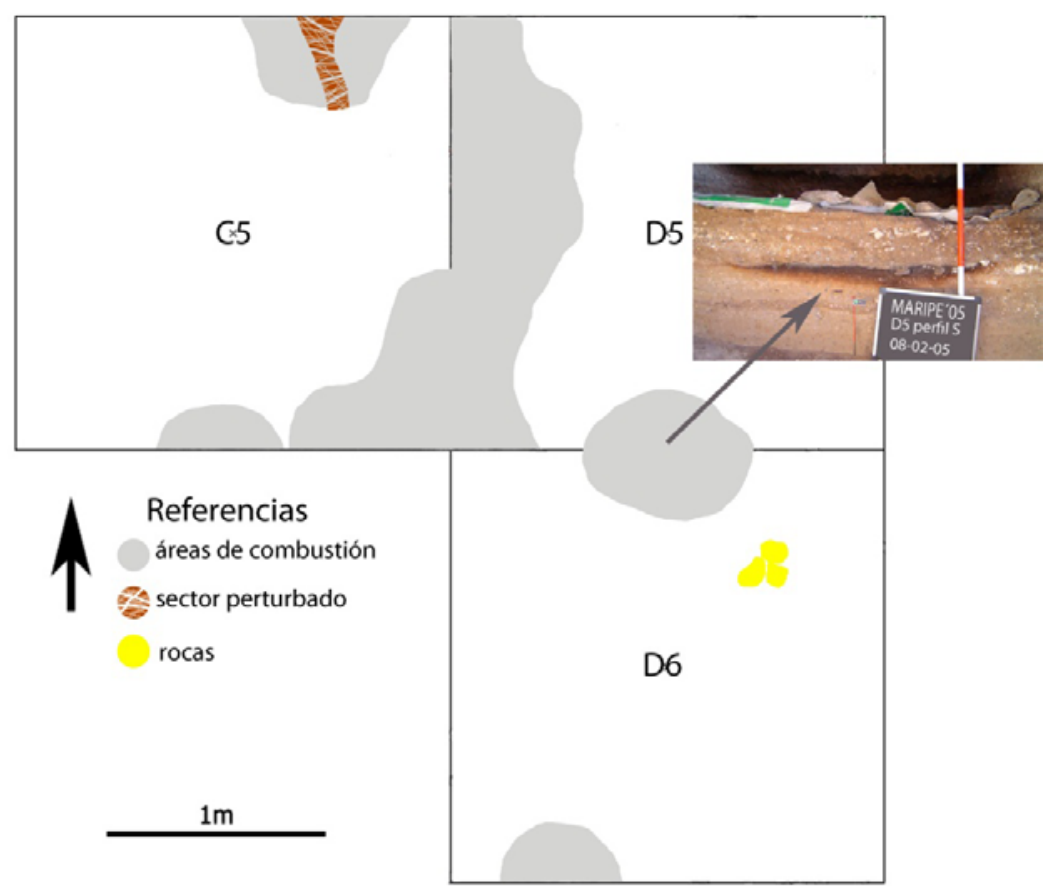

Figura 7.18. Esquema de rasgos e indicadores de procesos y agentes tafonómicos identificados durante las excavaciones de Capa 4 de $\mathrm{CN}$ en MA.

\subsubsection{Abundancia taxonómica y anatómica}

Los resultados obtenidos muestran que todas las especies identificadas en el conjunto se corresponden con las que en la actualidad habitan el área. En la tabla 7.4 se observa que la especie más representada en el conjunto es Lama guanicoe. Los restos asignados a dicha especie representan el $41,68 \%$ del NISP y es seguida en importancia por los mamíferos de tamaño grande $(24,53 \%)$ y los mamíferos indeterminados $(14,27 \%)$. Entre las aves, los rheidos adquieren frecuencias relativamente importantes después de los guanacos (16,52\%). Los restantes taxa presentan frecuencias bajas (menores al 1\%), entre ellos se destaca el registro de Felis concolor y Homo sapiens (Tabla 7.4).

Con respecto de la representación de partes anatómicas del guanaco fueron determinados tanto elementos del esqueleto axial como del esqueleto apendicular (Tabla 7.5). El MNI para guanaco fue estimado a partir de la tibia proximal y el metatarso proximal en 5. Siguiendo los criterios de edad relacionados a la fusión de las epífisis, al menos dos de los guanacos corresponderían a ejemplares subadultos, siendo los 3 
restantes adultos.

\begin{tabular}{|l|c|c|c|}
\hline & NISP & $\%$ NISP & M NI \\
\hline Ave indet. & 1 & $0,13 \%$ & - \\
\hline Rheidae* & 132 & $16,52 \%$ & - \\
\hline Mamífero Indet. & 114 & $14,27 \%$ & - \\
\hline Mamifero Grande & 196 & $24,53 \%$ & - \\
\hline Dasipodidae sp. & 2 & $0,25 \%$ & 1 \\
\hline Rodentia indet. & 3 & $0,38 \%$ & 1 \\
\hline Felis concolor & 6 & $0,75 \%$ & 1 \\
\hline Artiodactyla & 6 & $0,75 \%$ & 1 \\
\hline Camelidae & 4 & $0,50 \%$ & 1 \\
\hline Lama sp. & 1 & $0,13 \%$ & 1 \\
\hline Lama guanicoe & 333 & $41,68 \%$ & 5 \\
\hline Homo sapiens & 1 & $0,13 \%$ & 1 \\
\hline * 131 especímenes corresponden a \\
fragmentos de cáscara de huevo
\end{tabular}

Tabla 7.4. Abundancia taxonómica en Capa 4 de CN de MA.

El análisis de la fragmentación a partir de la relación entre MNE/NISP de guanaco evidencia que la misma ha sido alta en el conjunto de Capa 4 de $\mathrm{CN}$ ya que se obtuvo un valor de 0,44. Esta alta fragmentación podría ser la responsable de que una cantidad importante de especímenes $(38,8 \%)$ no hayan podido ser asignados a categorías más específicas que la Clase Mamífero grande e indeterminado. Asimismo, esta fragmentación podría ser la responsable de las diferencias registradas en la distribución entre los especímenes tridimensionados y el conjunto completo y que se mostraron en la Figura 7.17a y $7.17 \mathrm{~b}$.

Del análisis de la representación de unidades anatómicas de guanaco se desprende que los elementos más representados $(\mathrm{MAU} \%=100 \%)$ son el metatarso proximal y el sacro, seguidos por la tibia proximal (MAU\%=87,5\%), y en con menor frecuencia $($ MAU\% $=75)$ el axis (Tabla 7.5). Dentro del esqueleto axial la mandíbula alcanza una buena representación con un $\mathrm{MAU} \%=62,5 \%$ y es seguida por el cráneo y el atlas $($ MAU\% $=50 \%)$. Otras partes correspondientes al tronco del animal -i.e., vértebras cervicales, torácicas y lumbares, costillas y esternebras- adquieren frecuencias bajas (entre un 25\% y 4\% del MAU\%, respectivamente). No se registraron vértebras caudales. Con respecto al esqueleto apendicular, luego de los dos elementos distales mencionados anteriormente, también se registraron la diáfisis $(\mathrm{MAU} \%=62,5 \%)$ y la porción proximal del fémur $(\mathrm{MAU} \%=50 \%)$ con valores representativos. Algunos elementos del basipodio 
del miembro posterior -i.e., calcáneo, cuboide, endocuneiforme y navicular- tiene una baja a moderada representación en el conjunto, siendo menor la frecuencia que presentan el astrágalo y el fibular (Tabla 7.5). En cuanto a la representación de los elementos que pertenecen al miembro anterior, el metacarpo proximal y la diáfisis del radio-cúbito son los mejor representados $(\mathrm{MAU} \%=62,5 \%)$. Sin embargo, elementos como la escápula $($ MAU\% $=50 \%)$, la diáfisis del húmero y el radio-cúbito proximal $($ MAU\% $=37,5 \%)$ también fueron determinados. Gran parte de los elementos del carpo se encuentran ausentes -i.e., cuneiforme, escafoide, magnum, pisiforme y trapezoidemientras que otros como el unciforme y el lunar tienen baja representación. Entre los autopodios indiferenciados las mayores frecuencias se obtuvieron para la porción diafisiaria $(\mathrm{MAU} \%=56,25 \%)$ y distal $(\mathrm{MAU} \%=31,25 \%)$ de los metapodios mientras que las falanges se registraron en frecuencias más bajas (Tabla 7.5).

De este análisis se desprende que la unidad de trozamiento más representada corresponde al cuarto trasero del guanaco. Sin embargo, unidades como la pata delantera y la cabeza también adquieren buena representación. Es interesante destacar, tanto para la pata trasera como para la delantera, que los elementos distales -i.e., autopodio y zeugopodio- son los que adquieren frecuencias más elevadas, mientras que los elementos del estilopodio de ambas patas se encuentran en frecuencias más bajas. El análisis de los procesos y agentes tafonómicos que se desarrolla a continuación permitirá evaluar las desiguales frecuencias de ambas zonas diagnósticas del esqueleto y minimizar la equifinalidad en lo referente a selección humana de partes (intencionalidad) o acción de procesos destructivos. 


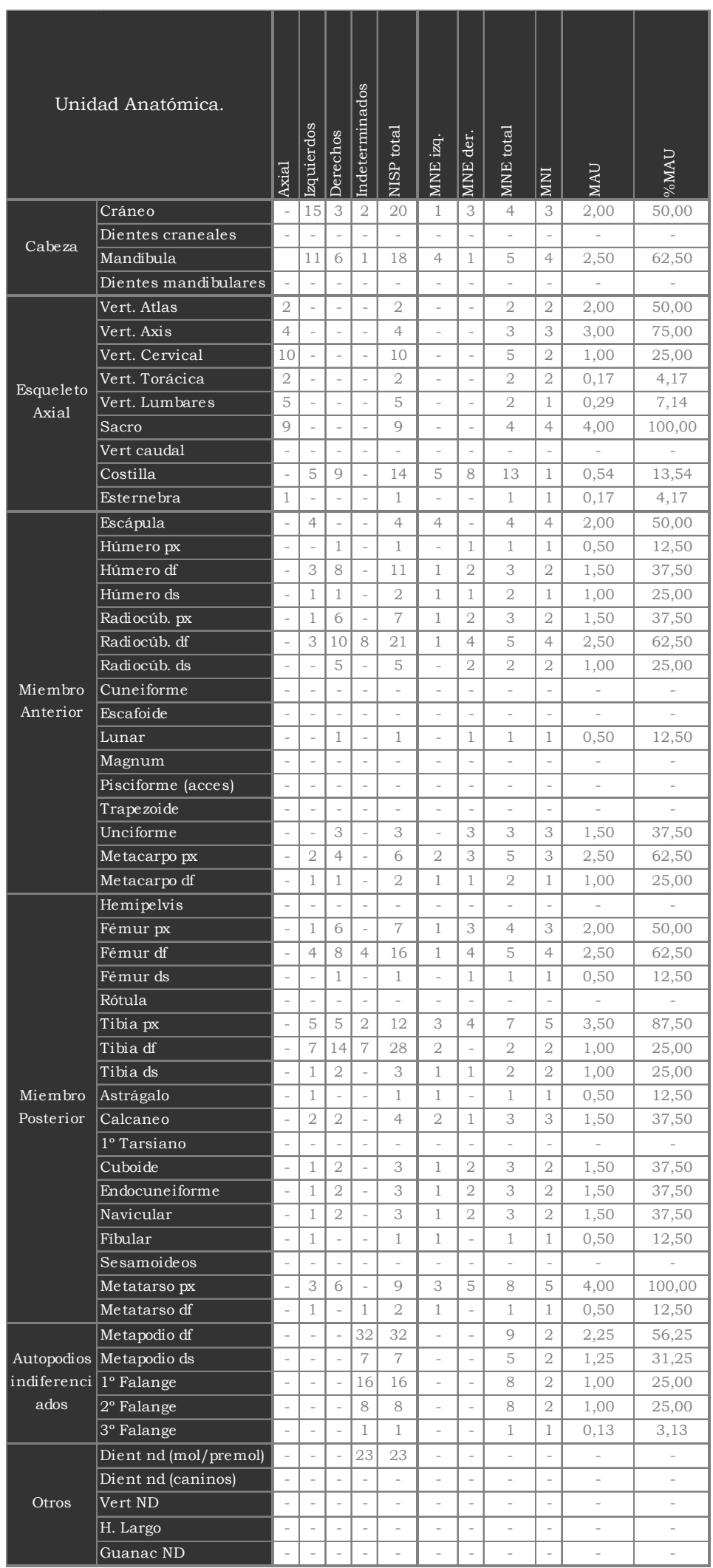

Tabla 7.5. Representación de partes anatómicas de guanaco en Capa 4 de $\mathrm{CN}$ de

MA. 
La distribución de los restos óseos de guanaco (Figura 7.19) muestra un patrón completamente distinto al observado con el conjunto completo. Los especímenes de guanaco se concentran fundamentalmente en el sector SW de D6 (94 especímenes por $\mathrm{m}^{2}$ ) y SE de D5 (44 especímenes por $\mathrm{m}^{2}$ ). Es interesante destacar que los sectores del oeste de C5 que concentraban la mayor cantidad de restos del conjunto completo (Figura 7.17b) son los que prácticamente no presentan restos de guanaco (Figura 7.19).

El gran número de especímenes de Mamífero de tamaño grande corresponde en su mayoría (ca. 60\%) a fragmentos de hueso largo que no han preservado características diagnósticas para su asignación taxonómica más específica, ya sea por el grado de fragmentación o por otros procesos tafonómicos destructivos como la disolución química o la cobertura de sales. Sin embargo, dichos restos tendrían amplias posibilidades de corresponder a $L$. guanicoe. La evaluación de si las partes anatómicas registradas en esta clase podrían estar complementando las ausentes entre los guanacos mostró que solamente se podrían incrementar los valores de NISP para porciones medias de costillas $(\mathrm{NISP}=29)$, fragmentos del cráneo $(\mathrm{NISP}=9)$ y vértebras $(\mathrm{NISP}=5)$ ya que la gran mayoría de estos restos corresponden a fragmentos de diáfisis de hueso largo (NISP= 117). El ajuste de estas determinaciones es una de las tareas pendientes ya que permitirá mejorar la resolución taxonómica del conjunto. Para ello la aplicación de otras técnicas y metodologías a las aquí desarrolladas (ADN, GIS, entre otras) seguramente puedan aportar en la solución de este problema.

En cuanto a los especímenes determinados como rheidos solo uno de ellos corresponde a una porción distal lateral de diáfisis de tarso-metatarso izquierdo. Los restantes especímenes asignados a este género corresponden a fragmentos de cáscara de huevo (NISP=131). En cuanto a los restos de cáscaras de huevo, su mayor parte se distribuye en los sectores NE de C5 y NW de D5 y en menor frecuencia en NW de C5 y NE de D5. El tarso-metatarso de rheido fue recuperado en el sector SW de D6, coincidiendo con el lugar donde se registró la mayor frecuencia de restos de guanaco.

Los restos determinados como Felis concolor (puma) corresponden en su totalidad a fragmentos de una misma mandíbula, todos ellos recuperados en el sector NE de D6. El resto asignado a Homo sapiens corresponde a un incisivo de leche que proviene del sector SE de D5. 


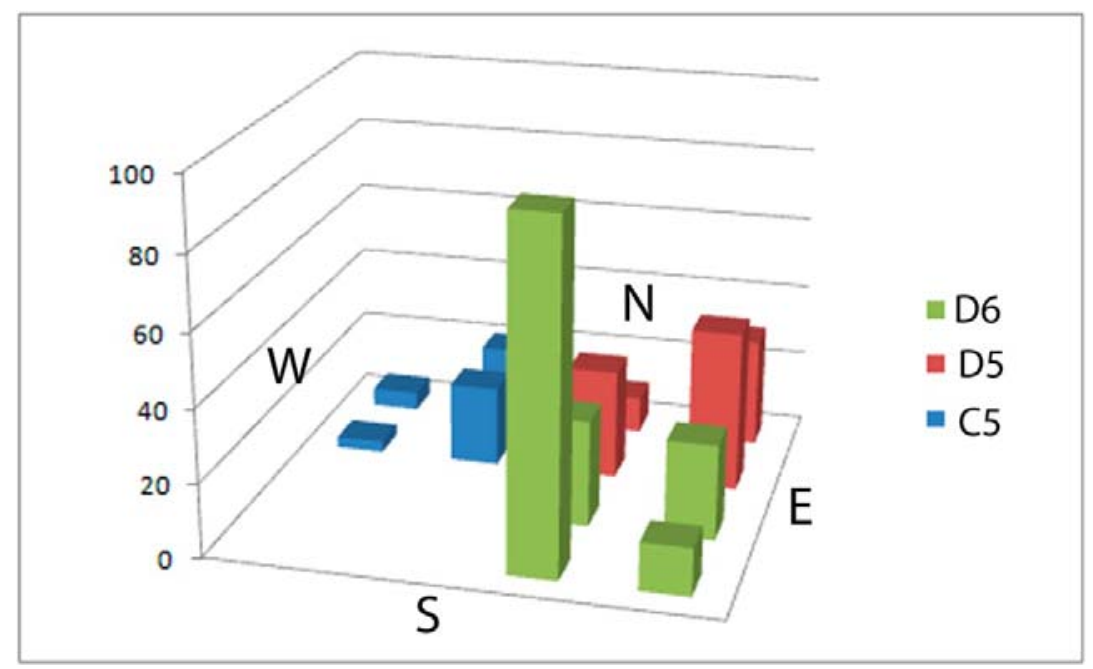

Figura 7.19. Densidad de restos óseos de guanaco por $\mathrm{m}^{2}$ en la Capa 4 de $\mathrm{CN}$ de MA.

Los valores están expresados en frecuencia de NISP por $\mathrm{m}^{2}$ (sector de cuadrícula).

\subsection{Análisis de la estrategia de transporte de partes anatómicas de guanaco}

Se realizaron distintas correlaciones estadísticas que nos permitieron evaluar las posibles causas de la representación de partes anatómicas del guanaco en la Capa 4 de de CN de MA (Figura 7.20).

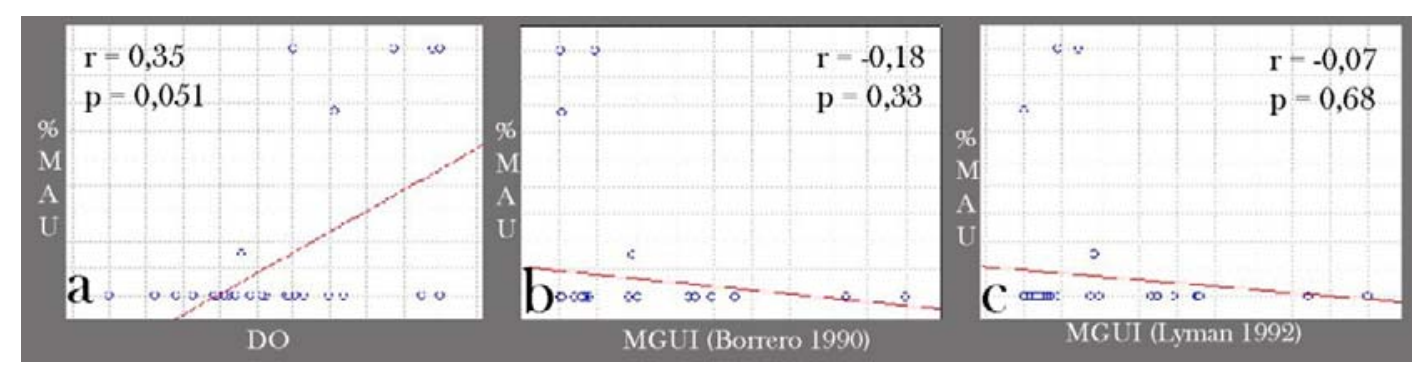

Figura 7.20. Correlaciones estadísticas de Spearman a) MAU\%-DO; b) MAU\%-Índice de

Utilidad (sensu Borrero 1990); c) \%MAU-Índice de Utilidad (sensu Lyman 1992).

Los resultados obtenidos indican que la frecuencia de partes anatómicas muestra una baja correlación positiva con la $\mathrm{DO}(\mathrm{r}=0,35 ; \mathrm{p}=0,05)$ lo que evidenciaría que los elementos más representados son los que presentan DO más alta (Figura 7.20a). Sin embargo, dado que el valor de $r$ es muy bajo y el valor de $p$ cae justo en el límite de significancia, esta correlación debería ser considerada con cautela. Por su parte, los resultados obtenidos al correlacionar las frecuencias de MAU\% con los dos índices de 
utilidad (Borrero 1990; Lyman 1992) se observa una ausencia completa de correlación (Figuras 7.20b y 7.20c). Estos resultados reflejarían falta de selección humana de las partes en relación a su alto o bajo rendimiento económico.

Considerando la propuesta interpretativa de estos resultados realizada por Lyman (1994: 264), el conjunto de la Capa 4 de CN caería entre la Clase 4 "lag or ravaged" y/o en la 5 que es la equifinalidad completa. La alternativa de la Clase 4 sugiere la posibilidad de que el conjunto haya estado expuesto a la acción de procesos mediados por DO. Mientras tanto, la Clase 5 indica que la frecuencia de partes anatómicas no puede ser interpretada de forma exclusiva ni por la acción de los procesos mediados por DO ni por la utilidad económica de esas partes.

Si bien en el conjunto fue determinada una frecuencia importante de elementos con baja DO y con muy buena preservación -i.e., elementos del sacro, esternebra, entre otros-, existen múltiples factores que pueden estar condicionando la preservación del mismo. Como se mencionó en el Capítulo 4, el estado de madurez osteológica que presenten los huesos introduce variabilidad en la DO entre los elementos del guanaco (Gutiérrez et al. 2010). Si bien consideramos que contemplar estas características del registro es fundamental para comprender mejor las causas de la destrucción ósea, el alto grado de fragmentación del conjunto dificulta este nivel de análisis. Evaluar si los distintos niveles de osificación en que se encuentren los especímenes pudo jugar un papel importante en la preservación del conjunto forma parte de la agenda de esta tesis.

Sin embargo, la Clase 4 (Lyman 1994) podría estar marcando un área que posiblemente sea de descarte final de partes anatómicas, las cuales, si atendemos a la cantidad de carne y grasa que aportarían sería muy baja, lo cual avala la hipótesis de área de descarte de aquellas unidades de bajo retorno. De todos modos los resultados detallados a continuación pueden aportar ideas independientes a las aquí obtenidas.

\subsubsection{Modificaciones de las superficies óseas}

\subsection{Patrones de modificaciones naturales}

Los resultados del análisis de las superficies óseas de los restos de guanaco (Figura 7.21) muestran que el $96 \%$ de los especímenes se encuentran en estadios bajos de meteorización (entre el estadio 0 y 2 sensu Behrensmeyer 1978). La tendencia observada 
en el perfil de meteorización indicaría que los materiales estuvieron poco tiempo expuestos a las condiciones meteóricas y que el enterramiento fue relativamente rápido y sincrónico. Solamente el $4 \%$ del conjunto registró estadios de meteorización más elevados (estadio 3 de Behrensmeyer 1978). Si bien este estadio podría implicar pérdida ósea en el conjunto de Capa 4 de $\mathrm{CN}$, la frecuencia de especímenes en ese nivel es despreciable frente al $96 \%$ de restos en buen estado de preservación. A favor de este argumento encontramos lo dicho anteriormente respecto de la alta frecuencia de partes anatómicas con baja DO (elementos del sacro y esternebras), y por lo tanto con mayor probabilidad de encontrarse destruidos frente a la acción de estos procesos. La alta fragmentación registrada también podría ser una de las causas de que algunos materiales (los más astillados o pequeños) se meteoricen más que otro. Sin embargo, y más allá de lo esperado para huesos masivos o con altas chances de supervivencia como las diáfisis de tibias (Marean y Cleghorn 2003), el trabajo de Belardi et al. (2010), esclarece acerca de la posibilidad de que la meteorización sea más acelerada sobre las diáfisis que sobre las epífisis, proceso que se vería acentuado por la fragmentación humana o no- humana de estas unidades.

El análisis de la tendencia de meteorización entre los elementos axiales y apendiculares del esqueleto del guanaco permitió observar algunas diferencias (Figura 7.21). Mientras que la mayor cantidad de los elementos axiales se concentra entre los estadios 1 y 2, los apendiculares presentan una mayor heterogeneidad, alcanzando inclusive hasta el estadio 3 de meteorización (Figura 7.21). Dado que los especímenes que presentan superficies en estadio 3 corresponden a elementos con valores medios a altos de DO -i.e., articulares, diáfisis de húmero y de metapodio-, pensamos que la fragmentación del conjunto, previa a su depositación, sería una hipótesis más parsimoniosa para esta situación. De modo similar esta interpretación ha sido propuesta para contextos del Holoceno medio y tardío de los sectores cordilleranos (De Nigris 2004; Mengoni Goñalons 1999; Rindel 2009). 


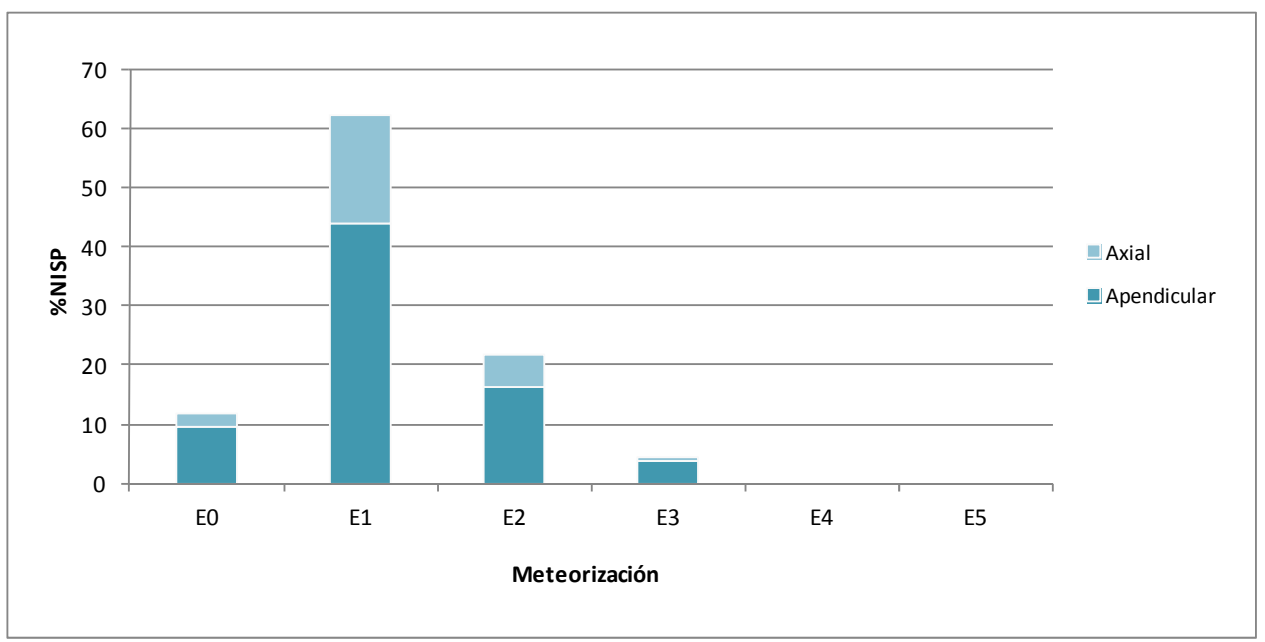

Figura 7.21. Tendencia de la meteorización en especímenes asignados a $L$. guanicoe en el conjunto de Capa 4 de CN de MA. Los valores son expresados en NISP\%.

La presencia de otros patrones de modificación producidos por procesos o agentes naturales fue registrada en bajos porcentajes (Figura 7.22a). Los depósitos de manganeso son los más representados y se reconocieron en un 6\% de los especímenes. Estos depósitos aparecen en forma de manchas dispersas en la superficie de los huesos y que en algunos casos cubren sectores mayores de la superficie (Figuras 7.23a y 7.23b). Otras modificaciones corresponden a las producidas por roedores $(3,6 \%)$, ellas siempre se registraron asociadas a los bordes de los huesos formando surcos cortos y paralelos (Figura 7.23c). Modificaciones producidas por raíces (Figura 7.23d) y carnívoros se reconocieron en muy pocos especímenes óseos (1,8\% y 0,9\% respectivamente). Solamente fue identificado un espécimen con abrasión y uno teñido. 


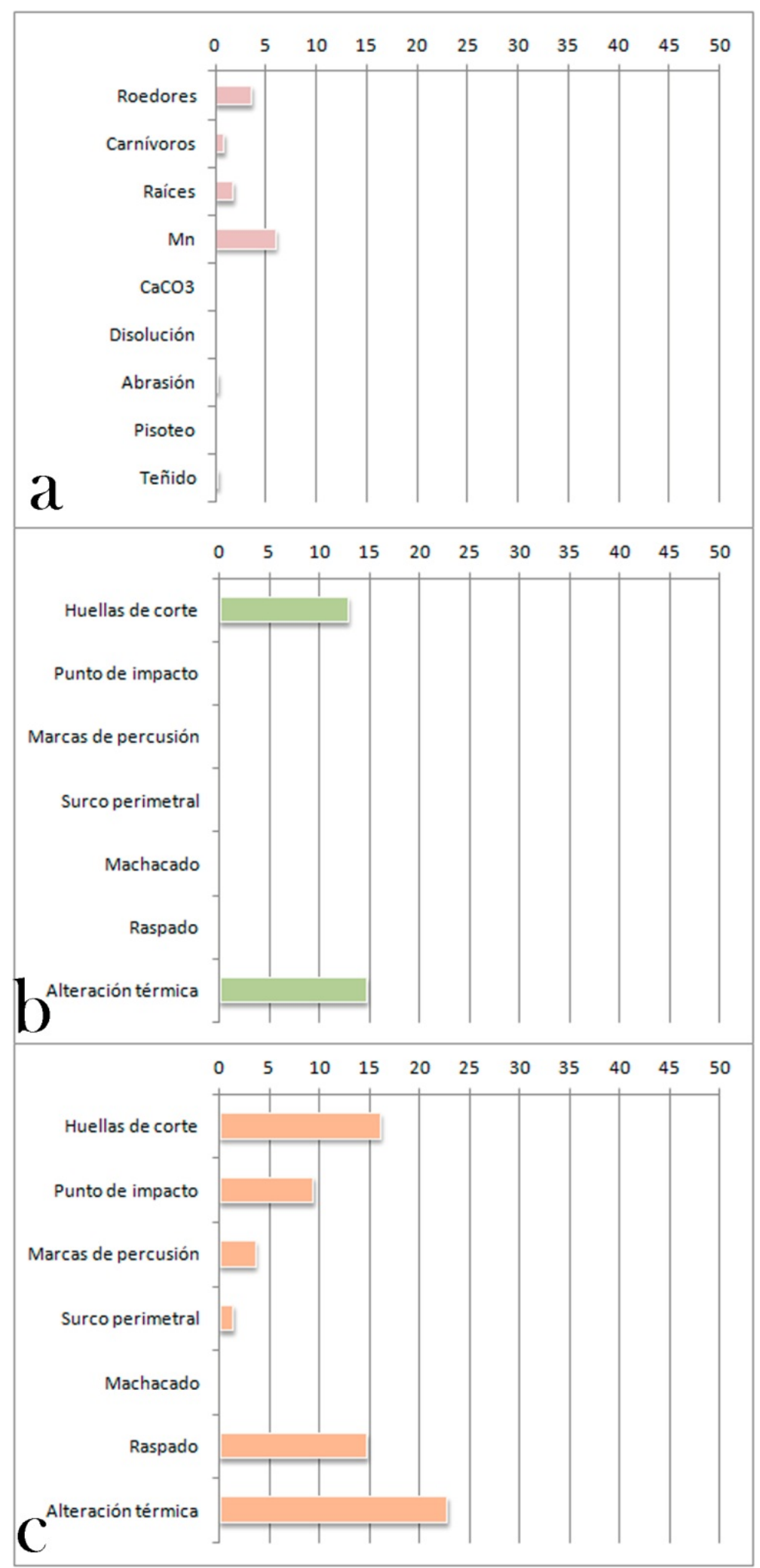

Figura 7.22. Frecuencia porcentual de especímenes óseos de guanaco con presencia de modificaciones: a) naturales; b) modificaciones antrópicas en especímenes del esqueleto axial; c) modificaciones antrópicas en el esqueleto apendicular. 

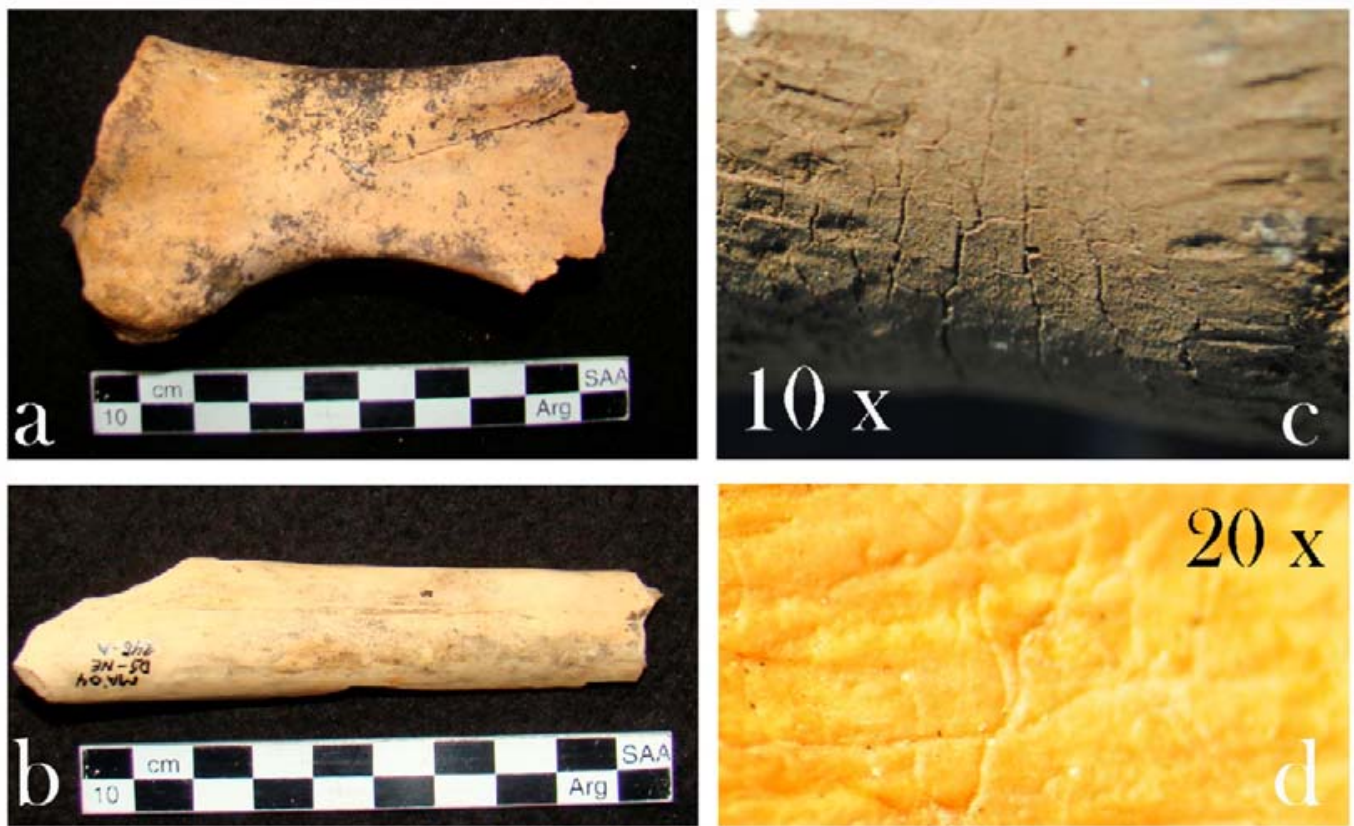

Figura 7.23. Modificaciones naturales en Capa 4 de CN de MA: a) depósitos de manganeso sobre escápula con claro patrón dendrítico; b) pequeñas manchas de manganeso sobre diáfisis anterior de metapodio con fractura antrópica; c) marcas de roedor en porción distal de falange proximal con alteración térmica; d) improntas de raíces en vértebra cervical.
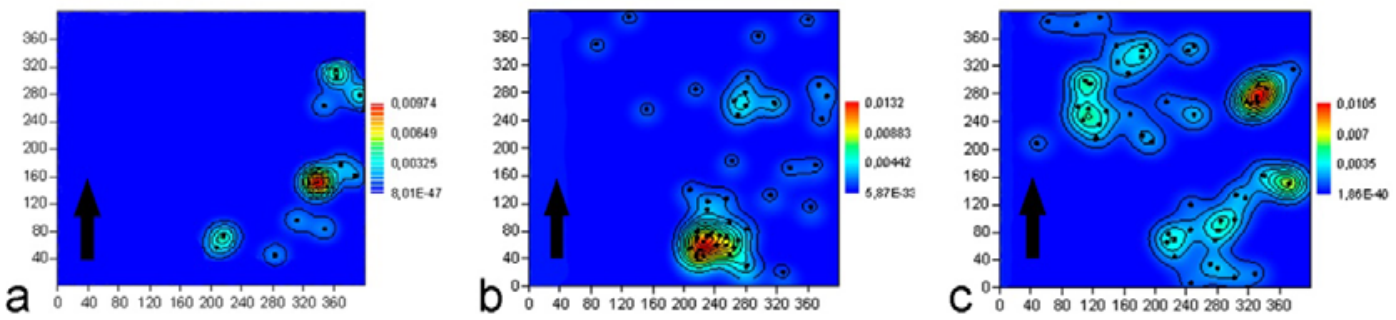

Figura 7.24. Distribución espacial de especímenes con modificaciones en las cuadrículas excavadas de CN (C5, D5 y D6); a) especímenes con depósitos de manganeso; b) especímenes con presencia de huellas de corte; c) especímenes que presentan alteración térmica.

Los especímenes con manchas de manganeso se encuentran distribuidos fundamentalmente en el sector este de D5 y D6, alcanzando en este último las frecuencias más elevadas (Figura 7.24a). Esta distribución de los especímenes con manganeso estaría indicando que posiblemente en el sector NE de D6 y Este de D5 haya habido condiciones de mayor humedad que en el resto del área excavada. Más de un 
50\% de los especímenes con depósitos de manganeso localizados en el este sector (NE de D6 y SE de D5) corresponden a elementos del autopodio del guanaco. Dado que el manganeso que se deposita sobre los huesos se puede liberar como resultado de la descomposición de materia orgánica (Marín Arroyo et al. 2008; Shahack-Gross et al. 1997) es posible pensar que proceden de la degradación de los tejidos blandos que puedan haber quedado adheridos a estas partes.

Los especímenes con marcas de roedores que se distribuyen dispersos en el área excavada, no se encuentran asociados con el sector perturbado en el NE de la cuadrícula C5 (Figura 7.18), por el contrario una mayor cantidad de ellos proviene de la cuadrícula D6.

Los especímenes con marcas de raíces provienen de la cuadrícula D6, mientras que los que registraron marcas de carnívoros proceden de D5.

\subsection{Patrones de modificación antrópica}

Se reconocieron modificaciones antrópicas tanto en elementos del esqueleto axial como apendicular de los guanacos, encontrando en este último las mayores frecuencias y variedades (Figuras $7.22 \mathrm{~b}$ y $7.22 \mathrm{c}$ ).

De todos los tipos de modificaciones reconocidos, la alteración térmica de los especímenes es la que alcanza la mayor frecuencia ya que se registra en un $37 \%$ del conjunto, es la más representativa tanto entre los elementos axiales como apendiculares (Figuras 7.22b y 7.22c). Los elementos quemados presentan superficies enrojecidas y/o ennegrecidas (Figura 7.25a), no habiéndose encontrado especímenes en estado calcinado.

En segundo lugar, también en frecuencias elevadas, se registran huellas de corte (Figuras 7.25c-f) en los especímenes del esqueleto axial (12,8\%) y apendicular (16\%). En el esqueleto axial, además de la alteración térmica y las huellas de corte, no se registraron otras modificaciones antrópicas. 

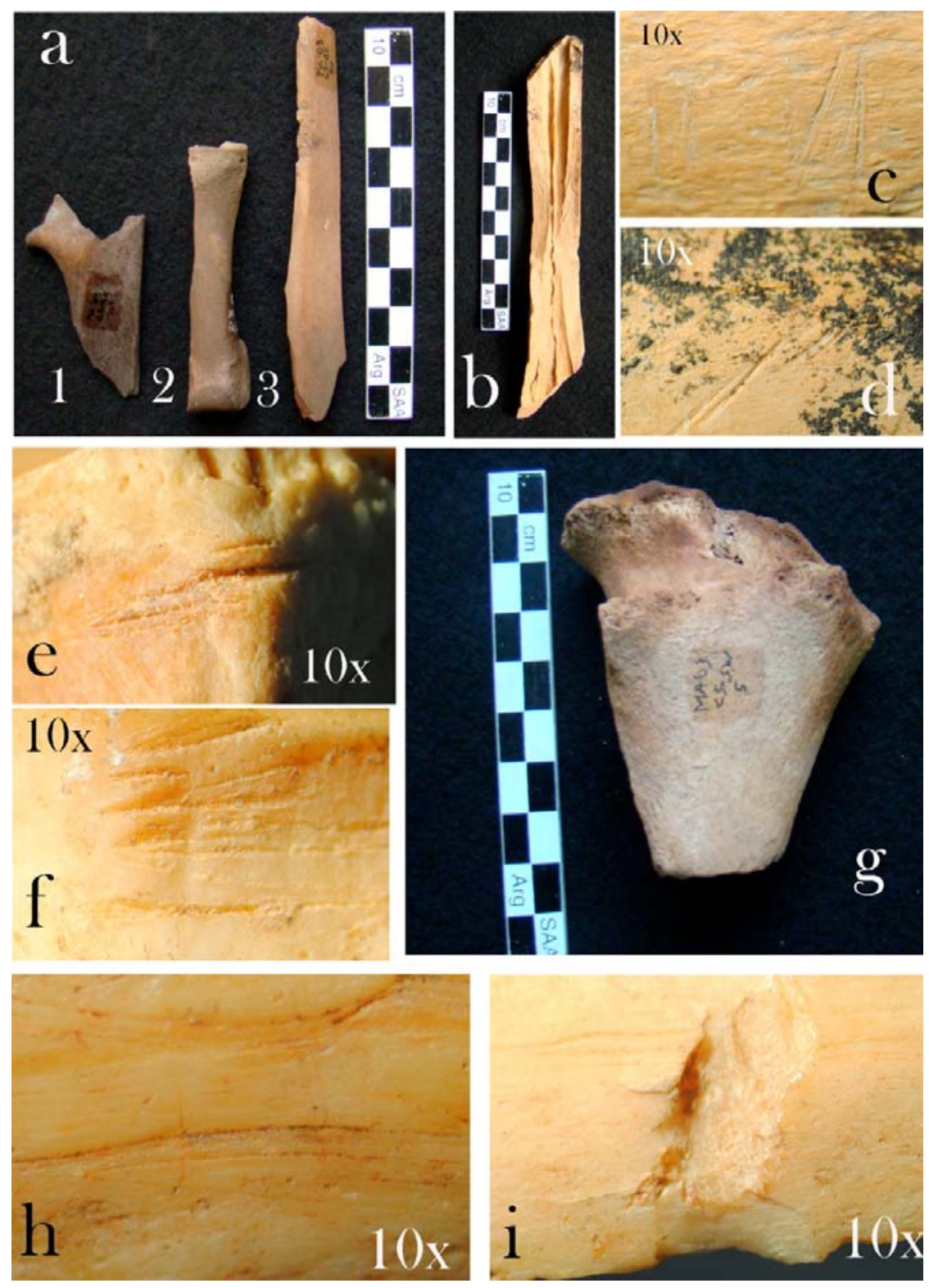

Figura 7.25. Modificaciones culturales en Capa 4 de CN de MA. a) Alteración térmica en especímenes óseos (1- fragmento de rama ascendente de mandíbula izquierda; 2- falange proximal con fractura longitudinal; 3- Diáfisis de tibia izquierda con posibles marcas de percusión); b) diáfisis de metapodio con fractura longitudinal y negativos de impacto; c) huellas de corte en costilla; d) huellas de corte en escápula; e) huellas de desarticulación en metatarso; f) huellas de corte en metatarso; g) fractura transversal por aserrado perimetral en fémur derecho; h) marcas de raspado sobre diáfisis de metatarso derecho; i) marcas de raspado y percusión en diáfisis de metapodio con desprendimiento de lasca ósea.

En el esqueleto apendicular, además de las huellas de corte se reconocieron otros 
tipos de modificaciones relacionadas a prácticas de procesamiento. Entre ellas, las marcas de raspado (Figuras $7.25 \mathrm{~h}$ y $7.25 \mathrm{i}$ ) se registraron en un $14,7 \%$ de los especímenes, todos ellos correspondientes a huesos largos. Otras modificaciones culturales se registraron en frecuencias más bajas, entre ellas encontramos un 9,3\% de los especímenes con puntos de impacto (Figura 7.25b), y un 3,7\% de restos con marcas de percusión (Figura 7.25i), todos ellos exclusivamente sobre elementos correspondientes a huesos largos. En dos fémures y una tibia, todos derechos y juveniles, se observa la presencia de fractura transversal por surco perimetral (Figura 7.25g).

Las huellas de corte estarían vinculadas al procesamiento primario y secundario de los guanacos. Sin embargo, las restantes marcas presentes en el esqueleto apendicular podrían relacionarse con la etapa final de la reducción de las carcasas, ya que reflejan la intencionalidad de fracturar los huesos, sea para cocción, consumo de médula o para manufactura de instrumentos óseos. El elevado índice de fragmentación obtenido para este conjunto avala esta hipótesis ya que puede ser considerado un indicador de conjuntos que resultan de actividades de consumo y descarte (De Nigris 2004).

La distribución de los especímenes que exhibieron huellas de corte (Figura 7.24b) permite observar que una importante frecuencia de los mismos se concentra en el sector SW de D6, estando algunos de ellos agrupados en el sector sur de D5 y los restantes, dispersos en la superficie excavada. Este patrón se corresponde con el observado en la Figura 7.19 la cual muestra que la mayor frecuencia de restos de guanaco se concentra en esas mismas áreas de la excavación. Consideramos que esta distribución podría estar reflejando un patrón de descarte en un sector particular del sitio.

El análisis de los tipos de fracturas registrados en los 189 (56,8\%) especímenes de huesos largos nos permitió reconocer un total de 309 fracturas ya que en su mayor parte, cada espécimen presentaba más de un tipo de fractura. Entre los patrones de fractura identificados se pudieron discriminar 196 especímenes con fractura antrópica y 113 con fracturas post-depositacionales (Figura 7.26).

Las fracturas helicoidales $(29,7 \%)$ son numerosas aunque la mayor frecuencia (33\%) la alcanzan las longitudinales (Figura 7.26). En los especímenes con fractura helicoidal, además se registraron atributos asociados como puntos de impacto, huellas de corte y marcas de raspado, entre los más representativos. La ausencia de marcas de carnívoros sobre el conjunto avala su origen antrópico. 


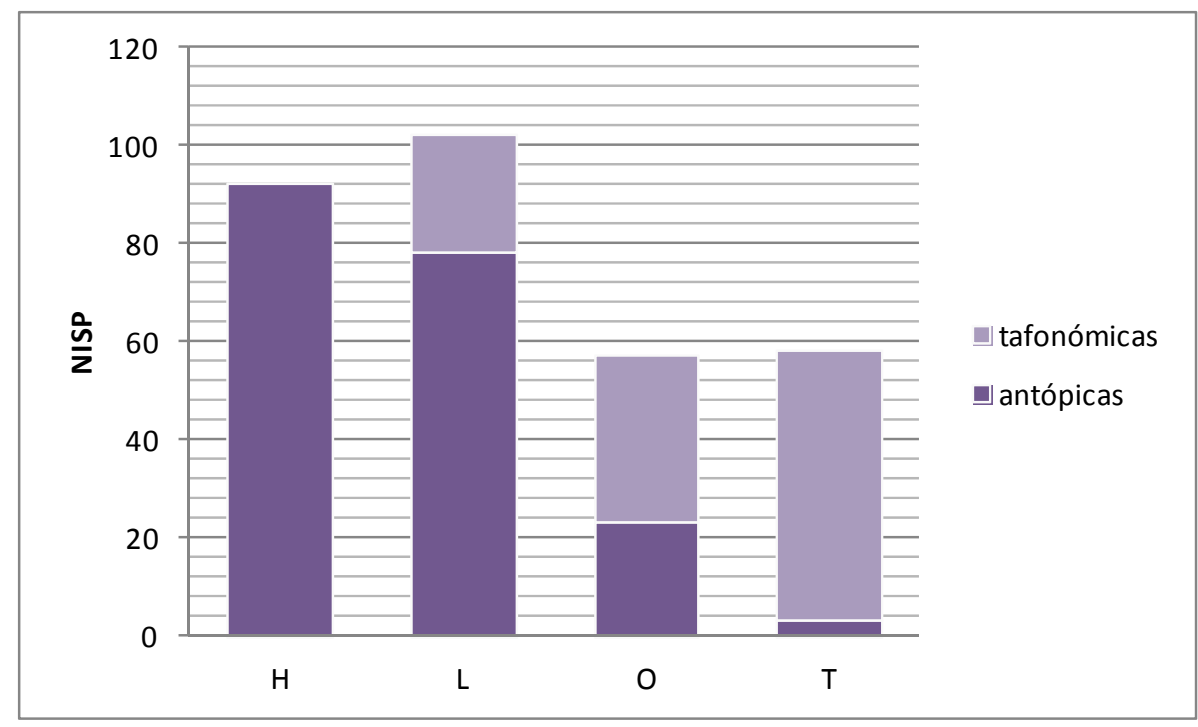

Figura 7.26. Frecuencia absoluta y tipos de fracturas identificadas: H) helicoidal; L) longitudinal; O) oblicua; T) transversal.

De total de restos óseos con fracturas longitudinales (Figura 7.26), un número de $78(76,5 \%)$ pueden ser atribuidas al agente antrópico ya que presentaron superficies suaves, resultado de la fractura del hueso en estado fresco. La presencia de marcas de raspado o puntos de impacto asociados a los bordes de fractura, y en varios casos la existencia de huellas de corte, avalan esa idea. Por su parte, las 24 fracturas longitudinales que restan $(23,5 \%)$, no mostraron características que permitan vincularlas a este patrón, por el contrario parecen ser resultado de otros procesos tafonómicos no culturales.

Entre las fracturas oblicuas (Figura 7.26) 23 (40,35\%) presentaron atributos como huellas de corte, punto de impacto y/o marcas de raspado además de superficies suaves que permiten suponer que resultan de la intencionalidad humana. Por el contrario, las 34 $(59,65 \%)$ restantes carecen de marcas culturales de procesamiento y presentan superficies rugosas que nos llevan a proponer un origen tafonómico para ellas. Las fracturas transversales (Figura 7.26), con excepción de las 3 que mostraron aserrado perimetral (Figura 7.25g), son resultado de la fractura del hueso en estado seco y por tanto, consideradas resultado de la acción de agentes naturales.

La mayoría de los especímenes quemados $(\mathrm{NISP}=51)$ corresponden a elementos del esqueleto apendicular del guanaco, mientras que un $\mathrm{NISP}=16$ pertenecen a unidades axiales. El análisis de la distribución espacial de los restos óseos quemados (Figura 7.24c) permite observar que la mayor densidad $(26,4 \%)$ se concentran en el sector SE de D5, SW de D6 (23,8\%) y SE de C5 (20\%), mientras que los restantes se encuentran dispersos. 
En el sector SE de D5, si bien solo se recuperaron 6 especímenes quemados (8,9\%), se encuentra la concentración más densa. En términos generales, los sectores donde se concentran los huesos quemados no coinciden enteramente con las estructuras de combustión mapeadas (Figura 7.18). Por el contrario, ellos se ubican fundamentalmente en los alrededores de estas estructuras, tal distribución quizá podría estar reflejando, de no ser resultado de la acción de agentes perturbadores, actividades de consumo en torno a las zonas de encendido de fuegos. Las características de espesor y buena delimitación de los fogones registrados en esta capa serían un argumento a favor de esta idea.

En esta capa se identificaron 3 artefactos óseos formatizados por uso sobre huesos de guanaco, dos de ellos sobre diáfisis de tibia (Figura 27a), el tercero sobre diáfisis de metapodio (Figura 27b). Los dos primeros parecen haber sido utilizados como retocadores blandos ya que presentan abundantes marcas de percusión localizadas. El tercer artefacto es una diáfisis de radio-cúbito que presenta abundantes marcas de raspado localizadas y no asociadas directamente al borde de fractura (Figura 27c). En esta capa también se recuperó un artefacto óseo formatizado tipo punzón (Figura $7.27 \mathrm{~d}$ ) confeccionado sobre hueso largo indeterminado de mamífero y una cuenta tubular decorada sobre un hueso largo de ave (Figura 7.27e). Además, y al igual que en Capa 5 de $\mathrm{CN}$, en un fragmento de diáfisis de tibia izquierda y en un calcáneo derecho juvenil de guanaco, se identificó la presencia de manchas rojas que posiblemente puedan corresponder a restos de pigmentos o pintura preparada (Figura 7.28). Esta última observación, como se sostuvo para el conjunto de Capa 5, podría guardar relación con la producción de pinturas rupestres registrada en la cueva. 


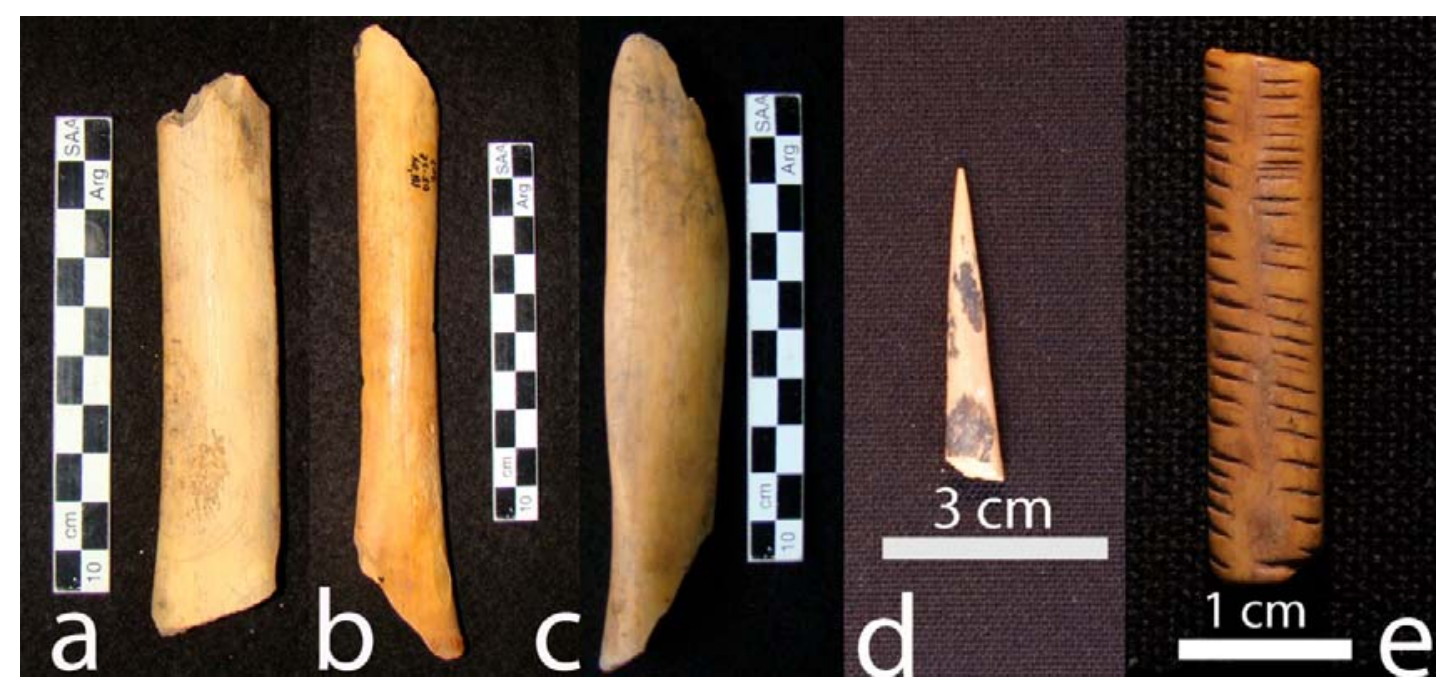

Figura 7.27. Artefactos óseos formatizados por uso: a) diáfisis de tibia; b) diáfisis de metapodio; c) diáfisis de radio-cúbito; d) punzón sobre hueso largo de mamífero; e) cuenta tubular sobre hueso largo de ave.
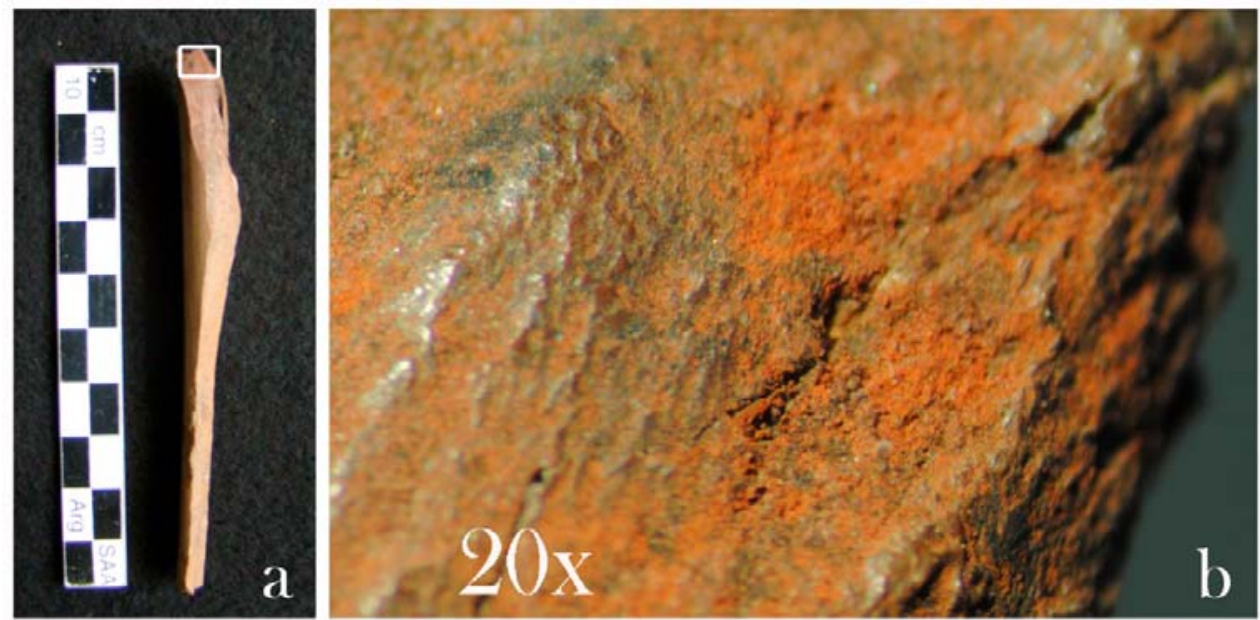

Figura 7.28. Pigmento rojo sobre diáfisis de tibia: a) detalle del fragmento diafisiario con localización del pigmento; b) detalle del pigmento depositado sobre el borde de fractura.

\subsubsection{Capa 3 de Cámara Norte}

El conjunto procedente de la Capa 3 de CN de MA está conformado por un total de 1320 restos arqueofaunísticos. De ese total un 33,86\% del conjunto pudo ser 
determinado a algún nivel anatómico o taxonómico (NISP=447), quedando el 66,14\% $(\mathrm{NSP}=873)$ del conjunto en la categoría indeterminados. La mayor cantidad de especímenes indeterminados $(\mathrm{NSP}=854)$ corresponden a pequeñas astillas o fragmentos indeterminados de hueso largo $(\mathrm{NSP}=15)$ o plano $(\mathrm{NSP}=4)$.

El conjunto de especímenes tridimensionados de Capa 3 se encuentra distribuido en las tres cuadrículas excavadas en CN (Figura 7.29a). Sin embargo, y como puede observarse en la Figura 7.29a, la mayor cantidad de restos tridimensionados se encuentran en la cuadrícula D6 y en el sector SE de D5.

El análisis de la densidad de restos óseos por $\mathrm{m}^{2}$ (Figura 7.29b), contemplando tridis y generales, permite observar que el sector SE de D5 concentra el 29\% de las arqueofaunas (384 especímenes por $\mathrm{m}^{2}$ ). Frecuencias elevadas también se observan en NE (167 restos por $\left.\mathrm{m}^{2}\right)$, SW $(9,7 \%)$ y NW $(9,1 \%)$ de C5 y de D5 (8,5\%). Los restantes sectores de D5 -i.e., NW y SW-presentan densidades moderadas de restos (ca. 95 especímenes por $\mathrm{m}^{2}$ ) siendo más bajas las densidades que se observan en el sector SE de D5 y todos los sectores de D6. A partir de este análisis es posible reconocer una fuerte concentración de restos óseos en el SE de D5 que concuerda con la distribución de los materiales tridimensionados (Figura 7.29a). Esta mayor densidad en ese sector permite suponer que el mismo pudo corresponder con un área de descarte diferencial dentro del sector excavado. Sin embargo, a excepción de este sector, no se observan coincidencias entre la distribución de los tridis y el conjunto completo (Figuras 7.29a y 7.29b respectivamente). Esta situación podría estar indicando la existencia de grados más elevados de fragmentación en los restos de la cuadrícula C5 y sectores del norte y SW de D5. 


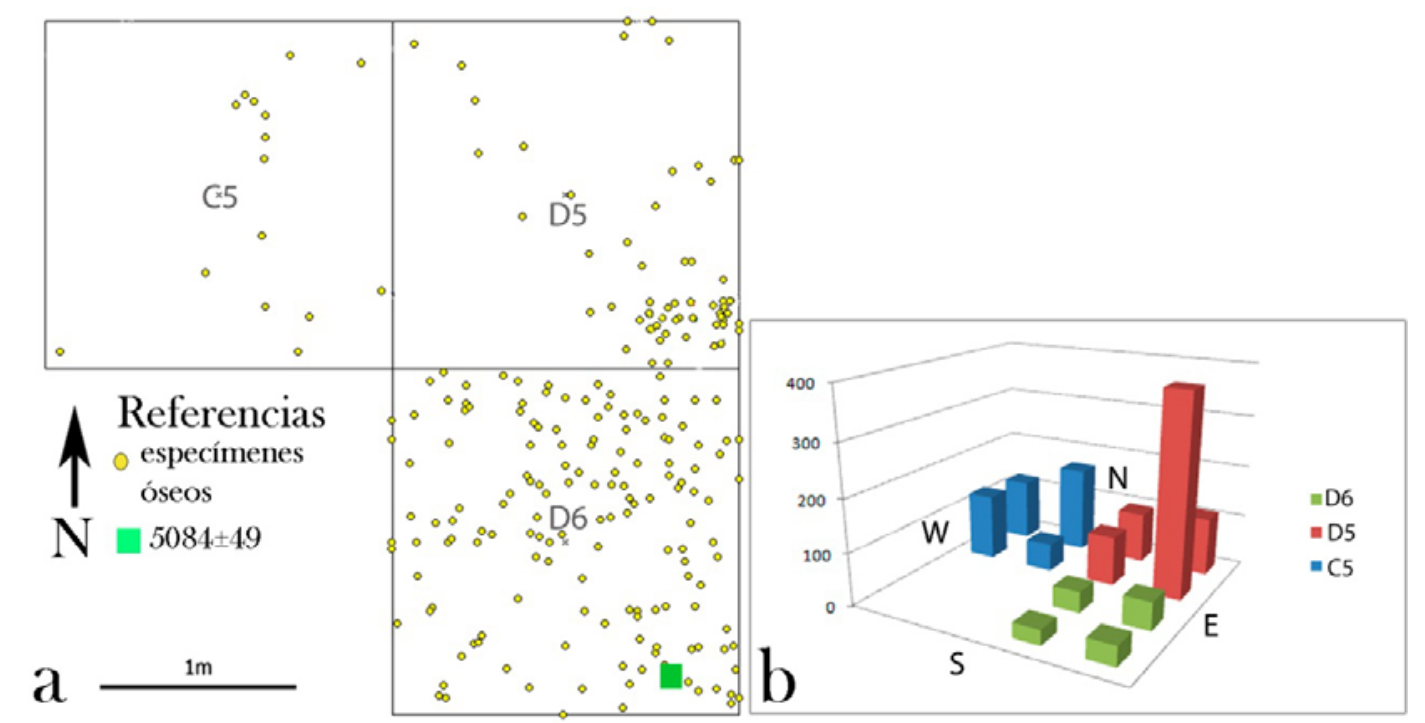

Figura 7.29. a) Distribución en planta de los especímenes tridimensionados en la Capa 3

de CN de MA; b) densidad de restos óseos por cuadrícula (C5, D5 y D6) y sector de excavación (NE, NW, SE y SW). Valores expresados en frecuencia de NISP por m².

Durante las excavaciones de la Capa 3 fueron identificadas dos áreas de combustión en la cuadrícula D6 (Figura 7.30). En esta misma cuadrícula se describieron y mapearon tres sectores circulares cuyo sedimento interior se presentaba suelto y que por sus características podría corresponder con cuevas (Figura 7.30). Por el tamaño de estas estructuras de cavado podría ser resultado de la actividad de animales fosoriales como los dasipódidos y los Ctenomys sp. En el sector NW de D6 fue mapeada una concentración de fragmentos de cáscara de huevo de rheidos, mientras que en el NE de D5 se registraron dos concentraciones de gramíneas o vegetales que también se observan en el perfil. Por otro lado, en el SE de D5 apareció una concentración de restos óseos más densa que la observada en el resto de la excavación, en ella se recuperaron mayormente restos apendiculares de guanaco entre los que había un autopodio articulado. 


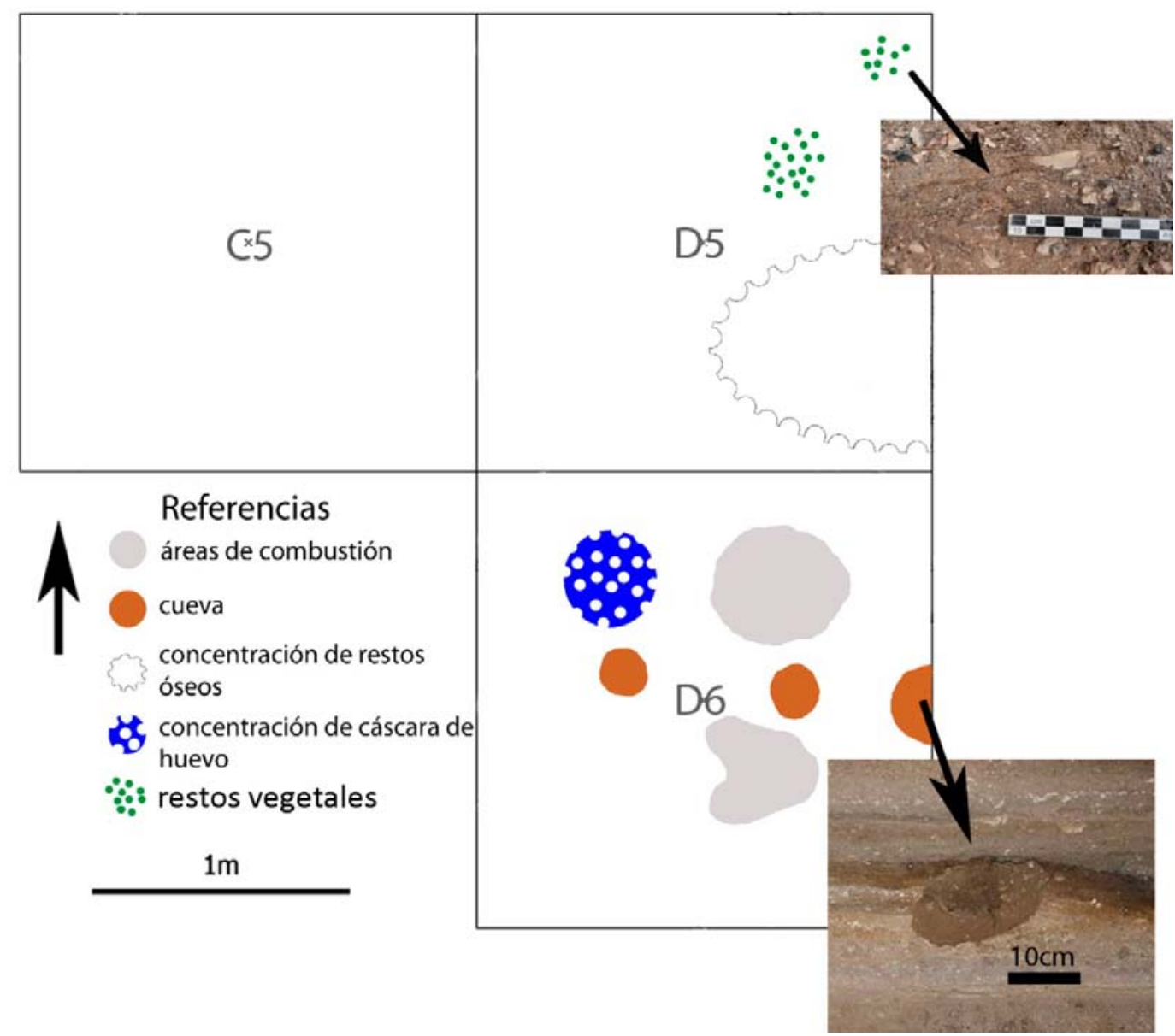

Figura 7.30. Esquema en planta y foto de perfil, mostrando los rasgos e indicadores de procesos y agentes tafonómicos identificados durante las excavaciones de Capa 3 CN de

MA.

\subsubsection{Abundancia taxonómica y anatómica}

Todas los especímenes óseos identificados corresponden a especies que actualmente habitan el área. Los análisis realizados permiten observar que la especie más representada en el conjunto es Lama guanicoe con un 32,2\% del NISP\% (Tabla 7.6). En segundo lugar aparecen los rheidos que representan el 25,9\%, seguido de los mamíferos grandes $(19,4 \%$ del NISP\%) y de los mamíferos indeterminados (19\%). Otras especies y categorías taxonómicas fueron identificadas pero en frecuencias muy bajas que representan menos del 1\% del NISP\% del conjunto (Tabla 7.6). 


\begin{tabular}{|l|c|c|c|}
\hline & NISP & \%NISP & M NI \\
\hline Reptilia indet. & 1 & $0,22 \%$ & 1 \\
\hline Ave indet. & 4 & $0,89 \%$ & - \\
\hline Rheidae* & 116 & $25,95 \%$ & - \\
\hline Mamífero Indet. & 85 & $19,02 \%$ & - \\
\hline Micromamifero & 2 & $0,45 \%$ & - \\
\hline Mamífero Grande & 87 & $19,46 \%$ & - \\
\cline { 1 - 2 } Dasipodidae & 1 & $0,22 \%$ & 1 \\
\cline { 1 - 2 } Artiodactyla & 4 & $0,89 \%$ & 1 \\
\cline { 1 - 2 } Camelidae & 2 & $0,45 \%$ & 1 \\
\cline { 1 - 2 } Lama sp. & 1 & $0,22 \%$ & 1 \\
\hline Lama guanicoe & 144 & $32,21 \%$ & 5 \\
\hline *los 116 especímenes corresponden a \\
fragmentos de cáscara de huevo
\end{tabular}

Tabla 7.6. Abundancia taxonómica en la Capa 3 de CN de MA.

En cuanto a la representación de partes anatómicas del guanaco, encontramos que los elementos del esqueleto apendicular se encuentran mejor representados que los del esqueleto axial (Tabla 7.7). La estimación del MNI se realizó a partir de la diáfisis de la tibia que indica que al menos fueron necesarios 5 guanacos para dar cuenta de las partes anatómicas representadas en el conjunto. Según los criterios de edad establecidos a partir de la fusión de las epífisis, al menos uno de los individuos podría corresponder a un chulengo.

La relación entre el MNE y el NISP de guanaco dio por resultado 0,51 indicando que el mismo presenta una fragmentación moderada.

El análisis de las frecuencias de MAU\% muestra que la diáfisis de tibia es la que presenta los valores más elevados $(\mathrm{MAU} \%=100 \%)$ seguidas por la diáfisis del fémur que, si bien alcanza frecuencias mucho más bajas (50\% del MAU\%), es el segundo elemento más representado (Tabla 7.7). Las diáfisis de los metapodios, la tibia proximal y el radiocúbito distal representan el 37,5\% del MAU \%. Siguiendo con las frecuencias que registran los elementos del esqueleto apendicular tenemos la escápula, la diáfisis del húmero, el radio- cúbito proximal y el metacarpo proximal con un MAU\% del 25\%. Algunos articulares tanto de la pata delantera -e.g., lunar- como trasera -e.g., astrágalo, calcáneo, cuboide, endocuneiforme y navicular- alcanzan, al igual que los metatarsos el $12,5 \%$ del MAU\%. Entre los elementos indiferenciados del autopodio del guanaco, la mayor frecuencia después de las diáfisis del metapodio se registra para la falange media $($ MAU\% $=15,63 \%)$. Una situación llamativa es que estando presentes las porciones 
diafisiarias del estilopodio anterior y posterior (húmero y fémur respectivamente), se encuentren completamente ausentes sus porciones proximales y distales (Tabla 7.7). Varios carpianos y tarsianos tampoco fueron identificados en el conjunto.

En lo que compete al esqueleto axial, menos representado que el apendicular, encontramos que la cabeza es la unidad que alcanza los valores más elevados del MAU\% (Tabla 7.7), siendo un 37,5\% del MAU\% los valores que corresponden al cráneo y un 25\% a la mandíbula. Los restantes elementos del esqueleto axial se encuentran en frecuencias muy bajas o no están presentes -i.e., vértebras cervicales, costillas, vértebras lumbares-.

Del análisis de las frecuencias de MAU\% se desprende que la unidad de trozamiento más representada corresponde al cuarto trasero del animal, especialmente la fracción distal que corresponde con el autopodio y zeugopodio. El segundo lugar de importancia entre las unidades de trozamiento lo ocupa el miembro anterior y la cabeza, el primero de estos sigue el mismo patrón de representación que el descripto para el miembro posterior. Esta variación en las frecuencias posiblemente pueda ser consecuencia de la acción de distintos procesos y agentes tafonómicos entre los que las actividades de selección humana podrían jugar un papel preponderante. Esta situación se evalúa más adelante al considerar los distintos agentes y procesos que estuvieron involucrados en la formación del conjunto.

El análisis de distribución y densidad de restos óseos de guanaco (Figura 7.31) muestra una tendencia en parte similar a la registrada para el conjunto completo (Figura 7.29b), ya que coinciden en que la mayor concentración de especímenes se encuentra en el sector SE de D5 (45 especímenes de guanaco por $\mathrm{m}^{2}$ ). Esa concentración ósea, también es coincidente con la mapeada durante las excavaciones y en la que se registraron elementos del autopodio articulados (Figura 7.30). Sin embargo, se observan diferencias en la concentración arqueofaunística de los restantes sectores y cuadrículas. En el caso de los restos de guanaco, luego de la concentración del SE de D5, se observa una densidad considerable en el sector NE de D6 (24 especimenes por $\mathrm{m}^{2}$ ) y SE de D6 (22 por $\left.\mathrm{m}^{2}\right)$. Una densidad moderada en NW (15 por $\left.\mathrm{m}^{2}\right)$ y $\mathrm{SW}\left(11\right.$ por $\left.\mathrm{m}^{2}\right)$ de $\mathrm{D} 6$ y una baja densidad (menor o igual a 6 especímenes por $\mathrm{m}^{2}$ ) en los demás sectores -i.e., NE, NW y SW de D5 y NE, SE y SW de C5- estando completamente ausentes los restos de guanaco en el sector NW de C5 (Figura 7.31). 


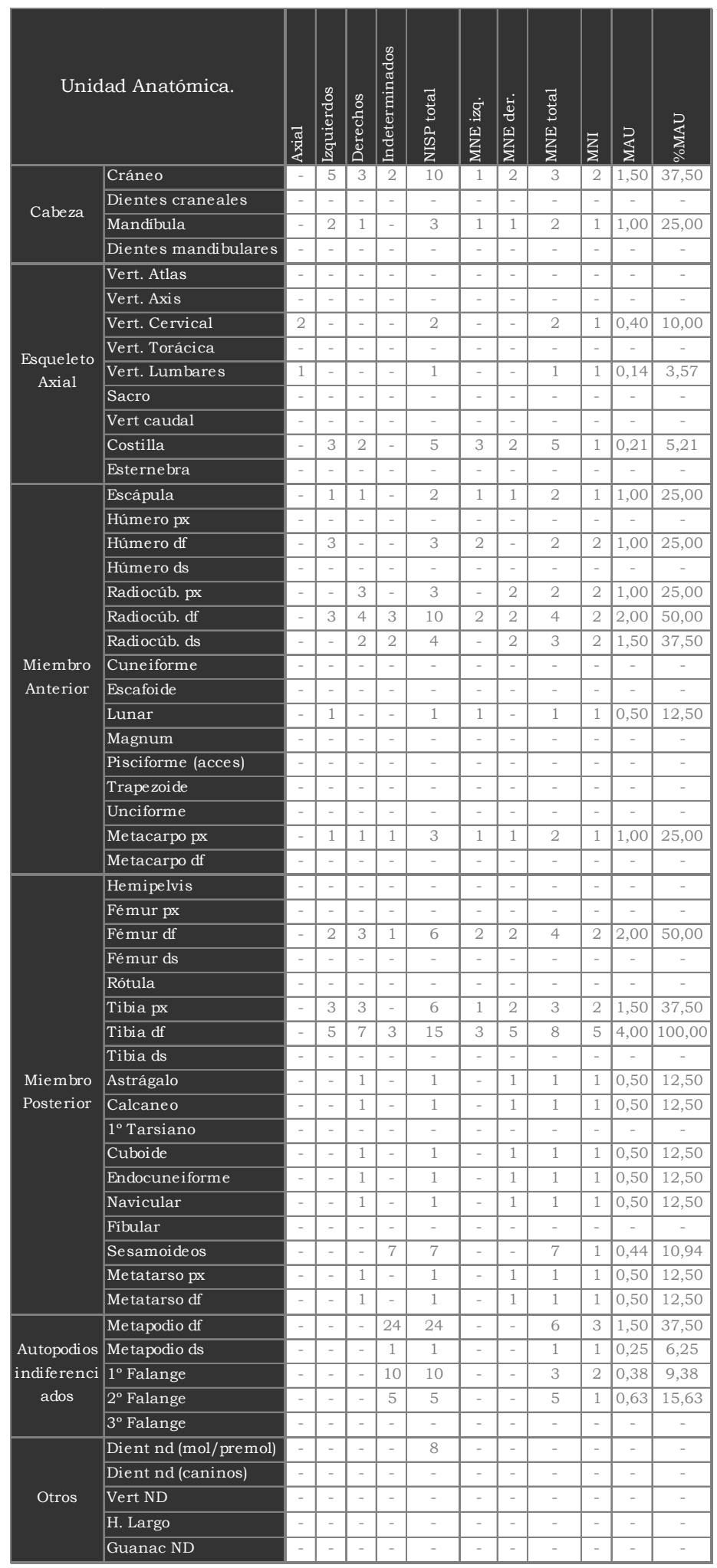

Tabla 7.7. Representación de partes anatómicas de guanaco en la Capa 3 de CN de MA.

El gran número de especímenes de Mamífero de tamaño grande corresponde en su 
mayoría $(57,4 \%)$ a fragmentos de hueso largo que no han preservado, o por el grado de fragmentación que tienen o por la acción de procesos tafonómicos, rasgos o características diagnósticas para poder ser asignados a una categoría taxonómica más específica. Sin embargo, dichos restos tendrían amplias posibilidades de corresponder a L. guanicoe. La evaluación de si las partes anatómicas registradas en esta clase podrían estar complementando las ausentes entre los guanacos mostró que solamente se podrían incrementar los valores de NISP de dientes ya que se han recuperado fragmentos pequeños de esmalte $(\mathrm{NISP}=26)$, los fragmentos medios de costillas $(\mathrm{NISP}=5)$, fragmentos del cráneo $(\mathrm{NISP}=2)$, mandíbula $(\mathrm{NISP}=2)$ y vértebras $(\mathrm{NISP}=2)$.

En cuanto a los especímenes determinados como rheidos solamente se identificaron fragmentos de cáscara de huevo $(\mathrm{NISP}=116)$. Con respecto a la distribución que adquieren, como fue sostenido anteriormente, una concentración de ellos pudo ser registrada en el NW de D6 (Figura 7.30), sin embargo una importante cantidad también proviene de los sectores SE de D5 y NW de C5, y en menor frecuencia del SW y NE de C5 y NW y SW de D5.

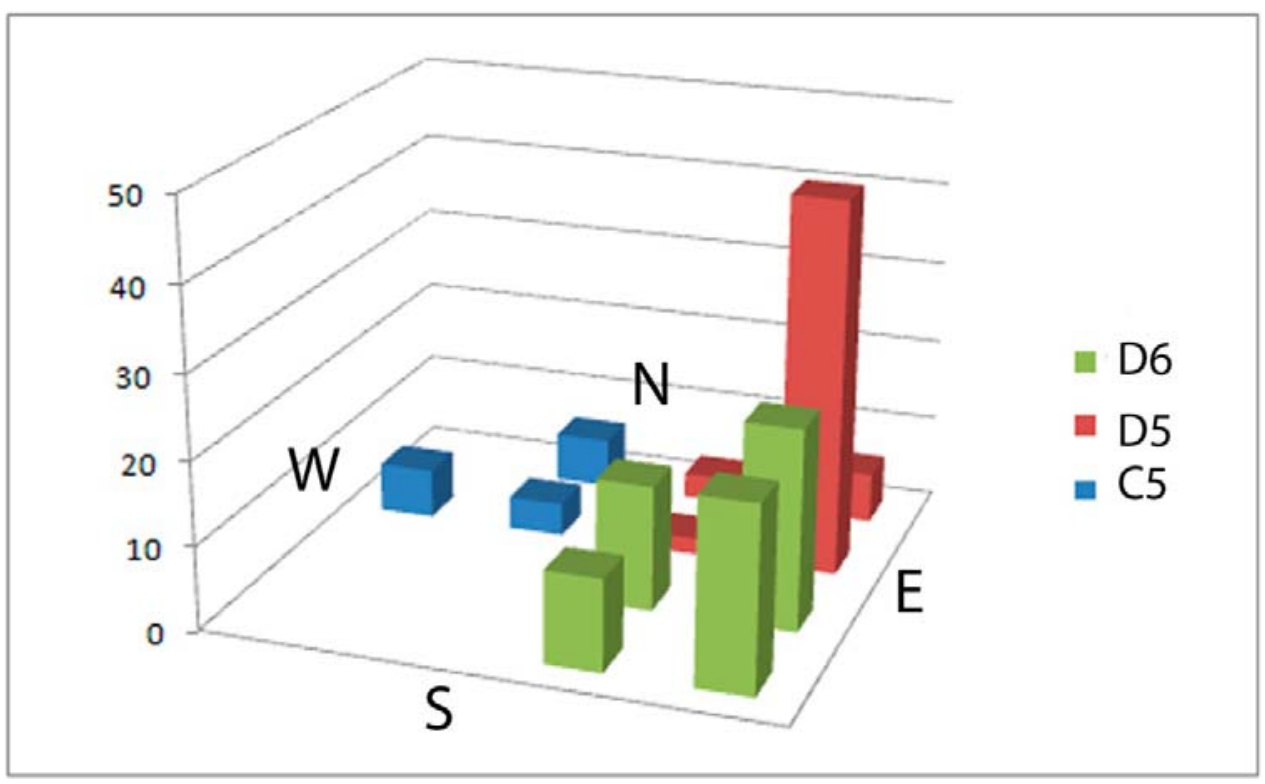

Figura 7.31. Densidad de restos óseos de guanaco por sector de cuadrícula en la Capa 3 de $\mathrm{CN}$ de MA. Valores expresados en frecuencia de NISP por $\mathrm{m}^{2}$.

\subsection{Análisis de la estrategia de transporte de partes anatómicas de guanaco}

Se realizaron las correlaciones estadísticas de Spearman para evaluar las posibles 
causas de tal representación de partes anatómicas del guanaco en el conjunto de la Capa 3 de CN (Figura 7.32).

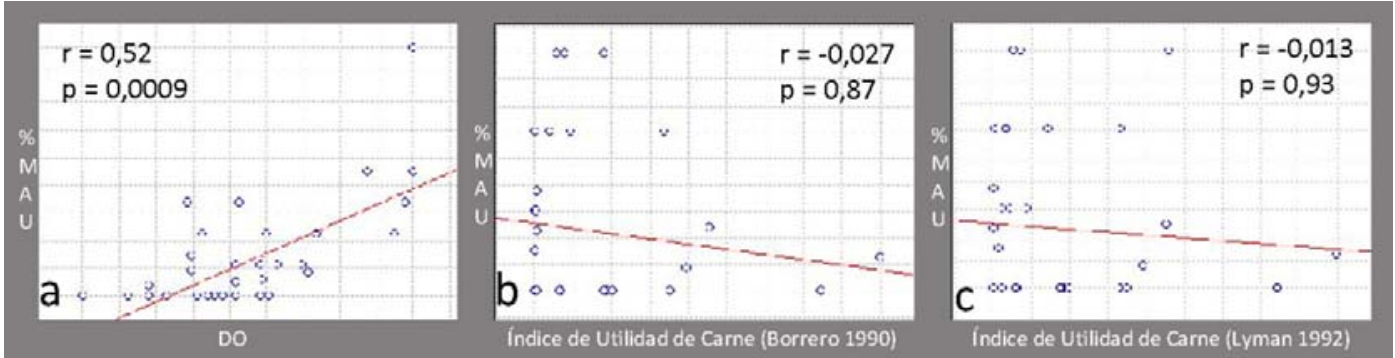

Figura 7.32. Correlaciones estadísticas de Spearman: a) MAU\%-DO; b) MAU\%-Índice de Utilidad (sensu Borrero 1990); c) MAU\%-Índice de Utilidad (sensu Lyman 1992).

Los resultados obtenidos muestran que la frecuencia de partes anatómicas se correlaciona de forma moderada y positiva con la $\mathrm{DO}(\mathrm{r}=0,52 ; \mathrm{p}<0,05)$ lo que evidencia una tendencia en la que los elementos más representados son los que tienen DO más alta (Figura 7.32a). Por otro lado, los resultados alcanzados al correlacionar las frecuencias de MAU\% con los dos índices de utilidad (Borrero 1990; Lyman 1992) permiten observar, en ambos casos, una ausencia completa de correlación (Figuras 7.32b y 7.32c). Estos resultados no reflejan un patrón de selección antrópico que se relacione estrictamente con aporte energético que dichas partes hacen a la dieta.

Considerando la propuesta interpretativa realizada por Lyman (1994: 264), el conjunto de la Capa 3 de CN de MA caería en la Clase 4 "lag or ravaged", sugiriendo la posibilidad de que haya estado expuesto a la acción de procesos mediados por DO y por tal motivo, elementos con menor DO no se encuentren representados en el conjunto. Este conjunto muestra la misma tendencia que el conjunto de Capa 5 por lo cual las interpretaciones son las mismas que las anteriormente discutidas.

\subsubsection{Modificaciones de las superficies óseas}

\subsection{Patrones de modificaciones naturales}

Los resultados obtenidos del análisis de modificaciones óseas en restos de guanaco permiten observar que el $96 \%$ de los especímenes se encuentran entre los estadios 0 y 2 
de Behrensmeyer (1978). La tendencia que se observa (Figura 7.33) indica una buena preservación del conjunto zooarqueológico debido a un tiempo relativamente corto de exposición. Esta información es congruente, como se mencionó anteriormente, con la tasa de sedimentación estimada para esta cámara y que sugiere una buena integridad para el conjunto. El registro de escasos restos óseos (4\%) con superficies en estadio 3 (Figura 7.33), podría deberse a diferentes causas entre las que se contemplan factores que pueden producir meteorización diferencial como es la fracturación previa de los huesos.

El análisis de la meteorización en elementos axiales y apendiculares permite observar la tendencia ya descripta para el conjunto completo (Figura 7.33). Las diferencias solo se registraron en las frecuencias de especímenes axiales y apendiculares, lo que concuerda con la representación de partes anatómicas identificadas para el conjunto (Tabla 7.7). Este patrón avala la hipótesis de que las diferencias en la meteorización podrían guardar relación con alguna de las causas que introducen variabilidad y que fueron mencionadas anteriormente.

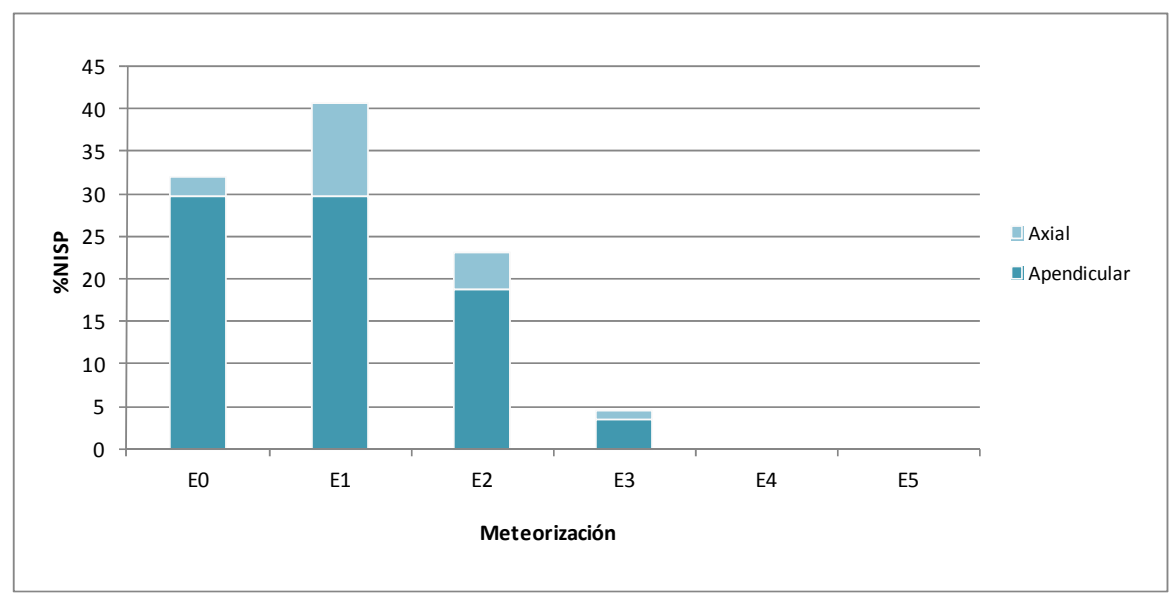

Figura 7.33. Tendencia de la meteorización en especímenes asignados a L. guanicoe en el conjunto de Capa 3 de CN de MA. Los valores son expresados en \%NISP. 


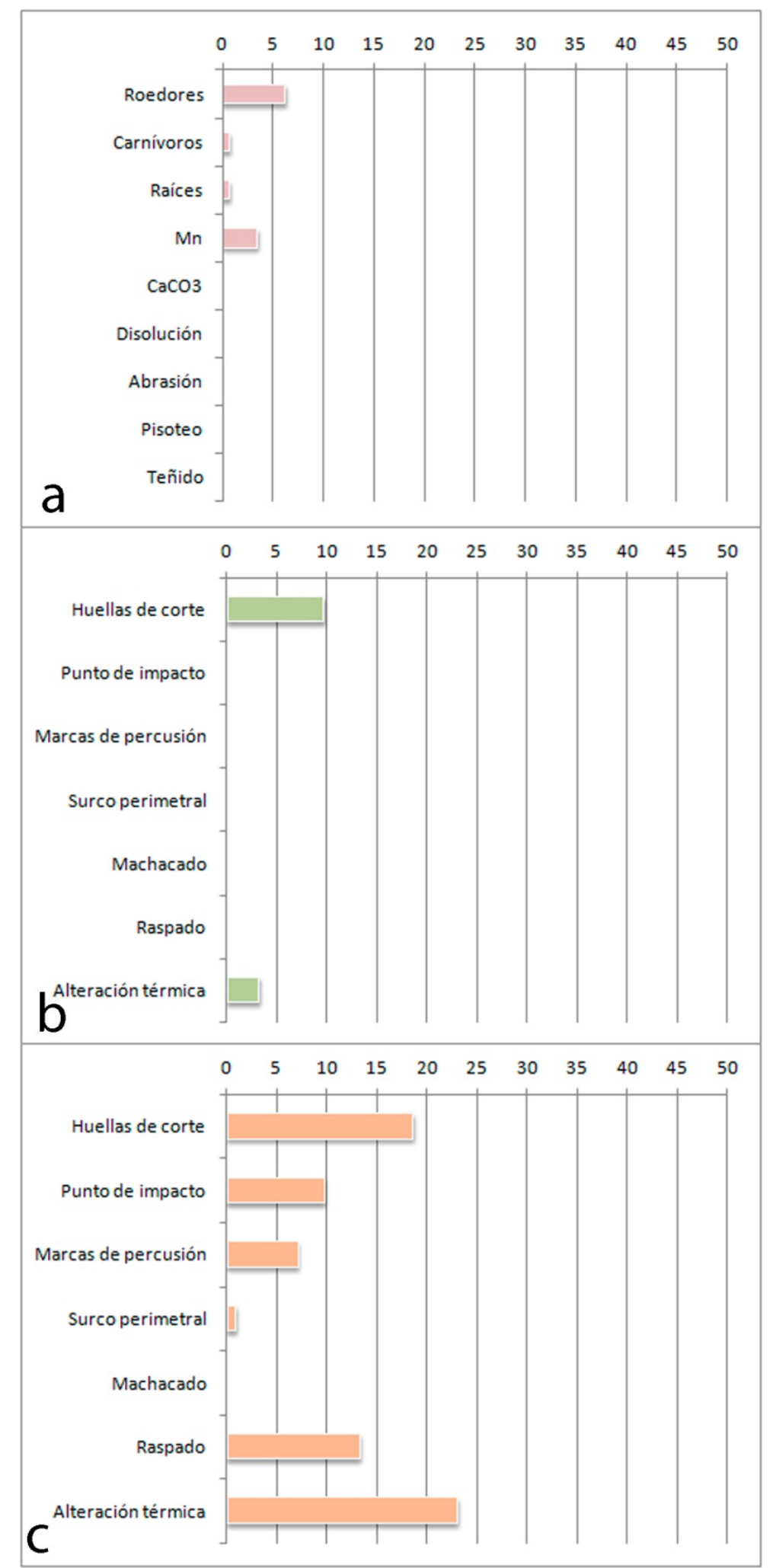

Figura 7.34. Frecuencia porcentual de especímenes óseos de guanaco con modificaciones: a) naturales; b) modificaciones antrópicas en especímenes del esqueleto axial; c) modificaciones antrópicas en el esqueleto apendicular. 
Se registraron otras modificaciones naturales sobre las superficies óseas de las arqueofaunas aunque todas en bajos porcentajes (Figura 7.34a). En un 6,25\% de los restos se reconocieron modificaciones provocadas por la acción de roedores, todas se encuentran en elementos apendiculares y muestran el patrón característico de surcos poco profundos, cortos y paralelos, asociados a los bordes de los especímenes (Figura 7.35a). En un 3,5\% de los especímenes se determinó la presencia de manchas de manganeso, las mismas se presentan dispersas o cubriendo parcialmente la superficie de los huesos (Figura 7.35b). Las modificaciones producidas por raíces y carnívoros sobre los especímenes se registran en porcentajes menores al $1 \%$.
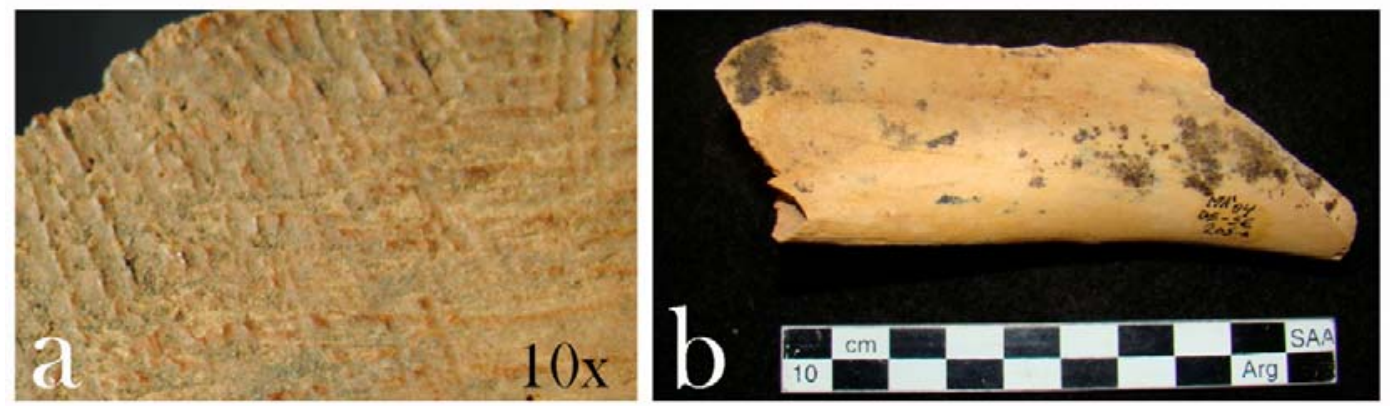

Figura 7.35. Modificaciones naturales: a) marcas de roedor sobre borde de fractura en diáfisis de tibia; b) manchas de manganeso sobre una porción de diáfisis de tibia.
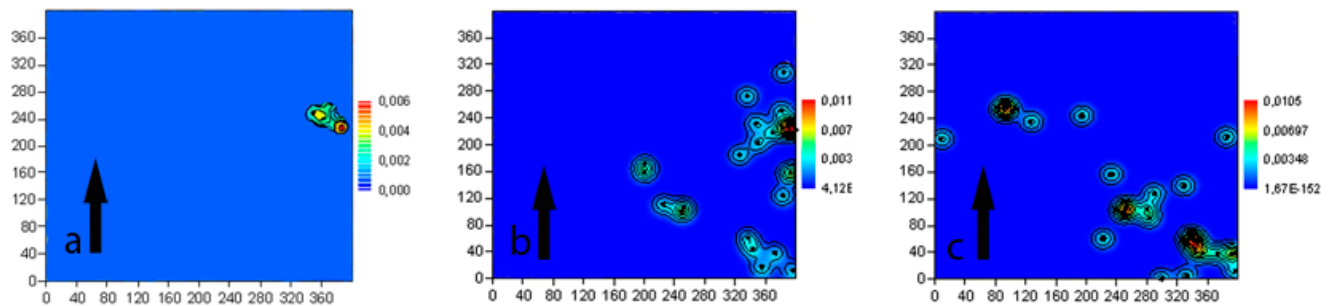

Figura 7.36. Distribución espacial de especímenes con modificaciones en las superficies en las cuadrículas excavadas de CN (C5, D5 y D6): a) especímenes con manganeso; b) especímenes con huellas de corte; c) especímenes con alteración térmica.

Todos los especímenes con depósitos de manganeso se encuentran concentrados en el sector SE de D5 (Figura 7.36a). Si bien los manganesos pueden liberarse a partir de distintos procesos (ver Capítulo 6), esta situación estaría indicando mayor humedad en dicho sector. La coincidencia tan delimitada entre este sector y el que registró la concentración ósea con partes del autopodio articuladas (Figura 7.30) sugiere una 
procedencia vinculada a la descomposición de materia orgánica (Marín Arroyo et al. 2008; Shahack-Gross et al. 1997). Es posible que hayan quedado tejidos blandos adheridos a estos elementos y que el manganeso se haya liberado durante su descomposición depositándose sobre los huesos. Sin embargo, no se descarta la posibilidad de que hayan existido condiciones micro-locales de humedad efectiva, como fue expresado para las otras capas. Esto estaría avalado, como se mencionó en la descripción del perfil estratigráfico presentada anteriormente, por la presencia de gravas abiertas en este nivel de la secuencia.

\subsection{Patrones de modificación antrópica}

Distintos patrones de modificación antrópica se reconocieron tanto en los especímenes del esqueleto axial como apendicular (Figuras 7.30a y 7.30b), en su mayoría corresponden a marcas de procesamiento humana aunque también se identificaron restos óseos quemados que podrían ser el resultado del descarte de huesos al fuego, y no de la expresión de acciones de cocción en seco de determinadas porciones de carne con hueso.

Entre las marcas de procesamiento, las que adquieren frecuencias más elevadas son las huellas de corte, las mismas fueron identificadas tanto entre los elementos axiales (Figura 7.37a) como entre los apendiculares (Figuras 7.37b y 7.37c) alcanzado en este último porcentajes de representación más elevados $(18,5 \%)$ que en los elementos axiales $(9,6 \%)$.

Otras modificaciones que se relacionan con el procesamiento secundario y reducción de las presas también fueron identificadas, como es de esperar, con mayor variabilidad y frecuencia en los elementos apendiculares (Figura 7.34b). Entre estas modificaciones, las marcas de raspado, paralelas a los bordes de fractura (Figura 7.37d) han sido reconocidas en un $13,3 \%$ de los restos apendiculares.

En cuanto a las modificaciones que exclusivamente se han registrado en elementos apendiculares (Figura 7.34c) encontramos que en un 9, 7\% de estos restos presentan puntos de impacto (Figura 7.37f), mientras que en un 7\% fue posible reconocer marcas de percusión. Solamente se observó la presencia de surco perimetral en un radio-cúbito derecho (Figura 7.37e). 

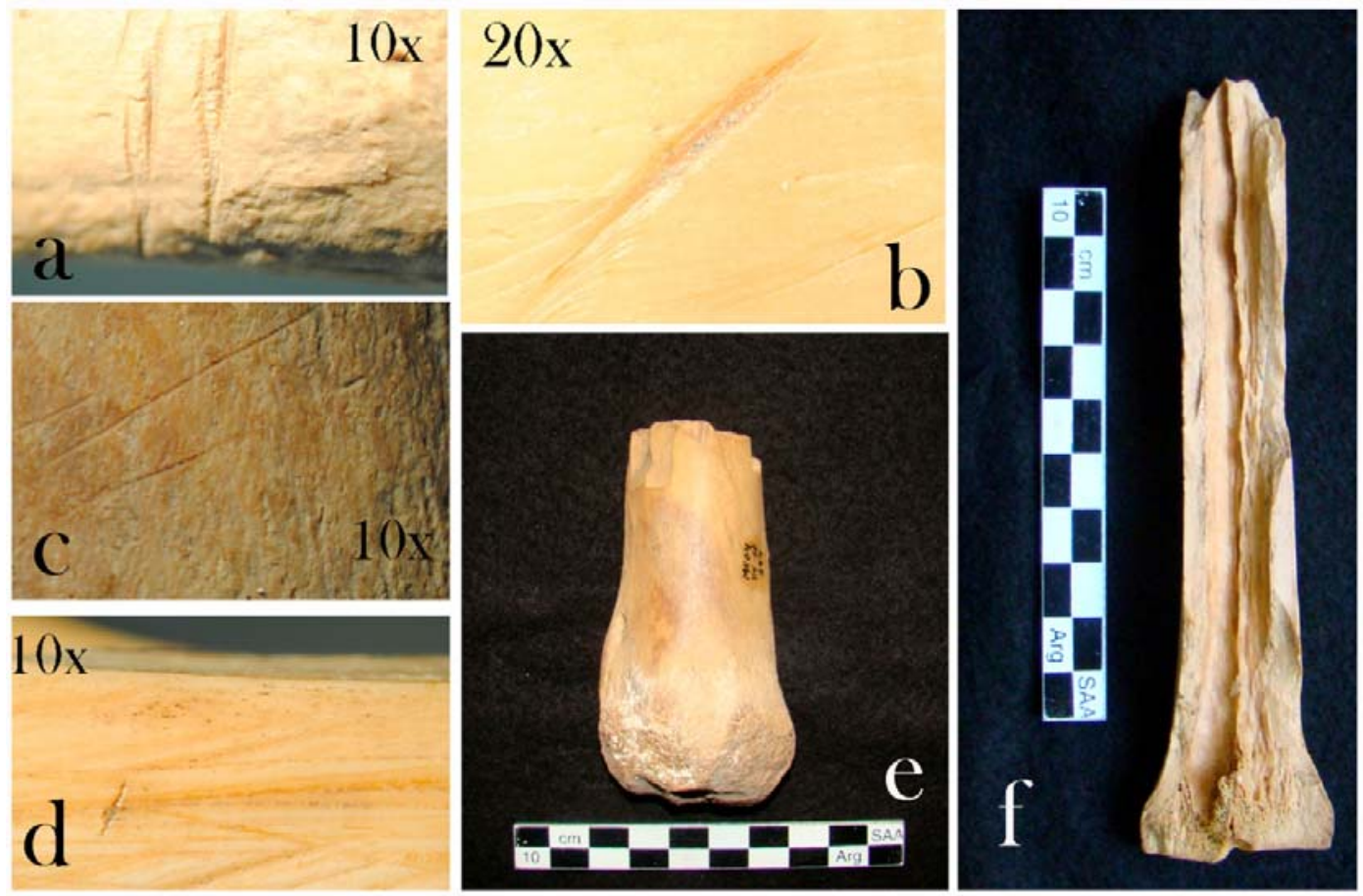

Figura 7.37. Modificaciones culturales: a) huellas de corte en costilla izquierda; b) huella de corte con estrías sobre diáfisis de fémur derecho; c) huellas de corte sobre radio-cúbito derecho; d) marcas de raspado asociadas a borde de fractura longitudinal de metatarso derecho; e) surco perimetral en radio-cúbito distal derecho con negativos de lascados; f) metatarso derecho con fractura longitudinal y negativos de impacto.

A pesar de todo, el registro de modificaciones por calor en los huesos es el más elevado registrándose en ca. 19\% de los especímenes óseos del conjunto de Capa 3 de $\mathrm{CN}$, incluyendo tanto elementos axiales como apendiculares del guanaco (Figuras 7.34b y 7.34c).

En cuanto a la distribución en planta que adquieren los especímenes con presencia de huellas de corte (Figura 7.36b), encontramos que la mayor cantidad se localiza en el sector SE de D5, coincidiendo con el área de mayor densidad de restos óseos y de guanaco (Figura 7.31). Otros se encuentran medianamente dispersos en la cuadrícula D6, no habiéndose registrado restos de guanaco con huellas de corte en C5 (Figura 7.36b). Respecto de la distribución de huesos quemados, encontramos la mayor concentración de los mismos en SE de D6 y en un sector intermedio entre el NW y SW de la misma cuadrícula (Figura 7.36c). Esta mayor concentración de especímenes óseos quemados concuerda con el sector de las áreas de combustión (Figura 7.30). Otra concentración, aunque más pequeña, se registra en la porción NE del sector SW de C5, estando estos 
materiales ausentes en la cuadrícula D5.

Un total de 146 fracturas fueron registradas en 90 especímenes de huesos largos (62,5\%), de ellas 102 se asignan a patrones antrópicos y 44 a tafonómicos (Figura 7.38).

Las fracturas helicoidales (38,3\%) son las más numerosas (Figura 7.38), en su gran mayoría se registran atributos tecnológicos asociados a ellas que nos permiten atribuirlas al agente humano. Entre las marcas asociadas encontramos puntos de impacto, marcas de raspado y percusión y huellas de corte. La ausencia de modificaciones producidas por carnívoros (Figura 7.34a) respalda que el agente humano fue el productor de las mismas.

El segundo grupo abundante es el de las fracturas longitudinales que representa el 28,7\% $(\mathrm{n}=42)$ del total (Figura 7.38). De ellas $7(16,6 \%)$ no presentan ningún atributo asociado que permita vincularlas a la intencionalidad humana y por lo tanto, son consideradas resultado de causas tafonómicas.

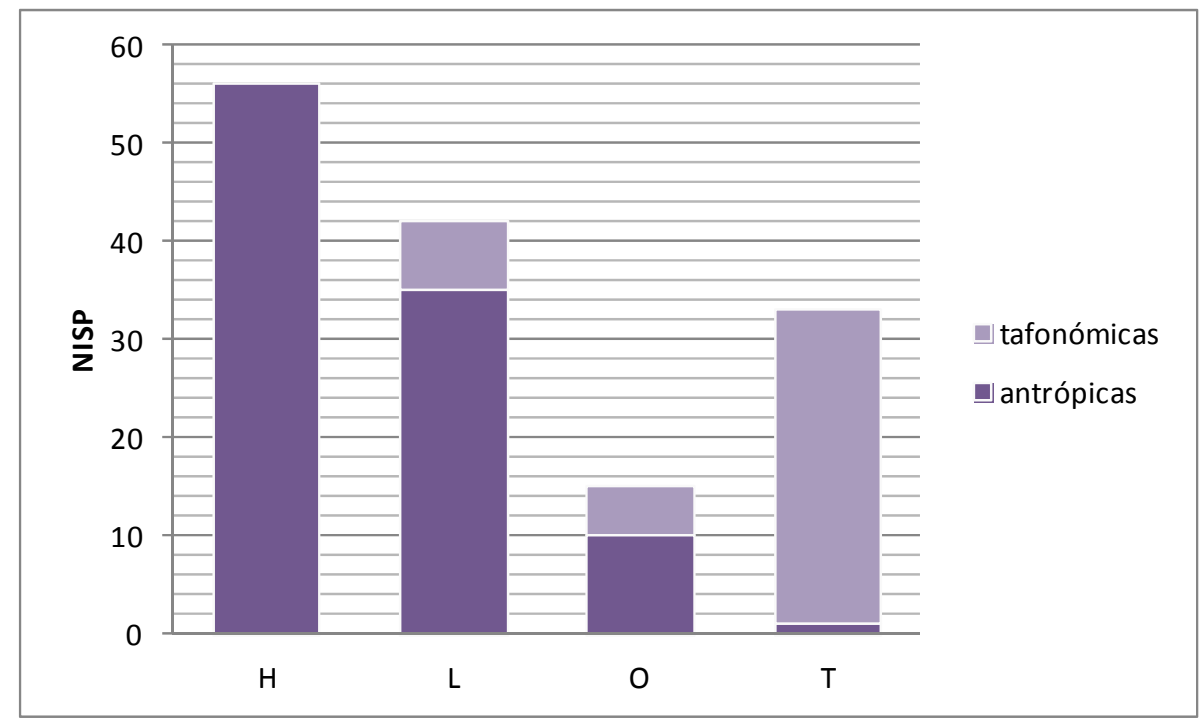

Figura 7.38. Frecuencia absoluta y tipos de fracturas identificadas: H) helicoidal; L) longitudinal; O) oblicua; T) transversal.

Entre las fracturas oblicuas $(10,3 \%)$, el $66,6 \%(n=10)$ presentaron atributos como huellas de corte, punto de impacto y/o marcas de raspado además de superficies suaves que permiten atribuirlas al agente humano (Figura 7.38). Por el contrario, las 5 restantes $(33,4 \%)$ carecen de marcas culturales de procesamiento y presentan superficies rugosas que nos conducen a proponer un origen tafonómico para ellas. Las fracturas transversales (Figura 7.38), con excepción de la registrada en un radio-cúbito derecho por medio de surco perimetral (Figura 7.37e), evidencian un estado seco del hueso en el momento en 
que se fragmentó, y por tanto son consideradas resultado de la acción de agentes naturales.

En este nivel fueron recuperados dos artefactos formatizados por uso. Uno de ellos confeccionado sobre una diáfisis de metatarso de guanaco (Figura 7.39a), el otro sobre una diáfisis de radio-cúbito (Figura 7.39b). Además, se recuperó un pequeño fragmento óseo decorado con líneas incisas paralelas entre sí (Figura 7.39c).
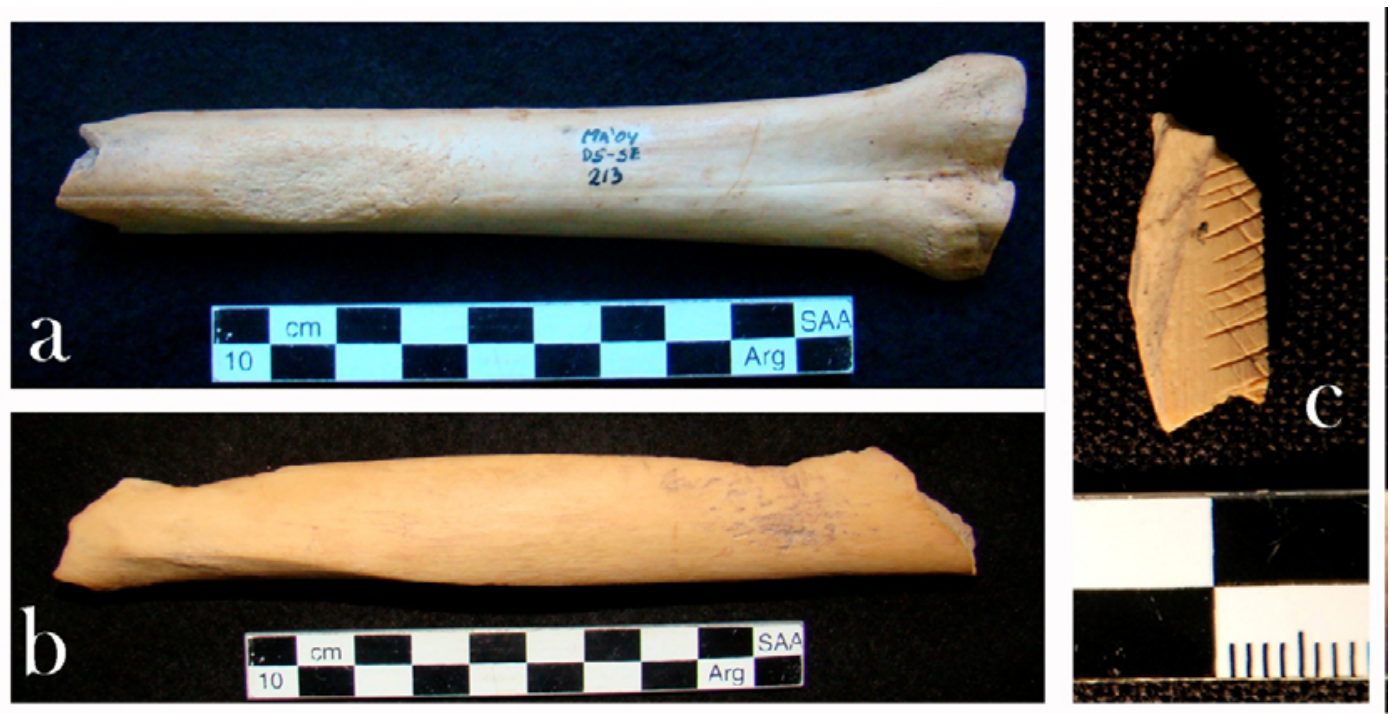

Figura 7.39. a y b) Artefactos óseos formatizados por uso, uno sobre metatarso (a), otro sobre diáfisis de radio-cúbito (b); c) fragmento óseo decorado.

\subsubsection{Capa 2 de Cámara Norte}

El conjunto correspondiente a esta capa es el que presenta menor cantidad de restos faunísticos de toda la secuencia arqueológica, está integrado por un total de 262 especímenes óseos, de los cuales sólo un 12,97\% (NISP=34) pudieron ser determinados a algún nivel o categoría taxonómica y/o anatómica. El grado de fragmentación de este conjunto es elevado, siendo el $87,02 \%$ del total $(\mathrm{NSP}=228)$ pequeños fragmentos de diáfisis de hueso largo o fragmentos de hueso plano carentes de rasgos diagnósticos y, por lo tanto, fueron asignados a la categoría indeterminados.

Los materiales tridimensionados solamente provienen de la cuadrícula D6 (Figura 7.40a). Sin embargo, el conjunto completo integrado por especímenes tridimensionados y 
generales, fue recuperado en las tres cuadrículas excavadas, aunque no en todos los sectores de ellas (Figura 7.40b). El análisis de densidad de restos óseos por $\mathrm{m}^{2}$ (Figura 7.40b) permite observar que el sector SE de la cuadrícula C5 concentra casi el 68\% del conjunto, registrándose muy bajas densidades en los restantes sectores de las cuadrículas y no habiéndose recuperado ningún resto óseo en los sectores NE y SW de C5 ni en el Este de D5. La diferencia en la distribución y densidad entre los especímenes tridimensionados y el conjunto completo posiblemente esté en relación con la elevada fragmentación del conjunto.

Durante las excavaciones de la Capa 2 fue identificada un área de combustión en el vértice SE de la cuadrícula D6 (Figura 7.41). En la parte central de dicha cuadrícula fue mapeado un hoyo que contenía sedimento suelto, posiblemente por las dimensiones del mismo, corresponda a un túnel producido por actividad fosorial de roedores (Figura 7.41). En el sedimento de su interior fueron encontrados escasos materiales que, como se indicó en el Capítulo 6, fueron separados del conjunto total para un posterior análisis.

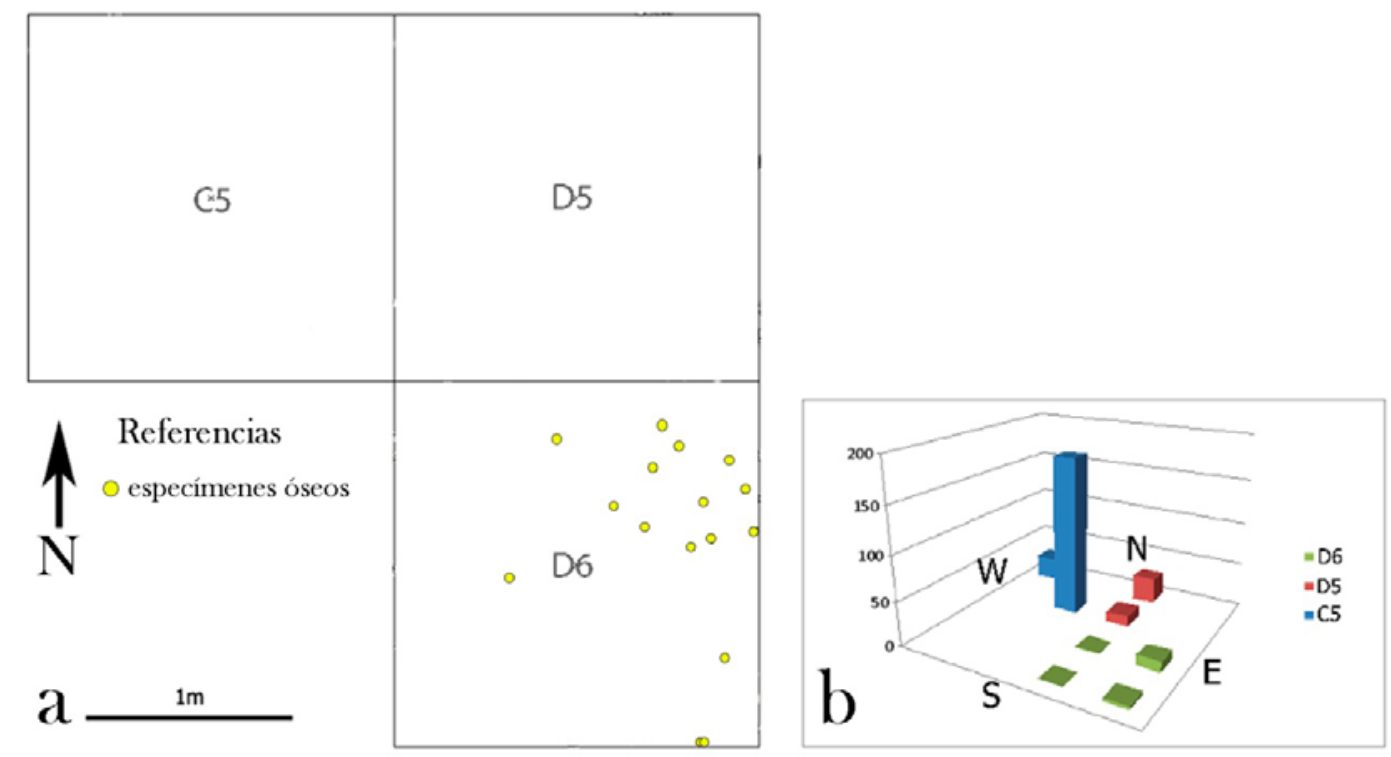

Figura 7.40. a) Distribución de los especímenes tridimensionados en planta, b) frecuencia de restos óseos por cuadrícula (C5, D5 y D6) y sector de excavación (NE, NW, SE y $\mathrm{SW}$. Los Valores se expresan en \%NISP por $\mathrm{m}^{2}$. 


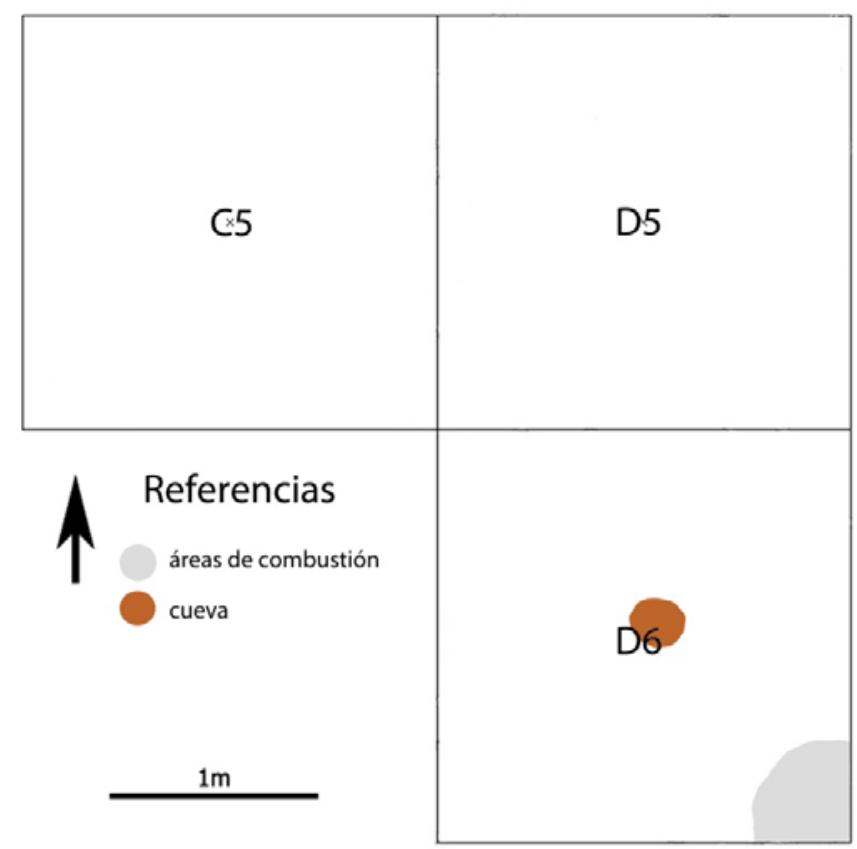

Figura 7.41. Esquema de rasgos e indicadores de procesos y agentes tafonómicos identificados durante las excavaciones de la Capa 2 de $\mathrm{CN}$ de MA.

\subsubsection{Abundancia taxonómica y anatómica}

Los resultados obtenidos muestran que todas las especies identificas corresponden a fauna que en la actualidad habita el área. La especie más representada en el conjunto es Lama guanicoe (Tabla 7.8). Los restos asignados a dicha especie representan el 47,06\% del NISP\% y es seguida en importancia por los mamíferos de tamaño grande $(23,53 \%)$ y los mamíferos indeterminados (17,65\%). Los rheidos ocupan el cuarto lugar en importancia representando el 11,7\% del NISP\%. Aunque es altamente probable que los huesos asignados a Mamífero grande correspondan a guanaco, en este sentido podría considerarse que los ñandúes habrían sido las aves más representadas después de los guanacos, siendo esta una tendencia similar a la mayoría de los sitios arqueológicos de la meseta patagónica (Miotti 1998; Miotti y Salemme 1999). 


\begin{tabular}{|l|c|c|c|}
\hline & NISP & \%NISP & M NI \\
\hline Rheidae* $^{*}$ & 4 & $11,76 \%$ & - \\
\hline Mamífe ro Indet. & 6 & $17,65 \%$ & - \\
Mamífe ro Grande & 8 & $23,53 \%$ & - \\
\cline { 1 - 2 } Lama guanicoe & 16 & $47,06 \%$ & 2 \\
\hline
\end{tabular}

* 4 fragmentos de cáscara de huevo

Tabla 7.8. Abundancia taxonómica en la Capa 2 de CN de MA.

La representación de partes anatómicas del guanaco está dominada por elementos del esqueleto apendicular. Un único elemento del esqueleto axial aparece en este contexto y corresponde a una vértebra torácica (Tabla 7.9).

El MNI para guanaco fue estimado en 2. Siguiendo los criterios de edad relacionados a la fusión de las epífisis, al menos uno de los guanacos correspondería a un chulengo.

El análisis de la fragmentación a partir de la relación entre MNE/NISP de guanaco evidencia que la misma es moderada a baja en el conjunto ya que se obtuvo un valor de 0,62. Este índice de fragmentación está sobreestimado en cuanto al grado de completitud, debido a que la mayoría de los elementos completos se corresponden con la especie Lama guanicoe, pero los demás especímenes asignados a categorías genéricas y mayores (ver Tabla 7.8) revisten una fragmentación alta.

Del análisis de la representación de unidades anatómicas de guanaco se desprende que los elementos más representados $(\mathrm{MAU} \%=100 \%)$, a excepción del radio-cúbito y los autopodios indiferenciados, todos corresponden a la pata trasera -i.e., diáfisis de fémur y de tibia-. Es interesante destacar la ausencia de porciones tanto distales como proximales de los huesos largos (Tabla 7.8).

De este análisis se desprende que la principal unidad de trozamiento corresponde al cuarto trasero del animal; sin embargo, escasos elementos del zeugopodio anterior como del tronco han sido determinados (Tabla 7.9).

El análisis de los procesos y agentes tafonómicos desarrollado a continuación permitirá evaluar si estas frecuencias responden a una selección humana de partes o si son resultado de la acción de procesos destructivos. 


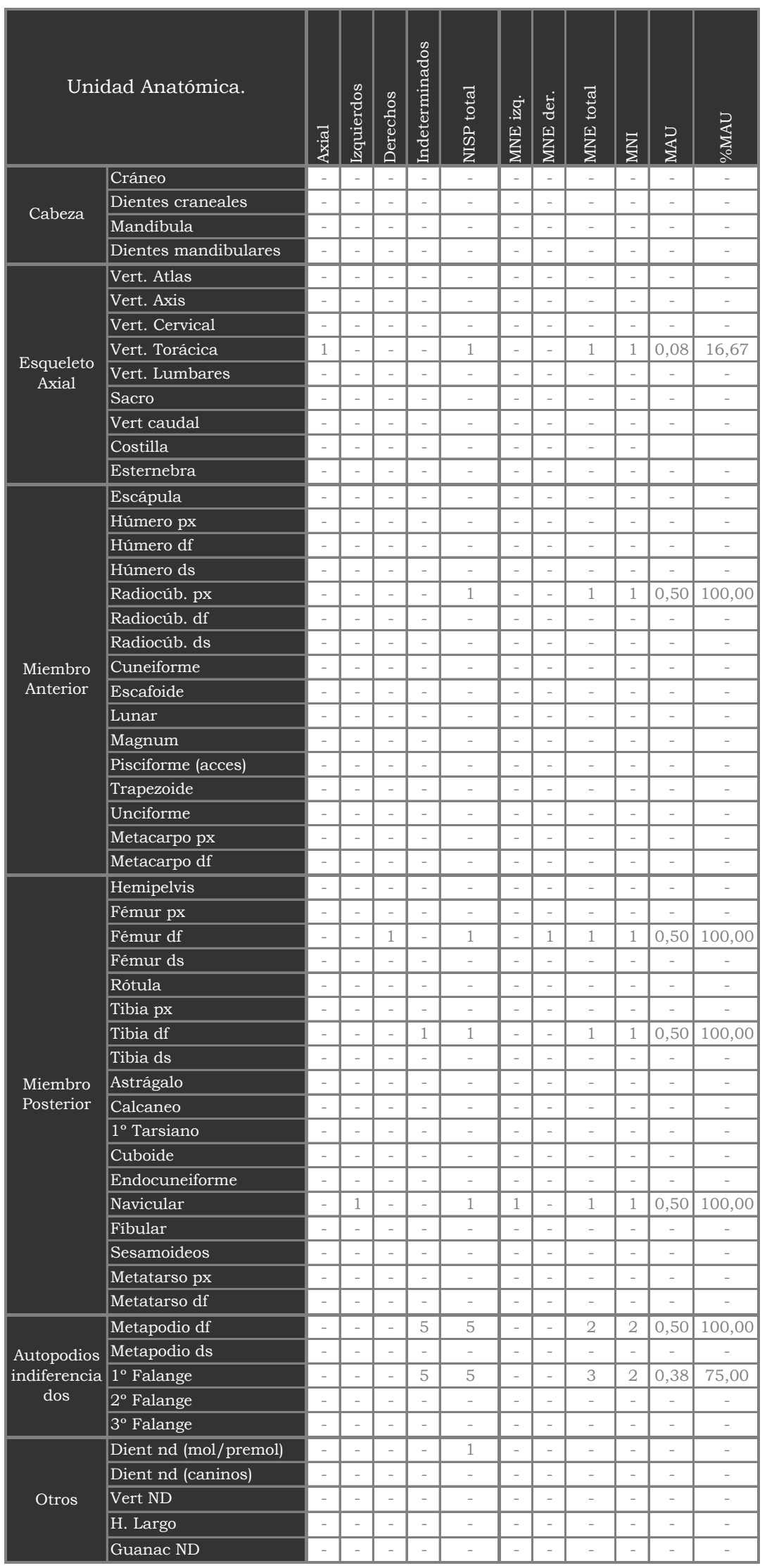

Tabla 7.9. Representación de partes anatómicas de guanaco en Capa 2 de CN de MA. 
La distribución de los restos óseos de guanaco (Figura 7.42) muestra un patrón completamente distinto al observado para el conjunto completo. Los especímenes de guanaco se concentran fundamentalmente en los sectores NE de D6 (6 especímenes por $\left.\mathrm{m}^{2}\right)$ y SW de D5 (5 especimenes por $\left.\mathrm{m}^{2}\right)$ y SE de C5 (3 especimenes por $\left.\mathrm{m}^{2}\right)$.

Los especímenes de Mamífero de tamaño grande corresponden en su mayoría (ca. $70 \%$ ) a fragmentos de hueso largo que no han preservado, o por el grado de fragmentación que tienen o por la acción de procesos tafonómicos, rasgos o características diagnósticas para poder ser asignados a una categoría taxonómica más específica. Sin embargo, dichos restos tendrían amplias posibilidades de corresponder a L. guanicoe como se expresó más arriba, aunque la evaluación de si las partes anatómicas registradas en esta clase podrían estar complementando las ausentes entre los guanacos no permitió observar diferencias con lo registrado para los guanacos.

Los especímenes determinados como rheidos corresponden a fragmentos de cáscara de huevo $(\mathrm{NISP}=4)$ procedentes del sector NW de la cuadrícula D5.

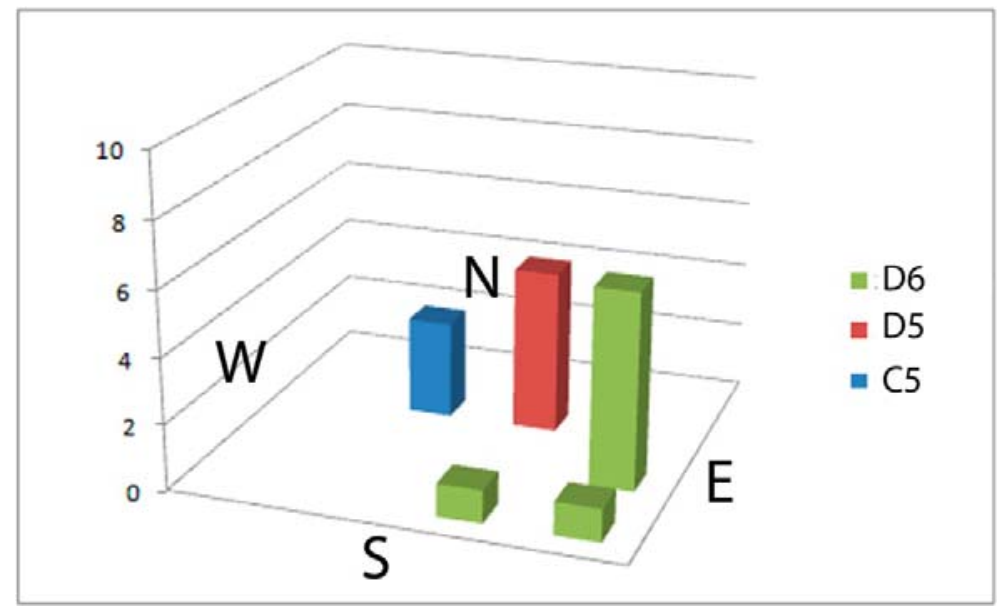

Figura 7.42. Distribución de restos óseos de guanaco por sector de cuadrícula

7.2.4.1.1. Análisis de la estrategia de transporte de partes anatómicas de guanaco

Se realizaron distintas correlaciones estadísticas que nos permitieron evaluar las posibles causas de la representación de partes anatómicas del guanaco en la Capa 2 de CN de MA (Figura 7.43). 


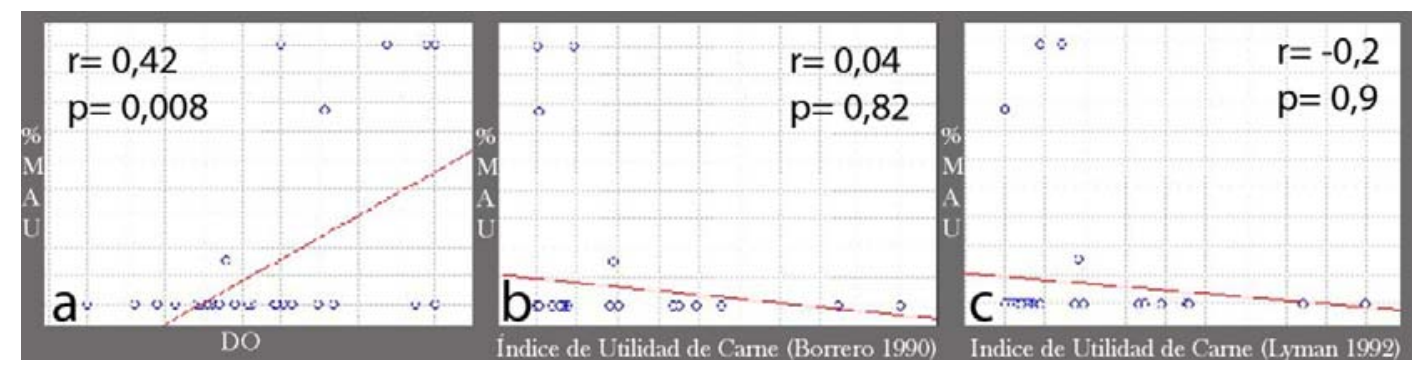

Figura 7.43. Correlaciones estadísticas de Spearman: a) MAU\%-DO; b) MAU\%-Índice de Utilidad (sensu Borrero 1990); c) MAU\%-Índice de Utilidad (sensu Lyman 1992).

Los resultados obtenidos permiten observar que la frecuencia de partes anatómicas alcanza una baja correlación positiva con la DO $(\mathrm{r}=0,42 ; \mathrm{p}<0,05)$ lo que indica que los elementos más representados son los que presentan DO más alta (Figura 7.43a). Por su parte, al correlacionar las frecuencias de MAU\% con los dos índices de utilidad (Borrero 1990; Lyman 1992) observamos una ausencia completa de correlación (Figuras 7.43b y 7.43c). Estos resultados reflejarían ausencia de una clara estrategia de selección humana de las partes en relación a su alto o bajo rendimiento económico.

Considerando la propuesta interpretativa de estos resultados realizada por Lyman (1994: 264), el conjunto de la Capa 2 de CN caería en la Clase 4 "lag or ravaged". Esta clase sugiere la posibilidad de que el conjunto haya estado expuesto a la acción de procesos mediados por DO. En este caso, a diferencia de los otros subconjuntos faunísticos del sitio, este proceso es más marcado, pero no se descarta la posibilidad que dado el pequeño tamaño y fragmentación de la muestra, exista aquí un sesgo estadístico.

\subsubsection{Modificaciones de las superficies óseas}

\subsection{Patrones de modificaciones naturales}

Los resultados del análisis de las superficies óseas de restos de guanaco muestran un perfil de meteorización que concentra a todo el conjunto en estadios de meteorización baja (Figura 7.44). Esta tendencia hacia los niveles más bajos de meteorización indica que los materiales estuvieron poco tiempo expuestos a las condiciones meteóricas. Esa información sumada a los valores estimados para la tasa de sedimentación de $\mathrm{CN}$, apoyan un enterramiento rápido del conjunto y sugieren una alta integridad del mismo. 
Entre los patrones de modificación producidos por procesos o agentes naturales solamente se reconocieron marcas de roedores (Figura 7.45a) en dos especímenes del esqueleto apendicular (Figura 7.46a). Cada uno de ellos procede de un sector de la cuadrícula D6 (NE y SW). Su localización es próxima al único sector, dentro de este nivel, en el que se registró un agujero con sedimento removido y que posiblemente indique la presencia de una cueva (Figura 7.41).

No se registran otras modificaciones naturales sobre los especímenes óseos de guanaco. La ausencia de depósitos de manganeso y/o carbonato sobre los huesos se puede relacionar a que los rasgos del perfil, como las gravas abiertas, que sugieren presencia de agua, se registran en niveles inferiores de la secuencia. Esto podría estar indicando que tales condiciones de humedad fueron anteriores a que el conjunto de la Capa 2 se deposite.

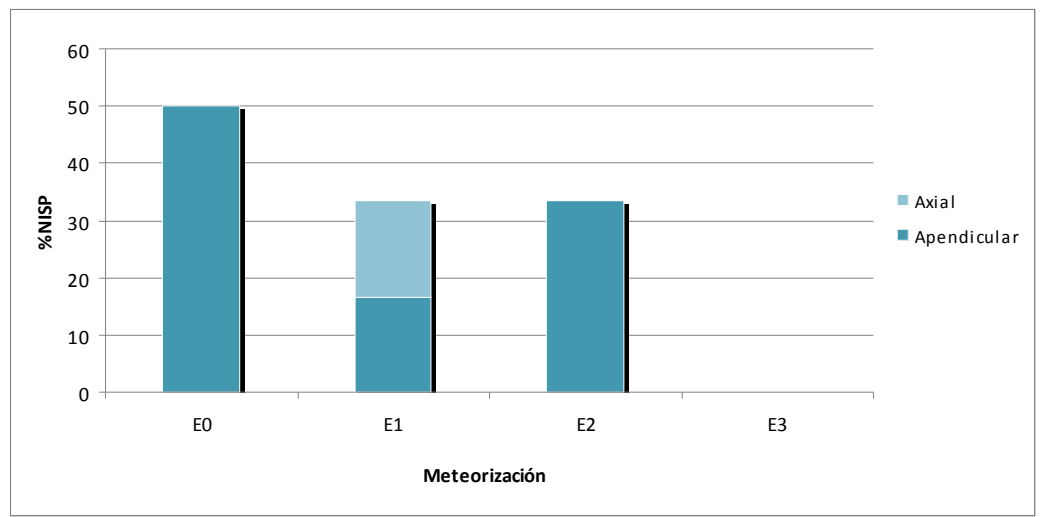

Figura 7.44. Tendencia de la meteorización en especímenes asignados a L. guanicoe en el conjunto de la Capa 2 de CN de MA. Los valores son expresados en NISP\%.
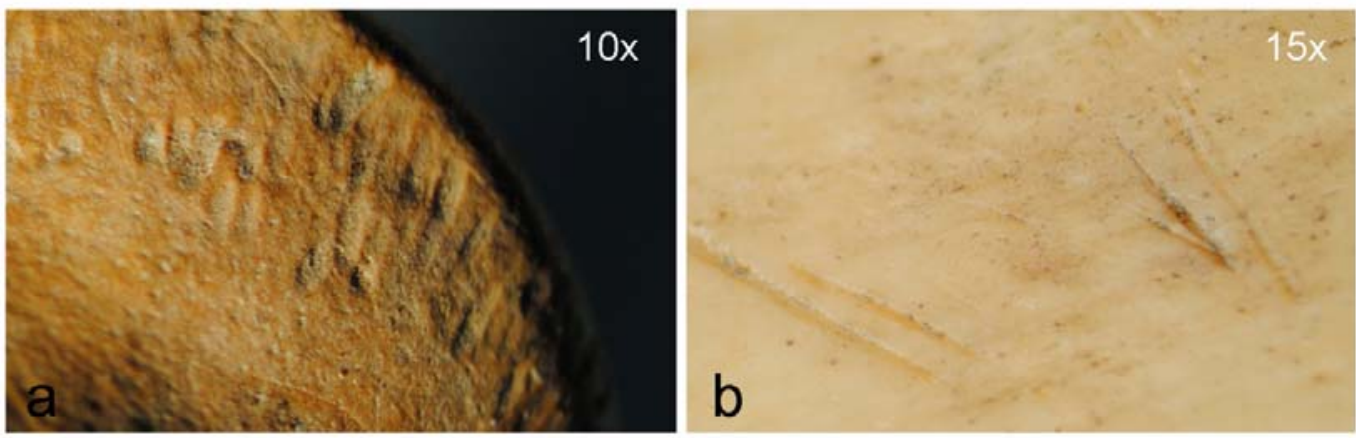

Figura 7.45. Modificaciones naturales y culturales en Capa 2 de CN de MA. a) marcas de roedor en epífisis distal de falange proximal; b) huellas de corte en falange proximal.

La ausencia de marcas de raíces sobre el conjunto estaría indicando tanto la 
ausencia de cobertura vegetal en el momento en que se depositó el conjunto, como en momentos posteriores a su enterramiento.

No se descarta, como se dijo anteriormente, que por tratarse de un conjunto pequeño exista algún sesgo en las interpretaciones acerca del registro de las modificaciones y en consecuencia de la historia tafonómica del conjunto. Estas hipótesis deberán ser evaluadas a futuro a partir del análisis de modificaciones óseas de todos los especímenes del conjunto.

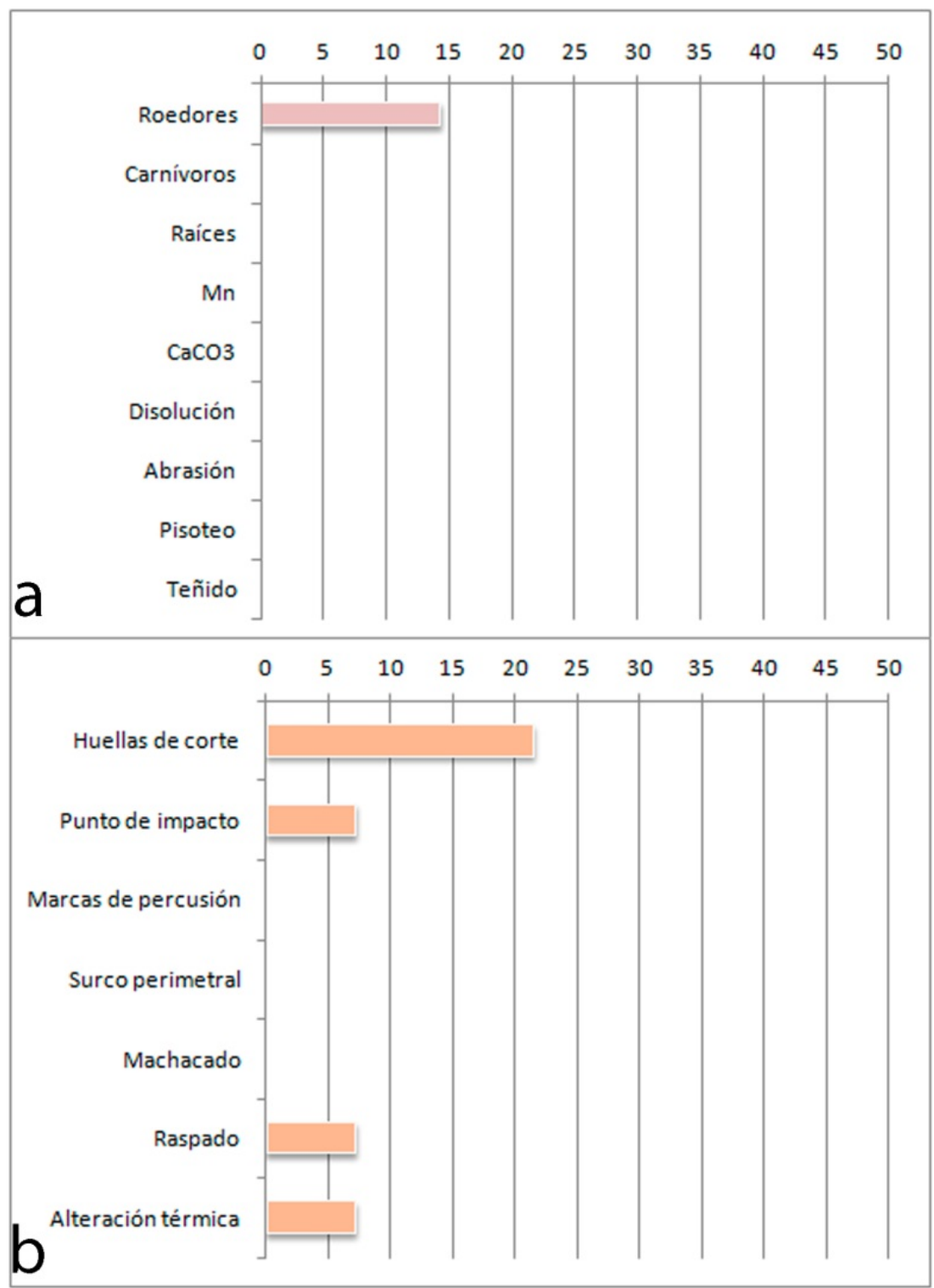

Figura 7.46. Frecuencia porcentual de especímenes óseos de guanaco con modificaciones: a) naturales; b) modificaciones antrópicas en el esqueleto apendicular. 


\subsection{Patrones de modificación antrópica}

Se reconocieron modificaciones antrópicas únicamente en elementos del esqueleto apendicular (Figura 7.46b). Entre las modificaciones registradas la mayor frecuencia la presentan las huellas de corte (Figura 7.41b) que se reconocieron en 3 especímenes óseos. Otras modificaciones vinculadas al procesamiento de las presas como puntos de impacto y raspado se reconocieron solamente en un espécimen óseo (Figura 7.46b).

Solamente un resto óseos mostró signos de alteración térmica (Figura 7.46b), el mismo procede del sector $\mathrm{SW}$ de $\mathrm{D} 6$, coincidiendo con la única área de combustión registrada durante los trabajos de campo en este nivel estratigráfico.

El análisis de los tipos de fracturas registrados en los 13 especímenes de huesos largos $(81,3 \%)$, nos permitió reconocer un total de 13 fracturas. Entre los patrones identificados (Figura 7.47) se determinó la presencia tanto de causas antrópicas $(\mathrm{n}=11)$ como tafonómicas $(\mathrm{n}=2)$.

Las fracturas helicoidales $(53,8 \%)$ son las más numerosas, sin embargo, las longitudinales producidas con el hueso en estado fresco también adquieren importante frecuencia (30,76\%) (Figura 7.46). Los especímenes con estos dos tipos de fractura presentaron superficies suaves que evidencian el estado fresco del hueso al momento de fracturarse y registran atributos tecnológicos asociados. Esta situación sumada a la ausencia de marcas de carnívoros en los especímenes óseos nos permite sostener un origen cultural para ellas.

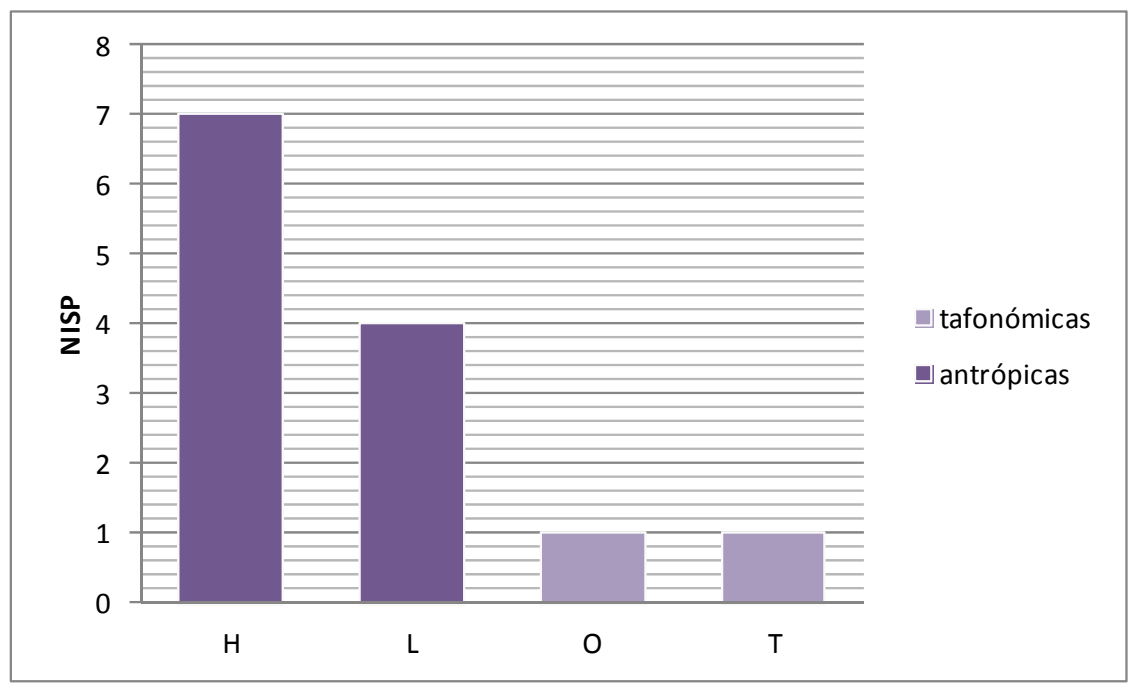

Figura 7.47. Frecuencia absoluta y tipos de fracturas identificadas: H) helicoidal; L) longitudinal; O) oblicua; T) transversal. 
Si bien las fracturas oblicuas y transversales se registraron en bajas frecuencias (Figura 7.47), es interesante aclarar que por sus características parecen haberse producido cuando el hueso ya se encontraba seco y por lo tanto son consideradas resultado de procesos tafonómicos.

Si bien el conjunto de la Capa 2 de $\mathrm{CN}$ de MA es pequeño, los patrones de modificaciones de huellas de corte, los puntos de impacto y fracturas intencionales, sugieren actividades vinculadas al procesamiento secundario de las presas y descarte de unidades de bajo rendimiento. En relación a la distribución espacial de los materiales se propone al sector de la cuadrícula D6 como la principal área de actividad dentro de este nivel de ocupación del Holoceno tardío. Esas actividades se habrían desarrollado en torno al fogón registrado en el sector sur de esa misma cuadrícula.

\subsection{CÁMARA SUR DE CUEVA MARIPE}

Los restos faunísticos de esta cámara (en adelante CS) proceden de dos cuadrículas excavadas hasta el nivel de la roca de base -i.e., A12 y B12- entre las que totalizan una superficie de $8 \mathrm{~m}^{2}$. En ellas se recuperaron, a partir de los métodos de tridimensión y zaranda, un total de 4.313 especímenes entre los que están incluidas pequeñas astillas óseas y fragmentos de cáscara de huevo. Estos materiales proceden de 7 niveles artificiales de excavación que fueron agrupados, según los fechados radiocarbónicos obtenidos, en 3 unidades analíticas o capas. Esta decisión se toma en función de lo expresado en la sección 7.1 de este capítulo, acerca de la característica comprimida de la secuencia estratigráfica de CS, que además, según la tasa sedimentaria estimada, presenta una resolución arqueológica menor a la de $\mathrm{CN}$.

Siguiendo estos criterios, el conjunto total de CS proviene de 3 niveles o capas. La Capa 3 es la más profunda de la secuencia e integra los materiales procedentes de los niveles artificiales que van de 180-200 $\mathrm{cm}$. En ella se recuperaron un total de 221 especímenes. Los dos fechados radiocarbónicos (ca. 9500 y 8300 años AP) obtenidos en este nivel indican que el conjunto corresponde a la primera etapa propuesta para el poblamiento del área y correspondiente a la transición Pleistoceno- Holoceno.

La Capa 2, con dos fechados radiocarbónicos (ca. 7700 y 4100 años AP), 
corresponde según los criterios cronológicos definidos en el Capítulo 2 al Holoceno medio. Aquí fueron agrupados los materiales que proceden de los niveles artificiales que van desde 160 hasta $180 \mathrm{~cm}$. En este nivel se recuperaron un total de 1256 especímenes óseos.

La Capa 1 y la más superior de la secuencia, fue asignada al Holoceno tardío ya que el único fechado radiocarbónico realizado arrojó una antigüedad de ca. 1100 años AP en la base. Aquí se agruparon los materiales provenientes de los niveles artificiales que van desde 130 hasta $160 \mathrm{~cm}$. En este nivel también fueron recuperados materiales relacionados a la ocupación histórica de la familia Maripe que habitó la cueva hasta mediados del s. XX. Aquí fue recuperado el conjunto más grande de restos de CS, integrado por un total de 2836 especímenes óseos.

\subsubsection{Capa 3 de Cámara Sur}

Del total de 221 especímenes óseos que integran este conjunto, un 51,6\% (NISP= 114) pudieron ser determinados a algún nivel o categoría taxonómica y/o anatómica, mientras que 107 restos $(48,4 \%)$ quedaron en la categoría indeterminados. Los especímenes indeterminados corresponden a pequeños fragmentos de diáfisis de hueso largo o fragmentos de hueso plano que no preservaron rasgos o características diagnósticos que permitan su asignación a niveles más específicos.

El análisis de la distribución espacial de los especímenes tridimensionados (Figura 7.48a) muestra que la mayor frecuencia se registra en la cuadrícula A12, siendo escasos los especímenes tridimensionados en B12.

$\mathrm{El}$ análisis de la densidad de restos óseos, que incluye los trimensionados y los recuperados a través de zaranda, permite observar que la cuadrícula A12 concentra el 98,2\% del total del conjunto (Figura 7.48b). La mayor densidad de especímenes por $\mathrm{m}^{2} \mathrm{o}$ sector de cuadrícula, se registra en el NW de A12 (140 especímenes por m²), siendo el NE de esa misma cuadrícula también un sector con alta concentración de restos óseos (76 especímenes por $\mathrm{m}^{2}$ ). En los sectores $\mathrm{SW}$ y SE de A12 se observan densidades moderadas (13 y 32 especímenes óseos por $\mathrm{m}^{2}$, respectivamente,). Al contrario de lo que ocurre con A12, el registro en B12 es escaso (Figura 7.48b), solo se registraron 4 especímenes óseos: 3 de ellos en el sector SW y 1 en el NE. Estos resultados muestran 
que la tendencia de distribución de restos entre el conjunto completo y los especímenes tridimensionados es similar.

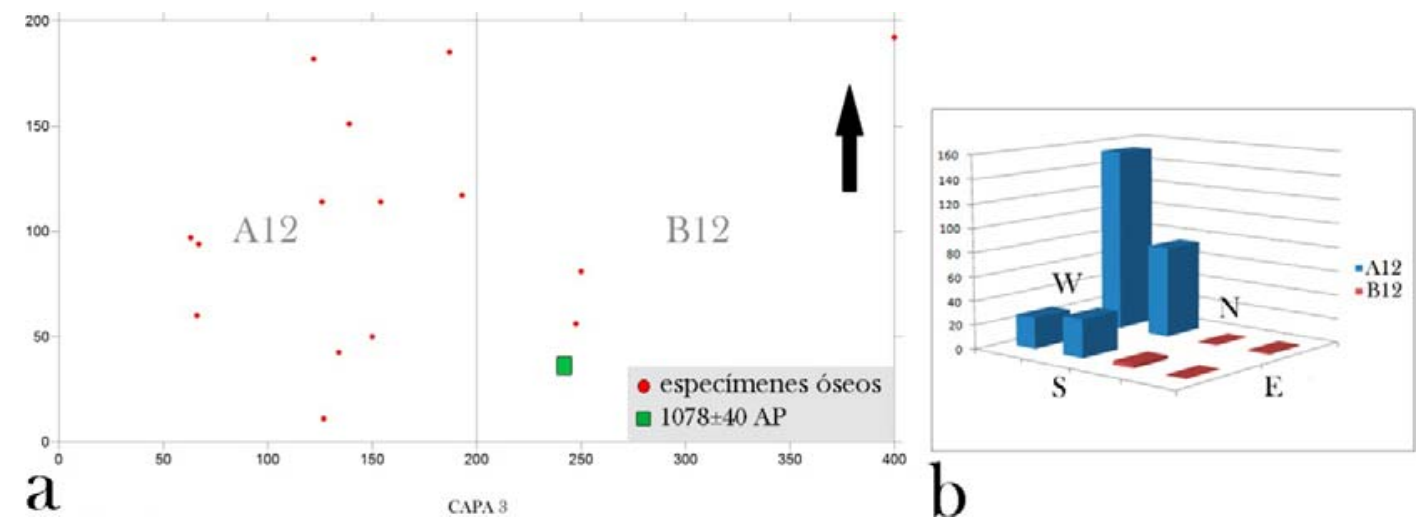

Figura 7.48. a) Distribución en planta de los especímenes tridimensionados en Capa 3 de CS; b) densidad de restos óseos por cuadrícula (A12 y B12) y sector de excavación (NE, NW, SE y SW). Frecuencia expresada en valores de NISP por $\mathrm{m}^{2}$.

Esta distribución con alta densidad de restos en la cuadrícula A12 puede estar vinculada con el buzamiento que registra la roca de base sobre la que apoya este nivel y cuya altura es superior en la cuadrícula B12. En B12 la roca aflora con mayor altura sobre el perfil este y cae con pendiente hacia el oeste y noroeste (Figura 7.49a).

Durante las excavaciones se identificaron dos áreas de fogón, una en el sector SW de la cuadrícula B12 (Figura 7.49a), la otra en el sector SE de A12. En la base de este nivel y sobre la roca de caja también se registró la presencia de raíces en el sector sur de la cuadrícula A12 (Figura 7.49b). En el sector NW de la cuadrícula A12 se registró un sector con sedimentos perturbados que posiblemente correspondían a una galería de roedores. Este sector perturbado tenía entre 8 y $10 \mathrm{~cm}$ de ancho y alrededor de $1,10 \mathrm{~m}$ de largo con dirección NW-SE. Se originaba en el vértice NW de la cuadrícula A12 y 10 cm antes de llagar a su extremo SE presentaba otra galería transversal con la que formaba una “T”. Un sector perturbado más pequeños se registró en el NE de A12. Los escasos materiales arqueológicos que se encontraban en esos sectores perturbados fueron separados del conjunto por considerar dudosa su procedencia. No se descarta que la mayor frecuencia de especímenes de tamaño pequeño en el NE y NW de A12 pueda guardar relación con tal perturbación. 

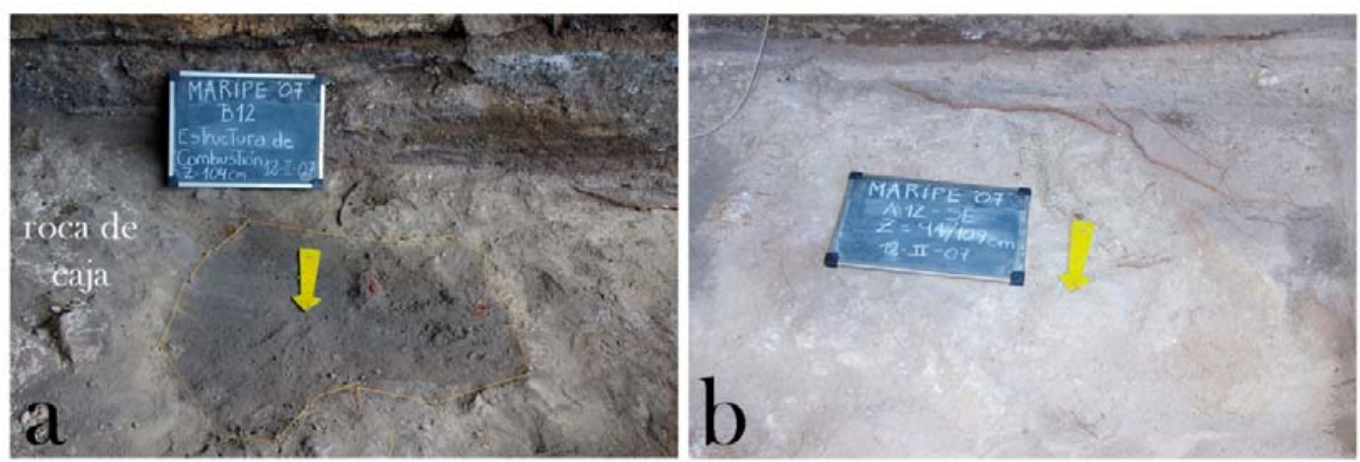

Figura 7.49. Rasgos identificados durante las excavaciones de la Capa 3 de CS: a) sur de la cuadrícula B12 mostrando el fogón registrado en el sector SW y la roca de caja que aflora hacia el este; b)sector sur de la cuadrícula A12 que muestra la presencia de bioturbación producida por raíces.

\subsubsection{Abundancia taxonómica y anatómica}

Los resultados obtenidos indican que el guanaco es la especie más representada en el conjunto con un 21\% del NISP\% (Tabla 7.10). Se observa una gran representación de Mamíferos de tamaño grande (72\% del NISP\%), mientras que los especímenes correspondientes a Mamíferos indeterminados registran frecuencias bajas $(4,3 \%$ del NISP\%). Estos especímenes no pudieron ser asignados a categorías taxonómicas más específicas debido a la ausencia de rasgos o características diagnósticos que permitan una mejor determinación. Esta dificultad por no poder determinar a nivel específico un porcentaje tan elevado del conjunto podría estar en relación al grado de fragmentación de los elementos y no se descarta un deterioro por procesos post-depositacionales.

La presencia de rheidos es escasa, los tres restos asignados a estas aves están representados por una diáfisis de tarso-metatarso izquierda y dos fragmentos de cáscara de huevo.

El análisis de la representación de partes anatómicas del guanaco muestra que si bien están representados tanto los elementos del esqueleto apendicular como del axial, el primero de estos es el que alcanza frecuencias más elevadas (Tabla 7.11).

Se evaluó la completitud anatómica del guanaco a partir de la relación entre MNE/NISP, los resultados indican una fragmentación moderada del conjunto dando un valor de 0,62. Esta fragmentación sería una de las causas principales de la baja proporción 
de muestra identificada específicamente (Tabla 7.10).

\begin{tabular}{|l|c|c|c|}
\hline & NISP & \%NISP & M NI \\
\hline Rheidae* & 3 & $2,63 \%$ & 1 \\
\hline Mamifero Indet. & 5 & $4,39 \%$ & - \\
\hline Mamífero Grande & 82 & $71,93 \%$ & - \\
\hline Lama guanicoe & 24 & $21,05 \%$ & 1 \\
\hline
\end{tabular} $\begin{aligned} & \text { * } 2 \text { especímenes corresponden a fragmentos } \\
& \text { de cáscara de huevo }\end{aligned}$

Tabla 7.10. Abundancia taxonómica en la Capa 3 de CS de MA.

El análisis de las unidades anatómicas del guanaco muestra que los elementos más representados $(\mathrm{MAU} \%=100 \%)$ son el hueso hioides, el sacro y la diáfisis de la tibia (Tabla 7.11). Dentro del esqueleto axial, el único elemento adicional al hioides y el sacro, es la presencia de cráneo $(\mathrm{MAU} \%=50 \%)$, determinada a partir de una porción izquierda de maxilar. No se identifican en el conjunto otras partes correspondientes al esqueleto axial de los guanacos. De esta manera, todos los elementos vertebrales, las costillas y las esternebras se encuentran ausentes (Tabla 7.11). Esta representación de partes que se observa en este sector de la cueva podría estar complementando las frecuencias registradas en $\mathrm{CN}$ para este mismo lapso temporal. Esta información se discute en la siguiente sección de este capítulo donde se integran los resultados obtenidos en MA para los distintos momentos de ocupación.

Con respecto al esqueleto apendicular, las frecuencias más elevadas se expresan para los elementos del miembro posterior (Tabla 7.11). La pata trasera es la que se encuentra más completa ya que están presentes los elementos del estilopodio, zeugopodio y autopodio. Por su parte, la pata delantera solo se registra a partir de elementos del estilopodio y zeugopodio. Con respecto a los elementos del autopodio, además del astrágalo identificado, entre los autopodios indiferenciados, se registra la presencia de 2 metapodios, 2 falanges proximales y 1 falange media (Tabla 7.11).

La presencia de ambas cinturas fue determinada a partir del registro de un fragmento escapular derecho y la pequeña escotadura ciática de la hemipelvis derecha (Tabla 7.11). 


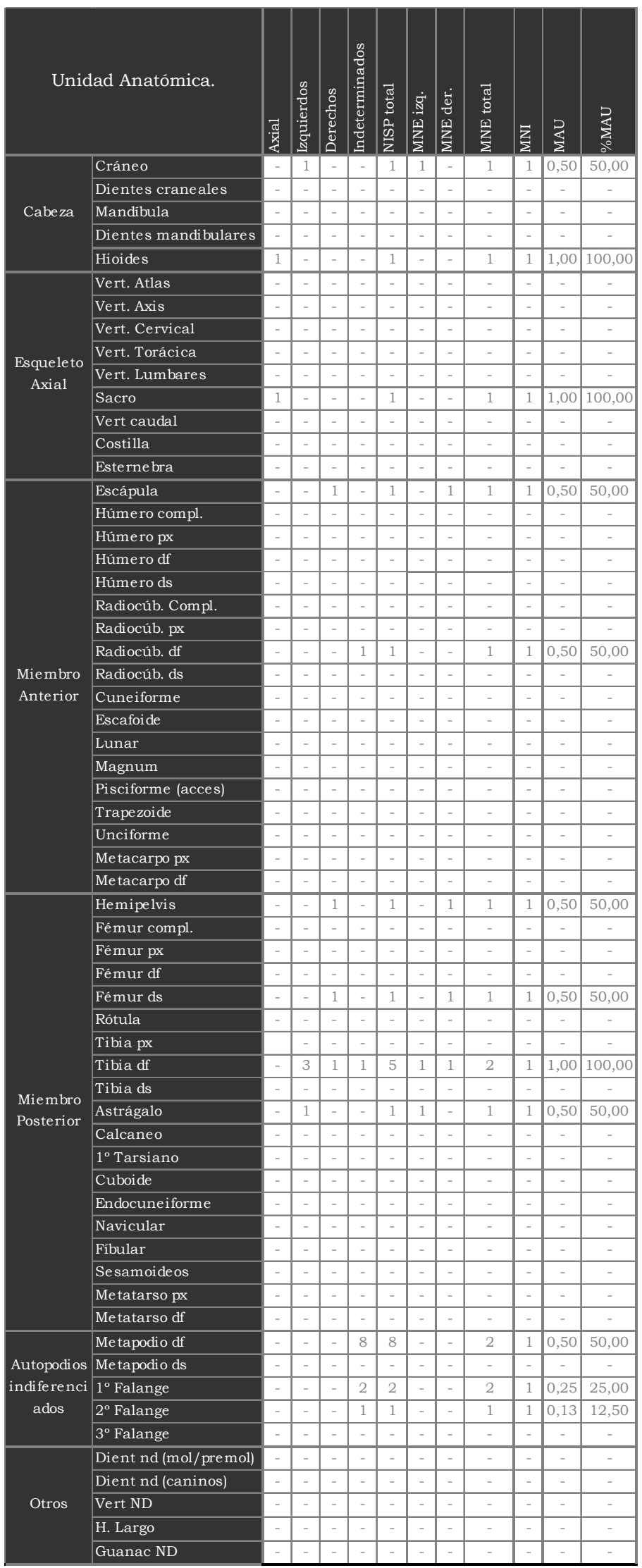

Tabla 7.11. Representación de partes anatómicas de guanaco en la Capa 3 de CS en MA. 
El registro de partes de la cabeza o el miembro posterior con las frecuencias más elevadas, permite suponer, de no mediar procesos tafonómicos que hayan modificado o destruido parte del conjunto, que una selección de partes pudo haber tenido lugar. Sin embargo, la ausencia de todos los elementos correspondiente al tronco de estos animales sugiere que el sacro probablemente haya ingresado adherido a la cintura pélvica y no como parte de la columna vertebral. La presencia del hueso hioides podría estar indicando el transporte al sitio de la lengua de los guanacos. Las crónicas resaltan la importancia de las vísceras, así como las glándulas parótidas (las mollejas) y la lengua como importantes alimentos entre los cazadores-recolectores de Patagonia (Claraz 1988; Musters 1964, Miotti y Marchionni 2009, entre otros). Estas partes además de aportar buenas proporciones de grasa podrían ser seleccionadas por su excelente palatabilidad.

La distribución de los restos óseos de guanaco (Figura 7.50) muestra un patrón similar al que se observa para el conjunto completo donde la cuadrícula A12 concentra la mayor cantidad de restos. Sin embargo, se observa una variación en las densidades por sector que permite sugerir una distribución más homogénea en toda la cuadrícula A12, fundamentalmente con mayor concentración de restos óseos de guanaco en los sectores NW (8 especímenes por $\left.\mathrm{m}^{2}\right)$, SE $\left(7\right.$ especímenes por $\left.\mathrm{m}^{2}\right)$ y $\mathrm{SW}$ (6 especímenes por $\mathrm{m}^{2}$ ). En la cuadrícula B12, el único resto óseo de guanaco procede del sector NE.

Es posible pensar que el gran número de especímenes de mamíferos de tamaño grande tenga altas posibilidad de corresponder a restos óseos de guanaco, sin embargo, como fue dicho anteriormente, la falta de atributos diagnósticos no nos permite una determinación más específica de los mismos. A pesar de ello, evaluamos la representación de partes anatómicas identificadas entre los mamíferos grandes para ver si existían posibilidades de que estén complementando las registradas para los guanacos. De este análisis encontramos que un 79\% de los restos de estos mamíferos corresponden a pequeños fragmentos de esmalte dentario, el porcentaje restante corresponde a fragmentos de diáfisis de huesos largo. Trabajos futuros serán necesarios a partir de la aplicación de otras técnicas y metodologías, para ajustar estas determinaciones y alcanzar una mejor resolución taxonómica del conjunto. 


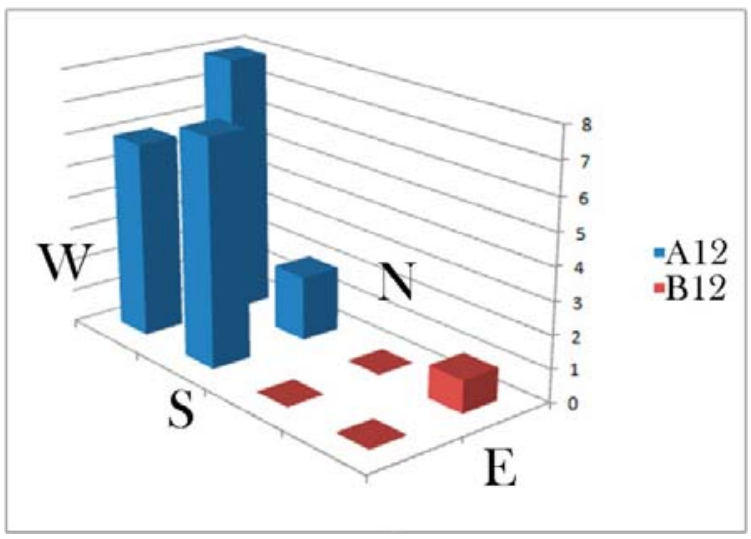

Figura 7.50. Distribución de restos óseos de guanaco por sector de cuadrícula en la Capa 3 de CS. Valores expresado en frecuencias de \%NISP por $\mathrm{m}^{2}$.

\subsection{Análisis de la estrategia de transporte de partes anatómicas de guanaco}

Las correlaciones de MAU\% obtenidas para el conjunto de la Capa 3 de CS con los índices de utilidad del guanaco (Borrero, 1990; Lyman 1992) y de densidad ósea (DO) (Elkin, 1995) indican, como se puede observar en la Figura 7.51a, que la frecuencia de partes anatómicas (MAU\%) y la DO se correlacionan de forma no significativa estadísticamente $(\mathrm{r}=0,9 ; \mathrm{p}>0,05)$.

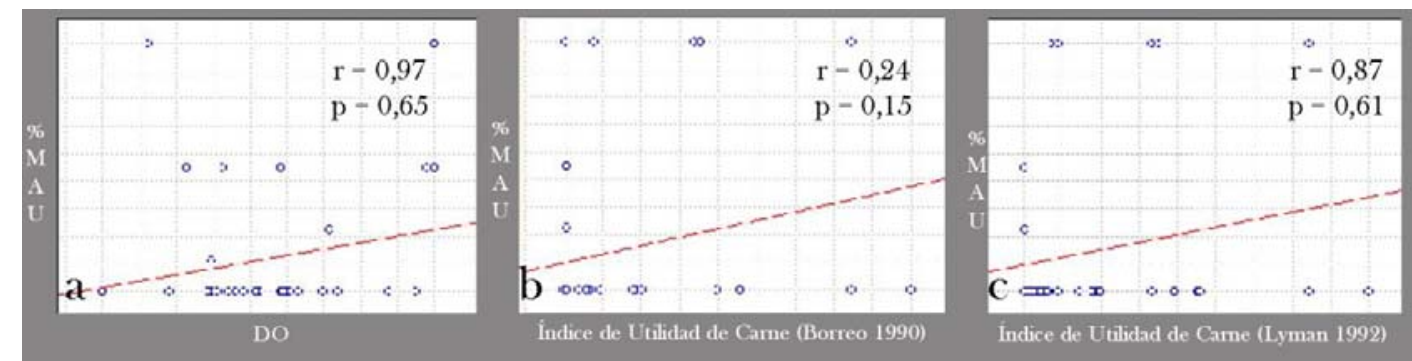

Figura 7.51. Correlaciones estadísticas de Spearman: a) MAU\%-DO; b) MAU\%-Índice de Utilidad (sensu Borrero 1990); c) MAU\%-Índice de Utilidad (sensu Lyman 1992).

Lo mismo ocurre cuando se hacen las correlaciones entre MAU\% y los índices de utilidad de carne (Figuras 7.51b y 7.51c). Tanto con el índice propuesto por Borrero en $1990(\mathrm{r}=0,24 ; \mathrm{p}>0,05)$ como por el sugerido por Lyman en $1992(\mathrm{r}=0,8 ; \mathrm{p}>0,05)$.

El análisis de estos resultados a partir de las clases propuestas por Lyman (1994) permite observar que el conjunto estudiado caería en la Clase 5 de equifinalidad. De esta manera, no es posible determinar si el conjunto es resultado de una estrategia particular - 
e.g., gourmet o utilidad reversa-, si es resultado de la acción de procesos mediados por densidad ósea -e.g., meteorización, transporte fluvial, acción de carnívoros-, o si resulta de una combinación de ambas posibilidades. Aunque en este caso, la fuerte representación que adquiere el cráneo y la pata trasera nos lleva a pensar más en una selectividad que en la acción de procesos destructivos. Esta hipótesis es apoyada por la elevada frecuencia con que se registran los elementos del sacro, cuya DO es baja y por lo tanto tienen chances de ser destruidos frente a la acción de estos procesos. La ausencia de elementos con altas chance de supervivencia como el húmero o las porciones proximales y de diáfisis del fémur también da sustento a esta idea.

\subsubsection{Modificaciones de las superficies óseas}

\subsection{Patrones de modificaciones naturales}

El análisis de las superficies de los especímenes correspondientes a guanaco muestra una baja meteorización (Figura 7.52) que ubica a todo el conjunto entre los estadios 1 y 2 (Behrensmeyer 1978). Esta tendencia con superficies poco meteorizadas estaría indicando que los materiales de la Capa 3 de CS tuvieron un tiempo relativamente corto de exposición y un enterramiento sincrónico.

$\mathrm{Al}$ comparar la meteorización de los restos óseos del esqueleto apendicular y los escasos especímenes del esqueleto axial (Figura 7.52) se observa que estos últimos se ubican todos en el estadio 1 (Behrensmeyer 1978). Los elementos axiales en general presentan una menor DO respecto de los apendiculares, y por lo tanto, tienen una mayor probabilidad de ser más meteorizados que estos incluso durante período igual de exposición. Esta observación es importante ya que el buen estado de preservación de sus superficies induce a pensar que si los procesos de destrucción mediados por densidad, como la meteorización, hubiesen sido relevantes sobre el conjunto, estos elementos axiales deberían registrarse con mayor deterioro. Sin embargo, no podemos descartar la que los procesos destructivos hayan actuado diferencialmente sobre algunos materiales (Gutiérrez et al. 2010; Massigoge et al. 2010). Esta discusión puede contribuir a interpretar la incertidumbre que genera la ausencia de correlación entre el MAU\% y la DO. No obstante, la tendencia de meteorización apoya la hipótesis propuesta más arriba y que sugiere que las frecuencias de partes anatómicas podrían responder a una estrategia 
de selección y no a la acción de procesos destructivos. El nivel de meteorización registrado permite proponer que los procesos mediados por densidad no parecerían haber sido tan importantes sobre el conjunto de la Capa 3 de CS. La mayor meteorización que se registra en los elementos apendiculares podría, de esta manera, vincularse a un estado más fragmentario de esos elementos en el momento de su depositación. La evaluación de esta hipótesis será contemplada en futuros trabajos.

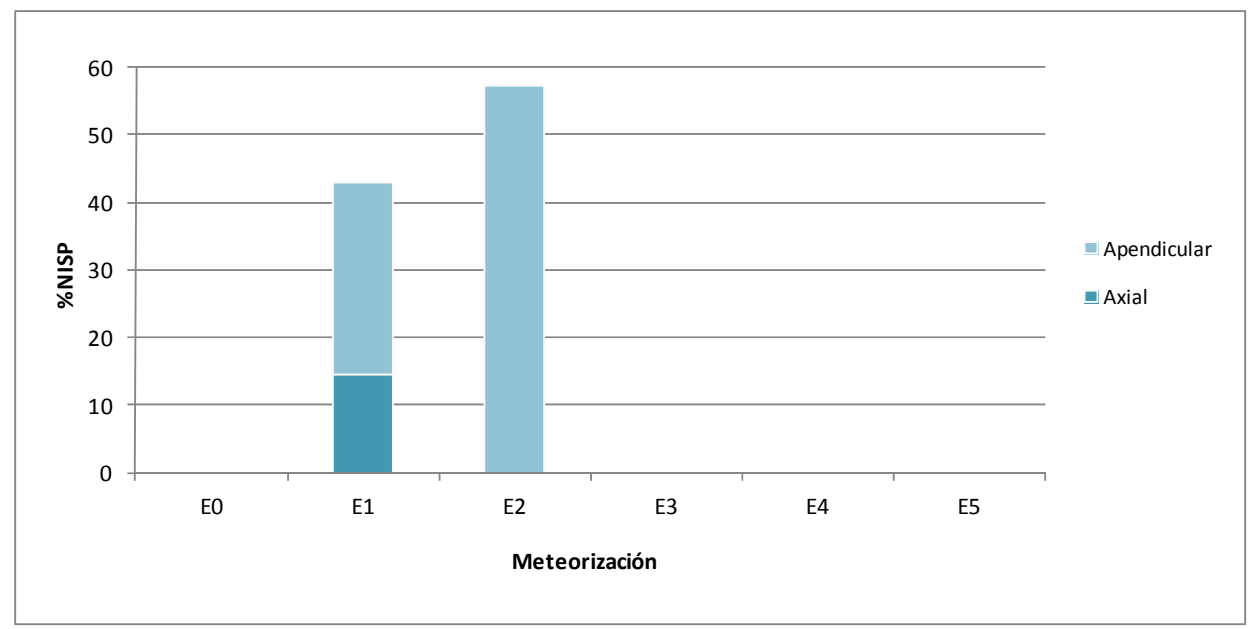

Figura 7.52. Tendencia de la meteorización en especímenes asignados a $L$. guanicoe en el conjunto de Capa 3 de la CS de MA. Los valores son expresados en NISP\%.

El registro de modificaciones producidas por agentes o proceso naturales permitió observar la presencia de depósitos de carbonato solamente en dos especímenes apendiculares (Figura 7.53a). Estos carbonatos consisten en depósitos puntuales que se localizan en el tejido esponjoso o en alguna rugosidad del tejido cortical, y que prácticamente no cubren ni obliteran la superficie del hueso. Los dos especímenes óseos con depósito de carbonatos fueron recuperados en la cuadrícula A12, uno en el sector NE, el otro en el NW. Este tipo de sales provienen de la disolución de rocas o sedimentos carbonáticos (Courty et al. 1989; Gutiérrez 2004). Dado que este nivel se encuentra en contacto con la roca de base (ignimbrita) es posible pensar en ella como fuente de procedencia. Para la evaluación de esta hipótesis será necesario el análisis composicional de esta roca. Estos estudios, al igual que los análisis sedimentológicos del sitio, actualmente se encuentran en proceso como parte del trabajo de tesis doctoral que está realizando Bruno Mosquera. 


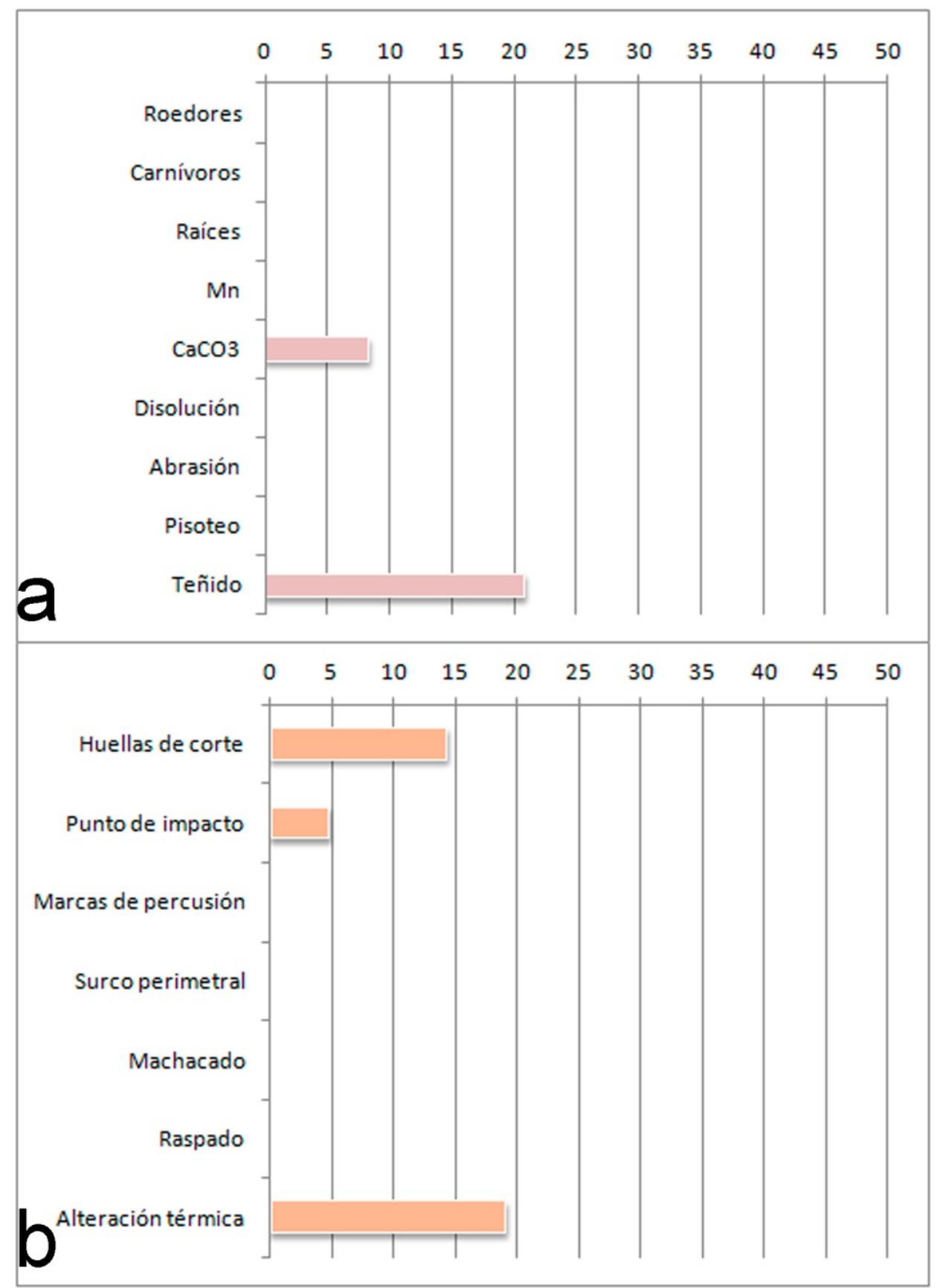

Figura 7.53. Frecuencia porcentual de especímenes óseos de guanaco con modificaciones: a) naturales; b) modificaciones antrópicas en especímenes del esqueleto apendicular.

Cinco especímenes óseos fueron asignados a la categoría "teñidos” (Figura 7.53a) porque presentan superficies ennegrecidas y no fue posible determinar si se debe a la exposición al fuego o a depósitos de manganeso. 
Entre los especímenes de Capa 3 de CS no se registraron modificaciones producidas por carnívoros ni por roedores, a pesar de que se había registrado la presencia de sectores perturbados por posibles galerías. La ausencia de marcas de roedor sobre los huesos sugiere que estos animales sólo podrían haber modificado parte del conjunto al desplazarse por los túneles. Sin embargo, la separación de los materiales asociados a estos sectores perturbados del resto del conjunto hace más confiables las interpretaciones que se realizan.

En este conjunto tampoco se registraron marcas producidas por la acción de raíces sobre las superficies óseas. De esta manera es posible suponer que, si bien fue registrada la presencia de raíces en este nivel de la excavación (Figura 7.49b), las mismas no habrían modificado ni afectado al conjunto.

\subsection{Patrones de modificación antrópica}

El estudio de modificaciones culturales de las superficies óseas permitió observar que las mismas están presentes tanto en restos correspondientes al esqueleto axial como apendicular de los guanacos. Entre los elementos axiales solamente se observa la presencia de huellas de corte en uno de los tres especímenes (33\%) que representa a esta región del esqueleto. Por su parte, entre los especímenes del esqueleto apendicular (Figura 7.53b), además de observar huellas de corte en un 14, 2\% (Figura 7.54a), se registra un 4,7\% de especímenes con punto de impacto y un $19 \%$ de especímenes con signos de alteración térmica $(\mathrm{n}=4$; Figura $7.54 \mathrm{~b})$. La mayor variabilidad y frecuencia de marcas de procesamiento en el esqueleto apendicular respecto del axial, seguramente guarda relación con las diferencias de tamaño entre ambas muestras ya que solamente, y como se mencionó antes, el esqueleto axial está representado por tres especímenes.

Los especímenes con huellas de corte $(n=4)$ se encuentran distribuidos en el NW de A12 ( $n=2)$, en el SE de A12 ( $n=1)$ y en el NE de B12 ( $n=1)$ mostrando una disposición más o menos dispersa en el área excavada. Mientras que los especímenes con alteración térmica ( $\mathrm{n}=4$ ) proceden todos de A12: NW (2), SW (1) y SE (1). Si bien son escasos los restos quemados, los dos registrados en el sector sur de A12 estarían en cercanías del fogón registrado en el sector SE de A12. No se registraron materiales óseos quemados asociados con el fogón del SW de B12. 

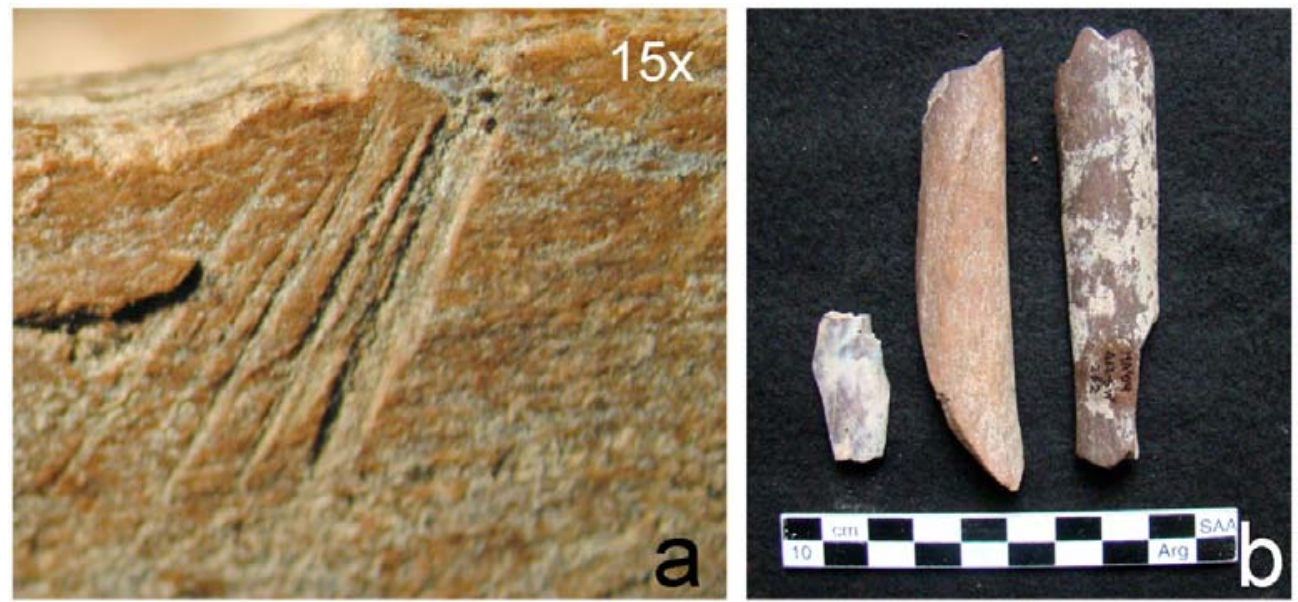

Figura 7.54. Modificaciones de origen antrópico Capa 3 CS de MA: a) huellas de corte en diáfisis de tibia; b) especímenes alterados térmicamente.

El análisis de fracturas realizado sobre los 17 especímenes de huesos largos de guanaco (71\%), nos permitió identificar un total de 20 fracturas entre las que fueron reconocidos tanto patrones de tipo antrópico como otros de tipo tafonómico (Figura $7.55)$.

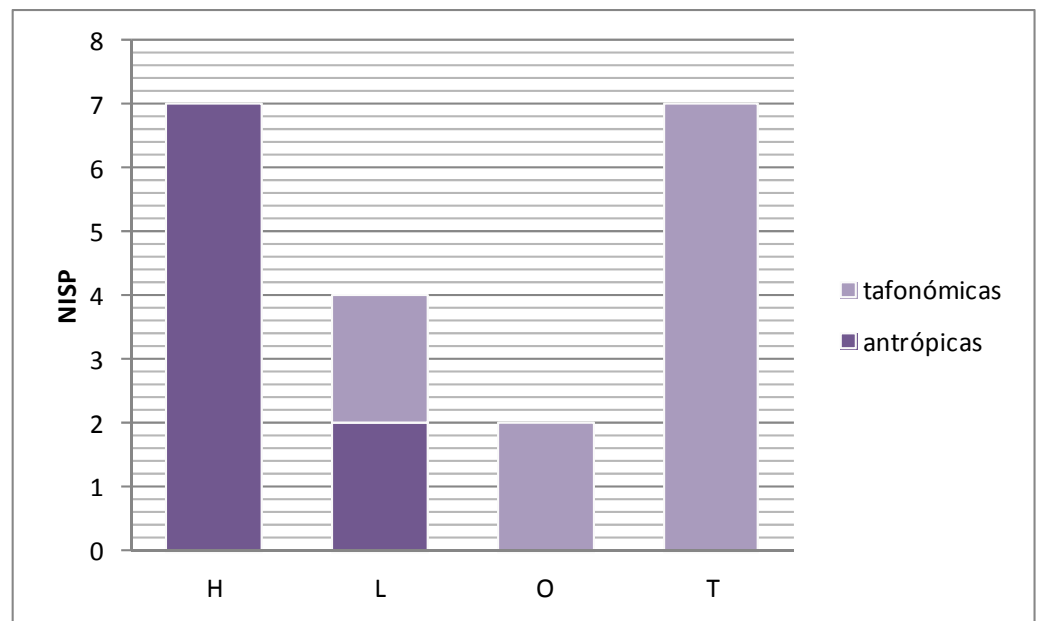

Figura 7.55. Frecuencia absoluta y tipos de fracturas identificadas: $\mathrm{H}$ ) helicoidal; L) longitudinal; O) oblicua; T) transversal.

El análisis realizado muestra que las frecuencias más elevadas se registran para las fracturas helicoidales y transversales. El primero de estos tipos se corresponde con un patrón antrópico que resulta de la aplicación de una fuerza dinámica sobre el hueso en estado fresco. La ausencia de modificaciones producidas por carnívoros en el conjunto 
brinda soporte a esa interpretación. Las fracturas transversales representan un patrón tafonómico con bordes irregulares o rectos y donde no se observa aserrado perimetral que haya permitido debilitar el tejido óseo y conducir la fractura. De las fracturas longitudinales, la mitad muestra un patrón compatible con el antrópico; las otras dos carecen de estas características y son interpretadas como resultado de procesos tafonómicos que actuaron cuando el hueso ya se encontraba seco. Lo mismo ocurre con las dos fracturas oblicuas. De esta manera, el $45 \%$ de las fracturas identificadas son compatibles con un patrón intencional de fracturar los huesos en estado fresco.

En este nivel no se identificaron artefactos óseos que evidencien el uso del hueso como materia prima.

\subsubsection{Capa 2 de Cámara Sur}

El conjunto correspondiente a la Capa 2 de CS está integrado por un total de 1256 especímenes óseos. De los cuales un 48,96\% (NISP=307) fueron determinados a algún nivel o categoría taxonómica y/o anatómica. Por su parte, el 51,04\% del total del conjunto $(\mathrm{NSP}=949)$ corresponden a pequeños fragmentos de diáfisis de hueso largo o fragmentos de hueso plano carentes de rasgos diagnósticos y, por lo tanto, integran la categoría indeterminados.

El análisis de la distribución espacial de los especímenes óseos tridimensionados (7.56a) muestra que la mayor cantidad se registra en la cuadrícula B12 y en el sector NE de A12. En los restantes sectores de A12 prácticamente no se registraron restos por tridimensión (Figura 7.56b).

$\mathrm{El}$ análisis de densidad de especímenes por $\mathrm{m}^{2}$ considerando el conjunto completo (tridis y generales) muestra que la mayor densidad de restos óseos se registra en la cuadrícula A12, con una mayor frecuencia en los sectores SE y SW (Figura 7.56b). Esta diferencia que se observa entre la distribución de los tridis (Figura 7.56a) y los sectores de mayor densidad para el conjunto completo (Figura 7.56b) posiblemente esté relacionada con la presencia de un gran número de especímenes pequeños recuperados a través de zaranda. De alguna manera, esta situación pondría en evidencia la fragmentación del conjunto, condición que se evalúa más adelante. 


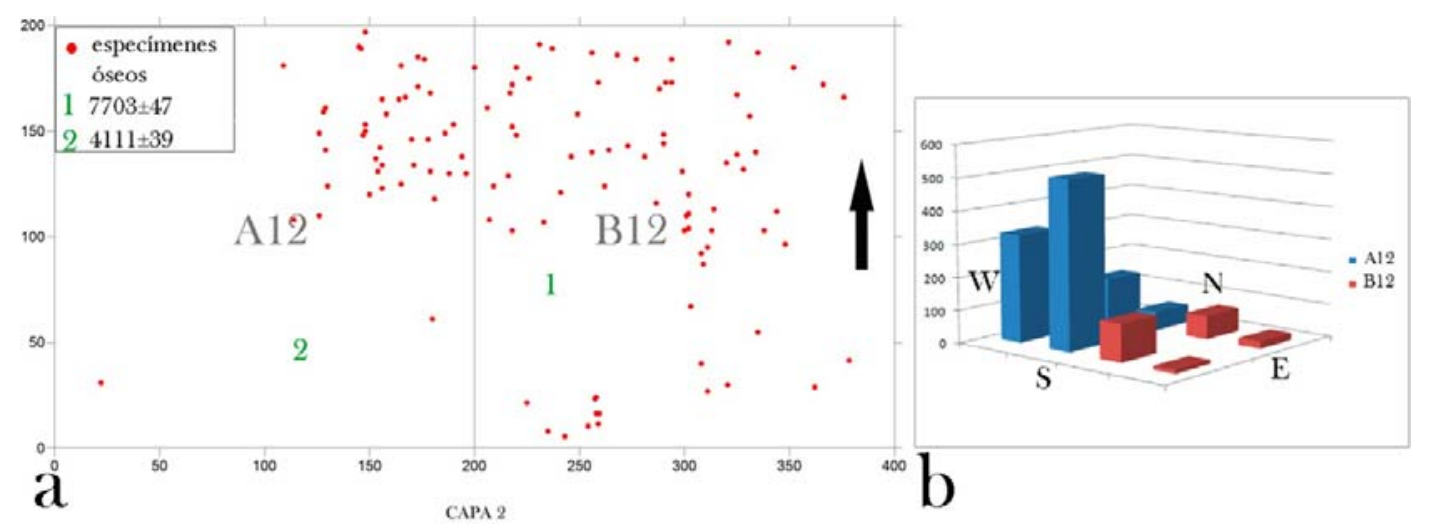

Figura 7.56. a) Distribución en planta de los especímenes tridimensionados en la Capa 2

de CS de MA; b) densidad de restos óseos por cuadrícula (A12 y B12) y sector de excavación (NE, NW, SE y SW). Los valores se expresan en frecuencia de NISP por $\mathrm{m}^{2}$.

Durante las excavaciones de la Capa 2 de CS se identificaron distintas áreas de combustión. Una de ellas en el vértice SE del sector SW de B12; todas las otras se registraron en A12: una sobre la pared sur del sector SE; otra en el vértice SW del mismo sector; otra en el sector NW de A12 y, finalmente, otra en el centro de la cuadrícula con orientación norte sur. En la pared este del sector SE de A12 se registró un pozo de unos $30 \mathrm{~cm}$ de diámetro cuyo sedimento se encontraba removido y $\sin$ materiales arqueológicos. En el sector NW de A12 se registró un pequeño agujero que podría corresponder a la boca de una galería o cueva. En este nivel se describió la presencia de raíces en el sector $\mathrm{SW}$ de $\mathrm{B} 12$.

\subsubsection{Abundancia taxonómica y anatómica}

Los resultados obtenidos muestran que todas las especies identificadas en el conjunto de la Capa 2 de CS actualmente habitan el área de estudio. De ellas Lama guanicoe es la mejor representada del conjunto (Tabla 7.12). Los especímenes asignados a esta especie representan el 49,5\% del NISP\%.

Tanto los mamíferos indeterminados (12\% del NISP\%) como los mamíferos de tamaño grande (ca. 38\% del NISP\%) son abundantes en el conjunto (Tabla 7.12). Ellos no pudieron ser determinados a niveles más específicos porque carecen de rasgos o 
características diagnósticas que lo permitan. Al igual que en los otros conjuntos de la cueva, esta ausencia de atributos específicos pueda estar relacionada con un alto nivel de fragmentación del conjunto o con un importante deterioro de las superficies óseas.

Las únicas aves que se registran son los rheidos y su frecuencia es muy baja (Tabla 7.12). Ellos se encuentran representados por una falange y por un fragmento de cáscara de huevo.

\begin{tabular}{|l|c|c|c|}
\hline & NISP & \%NISP & M NI \\
\hline Rheidae* $^{*}$ & 2 & $0,65 \%$ & - \\
\hline Mamifero Indet. & 37 & $12,05 \%$ & - \\
\hline Mamifero Grande & 116 & $37,79 \%$ & - \\
\hline Lama guanicoe & 152 & $49,51 \%$ & 3 \\
\hline
\end{tabular}

* 1 espécimen corresponde a un fragmento de cáscara de huevo

Tabla 7.12. Abundancia taxonómica de la Capa 2 de CS de MA.

Con respecto a la representación de partes anatómicas del guanaco, en el conjunto de Capa 2 de CS se identificaron tanto elementos del esqueleto axial como del esqueleto apendicular (Tabla 7.13). El MNI para guanaco fue estimado en 3 a partir de la diáfisis de la tibia y de los metapodios indiferenciados. Siguiendo los criterios de edad relacionados a la fusión de las epífisis uno de los guanacos podría corresponder a un individuo juvenil.

El análisis de la fragmentación a partir de la relación entre MNE/NISP de guanaco evidencia una fragmentación moderada del conjunto ya que se obtuvo un valor de 0,54. Este resultado es similar al observado en otros conjuntos de la cueva.

Del análisis de la representación de unidades anatómicas de guanaco se desprende que los elementos más representados $(\mathrm{MAU} \%=100 \%)$ son la diáfisis de la tibia y los metapodios indiferenciados. Luego de esos elementos, dentro del esqueleto apendicular, la pata delantera es la mejor representada (Tabla 7.13) con frecuencias elevadas para la escápula (80\% del MAU\%), el húmero distal, el metacarpo y el unciforme $(60 \%$ del MAU\%). El radio-cúbito también se encuentra representado pero en frecuencias menores (40\% del MAU\%). En cuanto a la pata trasera, como fue dicho anteriormente, la mejor representación la adquiere la tibia a través de su diáfisis. La pelvis y los tarsianos se encuentran bien representados (60\% del MAU\%), sin embargo los restantes elementos del miembro posterior registran frecuencias bajas (Tabla 7.13). Mientras los metatarsos representan un 40\% del MAU\%, el fémur solo alcanza el 20\% del MAU\%. 


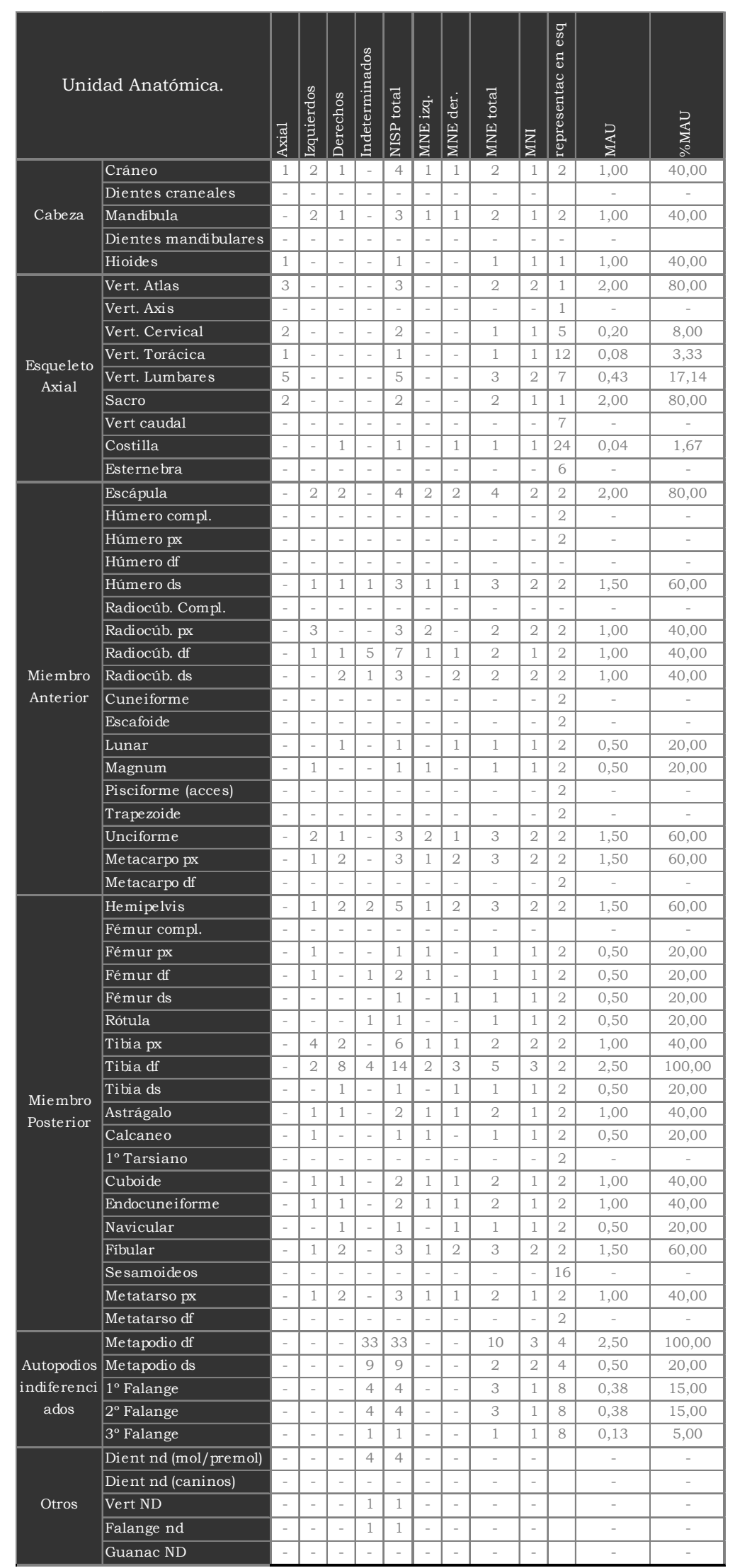

Tabla 7.13. Representación de partes anatómicas de guanaco en la Capa 2 de CS de MA. 
Con respecto al esqueleto axial de los guanacos, la vértebra atlas y el sacro tienen una muy buena representación (80\% del MAU\%), seguido por los distintos elementos de la cabeza cuyas frecuencias alcanzan el $40 \%$ del MAU\% (Tabla 7.13). Otros elementos axiales como vértebras y costillas se encuentran en frecuencias bajas (<20\% MAU\%), entre ellos las vértebras lumbares son las mejor representadas (Tabla 7.13).

De este análisis se desprende que las unidades de trozamiento más representadas corresponden al cuarto delantero y trasero del guanaco. Mientras que el primero tiene una mejor representación de los elementos proximales (escápula y húmero), el trasero alcanza mejores frecuencias de los elementos distales (tibia y tarsianos). Sin embargo, unidades como la cabeza también adquieren buena representación. Como fue dicho anteriormente para el conjunto de la Capa 3 de CS, donde al igual que en este conjunto también se determinó la presencia del hueso hioides, su importancia radica en que podría estar indicando el ingreso de la lengua del guanaco al sitio. Con respecto a la alta representación del sacro, es más probable que éste haya ingresado adherido a la pelvis que junto con los elementos del tronco de los guanacos, que se encuentran poco representados. Sin embargo no se descarta la posibilidad de que alguno de los guanacos haya ingresado enteros al sitio como resultado de cacerías cercanas a la cueva.

La distribución de los restos óseos de guanaco (Figura 7.57) muestra un patrón similar al observado para el conjunto completo donde la mayor densidad de restos se registra en la cuadrícula A12. Sin embargo, se observa que la densidad de restos de guanaco es más homogénea entre los cuatro sectores de A12 y el NW y SE de B12 (Figura 7.57) que lo que se observa en el conjunto completo, con una alta densidad para los sectores del este de A12 (Figura 7.56b).

El gran número de especímenes de Mamífero de tamaño grande corresponde en su mayoría (ca. 70\%) a fragmentos de hueso largo. Sin embargo, dichos restos tendrían amplias posibilidades de pertenecer a $L$. guanicoe. La evaluación de si las partes anatómicas registradas en esta clase podrían estar complementando las ausentes entre los guanacos mostró que solamente se podrían incrementar los valores de NISP para porciones medias de costillas $(\mathrm{NISP}=12)$, los fragmentos del cráneo $(\mathrm{NISP}=2)$, los fragmentos de esmalte dental $(\mathrm{NISP}=8)$ y de hoja escapular $(\mathrm{NISP}=1)$. Evaluar a partir de otras técnicas y metodologías la posibilidad de que varios de estos especímenes correspondan a guanaco será un trabajo a desarrollar con posterioridad, y que seguramente permitirá ajustar los valores de abundancia taxonómica del conjunto. Los análisis osteométricos, los estudios de ADN o la aplicación de GIS pueden constituir, 
entre otros, aportes metodológicos válidos para abordar este problema.

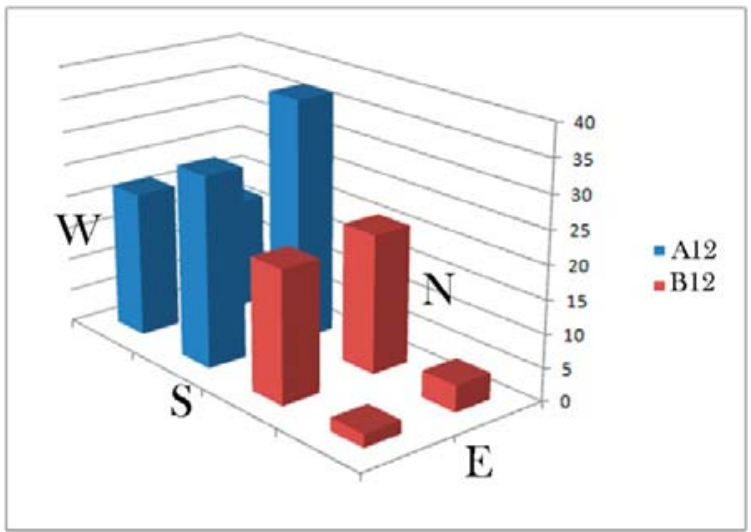

Figura 7.57. Densidad de restos óseos de guanaco por sector de cuadrícula en Capa 2 de CS de MA. Los valores se expresan en frecuencia de NISP por $\mathrm{m}^{2}$.

\subsection{Análisis de la estrategia de transporte de partes anatómicas de guanaco}

Se realizaron las distintas correlaciones estadísticas de Spearman para evaluar las posibles causas de la representación de partes anatómicas del guanaco en el conjunto de la Capa 2 de CS de MA (Figura 7.58).

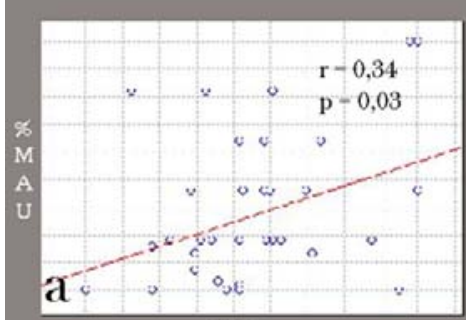

DO

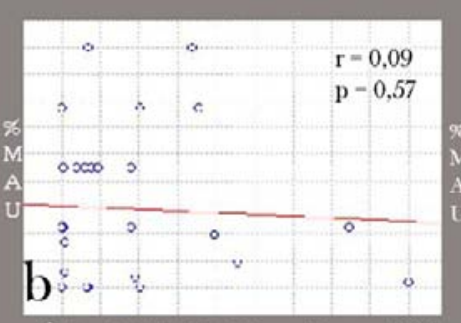

fincice de Utilidad de Came (Borrero 1990)

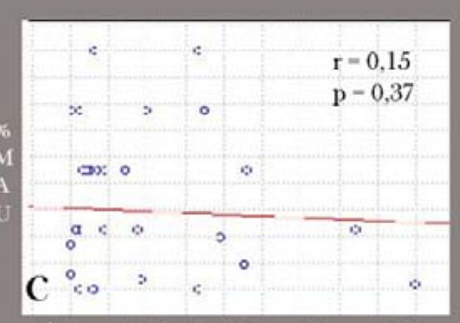

fincice de Utalidad de Came (Lyman 1992)

Figura 7.58. Correlaciones estadísticas de Spearman: a) MAU\%-DO; b) MAU\%-Índice de Utilidad (sensu Borrero 1990); c) MAU\%-Índice de Utilidad (sensu Lyman 1992).

Los resultados obtenidos indican una correlación baja pero significativa entre el MAU\% y la DO $(\mathrm{r}=0,34 ; \mathrm{p}<0,05)$. Esto evidenciaría una tendencia a que los elementos más representados son los que presentan DO más alta y, por lo tanto, no se descarta que procesos de destrucción mediados por densidad o factores intra-taxonómicos de la DO, puedan haber actuado sobre el conjunto provocando el deterioro o desaparición de 
algunos elementos poco densos o más inmaduros osteológicamente.

Por otro lado, los resultados obtenidos al correlacionar las frecuencias de MAU\% con los dos índices de utilidad (Borrero 1990; Lyman 1992) permiten observar una ausencia completa de correlación (Figuras $7.58 \mathrm{~b}$ y 7.58c). Estos resultados reflejarían falta de selección humana de las partes en relación a su alto o bajo rendimiento económico.

Considerando la propuesta interpretativa de estos resultados realizada por Lyman (1994: 264), el conjunto de la Capa 2 de CS caería en la Clase 4 "lag or ravaged". Esta clase sugiere la posibilidad de que el conjunto haya estado expuesto a la acción de procesos mediados por DO. Sin embargo, y aunque en el conjunto fue determinada una frecuencia importante $(80 \%$ del MAU\%) de elementos del sacro, cuya DO se encuentra entre las más bajas (Elkin 1995; Elkin y Zanchetta 1991), no podemos descartar que los procesos destructivos puedan haber actuado diferencialmente sobre elementos de individuos más jóvenes. Evaluar la incidencia de estos factores sobre el conjunto forma parte de la agenda de esta investigación.

\subsubsection{Modificaciones de las superficies óseas}

\subsection{Patrones de modificaciones naturales}

Los resultados del análisis de las superficies óseas de los restos de guanaco muestran que el 86,5\% de los especímenes se encuentran en estadios bajos de meteorización (1 y 2 sensu Behrensmeyer 1978) (Figura 7.59). Esta condición indica una buena preservación del conjunto zooarqueológico, posiblemente resultado de un tiempo relativamente corto de exposición y enterramiento sincrónico. La presencia de un 13,4\% de especímenes en el estadio 3 de meteorización podría indicar la existencia, aunque en bajos porcentajes, de pérdida ósea (Behrensmeyer 1978; Borrero 2007). Posiblemente esa pérdida ósea pueda estar relacionada a un deterioro mayor de algunas superficies óseas, en ese caso la expectativa sería que los elementos que muestren la mayor meteorización del conjunto sean los que aún no alcanzaron una completa osificación, los de baja DO o los que han sido fragmentados previo a su depositación.

El análisis de la meteorización que presentan los elementos axiales y apendiculares del esqueleto del guanaco muestra una tendencia similar para ambas regiones del esqueleto (Figura 7.59). De esta manera, es posible que la mayor meteorización exhibida 
por un porcentaje menor del conjunto, pueda estar más relacionada a una fragmentación previa de los materiales que a una cuestión de DO diferencial.

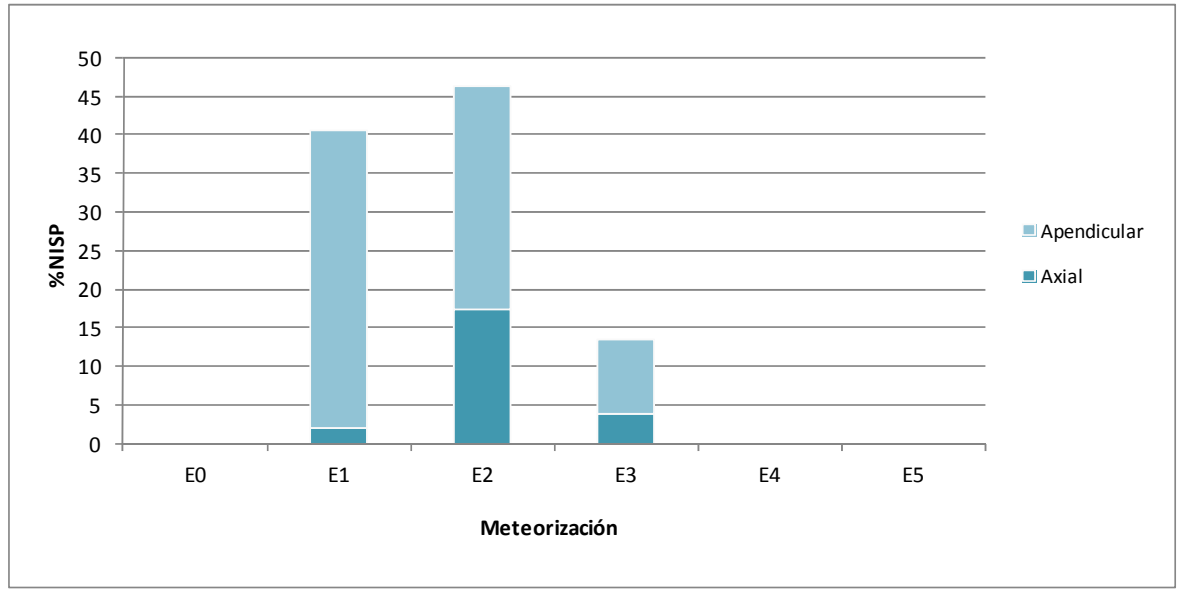

Figura 7.59. Tendencia de la meteorización en especímenes asignados a L. guanicoe en el conjunto de la Capa 2 de CS de MA. Los valores son expresados en NISP\%.

No se registró ningún patrón de modificación producido por procesos o agentes naturales en porcentajes elevados (Figura 7.60a). Las modificaciones que alcanzan frecuencias más elevadas corresponden a los depósitos de manganeso que se registraron en un 9,8\% de los especímenes. Estos depósitos se presentan cubriendo parcial o totalmente la superficie de los huesos (Figura 7.61). El origen de estos manganesos puede estar vinculado a la disolución de la roca de caja (López-González et al. 2006) como se sugirió para la Capa 3, o pueden haber sido liberados durante la descomposición de materia orgánica (Marín Arroyo et al. 2008; Shahack-Gross et al. 1997). A favor de esta última alternativa encontramos que en este nivel de la secuencia estratigráfica, y como fue descripto en el Capítulo 3, Rabassa et al. (2007) describe la presencia de moteados negros que resultan de la alteración de raíces y guano, y hacia la parte superior observa precipitación de sales que indican condiciones de humedad local. El agua necesaria para que estos manganesos sean transportados pudo provenir del manantial intermitente ubicado en el fondo de la CS de MA cuyo detalle fue brindado al inicio del capítulo. A partir de esas características observadas en la estratigrafía, la expectativa era la de registrar modificaciones de raíces y depósitos de carbonatos sobre los huesos. Sin embargo, los resultados obtenidos indican que estas modificaciones se registran en menos de un $2 \%$ de los especímenes (Figura 7.60a). De esta forma, entendemos que la existencia de raíces alteradas y precipitación de sales en el perfil no habrían afectado el conjunto óseo. 
Los especímenes con manchas de manganeso se encuentran concentrados en la intersección entre los sectores NE y SE de la cuadrícula A12. Este patrón de distribución con alta densidad de depósitos de manganeso sobre los huesos en un sector específico, podría estar indicando la existencia de alguna condición de humedad diferencial (Figura 7.62a).

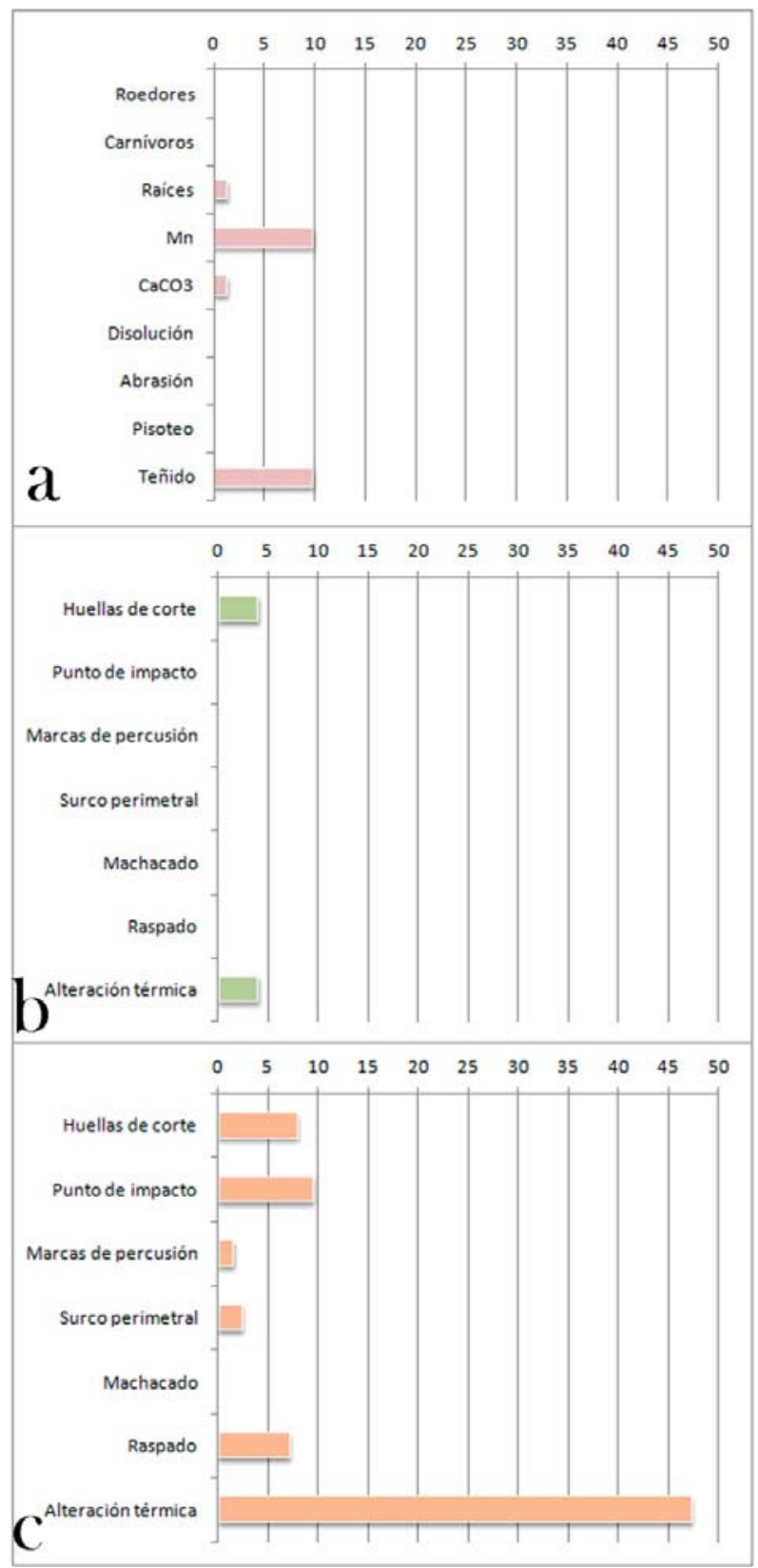

Figura 7.60. Frecuencia porcentual de especímenes óseos de guanaco con modificaciones: a) naturales; b) modificaciones antrópicas en especímenes del esqueleto axial; c) modificaciones antrópicas en el esqueleto apendicular. 


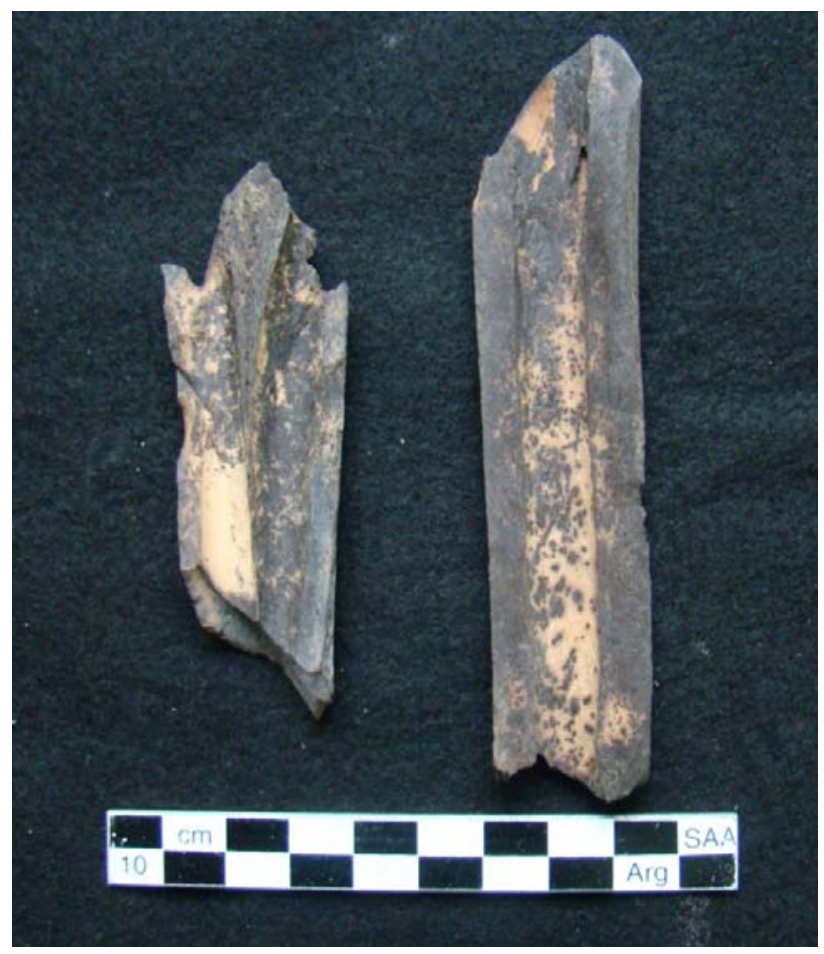

Figura 7.61. Modificaciones naturales en Capa 2 de CS: depósitos de manganeso
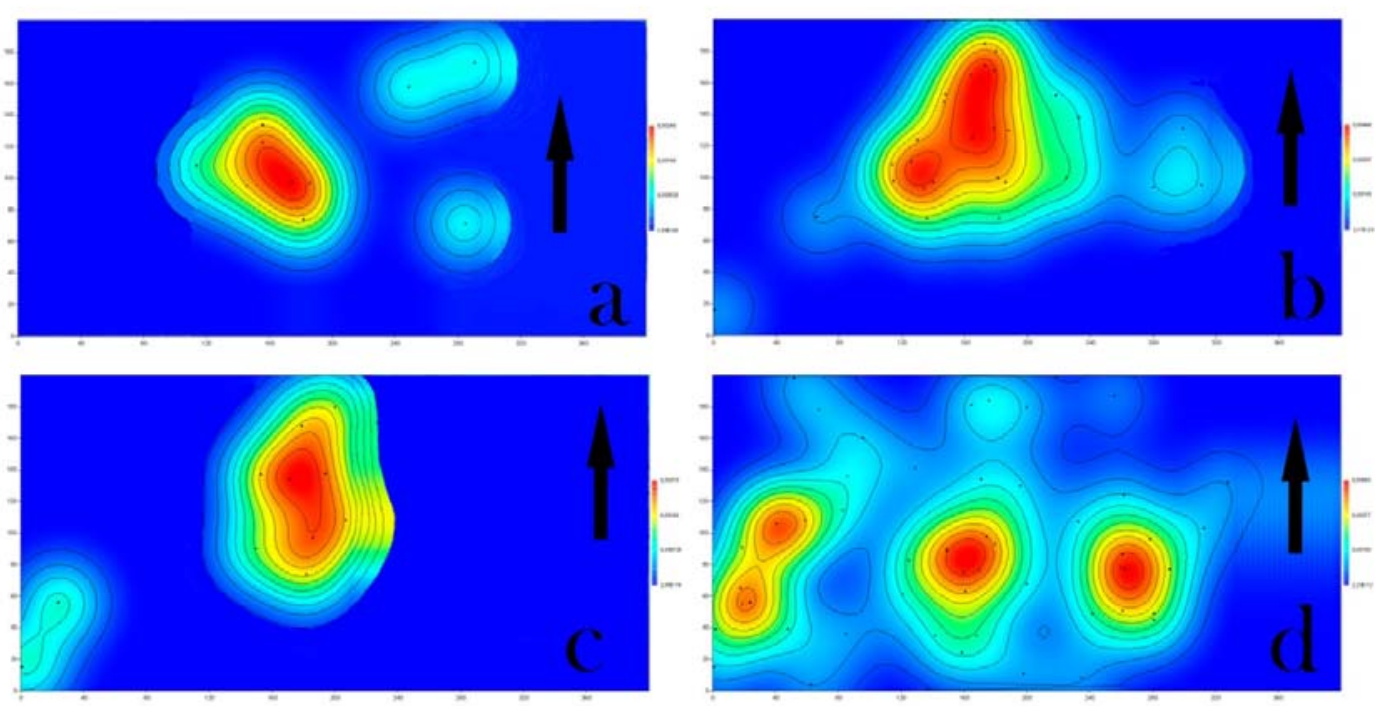

Figura 7.62. Distribución espacial de especímenes con modificaciones en las superficies en Capa 2 de CS de MA: a) especímenes con manganeso; b) especímenes teñidos; c) especímenes con huellas de corte; d) especímenes con alteración térmica. 
Un 9,86\% de los especímenes óseos fueron asignados a la categoría teñidos ya que no fue posible determinar la causa de su ennegrecimiento. Ellos presentan una distribución (Figura 7.62b) cuyo patrón se asemeja al que presentan los especímenes con manganeso, aunque con una densidad mayor hacia el sector NE de A12.

No se registran en el conjunto de Capa 2 de CS modificaciones que puedan ser atribuidas a la acción de agentes carnívoros o roedores. La ausencia de marcas de carnívoros avala la hipótesis sugerida de un tiempo corto de exposición del conjunto.

\subsection{Patrones de modificación antrópica}

Se reconocieron modificaciones antrópicas tanto en elementos del esqueleto axial como apendicular, encontrando en este último las mayores frecuencias y variedades (Figuras $7.60 \mathrm{~b}$ y $7.60 \mathrm{c})$.

Entre los especímenes correspondientes al esqueleto axial de los guanacos se observa que un $4 \%$ de ellos registra la presencia de huellas de corte y una frecuencia igual de especímenes axiales presenta alteración térmica (Figura 7.60b).

En cuanto al esqueleto apendicular (Figura 7.60c), entre la marcas que resultan del procesamiento de las carcasas, encontramos que una frecuencia cercana al $8 \%$ de los especímenes presentan huellas de corte (Figura 7.63a). En un 9,5\% de los especímenes apendiculares además, se observa la presencia de puntos de impacto (Figura 7.63b) vinculados a la producción intencional de fracturas a través de golpe. Las marcas de raspado, también vinculadas a la obtención de fracturas se registran en un $6 \%$ de los especímenes.

Mientras que en un único espécimen se observaron marcas de percusión, otros tres elementos registran fractura transversal por surco o aserrado perimetral (Figura 7.63c).

Los especímenes con huellas de corte presentan un patrón de distribución similar al observado para las modificaciones naturales, mostrando coincidencia en el sector donde registran la mayor densidad (Figura 7.62c). Las huellas de corte estarían vinculadas a las distintas etapas del procesamiento de los guanacos. Sin embargo, la presencia de puntos de impacto, marcas de percusión y surco perimetral podrían relacionarse con la etapa final de la reducción de las carcasas ya que reflejan la intencionalidad de fracturar los huesos, sea para cocción, consumo de médula o para manufactura de instrumentos óseos.

Una frecuencia importante de restos óseos axiales y apendiculares presentan signos 
de alteración térmica (Figuras 7.60b y 7.60c). Ellos totalizan el $40 \%$ del conjunto que corresponde a la especie L. guanicoe. Estos restos óseos quemados que en su gran mayoría se presentan carbonizados; según los criterios de color establecidos en el Capítulo 6, se agrupan en tres sectores de mayor densidad (Figura 7.62d). Dos de ellos corresponden a la cuadrícula A12, sectores SE y SW respectivamente; el tercero se localiza en el SW de la cuadrícula B12. Esta distribución de los materiales quemados muestra un patrón similar de distribución que el exhibido por los fogones y se encuentran asociados a ellos.

El registro de alteración térmica en una falange de rheido estaría evidenciando la utilización antrópica de estas aves en el sitio durante el Holoceno medio.

El análisis de los 94 especímenes de huesos largos (62\%) nos permitió reconocer un total de 156 fracturas (Figura 7.64). Entre los patrones de fractura identificados se determinó la presencia tanto de causas antrópicas $(\mathrm{n}=98)$ como tafonómicas $(\mathrm{n}=58)$.

Las fracturas helicoidales $(23,7 \%)$ son numerosas aunque la mayor frecuencia (40\%) la alcanzan las longitudinales (Figura 7.64). Del total de restos óseos con fracturas longitudinal, $45(72,5 \%)$ presentan superficies suaves y pueden ser atribuidas al agente antrópico ya que además registran atributos asociados como puntos de impacto y marcas de raspado. Estas fracturas posiblemente sean el resultado de la fragmentación del hueso en estado fresco y de forma intencional. Por su parte, las $17(27,5 \%)$ fracturas longitudinales que restan no registran características que permitan vincularlas a este patrón, por el contrario parecen ser resultado de otros procesos tafonómicos. 


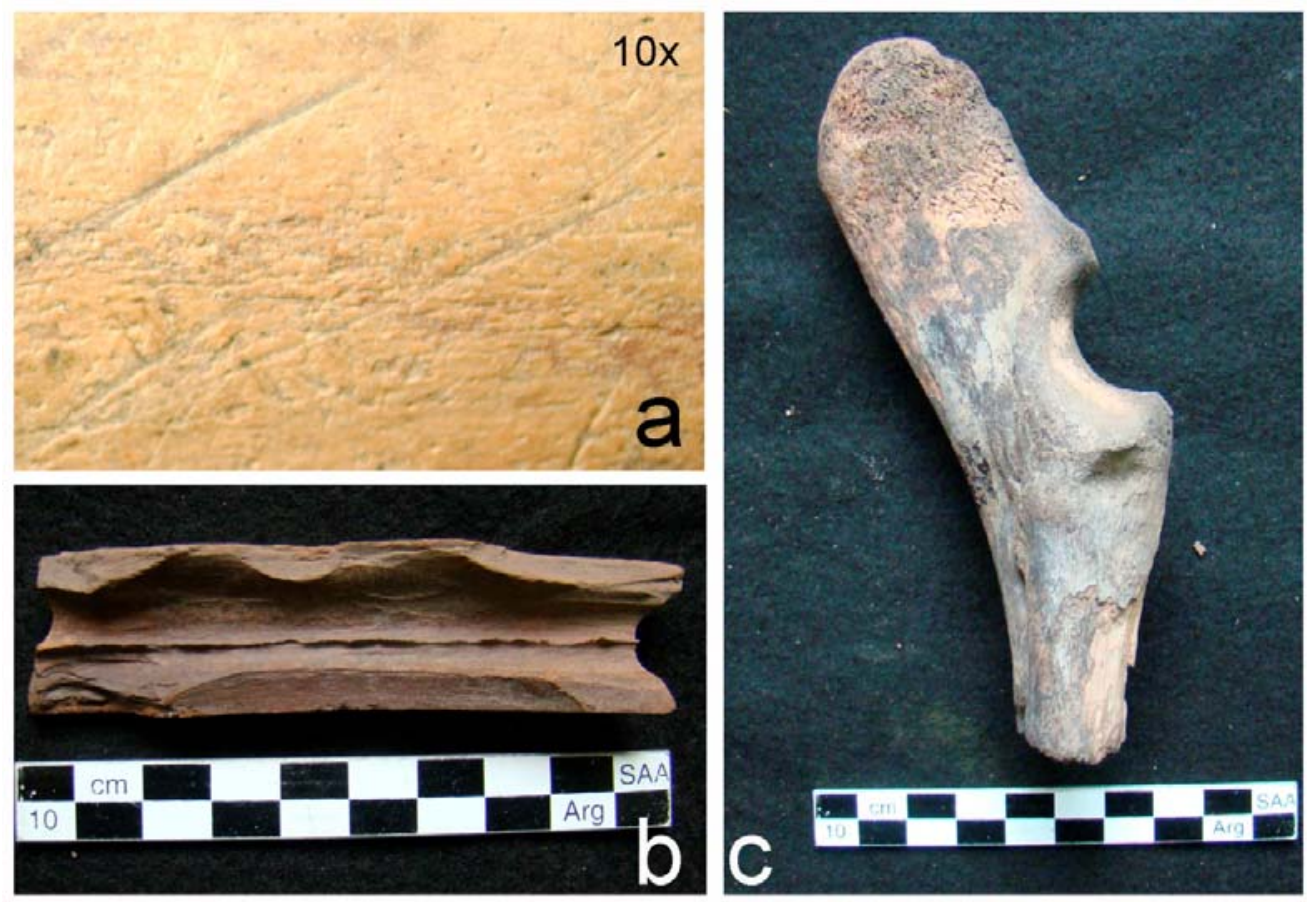

Figura 7.63. Modificaciones culturales en Capa 2 de CS en MA: a) huellas de corte sobre metapodio; b) negativos de impacto en diáfisis de metapodio; c) surco perimetral en radio-cúbito proximal.

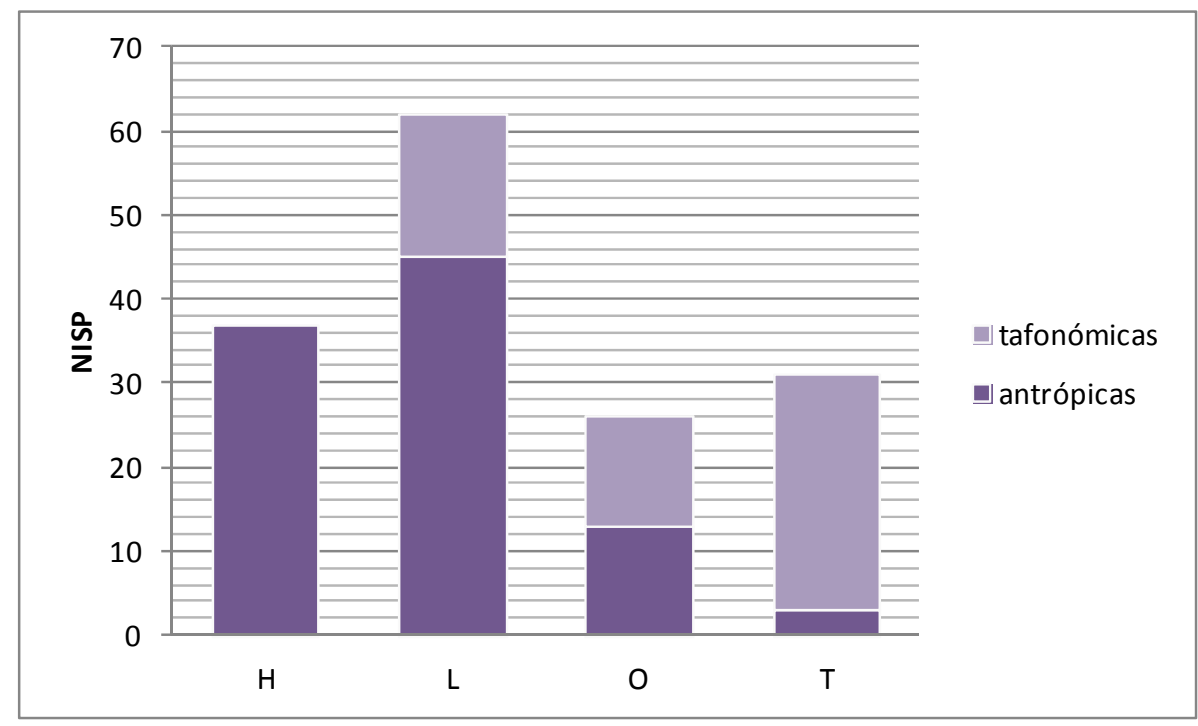

Figura 7.64. Frecuencia absoluta y tipos de fracturas identificadas: H) helicoidal; L) longitudinal; O) oblicua; T) transversal.

Entre las fracturas oblicuas el $48,15 \%(\mathrm{n}=13)$ presentan atributos como huellas de 
corte, punto de impacto y/o marcas de raspado además de superficies suaves que permiten sugerir que resultan de la intencionalidad humana (Figura 7.64). Por el contrario, las restantes $(51,85 \%)$ carecen de indicadores culturales de procesamiento y presentan superficies rugosas. Por tal motivo consideramos para ellas un origen tafonómico. Las fracturas transversales (Figura 7.64), a excepción de las 3 que son resultado de un aserrado perimetral intencional para debilitar el hueso y guiar la fractura (Figura 7.63c), el resto se produjeron con el hueso en estado seco y por tanto, consideradas resultado de la acción de agentes naturales.

En esta capa se identificó un artefacto óseo formatizado sobre una diáfisis de hueso largo de mamífero (Figura 7.65a) y dos fragmentos decorados con líneas paralelas incisas (Figuras $7.65 \mathrm{~b}$ y $7.65 \mathrm{c}$ ).
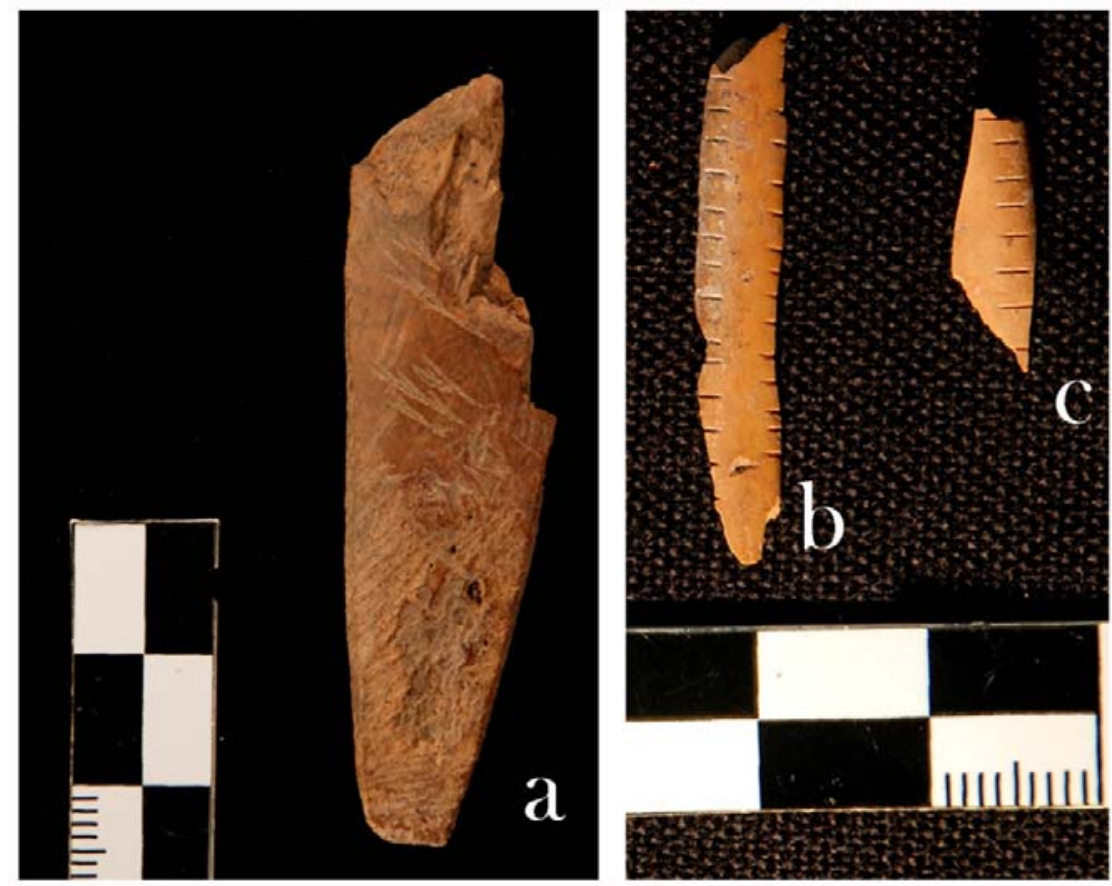

Figura 7.65. a) Artefacto óseo formatizado; b y c) fragmentos decorados con líneas incisas paralelas.

\subsubsection{Capa 1 de Cámara Sur}

El conjunto procedente de la Capa 1 de la CS de MA está conformado por un total de 2836 restos arqueofaunísticos. De ellos, el 19,95\% pudo ser determinado a algún nivel 
anatómico o taxonómico $(\mathrm{NISP}=566)$, quedando los restantes $(\mathrm{NSP}=2270)$ como indeterminados. La mayor cantidad de especímenes indeterminados corresponden a pequeñas astillas o fragmentos óseos. Siendo esta la Capa que registra la mayor fragmentación de todos los niveles analizados en la cueva.

El conjunto de especímenes tridimensionados de la Capa 1 de CS se encuentra distribuido en el sector NE de la cuadrícula A12 y en los sectores NE y SE de la cuadrícula B12 (Figura 7.66a).

$\mathrm{El}$ análisis de las frecuencias óseas, contemplando el conjunto completo (tridis y generales) muestra que la cuadrícula A12 concentra la mayor cantidad de especímenes (62,3\%). Por otro lado, el análisis de la densidad de restos óseos por $\mathrm{m}^{2}$ (Figura 7.66b) muestra que el sector NE de A12 presenta la mayor densidad concentrando cerca del 40\% del conjunto de Capa 1. Los sectores NE y SE de B12 y SE de A12 si bien presentan densidades muy inferiores a la que se observa en el NE de A12, registran valores elevados (alrededor de 350 especímenes por $\mathrm{m}^{2}$ cada uno). Una menor densidad (menos de 200 especímenes óseos por $\mathrm{m}^{2}$ ) se registra en los sectores NW y SW de A12 y B12 (Figura 7.66b). Este análisis permite observar una diferencia en la distribución y densidad entre los restos óseos tridimensionados (Figura 7.66a) y el conjunto completo (Figura 7.66b).

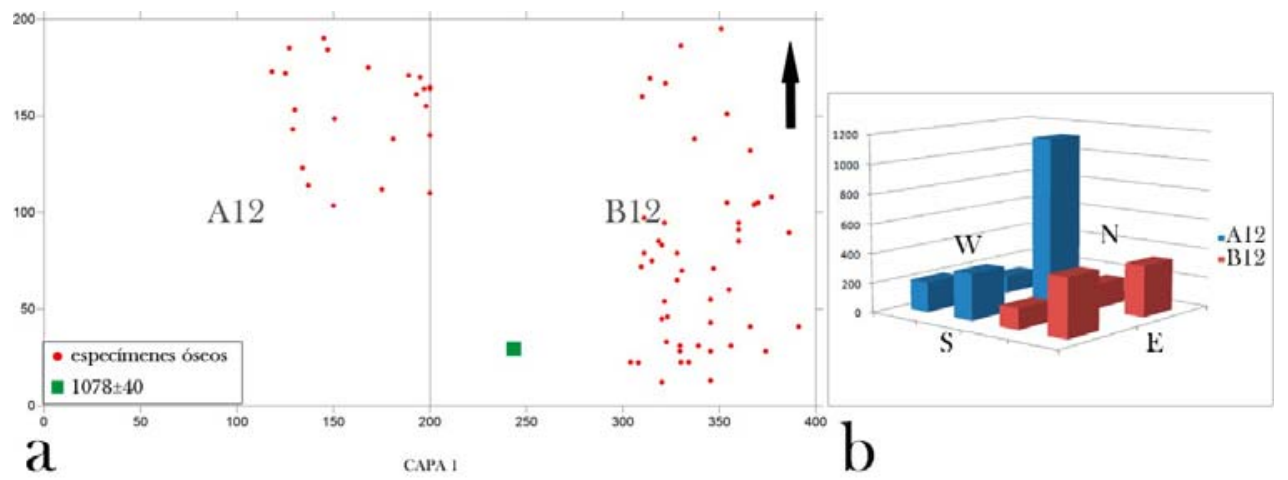

Figura 7.66. a) Distribución en planta de los especímenes tridimensionados en Capa 1 de

CS de MA; b) densidad de restos óseos por cuadrícula (A12 y B12) y sector de excavación (NE, NW, SE y SW).

Durante las excavaciones de la Capa 1 se identificaron tres áreas principales de combustión. Una de ellas en el sector NW de la cuadrícula B12, otra en el vértice NE del sector homónimo de A12 y la tercera en el Sur de A12, abarcando el sector SE y SW. En este nivel se registró la presencia de un gran bloque de basalto en el norte de la cuadrícula 
A12, entre los sectores NE y NW (Figura 7.67a). Este bloque de unos $65 \mathrm{~cm}$ de diámetro, apoyaba sobre la base de este nivel. Durante las excavaciones de B12, desde el perfil este y con dirección NW, se registró un pircado hecho con piedras locales (Figura 7.67b), posiblemente resultado de la ocupación post-hispánica que tuvo la cueva.
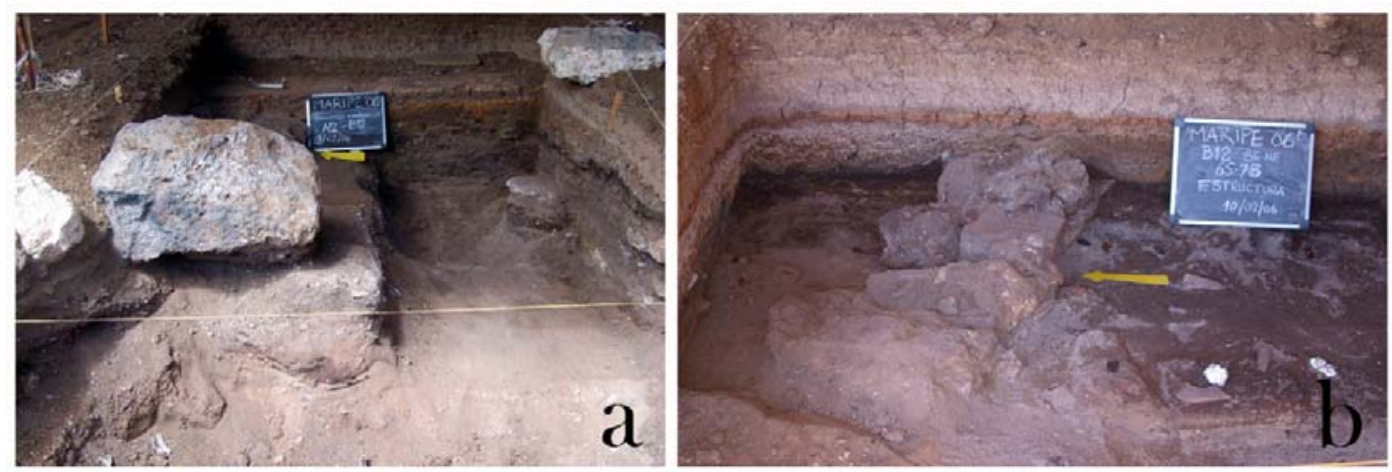

Figura 7.67. a) Bloque de basalto en sectores NE y NW de A12; b) pared de piedra o pirca en el este de la cuadrícula B12.

\subsubsection{Abundancia taxonómica y anatómica}

Los análisis realizados permiten observar que la especie más representada en el conjunto es Lama guanicoe con un 33,57\% del NISP\% (Tabla 7.14). En segundo lugar se identifican mamíferos de tamaño grande (28,9\% del NISP\%) y mamíferos indeterminados (16,7\%). Los rheidos se encuentran representados en un 2,65\% del NISP. Además, se identificaron restos de Ovis aries (oveja) y un elevado número de restos de micromamíferos (Tabla 7.14). Escasos especímenes (< 1\% del NISP) de otras especies fueron determinados, entre los que se destacan restos de aves de distintos tamaños y 5 fragmentos de valva (Tabla 7.14). 


\begin{tabular}{|l|c|c|c|}
\hline & NISP & \%NISP & M NI \\
\hline Ave Indet. & 1 & $0,18 \%$ & - \\
\hline Ave peq. & 3 & $0,53 \%$ & - \\
\hline Ave Gde. & 1 & $0,18 \%$ & - \\
\hline Rheidae* & 19 & $3,33 \%$ & 1 \\
\hline Mamifero Indet. & 95 & $16,67 \%$ & - \\
\hline Micromamifero & 62 & $10,88 \%$ & - \\
\hline Mamifero peq. & 1 & $0,18 \%$ & - \\
\hline Mamifero Gde. & 164 & $28,77 \%$ & - \\
\hline Artiodactyla & 1 & $0,18 \%$ & \\
\hline Ovis aries & 28 & $4,91 \%$ & 1 \\
\hline Lama guanicoe & 190 & $33,33 \%$ & 2 \\
\hline Caracol & 5 & $0,88 \%$ & - \\
\hline *i2 especimes
\end{tabular}

* 12 especimenes corresponden a fragmentos de cáscara de huevo

Tabla 7.14. Abundancia taxonómica en la Capa 1 de CS de MA.

La relación MNE/NISP arroja un valor de 0,42 que indica la existencia de una alta fragmentación en el conjunto. El MNI estimado para guanaco es 2, siendo al menos uno de los individuos un chulengo.

Se registra la presencia tanto de elementos axiales como apendiculares del guanaco (Tabla 7.15). Los que alcanzan las frecuencias más elevadas son la mandíbula (100\% del MAU\%) y los metatarsos (100\% del MAU\%).

Dentro del esqueleto apendicular, la frecuencia de partes muestra un patrón similar entre el miembro anterior y el posterior. Dentro de la pata delantera, los valores más elevados los registra la diáfisis del húmero (75\% del MAU\%). Sin embargo, los restantes elementos también fueron determinados en frecuencias que varían entre un 25\% y un 50\% del MAU\% (Tabla 7.15). Las únicas ausencias para el miembro anterior se observan para la porción proximal del húmero y de radio-cúbito además de para algunos carpianos (Tabla 7.15).

Con respecto al miembro posterior, luego de la elevada frecuencia que presentan los metatarsos, encontramos que la diáfisis de la tibia alcanza el 75\% del MAU\%. Los restantes elementos se encuentran presentes en frecuencias que van de un $25 \%$ a un $50 \%$ del MAU\%. Además de la ausencia de algunos elementos del tarso, la única porción que no se registra es la tibia proximal (Tabla 7.15).

Una diferencia que se observa en la representación de los miembros consiste en una tendencia a mayor frecuencia de los elementos distales (metapodio y tibia) en la pata 
posterior (Tabla 7.15).

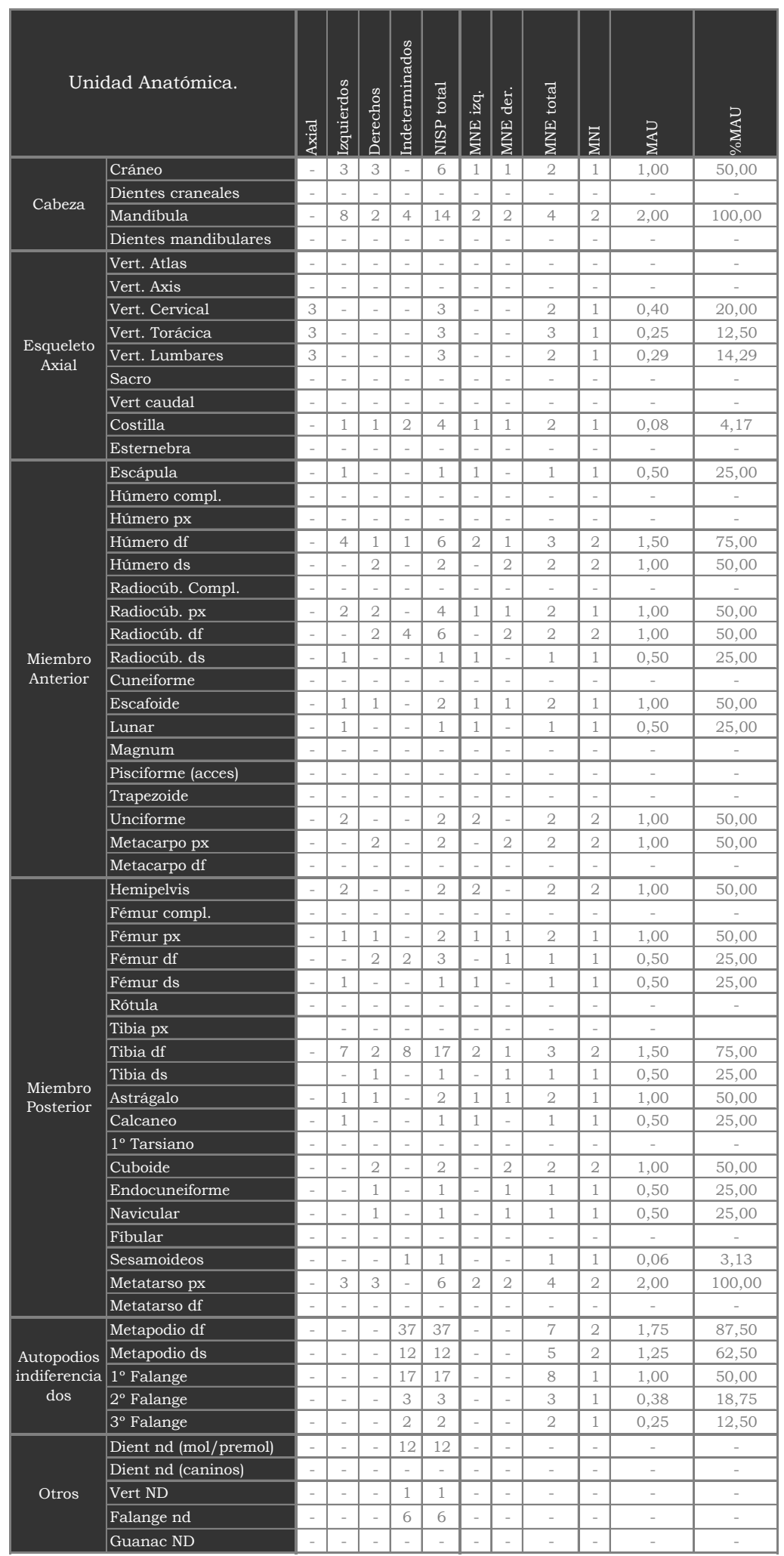

Tabla 7.15. Representación de partes anatómicas de guanaco en la Capa 1 de CS en MA. 
En la Tabla 7.15 se observa además, una frecuencia importante de autopodios indiferenciados, entre los que los metapodios alcanzan el mayor porcentaje. Estos valores refuerzan la tendencia de una representación importante de los elementos del autopodio de los guanacos.

En cuanto a los elementos del esqueleto axial, como se dijo anteriormente, la cabeza se encuentra representada por la mandíbula que alcanza los valores máximos de MAU\%, y por el cráneo $($ MAU\%= 50). En lo que compete a los elementos del tronco de los guanacos, están representadas en bajas frecuencias las vértebras cervicales, las torácicas, las lumbares y las costillas, todos en valores inferiores al 20\% del MAU\% (Tabla 7.15).

De este análisis se desprende que las principales unidades de trozamiento serían la cabeza y los cuartos. Dentro de los cuartos, la porción distal de la pata trasera es la de mayor frecuencia. Este patrón de representación podría estar reflejando una estrategia de descarte particular que será evaluada más adelante.

El análisis de densidad y distribución de restos óseos de guanaco (Figura 7.68) muestra una tendencia distinta a la que se observa para el conjunto completo (Figura 7.66b) donde el sector NE de A12 concentra la mayoría de los materiales. En el caso de los guanacos, la mayor densidad de restos se concentra en dos sectores, el NE de A12 y el SE de B12, cada uno de los cuales registra más de 50 especímenes de guanaco por $\mathrm{m}^{2}$ (Figura 7.68). En los demás sectores, si bien todos presentan restos de guanaco, ninguno de ellos supera los 20 especímenes por $\mathrm{m}^{2}$. De esta forma, la distribución de los restos de guanaco se presenta con valores de densidad más homogéneos entre los distintos sectores que los registrados para todo el conjunto.

El gran número de especímenes de Mamífero de tamaño grande corresponde en su mayoría $(57,3 \%)$ a fragmentos de hueso largo que no han preservado, o por el grado de fragmentación que tienen o por la acción de procesos tafonómicos, rasgos o características diagnósticas para poder ser asignados a una categoría taxonómica más específica. Sin embargo, dichos restos tendrían amplias posibilidades de corresponder a L. guanicoe. La evaluación de si las partes anatómicas registradas en esta clase podrían estar complementando las ausentes entre los guanacos mostró que solamente se podrían incrementar los valores de NISP para los fragmentos medios de costillas (NISP=23), para los dientes a partir de pequeños fragmentos de esmalte $(\mathrm{NISP}=18)$, para las vértebras ( $\mathrm{NISP}=8$ ), y para el cráneo a partir de algunos escasos fragmentos ( $\mathrm{NISP}=2$ ). 


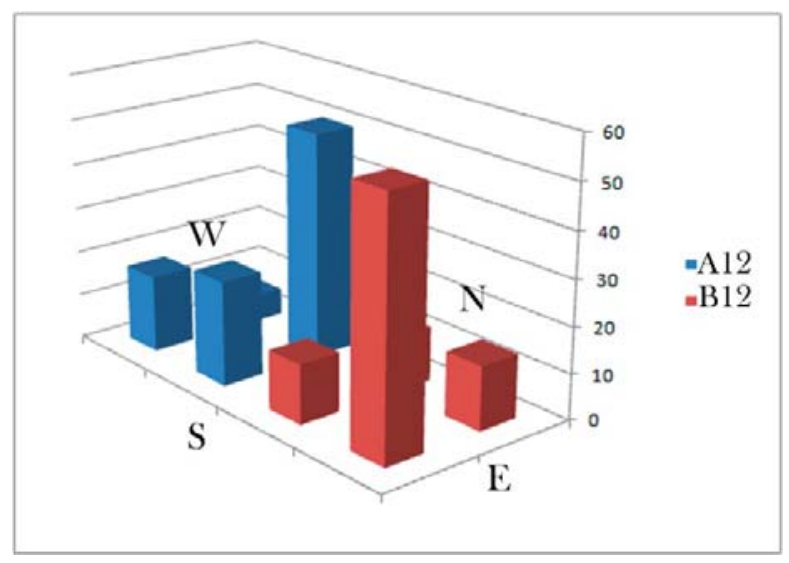

Figura 7.68. Distribución de restos óseos de guanaco por sector de cuadrícula en la Capa 1 de CS.

\subsection{Análisis de la estrategia de transporte de partes anatómicas de guanaco}

Las correlaciones de Spearman para la especie Lama guanicoe, dieron los siguientes resultados (Figura 7.69). Es decir, que la frecuencia de partes anatómicas se correlaciona de forma positiva con la DO $(\mathrm{r}=0,62 ; \mathrm{p}<0,05)$, sugiriendo que los procesos mediados por densidad habrían actuado sobre aquellos elemento de menor DO provocando su destrucción parcial o total (Figura 7.69a). Por otro lado, los resultados alcanzados al correlacionar las frecuencias de MAU\% con los dos índices de utilidad de carne, muestran en ambos casos una ausencia completa de correlación (Figuras 7.69b y 7.69c). Estos resultados no reflejan un patrón de selección antrópico que se relacione estrictamente con el aporte cárnico que dichas unidades hacen a la dieta.

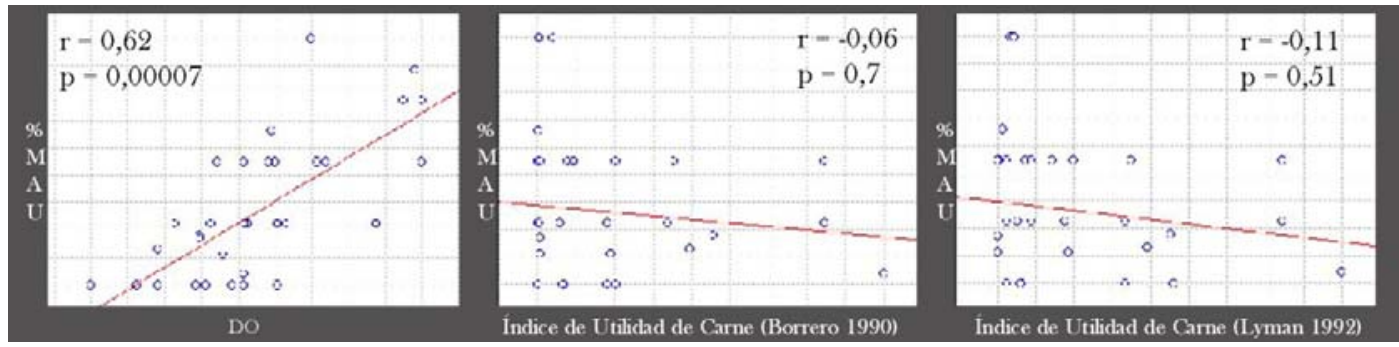

Figura 7.69. Correlaciones estadísticas de Spearman: a) MAU\%-DO; b) MAU\%-Índice de Utilidad (sensu Borrero 1990); c) MAU\%-Índice de Utilidad (sensu Lyman 1992).

Considerando la propuesta interpretativa realizada por Lyman (1994: 264), el conjunto de Capa 1 caería en la Clase 4 "lag or ravaged", sugiriendo la posibilidad de que 
haya estado expuesto a la acción de procesos mediados por DO. No obstante, y como fue mencionado para los otros conjuntos, los factores intrínsecos de variabilidad de la DO, también pueden estar jugando un papel importante en estos resultados. Por tal motivo no se descarta la pérdida de especímenes de individuos juveniles o cría. Por otro lado, la existencia de una estrategia vinculada al transporte de unidades de bajo rendimiento energético pero que pueden aportar otros productos como médula o tendones, no se descarta para la interpretación del conjunto.

\subsubsection{Modificaciones de las superficies óseas}

\subsection{Patrones de modificaciones naturales}

Los resultados obtenidos del análisis de modificaciones óseas en restos de guanaco permiten observar que un $69 \%$ de los especímenes registran estadios bajos de meteorización (estadios 1 y 2 sensu Behrensmeyer 1978) (Figura 7.70). Sin embargo, un $31 \%$ de los especímenes exhibieron una meteorización en estadio 3 que estaría indicando un mayor deterioro de las superficies y posible pérdida ósea en el conjunto. Esta tendencia que concentra la mayor parte del conjunto en estadios menores al 3 indicaría un tiempo relativamente corto de exposición y un enterramiento sincrónico, que se podría traducir en una relativamente buena preservación del conjunto.

El análisis de la meteorización en elementos axiales y apendiculares permitió observar la misma tendencia que para el conjunto completo (Figura 7.70). De esta manera no fue posible identificar variaciones en la meteorización que puedan estar relacionadas a las distintas regiones del esqueleto $\mathrm{y}$, por lo tanto, a las diferencias de DO propias de cada una. Es posible que la presencia de una fracción menor del conjunto en un estadio 3 de meteorización, pueda estar más en relación con una característica de fragmentación elevada del conjunto que con estas diferencias de DO entre especímenes axiales y apendiculares. De todas formas, para la interpretación de la meteorización, se considera, al igual que para la DO, la variabilidad intra-taxonómica que puede producir una meteorización diferencial sobre el conjunto. 


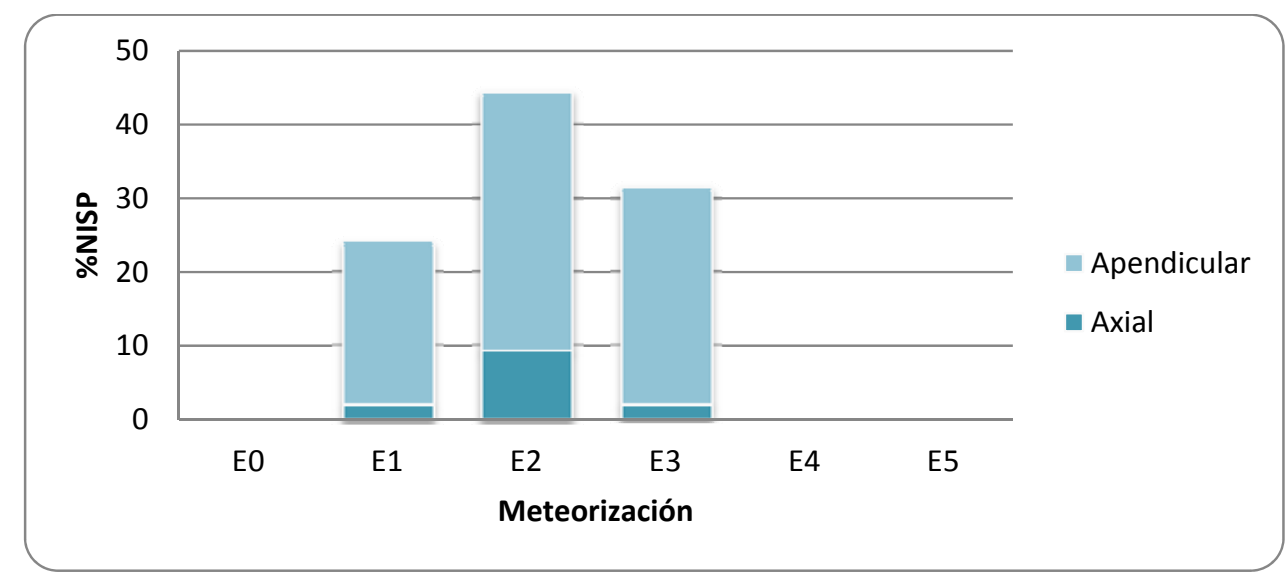

Figura 7.70. Tendencia de la meteorización en especímenes asignados a L. guanicoe en el conjunto de la Capa 1 de CS de MA. Los valores son expresados en \%NISP.

Se registraron otras modificaciones naturales sobre las superficies óseas de las arqueofaunas (Figura 7.71a). En un 8,94\% de los restos se registra la presencia de depósitos de manganeso (Figura 7.72a). Estos depósitos estarían indicando la existencia de alguna condición de humedad. Esto se relaciona con que, sea que provengan de la disolución de una roca carbonática o de la descomposición de materia orgánica, requieren agua para ser transportados y cambios de $\mathrm{pH}$ para precipitar sobre los huesos (López-González et al. 2006; Marín Arroyo et al. 2008; Shahack-Gross et al. 1997).

Otras modificaciones de origen natural como las provocadas por la acción de roedores, carnívoros, raíces, carbonatos y pisoteo también se encuentran presentes pero en frecuencias tan bajas que no superan el 1\% de los especímenes (Figura 7.71a). 


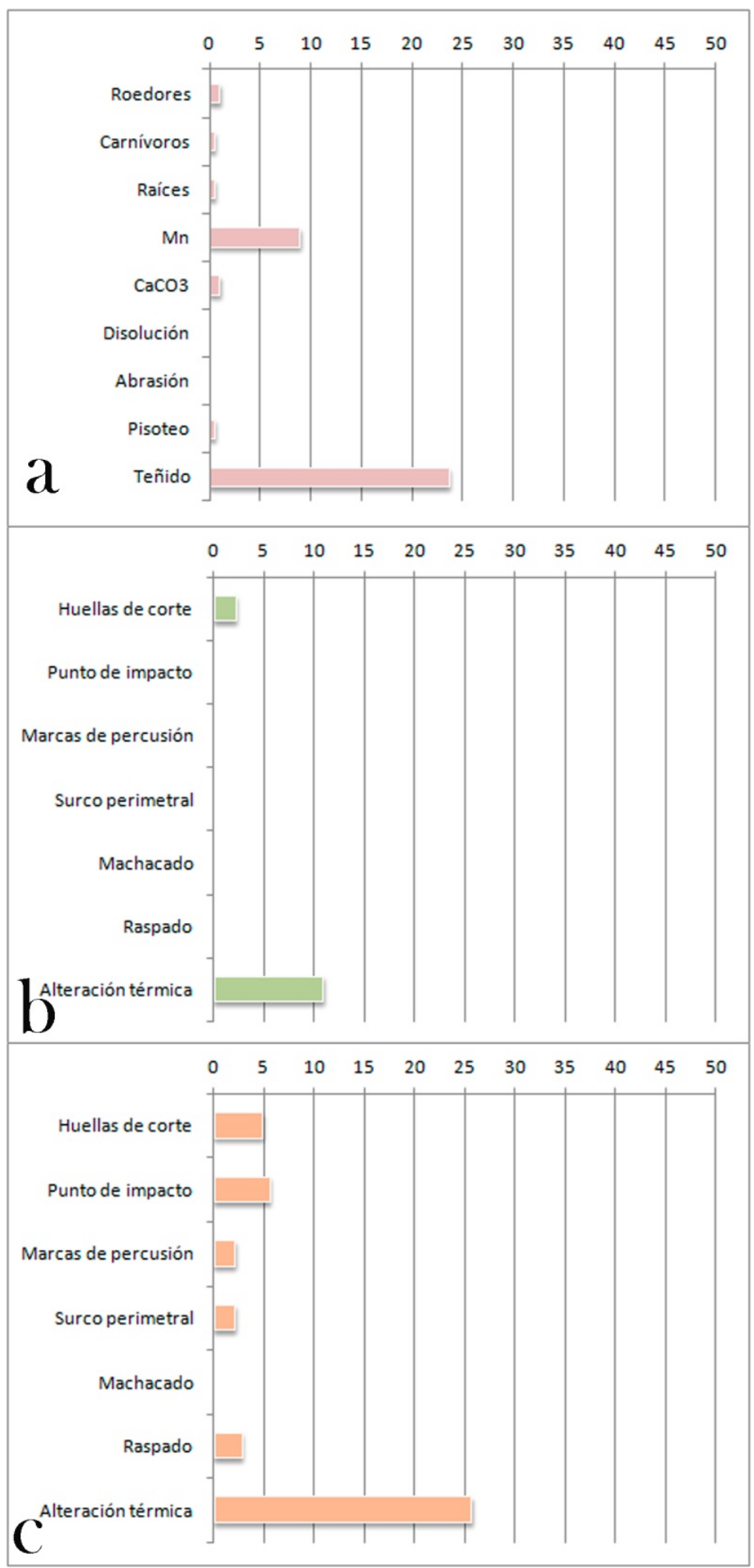

Figura 7.71. Frecuencia porcentual de especímenes óseos de guanaco con modificaciones: a) naturales; b) modificaciones antrópicas en especímenes del esqueleto axial; c) modificaciones antrópicas en el esqueleto apendicular. 

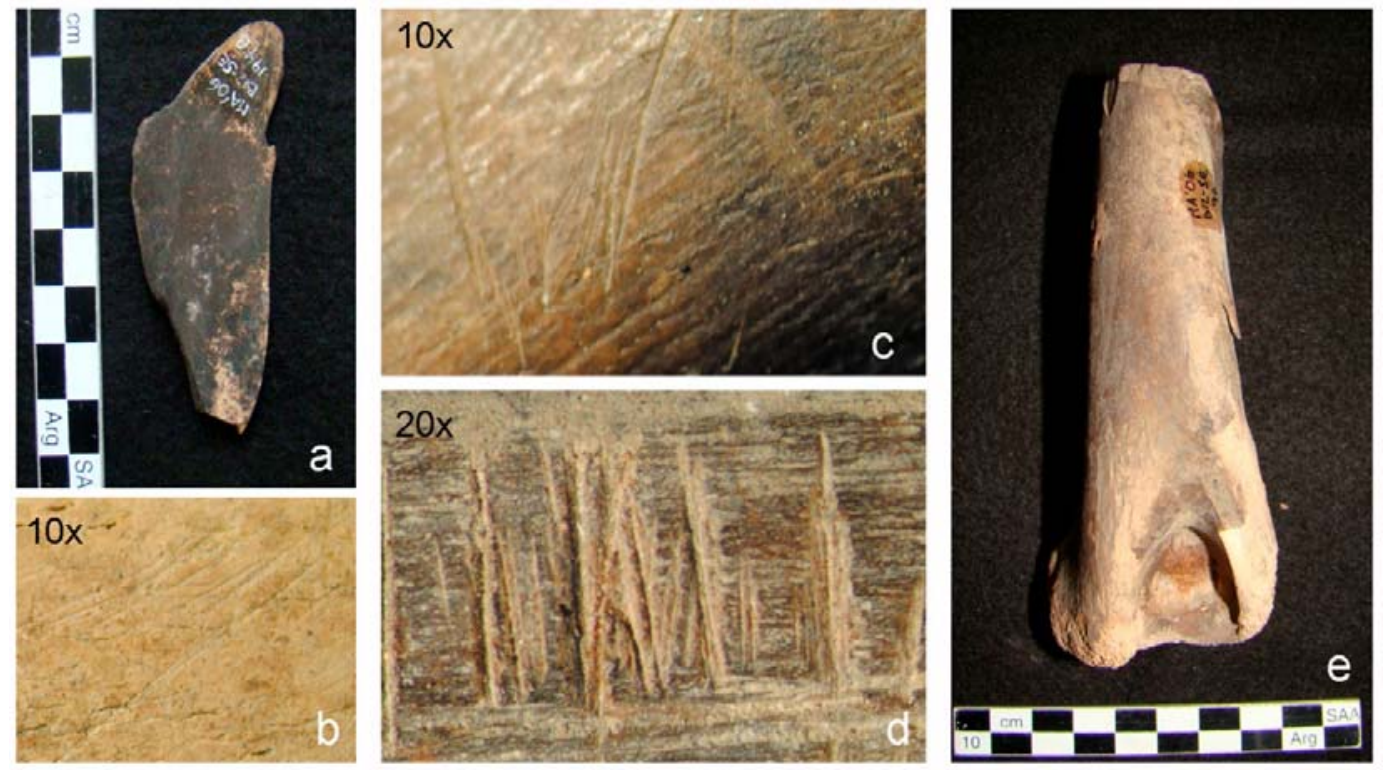

Figura 7.72. Modificaciones naturales y culturales en el conjunto de Capa 1 de CS de MA. a) depósito de manganeso; b) huellas de corte en vértebra torácica; c) huellas de corte en húmero distal; d) huellas de corte en diáfisis de metapodio; e) húmero distal con surco perimetral.
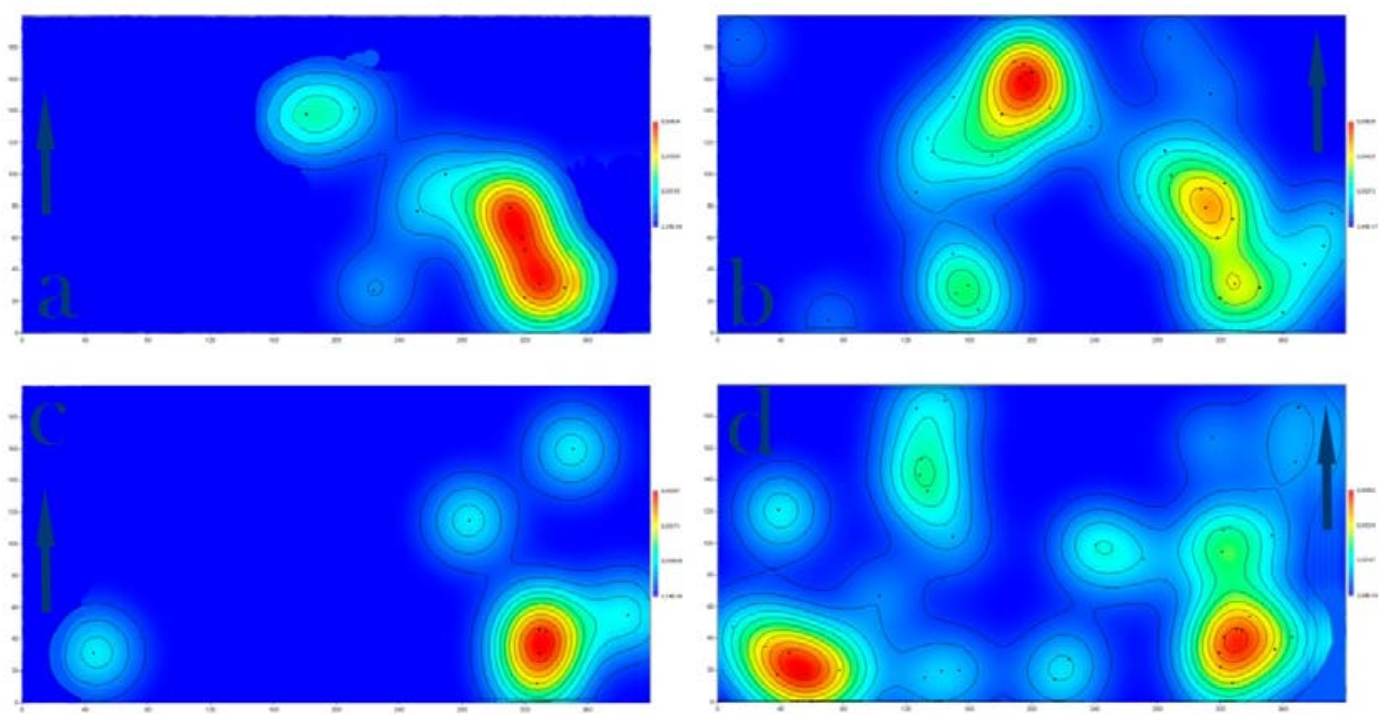

Figura 7.73. Distribución espacial de especímenes con modificaciones en las superficies:

a) especímenes con manganeso; b) especímenes teñidos; c) especímenes con huellas de corte; d) especímenes con alteración térmica.

Los especímenes con manchas de manganeso (Figura 7.72a) se encuentran todos concentrados en el sector SE de B12 (Figura 7.73a). Esta distribución estaría indicando 
que posiblemente en ese sector existieron condiciones de mayor humedad que en los restantes.

Un porcentaje importante $(23,68 \%)$ de especímenes fueron agrupados en la categoría de teñidos ya que sus superficies se encontraban ennegrecidas, y no pudo determinarse si eso era producto de la alteración térmica o de depósitos de manganeso. El análisis de la distribución de estos especímenes permite observar (Figura 7.73b) una concentración menor en el sector SE de B12. Sin embargo, una mayor densidad de restos teñidos se registra en el sector NE de A12 (Figura 7.73b). La menor de estas concentraciones coincide con el sector donde se registra una densidad alta de especímenes con manganeso. Esta superposición podría sugerir que esos especímenes ennegrecidos tienen altas posibilidades de estar así de oscurecidos por la presencia de manganesos en sus superficies.

\subsection{Patrones de modificación antrópica}

Distintos patrones de modificación antrópica se reconocieron tanto en los especímenes del esqueleto axial como apendicular (Figuras 7.71 b y $7.71 \mathrm{c}$ ). La frecuencia más alta corresponde a restos óseos quemados aunque también se observa una gran variedad de marcas vinculadas al procesamiento de las carcasas.

Entre las marcas de procesamiento, en el esqueleto axial solamente un espécimen presentó huellas de corte (Figura 7.72b), mientras que una frecuencia más elevada $(10,8 \%)$ se observa para restos óseos termoalterados (Figura 7.71b).

Entre las modificaciones que se registran sobre especímenes apendiculares (Figura 7.71c), las que alcanzan la mayor frecuencia corresponden a los especímenes quemados $(25,69 \%)$. Con respecto a las marcas estrictamente relacionadas al procesamiento de los guanacos, los puntos de impacto $(5,5 \%)$ para fracturar el hueso y las huellas de corte $(4,86 \%)$ son las más frecuentes (Figuras $7.72 \mathrm{c}$ y $7.72 \mathrm{~d}$ ). Otras marcas relacionadas al procesamiento secundario de los guanacos, como las marcas de percusión y de raspado, se registran en frecuencias menores al 2\% (Figura 7.71c).

Los especímenes que presentan huellas de corte se distribuyen con mayor densidad y casi exclusivamente en el sector SE de la cuadrícula B12 (Figura 7.73c).

Entre los especímenes quemados del esqueleto axial y apendicular, alcanzan una frecuencia del 22,15\% en el conjunto. Su distribución (Figura 7.73d) muestra que dos áreas de mayor densidad, una en el sector SE de B12 y la otra en el sector SW de A12. 
La primera de estas dos áreas coincide con el sector de mayor densidad de restos con depósito de manganeso, con lo especímenes teñidos y con las mayores frecuencias de especímenes con huellas de corte. En ese sentido, el sector SE de B12 se presenta como un área especial de actividad dentro del sitio; a pesar de ello, la distribución solapada de especímenes quemados y con manganeso en ese mismo sector no contribuye a esclarecer las causas de los especímenes ennegrecidos que también se concentran allí. Por otro lado, la densidad elevada de restos óseos quemados en el SW de A12 permite sugerir la existencia de algún fogón en ese sector.

Entre las modificaciones antrópicas identificadas en el conjunto, se reconoce la presencia de un espécimen de ave mediana y varios especímenes de oveja $(n=9)$ con alteración térmica en sus superficies. Esta información estaría indicando su utilización por parte de las sociedades que habitaron la cueva en estos momentos tardíos del Holoceno.

El análisis de los tipos de fracturas registrados en los 117 especímenes de huesos largos $(61,6 \%)$ nos permitió reconocer un total de 163 fracturas ya que la mayoría de los restos presentaba más de un tipo. Entre las posibles causas de fractura se identificaron tanto patrones antrópicos $(n=89)$ como tafonómicas $(n=74)$.

Las fracturas longitudinales (35\%) son las más numerosas en el conjunto (Figura 7.74), en su gran mayoría registran atributos asociados a ellas que nos permitieron atribuirlas al agente humano. Entre las marcas asociadas encontramos puntos de impacto, marcas de raspado, percusión y huellas de corte. El extremadamente bajo registro de modificaciones producidas por carnívoros (Figura 7.71a) respalda el rol del agente humano como responsable. En 19 especímenes con fracturas longitudinal (33,3\%), no se registró este patrón antrópico característico y por lo tanto, son consideradas productos tafonómicos.

Se registró un 20,2\% de especímenes con un patrón de fractura helicoidal, resultado de fracturar el hueso por medio de una fuerza dinámica cuando éste aún se encontraba en estado fresco. Estas fracturas son consideradas de tipo intencional y, por lo tanto, asignadas al agente antrópico.

Una importante frecuencia de restos óseos registra un patrón de fractura transversal (23\%). Estas fractura, a excepción de las que registran los 3 especímenes con presencia de surco perimetral, son atribuidas a una causa tafonómica ya que sus bordes de fractura son irregulares y presentan superficies rugosas, lo cual indica que el hueso se fragmentó cuando se encontraba en estado avanzado de deshidratación (seco).

Finalmente, el registro de fracturas oblicuas se observó en un 21\% de los 
especímenes (Figura 7.74). De estas fracturas, 15 (44,11\%) presentan superficies suaves y sin cambio de coloración lo que permite pensar que se produjeron cuando el hueso aún se encontraba fresco, y posiblemente sean resultado de actividad cultural. Las 19 fracturas oblicuas restantes $(55,9 \%)$, muestran patrones irregulares (astillados, escalonados) por lo que se considera un origen tafonómico para ellas.

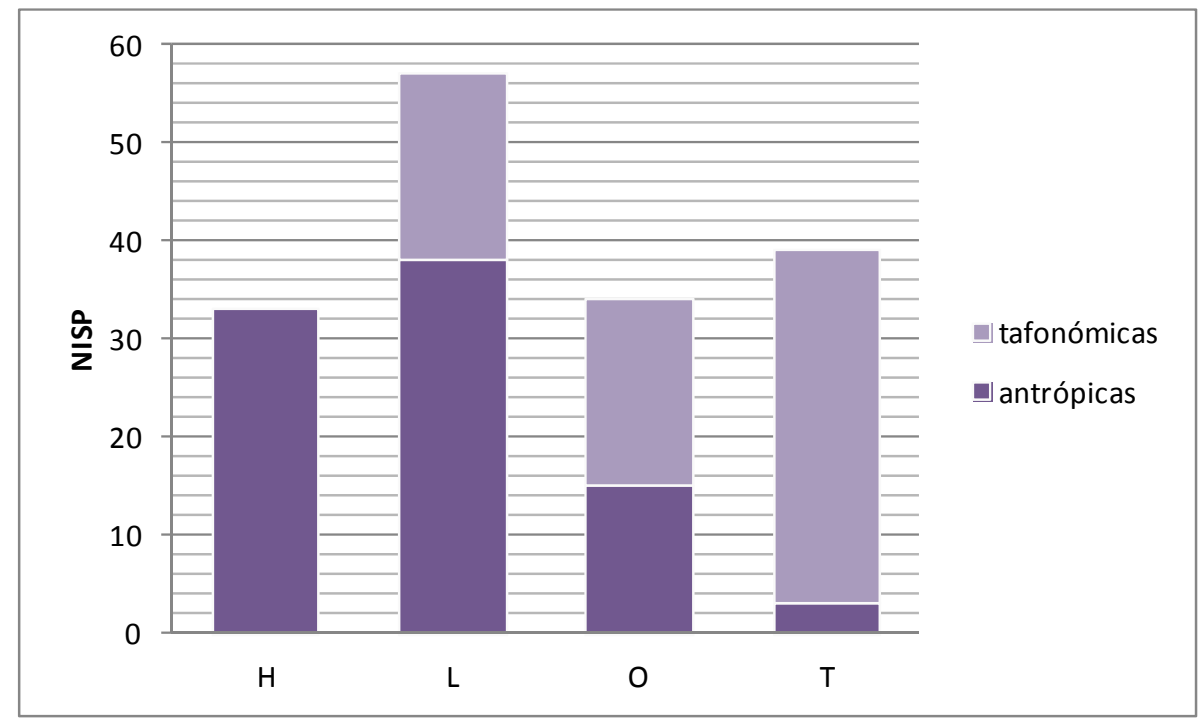

Figura 7.74. Frecuencia absoluta y tipos de fracturas identificadas: H) helicoidal; L) longitudinal; O) oblicua; T) transversal.

En este nivel, además de los tres huesos con surco perimetral, que podrían ser considerados formas base o instrumentos, no se registraron instrumentos o artefactos óseos formatizados.

\subsection{DISCUSIÓN DE LA VARIABILIDAD INTRASITIO}

Se analizaron un total de 7 conjuntos zooarqueológicos procedentes de dos sectores excavados en el sitio MA, y que corresponden a las partes más externas de las CN y CS de la cueva (Figura7.2). La información cronológica existente para el sitio indica que la cueva fue habitada desde la primera etapa de ocupación de la localidad (Tabla 7.1), siendo asimismo una de las más tempranas ocupaciones del área de cabeceras de la cuenca en estudio. Dicha ocupación corresponde a momentos de la transición 
Pleistoceno-Holoceno y del Holoceno temprano. Sin embargo, se destaca que en esta cueva la redundancia de ocupaciones fue a lo largo del Holoceno, llegando hasta tiempos recientes (primera mitad del siglo XX).

En esta sección de discusión de la variabilidad intrasitio, las etapas de poblamiento propuestas para el área (ver Capítulo 2 y 5) son utilizadas como unidades temporales de análisis. De esta manera, la discusión se centra en la comparación entre conjuntos con cronologías similares. Conocer los distintos procesos y agentes que afectaron a los conjuntos zooarquelógicos permitió evaluar en cada uno los aspectos particulares de su historia de formación.

\subsubsection{Transición Pleistoceno-Holoceno y Holoceno temprano en MA}

Para este lapso ocupacional del área, en MA se recuperaron dos conjuntos arqueofaunísticos: el correspondiente a Capa 5 de $\mathrm{CN}$ y el procedente de Capa 3 de CS. Si bien los fechados de CS (entre ca. 9500 y 8300 años AP) indican que ese sector de la cueva se habría ocupado antes que CN (ca. 8900 y 8700 años AP), en esta última las fechas radiocarbónicas proceden del techo de la Capa 5 y, por lo tanto, la expectativa es que su base alcance una antigüedad similar a la CS.

Los análisis distribucionales (Figuras 7.5 y 7.48) permiten sugerir que en ambas cámaras la fragmentación fue la más baja de toda la secuencia, que existieron lugares particulares con mayor concentración de restos arqueofaunísticos y que en CS se concentran en 2 zonas, una alrededor de un fogón en el sector más interno y otra sin relación a estructuras de combustión, y más cercana a la boca de la cueva. Por su parte, en $\mathrm{CN}$ las concentraciones coinciden con el entorno inmediato y el interior de los fogones. 


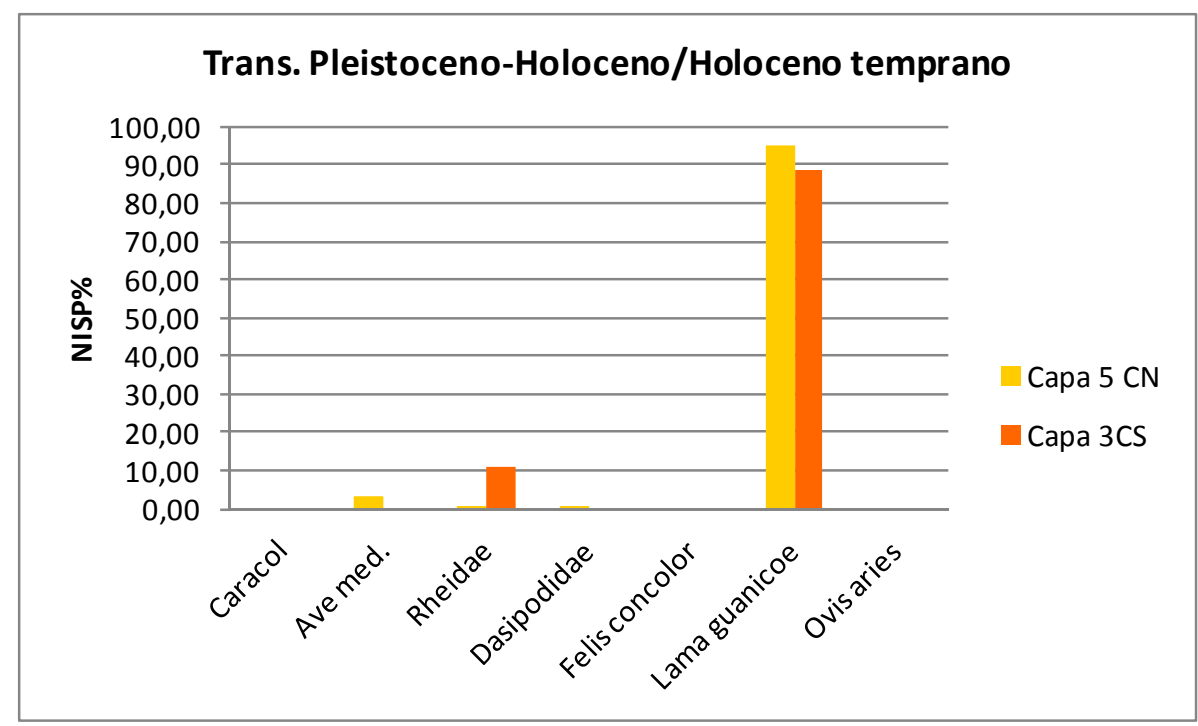

Figura 7.75. Abundancia relativa de especies aprovechadas durante la transición

Pleistoceno-Holoceno y el Holoceno temprano en MA.

En cuanto a las especies identificadas, y que registran alguna evidencia de haber sido utilizadas por los primeros grupos cazadores-recolectores que habitaron la cueva, sin duda Lama guanicoe es la que se encuentra mejor representada, alcanzando en CN frecuencias mayores que en CS (Figura 7.75). En ninguno de los dos conjuntos se identificó, hasta el momento, fauna pleistocénica extinguida; todos los especímenes identificadas corresponden a taxones que actualmente habitan el área. La única excepción la podrían constituir los dos restos óseos de rheidos, cada uno procedente de uno de los conjuntos. Hasta el momento no fue posible asignarlos a alguna de las dos especies vivientes en Patagonia: Rhea americana (ñandú grande o de las pampas) en Nordpatagonia, y Pterocnemia pennata (ñandú petiso o choique) hacia el sur (Cardich y Miotti 1983; Tambussi y Tonni 1985). Sin embargo, en el caso de que alguno de esos especímenes corresponda a $R$. americana no nos estaríamos refiriendo a una especie extinguida sino a su desaparición del área como resultado del desplazamiento hacia el norte (Cardich y Miotti 1983; Miotti y Salemme 1999; Salemme y Miotti 1987; Tambussi y Tonni 1985). Si esta determinación fuera posible de alcanzar, apuntaría a que podamos afinar las hipótesis paleoambientales ya que, como se propone en esos trabajos, $R$. americana no estuvo disponible en el área después de los $9000 \mathrm{AP}$, momento en que las condiciones ambientales se vuelven más erémicas. De esta forma, y como se observa en la Figura 7.75, tanto los rheidos como las aves de tamaño mediano habrían tenido una importancia como recurso complementario en la economía de estos grupos desde los 
inicios del poblamiento del sector de cabecera de cuenca.

En el conjunto de CN, un 35,2\% de los especímenes quedaron indeterminados mientras que en CS esa frecuencia alcanza el 48,4\% del conjunto. Esta dificultad por determinar un mayor porcentaje de especímenes en cada conjunto posiblemente esté relacionada con la fragmentación existente y/o preservación del mismo. Esta situación podría ser la responsable de que esa cantidad de fragmentos no hayan preservado características diagnósticas para su determinación. De todas formas, la diferencia en los porcentajes de indeterminados entre los conjuntos estaría indicando que los procesos responsables de la transformación (como fracturación, quemado, tinción y carbonatación) de los elementos óseos habrían sido más intensos en el conjunto de CS (Figura 7.76). Esta tendencia a una menor preservación del conjunto de CS también fue observada por Lynch (2012) en los materiales líticos de MA, donde registra una preservación diferencial de rastros de uso, siendo esta menor en $\mathrm{CS}$ que en $\mathrm{CN}$.

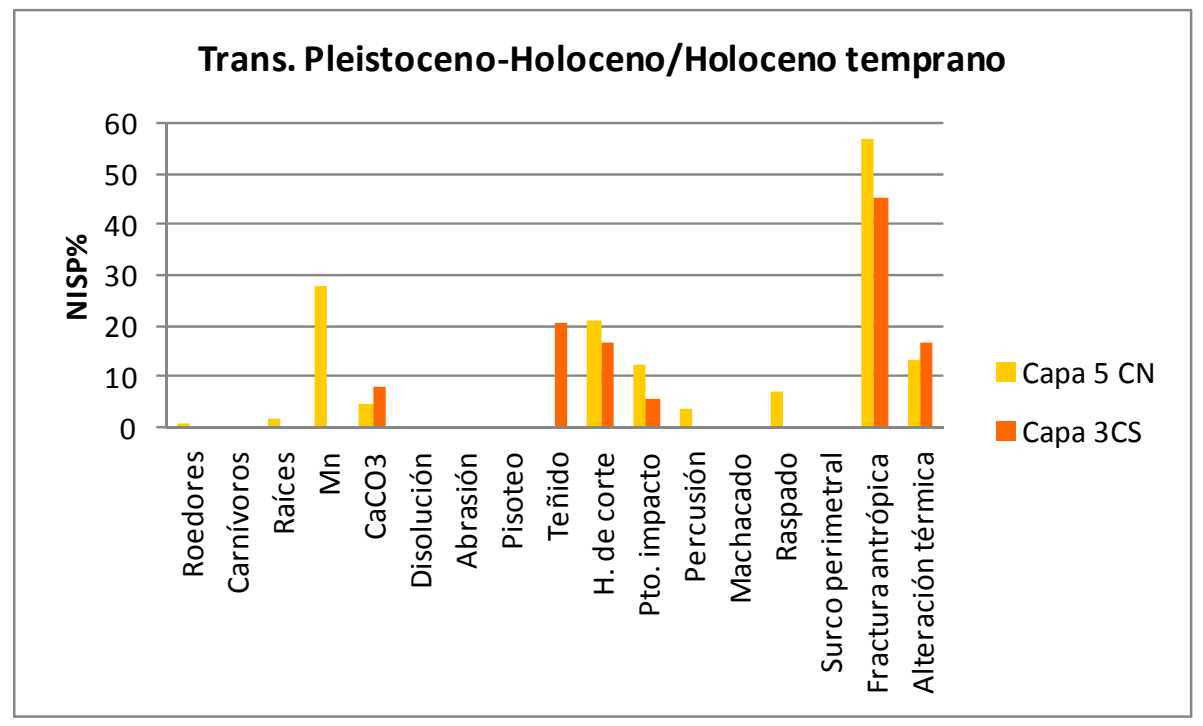

Figura 7.76. Modificaciones sobre las superficies de especímenes óseos correspondientes a los conjuntos del Pleistoceno final- Holoceno temprano en MA.

El guanaco aparece como el principal recurso económico de los cazadores recolectores que habitaron MA durante los primeros momentos de ocupación del área (Figura 7.75). Esta tendencia difiere de la expectativa que proponen los modelos de poblamiento del área con el desarrollo de una estrategia más generalista, aunque con un componente importante en el guanaco, complementada por otras especies entre las que se encuentran los megaherbívoros pleistocénicos (Borrero 1994-95; Miotti 1998; Miotti y 
Salemme 1999). Aquí, la estrategia que se observa se encuentra totalmente centrada en el recurso guanaco, posiblemente debido a que en estos momentos las poblaciones de estas especies pleistocénicas ya se encontraban prácticamente extinguidas (Miotti y Salemme 1999). Si bien se registra la presencia de rheidos, que podrían constituir un recurso complementario, su bajísima representación en el registro apoya la hipótesis de una estrategia económica completamente basada en estos camélidos.

Sin embargo, como veremos en el capítulo siguiente, en Piedra Museo para la parte final de las ocupaciones humanas de Capa 4/5 (ca. 9000 AP), la desaparición de fauna pleistocénica ya está marcando una tendencia hacia una estrategia focalizada en los camélidos (guanacos y L. gracilis), pero con un espectro mayor de otras especies que el de MA.

Esta tendencia especializada en guanacos es asimismo compartida por ocupaciones de otras cuevas de la meseta, del mismo rango temporal, como las del área del Pinturas (De Nigris 2004; Mengoni Goñalons y Silveira 1976; Silveira 1979), de los lagos cordilleranos (Civalero y Aschero 2003; Franco y Borrero 2003; Miotti y Salemme 1999; Salemme y Miotti 2008; entre otros muchos).

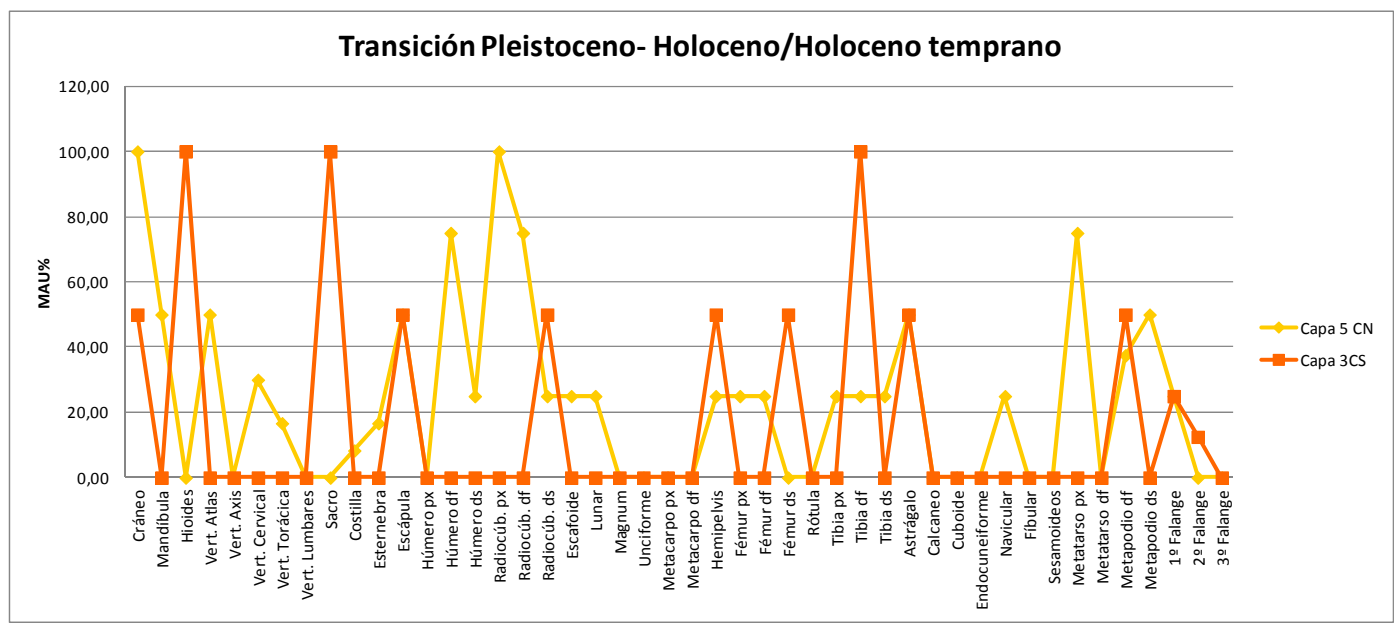

Figura 7.77. Representación de unidades anatómicas en los conjuntos de fines del Pleistoceno y Holoceno temprano en MA.

La frecuencia de partes anatómicas de guanaco muestra que en el conjunto de $\mathrm{CN}$ el cráneo y el radio-cúbito proximal son los elementos más representados (Tabla 7.3 y Figura 7.77). En cuanto a las unidades de trozamiento, esa representación sugiere que en CN la cabeza y la pata delantera, principalmente el zeugopodio y estilopodio, habrían sido las principales unidades transportadas al sitio; en segundo lugar, se encontrarían los 
elementos distales de la pata trasera. Por el contrario, en la CS, las unidades más representadas son la cabeza y la pata trasera (Tabla 7.11 y Figura 7.77). Esto muestra que si bien en ambos conjuntos la cabeza parece ser una unidad seleccionada, se registran variaciones respecto a las decisiones de transporte del esqueleto apendicular. En CN se habría priorizado la pata delantera y en CS la mayor importancia la habría tenido la trasera.

Dado que el hueso hioides se puede considerar como el que va adherido a la lengua, su presencia en el conjunto de CS podría indicar el ingreso de este órgano como parte importante para la alimentación (De Nigris 2004; Mengoni Goñalons 1999; Miotti 1998, entre otros). Se destaca que si bien no existen datos numéricos de DO del hioides para la especie $L$. guanicoe, la misma es aun de bajo rango $(0,36)$ para Bison (Kreutzer 1992), lo que implicaría que, conociendo la tendencia menor de la densidad mineral ósea de los huesos de guanacos, este valor podría ser aun más bajo. Las fuentes etnográficas y etnoarqueológicas también destacan la importancia de estos órganos de los grandes ungulados, ya que son apreciados por su aporte alimenticio y en muchos grupos son considerados manjares (Claraz 1988; De Nigris 2004; Kelly 1995; Miotti 1998; Musters 1964).

Las frecuencias de unidades anatómicas de guanaco entre CN y CS (Figura 7.77) podrían estar complementándose; sin embargo hasta el momento no fue posible establecer remontajes entre estos conjuntos. Esta hipótesis deberá ser evaluada a partir de nuevas evidencias que nos permitan mejorar la resolución temporal de las ocupaciones, ya que las diferencias en los fechados entre cámaras, si bien se solapan, muestran un rango de variación de ca. 1200 años.

El análisis de la fragmentación de los conjuntos a partir de la relación MNE/NISP de guanaco mostró que la tendencia a una fragmentación moderada a alta es similar en las dos cámaras. Esto lleva a cuestionar a la fragmentación como único responsable de los distintos niveles de identificabilidad alcanzados en los dos conjuntos. Profundizar el análisis de la fragmentación de especímenes de otras especies así como de los indeterminados, es una línea de análisis que se prevé desarrollar a futuro para alcanzar una mejor interpretación acerca de esta problemática.

Los resultados de las correlaciones indican que el conjunto de CN (Figura 7.7) caería en la Clase 4 de Lyman (1994), mientras que el conjunto de CS (Figura 7.51) lo haría en la Clase 5. El factor común entre estos dos resultados es la ausencia de correlación entre los índices de utilidad de carne (Borrero 1990; Lyman 1992) y la 
frecuencia de partes anatómicas (MAU\%). De esta manera, el resultado no significativo de correlación no sugiere la existencia de una clara estrategia de transporte en relación con el aporte cárnico de estas unidades. Por otro lado, la diferencia que se registra entre los dos conjuntos consiste en cómo se correlacionan el MAU\% y la DO. En el caso de CN hay una correlación moderada y significativa que sugiere la acción de procesos tafonómicos sobre el conjunto. Por su parte, en CS la correlación del MAU\% y la DO no es significativa. De todo esto se desprende que el conjunto de $\mathrm{CN}$ es el que tiene la mayor probabilidad de haber sufrido la acción de procesos destructivos, sin embargo, los distintos procesos que actúan mediados por densidad como la meteorización, han sido más intensos en el conjunto de CS, donde además se registra la menor tasa de depositación. Si bien consideramos que la representación de partes anatómicas densas en CN puede ser resultado de decisiones humanas, no se descarta la posibilidad de que elementos óseos de menor densidad relativa se puedan haber destruido. En este caso, posiblemente debido al procesamiento previo de los huesos aunque no desechamos factores de variabilidad intra-taxonómica. En ninguno de los dos conjuntos el rendimiento calórico de las unidades parece haber sido el factor que influyó en las decisiones de transporte. Sin embargo, las proporciones de huesos del autopodio y zeugopodio son medianas a altas en ambas cámaras (Figura 7.77), lo cual, y como fue discutido en trabajos previos (Miotti y Marchionni 2011, 2012), avala la hipótesis de una introducción intencional de estas unidades ya sea porque los metacarpos y metatarsos son excelentes huesos para la confección de herramientas como percutores y presionadores, además de aportar un tipo de grasa insaturada de mejor ingestión y palatabilidad (Morín 2007), o porque son partes que podrían ir adjuntas a los cueros de los animales cazados cuando son transportados a las zonas de procesamiento de los alimentos e insumos.

Del análisis de modificaciones de las superficies óseas, encontramos que ambos conjuntos zooarqueológicos muestran estadios bajos de meteorización, resultando de un enterramiento relativamente rápido y sincrónico (Figuras 7.8 y 7.52). En el conjunto de CN se registró una bajísima frecuencia $(3,2 \%)$ de especímenes en estadio 3 de meteorización. Dado que esa meteorización solamente se observa en fragmentos del esqueleto axial, creemos posible que se deba a la menor DO que estos elementos presentan respecto de los apendiculares y, por lo tanto, a su mayor probabilidad de ser meteorizados incluso durante un mismo tiempo de exposición. Sin embargo, sabemos que tanto la DO como las tendencias de meteorización que puede exhibir un espécimen óseo se encuentran influidas por el grado de osificación que cada elemento particular 
registra presenta (Gutiérrez et al. 2010; Massigoge et al. 2010). El grado de fragmentación registrado en estos conjuntos arqueológicos, en la mayoría de los casos no permite aproximarse a una estimación de edad; sin embargo creemos que estos aspectos deben ser considerados ya que generan una supervivencia diferencial de unidades, con menos chances de sobrevivir cuando no se ha alcanzado una completa osificación de los elementos.

El registro de modificaciones naturales de las superficies óseas muestra que ninguno de los dos conjuntos registra marcas producidas por carnívoros, disolución química, abrasión o pisoteo (Figura 7.76). La ausencia de marcas de carnívoros en ambos conjuntos avala la hipótesis sobre un breve tiempo de exposición en superficie ya que estos agentes pueden actuar de dos formas: 1) como depredadores, en cuyo caso los patrones de daños en los huesos adoptan un patrón de intenso marcado y fracturas en topografías específicas; 2) como carroñeros de las presas descartadas por los humanos. Sin embargo, en ambas situaciones, actúan sobre el contexto tanático, no sobre el tafonómico (Borrero y Martin 1996; Borrero et al. 2005; Brain 1981; Haynes 1980; Martin 2008; Mondini 2002, entre muchos otros)

Respecto de las acreciones y tinciones óseas (Figura 7.76), sólo en CN se registran especímenes con depósito de manganeso (28\%). Esta diferencia estaría indicando que el depósito de la Capa 5 de $\mathrm{CN}$ estuvo sometido en algún momento a condiciones de humedad que no se observan en CS. La presencia de gravas abiertas descriptas en el perfil de CN (Miotti et al. 2011; Rabassa et al. 2007) apoya la idea de que las condiciones postdepositacionales de humedad solo se observen sobre el conjunto de CN. Sin embargo, en CS un porcentaje elevado de especímenes (20,8\%) fue catalogado como teñido dado que presentaban sus superficies ennegrecidas, y no fue posible determinar la causa. Esta es una cuestión sobre la que habrá que indagar en posteriores trabajos, ya que de corresponder con depósitos de manganeso indicaría condiciones similares de humedad en ambas cámaras. En el caso de que estudios posteriores indiquen que ese ennegrecimiento se debe a la presencia de manganesos en CS, evaluar su procedencia sería una de las actividades en agenda ya que podría indicar procesos postdepositacionales distintos en cada cámara.

En ambos conjuntos se registraron depósitos de carbonato en bajos porcentajes (Figura 7.76) siendo un poco más elevados los de CS. La presencia de carbonato en ambos conjuntos, al igual que el manganeso, estaría indicando condiciones de humedad ya que estas sales se transportan disueltas en agua. Probablemente su procedencia se 
relacione a la descomposición de la roca de base de la cueva que entra en contacto con este nivel estratigráfico basal.

Mientras que en $\mathrm{CN}$ la frecuencia de marcas de raíces es muy baja (Figura 7.76), en CS directamente no se registran. Esto es contrario a la expectativa que teníamos ya que en CS, durante las excavaciones, se registró la presencia en este nivel de raíces de arbustos que crecen en el talud de la cueva (Collihuaya interquerrina, Duraznillo; Berberis buxifolia, Calafate). Si bien en CN los arbustos también crecen en la boca de la cueva, sus raíces no ingresan al depósito estratigráfico. Consideramos, siguiendo los patrones descriptos por Montalvo (2002), que estas improntas sobre escasos especímenes en CN indican la existencia de cubierta vegetal de gramíneas (Festuca gracillima, coirón dulce; Stipa chrysophylla, coirón amargo) en el momento en que los restos se depositaron. Esta diferencia invita a pensar dos posibilidades: una que la cubierta vegetal se encontraba tanto en $\mathrm{CN}$ como en CS pero que en esta última no afectó las superficies óseas del conjunto; la otra es que los conjuntos de $\mathrm{CN}$ y CS no sean contemporáneos o que las condiciones diferentes de humedad y reparo hayan favorecido una cubierta vegetal en CN pero no en CS.

Tanto en CN como en CS se registraron, en este nivel, sectores perturbados que podían considerarse galerías o cuevas de roedores. A pesar de ello, solamente se registró un $0,8 \%$ de especímenes con marcas asignables a dientes de roedores en CN (Figura 7.76). Si bien la acción de estos roedores sobre el conjunto parece ser baja, dada la presencia de galerías en este nivel que indican la acción de estos agentes una vez que el conjunto fue enterrado, no se descarta que los mismos hayan influido en el desplazamiento horizontal o vertical de los huesos.

El registro de modificaciones antrópicas es abundante en ambas cámaras aunque la mayor frecuencia y variedad se registra en CN (Figura 7.76). El presencia de especímenes con huellas de corte (Figura 7.76), si bien es más elevado en CN (21\%) que en CS $(16,6 \%)$ es importante en ambos conjuntos indicando actividades de procesamiento de las presas. Entre las fracturas identificadas, $\mathrm{CN}$ registra un porcentaje mayor de tipos antrópicos $(57 \%)$ que en CS (45\%). Esta diferencia también se registra en otros patrones de modificación reconocidos y vinculados al procesamiento secundario de las carcasas. Entre esas modificaciones en $\mathrm{CN}$ se registró la presencia de puntos de impacto, de marcas de raspado y marcas de percusión (Figura 7.76). Todas estas modificaciones se relacionan con la búsqueda intencional de impactar en lugares estratégicos del hueso, para fragmentarlo con mayor control. Es posible que estas modificaciones estén 
indicando acceso a la médula ósea, sugiriendo su consumo en el sitio. El controlar la fractura de los huesos es una acción planificada para no astillar el mismo y producir una fractura limpia, sin astillas que puedan incrustarse en la médula y dificultar la ingesta humana. Sin embargo, en este nivel de CN se recuperó un instrumento con intenso micro-pulido en el borde de fractura, que estaría indicando además, la importancia del control de la fractura del hueso para obtener formas base para la producción de instrumentos (Miotti y Marchionni 2011). Esta situación sugiere, entonces, que además de la fractura intencional de los huesos para consumo de médula, ésta pudo estar relacionada a la búsqueda de formas base para la confección de instrumentos óseos. De todas estas modificaciones, en CS además de las huellas de corte se identificaron puntos de impacto avalando la fracturación intencional y controlada de los huesos (Figura 7.76).

Ambos conjuntos presentan especímenes óseos termoalterados que, en ambos sectores, se distribuyen acorde a la disposición que presentan los fogones. En CS, aunque escasos, se encuentran asociados al fogón registrado en el sur de A12.

Si bien más allá de los humanos se han identificado varios y variados agentes y procesos tafonómicos involucrados en la formación de los dos conjuntos, todos ellos están presentes en frecuencias bajas, que no estarían mostrando un problema en la integridad de los conjuntos. La mayor frecuencia registrada para las manchas de manganeso en $\mathrm{CN}$, podrían haber ocultado algunas marcas tanto culturales como naturales. De todas formas, la ausencia de modificaciones producidas por carnívoros tanto en CN como en CS, sumado a una alta frecuencia de huellas de corte, fracturas intencionales y marcas vinculadas al procesamiento secundario de los guanacos indican que el principal agente responsable de la generación de los conjuntos ha sido el antrópico.

La gran cantidad y variedad de marcas de procesamiento en $\mathrm{CN}$ permiten sugerir que en ese sector de la cueva se habrían realizado distintos tipos de actividades relacionadas con el procesamiento de huesos largos para la obtención de médula y la producción de instrumentos óseos. La evidencia de instrumentos óseos y de pigmentos en las superficies interna y externas de algunos huesos largos soporta la hipótesis de la realización de actividades específicas en este sector de la cueva.

Los numerosos indicadores de una variada e intensa actividad cultural que determinamos en $\mathrm{CN}$ refuerzan la hipótesis de que tanto los procesos depositacionales como los post-depositacionales que afectaron el conjunto no lo han hecho de forma intensa. La muy buena preservación del conjunto y de las marcas, sumado a la mayor tasa 
de sedimentación registrada en CN respecto de CS donde la secuencia estratigráfica es comprimida (Miotti et al. 2007), avalan la hipótesis de mayor integridad en CN.

Para estos momentos (entre ca. 9500 y 8300), la cueva habría sido habitada tanto en CN como en CS; seguramente las condiciones diferentes que cada cámara ofrece en materia de abrigo, luz y humedad y que se perciben en la actualidad también hayan tenido un correlato en el pasado, influyendo en los distintos usos y actividades que en cada una se desarrollaron. Es posible que en $\mathrm{CN}$ el principal sector de fogones en el SW de D6 indique un área de actividades específicas. La mayor frecuencia de especímenes que resultan de la fractura intencional de los huesos asociados a esa área de combustión, posiblemente estén indicando actividades de consumo, incluyendo el consumo de médula y producción de artefactos óseos en torno a él. Sin embargo, el área de fogones de CS parece estar indicando un área más relacionada a actividades de consumo y descarte; la fragmentación del conjunto, la mayor frecuencia de restos óseos quemados asociados a estas áreas, y la ausencia de instrumentos óseos, avalan esta hipótesis.

Ambos conjuntos muestran una estrategia focalizada en el guanaco sin complemento de especies pleistocénicas de megaherbívoros, lo que estaría indicando, de acuerdo a las fechas que se manejan para la extinción de estos animales (Miotti y Salemme 1999 y bibliografía allí citada), que para estos momentos en el sector de las cabeceras estas especies no habrían estado disponibles.

\subsubsection{Holoceno medio en $M A$}

Para este período se recuperaron tres conjuntos arqueológicos en MA, dos de ellos procedentes de CN (Capa 3 y Capa 4) y el tercero procede de la Capa 2 de CS. La mejor resolución temporal se registra para la Capa 2 de CS con dos fechados radiocarbónicos para estos momentos del Holoceno (ca. 7700 y 4100 años AP). Por su parte, la CN presenta para la Capa 4 un único fechado de ca. 3200 años AP en su techo, lo que indicaría ocupaciones entre ca. 8700 años AP (techo de Capa 5) y estos momentos. Sin embargo, en la Capa 3 el único fechado radiocarbónico obtenido (ca. 5000 años AP) manifiesta una inversión de fechas en $\mathrm{CN}$, aunque no se obtuvieron señales de inversión estratigráfica en ningún sector de la excavación. Encontramos que este registro invertido puede guardar relación con diversas cuestiones que exceden las posibilidades que se 
evalúan en esta tesis. Los distintos argumentos que podrían ayudar a comprender esta situación, aquí son presentados como hipótesis que deberán ser evaluadas a la luz de los análisis geoarquelógicos que están siendo realizados en el sitio, así como a partir de la realización de nuevos fechados, que también están en proceso. Las distintas hipótesis a contrastar para comprender mejor la cronología y la formación de los conjuntos en $\mathrm{CN}$ son las siguientes:

1) el modelo digital utilizado para la separación de los conjuntos a partir de los perfiles estratigráficos descriptos podría estar introduciendo algún error al modelizar las distintas capas de la estratigrafía y particionar los conjuntos;

2) la inversión de fechas podría guardar relación con variaciones propias de la topografía interior de la cueva (desniveles);

3) algún problema de asociación entre alguna de las muestras fechadas y el resto del depósito arqueológico.

4) el uso de métodos standard y AMS para fechar también puede ser una fuente de variabilidad.

Los análisis de distribución y densidad de restos óseos en los tres conjuntos muestran que, salvo en el conjunto de Capa 3 de $\mathrm{CN}$, no hay coincidencia entre las áreas con mayor cantidad de elementos tridimensionados y los sectores donde el conjunto completo muestra la mayor densidad. En la Capa 4 de CN, mientras la mayor cantidad de tridis se registra en la cuadrícula D6, especialmente en el sector del SW, el conjunto completo presenta la mayor densidad de restos entre los sectores del este de C5 y oeste de D5 (Figura 7.17). En el caso de la Capa 3 de $\mathrm{CN}$, donde se registra la mayor coincidencia, los tridis son más abundantes en la cuadrícula D6 y SE de D5, mientras que las mayores densidades para el conjunto entero se registran en valores sorprendentemente altos para el sector SE de D5 (Figura 7.29). Por su parte, el conjunto de Capa 2 CS muestra una mayor distribución de tridis en los sectores NE de A12 y NW de B12, mientras que el conjunto completo presenta mayor densidad en el SW y SE de A12 (Figura 7.56). Estas diferencias podrían estar indicando una elevada fragmentación de los conjuntos ya que, al incorporar al análisis los generales, modifican la tendencia registrada por los tridimensionados. De todas formas, los sectores de mayor densidad de restos óseos podrían estar indicando, en caso de presentar una elevada fragmentación de los especímenes, áreas de consumo y descarte.

Estas concentraciones reflejarían cambios en el uso del espacio en $\mathrm{CN}$ entre el conjunto de Capa 4 y Capa 3. Mientras el primero de estos indica que la principal área de 
descarte se localiza en la intersección entre D5 y C5, el de Capa 3 la ubica en el sector SE de D5. En CS, los sectores del sur de A12 son los que presentan la mayor densidad y por tanto los que parecen significar espacios de descarte.

En los tres conjuntos se registra un alto porcentaje de especímenes indeterminados, esta dificultad puede estar relacionada con una alta fragmentación del conjunto, los que sin dudas aceleraron los procesos post-depositacionales de destrucción mecánica y física (diagénesis). Cualquiera de las dos alternativas implica que una cantidad importante de especímenes óseos no preservaron características diagnósticas que permitan asignarlos a alguna categoría taxonómica. De los tres conjuntos, el que procede de la Capa 2 de CS es el que registra el porcentaje más elevado de especímenes indeterminados $(75,5 \%$ del conjunto), mientras que el menor porcentaje de indeterminados lo registra el conjunto de Capa 3 de CN (66,13\%).

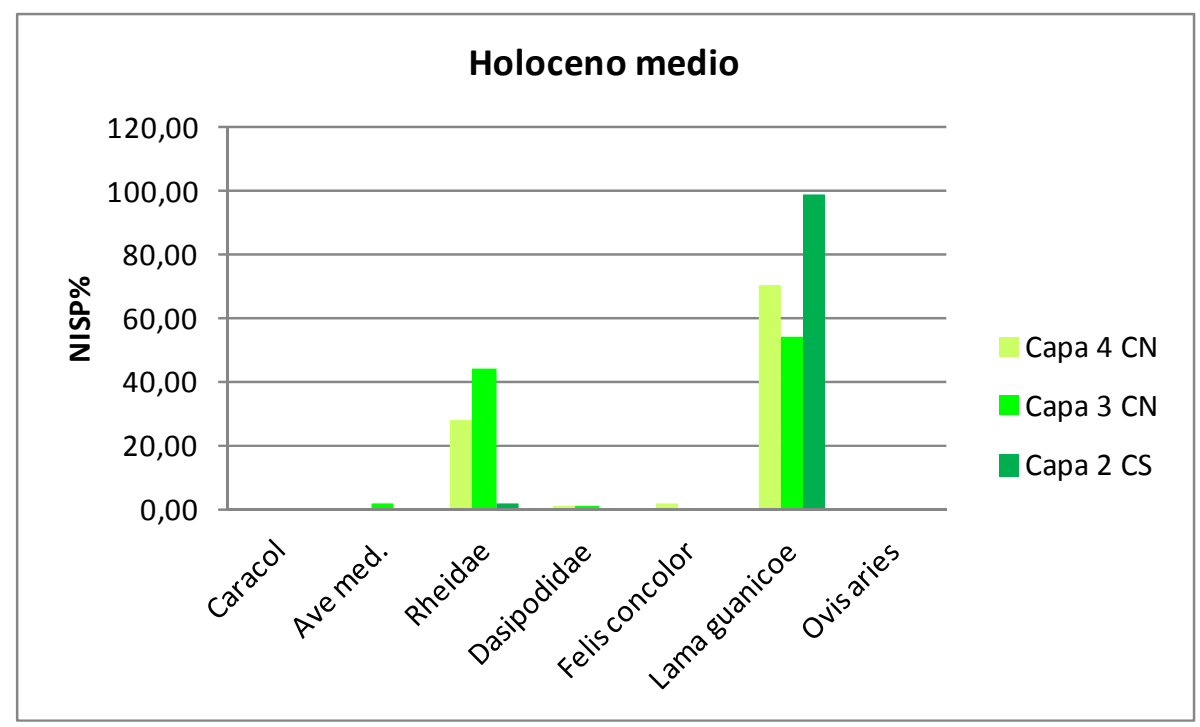

Figura 7.78. Abundancia relativa de especies aprovechadas durante el Holoceno medio en MA.

De los análisis de abundancia taxonómica realizados en los tres conjuntos del Holoceno medio, los resultados indican que la especie mayormente representada en ellos es el guanaco (Figura 7.78). Esta tendencia concuerda con la que exhibe el registro zooarqueológico de toda el área (Aguerre 1994; Aguerre y Pagano 2003; Aguerre et al. 1994 a, 1994 b; Cardich y Miotti 1983; Durán et al. 2003; Frank 2011; Miotti 1996, 1998; Miotti et al. 1999; Paunero et al. 2007, y bibliografía citada en el Capítulo 3) y con la expectativa de los modelos de poblamiento que proponen para estos momentos del 
Holoceno una estrategia centrada en la caza especializada del guanaco tanto en Patagonia (Borrero 1989, 1994-95; Miotti 2008; Miotti y Salemme 1999, 2004) como en la región Pampeana (Martínez y Gutiérrez 2004).

Todas las especies determinadas para los conjuntos del Holoceno medio actualmente habitan el área de estudio. En los tres conjuntos se determinó la presencia de escasos restos óseos y fragmentos de cáscara de huevos de rheidos. Mientras que la frecuencia de los especímenes óseos correspondientes a este género sólo se registró en Capa 4 de $\mathrm{CN}$ y en Capa 3 de CS con valores de NISP= 1 en cada caso. La presencia de fragmentos de cáscara de huevo se registra en los tres conjuntos aunque en los de $\mathrm{CN}$ en frecuencias muy elevadas (NISP> 115 en cada conjunto) respecto de CS $(\mathrm{NISP}=1)$. Esto sugiere la posibilidad de un uso estacional de la cueva, al menos en alguna de las ocupaciones de $\mathrm{CN}$ durante el Holoceno medio. Esta hipótesis deberá ser evaluada a partir de la búsqueda de otros indicadores de estacionalidad que puedan existir en el sitio. Su abordaje es importante ya que también podrían significar un uso de los huevos diferido de la época de reproducción de estas aves (primavera-verano) pudiendo haber sido utilizados oportunísticamente, es decir que se los encontró ya abiertos y se los usó como contenedores, sin que su uso se refiera a consumo humano en primera instancia. De todas formas, la importancia de los rheidos como recurso complementario a los guanacos durante el Holoceno medio fue propuesta por varios autores para el área patagónica (Miotti 1998; Miotti y Salemme 1999; Tambusi y Tonni 1985) y MA presenta evidencia que apoya esa hipótesis.

El registro de otras especies en frecuencias bajas fue posible en los conjuntos de CN. Mientras que en el conjunto de Capa 4 se identificó la presencia de roedores, dasipódidos, puma y un diente humano, en la Capa 3 se determinó la presencia de reptiles y dasipódidos (Figura 7.78). Pensamos que el registro de roedores y reptiles en estos conjuntos no refleja una incorporación antrópica al sitio, sin embargo, no descartamos que la presencia de dasipódidos y puma pueda responder a una utilización humana de estas especies. Los fragmentarios y escasos restos recuperados hasta el momento no nos permiten ajustar esta evaluación. El registro de restos de puma en un nuevo sector excavado del sitio (panel $6 \mathrm{~B}$ de $\mathrm{CN}$ ) y cuyo análisis no fue incorporado en esta tesis pero se encuentra en proceso, esperamos pueda arrojar claridad sobre este asunto.

La representación de unidades anatómicas de guanaco varía en cada conjunto (Figura 7.79). En la Capa 4 de $\mathrm{CN}$ las principales unidades corresponden al metatarso y 
al sacro, seguidas en importancia por la tibia y el fémur. Esta frecuencias indican que el cuarto trasero habría sido una de las unidades de transporte priorizadas en este conjunto. Sin embargo, en frecuencias más bajas se registran para elementos de la pata delantera (principalmente la escápula y el radio-cúbito), la cabeza, el atlas y el axis también adquieren una representación moderada. Estas frecuencias sugieren un ingreso de estas unidades (cuarto delantero y cabeza) al sitio con menos frecuencia que el cuarto trasero.

El conjunto de Capa 3 de $\mathrm{CN}$, al igual que el conjunto de Capa 4, muestra una mayor representación de elementos correspondientes al miembro posterior (Figura 7.79). En este caso los elementos que adquieren mayor importancia son la tibia y el fémur; sin embargo, la frecuencia que se registra para el radio-cúbito sugiere que el miembro anterior también habría ingresado al sitio.

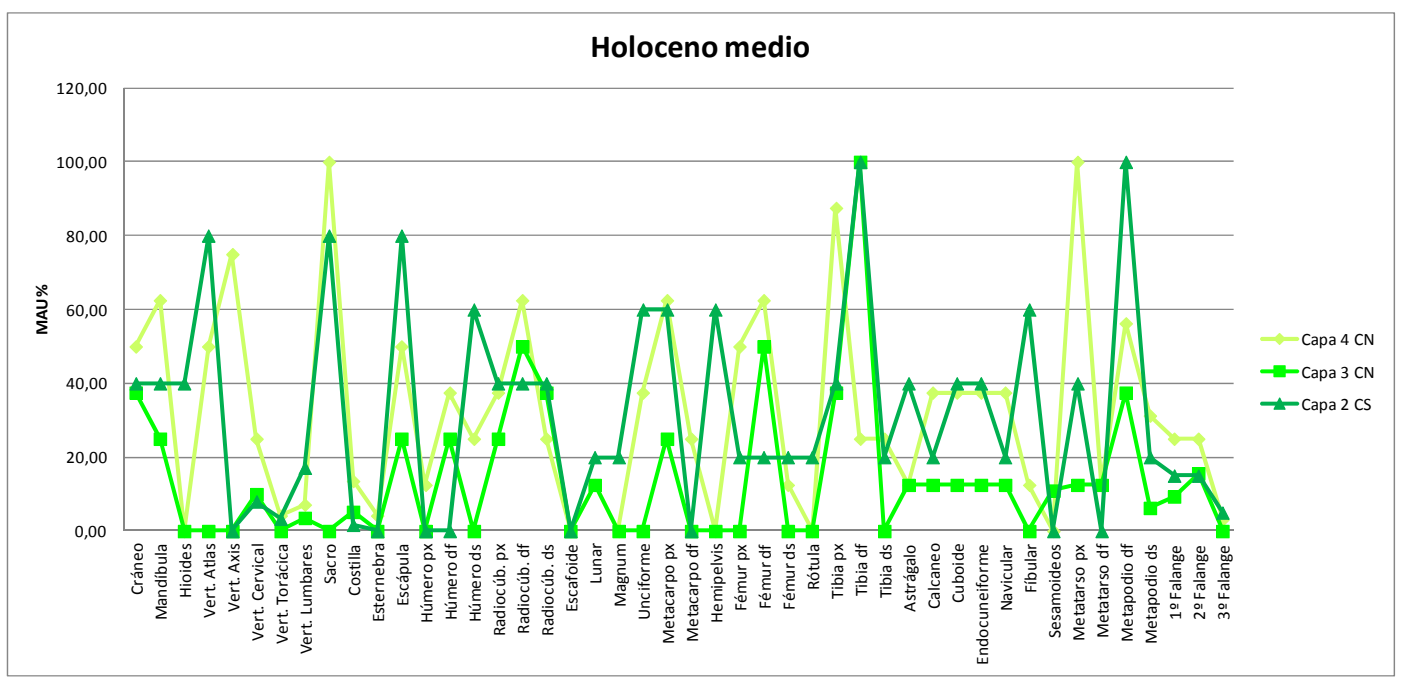

Figura 7.79. Representación de unidades anatómicas en los conjuntos del Holoceno medio en MA.

Por su parte el conjunto de la Capa 2 de CS muestra una tendencia similar a la observada en los conjuntos de CN registrando una mayor representación del esqueleto apendicular (Figura 7.79). En este caso la tendencia indica una mayor frecuencia para el miembro posterior, principalmente para las porciones distales. Una representación pareja de los distintos elementos del miembro anterior y una baja representación de la cabeza. Este patrón refleja una selección de partes similar a la registrada en la Capa 4 de $\mathrm{CN}$.

El análisis de la fragmentación de los conjuntos a partir de la relación entre MNE/NISP de guanaco muestra que todos los conjuntos están fragmentados, siendo ésta más elevada en Capa 4 y 3 de CN (0,44 y 0,51, respectivamente) que en Capa 2 de CS 
$(0,54)$. Esta fragmentación podría guardar relación con las diferencias mencionadas anteriormente respecto de la distribución de los materiales. La presencia de fragmentos pequeños que pueden haber sido recuperados en zaranda modifica la tendencia de distribución observada a partir de los especímenes tridimensionados.

Los resultados de las correlaciones entre el MAU\%, la DO y los índices de utilidad de carne muestran que los conjuntos de Capa 4 de CN (Figura 7.20), Capa 3 de CN (Figura 7.32) y Capa 2 de CS (Figura 7.58) caen en la Clase 4 de "lag or ravaged" (Lyman 1994). Esta clase sugiere que los tres conjuntos habrían estado expuestos a la destrucción de procesos mediados por densidad mineral (DO). En los conjuntos de Capa 4 de $\mathrm{CN}$ y de Capa 2 de CS se encontró una frecuencia alta de elementos de baja DO que se esperaría hayan desaparecido o estén muy deteriorados si estos procesos hubiesen sido importantes sobre el conjunto. Sin embargo, no podemos descartar que la DO haya actuado, como se dijo anteriormente, de forma diferencial sobre especímenes de individuos más jóvenes.

El análisis de los perfiles de meteorización obtenidos para los tres conjuntos (Figuras 7.21, 7.33 y 7.59) sugiere un corto tiempo de exposición y enterramiento sincrónico en todos. Sin embargo, comparativamente, el conjunto de Capa 2 de CS es el que presenta la mayor meteorización. En cuanto a los escasos restos en estadio 3 de meteorización, los conjuntos de $\mathrm{CN}$ lo registran para elementos apendiculares y, por lo tanto, si bien puede haber existido una meteorización diferencial de los especímenes (Massigoge et al. 2010), la fragmentación previa a la depositación podría haber sido una de las responsables de que esta pequeña cantidad de restos muestren meteorización más elevada. A favor de esta propuesta tenemos los índices estimados que indican que estos dos son los conjuntos con mayor fragmentación. En el caso de la Capa 2 de CS, el estadio 3 de meteorización se registra fundamentalmente en especímenes del esqueleto axial cuya DO es baja. En este caso, es esperable que esa mayor meteorización esté relacionada a la baja DO de algunos elementos más que a una elevada fragmentación del conjunto. A favor de ellos encontramos para este conjunto el menor grado de fragmentación. Sin embargo, en los tres conjuntos se recuperaron escasos elementos que corresponden a individuos cría y juveniles, en ese sentido, la pérdida de elementos osteológicamente inmaduros no es descartada para ninguno de los conjuntos del Holoceno medio.

Si consideramos la información de las correlaciones significativas con la DO y los perfiles de meteorización, el conjunto de CS es el que tiene más probabilidades de haber sido afectado por procesos de destrucción mediados por densidad. Sin embargo, estos no 
habrían sido lo suficientemente intensos ya que partes de baja DO se han preservado. En cuanto a los conjuntos de $\mathrm{CN}$, se observa que los especímenes con baja DO tienen buena preservación siendo más elevada la meteorización de los fragmentos del esqueleto apendicular. Esto indica que en este sector de la cueva los procesos de destrucción mediados por densidad no habrían sido tan importantes. De esta manera, es posible suponer que la correlación que indica una importante representación de elementos con alta DO en los conjuntos de Capa 3 y 4 de CN esté indicando, posiblemente, un transporte intencional de esas unidades, aunque no relacionado con el aporte de carne. Quizás otras decisiones de transporte vinculadas a la importancia que tienen estas partes de alta densidad y bajo contenido de carne, como fuente de médula, tendones y materia prima ósea, puedan brindar un marco interpretativo para la representación de las unidades anatómicas de guanaco en CN. En este sentido, una estrategia de potenciación (Miotti 1998) del recurso guanaco durante las ocupaciones del Holoceno medio en MA parece haber tenido lugar. La misma se encuentra avalada, como se verá más adelante, por el aprovechamiento integral de este recurso tanto para consumo de carne y médula como para la producción de distintos artefactos óseos.

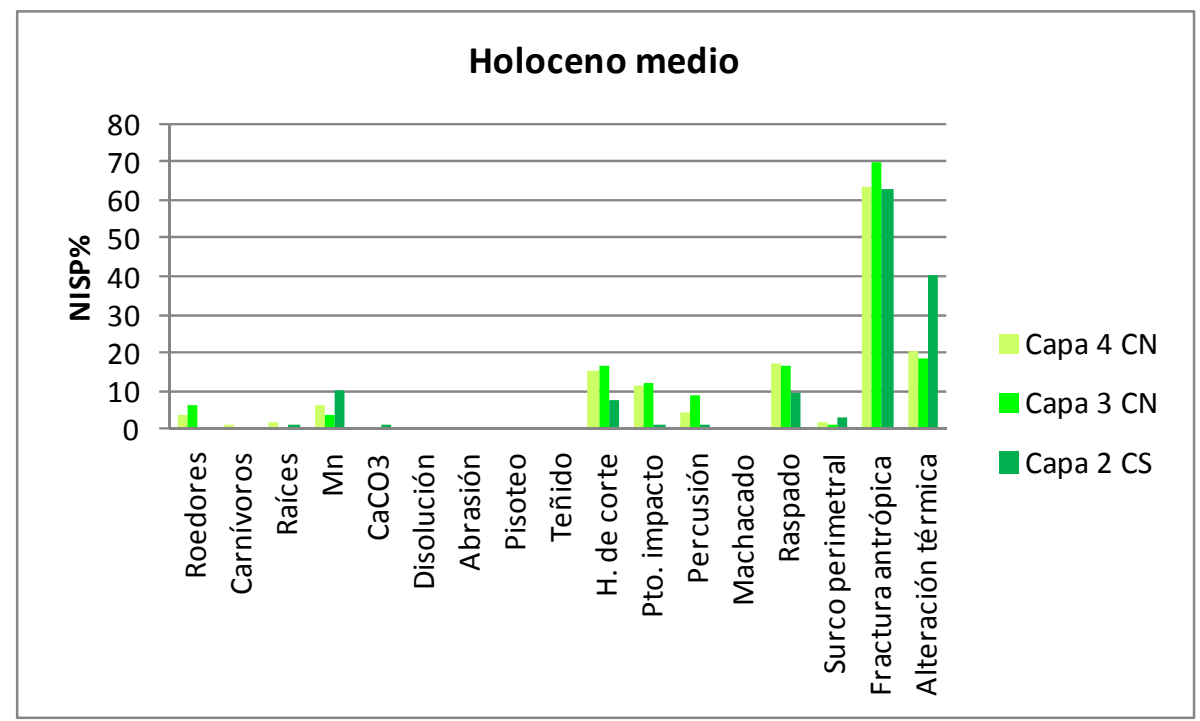

Figura 7.80. Modificaciones sobre las superficies de especímenes óseos correspondientes a los conjuntos del Holoceno medio en MA.

El registro de modificaciones naturales muestra tendencias distintas entre los conjuntos de Capa 3 y 4 de CN (Figura 7.22a; 7.34a y Figura 7.80) y el conjunto de Capa 2 de CS (Figura 7.60a y Figura 7.80). Por un lado, se observa que las frecuencias con que 
las modificaciones naturales se registran son relativamente bajas en los dos conjuntos, aunque en CS afectan un porcentaje mayor de restos que en CN. Mientras que en CN los principales registros corresponden a modificaciones producidas por la acción de roedores y por los depósitos de manganeso, en CS las mayores frecuencias corresponden a depósitos de manganeso y a especímenes teñidos (Figura 7.80).

Los depósitos de manganeso son las únicas modificaciones naturales que se registran en los tres conjuntos (Figura 7.80). Sus frecuencias más elevadas se observan en la Capa 2 de CS y luego en la Capa 4 de CN. Si bien el manganeso indica condiciones de humedad para estos depósitos, no se descarta que su procedencia sea diferente dado que cada secuencia estratigráfica presenta rasgos distintos que pueden estar indicando la presencia de agua, disolución de rocas y descomposición de tejido blando adherido a los huesos por largo tiempo.

La presencia de modificaciones por roedores solamente observada en bajas frecuencias en CN (Figura 7.80) podría estar relacionada al registro de galerías y cuevas durante las excavaciones tanto de la Capa 3 como 4 de CN. Por el contrario, su ausencia en CS es coherente ya que no se registraron perturbaciones en los sedimentos. El registro de las galerías en $\mathrm{CN}$ sugiere que la acción de los roedores sobre el conjunto habría sido post-entierro.

El registro de modificaciones producidas por carnívoros no alcanza el $1 \%$ de los especímenes en CN (Figura 7.80), y no fueron registras en el conjunto de CS. Esta baja frecuencia indicaría que los carnívoros no habrían sido importantes agentes en la formación de los conjuntos avalando el rápido enterramiento del mismo.

El registro de modificaciones por raíces es escaso en las dos cámaras. Pequeños depósitos de carbonato fueron observados en escasos restos provenientes del conjuntos de CS $(<2 \%)$ (Figura 7.80).

La presencia de modificaciones culturales es variada y abundante en los tres conjuntos, sin embargo las mayores frecuencias se registran en los dos conjuntos de $\mathrm{CN}$ (Figura 7.80). En los tres conjuntos se reconocieron distintos tipos de marcas vinculadas al procesamiento de las presas, entre ellas encontramos huellas de corte, marcas de percusión, puntos de impacto y fracturas intencionales en altos porcentajes, entre las que se registran tipos transversales por aserrado perimetral (Figura 7.80).

Entre los elementos axiales solamente se determinó la presencia de huellas de corte. El conjunto de Capa 4 de $\mathrm{CN}$ es el que presenta los porcentajes más elevados de este tipo de marcas. Por el contrario, los especímenes correspondientes al esqueleto 
apendicular de los guanacos registran una alta variedad de tipos de marcas de procesamiento. Entre ellas, las huellas de corte son las más representadas en los tres conjuntos y sus porcentajes son más elevados en CN que en CS (Figura 7.80). Dentro de $\mathrm{CN}$ el conjunto de Capa 3 es el que registra el mayor porcentaje de huellas de corte en los especímenes apendiculares de los guanacos.

La presencia de puntos de impacto que indican la fracturación intencional de los huesos por medio de la aplicación de una fuerza dinámica se registró en porcentajes similares en los tres conjuntos (ca. 10\%). Esto muestra coherencia con que en los tres conjuntos más de un $62 \%$ de los patrones de fracturas identificados fueron considerados de origen antrópico. De esta manera se podría sostener que las actividades vinculadas a la extracción y consumo de médula o a la obtención de formas base para la confección de artefactos fue similar en los tres conjuntos. Sin embargo, el índice de fragmentación obtenido indica que el conjunto de la Capa 4 de $\mathrm{CN}$ está más fragmentado y, por lo tanto, podría estar reflejando algún tipo de aprovechamiento más intensivo de los guanacos. La elevada frecuencia de marcas de raspado en los tres conjuntos también es un indicador de la preparación del hueso para su fractura intencional y controlada. Estas marcas se registran con mayor frecuencia en el conjunto de Capa 4 de $\mathrm{CN}$ lo que estaría avalando un uso más intensivo de los guanacos.

Los tres conjuntos presentan un porcentaje elevado de especímenes alterados térmicamente (Figura 7.80); sin embargo, en el conjunto de Capa 2 de CS estos especímenes (40\%) doblegan las frecuencias registradas en los conjuntos de CN. La presencia de alteración térmica en los tres conjuntos es consistente con el registro de áreas de fogones en todos los casos. Sin embargo, el alto porcentaje con que se registran en CS permite pensar que allí pudo existir un área de descarte particular y con características distintas a las registradas en los conjuntos de $\mathrm{CN}$.

En los tres conjuntos se reconocieron distintos artefactos óseos y fragmentos óseos decorados. El registro de una abundante cantidad de artefactos formatizados por uso, que se reconocen como fragmentos diafisiarios con sectores que concentran gran cantidad de marcas de percusión, solamente se realizó en los conjuntos de CN. Estos instrumentos, podrían haber sido utilizados como retocadores blandos, en ese sentido sugieren que en CN se podrían haber realizado actividades específicas de talla. Los resultados de los análisis de la tecnología lítica desarrollados por Hermo (2008) para los conjuntos líticos que proceden de estos niveles avalan esta hipótesis.

Tanto en el conjunto de Capa 2 de CS como en el de Capa 3 de CN se 
recuperaron pequeños fragmentos óseos con un patrón de decoración similar caracterizado por la presencia de líneas incisas cortas y paralelas entre sí. En el conjunto de Capa 4 de $\mathrm{CN}$ fue recuperado un cilindro de hueso de ave con el mismo diseño de decoración.

En la Capa 2 de CS además, fue recuperado un instrumento óseo formatizado sobre un hueso largo de mamífero cuya función es desconocida. En la Capa 4 de CN y a diferencia de lo que se registra en los otros dos conjuntos, se reconoció la presencia de pigmento rojo sobre dos especímenes óseos. Si bien las ocupaciones del Holoceno medio en MA indican actividades domésticas en el sitio, las distintas observaciones realizadas entre las cámaras sugieren un uso diferente del espacio interior. La CS parece haber funcionado más como un área vinculada a actividades de consumo y descarte, mientras que en $\mathrm{CN}$ parecen haberse desarrollado actividades más relacionadas al procesamiento secundario, manufactura de instrumentos y otras actividades específicas. La elevada frecuencia de artefactos óseos que se registra en MA durante el Holoceno medio, estaría indicando un uso significativo del hueso como materia prima.

\subsubsection{Holoceno tardío en $M A$}

Para el lapso temporal del Holoceno tardío en MA se estudiaron dos conjuntos arqueológicos. Uno es el correspondiente a la Capa 1 de CS con un fechado en su base de ca. 1100 años AP. El otro es el correspondiente a la Capa 2 de CN que, si bien aún no posee fechados radiocarbónicos, creemos que refleja el uso de MA durante el Holoceno tardío ya que apoya sobre las capas con antigüedades para el Holoceno medio.

El análisis de distribución y densidad de restos óseos muestra diferencias entre los sectores donde se concentran los restos tridimensionados y aquellos de mayor densidad del conjunto de Capa 2 de CN. Mientras los huesos tridimensionados fundamentalmente se distribuyen en el sector NE de D6 y prácticamente no hay registros en el resto de la superficie excavada, el conjunto completo alcanza una altísima densidad en el sector SE de C5 (Figuras 7.40a y 7.40b). En el caso de la Capa 1 de CS, la distribución entre los tridis y los sectores de mayor densidad del conjunto completo indican coincidencias en dos sectores principales, uno corresponde al este de la cuadrícula B12 y el otro corresponde al sector NE de A12 (Figuras 7.66a y 7.66b). Las diferencias del conjunto de 
Capa 2 de CN podrían estar vinculadas a una fragmentación elevada del conjunto.

Del análisis de abundancia taxonómica se puede observar que en ambos conjuntos un elevado porcentaje de especímenes se encuentran indeterminados. Esta frecuencia en la Capa 2 de CN alcanza el 87\% del NSP mientras que en la Capa 1 de CS corresponde al $80 \%$. Ya sea por un grado elevado de fragmentación o por una mala preservación del conjunto, estas frecuencias indican que una parte importante de los especímenes no preservaron características que permitan su asignación anatómica o taxonómica.

Entre los especímenes óseos que pudieron ser determinados a alguna categoría taxonómica encontramos que en ambos conjuntos, y al igual que en toda la secuencia ocupacional de MA, el guanaco ha sido el principal recurso económico (Figura 7.81). El registro de ambos conjuntos muestra únicamente la presencia de especies que actualmente habitan el área de estudio, entre ellas el guanaco es la mejor representada. En CN además se identificó la presencia de escasos fragmentos de cáscara de huevo de ñandú. Por su parte, en CS también se recuperaron restos óseos y fragmentos de cáscara de huevo de estas aves. La presencia de restos de oveja, escasos huesos de aves pequeñas, micromamíferos y fragmentos de caracol en CS marcan una clara diferencia con el registro zooarqueológico de $\mathrm{CN}$ para el Holoceno tardío. Posiblemente esta diferencia pueda estar vinculada a la ocupación histórica que se registró en el sitio y a la que se hizo referencia tanto en el Capítulo 2 como al inicio de éste. El registro de oveja, como especie introducida, claramente está relacionado a estos momentos de ocupación; sin embargo, su presencia no fue registrada en $\mathrm{CN}$ por lo que no hay evidencias materiales que sugieran el uso de este sector de la cueva en tiempos históricos.

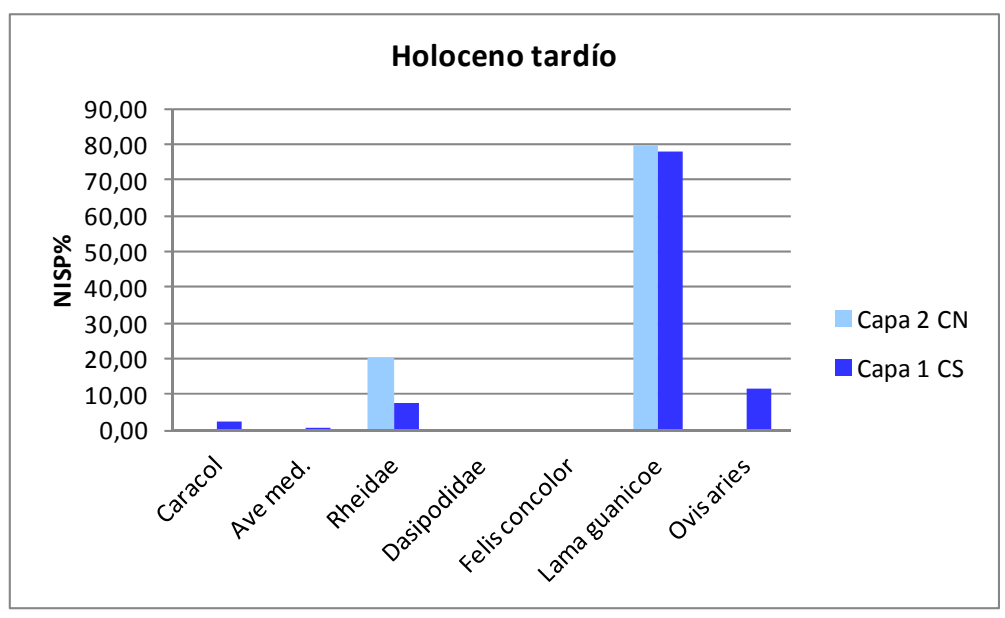

Figura 7.81. Abundancia relativa de especies aprovechadas durante el Holoceno medio en MA. 
El análisis de la representación de partes anatómicas de guanaco muestra que en CN las unidades más representadas indican que la pata trasera habría ingresado completa al sitio, convirtiéndose de esa manera en la principal unidad transportada (Figura 7.82). De la pata delantera solamente se registra la presencia del radio-cúbito proximal en frecuencias elevadas. En cuanto a la representación que adquieren las unidades anatómicas en CS se registra una mayor cantidad de elementos que en CN, sus frecuencias indican que las principales unidades transportadas al sitio habrían sido los cuartos y la cabeza. Dentro del esqueleto apendicular, los elementos distales de la pata trasera cobran mayor importancia.

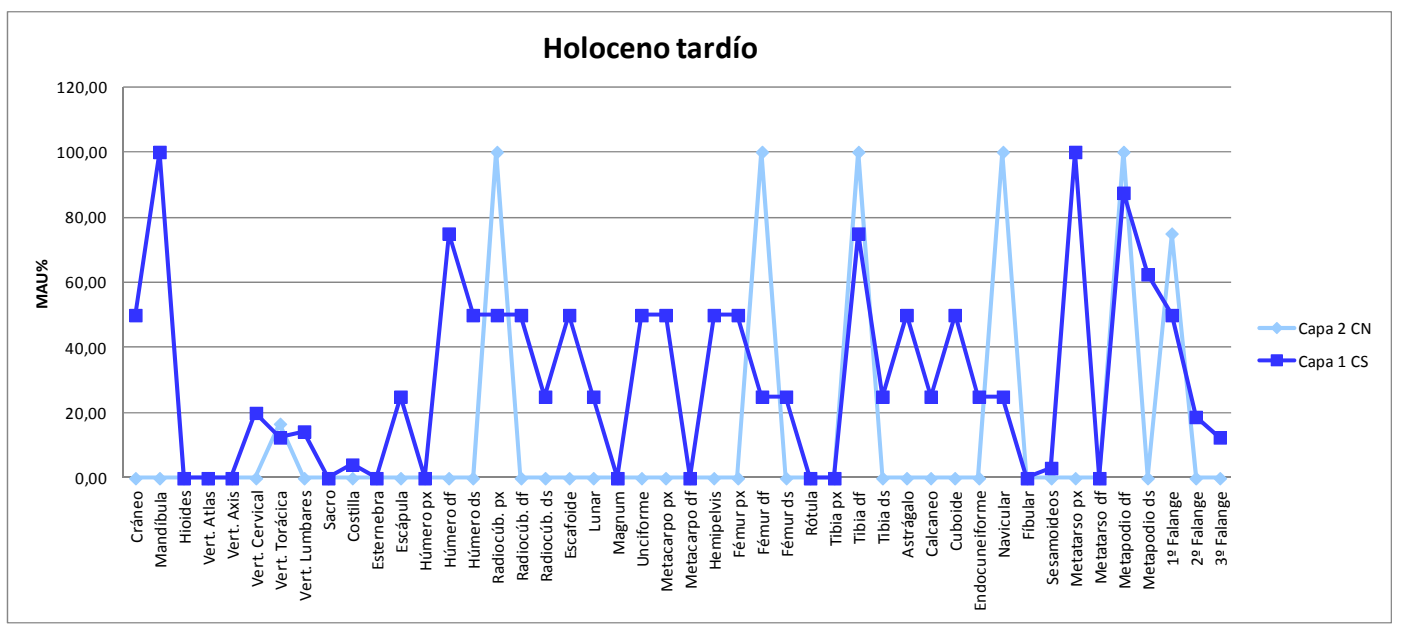

Figura 7.82. Representación de unidades anatómicas en los conjuntos del Holoceno tardío en MA.

$\mathrm{El}$ análisis de la fragmentación del conjunto a partir de la relación MNE/NISP de guanaco, indica que el conjunto de la Capa 1 de CS presenta una alta fragmentación $(0,42)$ mientras que el conjunto de Capa 2 de $\mathrm{CN}$ registra una moderada a baja fragmentación $(0,62)$. Estos valores no permiten explicar que el mayor porcentaje de especímenes indeterminados en $\mathrm{CN}$ ni las diferencias en la distribución de ese conjunto se deban a un registro más fragmentado que el de CS. Sin embargo, creemos necesario buscar otras formas alternativas que permitan evaluar la fragmentación ya que, en caso de estar muy fragmentado el conjunto, esa condición podría haber afectado de forma extrema las determinaciones, y en tal sentido, la relación MNE/NISP de guanaco estaría sesgada. La aplicación de otras metodologías que consideren a todos los taxa podrían ser de utilidad para aclarar este problema.

Los resultados de las correlaciones entre el MAU\%, el MGUI y la DO muestran 
que tanto el conjunto de la Capa 1 de CS (Figura 7.69) como el de la Capa 2 de CN (Figura 7.43) corresponden a la Clase 4 (Lyman 1994). Esta clase sugiere la acción de procesos de destrucción mediados por densidad mineral en el conjunto y ausencia de una clara estrategia de selección humana de partes vinculada a su alto o bajo rendimiento económico.

Los perfiles de meteorización obtenidos muestran una buena preservación del conjunto de $\mathrm{CN}$ que evidencia un tiempo relativamente corto de exposición (Figura 7.44). El perfil obtenido para el conjunto de CS (Figura 7.70), si bien registra la mayor parte de los especímenes en estadios bajos, una porción menor del mismo (ca. 30\%) presenta estadios más elevados de meteorización principalmente sobre restos del esqueleto axial. Esta tendencia del conjunto de CS indica que los especímenes con superficies más deterioradas corresponden a los que tienen una menor DO, por lo tanto sería esperable que este conjunto haya sido afectado por los procesos de destrucción mediados por densidad. Sin embargo no es posible descartar otros factores que pueden influir en una DO diferencial de las partes (Gutiérrez et al. 2010) y cuya evaluación forma parte de la agenda de esta tesis.

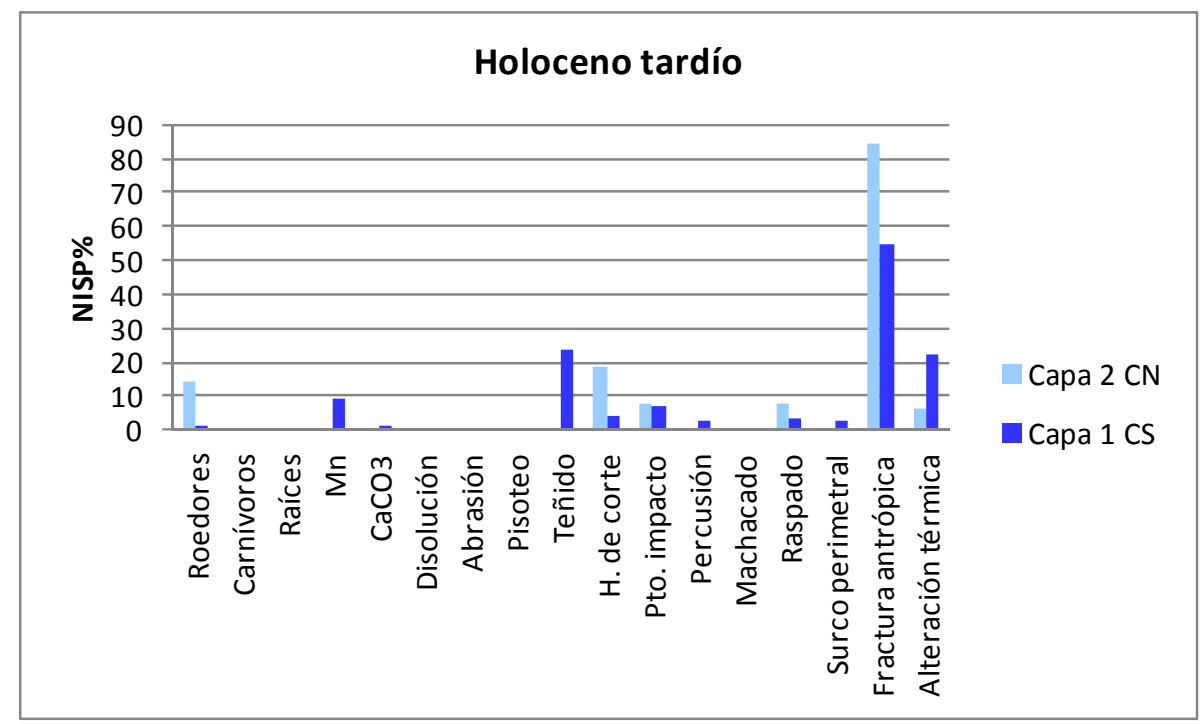

Figura 7.83. Modificaciones sobre las superficies de especímenes óseos correspondientes a los conjuntos del Holoceno tardío en MA.

Entre las modificaciones naturales reconocidas en estos conjuntos (Figura 7.83) encontramos que en $\mathrm{CN}$ solamente se registró la presencia de marcas de roedores. Estos animales afectaron un $14 \%$ del conjunto, y dado que en este nivel se identificó la 
presencia de galerías creemos que el daño sobre el conjunto se pudo producir una vez que el mismo ya se encontraba enterrado.

Por su parte, el conjunto de la CS registra modificaciones de distintos agentes naturales (Figura 7.83), entre ellos la presencia de depósitos de manganeso en un 9\% de los especímenes es el más importante. Esta condición de humedad que indica la presencia de manganesos no se registra en el conjunto de CN. En el conjunto de Capa 1 de CS se reconocieron modificaciones producidas por raíces, carnívoros, roedores y depósitos de carbonatos, ninguno de ellos en más de $1 \%$ de los especímenes óseos (Figura 7.83). Esta información estaría indicando que el conjunto de CS presenta una menor integridad arqueológica ya que una mayor cantidad de agentes y procesos tafonómicos parecen haberlo afectado. El alto porcentaje de especímenes teñidos en CS presenta una dificultad para discernir acerca de las causas de ennegrecimiento en un $23 \%$ de los especímenes.

El registro de modificaciones culturales en el conjunto de $\mathrm{CN}$ solamente permitió determinar marcas de procesamiento en elementos del esqueleto apendicular del guanaco (Figura 7.83). Entre estas modificaciones más de un 20\% de los especímenes del esqueleto apendicular presentan huellas de corte; mientras que ca. del 7\% de los especímenes apendiculares registra modificaciones como puntos de impacto y marcas de raspado, que están relacionadas con la búsqueda intencional de fracturas. A diferencia de lo que se observa en $\mathrm{CN}$, en el conjunto de Capa 1 de $\mathrm{CS}$ se registraron modificaciones culturales sobre especímenes tanto del esqueleto axial como apendicular. Mientras que sobre los especímenes del esqueleto axial solo se observan porcentajes bajos de huellas de corte (ca. 3\%), en el esqueleto apendicular, aunque todas en frecuencias ca. al 5\%, se observan variedad de modificaciones (Figura 7.83). Entre estas modificaciones culturales encontramos huellas de corte, puntos de impacto, marcas de percusión, marcas de raspado y la presencia de fracturas transversales por surco perimetral.

Todas estas modificaciones culturales representan actividades de procesamiento primario y secundario, con claras marcas que manifiestan la intencionalidad de acceder a la médula ósea de hueso, se observan en frecuencias más importantes en CN que en CS.

En ambos conjuntos se registran especímenes quemados que en $\mathrm{CN}$ representan el $6 \%$ del conjunto y en CS el 22\%. Esta diferencia, sumada a la mayor fragmentación del conjunto de CS podría indicar que aquí funcionó un área de descarte diferencial de la observada en $\mathrm{CN}$.

Para estos momentos tardíos en MA Miotti (2012) propone una estrategia, al igual 
que para Patagonia meridional, caracterizada por la potenciación (Miotti 1998) del recurso guanaco. La información aquí presentada avala esa hipótesis que sostienen la existencia de una mayor inversión de trabajo para la obtención de nutrientes y productos de los recursos tradicionalmente explotados (Miotti 1998). 


\section{CAPÍTULO 8}

\section{ANÁLISIS DE LOS CONJUNTOS ZOOARQUEOLÓGICOS DE ALERO EL PUESTO 1 DE PIEDRA MUSEO}

En este capítulo se presentan los resultados obtenidos a partir del análisis zooarqueológico de los tres conjuntos provenientes del sitio Alero El Puesto 1 (AEP-1) en la localidad arqueológica de Piedra Museo (PM). Una muestra menor de los dos conjuntos del Componente Inferior del sitio (Capa 6 y Capa 4/5) fue estudiada en trabajos previos (Miotti 2003; Miotti y Salemme 2005; Miotti et al. 1999). En esta tesis se amplía la muestra de cada conjunto al incorporar especímenes recuperados en excavaciones posteriores al año 1996, y se discute la información generada previamente a la luz de los nuevos resultados. De esta forma, los resultados aquí presentados provienen del re-análisis del conjunto recuperado hasta 1996 en las capas 4/5 y 6 de PM y del estudio de los nuevos materiales de estos mismos conjuntos y del recuperado en la Capa 2. Los criterios seguidos para el análisis y comparación de los mismos fueron descriptos en el Capítulo 6.

El capítulo se encuentra estructurado en cinco partes principales, la primera sección presenta la información generada con anterioridad a esta tesis para el sitio en cuestión. Las tres secciones siguientes corresponden a los análisis cuali y cuantitativos desarrollados para cada uno de los conjuntos zooarqueológicos del sitio. Los mismos fueron partitivamente diferenciados en tres conjuntos que, del más antiguo al más reciente, son: Capa 6, Capa 4/5 y Capa 2 (Miotti 2004; Miotti et al. 2000). La quinta sección analiza y discute la variabilidad zooarqueológica y tafonómica registrada en el sitio sobre la base de la nueva información obtenida para los distintos momentos de ocupación humana. 


\subsection{ESTADO DE CONOCIMIENTO ARQUEOLÓGICO Y ZOOARQUEOLÓGICO EN PIEDRA MUSEO}

La localidad arqueológica Piedra Museo (PM)se ubica en el sector de base de la cuenca del Zanjón Rojo, en la estancia San Miguel, provincia de Santa Cruz, a 47ํ5 $3^{\prime}$ $42^{\prime \prime}$ sur y 67은 52' 04' ' oeste (Capítulo 2: Figura 2.2; Capítulo 3: Figura 3.1). Está integrada por aleros y abrigos rocosos que rodean una depresión que fue ocupada durante la transición Pleistoceno-Holoceno y posiblemente hasta el Holoceno medio por un lago, actual depresión salina (Miotti 1992; Zárate et al. 2000). El sitio excavado (AEP1) corresponde a un alero y un abrigo rocoso (Figuras 8.1a, 8.1b), que se abren en la base de un conglomerado tobáceo, relicto de una ingresión marina pre-jurásica denominada Formación El Museo (Panza 2001).

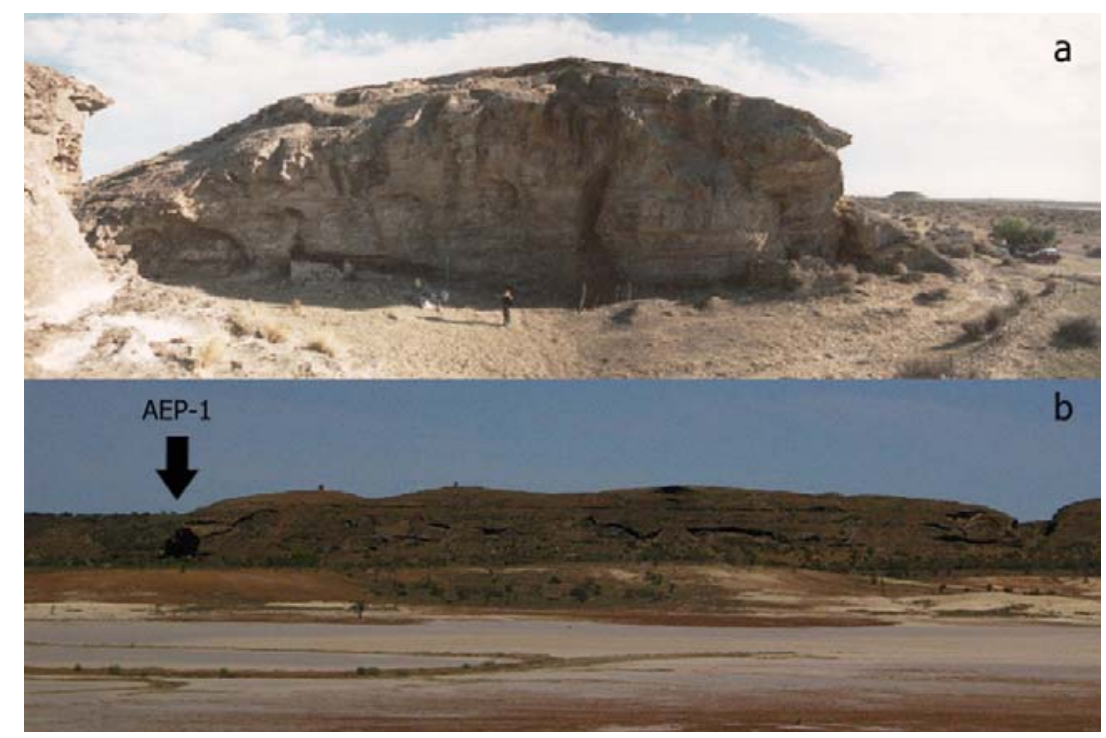

Figura 8.1. a) Sitio AEP-1; b) localidad arqueológica Piedra Museo.

Las excavaciones arqueológicas del sitio se realizaron entre el año 1990 y 1999 bajo la dirección de la Dra. Miotti. La superficie total excavada es de 41,25 m² (Figura 8.2). 


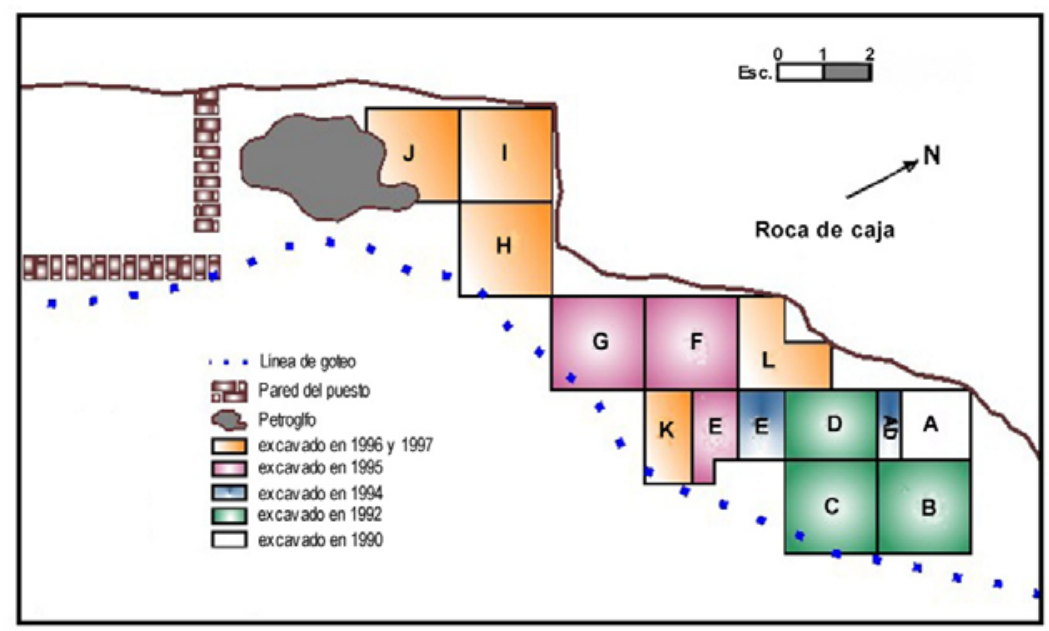

Figura 8.2. Planta de excavación del sitio AEP-1.

\subsubsection{Contexto Geoarqueológico}

A escala local y de sitio "La localidad Piedra Museo se ubica en un sector de afloramiento de sedimentitas marinas eocenas que tienen entre 12 a $15 \mathrm{~m}$ de espesor" (Zárate et al. 2000:57) y cuya superficie es mapeable en aproximadamente 12 km². Dos niveles de pedimentos fueron identificados tanto al NE como al W de AEP-1, los mismos indican dos ciclos de generación de superficies de planación separados por un episodio de reactivación y profundización del nivel de base del zanjón. Hacia el pie del afloramiento se desarrollan concavidades basales que dan origen a los aleros. Alero El Puesto 1 (AEP-1-) se ubica en uno de estos cañadones que cortan el afloramiento (Figura $8.1 \mathrm{~b})$, este corte tiene unos $20 \mathrm{~m}$ promedio de ancho $(28 \mathrm{~m}$ en su sector más ancho registrado entre AEP-1 y el punto medio del bloque aflorante al SW), el cuál posiblemente ha sido en el pasado una línea de escurrimiento continuo.

La estratigrafía del sitio fue descripta a partir del perfil tipo ubicado en la pared NE de la cuadrícula $\mathrm{L}$, en la que se efectuaron además, los muestreos para análisis sedimentológico, mineralógico y polínico (Figura 8.3a). Este perfil tipo fue seleccionado por la continuidad lateral y las variaciones verticales de los atributos textura y color, los cuales facilitaron la identificación de dos unidades estratigráficas. La unidad superior (UE 1) contiene una única capa que es el eólico actual; la unidad estratigráfica 2 (UE 2), integrada por las capas 2 a 6, corresponde a un suelo enterrado (Figura 8.3a) (Miotti et al. 
2003; Zárate et al. 2000). El límite inferior de la UE 1 corresponde a una superficie de discordancia erosiva (Figura 8.3b), mientras que los límites entre las capas 2 a 6 son transicionales debido a que corresponden a horizontes pedogénicos (Figura 8.3a).

La composición granulométrica de la UE 1 presenta clara diferencia con las capas subsiguientes, ésta corresponde a una arena de color castaño con gravas finas y sábulos. Las Capas 2 a 6 corresponden a la secuencia morfológica de un perfil de suelo desarrollado a partir de material parental de aporte mixto eólico-cuencal de granulometría casi constante (Blasi et al. 1997; Zárate et al. 2000). La Capa 2, es el horizonte IIA y está truncado por la discordancia de erosión que tiene un límite lateralmente continuo y ondulado, verticalmente este límite es neto (Figura 8.3b); IIA es una arena muy fina, a veces arcillosa, suelta y muy friable, de color castaño amarillento con un espesor promedio de $15 \mathrm{~cm}$, el límite inferior es gradual que pasa hacia abajo a una estructura laminar. La Capa 3 es el horizonte IIBt compuesto por limo arcilloso de color castaño a castaño oliváceo con escasos cutanes; tiene un espesor promedio de 20 cm y su límite inferior es suave y gradual. En la parte inferior muestra nódulos calcáreos y carbonatación que se hace más pronunciada hacia las paredes de las cuadrículas más externas del alero. La Capa 4 es el horizonte IIB31 del perfil de suelo, corresponde a un limo areno arcilloso castaño grisáceo o castaño; con un espesor medio de $20 \mathrm{~cm}$ y un límite inferior gradual y suave. La Capa 5 es el horizonte IIB32, es limo arcilloso de color castaño oscuro y su espesor es de unos $15 \mathrm{~cm}$, presenta bioclastos de la roca de caja, su límite es gradual y suave. La Capa 6 corresponde al horizonte IIIC del perfil de suelo, es una arena castaño oscura amarillenta que pasa hacia abajo a la sedimentita coquinoide de la roca de base (Zárate et al. 2000).
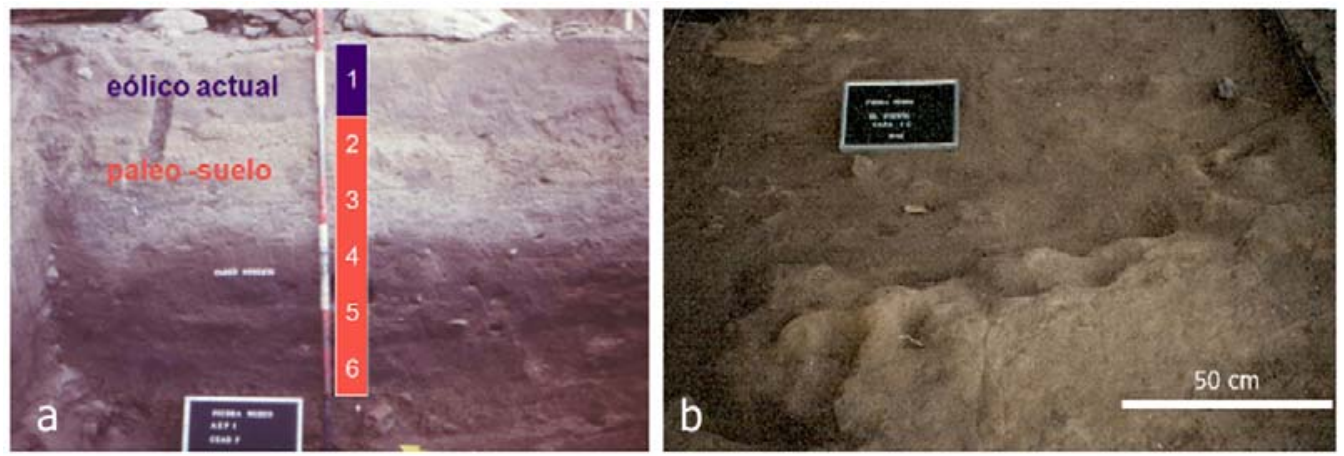

Figura 8.3. a) Perfil estratigráfico del sitio AEP-1; b) techo de Capa 2 mostrando la discordancia erosiva y superficie ondulada resultado de mal drenaje (fotografía tomada por Miotti en 1995). 
El aporte detrítico del perfil, provendría de aporte intracuencal de naturaleza eólica y por descascaramiento y derrumbes de la roca meteorizada del alero. Estos últimos con mayor representación en la Capa 3 y techo de la Capa 4, que corresponderían a momentos del Holoceno temprano, posteriores al 9 ka AP.

Por otra parte, los análisis texturales y morfológicos del perfil de suelos del alero indican que la Capa 2 ha sido re-trabajada bajo condiciones locales (intracuencales) de drenaje deficiente, con someras áreas de encharcamiento y con procesos de óxidoreducción alternantes. Esto se evidencia principalmente por la presencia de nódulos y moteados de Fe y Mn (Rabassa 1997; Zárate et al. 2000) así como en la superficie ondulada del techo de la Capa 2 que es resultado de esta situación de mal drenaje (Figura $8.3 \mathrm{~b})$.

Todas las unidades estratigráficas se registraron en toda la superficie excavada del sitio, la única excepción corresponde a la Capa 6, que por la altura de la roca de base, no aparece en el sector bajo el alero y que corresponde a las cuadrículas H, I y J (Figura 8.2).

Los análisis polínicos realizados (Borromei 2000; 2003) muestran dos cambios vegetacionales entre 12.890 y 7670 años AP. El primero sería cercano a los 11.000 años AP donde la estepa arbustiva de Asteracea es remplazada por una estepa graminosa, dando indicios de mayor disponibilidad relativa de humedad, quizá asociado a un incremento de precipitaciones en condiciones frías. El segundo cambio, cercano a los 9500 años AP, correspondería al reemplazo de la estepa graminosa por una estepa arbustiva de Ephedra y Asteraceae, indicando una vegetación arbustiva de ambiente semidesértico, con menor humedad disponible y relacionada a menores precipitaciones y/o más altas temperaturas. Esta información es congruente con los horizontes del suelo y las dataciones obtenidas para las distintas ocupaciones del alero (Miotti et al. 2003). La tendencia general de todas las secuencias polínicas de la región (ver Capítulo 2) indican que hacia el Holoceno tardío el clima va adoptando las características actuales de aridez.

\subsubsection{Caracterización de los conjuntos y cronología}

A partir del derrumbe masivo del alero, en AEP-1 fueron identificados dos componentes (el superior y el inferior). Dentro de la matriz del componente superior, se encuentran las Capas1, 2 y 3 (Miotti 1992, 1996; Miotti et al. 1999). La Capa 1 carece de 
fechados radiocarbónicos pero es asignable al Holoceno tardío, y la Capa 3 corresponde a un hiato ocupacional. En la Capa 2 se registró la ocupación más tardía del sitio asignada al Holoceno Medio (Tabla 8.1).

Por su parte, el componente inferior contiene las Capas 4, 5 y 6 , y presenta las ocupaciones más tempranas. Dentro de la Capa 4 fueron registrados, hacia el sector exterior a la línea de goteo, bloques correspondientes al derrumbe del techo del alero que evidenciarían para este momento de ocupación, una superficie cubierta mayor a la actual (Miotti et al. 1999). Dentro de este componente se han identificado al menos dos resoluciones arqueológicas correspondientes a la transición Pleistoceno-Holoceno (Tabla 8.1), la primera corresponde a la Capa 6, con fechados entre ca. 12.800 y 11.000 años AP, la segunda ocupación se registra en las Capas 4 y 5 cuyos fechados radiocarbónicos van desde ca. 10.500 años AP hasta ca. 9200 años AP (Tabla 8.1).

\begin{tabular}{|c|c|c|c|c|c|}
\hline UE & Código & Tipo & Años $\mathbf{C}^{\mathbf{1 4}}$ AP & $\boldsymbol{\delta}^{\mathbf{1 3}} \mathbf{C}$ & Material \\
\hline 2- media & NSRL- 11167 & AMS & $7470 \pm 140$ & $-23,1$ & Carbón \\
2- base & LP 450 & estándar & $7670 \pm 110$ & S/D & óseo- L. guanicoe \\
4- techo & LP 949 & estándar & $9230 \pm 105$ & $-22,2$ & óseo- L. guanicoe \\
4- base & LP 859 & estándar & $9710 \pm 105$ & $-20,2$ & óseo- L. guanicoe \\
5 & AA- 8428 & AMS & $10400 \pm 80$ & $-25,8$ & óseo- Camelidae \\
5 & OXA 9249 & AMS & $10470 \pm 65$ & $-26,6$ & Carbón \\
6 & OXA 8527 & AMS & $10390 \pm 70$ & $-18,1$ & óseo- L. guanicoe \\
6 & GRA 9837 & AMS & $10470 \pm 60$ & S/D & Carbón \\
6 & OXA 8528 & AMS & $10925 \pm 65$ & $-19,3$ & óseo- Hippidion saldiasi \\
6 & AA- 27950 & AMS & $11000 \pm 65$ & $-23,4$ & Carbón \\
6 & AA- 20125 & AMS & $12890 \pm 90$ & $-25,8$ & Carbón \\
\hline
\end{tabular}

Tabla 8.1. Fechados radiocarbónicos de AEP-1 (tomado de Miotti et al. 2000, 2003).

\subsubsection{Componente Inferior}

El componente inferior está representado, como se dijo anteriormente, por 3 capas (4, 5 y 6), cada una de las cuales se corresponde con un horizonte del paleosuelo, registrándose un límite transicional entre las tres capas (Miotti et al. 1999).

Los remontajes practicados entre especímenes de capas 4 y 5 permiten sostener que corresponden a un único evento ocupacional. A partir del trabajo de remontajes realizado por Giardina et al. 2000 se unificaron los materiales en lo que se definió como 
Capa 4/5. Sin embargo, los fechados radiocarbónicos entre la base de Capa 5 y el techo de Capa 4 indican un lapso de mil años, por lo que es más parsimonioso validar la hipótesis de varios eventos de caza y descarte de partes de las presas en el mismo lugar

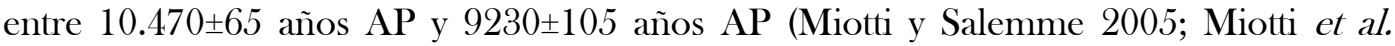
1999, 2000). Sin embargo, en ningún caso se observó que materiales de la Capa 5 remonten con los de la Capa 6 por lo que esta última ha sido interpretada como una ocupación independiente y previa a las de la Capa 4/5. Ambas ocupaciones han sido interpretadas como resultado de actividades limitadas y relacionadas al procesamiento primario de grandes animales (Miotti 1995; Miotti et al. 1999).

Los fechados obtenidos para la Capa 6 (Tabla 8.1) muestran una dispersión que va desde $12.890 \pm 90$ años $\mathrm{AP}$ a $10.390 \pm 70$ años $\mathrm{AP}$, pudiendo ser ambos outliers estadísticos. Esta capa posee baja cantidad de materiales y las características tecnomorfológica de los artefactos líticos (Cattáneo 2005; Miotti y Cattáneo 2003; Miotti y Salemme 2005; Miotti et al. 1999, 2003), evidencian la necesidad de poder ajustar la resolución temporal y los análisis tafonómicos antes de considerar la posibilidad de varias ocupaciones diacrónicas en esta unidad.

Los estudios arqueofaunísticos de este componente no han incluido en el análisis la totalidad de la muestra zooarqueológica debido a que parte de ella (la correspondiente al los últimos año de excavación del sitio) aún no había sido procesada para el análisis. En esta tesis se aborda el estudio completo de las arqueofaunas de AEP-1, a partir de desarrollo de una línea de investigación tafonómica aún no aplicada sistemáticamente en las investigaciones arqueológicas del área aunque exitosa en otras regiones (Barberena 2008; Belardi 1999; Borrero 1988, 2000, 2001; Borella 2002; Cruz 2003; L’Heureux y Borrero 2002; Martin y Borrero 1997; Martin 2008, entre otros).

Las tendencias obtenidas en trabajos previos sobre el análisis de la abundancia taxonómica indican que el principal taxón representado en este componente, como en los demás de la secuencia fue el guanaco (Lama guanicoe), mientras que aquí el segundo taxón más popular fueron las aves corredoras, rheidos (Miotti et al. 1999). En este último caso se registraron para ambas ocupaciones (Capa 6 y Capa 4/5) dos géneros diferentes: Rhea y Pterocnemia; de ellos el primero corresponde a una especie que actualmente no habita en el área (Miotti y Tonni 1996; Miotti et al. 1999; Salemme y Miotti 1998).

De la megafauna identificada en Capa 6, únicamente Hippidion saldiasi y Lama gracilis presentan evidencias de acción humana (huellas de corte y fractura helicoidal con puntos de impacto), y son los que tienen una representación complementaria también en 
la Capa 4/5 (Miotti 2003; Miotti et al. 1999; Miotti y Salemme, 2005). Esto evidencia una estrategia de subsistencia generalista favorecida por la alta diversidad de especies presentes en el ambiente para ese momento (Miotti y Salemme 1999, 2005; Miotti et al. 1999, 2000).

La tendencia de meteorización es decreciente hacia los estadíos de mayor meteorización con un 70\% de especímenes, tanto en Capa 6 como en Capa 4/5, que caen en las categorías 1 y 2 (Miotti 2003: Figura 5). Miotti (2003) nota que el grado de fragmentación ósea es muy bajo y que las manchas de manganeso y las acresiones carbonáticas en las superficies de los especímenes son abundantes, sin embargo, en la mayoría de los casos ha permitido conservar la integridad anatómica de los especímenes.

La distribución de las unidades anatómicas en Capa 4/5 adopta configuración de pilas de descarte, fundamentalmente en las cuadrículas $\mathrm{C}, \mathrm{D}$ y F, y donde partes de las patas y de la columna vertebral se presentan articuladas (Miotti et al. 1999; Miotti y Salemme 2005). En este nivel es en el que fueron recuperados dos fragmentos de punta cola de pescado (Miotti 1992) y en el que Cattáneo (2002) registra tres áreas de concentración de restos líticos, una en la cuadrícula $\mathrm{C}$ y alrededores $(\mathrm{B}$ y $\mathrm{D})$, cuadrícula $\mathrm{F}$ y alrededores (E y G) y en menor proporción en la K y L, siendo baja la concentración de restos en las cuadrículas que están bajo el alero ( $\mathrm{H}$, I y J). Estas concentraciones óseas no se registran en Capa 6 (Miotti et al. 1999), en cuanto a la distribución de los materiales líticos, la mayor densidad se registra en el sector más externo del alero (Cattáneo 2002).

Las partes anatómicas más representadas del guanaco son las de bajo rendimiento económico (Miotti et al. 1999, 2000). En el caso de la Capa 6 se encuentran elementos del esqueleto axial y apendicular, siendo sensiblemente mayor la representación de este último (tibia y radio-cúbito). En el caso de la Capa 4/5, están representadas todas la unidades anatómicas del guanaco, las mayores frecuencias se observan para el esqueleto axial, donde el máximo MAU\% se obtiene a partir de las vértebras lumbares y es secundado por el cráneo, las vértebras cervicales, el fémur y elementos de las cinturas (Miotti et al. 1999).

$\mathrm{El}$ análisis de las frecuencias de partes anatómicas permite interpretar a la Capa 6 como un locus de descarte de partes anatómicas de bajo rendimiento, un área con mayor influencia de la destrucción diferencial (Miotti et al. 1999; 2000). Por su parte, las unidades $4 / 5$ se correlacionaron de forma independiente. La Capa 4 correspondería a un locus de Clase 3 donde se da descarte de piezas esqueletarias de bajo valor económico y mediano a alto índice de destrucción; la Capa 5 correspondería a la Clase 2 (sensu 
Lyman 1994) planteando el problema de equifinalidad, que no ayuda para determinar la causa de las frecuencias observadas. A pesar de ello, los conjuntos de Capa 4/5 han sido considerados locus a los cuales se ingresaron algunas partes que se consumieron (contenido del cráneo, costillar y médula ósea de metapodios), y en otros casos se extrajo la carne de mayor utilidad, abandonando parte de las mismas enteras en las pilas mientras a otras se les habría extraído primero la médula y luego se las habría descartado en el sitio (Miotti et al. 1999). El análisis de frecuencias de partes anatómicas de la Capa 4 y de la Capa 5 por separado requiere incorporar los nuevos especímenes a la muestra y recalcular todas las unidades cuantitativas estimadas $\mathrm{y}$ realizar nuevamente las correlaciones debido a que los remontajes practicados indican que debemos analizar las dos unidades de forma conjunta.

La Capa 6 fue interpretada como un evento ocupacional reducido donde el uso del sitio en este momento, responde a un lugar de trozamiento primario de guanacos y posiblemente de caballos y camélidos extinguidos (Miotti y Salemme 2005; Miotti et al. 1999). Sin embargo, podría interpretarse que además se llevaron a cabo prácticas de aprovechamiento oportunista de algunas partes de mylodontinos, este enunciado estaría avalado por la falta de huellas de acción de carnívoros tanto en los escasos restos de Mylodon sp. como en los demás elementos (Miotti 1996). El contexto concuerda con una estrategia forager (Binford 1980; Bettinger 1991) de caza oportunista por encuentro, a diferencia de la Capa 4/5 en donde la estrategia empleada habría sido de caza programada por acecho a determinado tipo de presas, que en este caso particular esta apuntado a guanacos complementado con ñandúes (Miotti 1996; Miotti et al. 1999). La funcionalidad inferida para esta capa (Capa 4/5) a partir de las marcas de corte, el análisis de fracturas y las modificaciones óseas pre y post-depositacionales, nos habla de un locus de aprovisionamiento, desmembramiento y descarte de presas (Miotti y Salemme 2005; Miotti et al. 1999), pero a diferencia de la Capa 6, aquí se empleó una estrategia collector (Binford 1980) para el transporte de aquellas partes con mayor rendimiento hacia las bases residenciales que estarían alejadas de este complejo situacional de matanza y trozamiento (Miotti y Salemme 2005; Miotti et al. 1999).

A partir del análisis de materiales líticos con signos de alteración térmica y dada la ausencia de fogones estructurados, Cattáneo (2002) propone para la Capa 4/5 dos claras concentraciones de alteraciones térmicas asignables a fogones, una en el área interna del alero, entre el paredón rocoso y las concentraciones de huesos y restos líticos (I, J), y otra, en el sector externo ( $\mathrm{G}, \mathrm{F}$ y $\mathrm{E}$ ), y que probablemente se extiende hacia una zona no 
excavada aún. Mientras que en la Capa 6 , si bien los materiales líticos termoalterados son escasos podría suponerse al menos un área de fogón en el sector este de la cuadrícula D y oeste de B.

\subsubsection{Componente Superior}

En este componente solamente se registraron restos correspondientes a fauna viviente autóctona como guanaco y cánidos, ñandú petiso, armadillos y escasos restos de valvas marinas (Miotti y Salemme 2005). Los restos recuperados además de evidenciar actividades de caza y procesamiento, indican el uso del hueso como materia prima para la manufactura de instrumentos. El sitio fue ocupado como un área de actividades múltiples que involucraron el procesamiento, el descarte de restos y posiblemente otro recursos, la extracción de médula y el procesamiento de alimentos para ser consumidos (Miotti y Salemme 2005). Los análisis cualitativos y cuantitativos de la fauna correspondiente a este momento de ocupación del alero aún están pendientes y su estudio forma parte de la tesis en cuestión.

El análisis espacial de los materiales líticos (Cattáneo 2002) muestra que la mayor cantidad de los mismos se encuentran distribuidos en el sector bajo el alero y que corresponde a las cuadrículas H, I y J. Cattáneo (2002) propone que este sector podría haber funcionado como un área de descarte de productos líticos. Si bien, en este nivel durante las excavaciones no fueron identificadas fogones estructurados, a partir del análisis de la alteración térmica de los materiales Cattáneo (2002) propone cuatro sectores con concentración de materiales térmicamente alterados, los dos más importantes estarían en las cuadrículas $\mathrm{F}$ y $\mathrm{G}$, y los dos más pequeñas en $\mathrm{B}$ y $\mathrm{D} / \mathrm{C}$. En función de esta distribución espacial propone que la misma estaría indicando un importante uso del alero, con fogones sobre el portal y quizás áreas de descarte y fogones menores o de corta duración hacia la zona norte, y pegada a la pared rocosa.

\subsection{UNIDAD ESTRATIGRÁFICA 2- CAPA 6}

El conjunto zooarqueológico que proviene de esta capa constituye el más antiguo 
de toda la secuencia ocupacional del sitio y fue recuperado en el horizonte IIIC del perfil de suelo enterrado (Zárate et al. 2000). Los fechados radiocarbónicos realizados arrojaron antigüedades entre ca. 12.000 y 10.400 años AP (Tabla 8.1), por lo que el mismo correspondería a la transición Pleistoceno-Holoceno (Capítulo 2).

La muestra analizada está integrada por un total de 219 especímenes óseos, de los cuales el $84,4 \%(\mathrm{NISP}=185)$ pudo ser determinado a alguna categoría taxonómica y anatómica, quedando el 15,6\% restante como indeterminados (NISP=34).

Los 219 especímenes óseos recuperados proceden de 9 de las 12 cuadrículas excavadas en el sitio ya que, la Capa 6 , no fue registrada en el sector bajo el abrigo rocoso contiguo al alero (Figura 8.2).

La distribución en planta de los especímenes tridimensionados (Figura 8.4a) permite observar dos sectores con mayor concentración de restos óseos: uno localizado en la cuadrícula L y parte de la F, y el otro en la cuadrícula B. Por su parte, el análisis de densidad de restos óseos por $\mathrm{m}^{2}$ considerando el conjunto completo que incluye los especímenes tridimensionados y los recuperados a través de zaranda, muestra que los sectores de mayor densidad (Figura 8.4b) coinciden con los registrados para los especímenes tridimensionados (Figura 8.4a).

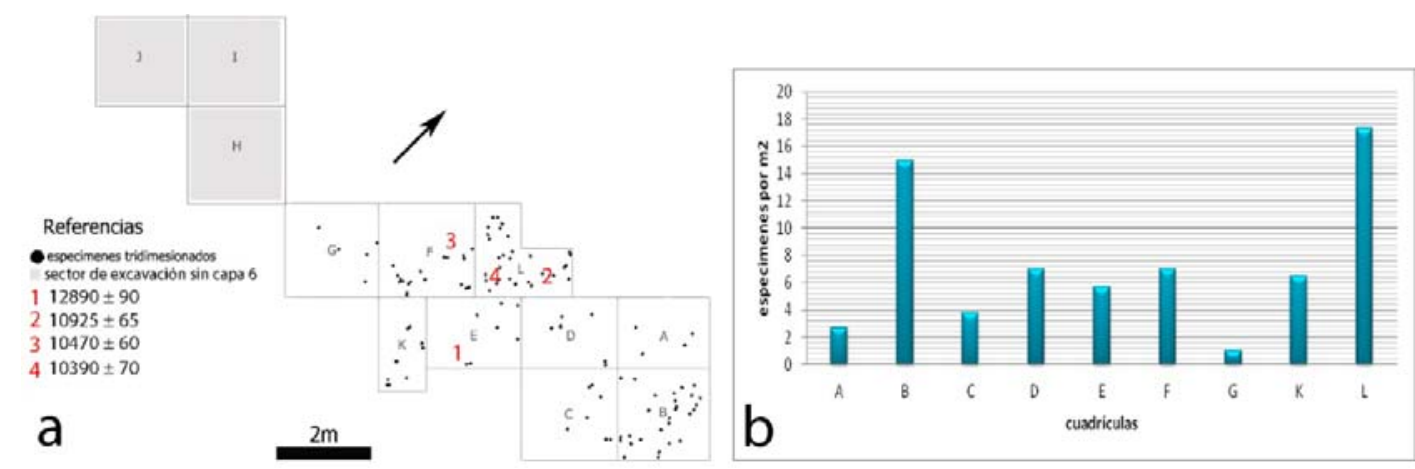

Figura 8.4. a) Distribución en planta de los especímenes tridimensionados y los fechados radiocarbónicos; b) densidad de restos óseos por $\mathrm{m}^{2}$ en las cuadrículas de Capa 6 de AEP-1. Los valores se expresan en NISP\% por $\mathrm{m}^{2}$.

Durante las excavaciones no se registraron ni delimitaron estructuras o áreas de combustión. Sin embargo, Cattáneo (2002) infiere, a partir del registro de concentraciones de artefactos líticos termoalterados, la posible existencia de un fogón en el sector este de la cuadrícula D y oeste de B. Además, durante las excavaciones realizadas se han recuperado restos de carbón vegetal, a partir de los cuales fue posible 
lograr tres de los fechados radiocarbónicos obtenidos para esta capa (Tabla 8.1). Durante los trabajos de campo no se registraron cuevas ni galerías que puedan ser atribuidas a la acción de roedores (Miotti et al. 1999).

\subsubsection{Abundancia taxonómica y anatómica}

Los resultados obtenidos indican una alta frecuencia de restos de camélidos (21,62\% del NISP), entre los que se destaca la presencia de Lama gracilis y Lama guanicoe (Tabla 8.2). Entre los camélidos un alto porcentaje de especímenes (35\% del NISP) fueron determinados como Lama sp. ya que corresponden a animales jóvenes o subadultos, y/o a fragmentos de diáfisis que no hicieron posible su asignación a un nivel más específico. Esta situación pone en evidencia la importancia económica que estos ungulados habrían tenido desde los inicios de la ocupación humana del área, hipótesis que fue formulada en trabajos previos (Miotti 1996; Miotti y Salemme 1999, 2005; Miotti et al. 1999).

\begin{tabular}{|l|c|c|}
\hline \multicolumn{1}{|c|}{ Taxa } & NISP & \%NISP \\
\hline Aves & 5 & 2,70 \\
\hline Rheidae & 4 & 2,16 \\
\hline Mamiferos grandes & 44 & 23,78 \\
\hline Canis sp. & 6 & 3,24 \\
\hline Mylodon sp. & 6 & 3,24 \\
\hline Hippidion saldiasi & 15 & 8,11 \\
\hline Lama sp. & 65 & 35,13 \\
\hline Lama gracilis & 28 & 15,13 \\
\hline Lama guanicoe & 12 & 6,49 \\
\hline
\end{tabular}

Tabla 8.2. Abundancia taxonómica en la Capa 6 de AEP-1.

Los équidos son los que alcanzan el segundo lugar en importancia según las frecuencias de NISP\% con que se registran (8,11\%), y son seguidas por los milodontinos (3,24\% del NISP), los cánidos (NISP= 3,24\%) y los rheidos (2,16\% del NISP) (Tabla 8.2).

Distintos investigadores proponen que los mamíferos pleistocénicos fueron aprovechados en forma complementaria y ocasional al guanaco para estos momentos (Borrero 1984, 2009; Gutiérrez y Martínez 2008; 8ñalons 1983, 1988; Miotti 1998; Miotti 
et al. 1988; Politis 1984; Politis y Messineo 2008). Los estudios realizados con anterioridad a esta tesis avalan esa hipótesis ya que registraron la presencia de marcas de procesamiento sobre los especímenes de Hippidion sp., Lama gracilis (Miotti 2003; Miotti et al. 1999; Miotti y Salemme 2005).

Una frecuencia elevada de restos óseos no pudo ser asignada a un nivel más específico que el de Clase Mammalia $(\mathrm{NISP}=44)$, esto se debe a que en su mayoría son fragmentos de diáfisis de huesos largos que no registran características o rasgos diagnósticos que permitan alcanzar niveles de identificabilidad más específicos.

Entre las especies determinadas Lama gracilis, Hippidion sp. y Mylodon sp. corresponden a fauna pleistocénica extinguida, mientras que Lama guanicoe es la especie de camélidos que hasta la actualidad habita el área de estudio. Para estos momentos en el área se registran dos géneros distintos de rheidos: Pterocnemia pennata (ñandú petiso) y de Rhea americana (ñandú grande), siendo Pterocnemia pennata el único de estos dos géneros con representación actual en la meseta ya que Rhea americana, si bien no se encuentra extinguida, actualmente no habita el área de estudio (Cardich y Miotti 1983; Miotti y Salemme 1999; Salemme y Miotti 1987; Tambussi y Tonni 1985).

La cantidad de restos asignados a $L$. guanicoe es escasa (Tabla 8.2), ya que solo se determinaron para esta especie elementos enteros y especímenes de individuos adultos que conservaban porciones de epífisis. Los especímenes que no presentaban estas características fueron agrupados a nivel del género Lama sp. Por tal motivo, los valores de NISP de guanaco se encuentran reducidos respecto a los publicados en trabajos previos (Miotti et al. 1999; Miotti y Salemme 2005).

Las estimaciones de abundancia anatómica de los guanacos se obtuvieron a partir de los escasos especímenes atribuidos a esta especie. Creemos que varias unidades podrían encontrar una mejor representación si consideramos además los restos de Lama sp. debido a que entre ellos seguramente hay guanacos. Esta decisión no es metodológicamente correcta (Grayson 1984) ya que dentro de los Lama sp. también podrían registrarse especímenes de L. gracilis. De esta manera, estimar la abundancia anatómica solamente para los especímenes de guanaco es una decisión que permite evitar la posible mezcla de partes anatómicas de especies diferentes.

El análisis de las unidades anatómicas del guanaco permitió identificar la presencia tanto de elementos del esqueleto axial $(\mathrm{MNE}=3)$ como del esqueleto apendicular $(\mathrm{MNE}=6)$. El número mínimo de individuos es uno (Tabla 8.3). 


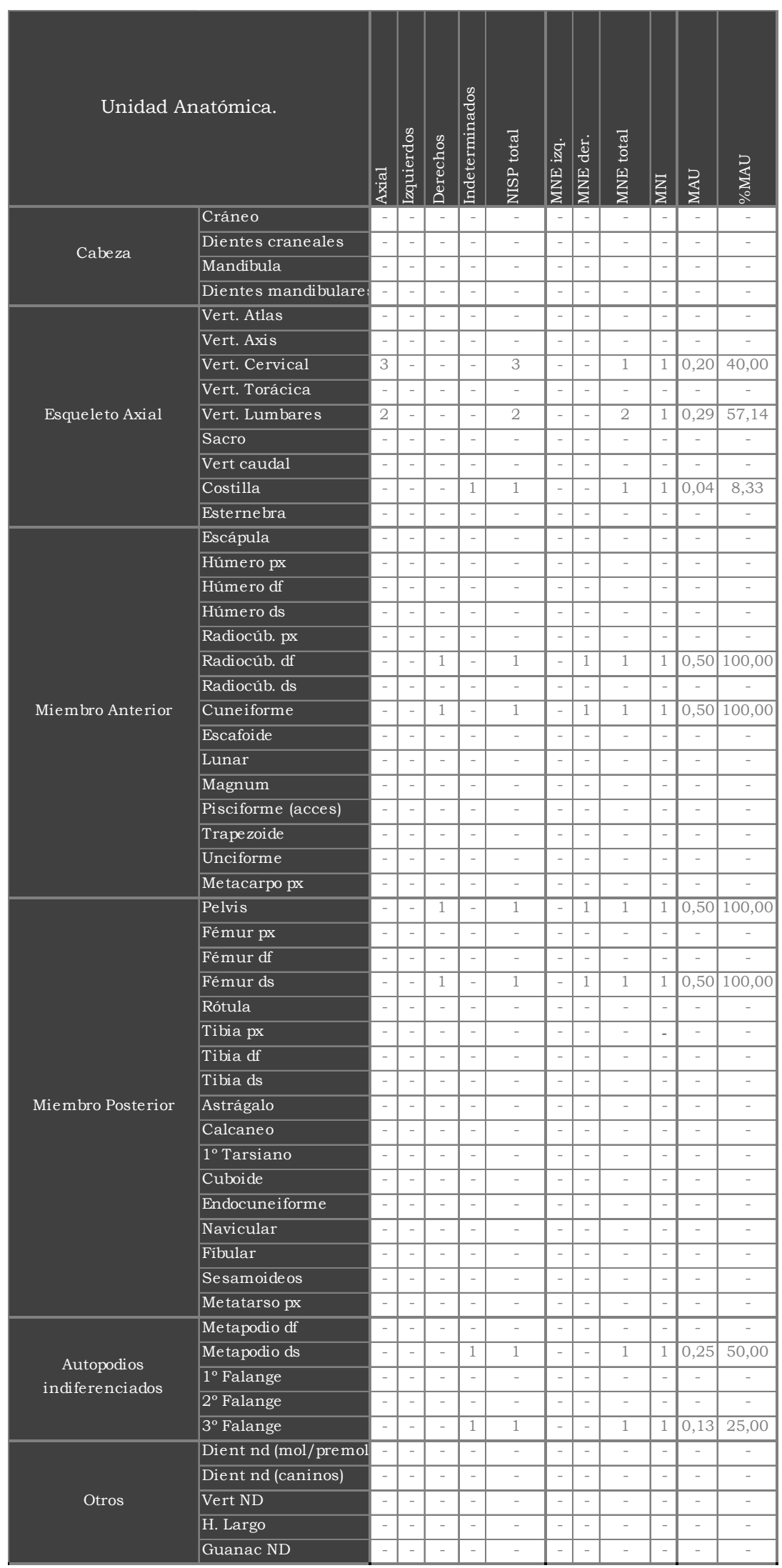

Tabla 8.3. Representación de partes anatómicas de los guanacos en Capa 6 de AEP-1. 
La relación entre el MNE/NISP para los guanacos arrojó un valor de 0,50 lo que estaría indicando una fragmentación moderada en la Capa 6. Este nivel de fragmentación posiblemente sea una de las causas por las que una gran cantidad de especímenes óseos no hayan conservado características diagnósticas para ser determinados a niveles más específicos que el de Lama sp. o Clase Mamífero.

El análisis de abundancia anatómica de los guanacos indica que los valores máximos de MAU\% (100\%) se registraron para la diáfisis del radio-cúbito y el cuneiforme del miembro anterior, y para la pelvis y el fémur distal en lo que compete al miembro posterior (Tabla 8.3). Otros elementos correspondientes al esqueleto apendicular del guanaco se registraron en frecuencias menores como los metapodios distales (50\%) y la tercera falange (25\%). Los restantes elementos correspondientes a miembros y cinturas no fueron identificados en el sitio. En cuanto a la representación de partes del esqueleto axial, solamente se determinaron restos óseos correspondientes al tronco de los guanacos siendo las vértebras lumbares $(57,1 \%$ del MAU\%), las vértebras torácicas (MAU\%=40\%) y las costillas $(8,3 \%$ del MAU\%) los únicos elementos representados. No fue identificado ningún espécimen óseo correspondiente a la cabeza de estos ungulados ni a las vértebras atlas y axis (Tabla 8.3). Esta situación podría indicar que, de no mediar procesos de destrucción, dicha unidad anatómica no habría sido transportada al sitio.

Con respecto al esqueleto apendicular, mejor representado que el axial, encontramos que tanto el miembro anterior como el posterior derecho adquieren una representación distinta. Mientras que en el miembro anterior se encuentran representados los elementos distales del zeugopodio y autopodio; en el miembro posterior los elementos con mayor frecuencia corresponden al estilopodio y a la cintura pélvica (Tabla 8.3).

De este análisis se desprende que tanto el cuarto delantero como el trasero son las unidades de trozamiento más representadas de los guanacos. Sin embargo, la representación de partes distintas en cada uno podría estar reflejando unidades menores de trozamiento que no serían las mismas para el cuarto delantero y trasero (Tabla 8.3).

Se evaluó la distribución de restos de guanacos en el área excavada del sitio. Los resultados obtenidos permiten observar que la mayor densidad se registra en las cuadrículas B, D y L coincidiendo de esta forma con la tendencia registrada para el conjunto completo (Figura 8.1b).

Los rheidos están representados por dos falanges y un tibio-tarso del esqueleto apendicular, mientras que el esqueleto axial, se encuentra representado por una única 
vértebra cervical. Los cánidos tienen un MNI de dos, y todos los elementos representados corresponden a partes distales del miembro posterior izquierdo (una tibia, un astrágalo, un calcáneo, un tarsal y dos metatarsos).

Los équidos están representados por distintos elementos tanto del esqueleto axial i.e., mandíbula, cráneo, vértebras torácicas y sacro- como del apendicular -i.e., falanges, metacarpo, metapodio, rótula y húmero-. Mientras que los milodontinos, solamente están representados por fragmentos de costillas.

Se evaluó si los especímenes óseos asignados a Lama sp. y Mamíferos de tamaño grande podían estar complementando las frecuencias de partes observadas en los guanacos. Los resultados obtenidos para los mamíferos fueron negativos ya que la gran mayoría de ellos $(60 \%)$ corresponden a fragmentos de diáfisis de hueso largo indeterminado y a fragmentos óseos indeterminados (32\%). Sin embargo, las frecuencias correspondientes a Lama sp. $(\mathrm{NISP}=65)$ podrían modificar algunos valores de NISP y MNE en los guanacos. Dentro del esqueleto axial, la cabeza seguiría ausente pero la región correspondiente al tronco podría estar mejor representada a partir de las vértebras cervicales, torácicas y lumbares, el sacro y algunos fragmentos de costillas. En cuanto al esqueleto apendicular tendríamos representados algunos elementos que estaban ausentes como la escápula, el húmero y la tibia, en algunos de estos casos sumando dos elementos (derecho e izquierdo). Otras unidades como el fémur y el radio-cúbito incrementarían su frecuencia de NISP y de MNE, al menos en uno izquierdo. Sería necesario a futuro ajustar estas medidas para aumentar la resolución taxonómica del conjunto, ya que es un trabajo que excede el propuesto para esta tesis. Para ello podrían desarrollarse vías independientes a la aquí utilizada que permitan alcanzar mejores niveles de identificabilidad, como por ejemplo los estudios de ADN y microscopía de altos aumentos para ver la estructura del hueso. Otros aportes metodológicos, como los desarrollados por Izeta (2004) y Barba y Domínguez-Rodrigo (2005) también podrían contribuir a la solución del problema de equifinalidad aquí presentado.

\subsubsection{Análisis de la estrategia de transporte de partes anatómicas del guanaco.}

Para evaluar las posibles causas de tal representación de unidades anatómicas en los guanacos se efectuaron distintas correlaciones estadísticas (Figura 8.5). Los resultados obtenidos indican que entre el MAU\% y la DO $(r=0,12 ; \mathrm{p}>0,05)$ hay ausencia de 
correlación. También se observa ausencia de correlación estadística entre el MAU\% y los valores de MGUI\% obtenidos tanto por Borrero (1990) como por Lyman (1992) (Figura 8.5b y 8.5c). Como se observó en el capítulo anterior, estas tendencias pueden estar influenciadas por el tamaño de la muestra que en este caso, es reducido (Grayson 1984).

El análisis de estos resultados a partir de las clases propuestas por Lyman (1994) no nos permite interpretar al conjunto como resultado de una estrategia de transporte particular. Dado que ambos coeficientes indican correlaciones no significativas, el conjunto correspondería a la Clase 5 de equifinalidad (Lyman 1994) por lo que no se puede determinar si es resultado de una estrategia particular -e.g., gourmet o utilidad reversa-, si es resultado de la acción de procesos mediados por densidad ósea -e.g., meteorización, transporte fluvial, acción de carnívoros-, o si resulta de una combinación de ambas posibilidades.

Estos resultados se diferencian de los estimados por Miotti et al. (1999) a partir de una muestra menor, que contemplaba los materiales recuperados en las excavaciones realizadas en el sitio hasta 1996. En esa oportunidad, los resultados mostraban que el conjunto podía ser interpretado como Clase 1 (Lyman 1994), lo que indicaba el descarte de unidades de bajo rendimiento. En esta oportunidad los resultados obtenidos por este método varían hacia una situación que presenta mayores dificultades de interpretación, ya que, como se dijo anteriormente, no refleja una estrategia particular de transporte.

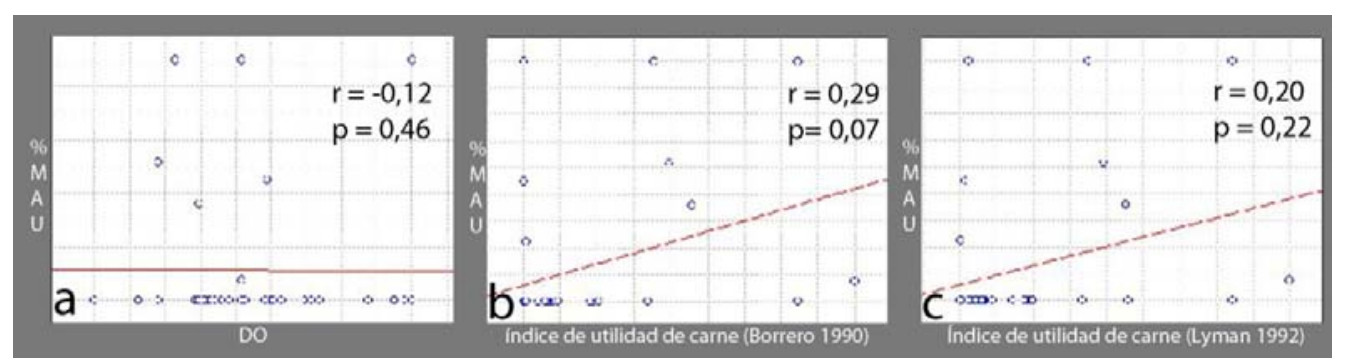

Figura 8.5. Correlaciones estadísticas de Spearman para las unidades anatómicas de los guanacos en Capa 6 de AEP-1: a) entre el MAU\% y la DO; b) entre el MAU\% y el MGUI\% (sensu Borrero 1990); c) entre el MAU\% y el MGUI\% (sensu Lyman 1992). 


\subsubsection{Modificaciones de las superficies óseas}

El análisis de las superficies óseas en busca de patrones de modificación atribuibles a los distintos procesos y agentes naturales y culturales, se llevó a cabo tanto sobre los especímenes de fauna actual como sobre los de fauna extinguida.

\subsubsection{Patrones de modificaciones naturales}

Los resultados obtenidos muestran que más del $88 \%$ del conjunto de restos óseos de camélido registran una meteorización relativamente baja (estadios 0, 1 y 2 de Behrensmeyer 1978) que indica un tiempo relativamente breve de exposición del conjunto (Figura 8.6). Esta situación, que caracteriza a la gran mayoría de los restos de manera homogénea, estaría indicando que el conjunto tuvo un enterramiento relativamente sincrónico.

El registro de escasos especímenes $(n=7)$ con una meteorización superior al estadio 2 (Figura 8.6), podría evidenciar un deterioro más profundo en las superficies óseas de algunos pocos restos con pérdida de tejido cortical por la exfoliación sufrida. Esta situación si bien podría relacionarse con las distintas densidades óseas de los elementos y, por lo tanto, a que frente a un mismo tiempo de exposición algunos restos se meteorizan más que otros. Debemos considerar que esta meteorización más elevada también puede ser resultado de los factores de variabilidad intra-taxonómica (Massigoge et al. 2010), o como fue observado por Miotti (2003), de la fragmentación previa de los especímenes.

Al comparar la meteorización exhibida entre los restos óseos del esqueleto apendicular y los del esqueleto axial (Figura 8.6) se observa que estos últimos son los que registran la meteorización más elevada y dispar del conjunto. Si bien esta tendencia es esperable debido a la variabilidad propia de DO entre estas unidades anatómicas (Behrensmeyer 1978), no podemos descartar que esta mayor meteorización esté influida por alguno de los factores mencionados anteriormente como son la presencia de individuos inmaduros o una fragmentación previa de los especímenes. De todas formas, la presencia escasa de especímenes en el estadio 3 y 4 de meteorización indicaría la existencia de una baja pérdida (Behrensmeyer 1978; Borrero 2007), vinculada con alguno de los factores arriba considerados. 


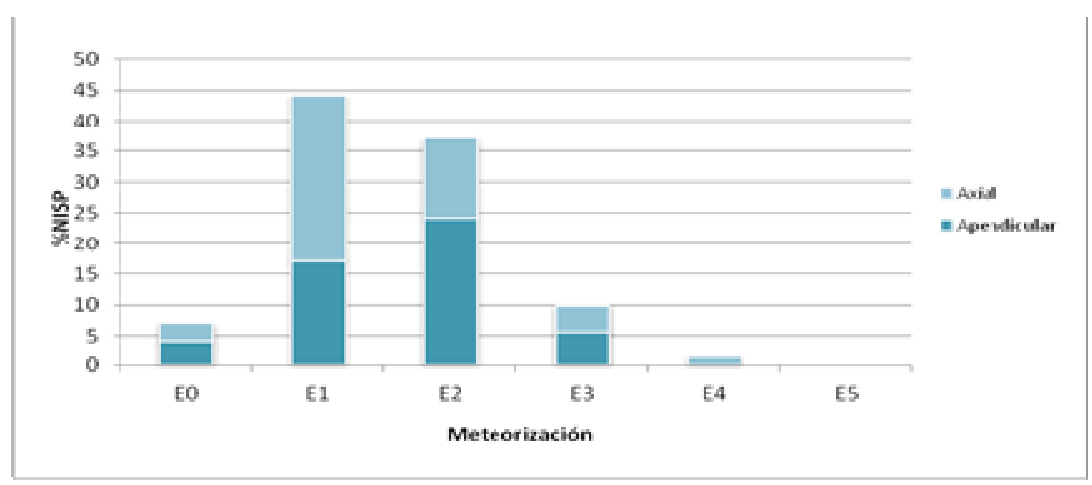

Figura 8.6. Tendencia de la meteorización en especímenes correspondientes a camélidos en el conjunto de Capa 6. Los valores son expresados en NISP\%.

El análisis de las superficies óseas permitió reconocer, además, otros patrones de modificaciones naturales (Figura 8.7a), entre ellos se observó que el óxido de manganeso es el que ha afectado a la mayor cantidad de especímenes (47\%). La depositación de manganeso se registró tanto en la superficie cortical como medular de los huesos, en forma de pequeñas manchas y a veces cubriendo parte importante de ella sin llegar a taparla por completo (Figura 8.8a y 8.8b). El registro de estos depósitos sobre la superficie de los huesos es indicador de condiciones de humedad ya que el manganeso puede ser transportado en agua y precipitar frente a cambios de pH (López-González et al. 2006). Su origen, en el caso de la Capa 6, podría estar relacionado a la disolución de rocas carbonáticas (López-González et al. 2006), cuyas características presenta la roca de base (coquina), sobre la que apoya este horizonte IIIC del suelo enterrado. La presencia de humedad aquí podría estar vinculada a fluctuaciones del nivel freático (Zárate et al. 2000).

Las modificaciones producidas por raíces, si bien en porcentajes muy inferiores a los depósitos de manganeso, también tienen una representación importante entre las modificaciones naturales (Figura 8.7a). Su presencia fue determinada en un ca. $14 \%$ de los especímenes de Capa 6 y en general consisten de surcos ramificados con diseño dendrítico (Figura 8.8b). Estas improntas presentan un patrón similar al descripto por Montalvo (2002) como resultado de la acción de raíces en la interfase elemento esquelético-sedimento. Esto indicaría la presencia de cubierta herbácea en el momento que los huesos fueron depositados y, por lo tanto, una acción de las raíces sobre los especímenes en los primeros momentos de su depositación. Esto es distinto a lo que habría sucedido con la precipitación de manganeso sobre los especímenes. Estas 
manchas se habrían depositado sobre los huesos cuando el conjunto ya se encontraba completamente enterrado. Seguramente por ello, en la mayor cantidad de los casos, el color de los surcos es más claro que la superficie del hueso, que en general se presenta cubierta parcialmente por manganeso. De esta forma, es posible interpretar que la depositación de los manganesos se produjo mientras las raíces se encontraban cubriendo parte de los restos óseos.

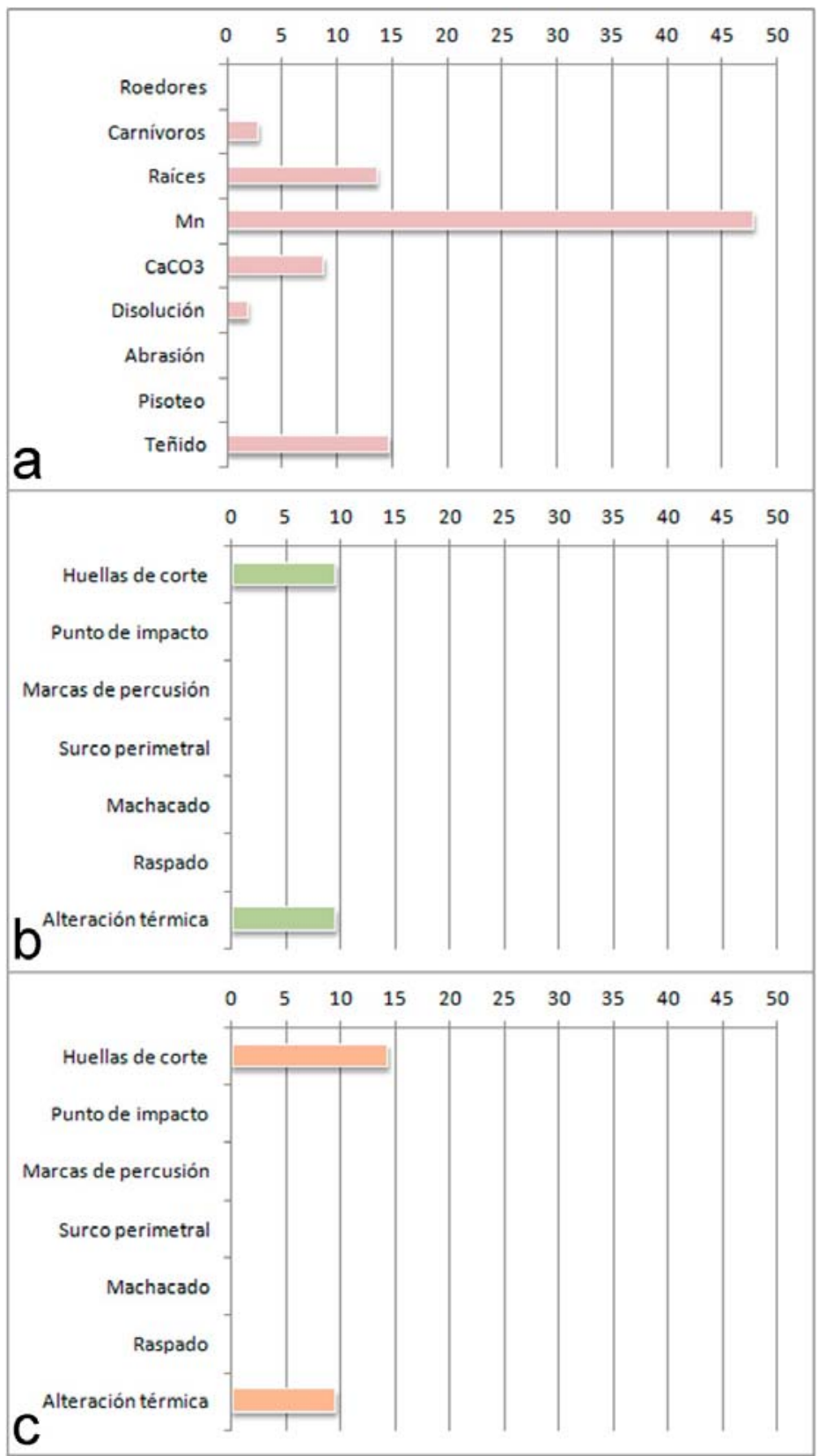

Figura 8.7. Frecuencia porcentual de especímenes óseos de camélidos con modificaciones: a) naturales; b) modificaciones antrópicas en especímenes del esqueleto axial; c) modificaciones antrópicas en el esqueleto apendicular. 
Estas elevadas frecuencias de depósitos de manganesos en la Capa 6 coinciden con lo registrado por Miotti et al. (1999: 123) sobre una muestra menor a la aquí estudiada. La diferencia radica en que en ese caso fueron interpretados como resultado de la acción de microorganismos mientras aquí se propone además, un origen vinculado con las características de la roca de base.

Otras modificaciones pudieron ser descriptas. Entre ellas se registró la presencia de depósitos de carbonato en una más baja frecuencia $(8,8 \%)$ que la registrada para el manganeso (47\%). El carbonato, al igual que el manganeso, se podrían haber originado a partir de la disolución de la roca de base carbonática y transportado disuelto en agua (Courty et al. 1989; Gutiérrez 2004).

En tres especímenes óseos se describió un patrón de marcas que podría corresponder a la acción de agentes carnívoros (Figura 8.8c y 8.8d). Trabajos previos (Miotti 2003; Miotti et al. 1999) sobre el Componente Inferior de AEP-1 (Capa 6 y 4/5) registraron un bajo porcentaje de especímenes con hoyuelos en sus superficies, sugiriendo que los carnívoros no habrían tenido un rol importante en la formación del conjunto (Miotti 2003: 158; Miotti et al. 1999: 124). Los nuevos resultados obtenidos para la Capa 6 confirman la baja incidencia de los carnívoros sobre el conjunto avalando esa hipótesis previa.

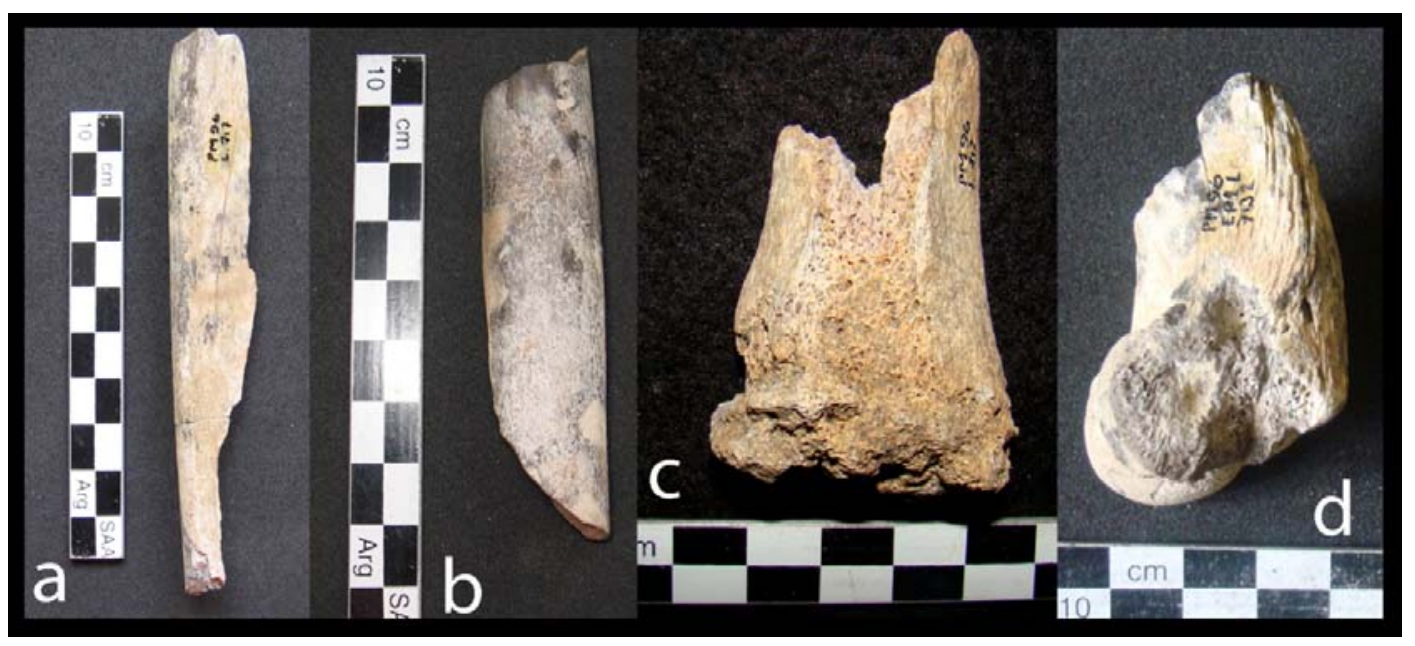

Figura 8.8. Modificaciones naturales: a) depósito de manganeso sobre diáfisis de radiocúbito distal de Lama sp.; b) marcas de raíces y depósito de manganeso sobre diáfisis de tibia de Lama sp.; c) modificaciones producidas por carnívoros sobre radio-cúbito distal de L. guanicoe; d) marcas de carnívoro sobre húmero distal de L. gracilis. 
No se registraron modificaciones producidas por roedores sobre el conjunto de Capa 6 lo que coincide con las observaciones previas y la ausencia de cuevas o galerías identificadas durante las excavaciones (Miotti et al. 1999: 124)

Un $14 \%$ de los especímenes óseos se asignaron a la categoría teñidos, ya que no fue posible distinguir si el ennegrecimiento de sus superficies se debía a la presencia de manganeso o a la acción del fuego (Figura 8.7a). En dos especímenes se registraron hoyos esféricos u ovales en sus superficies, debido a que no fue posible determinar si los mismos eran resultado de la digestión de carnívoros, de la acción ácida de de las raíces u otro tipo de proceso, la misma fue determinada como disolución química (Figura 8.7a).

El análisis de la distribución de los especímenes con manganeso (Figura 8.9a) permite observar una disposición homogénea en toda la superficie excavada del sitio. Sin embargo, puede apreciarse una mayor densidad en las cuadrículas L y B. Creemos que eso está relacionado más directamente con que son los sectores que concentran la mayor cantidad de restos óseos (Figura 8.4a y 8.4b), y no con áreas de depositación diferencial de manganeso y que indicarían condiciones de humedad diferentes.

Con respecto a la distribución de especímenes con marcas de raíces (Figura 8.9b), mostraron un patrón homogéneo y similar al observado para los especímenes con manganeso. Sin embargo, en este caso la mayor densidad de los mismos se encuentra en las cuadrículas más externas del alero como son B, C, D y E. Esta distribución presenta coherencia con la expectativa de que la cubierta vegetal se pudo desarrollar en el sector menos protegido del alero, por fuera de la línea de goteo (Figura 8.2). Allí, el sustrato y las condiciones de luz, sol y humedad deberían haber sido mejores que en el interior del alero.

Por su parte, considerando la distribución de especímenes con carbonatos se observa que en su mayoría se registraron en los sectores más externos del alero. De esta forma, adquieren una disposición similar a la observada para los especímenes con marcas de raíces. Dado que el carbonato, al igual que el manganeso es transportado disueltos en agua, la expectativa era que estos muestren un patrón de distribución semejante al exhibido por el manganeso. Posiblemente esta diferencia pueda deberse a que el carbonato ha tenido menor importancia que el manganeso en la formación del sitio y en consecuencia su registro es escaso $(n=9)$.

Los tres especímenes que presentan marcas atribuibles a carnívoros se encuentran distribuidos en los dos sectores con mayor concentración de restos (cuadrículas B y L). Por su parte, los dos restos con marcas de disolución química fueron recuperados en la 
cuadrícula C.
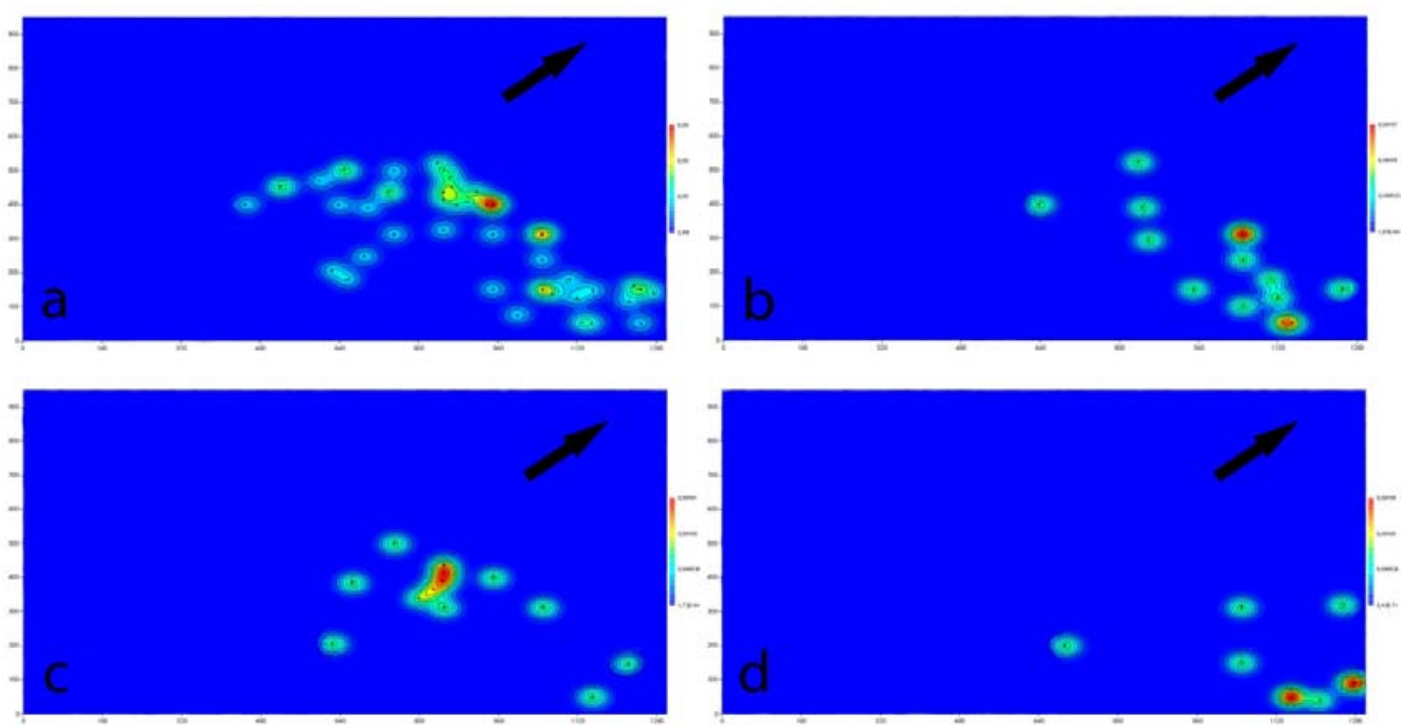

Figura 8.9. Distribución de especímenes con modificaciones en el área excavada: a) especímenes con depósitos de manganeso; b) especímenes con marcas de raíces; c) especímenes con presencia de huellas de corte; d) especímenes alterados térmicamente.

\subsubsection{Patrones de modificación antrópica}

El análisis macro y microscópico de las superficies óseas de los especímenes permitió reconocer la presencia de huellas de corte (Figura 8.10a y 8.10b) tanto en elementos del esqueleto axial como apendicular de los camélidos (Figura 8.7b y 8.7c). El mayor porcentaje fue registrado entre los elementos apendiculares (Figura 8.7c); sin embargo, la frecuencia observada entre los axiales (Figura 8.7b) no es despreciable. Si bien los restos con este tipo de modificación fueron registrados en varias cuadrículas, cerca de un 40\% de ellos se encuentran concentrados en el sector sur de L (Figura 8.9c). Esta densidad de restos con modificaciones vinculadas al procesamiento de las carcasas en uno de los sectores de L podría estar indicando un área especial de descarte, y diferente a la de la concentración de la cuadrícula B.

Además, se registraron claras huellas de corte sobre un fragmento de costilla de Mylodon sp. (Figura 8.10c). Esta información es novedosa porque aporta nuevos datos acerca del aprovechamiento antrópico de esta especie, que hasta el momento no había 
sido registrado en AEP-1. Este descubrimiento, como se verá más adelante, es relevante para las discusiones acerca del uso que las sociedades cazadoras-recolectoras hicieron de estas faunas pleistocénicas. También fue registrada la presencia de claras huellas de corte en una vértebra cervical de rheido. Este hallazgo, al igual que el de Mylodon sp. permite discutir acerca de la diversidad de especies explotadas en momentos tempranos del poblamiento de Patagonia.
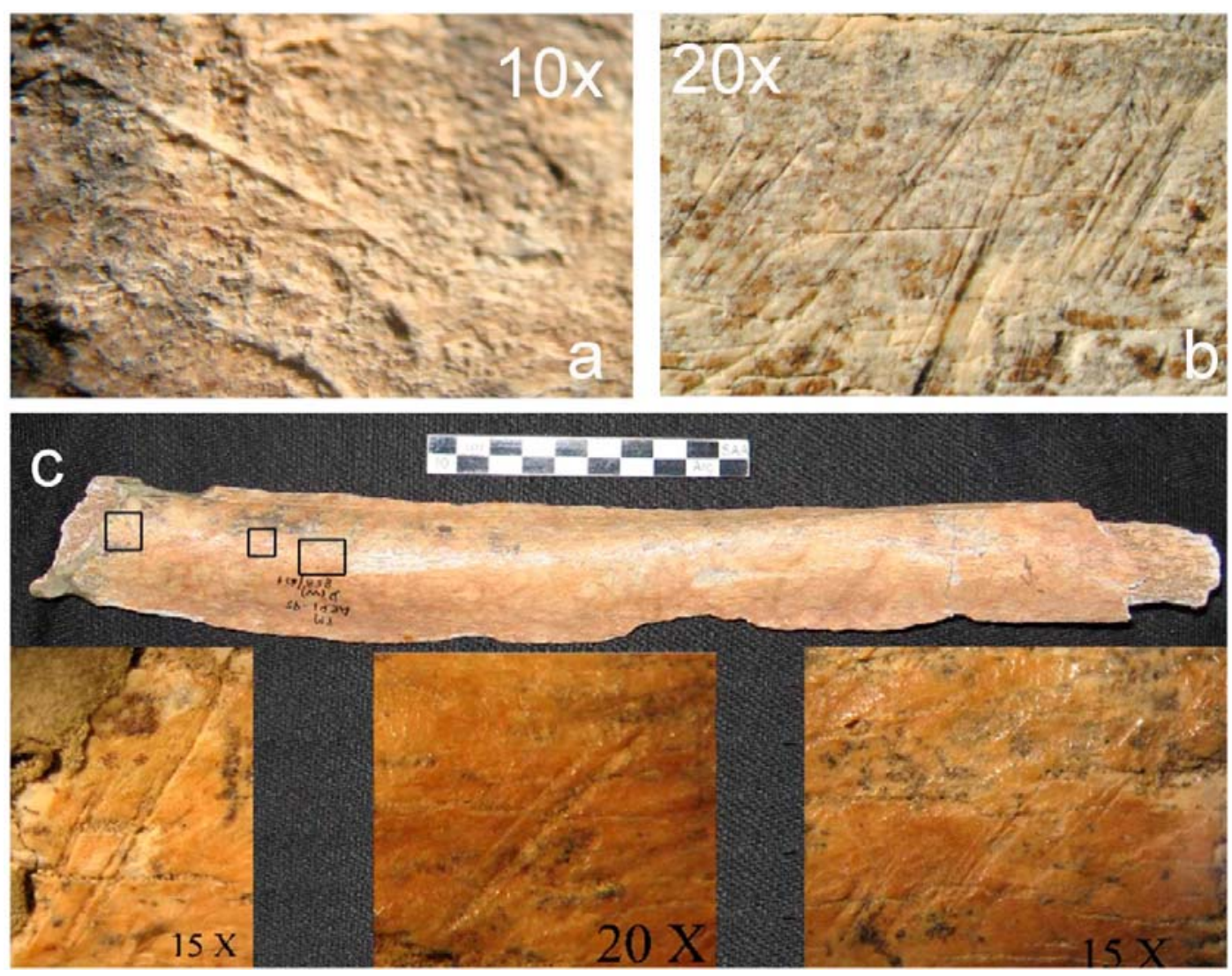

Figura 8.10: Huellas de corte: a) fémur de L. gracilis; b) tibia de Lama sp.; c) huellas de corte en costilla de Mylodon sp.

Se identificaron especímenes óseos termoalterados, tanto del esqueleto axial (Figura 8.7b) como del apendicular (Figura 8.7c) de los camélidos. La cantidad de especímenes quemados alcanza iguales porcentajes en una y otra región del esqueleto (Figura 8.7b y 8.7c). En este nivel no se reconocieron durante las excavaciones estructuras de combustión ni fogones. Sin embargo, el $60 \%$ de los especímenes óseos quemados se recuperaron en la cuadrícula B (Figura 8.9d). Esta situación avala la propuesta realizada por Cattáneo (2002), a partir del análisis de la distribución de los materiales líticos 
termoalterados y mencionada anteriormente, que sugiere la existencia de un fogón entre el oeste de B y este de D.

Un total de $47(44,7 \%)$ especímenes de la muestra corresponden a huesos largos de camélidos, en $25(53,2 \%)$ de ellos se pudieron determinar distintos patrones de fractura (Figura 8.11). De un total de 40 fracturas identificadas, 16 (40\%) correspondieron con un patrón de tipo helicoidal que resulta de la fragmentación del hueso en estado fresco. El registro de una importante frecuencia de huellas de corte sumado a la baja frecuencia de marcas de carnívoros permite argumentar que tales fracturas serían resultado del procesamiento de las carcasas por los humanos.

Se identificaron un total de 12 (30\%) fracturas longitudinales, 8 de ellas (66\%) presentaron características que indican que se realizaron intencionalmente con el hueso en estado fresco; las 4 fracturas longitudinales restantes (33\%) mostraron un patrón irregular característico de la fragmentación del hueso en estado seco y, por lo tanto, atribuible a la acción de agentes tafonómicos. Entre las fracturas oblicuas $(n=5)$ dos presentaron superficies suaves que resultarían de un estado hidratado del hueso al momento de la fractura, las restantes exhiben un patrón rugoso e irregular característico de las fracturas tafonómicas. Ninguna de las fracturas transversales mostró evidencia que permita atribuirla al agente antrópico.

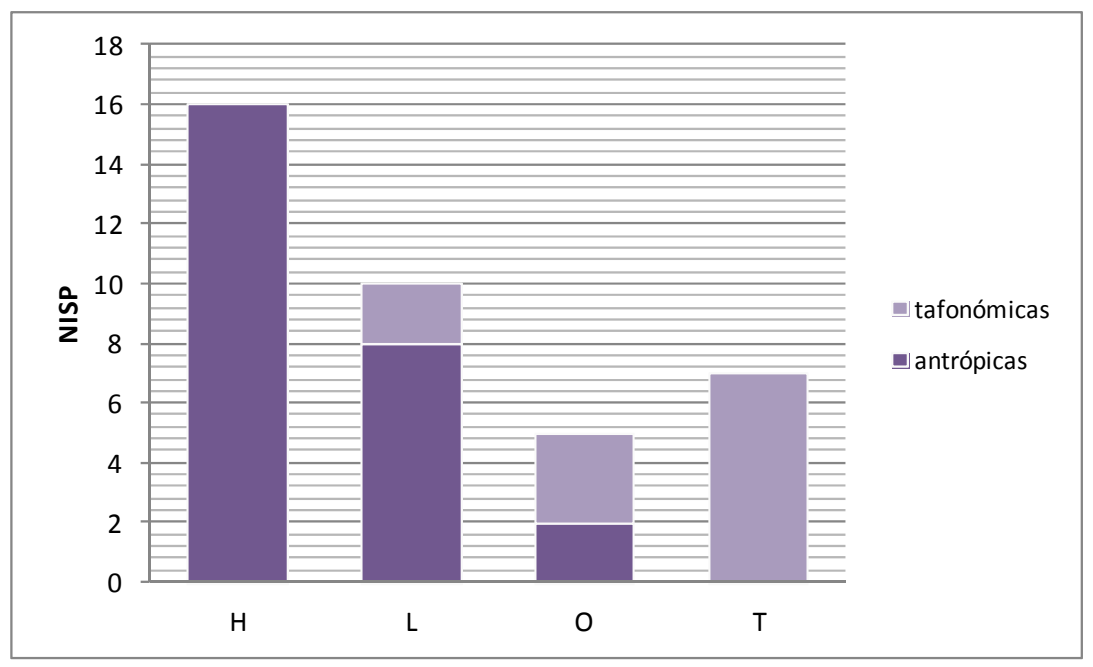

Figura 8.11. Frecuencia y tipos de fracturas identificadas: H) helicoidal; L) longitudinal; O) oblicua; T) transversal.

El registro de fracturas helicoidales, longitudinales y oblicuas vinculadas a un origen antrópico, por un lado permiten inferir, al menos de forma ocasional, la extracción y 
consumo de médula ósea de los camélidos. Por otro lado, aporta a la interpretación de la meteorización, ya que avala el estado fragmentario del conjunto cuando este fue abandonado por los humanos. Esto genera una expectativa de que los fragmentos más pequeños del conjunto presenten una meteorización más elevada que los más grandes.

En este conjunto además se identificaron modificaciones antrópicas en especímenes de cánidos que evidencian su utilización en estos primeros momentos de ocupación del sitio. Entre ellas tres huesos largos quemados (Figura 8.12a) y una tibia distal con fractura helicoidal (Figura 8.12b).
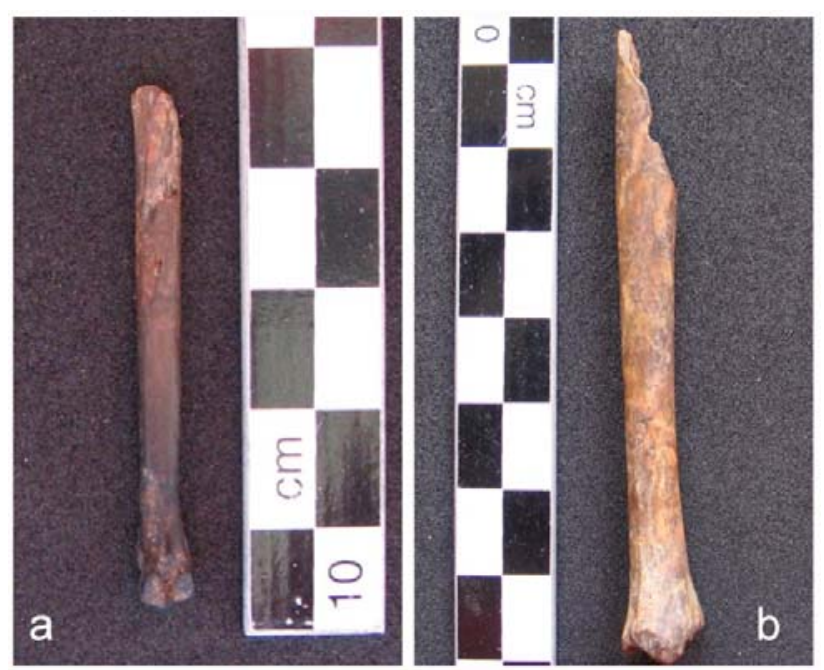

Figura 8.12: Modificaciones antrópicas en especímenes óseos de cánidos: a) alteración térmica en metapodio; b) tibia distal con presencia de fractura helicoidal.

La distribución espacial de los especímenes con huellas de corte y alteración térmica (Figuras 8.9c y 8.9d) permite suponer dos posibles áreas de actividades dentro del sitio. Una de ellas conformada por la cuadrícula L y sectores aledaños, allí se concentra la mayor cantidad de restos con evidencias de procesamiento de las carcasas. Por ello, posiblemente habría funcionado como un área de descarte luego del procesamiento de los camélidos y consumo ocasional de médula. El otro sector de actividad correspondería al área más externa del sitio (cuadrícula B y sector este de la cuadrícula A). Allí, si bien no fue identificada una estructura de combustión, la concentración de especímenes óseos quemados (Figura 8.9d) y líticos termoalterados (Cattáneo 2002) permite inferir su existencia, aunque ésta haya sido efímera.

Queda pendiente evaluar a partir de la ejecución de nuevos fechados radiocarbónicos, si estas dos posibles áreas de actividad responden a un único uso del 
alero o si pueden corresponder a usos del alero en distintos momentos del inicio de la ocupación humana del área. A favor de la segunda idea tenemos la amplitud de fechas obtenidas por radiocarbono (ca. 2.000 años) y que hasta el momento no hemos realizado fechados en el sector más externo del sitio.

\subsection{UNIDAD ESTRATIGRÁFICA 2- CAPA 4-5.}

En las capas 4 y 5 del sitio fue recuperado el conjunto que corresponde al segundo momento de ocupación humana entre ca. 9200 y 10.400 años AP (Tabla 8.1). Dichas capas corresponden al horizonte IIB del paleosuelo (Zárate et al. 2000).

$\mathrm{Al}$ igual que sucede con la Capa 6, una muestra de este conjunto, correspondiente a las excavaciones realizadas hasta 1996 fue estudiada por otros integrantes del equipo (Giardina et al. 2000; Miotti 1996, 2003; Miotti y Salemme 2005; Miotti et al. 1999). Los primeros análisis zooarqueológicos de las cuadrículas excavadas hasta 1992, que comprendieron A, B, C y D, permitieron formular las primeras hipótesis de ocupación y uso de la fauna (Miotti 1996: 30). En 1994 se ampliaron las excavaciones fuera del área de derrumbes, logrando de este modo diferenciar unidades estratigráficas lateralmente más continuas y con mayor definición vertical. Es entonces cuando las muestras zooarqueológicas se analizan en tres unidades: 4, 5 y 6 , cuya representación se observó en toda la planta de excavación. La apertura de las nuevas cuadrículas (E, F y G), y los fechados obtenidos hasta entonces (Miotti et al. 1999) permitieron definir la partición analítica en 3 capas, la más antigua 6 y la más moderna, 4. En 1999 se finaliza la ampliación de las excavaciones del sitio, con la incorporación de las cuadrículas H, I, J y $\mathrm{K}$ y lo que restaba por excavar de la cuadrícula A. A partir de este momento se realizan los remontajes óseos de toda la planta con lo cual se observa que algunos materiales de las capas 4 y 5 remontan mecánica o articularmente (Giardina et al. 2000; Miotti et al. 2000), a lo que se suman los trabajos geoarqueológicos (Zárate et al. 2000) y cronológicos (Miotti et al. 2003) que terminan definiendo a las capas 4 y 5 como una sola unidad de análisis. Su límite horizontal transicional, referente a 2 horizontes del mismo paleosuelo y los fechados radiocarbónicos sobrepuestos indican que ambas capas contenían un único depósito, por lo tanto y a partir de aquí se las ha considerado como unidad 4/5 (Miotti y Salemme 2005). Para esta tesis, esos materiales fueron re-analizados junto con los nuevos 
incorporados de los últimos años de excavación del sitio como el conjunto de la Capa $4 / 5$.

El conjunto estudiado está integrado por un total de 1038 especímenes óseos que fueron asignados a diferentes categorías anatómicas y taxonómicas. Estos restos se encuentran distribuidos en toda la superficie de la excavación (Figura 8.13a). Tal distribución no se da de forma homogénea ya que las cuadrículas con posición central presentan más concentración de restos, mientras que las más periféricas y externas, como A y B, registraron escasos especímenes. Los estudios previos identificaron, sobre la base de las características de concentración y articulación de los restos, acumulaciones o pilas óseas principalmente en las cuadrículas D a G (Miotti et al. 1999: Figura 3).

El análisis de densidad de restos óseos por cuadrícula, incluyendo además de los especímenes tridimensionados aquellos recuperados con zaranda, muestra que los valores más elevados ahora se registran en las cuadrículas E y F (Figura 8.13b). Estos sectores con mayor densidad coinciden con el sector donde se describieron las concentraciones o pilas (Miotti et al. 1999). Sin embargo, a excepción de las cuadrículas A y B que presentan una densidad muy baja (menos de 6 especímenes por $\mathrm{m}^{2}$ ), la cantidad de especímenes por $\mathrm{m}^{2}$ es elevada en todas las cuadrículas (Figura 8.13b.)

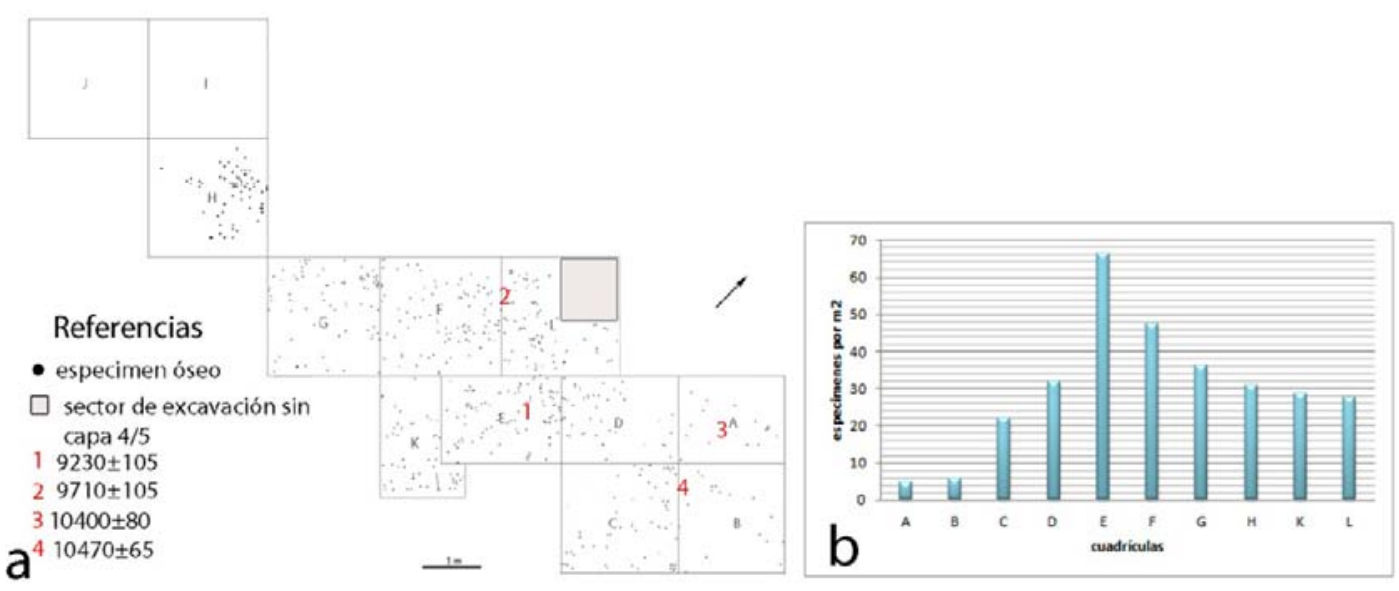

Figura 8.13. a) Distribución en planta de los especímenes tridimensionados y los fechados radiocarbónicos; b) densidad de restos óseos por cuadrícula (especímenes por $\mathrm{m}^{2}$ ) en la Capa 4/5 de AEP-1.

Durante las excavaciones en la Capa 4 hacia fuera de la línea de goteo actual (Figura 8.2), se registraron bloques correspondientes al derrumbe del techo del alero que indicarían, para este momento de ocupación, una mayor superficie de piso cubierta por 
techo rocoso (Miotti et al. 1999).

El análisis de la distribución de los materiales líticos termoalterados realizado por Cattáneo (2002) permite reconocer dos posibles sectores de fogones. Uno de ellos hacia el área más interna del alero (hacia el NW de las cuadrículas F y G), y el otro en el sector externo, ocupando la parte norte y este de C, oeste de B y SE de la cuadrícula D.

\subsubsection{Abundancia taxonómica y anatómica}

Los resultados obtenidos permiten afirmar que Lama guanicoe es la especie más representada en el conjunto (Tabla 8.4), dominando claramente el mismo con una frecuencia que supera el 79\% del NISP. En segundo lugar se encuentran los Mamíferos de tamaño grande $(9,5 \%$ del NISP), los cuales tienen alta probabilidad de corresponder a restos de guanaco pero por la carencia de rasgos diagnósticos no han podido ser asignados a niveles más específicos. Estas frecuencias son seguidas por una considerable cantidad de restos de rheidos $(\mathrm{NISP}=57)$ y aves indeterminadas $(\mathrm{NISP}=39)$. En menor frecuencia se identificaron especímenes correspondientes a Mamíferos indeterminados y pequeños, y a cánidos (Tabla 8.4).

\begin{tabular}{|l|c|c|}
\hline \multicolumn{1}{|c|}{ Taxa } & NISP & \%NISP \\
\hline Aves & 39 & 3,76 \\
\hline Rheidae & 57 & 5,49 \\
\hline Mamifero Indet. & 11 & 1,06 \\
\hline Mamifero pequeño & 1 & 0,10 \\
\hline Mamífero grande & 99 & 9,54 \\
\hline Canis sp. & 7 & 0,67 \\
\hline Lama gracilis* & 3 & 0,29 \\
\hline Lama guanicoe & 821 & 79,09 \\
\hline *Tomado de Miotti et al. 1999 & \\
\hline
\end{tabular}

Tabla 8.4. Abundancia taxonómica en Capa 4/5 de AEP-1.

El número mínimo de individuos (MNI) para el guanaco fue estimado en 10 (Tabla 8.5). Siguiendo los criterios de fusión de epífisis para estimación de edad, al menos dos de estos individuos corresponderían a ejemplares subadultos.

La relación entre el MNE/NISP arrojó un valor de 0,64 que estaría indicando una 
fragmentación moderada a baja del conjunto. Esta baja fragmentación podría ser una de las causas de que un 10,7\% del NISP no pueda, hasta el momento, ser asignado a un nivel más específico que el de Clase Mamífero.

$\mathrm{El}$ análisis de las unidades anatómicas de guanaco permite observar que todos los elementos de su esqueleto se encuentran representados (Tabla 8.5). Se observa que las frecuencias más elevadas corresponden a los elementos del esqueleto axial $(\mathrm{MNE}=289)$ que además, registra los valores máximos de MAU\% a partir de la mandíbula y los elementos del sacro (100\%). Los demás elementos del esqueleto axial, si bien presentan frecuencias más bajas, adquieren valores medios de MAU\% (ca. 50\%), entre ellos encontramos las vértebras lumbares, torácicas y cervicales, las costillas y el cráneo. Frecuencias menores al 20\% del MAU registraron las vértebras caudales y las esternebras (Tabla 8.5).

Por su parte, el esqueleto apendicular $(\mathrm{MNE}=201)$ si bien en frecuencias más bajas que el axial, encuentra buena representación de sus elementos (Tabla 8.5). No se registran diferencias entre las frecuencias de partes anatómicas correspondientes al miembro anterior y posterior. El patrón registrado muestra una mayor representación de los elementos del estilopodio por sobre los del autopodio y zeugopodio (Tabla 8.5).

Si consideramos las distintas unidades en las que se puede trozar la carcasa de un guanaco, todas se encuentran representadas, aunque las mayores frecuencias registradas para la cabeza (en mandíbula 100\%) y para la región de la cintura pélvica (sacro $100 \%$, hemipelvis $78 \%$, vértebras lumbares $64 \%$ y vértebras torácicas $58 \%$ ) sugieren un mayor descarte de estas unidades (Tabla 8.5).

El análisis de la distribución y densidad de restos de guanaco en Capa 4/5 no presenta diferencias con las tendencias observadas para el conjunto completo y presentadas en la Figura 8.13b.

El análisis para evaluar si las partes anatómicas de los Mamíferos de tamaño grande pueden complementar las unidades identificadas para los guanacos revela que solo podrían modificarse algunos valores de NISP. Entre los mamíferos las frecuencias más elevadas se registran para los fragmentos de hueso largo indeterminado $(n=39)$, los fragmentos medios de costillas $(\mathrm{n}=15)$ y los fragmentos de vértebras indeterminadas $(\mathrm{n}=$ 7). 


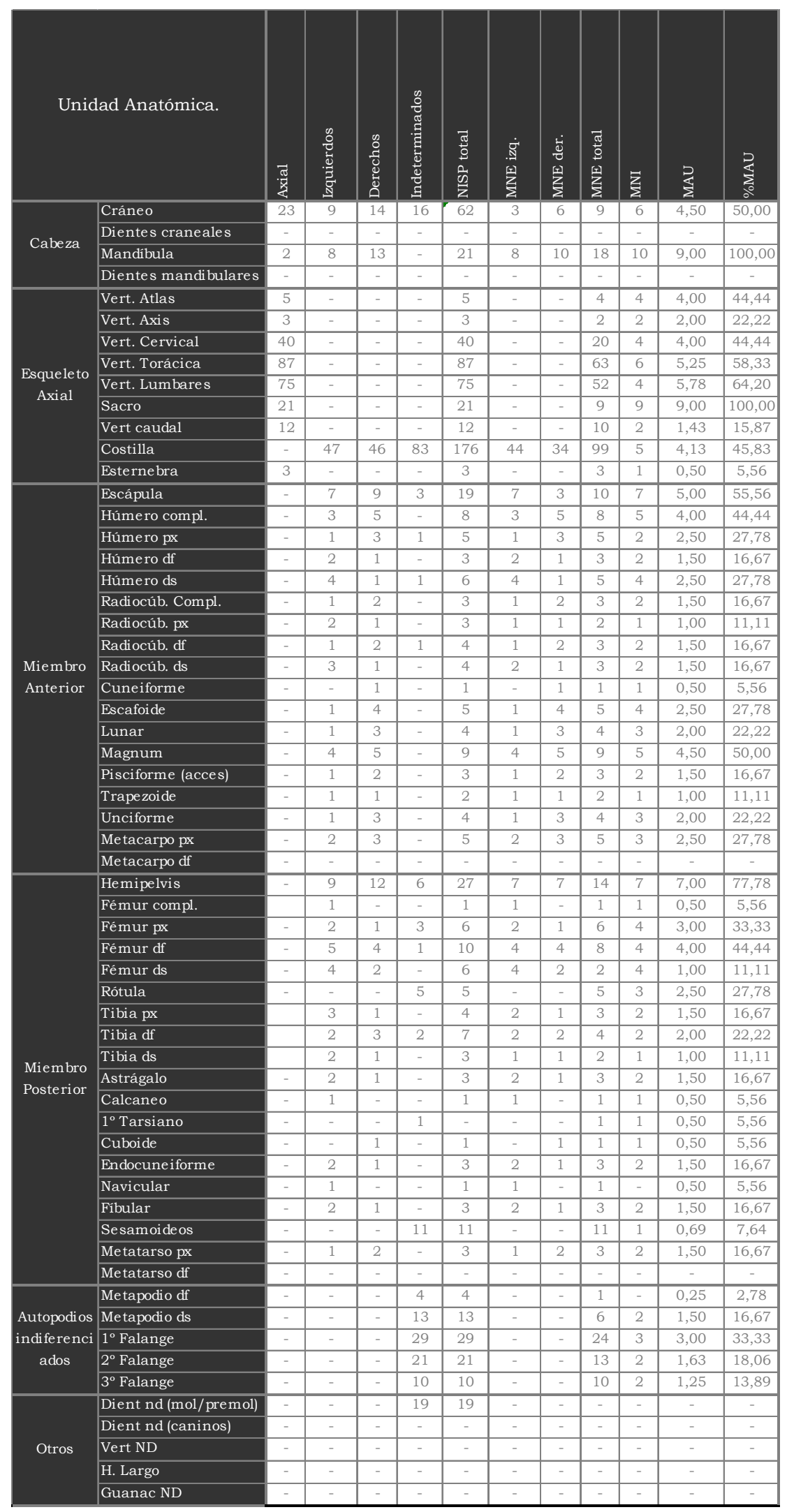

Tabla 8.5. Representación de unidades anatómicas del guanaco en Capa 4/5 de AEP-1. 
Del total de restos asignados a rheidos $(\mathrm{NISP}=57)$, un $89,5 \%$ de los mismos corresponde a fragmentos de las distintas falanges de esta ave, un análisis multivariado que permitió evaluar su asignación a la especie $R$. americana o $P$. pennata fue realizado por Miotti y Tonni (1996). Los restantes especímenes corresponden a fragmentos de vértebras, costillas y huesos largos.

Los cánidos se encuentran representados tanto por elementos axiales (fragmentos de cráneo, diente, atlas) como por apendiculares (astrágalo, falange y fragmento de radio).

Finalmente, entre las aves indeterminadas, la gran mayoría de restos corresponden a fragmentos indeterminados de hueso largo $(\mathrm{NISP}=30)$ y algunos fragmentos de elementos axiales como cráneo y coracoides.

\subsubsection{Análisis de la estrategia de transporte de partes anatómicas de guanaco}

El coeficiente de Spearman entre el MAU\% y la DO indica ausencia de correlación entre ambas variables (Figura 8.14a). Este resultado $(r=-0,27 ; p>0,05)$ sugiere que el conjunto podría estar poco sesgado por la acción de procesos de destrucción mediados por densidad. Sin embargo, trabajos experimentales en variabilidad intra-taxonómica de guanacos han demostrado que la destrucción por DO puede estar mediada por el desarrollo ontogénico de los individuos (Gutiérrez et al. 2010). En ese sentido, debemos considerar la posibilidad de que elementos osteológicamente inmaduros se hayan destruido y por tal motivo no estén siendo registrados en el conjunto. Por otro lado, como se verá más adelante, estas diferencias en la maduración ósea también conlleva a una meteorización diferencial (Massigoge et al. 2010).

Por su parte, la correlación entre el MAU\% y el índice de utilidad estimado por Borrero (1990) indicó la existencia de una correlación positiva moderada a baja $(r=0,38$; $\mathrm{p}<0,05)$, mientras que, al correlacionar los valores de MAU\% con los del índice de utilidad estimado por Lyman (1992), los resultados obtenidos $(r=0,24 ; p>0,05)$ indican ausencia de correlación (Figura 8.14b y 8.14c).

El análisis de estos resultados a partir de las clases propuestas por Lyman (1994: 264), nos presenta dos alternativas posibles para interpretar este conjunto de la Capa 4/5, una de ellas corresponde a la Clase 8 "bulk or gourmet utility", la otra a la Clase 5 que es la equifinalidad completa. La alternativa de la Clase 8, caracterizada por elementos de alto valor económico y baja DO, sugiere la posibilidad de que el conjunto no haya estado 
expuesto a la acción de procesos mediados por DO, siendo la representación de partes resultado de decisiones humanas de transporte. Mientras tanto, la Clase 5 indica que la frecuencia de partes anatómicas no puede ser interpretada de forma exclusiva ni por la acción de los procesos mediados por DO ni por la utilidad económica de esas partes.

Si bien los resultados obtenidos entre el Índice de Utilidad (Borrero 1990) y el MAU\% evidencian que la correlación es estadísticamente significativa, la misma sería relativamente baja. Sin embargo, creemos que entre las dos alternativas posibles, la correspondiente a la Clase 8 (Lyman 1994) es la que más se ajusta al conjunto. La ausencia de correlación entre el MAU\% y la DO se ve avalada por la alta frecuencia de partes anatómicas en buen estado de conservación y cuyo valores de densidad son bajos, ejemplo de ello son la altísima frecuencia de elementos del sacro, vértebras y esternebras (Tabla 8.5). Con esto no queremos decir que el conjunto no está mediado por DO sino que ésta no habría sido lo suficientemente intensa como para que los elementos con baja DO hayan desaparecido. Por otro lado, la elevada frecuencia de partes anatómicas que aportan grandes cantidades de calorías a la dieta como son las costillas y el fémur, sustenta la propuesta de una estrategia de vinculada a la selección humana. En este sentido creemos que la escasa presencia de las partes del autopodio puede estar indicando que las mismas sólo ingresaron al sitio en bajas proporciones. La ausencia de estas partes, que tienen altas chances de sobrevivir, como son los tarsianos y carpianos muy densos y masivos, avala un patrón de acumulación de partes con menor retorno económico y alto peso como la cintura pélvica. No se descarta que partes del esqueleto apendicular hayan sido abandonadas en el sitio luego de extraer su carne. Los cuartos también podrían haber sido acarreados con los cueros a otro lugar, en este caso, las porciones distales de las patas podrían haber ido adheridas a esos cueros.

Estos resultados se diferencian de los obtenidos por Miotti et al. (1999). En ese entonces, las correlaciones indicaban utilidad reversa para los dos conjuntos. Existía una variación entre Capa 4 y Capa 5 vinculada a que en el segundo de estos conjuntos el MAU\% no se correlacionaba significativamente con la DO mientras que en el primero, la correlación era significativa y negativa (Miotti et al. 1999: Tabla 4). Es posible que las diferencias observadas a partir de este método respondan por un lado al tamaño de la muestra analizada y por otro, a la unificación del conjunto en Capa 4/5.

Por los valores obtenidos de las correlaciones, es posible pensar una estrategia basada en el transporte de partes de mayor rendimiento al sitio, que sugiere además, el ingreso de guanacos enteros. Esta interpretación del sitio, avala la hipótesis propuesta por 
Miotti et al. (1999) de que los guanacos habrían sido producto de cacerías en las inmediaciones del alero, posiblemente a orillas del paleolago.

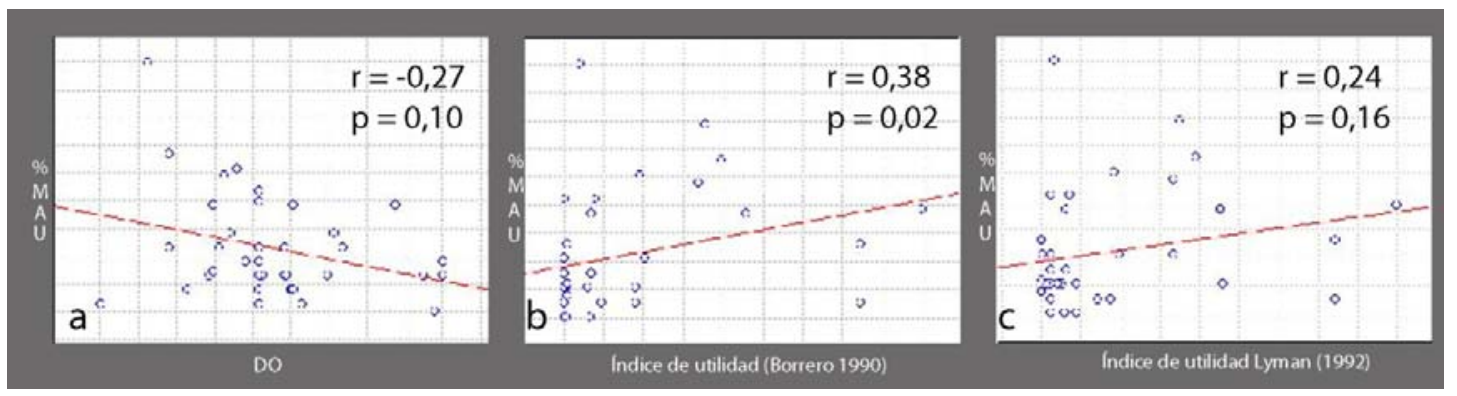

Figura 8.14. Correlaciones estadísticas de Spearman para las unidades anatómicas de los camélidos de Capa 4-5 a) entre el MAU\% y la DO; b) entre el MAU\% y el MGUI\% (sensu Borrero 1990); c) entre el MAU\% y el MGUI\% (sensu Lyman 1992).

\subsubsection{Modificaciones de las superficies óseas}

Una dificultad encontrada en este conjunto para el registro de las modificaciones consiste, como se verá más adelante, en la importante presencia de depósitos de carbonato cubriendo las superficies óseas. Esta situación en algunos casos no permitió realizar una observación completa del espécimen.

\subsubsection{Patrones de modificaciones naturales}

El análisis de las superficies de los especímenes correspondientes a guanaco muestra que la mayor cantidad de restos óseos (ca. 94\%) presentan, como se puede observar en la Figura 8.15, una meteorización relativamente baja (estadios 0, 1 y 2 de Behrensmeyer 1978). El hecho de que la mayor parte del conjunto muestre superficies poco meteorizadas estaría indicando que los materiales tuvieron un tiempo relativamente corto de exposición y un enterramiento sincrónico. El registro de escasos especímenes $(5,6 \%)$ en el estadio 3 de meteorización evidencia un deterioro más profundo de algunas superficies óseas. La presencia de abundantes elementos con baja DO, como se registra en este conjunto, avala la buena preservación del conjunto. Encontramos que la tendencia 
de meteorización en restos del esqueleto axial y apendicular es similar (Figura 8.15). Esto sugeriría que las variaciones en la meteorización no estarían relacionadas a la mayor o menor DO de algunos especímenes. Una posibilidad para interpretar estas variaciones estaría vinculada a la ontogenia de los guanacos (Massigoge et al. 2010). Es posible además, que la mayor fragmentación de algunos restos sea una causa de meteorización diferencial en el conjunto, esta hipótesis fue propuesta por Miotti (1992, 2003) para el Componente Inferior de AEP-1. Si bien, como se verá más adelante, la acción humana es la principal responsable de la fracturación en este conjunto, no se descarta la posibilidad de una fragmentación producida por otros agentes tafonómicos como los carnívoros (Binford 1981; Borrero y Martin 1996; Brain 1981; Marean 1995; Marean y Cleghorn 2003; Mondini 1995, entre otros). Esta última alternativa pensamos que tiene pocas chances de haber afectado al conjunto porque como se verá más adelante, el daño producido por carnívoros es bajo.

Fueron identificadas otras modificaciones naturales, tanto en elementos óseos del esqueleto axial como del apendicular de los guanacos. Como fue mencionado anteriormente, los depósitos de carbonato en este conjunto corresponden a las modificaciones naturales más importantes ya que se registraron en más de un $30 \%$ de los especímenes (Figura 8.16a). En general, estos depósitos se presentan como finas capas que cubren parcialmente la superficie de los huesos. Sin embargo, en algunos casos se vuelven espesos y llegan a cubrir más de un 70\% de la superficie de los especímenes (Figuras 8.17a y 8.17b). En esos casos, producen obliteración de la superficie ósea y no permiten observar la posible presencia de otras modificaciones. Posiblemente el carbonato provenga de la roca del afloramiento y de los bloques del derrumbe del alero que apoyan sobre la Capa 4, debido a que los procesos pedogenéticos favorecen la disolución de este tipo de rocas (Courty et al. 1989; Gutiérrez 2004).

Estas observaciones acerca de una gran concentración de concreciones de carbonatos sobre los huesos habían sido registradas por Miotti et al. (1999) e interpretadas como producto post-depositacional. Esta propuesta se presenta coherente con las nuevas observaciones realizadas. 


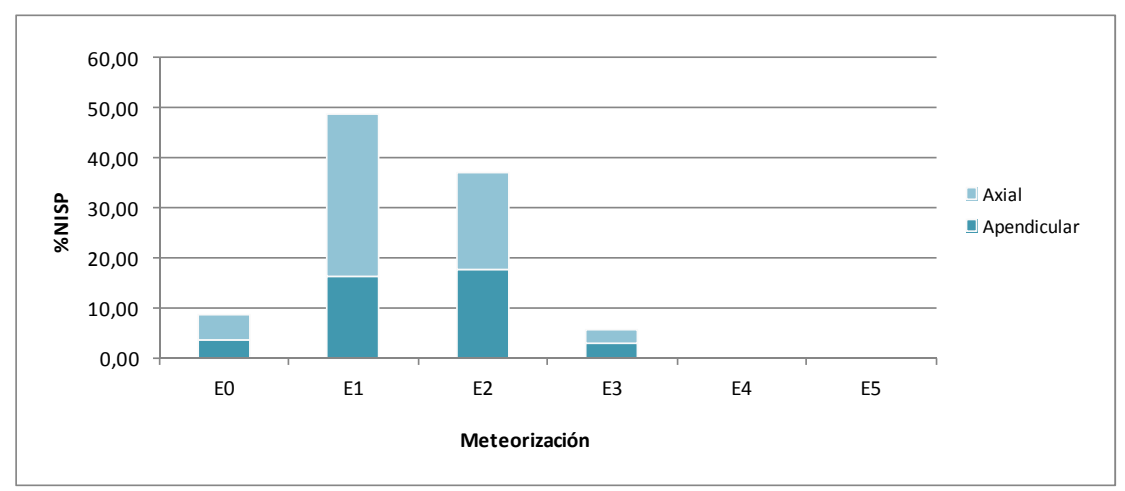

Figura 8.15. Tendencia de la meteorización en especímenes correspondientes a guanaco en el conjunto de Capa 4/5. Los valores son expresados en NISP\%.

Las manchas de manganeso se registran en un 17,5\% de los especímenes (Figura 8.16a), que se presentan en general como pequeños puntos dispersos sobre la superficie de los huesos (Figura 8.17c). Estos depósitos tendrían un origen post-depositacional y probablemente más de una procedencia posible. Al igual que el carbonato, puede provenir de la disolución de la roca carbonática del afloramiento o de los bloques de derrumbe del alero (López-González et al. 2006). Otra posibilidad para este conjunto puede estar vinculada a la liberación de manganeso por descomposición de materia orgánica (Marín Arroyo et al. 2008; Shahack-Gross et al. 1997). El agua necesaria para que el manganeso sea transportado pudo venir por filtración o por fluctuación del nivel freático que, según los estudios geológicos realizados en el sitios, pudo afectar las Capas 5 y 6 del sitio (Zárate et al. 2000). Por cómo se presentan estos depósitos sobre los especímenes óseos, es posible que el óxido de manganeso haya sido el primero en depositarse sobre los huesos, luego lo habrían hecho los carbonatos (Figura 8.17c). 


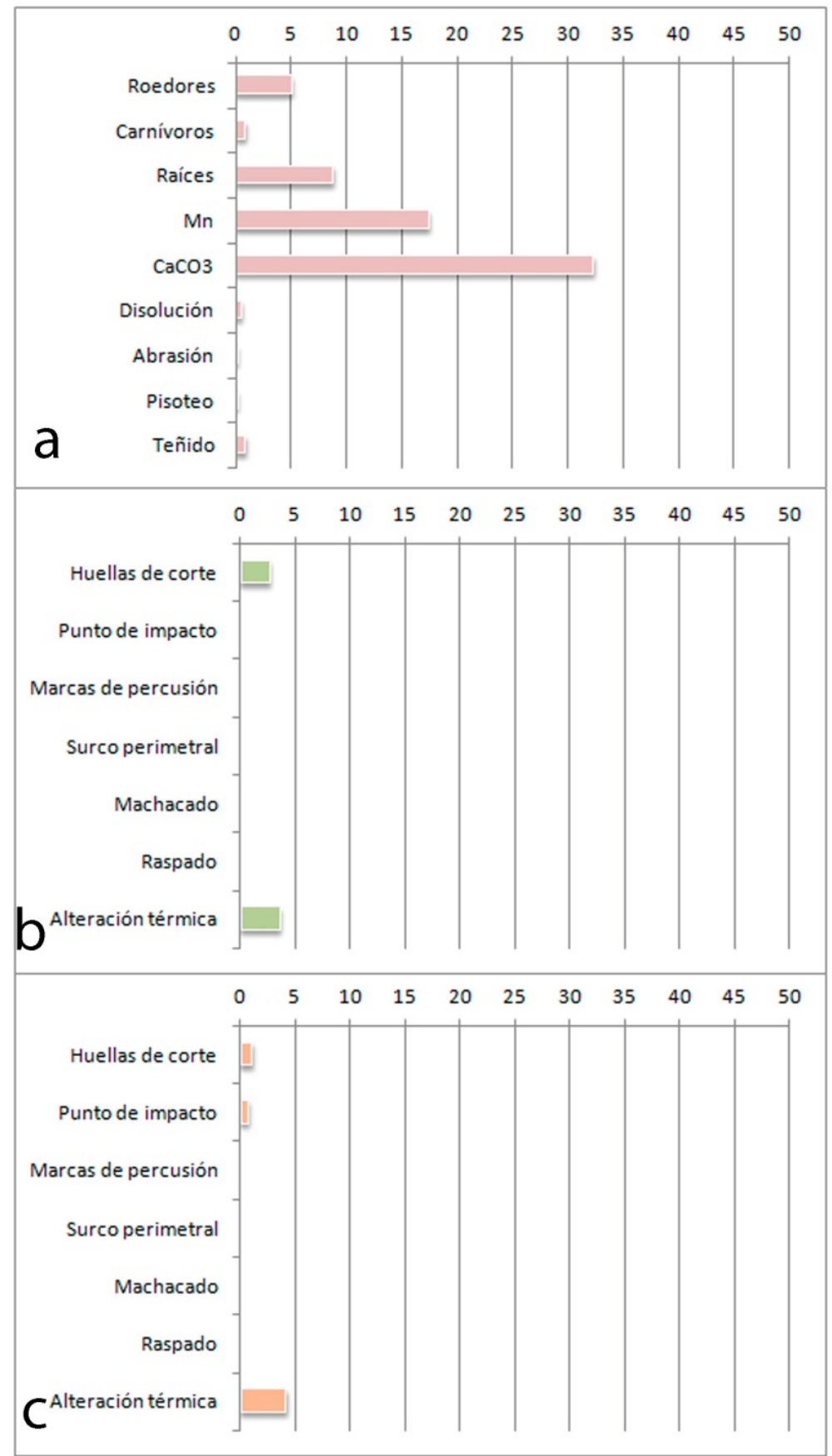

Figura 8.16. Frecuencia porcentual de especímenes óseos de guanaco con modificaciones: a) naturales; b) modificaciones antrópicas en especímenes del esqueleto axial; c) modificaciones antrópicas en el esqueleto apendicular.

También se registraron, aunque en porcentajes más bajos (Figura 8.16a), modificaciones debidas a la acción de pequeñas raíces, las cuales presentan un patrón ramificado de finos surcos zigzagueantes, generalmente de color más claro que las superficies óseas (Figura 8.17d). La presencia de improntas de pequeñas raíces sobre los 
especímenes óseos parece haber sido un proceso que afectó un pequeño porcentaje de este conjunto $(8,7 \%)$. Esto puede deberse a que la acción de raíces no es intensa en estos horizontes de suelo (IIB31 y IIb32) (Zárate et al. 2000: 58-60). Sin embargo, sí es mayor en las Capas 2 (IIA) y 3 (IIBt), en esta última con la máxima meteorización química de todo el perfil de suelo (Zárate et al. 2000: 60).
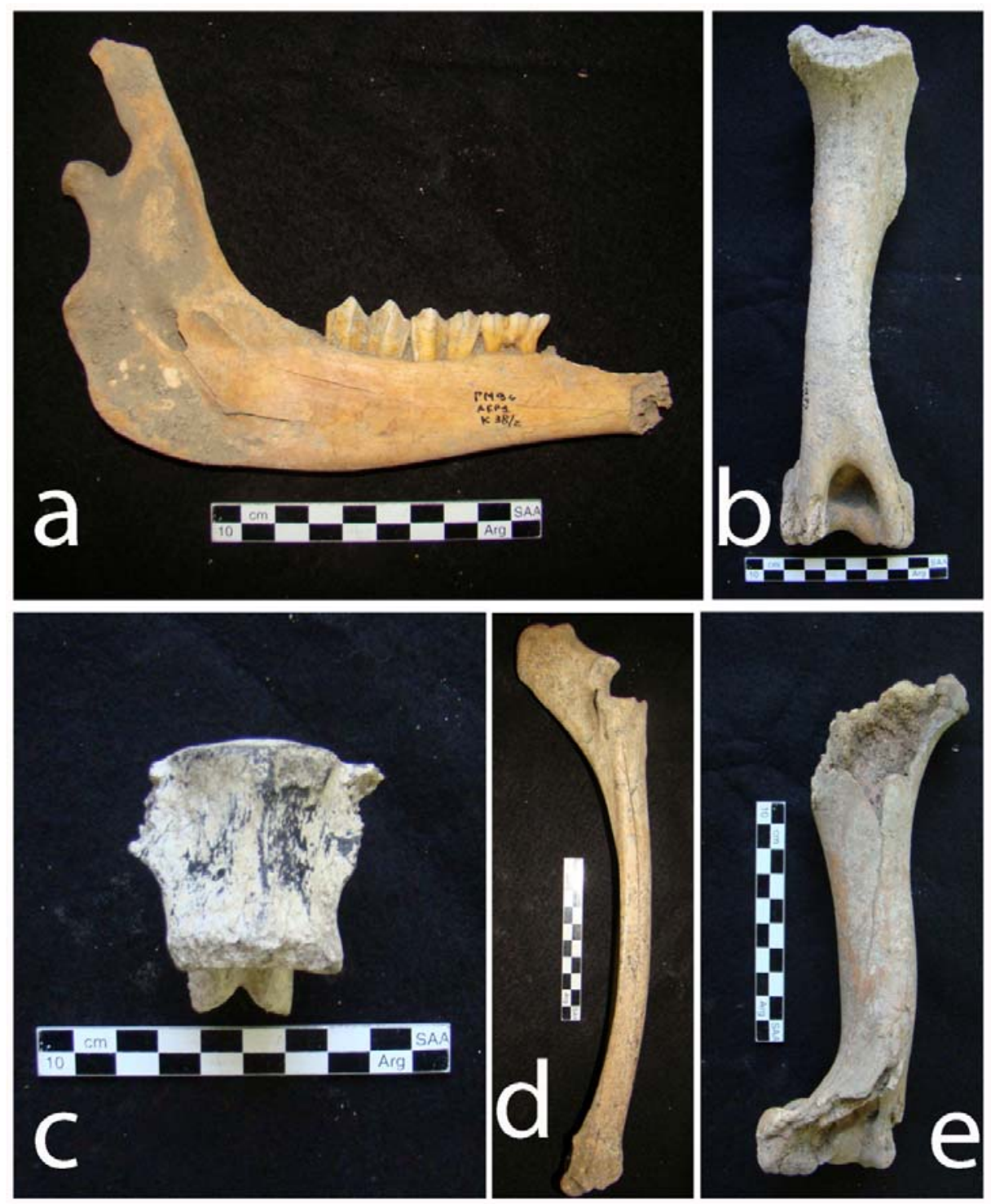

Figura 8.17. Modificaciones naturales: a) depósitos de carbonato sobre mandíbula de guanaco; b) depósito de carbonato sobre húmero de guanaco; c) vértebra lumbar de guanaco con depósito de manganeso cubierto por carbonato; d) radio-cúbito de guanaco con depósito de manganeso y marcas de raíces; e) húmero de guanaco con depósito de carbonato y daño de carnívoros en epífisis (cranulado en la proximal y de perforaciones en la distal). 
Otras modificaciones que resultan de procesos naturales fueron reconocidas pero en frecuencias menores. Entre ellas registramos en un 5\% de los especímenes marcas producidas por roedores (Figura 8.16a). Estas marcas se presentan como surcos cortos y paralelos, de sección transversal en U que se disponen a lo largo de los bordes de los especímenes. En porcentajes menores al 1\% se registraron modificaciones atribuidas a otros agentes como carnívoros (Figura 8.17e), disolución química, abrasión y teñido (Figura 8.16a).

Se analizó la distribución de especímenes con depósitos de carbonato (Figura 8.18a) y manganeso (Figura 8.18b) a partir de un Kernel density map. Si bien estos se presentan distribuidos en toda el área excavada del sitio, pueden observarse sectores con mayor densidad. Los restos con carbonato alcanzan mayor densidad entre el sector oeste de $\mathrm{C}$ y sur de D y hacia el este de F y oeste de E (Figura 8.18a). Por su parte, la distribución de especímenes óseos que registraron depósitos de manganeso muestra que los mismos se agrupan con mayor densidad en el sector norte de la cuadrícula E, en el oeste de L y este F (Figura 8.18b). Ambas distribuciones presentan un patrón que coincide con los sectores de mayor densidad de restos (Figuras $8.13 \mathrm{a}$ y $8.13 \mathrm{~b}$ ) y los sectores en los que fueron descriptas por Miotti et al. (1999) pilas o concentraciones óseas. Ambos sectores corresponden a las zonas de derrumbes masivos del techo del alero, lo cual debió haber enriquecido por disolución y re-depósito de los carbonato de la roca de caja.

De este análisis se desprende que los depósitos de carbonato y manganeso adquieren disposiciones similares, siendo mayor la frecuencia de los primeros. Esta situación podría responder a que ambas sustancias se depositaron sobre los huesos a partir de condición de humedad ya que ambos pueden provenir de la disolución de rocas carbonáticas y son transportados por agua (López-González et al. 2006; Courty et al. 1989; Gutiérrez 2004). Otra alternativa sería pensar que cada tipo de depósito tuvo orígenes distintos: el carbonato podría haberse disuelto en agua y luego depositado (Courty et al. 1989; Gutiérrez 2004), mientras que el manganeso podría provenir de la descomposición de materia orgánica (Marín Arroyo et al. 2008; Shahack Gross et al. 1997). La primera de estas ideas se ve apoyada por la pedogénesis registrada en el sitio (Zárate et al. 2000) ya que ésta favorece la disolución del carbonato (Courty et al. 1989; Gutiérrez 2004). La segunda idea estaría apoyada por la existencia en este nivel de unidades anatómicas articuladas, las cuales podrían haber sido descartadas en el lugar con parte del tejido blando adherido, su descomposición podría haber conducido a la 
liberación y depósito del manganeso (Marín Arroyo et al. 2008; Shahack Gross et al. 1997). En otros casos donde no se observan depósitos de manganeso sería probable que los especímenes hayan sido descartados luego de ser liberados del tejido blando. La tendencia a que partes del autopodio presenten mayor tinción que otros elementos del esqueleto es destacada por varios autores respondiendo a esta causa (Speth 1983; Tood 1987). Sin embargo, y como lo describen Zárate y colaboradores (2000), en la Capa 4 (IIB31) se registra en el perfil de suelos un importante moteado de manganeso debido en parte al deficiente drenaje de dicho paleosuelo, lo que además, pudo favorecer el teñido de los huesos.
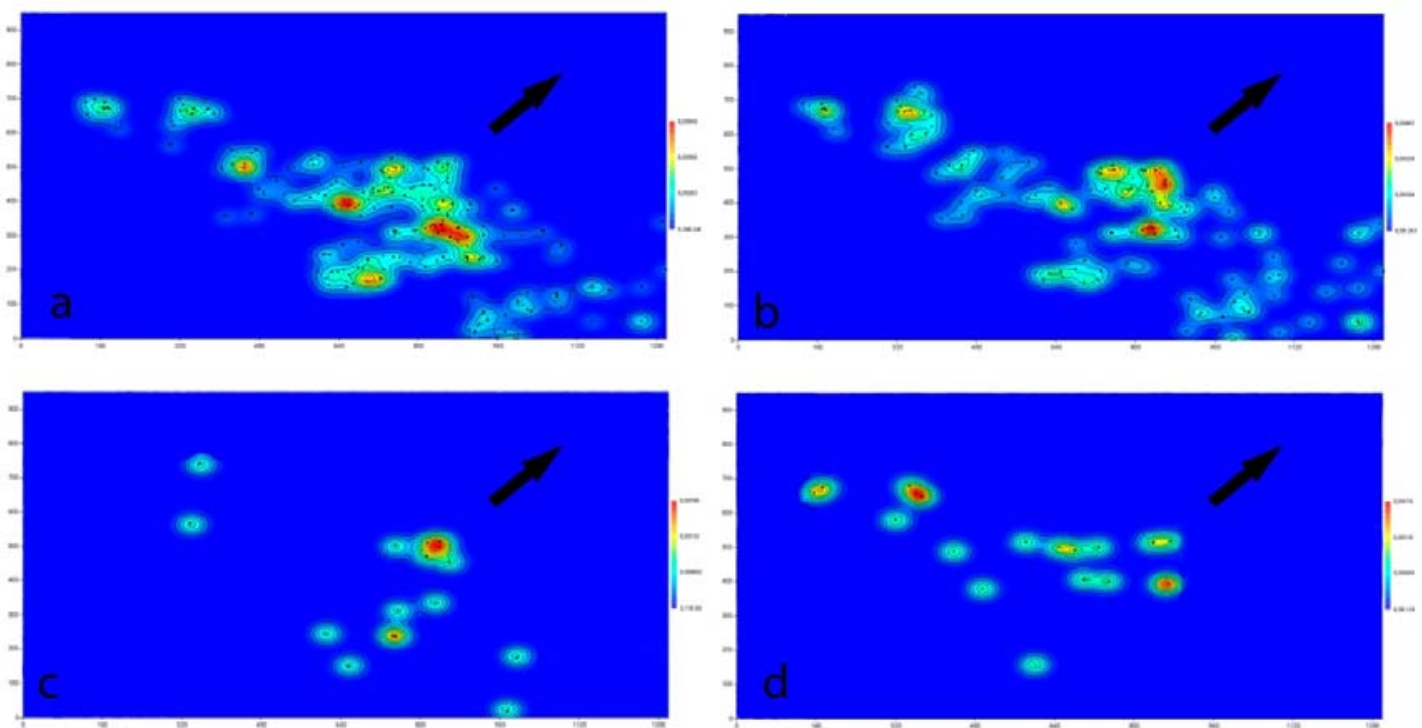

Figura 8.18. Distribución de los especímenes con modificaciones en sus superficies: a) depósitos de carbonato; b) depósitos de manganeso; c) huellas de corte; d) alteración térmica.

\subsubsection{Patrones de modificación antrópica}

Se reconocieron bajas frecuencias de modificaciones culturales tanto en elementos axiales como apendiculares de Lama guanicoe (Figura 8.16b y 8.16c). Entre ellos se identificaron patrones coincidentes con los descriptos para huellas de corte en un 2,8\% de los elementos axiales (Figura 8.19a). Por otro lado, entre los elementos apendiculares también se reconoció la presencia de huellas (Figura 8.19b) de corte pero en frecuencias 
menores (1,03\%) a las del esqueleto axial (Figura 8.16c). A excepción de las huellas de corte y de 2 especímenes de hueso largo que registraron claros puntos de impacto (Figura 8.16c), no se reconocieron otras marcas vinculadas al procesamiento humano de las presas. Esta baja frecuencia de marcas de procesamiento también había sido observada por Miotti et al. (1999) y atribuida, en parte, al deterioro de las superficies por alteración química post-depositacional.

Los especímenes con huellas de corte se distribuyen de forma dispersa en la superficie excavada; sin embargo, en el oeste de la cuadrícula L y en el sur de E se presentan más concentrados (Figura 8.18c). Esta disposición coincide con los dos sectores donde se concentran más restos óseos y que en trabajos previos fueron descriptos como pilas (Miotti et al. 1999).

Un 3,77\% de los especímenes de guanaco mostraron signos de alteración térmica (Figura 8.16 b y 8.16c). Si bien la frecuencia es baja, según las criterios de color, ellos presentaron estados que van desde el hueso quemado hasta el calcinado (Figura 8.19c) lo que estaría evidenciando distintos tiempos de exposición al calor (Buikstra y Swegle 1989; Cain 2005; Fernández Jalvo y Perales Piquer 1990; Shipman et al. 1984). Estos se distribuyen de forma dispersa en el área central de la excavación aunque se observan densidades mayores en el sector sur de la cuadrícula L y la cuadrícula H (Figura 8.18d). Ninguno de estos dos sectores principales coincide con los propuestos por Cattáneo (2002); sin embargo, un área con menor densidad de restos quemados puede observarse entre la cuadrícula $\mathrm{F}$ y $\mathrm{G}$, esta última podría corresponderse con una de las expectativas planteadas.

Se recuperaron un total de 140 especímenes de huesos largos de guanaco, de ellos solamente $47(33,6 \%)$ especímenes registraron 63 fracturas (Figura 8.20) ya que todos los elementos no se encontraban fragmentados. Por las características que presentaban los distintos tipos de fracturas, se puede sostener que $40(63,5 \%)$ podrían ser resultado de la fragmentación intencional del hueso en estado fresco. Las 23 fracturas restantes $(36,5 \%)$ serían resultado de procesos tafonómicos que actuaron cuando el hueso ya se encontraba deshidratado. Esta fragmentación intencional de los huesos podría estar indicando consumo ocasional de médula ósea. La presencia de puntos de impacto y huellas de corte asociadas a estos especímenes, además de la baja frecuencia de modificaciones producidas por carnívoros, permite sostener la hipótesis de que el agente humano fue la principal causa de esta fracturación.

En esta capa fue recuperado un artefacto óseo formatizado "tipo punzón” (Figura 
8.21). El mismo fue confeccionado sobre un metapodio de camélido con micropulido y posible tratamiento térmico. Esta evidencia sugiere que la fracturación intencional de los huesos también pudo estar relacionada a la obtención de formas base para la producción de artefactos.
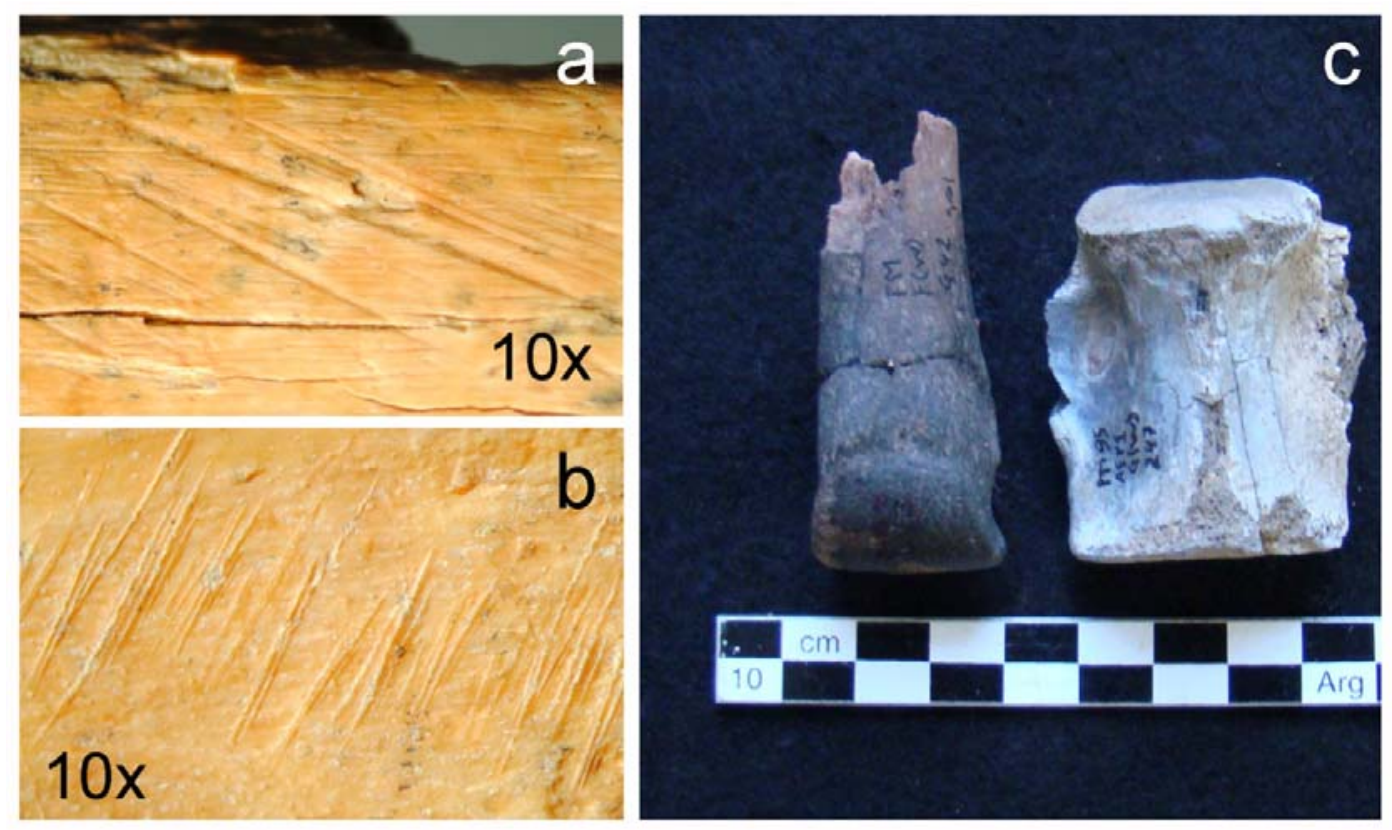

Figura 8.19. Modificaciones culturales: a) huellas de corte en costilla; b) huellas de corte en metapodio; c) alteración térmica.

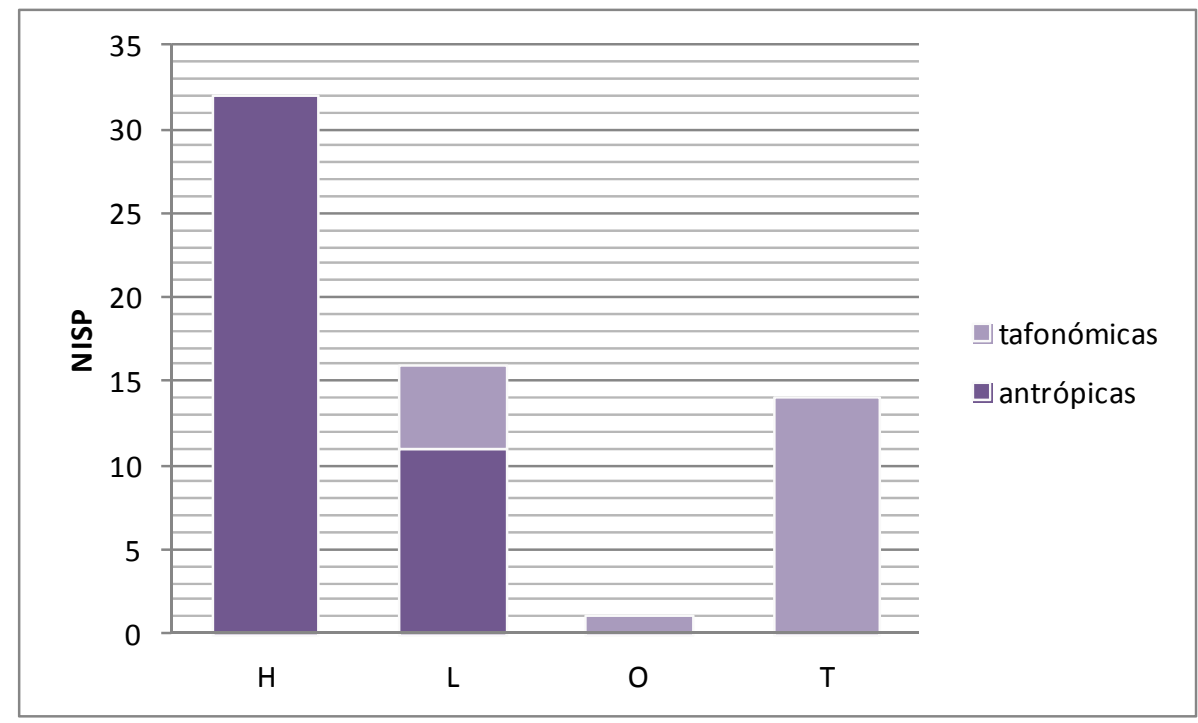

Figura 8.20. Frecuencia y tipos de fracturas identificadas en el conjunto de Capa 4/5 de AEP-1: H) helicoidal; L) longitudinal; O) oblicua; T) transversal. 


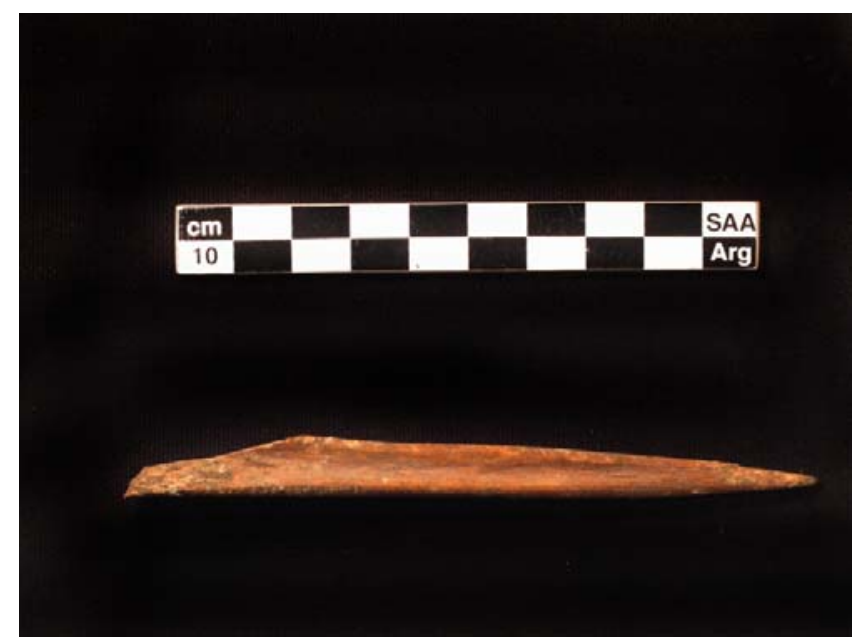

Figura 8.21. Artefacto óseo formatizado tipo punzón, sobre metápodo de camélido, Capa 4/5 de AEP-1.

El conjunto de la Capa 4/5, dominado por la presencia del guanaco, parece ser resultado fundamentalmente del transporte de partes anatómicas de alto rendimiento. Sin embargo, la alta representación de todas sus unidades, incluso aquellas que no aportan grandes cantidades de carne a la dieta, sugiere que los guanacos habrían sido cazados en las cercanías del sitio. Esta hipótesis propuesta previamente por Miotti et al. (1999) se muestra coherente a la luz de los nuevos resultados.

La baja fragmentación del conjunto, la concentración de restos óseo en áreas de mayor densidad, la presencia de partes anatómicas articuladas o en asociación primaria y la baja frecuencia de huellas de corte avalan la hipótesis de funcionalidad propuesta para este sitio que sugiere el desarrollo de actividades limitadas (Miotti 2003; Miotti y Salemme 2005; Miotti et al. 1999). Estas actividades habrían estado relacionadas fundamentalmente al procesamiento primario de las presas. Si bien la cantidad de huesos fragmentados es baja, el porcentaje de fracturas intencionales es elevado; esto nos lleva a pensar la posibilidad de un procesamiento secundario. El mismo estaría relacionado con un consumo ocasional de médula y con la búsqueda de materia prima ósea para la confección de instrumentos.

Si bien las modificaciones naturales son las más abundantes en este conjunto, no se registraron agentes o procesos que hayan afectado de manera significativa el depósito como para poner en dudar el papel jugado por los humanos en la formación del mismo. Los procesos que más afectaron el conjunto corresponden a los depósitos de carbonato y manganeso que han cubierto partes de los huesos reduciendo la visibilidad de otras 
marcas o deteriorando las superficies óseas.

\subsection{UNIDAD ESTRATIGRÁFICA 2- CAPA 2}

El conjunto arqueofaunístico de esta capa corresponde a las ocupaciones humanas del alero de los inicios del Holoceno medio (ca. 7700-7400 años AP). Fue recuperado del horizonte IIA del suelo local, truncado por una discordancia erosiva que marca el fin de las condiciones de estabilidad ambiental de la cuenca y el comienzo de un ciclo árido/erosivo que es el que se registra hasta la actualidad (Zárate et al. 2000). El mismo se encuentra integrado por un total de 2399 especímenes, de los cuales más el 76\% (NISP= 1833) fueron asignados a alguna categoría taxonómica y/o anatómica, quedando 566 restos óseos como indeterminados. Los restos óseos se distribuyen en las 12 cuadrículas excavadas del sitio, incluyendo la $\mathrm{H}$, la I y la J del sector más abrigado de AEP-1 (Figura 8.22a). Los restos recuperados en esta capa, si bien se presentan distribuidos en toda la superficie, registran una mayor concentración en las cuadrículas ubicadas bajo el abrigo rocoso (Figura 8.22a).

Por otro lado, el análisis de densidad de arqueofaunas por $\mathrm{m}^{2}$ considerando el conjunto completo (especímenes tridimensionados y generales) permite observar que los restos óseos se distribuyen con mayor densidad en la cuadrícula G (Figura 8.22b). Si bien ambas figuras (8.22a y 8.22b) muestran una distribución heterogénea de los restos óseos, no hay coincidencia en los sectores con mayor densidad. Es posible que esta diferencia se deba a una elevada fragmentación del conjunto y por ello, cuando se incorporan los materiales recuperados con zaranda, se observa una mayor concentración en la cuadrícula G. A pesar de esa diferencia, ambas figuras coinciden en que las cuadrículas del oeste $(\mathrm{H}, \mathrm{I}$ y J), ubicadas en el área más reparada del sitio, registran una alta concentración de restos.

$\mathrm{Si}$ bien durante las excavaciones de la Capa 2 no se identificaron fogones estructurados, en el sector sur de la cuadrícula C se encontró la mayor concentración de lítico que se pudo remontar y que corresponde a un núcleo estallado x calor (Miotti L. 2011, comunicación personal). El área de dispersión de este conjunto es de $15 \mathrm{~cm}^{2}$ y es de donde proviene el carbón fechado (Miotti L. 2011, comunicación personal). A partir del análisis de la distribución de los materiales líticos con alteración térmica, Cattáneo (2002) propuso un mayor uso del alero, con fogones sobre el portal (cuadrículas G y F) y 
quizás, áreas de descarte y fogones menores o de corta duración hacia la zona norte del paredón (cuadrículas C y D).

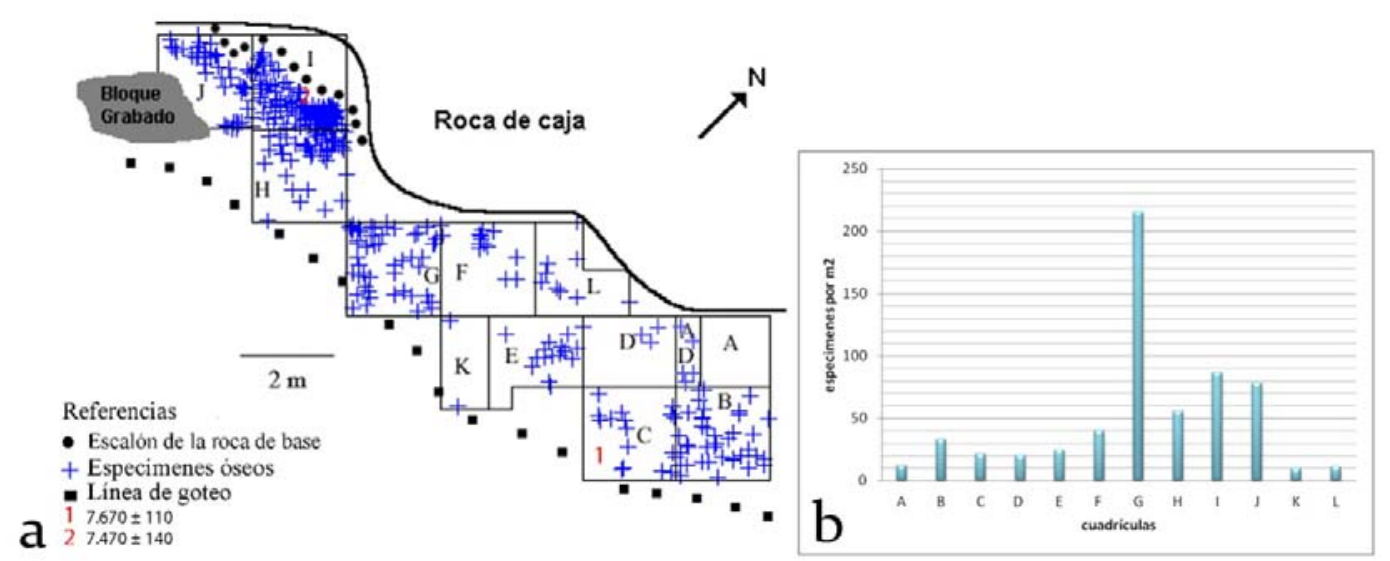

Figura 8.22. a) Distribución en planta de los especímenes tridimensionados y los fechados radiocarbónicos; b) densidad de restos óseos por cuadrícula (especímenes por $\mathrm{m}^{2}$ ) en Capa 2 de AEP-1.

Por otro lado, en el sector norte de las cuadrículas I y J se registra un escalón de la roca de base que ocupa parte de los sectores, estando ausente en los sectores del norte de estas cuadrículas la Capa 2 (Figura 8.22a). Se mencionó anteriormente que los bloques del derrumbe del alero apoyaban sobre la Capa 4, aunque en este nivel solamente son registrados en el sector sur de la cuadrícula J.

\subsubsection{Abundancia taxonómica y anatómica}

Todas las especies registradas corresponden a fauna que actualmente habita el área. Los resultados obtenidos permiten observar que la especie más representada en el conjunto de la Capa 2 de PM es Lama guanicoe (Tabla 8.5). Los restos asignados a estos ungulados representan el 26,5\% del NISP. Sin embargo, un importante número de especímenes óseos (>50\% del NISP) no pudieron ser determinados a categorías taxonómicas específicas, debido a la alta fragmentación del conjunto; por lo tanto, su status taxonómico quedó definido a nivel de Clase (Tabla 8.6). Es altamente probable que una gran parte de los especímenes determinados como mamíferos de tamaño grande $(\mathrm{NISP}=146)$ puedan corresponder a la especie L. guanicoe. 
También fue identificada una frecuencia importante de especímenes correspondientes a rheidos $(\mathrm{NSIP}=123)$ y aves indeterminadas $(\mathrm{NISP}=67)$. Las restantes especies identificadas son Duscisyon sp., Zaedyous pichyi, Canis sp. y Conepatus sp. ninguna de las cuales alcanza el 1\% del NISP (Tabla 8.6).

\begin{tabular}{|l|c|c|c|}
\hline & NISP & \%NISP & M NI \\
\hline Ave indet. & 67 & 3,66 & - \\
\hline Rheidae* & 123 & 6,71 & 5 \\
\hline Mamifero Indet. & 977 & 53,30 & - \\
\hline Mamífero Peq. & 5 & 0,27 & - \\
\hline Mamífero med. & 15 & 0,82 & - \\
\hline Mamífero grande & 146 & 7,97 & - \\
\hline Zaedyus pichiy & 3 & 0,16 & - \\
\hline Conepatus sp & 1 & 0,05 & 1 \\
\hline Canis sp & 1 & 0,05 & - \\
\hline Duscicyon sp & 4 & 0,22 & - \\
\hline Lama guanicoe & 487 & 26,57 & 9 \\
\hline Unionidae & 1 & 0,05 & 1 \\
\hline Caracol & 3 & 0,16 & 1 \\
\hline * 68 especímenes corresponden a fragmentos de cáscaras de \\
huevo
\end{tabular}

Tabla 8.6. Abundancia taxonómica en la Capa 2 de AEP-1.

Se registraron cuatro fragmentos de valvas: una correspondiente a un molusco dulceacuícola de gran tamaño y cuyas valvas son nacaradas en el interior, conocido como "almeja de río" y correspondiente a la familia Unionidae. En la actualidad estos moluscos habitan lagos cordilleranos y cuencas fluviales de alta energía como la del Paraná (Manceñido M. y S. Damborenea 2008, comunicación personal). Las otras tres corresponden a pequeños fragmentos fósiles (Griffin M. 2009, comunicación personal), que hasta el momento no han podido ser determinadas a nivel específico.

El análisis de las unidades anatómicas del guanaco permite observar que están presentes elementos tanto del esqueleto axial como del apendicular, adquiriendo este último las frecuencias más elevadas (más del 85\%) (Tabla 8.7). El MNI para guanaco fue estimado en 9 a partir del fibular izquierdo. Siguiendo los criterios de edad relacionados a la fusión de las epífisis, al menos uno de los guanacos correspondería con un individuo juvenil.

El análisis de la relación entre MNE/NISP de guanaco evidencia una alta 
fragmentación del conjunto ya que se obtuvo un valor de 0,47 . Por un lado, este grado de fragmentación podría justificar la diferencia que se observa entre la distribución de los especímenes tridimensionados y el conjunto completo (Figura 8.22a y 8.22b). Por otro lado, sirve como argumento de por qué una alta frecuencia de restos no pudieron ser asignados a niveles más específicos que los de Clase.

El análisis de las frecuencias de MAU\% (Tabla 8.7) permite observar que los elementos que presentan los valores más elevados son el fibular (100\% del MAU), el endocuneiforme $(\mathrm{MAU} \%=71,4 \%)$, el navicular $(\mathrm{MAU} \%=64,2 \%)$ y el metatarso $($ MAU\% $=42,8 \%)$. Esta situación pone de manifiesto que los elementos más representados son los del autopodio posterior del guanaco. El segundo lugar de importancia lo alcanzan los carpianos a partir del magnum (MAU\%= 50\%) y los autopodios indiferenciados como los metapodios $($ MAU\% $=50 \%)$ y las falanges $($ MAU\% ca. $40 \%$ cada una).

Tanto en el miembro anterior como posterior los elementos del zeugopodio -i.e., radio-cúbito y tibia- son los que siguen en importancia a los autopodios, siendo el fémur y el húmero los elementos de los miembros que presentan frecuencias más bajas. En este último caso, y a diferencia de lo mencionado para el autopodio y zeugopodio, el estilopodio anterior alcanza mejor representación que el posterior. Los elementos de las cinturas escapular y pélvica se encuentran en baja frecuencia ( $<10 \%$ del MAU\%). Por su parte, todos los elementos del esqueleto axial se encuentran poco representados $(<15 \%$ del MAU\%), la única excepción a esta situación la constituye el cráneo cuya abundancia fue estimada a partir de la bulla timpánica en 28,57\% del MAU\% (Tabla 8.7).

El análisis de estas frecuencias permite observar que las unidades de trozamiento más frecuentes corresponden a los cuartos del guanaco, adquiriendo el trasero los valores más elevados. Sin embargo, dentro de los miembros, los elementos distales son los más representativos. En cuanto al esqueleto axial, la unidad correspondiente a la cabeza muestra mejor representación que el tronco; de todas formas, ambas se encuentran en valores menores que los pertenecientes al esqueleto apendicular. Esta representación variable de las unidades de trozamiento podría estar reflejando alguna estrategia de transporte la cual fundamentalmente habría consistido en el descarte de unidades de bajo rendimiento cárnico. 


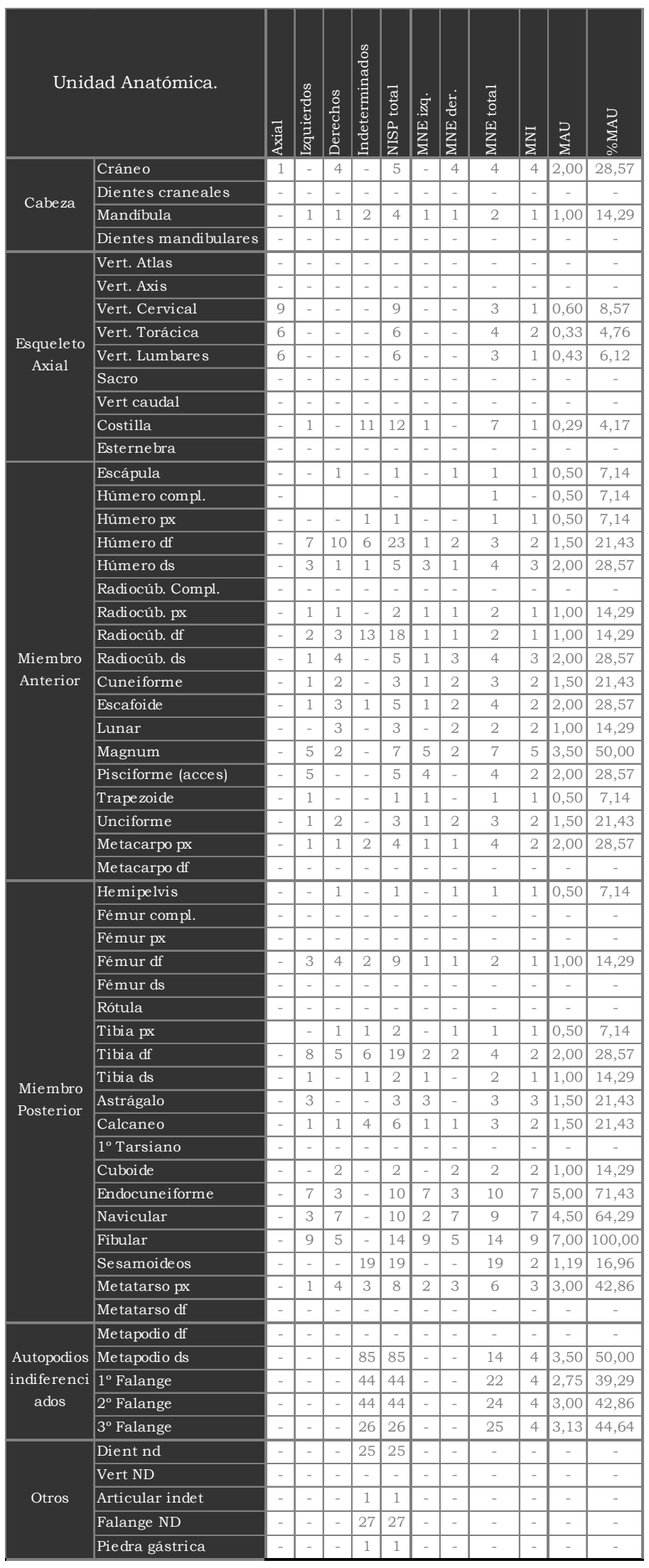

Tabla 8.7. Abundancia anatómica de L. guanicoe en Capa 2 de AEP-1. 
El análisis de densidad de restos óseos de guanaco por $\mathrm{m}^{2}$ (Figura 8.23) permite observar un patrón de distribución distinto al observado para el conjunto completo (Figura 8.22b). Mientras que el conjunto entero mostró una mayor concentración de restos en el sector correspondiente a la cuadrícula $\mathrm{G}$, los especímenes pertenecientes a guanaco se distribuyen con mayor densidad en dos sectores principales. El más denso de los dos sectores sería el que se encuentra bajo el alero y está integrado por las cuadrículas H, I y J; el otro sería más externo y estaría conformado por las cuadrículas B, C y D (Figura 8.23). Esta distribución se asemeja a la que se observa para los especímenes tridimensionados (Figura 8.22a) y esta situación, al igual que la planteada anteriormente, también podría estar relacionada con el grado de fragmentación que presenta la muestra.

Por su parte, se evaluaron las frecuencias de partes anatómicas correspondientes a mamíferos de tamaño grande para ver si podrían complementar las identificadas para los guanacos. Los resultados obtenidos indican que se podrían incrementar algunos valores de NISP correspondientes a fragmentos de vértebras $(\mathrm{NISP}=15)$ y de hoja escapular $(\mathrm{NISP}=7)$. Sin embargo, la mayor cantidad de especímenes de mamífero grande $(81,5 \%$ del NISP\%) corresponden a fragmentos de huesos largos carentes de rasgos o características diagnósticas que permitan mejores determinaciones. El ajuste de estas determinaciones, a partir del seguimiento de otras alternativas metodológicas que permitan mejorar el grado de resolución taxonómica del conjunto es una de las actividades que deberán abordarse luego de esta tesis. De esa forma será posible ajustar la resolución taxonómica del conjunto y mejorar las interpretaciones realizadas.

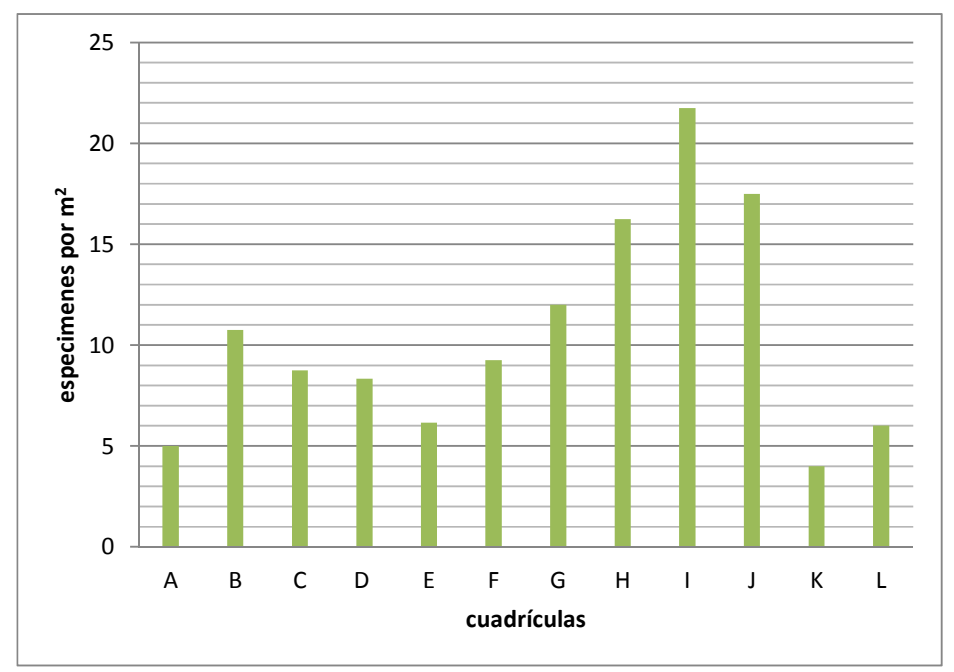

Figura 8.23. Densidad de restos óseos de guanaco por $\mathrm{m}^{2}$ en el conjunto de Capa 2 de AEP-1. Frecuencias expresadas en valores de NISP. 
Los rheidos se encuentran representados tanto por restos óseos (NISP= 55) como por fragmentos de cáscara de huevo $(\mathrm{NISP}=68)$. Excepto por la presencia de una única vértebra cervical, el resto de los elementos corresponden al esqueleto de las patas (98\%). Las falanges representan el $76 \%$ del total de los especímenes, seguido por el tibio-tarso (11\%) y el tarso-metatarso (7\%); otros elementos representados en bajas frecuencias corresponden al fémur $(2 \%)$ y a la fíbula $(2 \%)$. Los restos correspondientes a estas aves han sido recuperados en frecuencias variables en toda el área excavada, coincidiendo con el sector bajo el alero la mayor frecuencia de los mismos (cuadrículas H, I y J).

\subsubsection{Análisis de la estrategia de transporte de partes anatómicas de guanaco}

Para evaluar las causas de la representación de partes anatómicas del guanaco, se realizó las prueba estadística de Spearman entre los valores de MAU\% y DO (Figura 8.24a), sus resultados muestran la existencia de una correlación moderada entre ambas variables $(r=0,43 ; p=0,006)$. Esta covariación indicaría que el conjunto de la Capa 2 pudo ser afectado por procesos tafonómicos de destrucción ósea mediados por densidad. Por otro lado, la correlación de Spearman entre los valores de MAU\% y el MGUI (Borrero 1990) muestra la existencia de una correlación negativa moderada a alta (Figura 8.24b). Valores similares se observan al correlacionar las frecuencias de MAU\% con el índice de utilidad de carne propuesto por Lyman 1992 (Figura 8.24c).

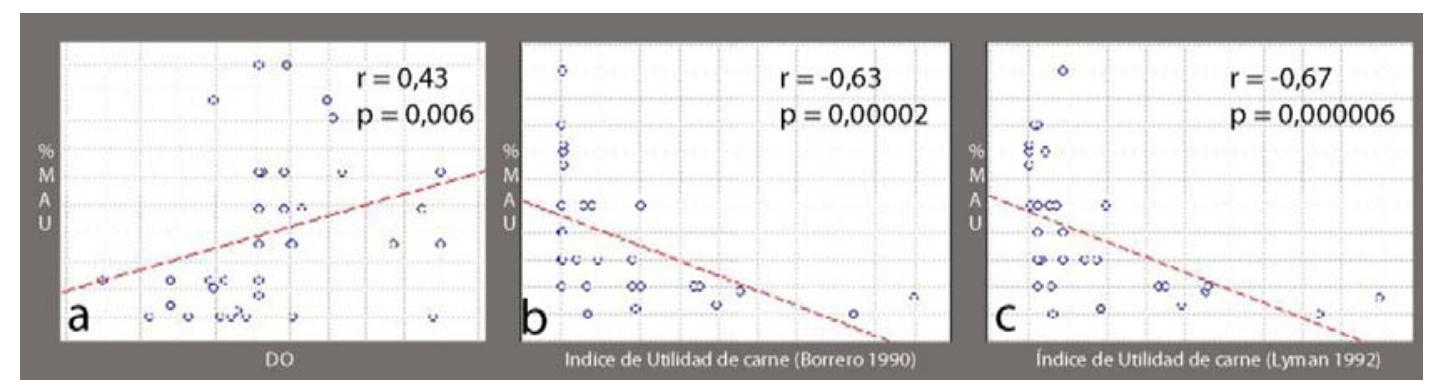

Figura 8.24. Correlaciones estadísticas de Spearman para las unidades anatómicas de guanaco en Capa 2: a) entre el MAU\% y la DO; b) entre el MAU\% y el MGUI\% (sensu Borrero 1990); c) entre el MAU\% y el MGUI\% (sensu Lyman 1992).

Considerando las clases propuestas por Lyman (1994), el conjunto de la Capa 2 caería en la Clase 1 de "reverse utility, lag or ravaged". Los conjuntos caracterizados en esta clase están constituidos por las unidades económicas de bajo rendimiento. Estas 
frecuencias pueden resultar de una estrategia de transporte vinculada a un procesamiento secundario y descarte de esas unidades. Sin embargo, para considerar esta hipótesis es necesario evaluar la acción de procesos de destrucción que pudieron hacer que las unidades con mayor DO hayan sobrevivido frente a otras con menor densidad.

\subsubsection{Modificaciones de las superficies óseas}

\subsubsection{Patrones de modificaciones naturales}

Los perfiles de meteorización obtenidos a partir del conjunto de Capa 2 (Figura 8.25) exhiben que más del $81 \%$ del mismo se ubica entre los estadios 1 y 2 de Behrensmeyer (1978), encontrándose cerca del 14\% en el estadio cero. Esta tendencia hacia los estadios bajos de meteorización evidencia un tiempo de exposición relativamente corto para el conjunto tanático. El registro de escasos especímenes $(4,1 \%)$ en estadio 3 de meteorización evidencia que el conjunto habría sufrido, aunque en niveles mínimos, destrucción diferencial ósea (Behrensmeyer 1978; Borrero 2007). Dicha pérdida podría relacionarse con un mayor deterioro de las superficies de los especímenes óseos con menor DO, o con la variabilidad intra-taxonómica que puede generar meteorización diferencial entre los mismos elementos óseos de una especie en función del estado de osificación que registren (Massigoge et al. 2010). Sin embargo y dada la escasa proporción de meteorización alta en todo el conjunto, la hipótesis de un área de descarte de unidades después de su procesamiento y consumo parece ser aún la más parsimoniosa a ser mantenida. En este sentido, consideramos que la fragmentación previa a la depositación de los huesos, pudo acentuar la acción de la meteorización sobre el conjunto.

$\mathrm{El}$ análisis de meteorización en especímenes correspondientes al esqueleto axial y apendicular de los guanacos evidencia una mayor heterogeneidad en la meteorización de los restos del esqueleto apendicular (Figura 8.25). Esta tendencia podría estar relacionada con algunas de las causas mencionadas anteriormente y que producen meteorización diferencial dentro de un mismo conjunto. Entre ellas consideramos los factores intrataxonómicos y la fragmentación diferencial de elementos apendiculares. 


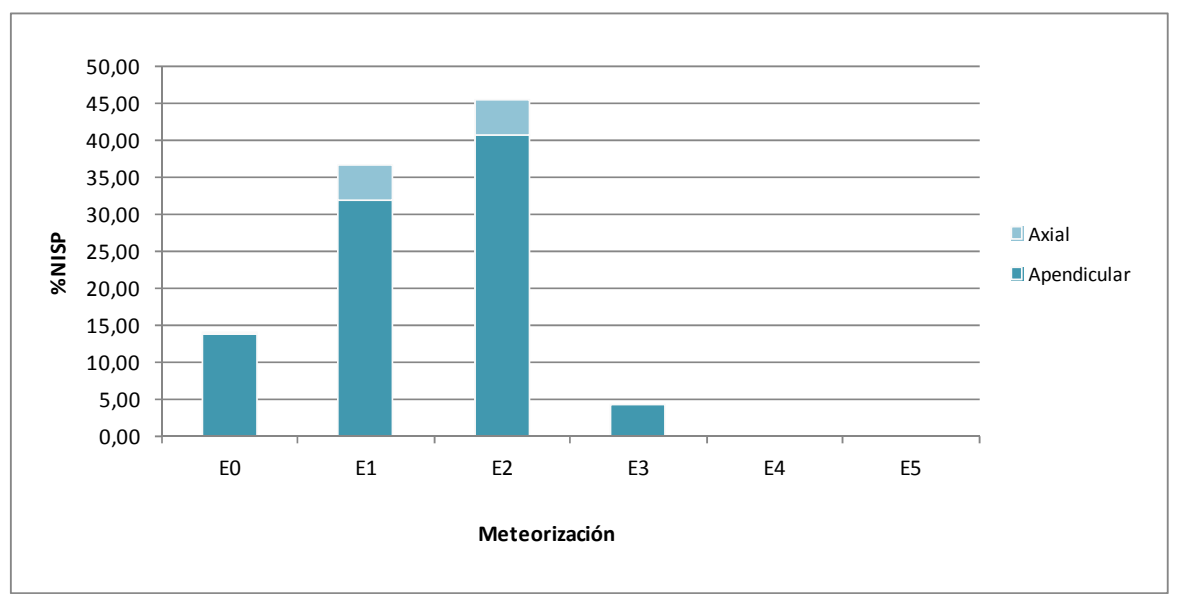

Figura 8.25. Tendencia de la meteorización en especímenes asignados a L. guanicoe en el conjunto de Capa 2 de PM. Los valores son expresados en NISP\%.

Otras modificaciones no antrópicas fueron observadas en el conjunto (Figura 8.26a). Las improntas de raíces son las que presentan más incidencia sobre el conjunto (21\%). Corresponden a surcos que adquieren diseños dendríticos de diámetros finos y se registran tanto en superficies corticales como medulares y bordes de fracturas (Figura 8.27a y 8.27b). En general, se caracterizan por presentar un color de surco más claro que la superficie cortical del hueso. Este tipo de traza indicaría la existencia de cobertura herbácea sobre el suelo en el momento que los restos fueron depositados (Montalvo 2002). Los especímenes con este tipo de modificación presentan un patrón de distribución (Figura 8.28a) con mayor densidad de restos hacia el área más reparada del sitio (cuadrícula H e I). Esta distribución no cubre la expectativa de que tales modificaciones serían más esperables hacia los sectores externos al alero donde las condiciones son más favorables para el desarrollo de la vegetación. Sin embargo, su distribución coincide por completo con el área en la que se concentra la mayor parte del conjunto estudiado (Figura 8.22a y 8.22b) y la mayor cantidad de especímenes de guanaco (Figura 8.23).

En un 19,3\% de los especímenes se registran moteados de manganeso cuya distribución e intensidad es heterogénea en las distintas arqueofaunas (Figura 8.27c). El óxido de manganeso depositado sobre las superficies óseas podría tener génesis diferentes: por un lado y como fue discutido para el conjunto de Capa 6, los procesos pedogenéticos (López-González et al. 2006); por otro, a partir de la descomposición de tejido blando adherido a las superficies óseas (Marín Arroyo et al. 2008; Shahack-Gross et al. 1997). Como se verá más adelante, debido a la alta fragmentación antrópica que 
presenta el conjunto es posible que estos especímenes sean resultado de actividades de procesamiento secundario y consumo. Por lo tanto, existe una gran probabilidad de que se hayan descartado limpios (sin tejido blando adherido). Es por esto que consideramos que las manchas de manganeso podrían guardar mayor relación con las características del horizonte IIA del suelo enterrado en el que fue recuperado el conjunto. La distribución de los restos con manganeso (Figura 8.28b) dentro del área excavada, si bien muestra algunos sectores con mayor densidad, los mismos coinciden con los lugares donde hay mayor frecuencia de restos óseos.

En un 5,7\% de los fragmentos óseos se observan depósitos de carbonato (Figura 8.27d); estos depósitos y acreciones generalmente aparecen asociados al canal medular, a sectores rugosos del hueso o a sectores con tejido esponjoso cuya estructura trabecular va rellenando. En el tejido compacto suele manifestarse como una película fina que cubre un área más o menos extensa de la superficie del hueso, generalmente formando una capa continua. Cabe mencionar que los depósitos de carbonato registrados en este nivel tienen un espesor mucho menor que los registrados en la Capa 4/5 y por tanto, aquí no alcanzan a obliterar la superficie del hueso. Los mismos podrían corresponder a sales provenientes de los sedimentos o de la roca del afloramiento (coquina), cuya disolución se ve favorecida por procesos pedogenéticos como el registrado en el sitio (Courty et al. 1989; Gutiérrez 2004).

Otras modificaciones de tipo natural han sido registradas pero su presencia sobre los especímenes es menos frecuente $(<2,5 \%)$. Estos casos contemplan las modificaciones producidas por la acción de mordisqueo de carnívoros pequeños, posiblemente zorros, que han generado hoyuelos y/o pequeñas perforaciones, y de roedores cuyas marcas se registraron en los bordes de escasos fragmentos de hueso largo (Figura 8.26a). 


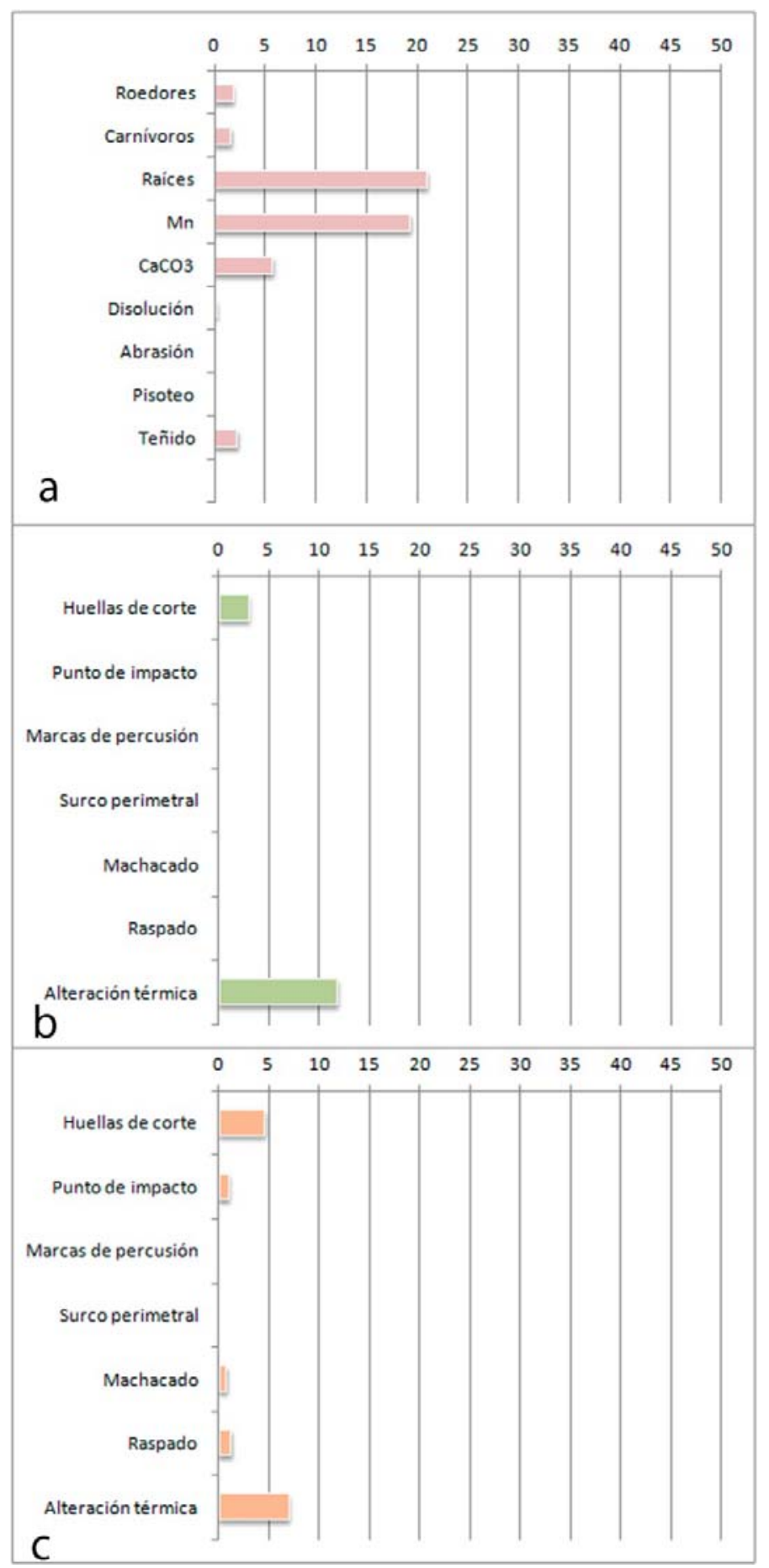

Figura 8.26. Frecuencia porcentual de especímenes óseos de guanaco con modificaciones en el conjunto de Capa 2 de AEP-1: a) naturales; b) modificaciones antrópicas en especímenes del esqueleto axial; c) modificaciones antrópicas en el esqueleto apendicular. 


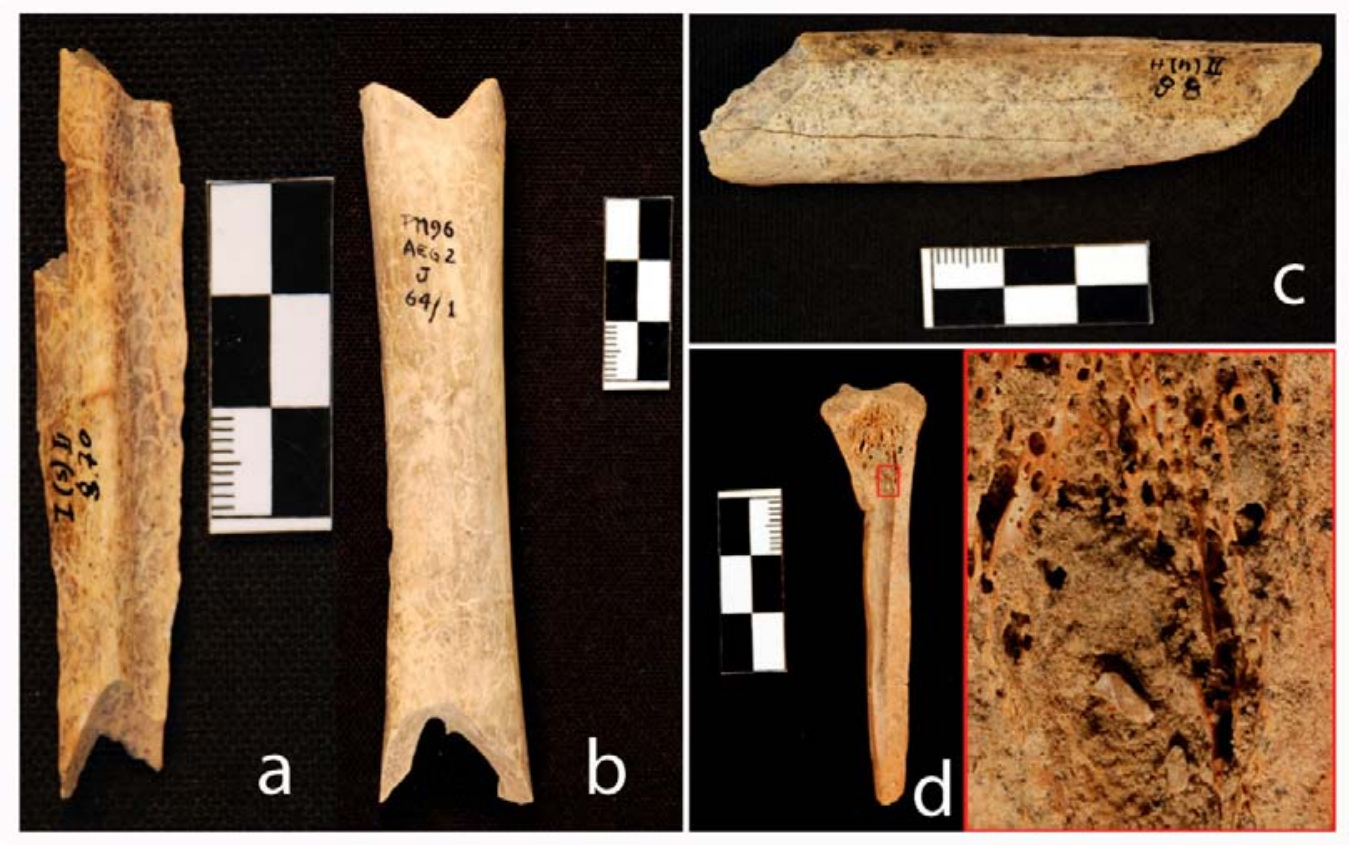

Figura 8.27. Modificaciones naturales en los especímenes de Capa 2 de AEP-1: a) marcas de raíces en diáfisis posterior de metapodio; b) marcas de raíces en diáfisis anterior de metapodio; c) manchas de manganeso en diáfisis anterior de metapodio; d) depósitos de carbonato y detalle del mismo en el canal medular de un metapodio.
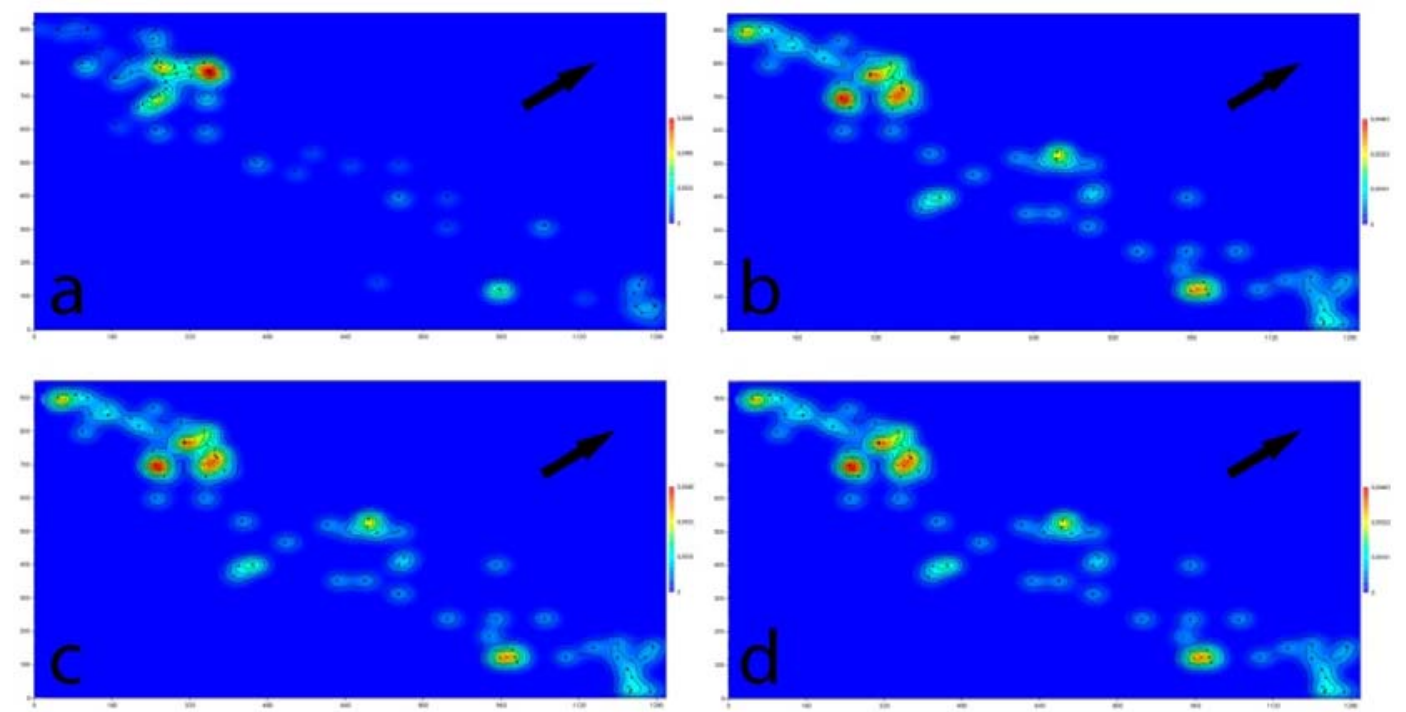

Figura 8.28. Distribución de los especímenes con modificaciones en Capa 2 de AEP-1: a) improntas de raíces; b) depósitos de manganeso; c) especímenes con huellas de corte; d) restos óseos termoalterados. 


\subsubsection{Patrones de modificación antrópica}

Para evaluar el rol del agente humano sobre el conjunto se llevó adelante el registro de las modificaciones de origen cultural (Figura 8.26b y 8.26c). Las huellas de corte (Figura 8.29a y 8.29b) se registran en un 4,3\% del total de los especímenes tanto del esqueleto axial (Figura 8.26b) como del esqueleto apendicular (Figura 8.26c). Entre los especímenes del esqueleto axial no se observan otras marcas relacionadas al procesamiento de las carcasas. Sin embargo, en los huesos correspondientes al esqueleto apendicular, aunque en bajas frecuencias, se registra la presencia de puntos de impacto, marcas de machacado y raspado (Figura 8.26c). Con respecto a la localización que presentan las huellas de corte, las mismas se podrían relacionar con actividades de cuereo, desarticulación y descarne (Binford 1981).

$\mathrm{Al}$ igual que como se observó anteriormente con los depósitos de manganeso, los especímenes que exhibieron huellas de corte en sus superficies, se distribuyen en toda el área excavada (Figura 8.28c). Sin embargo, su mayor concentración en dos sectores (cuadrículas H e I y cuadrícula B) podría sugerir la existencia de áreas particulares de descarte dentro del sitio.

Dentro de esta capa se registró un 7,5\% de restos tanto del esqueleto axial como apendicular, que presentaban signos de alteración térmica en sus superficies (Figura 8.26b y 8.26c). El patrón de distribución que ellos presentan (Figura 8.28d) es completamente similar al observado para los especímenes con manganeso (Figura 8.28b) y huellas de corte (Figura 8.28c), y que coincide con los sectores de mayor concentración de restos (Figuras 8.22 y 8.23). Estos sectores con mayor densidad de restos óseos quemados, no coinciden completamente con los registrados por Cattáneo (2002) a partir de los materiales líticos termoalterados. Por tal motivo, en caso de inferir alguna posible área de combustión a partir de los especímenes quemados, ésta tendría más chances de haberse registrado en el sector bajo el alero (cuadrículas $\mathrm{H}$ e I principalmente). Sin embargo, una concentración menor se observa en el sector de la cuadrícula B coincidiendo con el lugar de procedencia del carbón fechado y cercano a una de las áreas de combustión sugeridas por Cattáneo (2002).

Teniendo en cuenta las cuatro modificaciones principales observadas en el conjunto y su distribución espacial (Figura 8.28), se puede inferir que el sector de mayor reparo, y que contiene la mayor cantidad de huesos, coincidiría con áreas de consumo y descarte (mayor frecuencia de huellas de corte y alteración térmica). Lo cuál habría 
favorecido al desarrollo de modificaciones químicas de óxido-reducción (manchas de manganeso), el aumento de humedad respecto de otras partes del abrigo y, por lo tanto, el aumento de la vegetación.

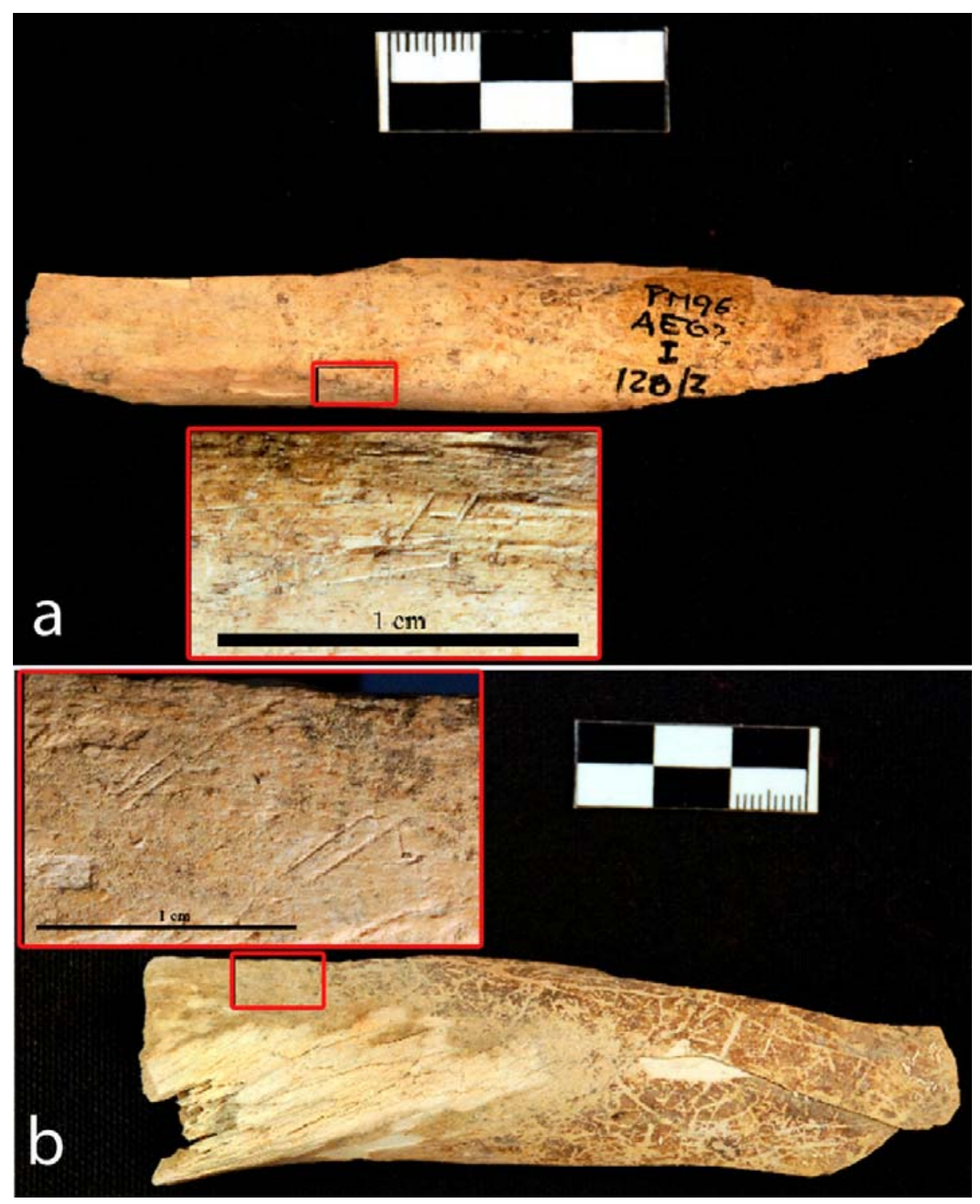

Figura 8.29. Modificaciones culturales: a) huellas de corte y manchas de manganeso en diáfisis de metapodio; b) huellas de corte en una diáfisis de húmero cuya superficie se encuentra descascarada por desprendimiento en el laboratorio gran parte de la costra de carbonato. Aún pueden observarse pequeñas concreciones de carbonato sobre la superficie cortical. La desaparición de esta cobertura permite ver el mayor grado de deterioro de la superficie ósea, donde aparecen numerosas fisuras, exposición del tejido trabecular y exfoliaciones. Asimismo se observa una fisura profunda, que comenzó en la superficie de fractura arqueológica 
En un total de $226(46,4 \%)$ especímenes de huesos largos de guanaco fueron determinadas 261 fracturas (Figura 8.30). Entre los patrones identificados la mayor frecuencia corresponde a la de fracturas longitudinales $(n=95)$, de las cuales un $77 \%$ presenta superficies suaves sin variación de color con respecto a la superficie cortical del hueso. Estas características permiten inferir que se realizaron cuando el hueso aún estaba fresco y posiblemente sean resultado de la actividad antrópica, ya que en muchos casos existen atributos (puntos de impacto, lascados, etc.) que avalan la hipótesis de una fuerza de percusión y no de compresión en la producción de las mismas. Por el contrario, el $23 \%$ restante muestran superficies rugosas y cambios en la coloración y por tanto, su origen es considerado tafonómico.

Las fracturas helicoidales (Figura 8.30) resultado de la fragmentación del hueso en estado fresco son interpretadas, debido a la presencia de atributos tecnológicos asociados y a la prácticamente nula acción de los carnívoros sobre el conjunto, como resultado de actividad cultural. Por otro lado, la frecuencia tanto de fracturas oblicuas como transversales (Figura 8.30), no pudo ser asignada al agente antrópico. Esto ocurre debido a que todas ellas presentaban signos de haberse producido cuando el hueso ya se encontraba deshidratado y por lo tanto sus superficies se presentaban irregulares.

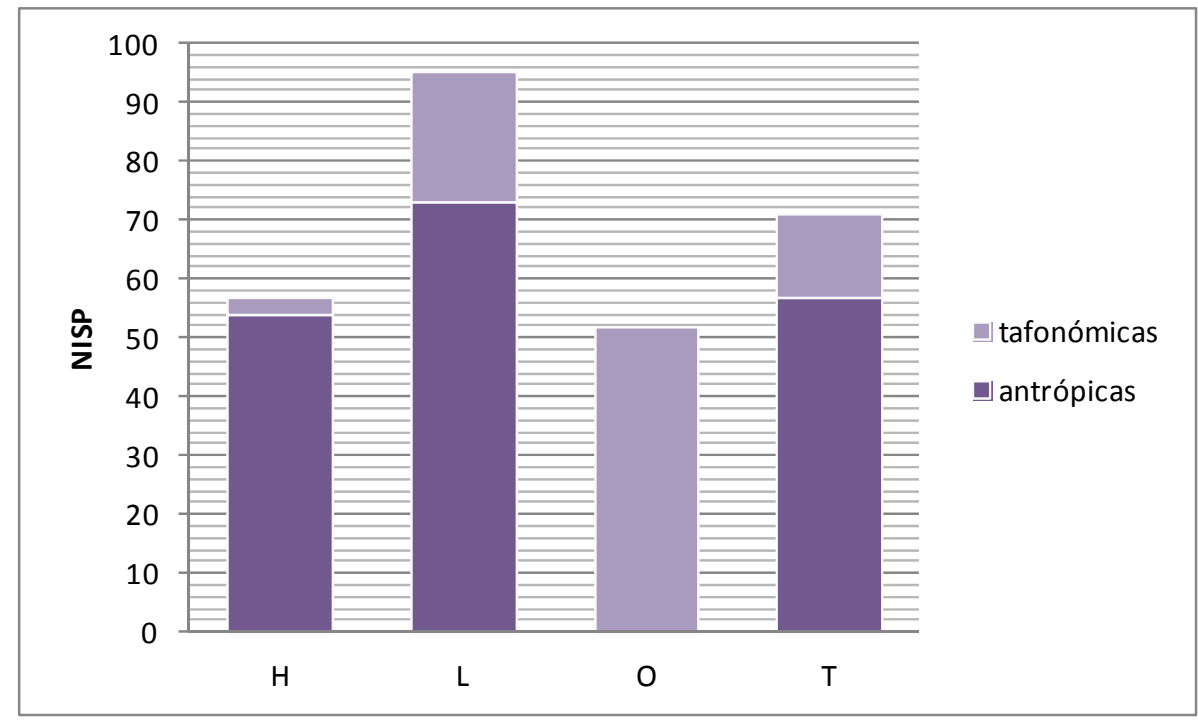

Figura 8.30. Frecuencia absoluta y tipos de fracturas identificadas en el conjunto de Capa 2 de AEP-1: H) helicoidal; L) longitudinal; O) oblicua; T) transversal.

Además, se registraron modificaciones antrópicas en especímenes de otras especies que permiten proponer su incorporación al registro como resultado de decisiones 
humanas. Entre los especímenes óseos asignados a rheidos $(n=55)$ un 9\% registran huellas de corte mientras que, un 20\% de los restos exhibían alteración térmica. También se identificaron fragmentos de cáscaras de huevos de estas aves quemados.

Ente los restos asignados a cánidos, se registra la presencia de un húmero distal quemado y, como se verá más adelante, un artefacto formatizado sobre un metapodio.

El fragmento de valva asignado a la Familia Unionidae, exhibe líneas incisas acompañando los bordes de la sección de valva. Creemos que su incorporación al registro puede estar relacionada a la elaboración de tecnofacturas.

En el conjunto de Capa 2 se identificaron tres artefactos formales elaborados en diáfisis de huesos largos con alto grado de diseño y que corresponden a útiles confeccionados para la concreción de funciones muy diferentes (Miotti y Marchionni 2011). Dos de estos instrumentos están confeccionados sobre huesos largos de guanaco, uno de ellos sobre una diáfisis de radio-cúbito derecho (Figura 8.31a) y el otro sobre una diáfisis anterior de metapodio (Figura 8.31b). El tercero de los instrumentos corresponde a un punzón confeccionado sobre un metapodio de hueso de cánido (Figura 8.31c).
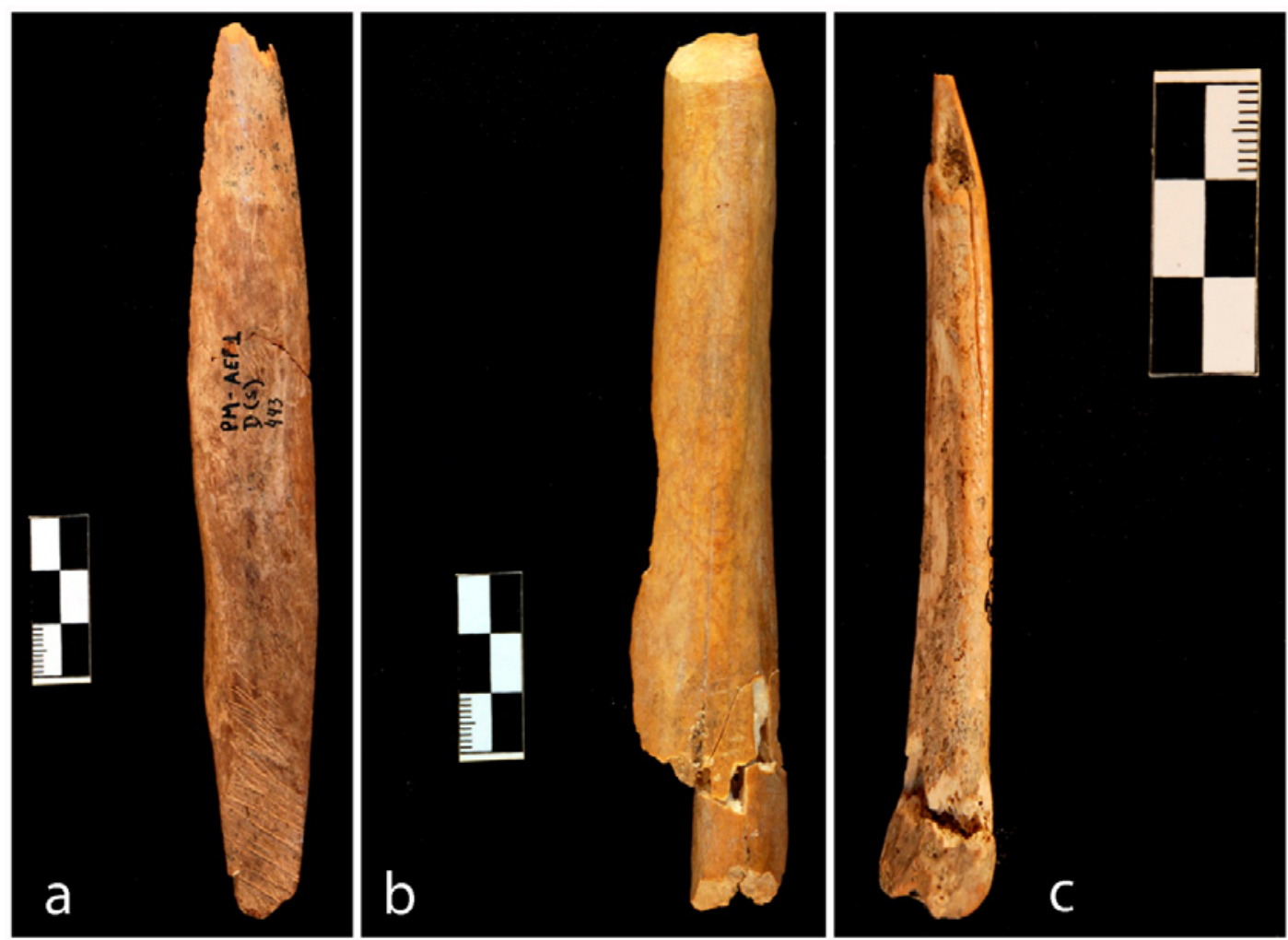

Figura 8. 31. Artefactos óseos formatizados en Capa 2 de AEP-1: a) sobre radio-cúbito izquierdo de guanaco; b) sobre diáfisis anterior de metapodio; c) punzón sobre metapodio de cánido. 
Los resultados obtenidos permiten reconocer la importancia del guanaco como el principal recurso económico para las sociedades cazadoras-recolectoras que habitaron AEP-1 en los inicios del Holoceno medio. Esta idea, fundamentada en las elevadas frecuencias de NISP y MNI registradas para los guanacos (Tabla 8.6), además se encuentra avalada por los distintos tipos de modificaciones antrópicas registrados en ellos (Figura 8.26b y 8.26c). Entre estas modificaciones, el registro de huellas de corte vinculadas a las distintas etapas del procesamiento de las carcasas (desarticulación, cuereo y descarne), la presencia de puntos de impacto y marcas de machacado y raspado en los huesos largos, sumado a los altos porcentajes de fracturas de origen intencional, avalan un uso integral del recurso guanaco. El mismo posiblemente haya tenido fines diversos, no solo alimenticios sino además, para la obtención de materia prima ósea para confección de útiles. Esta última propuesta se encuentra avalada por la presencia de dos artefactos óseos formatizados sobre hueso de guanaco, con alto nivel de diseño e inversión de trabajo (Figuras 8.31a y 8.31b).

La representación de partes anatómicas del guanaco muestra que las unidades con mayor frecuencia son las correspondientes a las porciones distales de los miembros. Si bien estas unidades no son una fuente de carne importante, los metapodios contienen una grasa de excelente calidad y gusto (Morin 2007; Rindel 2009), con un alto contenido de ácido oleico que facilita su digestión y mejora su sabor. Esta característica de su grasa, podría haber sido un importante factor para la decisión de su trasporte en el pasado. Además, estas unidades aportan elementos como los tendones y tejido cartilaginoso de utilidad para la intensificación en la obtención de grasas, así como en la producción de tecnofacturas; en este sentido estas partes son conocidas como el equipo de costura ("the hunter's sewing kit' Lyman 1994: 225). Su ingreso al sitio también podría deberse a que vienen adheridas a los cueros o a unidades de mayor rendimiento denominado "schlepp effect" por Perkins y Daly (1968).

El registro de modificaciones de las superficies óseas muestra que aquellas causadas por agentes o procesos naturales son las que alcanzan mayor frecuencia en el conjunto (Figura 8.26). Entre ellas, las más numerosas son las que podrían estar favorecidas por el proceso de pedogénesis registrado en el sitio. Si bien estas modificaciones se observaron en un gran número de especímenes, su afección sobre la superficie de los mismos no parece haber sido muy intensa. Las mismas nunca llegan a cubrir o a obliterar las superficies enteras de los restos óseos.

La meteorización evidencia un enterramiento sincrónico del conjunto y una 
relativamente buena preservación de sus superficies óseas. De esta manera, la baja correlación registrada entre el MAU\% y la DO (Figura 8.24a) podría vincularse más con el alto grado de fragmentación antrópica del conjunto que con la acción de proceso destructivos de origen natural, aún tomando en cuenta los recaudos expresados anteriormente respecto de la meteorización y las categorías de edad (Massigoge et al. 2010). Otra de las causas que podrían estar involucradas en la heterogénea meteorización que encontramos en esta conjunto puede vincularse con el deficiente drenaje que se registra en este horizonte de suelo (Figura 8.3).

Toda esta información avala la hipótesis de que el sitio habría funcionado como un locus de actividades vinculadas al procesamiento integral de los guanacos. El registro de modificaciones culturales en especímenes de rheidos, cánidos y moluscos, sugiere un uso complementario de estos taxa. Las huellas de corte registradas en los rheidos avalan la idea del consumo de estas aves; respecto de la utilización de los cánidos y los caracoles, creemos que la misma pudo estar principalmente relacionada a la confección de instrumentos y adornos.

Es posible que el patrón común de distribución que presentan las distintas modificaciones (Figura 8.28) esté evidenciando un área de descarte particular. Allí se registra no sólo la mayor concentración de huesos sino también la mayor frecuencia y variedad de modificaciones, tanto naturales como culturales. Probablemente, la existencia de un escalón de la roca de base en el norte de las cuadrículas $\mathrm{H}$ e I, sumado a la presencia de un bloque derrumbado del techo del alero en la cuadrícula J (Figura 8.26a) hayan favorecido tal concentración de restos en dicho sector. Sin embargo, el sector más protegido (cuadrículas $\mathrm{H}$, I y J) tendría altas probabilidades de haber funcionado para actividades de procesamiento de las presas, consumo y descarte, existiendo un área menor de actividades ubicada en la cuadrícula B. Esta tendencia, como se discutirá en la siguiente sección de este capítulo, marca un uso diferente del espacio respecto de los niveles inferiores del sitio.

\subsection{DISCUSIÓN DE LA VARIABILIDAD INTRASITIO}

Los conjuntos de las Capas 6 y 4/5 de AEP-1 cronológicamente corresponden al primer bloque temporal que abarca la transición Pleistoceno-Holoceno/Holoceno 
temprano, mientras que el conjunto de la Capa 2 corresponde al inicio del Holoceno medio (ver definición de bloques temporales en el Capítulo 2).

La superficie de la que proceden los especímenes óseos presenta variaciones particulares para cada uno de los tres conjuntos. En la Capa 6 (Figura 8.4a) es donde se observa la menor superficie utilizada en el sitio $\left(30 \mathrm{~m}^{2}\right)$. Creemos que para estos momentos el área cubierta por el alero pudo ser mayor, debido a que el derrumbe de diferentes bloques procedentes del techo habría sucedido con posterioridad a las ocupaciones de la Capa 4/5, esto sería en algún momento entre 9000 y 7500 años AP. La menor superficie utilizada también puede guardar relación, como se mencionó al inicio de este capítulo, con que esta capa no fue registrada en el sector de las cuadrículas H, I y J, debido a la altura que allí presenta la roca de base. El poco espacio utilizado, además, concuerda con lo esperado según los modelos existentes para el área (Borrero 1989-90; Miotti y Salemme 1999, 2004) que proponen para estas primeras instancias del poblamiento la presencia de grupos integrados por pocos individuos. Por lo tanto, no es esperable una redundancia marcada en el uso de los sitios (Borrero 1989-90). La superficie utilizada en Capa 4/5 (34,25 m², ver Figura 8.13a) supera a la de Capa 6, esto podría estar vinculado a la expectativa de uso más repetitivo de los sitios propuesta por Borrero (1989-90) para ca. 10.500 años AP. Para estos momentos el derrumbe del alero aún no habría acontecido, lo que indica un área mayor de reparo que la registrada para momentos posteriores (ocupaciones de Capa 2). Sin embargo, en este nivel, a diferencia de lo que se observa en Capa 6 y aunque de forma escasa, se registraron materiales arqueológicos en el sector de las cuadrículas H, I y J que podrían indicar mayor disponibilidad del espacio reparado por el alero hacia el sector oeste del sitio. Por su parte, la Capa 2 (Figura 8.22a) es en la que se observa la mayor superficie utilizada $(42,25$ $\mathrm{m}^{2}$ ); sin embargo, para estos momentos de ocupación del sitio ya se habría producido el derrumbe masivo del alero, lo que implicaría un área menor de reparo. A pesar de eso, los sectores más externos, como los de las cuadrículas A, B, C y D (Figura 8.22a), siguieron siendo utilizados aunque en menor medida.

De esta manera, el uso diferencial que las sociedades cazadoras-recolectoras hicieron de este abrigo en el pasado pudo, al menos, estar influido por dos cuestiones principales: una disponibilidad distinta del espacio con techo rocoso para cada uno de los 3 momentos de ocupación del sitio; la otra vinculada a las particularidades de los grupos humanos que caracterizaron cada una de estas etapas en cuanto a las estrategias de asentamiento y movilidad (Borrero 1989-90; Miotti y Salemme 2004). 
Los análisis de distribución y densidad de restos óseos avalan la tendencia observada hacia un mayor uso del espacio actualmente más externo del alero en las ocupaciones de la transición Pleistoceno-Holoceno. Este patrón se modifica hacia el Holoceno medio ya que el sector actualmente más protegido es el que se presenta como principal área de actividad de aquella época, luego de que el alero que cubría el área de las cuadrículas C, D y E había colapsado. A partir de estos análisis se observan cambios en las áreas de descarte para los distintos momentos de ocupación del sitio. Los cambios de dimensión sufridos por el alero y evidenciados a través de los derrumbes seguramente han influido sobre las diferentes disponibilidades del espacio bajo techo.

El conjunto procedente de Capa 2 es el que registra la mayor frecuencia de especímenes óseos $(\mathrm{NSP}=2399)$; sin embargo, es donde se observa el mayor porcentaje de restos indeterminados. Esto evidencia que es el nivel con menor resolución taxonómica del sitio. Por el contrario, el conjunto de la Capa 4/5 es el que registró el mejor nivel de determinación. Sin duda esta situación, al menos en la Capa 2, se encuentra relacionada al alto grado de fragmentación cultural que presenta el conjunto y que es avalado por el bajo índice de completitud anatómica $(\mathrm{MNE} / \mathrm{NISP}=0,47)$ y por el alto porcentaje de fracturas vinculadas al procesamiento humano de los guanacos (ca. $67 \%)$.

Con respecto a la abundancia taxonómica, los guanacos, los rheidos y los cánidos son el denominador común en los tres conjuntos de AEP-1 (Figura 8.32). Sin embargo, las frecuencias relativas de estos tres grandes grupos pone de manifiesto la diferencial importancia que los mismos habrían cobrado en la vida de los cazadores-recolectores que ocuparon el abrigo.

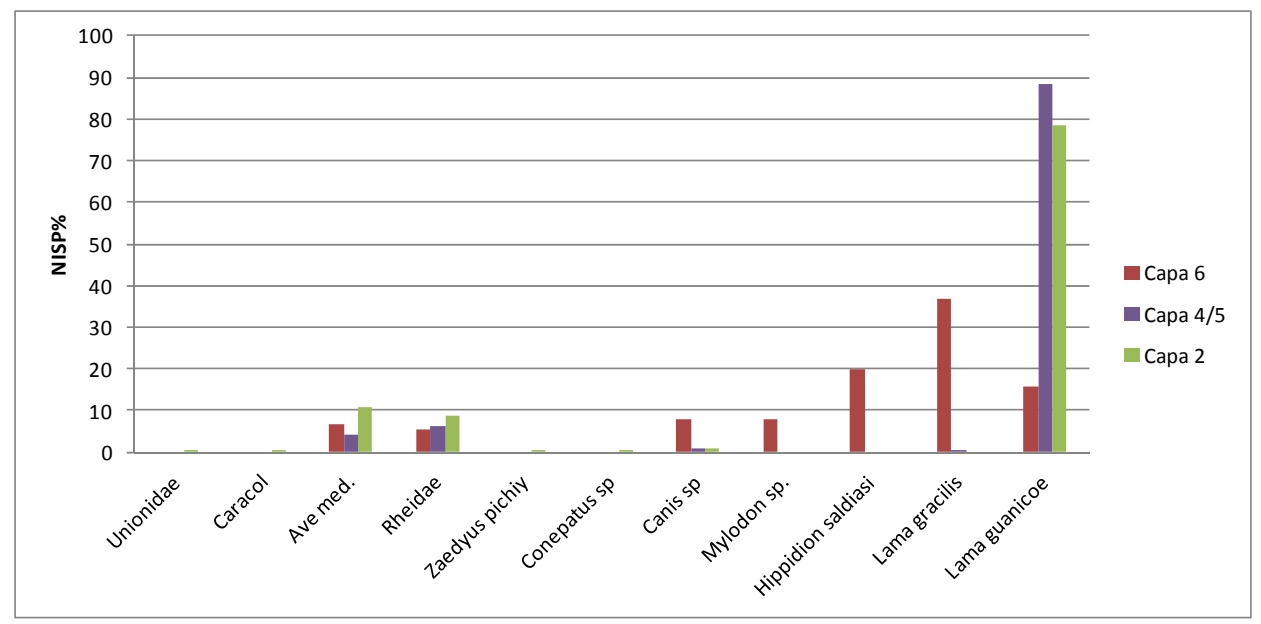

Figura 8.32. Diversidad taxonómica relativa en AEP-1. 
La mayor diversidad de especies de gran porte se da hacia finales del Pleistoceno (Capa 6) (Figura 8.32), concordante con un modelo cazador-recolector generalista de aprovechamiento de la fauna, basado en especies de alto retorno económico como los équidos y camélidos (Borrero 1989-90; Miotti y Salemme 1999, 2005). Se destaca asimismo, el aprovechamiento de grandes aves corredoras como los rheidos, de los que algunos en Capa 6 y base de 4/5 corresponderían a Rhea americana. Esta especie se retrae hacia el norte de Patagonia en el Holoceno, por lo que la asociación de la misma en los niveles profundos de Piedra Museo, junto con otras dos de mamíferos altamente pastadores, como son Hippidion sp. y Lama gracilis, permiten mantener la hipótesis de que la región fue una estepa graminosa en lugar de estepa arbustiva xérica (Alberdi et al. 2001; Miotti y Salemme 2005; Miotti y Tonni 1996; Miotti et al. 1999). Los rheidos no son las únicas aves representadas hacia el comienzo de la ocupación en el sitio (Figura 8.32); también se registran aves del rango de anátidos y gallináceas (patos, cisnes, cauquenes, martinetas), que en general tienen hábitos acuáticos y relacionados a cuerpos de aguas continentales (Miotti y Salemme 2005; Miotti et al. 1999). Este patrón de uso de aves y especies de mamíferos gregarios es acorde con movilidades de tipo locacional (Meltzer 2003; Rockman 2003). Para fines de la transición Pleistoceno-Holoceno (Capa $4 / 5)$ se comienza a perfilar la tendencia hacia la focalización del recurso guanaco (Figura 8.32). Sin embargo, los rheidos continúan siendo un recurso complementario, que a juzgar por las crónicas e información etnográfica (Claraz 1988; Miotti 1998; Musters 1964), continuarían cumpliendo este rol hasta momentos posthispánicos. El aumento del uso de los guanacos como recurso básico a fines de la transición Pleistoceno-Holoceno marca una tendencia hacia la especificación (Bettinger 1991; Koyama y Uchiyama 2006) que se confirma hacia el Holoceno medio (Capa 2). Esta tendencia hacia una estrategia centrada en el guanaco coincide con la que se observa en la región patagónica (Borrero 2001; De Nigris 2004; Goñi 2010; Mengoni Goñalons 1999; Rindel 2009, entre muchos otros) y pampeana (Martínez y Gutiérrez 2004). El rol jugado por los rheidos en estas primeras instancias del poblamiento del área como recurso complementario, se ve avalado por el novedoso registro de huellas de corte en una vértebra cervical que nos permite sostener su utilización por parte de los primeros grupos humanos.

El uso de la fauna pleistocénica en los conjuntos del Pleistoceno final-Holoceno temprano de AEP-1 (Capas 6 y 4/5) fue discutido en numerosos trabajos previos (Miotti 2003; Miotti y Cattáneo 2003; Miotti y Salemme 2005; Miotti et al. 1999;). Esos trabajos habían registrado la presencia de marcas de corte en Hippidion saldiasi y especímenes 
de camélidos (tanto L. gracilis como L. guanicoe), pero no en los restos del Mylodon sp. (Alberdi et al 2001; Miotti 2003; Miotti y Cattáneo 2003; Miotti y Salemme 2005; Miotti et al. 1999). La actualización de los datos en esta tesis continúa avalando las hipótesis previamente establecidas acerca del procesamiento de camélidos y el aprovechamiento oportunístico de los caballos (Miotti 1996; Miotti y Salemme 2005; Miotti et al. 1999). Sin embargo, un aporte novedoso de esta tesis corresponde al registro de claras huellas de corte en un fragmento de costilla de Mylodon sp. (Figura 8.10c), aunque esta evidencia es escasa, apoya la hipótesis de procesamiento humano para este taxón (Marchionni y Vázquez 2012). El aprovechamiento de milodontinos es recurrente en muchos lugares de la Patagonia; sin embargo, en la mayoría de los casos la naturaleza de la asociación o la ausencia de huellas antrópicas directas en esta arqueofauna ha permitido plantear una contemporaneidad entre las primeras poblaciones humanas con los últimos ejemplares de Xenartras, cuyas poblaciones ya estarían en proceso de reducción numérica, pero en muy pocos casos su uso como recurso de subsistencia (Borrero 2005, 2009; Borrero y Martin 2012). Si bien su representación en el conjunto de Capa 6 es muy baja, se sugiere una explotación ocasional posiblemente por carroñeo (Borrero 2009; Borrero y Franco 1997; Borrero y Martin 2012; Miotti y Salemme 1999).

La frecuencia de los cánidos habría sido más importante hacia el Pleistoceno final (Figura 8.32). Sin embargo la presencia alteración térmica y fractura helicoidal en huesos de cánido, así como la presencia de un artefacto formalizado, sugiere la utilización antrópica de este recurso durante la transición Pleistoceno-Holoceno (Capa 6), y su importancia como fuente de materia prima para la producción de instrumentos durante el Holoceno medio (Capa 2). Fuera de esto no hay evidencias que avalen el aprovechamiento de estos animales como recurso alimenticio.

Sin dudas, los guanacos y, en el caso de Capa 6 los camélidos, han sido la especie de mayor importancia a lo largo de toda la secuencia ocupacional del alero AEP-1 de Piedra Museo. Esto es coherente con la información registrada en otros sitios del Macizo que se refieren al guanaco como el principal recurso económico (Aguerre 1994; Aguerre y Pagano 2003; De Nigris 2004; Durán et al. 2003; Frank 2011; Mengoni Goñalons 197680; Mengoni Goñalons y Silveira 1976; Miotti 1998; Miotti et al. 2007; Pagano y Aguerre 2001; Paunero et al. 2007; Rindel 2009; Silveira 1979, entre otros). Asimismo, la importancia del guanaco como recurso principal se puede hacer extensiva, según la información arqueológica, a todo el ámbito patagónico extra-andino.

Como fue mencionado antes, el conjunto de Capa 6 es el que presenta la mayor 
diversidad taxonómica, tanto de grandes mamíferos como de aves (Tabla 8.2 y 8.32), ya que en el conjunto de Capa 4/5 (Tabla 8.3 y 8.32) solamente fue identificada la presencia de una única especie pleistocénica (L. gracilis). Esta tendencia hacia la reducción en la representación de megaherbívoros pleistocénicos en AEP-1 también se observa en distintos sitios de Pampa (Martínez y Gutiérrez 2004 y bibliografía allí citada) y Patagonia (Miotti y Salemme 1999 y bibliografía citada en Capítulo 2 y Capítulo 3 de esta tesis) y coincide con los últimos registros de estas especies, que en Patagonia llegan hasta ca. 8500 años AP (Miotti 1998; Miotti y Salemme 1999; Miotti et al. 1988; Tonni 1992). De esta manera, en el conjunto del Holoceno medio (Capa 2) solamente se registran especies que actualmente habitan el área de estudio.

En la Capa 6, si bien los guanacos se encuentran en bajas proporciones, la presencia de L. gracilis junto con la alta frecuencia de Lama sp. (Tabla 8.2) muestra que los camélidos han sido un recurso de mucha importancia para estos grupos. Esta caracterización de la Capa 6 marca una diferencia respecto de las otras dos capas ya que, tanto en la Capa 4/5 (Tabla 8.4) como en la Capa 2 (Tabla 8.6), los guanacos son la especie dominante y casi exclusiva del conjunto. Estos últimos conjuntos además se diferencian de la Capa 6 en la importante frecuencia de restos de rheidos que presentan. Los valores absolutos de restos de estas aves son más elevados en la Capa 2 donde además de restos óseos (NISP=55) se recuperó un importante número de fragmentos de cáscara de huevo $(\mathrm{NISP}=68)$ (ver Tabla 8.6). Sin embargo, los valores relativos de esta especie cobran otro significado del aprovechamiento de estas aves corredoras en la Capa 4/5 donde exclusivamente están representadas por restos óseos del esqueleto (NISP= 57). Aquí también nos encontramos en un dilema, ya que la ausencia de cáscaras de huevo en la capa inferior no permite inferir que los huevos de estas aves no fueron utilizados, sino que nos abre la posibilidad que:

a) Las ocupaciones de 4/5 no correspondan a la estación de fines de primavera y verano, cuando estas aves empollan.

b) Que sea un sesgo de muestreo y aun no se haya dado con un sector con este tipo de restos.

c) Que por conservación diferencial y debido al alto contenido cálcico y fragilidad de las cáscaras, las mismas no se hayan preservado, dado que aquí es donde se registra una muy alta depositación de carbonato.

Los modelos existentes para la Fase de Colonización del área (Miotti y Salemme 1999) proponen una estrategia generalista centrada en la caza del guanaco y 
complementada por un amplio rango de recursos, hipótesis que por otro lado es avalada por numerosos autores para la meseta patagónica (Borrero 1994-95, 2009; Miotti 1998; Miotti y Salemme, 1999; Miotti et al. 1988). Los conjuntos de las Capas 6 y 4/5, cronológicamente corresponden a esta etapa del poblamiento del área. Si bien encontramos que el conjunto de Capa 6 cumple tal expectativa, no ocurre lo mismo con el conjunto de Capa 4/5. Por el contrario, encontramos que la altísima representación de los guanacos, sumada a la importancia que cobran los rheidos, la ausencia de megamíferos pleistocénicos como los Hippidion y Mylodon, y la baja representación de 1 solo taxa pleistocénico extinguido (L. gracilis), evidencia un cambio de estrategia respecto de la que refleja el conjunto de Capa 6. Esta nueva estrategia estaría más centrada en el guanaco y se asemeja a la propuesta para momentos más tardíos del área, cuando los grupos cazadores se habrían adaptado hacia condiciones más áridas y centrado su subsistencia en el guanaco (Miotti y Salemme 1999). Lo mismo ocurre con el conjunto de la Capa 2, el cual se ajusta a esta estrategia y cumple las expectativas propuestas por los modelos para la Fase de Consolidación Territorial (Miotti y Salemme 1999) que coincide con la cronología de la ocupación.

Con respecto a la representación anatómica que tiene el guanaco en los distintos conjuntos de AEP-1, encontramos que el conjunto de Capa 4/5 se diferencia de los restantes en ser el único donde la mayor cantidad de especímenes y elementos determinados corresponden al esqueleto axial (Tabla 8.4). Esta observación difiere de lo que habitualmente se observa en los sitios de Patagonia donde generalmente los elementos más representados de los guanacos indican un predominio de las patas (De Nigris 2004, 2008; Mengoni Goñalons 1999; Miotti 1998; Rindel 2009). Por el contrario, los conjuntos de las Capas 6 y 2 (Tablas 8.2 y 8.6 respectivamente) alcanzan una mejor representación del esqueleto apendicular por sobre el axial.

El análisis comparativo de las frecuencias estandarizadas de MAU\% que se observa en la Figura 8.33, también muestra que la representación de unidades anatómicas de guanaco es distinta en cada conjunto. Mientras que en la Capa 6 las unidades más representadas corresponden al zeugopodio y autopodio anterior, y al estilopodio posterior y la pelvis (Figura 8.33), en la Capa 4/5 las unidades con mayor frecuencia corresponden a la cabeza y región de la cintura pélvica incluyendo el sacro, las vértebras lumbares, la pelvis y el fémur en menor frecuencia (Figura 8.33). En el caso de la Capa 2, la tendencia que se registra es completamente diferente, mostrando claramente una frecuencia elevada de los elementos distales de ambas patas (Figura 8.33). Como se dijo 
anteriormente, este último patrón de representación es recurrentemente registrado en diferentes localidades arqueológicas del interior de Patagonia (De Nigris 2008 y bibliografía allí citada).

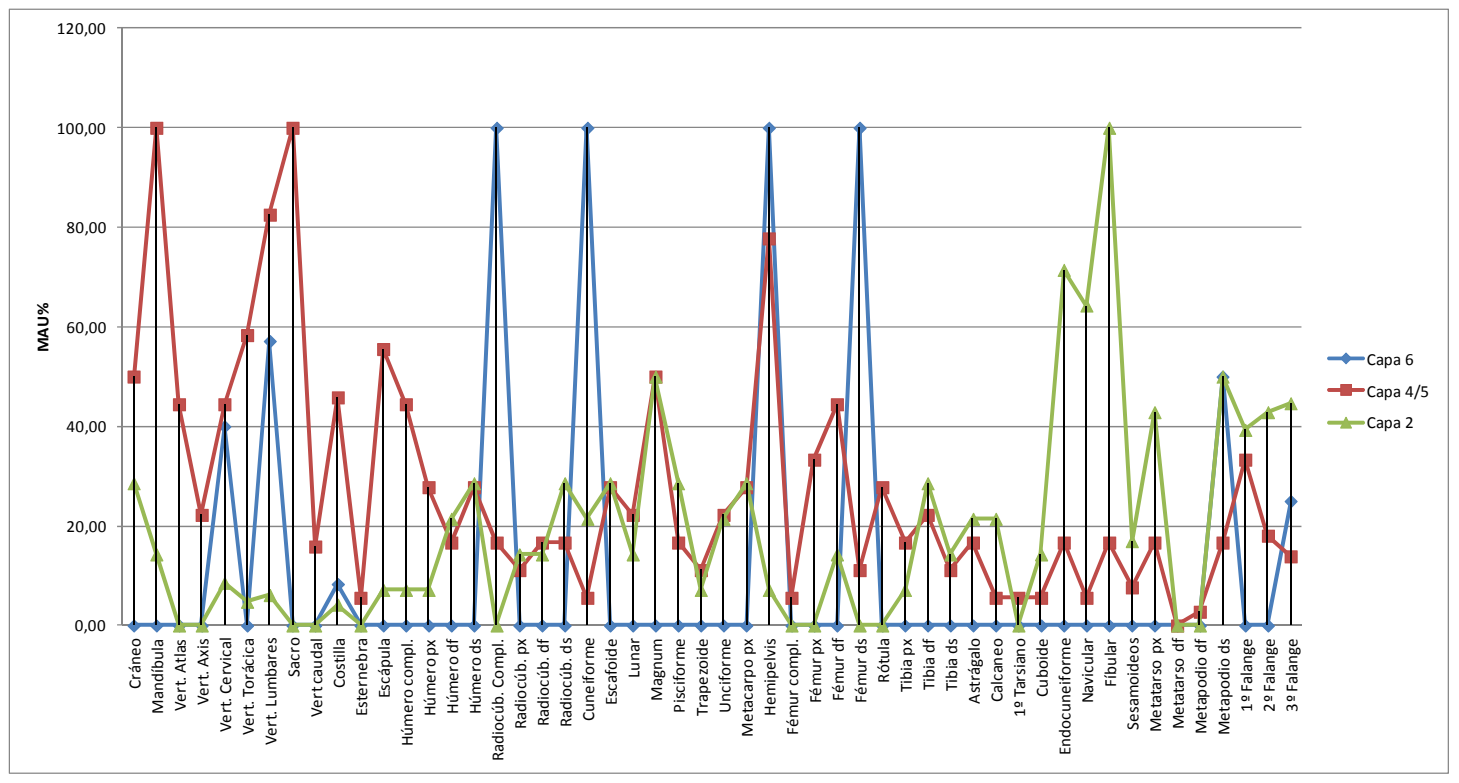

Figura 8.33. Representación de partes anatómicas de guanaco en AEP-1.

La diferencial representación de unidades anatómicas en cada conjunto también muestra diferencias cuando se correlacionan los valores de MAU\% con los de los índices de utilidad de carne (Borrero 1990; Lyman 1992) y con la DO. Los resultados sugieren distintas alternativas de interpretación en términos de transporte selectivo y preservación. En ese sentido las frecuencias de Capa 4/5 podrían haber resultado de una estrategia focalizada en el transporte de unidades de alto rendimiento y donde los procesos de destrucción mediados por densidad no parecen haber influido fuertemente en la representación de partes. Por su parte, el conjunto de Capa 2 reflejaría una estrategia en la cual se transportaron unidades de bajo valor económico, pero aquí parece haber más chances de que los procesos de destrucción mediados por densidad hayan afectado la preservación del conjunto. Algo diferente ocurre con el conjunto de Capa 6 donde la ausencia de correlación de las unidades anatómicas tanto con la DO como con los índices de utilidad, no sugiere ninguna alternativa clara para su interpretación; en este caso, esta situación de equifinalidad puede estar relacionada al tamaño de la muestra. Los análisis tafonómicos realizados nos permitieron discutir en qué medida estos patrones de representación están reflejando decisiones humanas de transporte. 
El análisis de la meteorización de las superficies óseas muestra una tendencia similar hacia una mayor representación de estadios bajos (de 0 a 2) para los tres conjuntos. En todos se registra un perfil homogéneo que evidencia un enterramiento sincrónico. Sin embargo, en cada conjunto, una frecuencia escasa de especímenes se registra en estadio 3. Las distintas causas que pueden producir esta mayor meteorización de algunos especímenes manifiesta la principal diferencia entre los conjuntos. Mientras que en Capa 6, esta situación podría estar relacionada a la menor densidad de algunas partes anatómicas en las que se registra la mayor meteorización. En Capa 2, dado que su registro se vincula a partes de mayor densidad y correspondientes a huesos largos, parecería estar más relacionada a la elevada fragmentación antrópica que presenta el conjunto. Esta fragmentación que resulta del alto procesamiento de las presas podría haber afectado la preservación del conjunto, a esto se suma la existencia de un drenaje deficiente del suelo que se evidencia en la superficie ondulada del techo de Capa 2. Este mal drenaje podría haber acentuado la meteorización de los especímenes a partir de la existencia de ciclos con mayor humedad. De todas formas, no se descarta que otros factores que aquí no están siendo profundizados también puedan haber causado meteorización diferencial entre los especímenes (Borrero 2007; Massigoge et al. 2010).

El escaso, y en algunos casos, dudoso registro de modificaciones atribuibles al agente carnívoro en los tres conjuntos (Figura 8.34), avala la hipótesis de que el principal agente acumulador fue el humano. Según la propuesta de Borrero (1989-90) para estos primeros momentos del poblamiento del área, la expectativa sería la de encontrar una mayor incidencia de los carnívoros y roedores que en momentos posteriores. La información paleoambiental (Capítulo 2) indica que para estos momentos tempranos distintas especies de carnívoros habitaban el área, entre ellos cánidos como Pseudalopex sp. (Miotti 1998) y Dusicyon sp. (Frank 2011) y félidos como el Puma (Felis concolor) (Miotti 1998) y Panthera sp. (Frank 2011). Sin embargo, el bajísimo registro de marcas de carnívoros que se presenta tanto en la Capa 6 como en la Capa 4/5, cuando la expectativa de encontrarlas es mayor (Borrero 1989-90), sugiere que la acción de estos animales sobre el registro ha sido despreciable. 


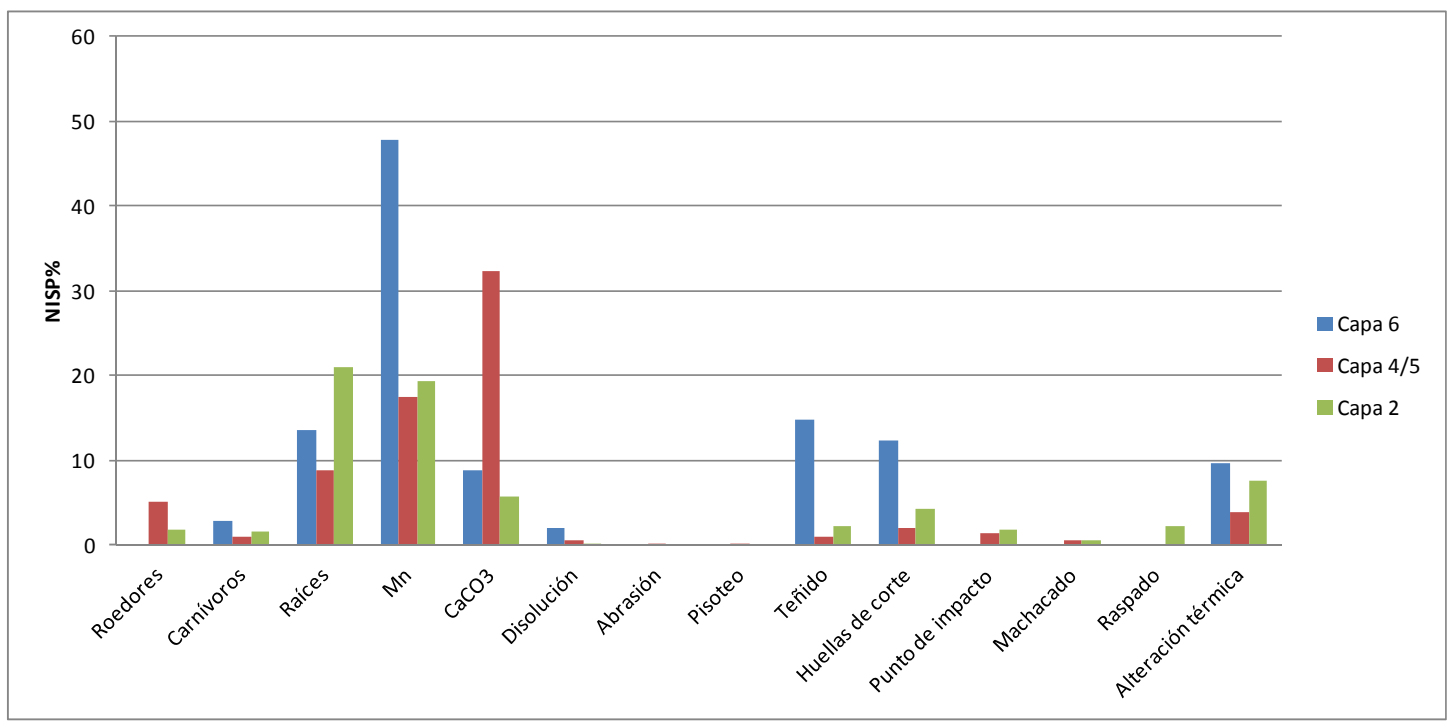

Figura 8.34. Variabilidad tafonómica en AEP-1.

Por otro lado, la acción de los roedores, ausente en el conjunto de Capa 6, fue registrada en baja frecuencia en los otros dos conjuntos (Figura 8.34). Esta baja representación de restos óseos con marcas de roedores, indica que estos agentes habrían tenido una baja incidencia sobre el conjunto. Si bien durante las excavaciones no se reconocieron galerías ni túneles que indiquen la actividad fosorial de estos animales, no se descarta que su acción se haya podido producir luego de que el conjunto fuese sepultado. Estas observaciones coinciden con lo registrado en trabajos previos por Miotti et al. (1999) con una muestra menor de materiales de estos conjuntos.

Las modificaciones naturales que parecen haber afectado un mayor porcentaje de restos en este sitio son las que en principio podrían estar vinculadas a las características del afloramiento en el que se emplaza el sitio y al proceso de pedogénesis que originó el paleosuelo del que provienen los tres conjuntos estudiados. Entre estas modificaciones encontramos las improntas de raíces, los depósitos de manganeso y los de carbonato. Si bien estas tres modificaciones se registraron en los tres niveles de ocupación, en cada uno de ellos alcanzan frecuencias diferentes (Figura 8.34).

En la Capa 6 los depósitos de manganeso sobre los restos óseos constituyen las modificaciones más importantes del conjunto, esto posiblemente pueda deberse a la descomposición de la roca de caja con la que entra en contacto y con las variaciones del nivel freático (Zárate et al. 2000). A su vez, esto puede haber influido en el mayor grado de fosilización que presenta el conjunto. La alta frecuencia de estos depósitos en este nivel podría indicar condiciones relativas de mayor humedad que en las Capas 2 y 4/5. 
Por otro lado, si bien los depósitos de carbonato se registraron en los tres conjuntos, estos son muy espesos y frecuentes en la Capa 4/5. Este tipo de sales, al igual que el manganeso, provienen de la disolución de sedimentos o rocas carbonáticas como la coquina de la roca de caja. En este caso particular, los bloques del derrumbe del techo del alero que apoyan sobre Capa 4 seguramente hayan sido una fuente principal de aporte de carbonato a este conjunto cuya disolución es favorecida por procesos pedogenéticos (Courty et al. 1989; Gutiérrez 2004; López-González et al. 2006). El proceso de pedogénesis a partir del cual se habrían diferenciado los distintos horizontes del perfil de AEP-1 habría comenzado entre el Holoceno temprano y Holoceno medio (entre 10.000 y 7000 años AP) (Zárate et al. 2000: 59). El agua necesaria para que estas sustancias sean transportadas pudo proceder del escurrimiento superficial o de las posibles variaciones del nivel freático que pudieron afectar los niveles más profundos del depósito, en contacto directo con la roca base (Zárate et al. 2000). No se descarta un aporte mixto para los manganesos que podría también haberse liberado como resultado de la descomposición de materia orgánica (Marín Arroyo et al. 2008; Shahack-Gross et al. 1997). Este aporte de manganesos sería más esperable en la Capas 2 y 4/5. En la primera avalada por encontrarse en un horizonte con características húmicas, la segunda por la presencia de moteado de manganeso en el material del Horizonte IIB31 (Capa 4) y por el registro de unidades anatómicas articuladas formando pilas. Sería probable entonces que el apilamiento de partes con tejido blando adherido a los huesos haya provocado óxido-reducción por desnaturalización de materia orgánica en descomposición, depositando el manganeso sobre los huesos. La presencia de ambos depósitos no sugiere una perturbación sobre la distribución de los restos óseos, pero si marca una reorganización de la coloración y consistencia de las superficies corticales pudiendo en algunos casos favorecer la pérdida del material.

Las improntas de raíces se registraron en porcentajes más elevados en el conjunto de la Capa 2 (Figura 8.34) y podrían indicar la existencia de una cobertura herbácea en el momento en que los huesos fueron descartados (Montalvo 2002). Esta mayor representación en Capa 2 podría estar vinculada a las características de horizonte húmico ya que parecen haberse producido en los primeros etapas de depositación del conjunto. El cual, no obstante, se depositó en un ambiente árido correspondiente a la cronología del depósito y a posteriori fue re-trabajado por las raíces cuando los proxy palinológicos del sitio indican el avance de la vegetación graminosa por sobre la estepa arbustiva en el ámbito de la cuenca (Borromei 2003). 
El registro de modificaciones de las superficies óseas permite sostener que en los tres conjuntos el principal agente acumulador de los restos óseos ha sido el antrópico. Entre las modificaciones atribuidas al agente humano, se destacan las claras huellas de corte en los tres conjuntos (Figura 8.34). Estas modificaciones se registran en mayor frecuencia en el conjunto de Capa 6. Sin embargo, en los especímenes de las Capas 4/5 y 2, además de huellas de corte, se observó aunque en bajos porcentajes, la presencia de puntos de impacto (Figura 8.34). Estas modificaciones vinculadas al procesamiento secundario de las presas y relacionado a la fracturación intencional de los huesos y al acceso a la médula ósea, se relacionan con el alto porcentaje de fracturas intencionales $(>$ 63\%) en estos conjuntos. Asimismo, el registro de marcas de raspado y machacado en el conjunto de Capa 2 (Figura 8.34), parece estar indicando un mayor procesamiento de los guanacos en el sitio durante el Holoceno medio y se encuentra avalado por el elevado índice de fragmentación aquí estimado (MNE/NISP=0,47).

Un alto porcentaje de fracturas atribuibles al agente humano se observa en los tres conjuntos indicando actividades de procesamiento secundario y acceso a la médula ósea. Es probable que en los conjuntos de las Capas 6 y 4/5 esta fracturación intencional de los huesos refleje un consumo ocasional de médula ósea. Por su parte, la fracturación de los huesos largos en el conjunto de Capa 2 podría indicar, además del consumo de médula ósea, la obtención de formas base para la confección de artefactos óseos. La mayor representación en Capa 2 de elementos correspondientes a las porciones distales de los miembros, sugiere un consumo de médula seleccionada (Morin 2007; Rindel 2009). Esta observación estaría relacionada a la proporción de ácido oleico que contienen estas grasas y cuya concentración es mayor cuanto más distales son los elementos apendiculares, lo que las transforma en grasas más fáciles de digerir y más "palatables” (Morin 2007). De esta forma, estas unidades sin contenido de carne se vuelven apetecibles para su transporte. Sin embargo, la presencia de artefactos óseos confeccionados sobre elementos distales de los miembros (Figuras 8.31a y 8.31b) sugiere que estas partes también pudieron ser transportadas y fracturadas con estos fines. Esta información avala la hipótesis de un uso integral de los guanacos durante el Holoceno medio en AEP-1. Asimismo, la elevada fragmentación registrada en este conjunto y la variedad de marcas de procesamiento en los huesos sugiere actividades de consumo y descarte (De Nigris 2004). La menor variedad de marcas de procesamiento en los conjuntos de las Capas 6 y 4/5, a diferencia de lo que se observa en Capa 2, sugieren el desarrollo de actividades más limitadas. 
Las modificaciones por alteración térmica sobre los huesos fueron registradas en los tres conjuntos (Figura 8.34), observándose los mayores porcentajes de restos quemados en las Capas 6 y 2. En el caso de Capa 6, los especímenes óseos quemados alcanzan la mayor densidad en el sector correspondiente a la cuadrícula B. Esta distribución coincide con los sectores donde se registró la presencia de materiales líticos termoalterados (Cattáneo 2002), por lo tanto la hipótesis de que el sector de la cuadrícula B pudo corresponder con un área de fogón parecería válida. En el caso de los especímenes quemados en el conjunto del Holoceno medio (Capa 2), la mayor densidad se registra en las cuadrículas $\mathrm{H}$ e I sugiriendo la existencia de una posible área de combustión en el sector actualmente más protegido del sitio. Una concentración menor de restos quemados se registró en el sector sur de la cuadrícula B. Esta última coincide con el sector del que procede la muestra de carbones fechados y por lo tanto también correspondería a un área de fogón. Por otro lado, en el conjunto de Capa 4/5 se registró un bajo porcentaje de especímenes óseos quemados, ellos se encuentran distribuidos en la cuadrícula H y sur de L. Una concentración menor se registra en las cuadrículas G y F. Este último sector sería el único que coincidiría con la expectativa sugerida por Cattáneo (2002) para áreas de fogón.

Estos sectores con mayor densidad de restos óseos quemados, a partir de los que podríamos inferir áreas de combustión en los tres momentos de ocupación de AEP-1, además indicarían áreas de actividades dentro del sitio. $\mathrm{Si}$ consideramos como se distribuyen estas modificaciones, encontramos que en Capa 6, la mayor cantidad de especímenes con huellas de corte se registran en el sector correspondiente a la cuadrícula L (Figura 8.9c) mientras que los huesos quemados se registran en la cuadrícula B (Figura 8.9d). Esta distribución podría estar indicando áreas de actividades diferentes dentro del sitio una vinculada con actividades de procesamiento (cuadrícula L) y la otra con la posible presencia de fogones. Respecto de la distribución de las modificaciones en Capa 4/5 estas se concentran principalmente entre la cuadrícula L y E (Figura 8.18) asociadas a los sectores de pilas lo que refuerza la idea de un área de descarte luego del procesamiento de los guanacos. En el caso del conjunto de Capa 2, los sectores de mayor densidad de especímenes con huellas de corte (Figura 8.28c) y la distribución de restos óseos quemados (Figura 8.28d) coinciden. Esta superposición podría estar indicando dos sectores en los cuales se pudieron desarrollar actividades vinculadas al consumo y descarte en torno a áreas de fogones; los cuales corresponderían a la cuadricula $\mathrm{B}$ y el sector de las cuadrículas $\mathrm{H}$ e I respectivamente, este último con mayor cantidad de 
materiales podría indicar un mayor uso de ese sector del sitio.

La variedad y frecuencia con que se registran los diferentes patrones de modificación evidencian que la historia tafonómica del sitio fue compleja ya que refleja la existencia tanto por procesos depositacionales como post-depositacionales. Sin embargo, no quedan dudas de que el principal agente acumulador del contexto fueron los humanos como resultado de las prácticas cinegéticas y de procesamiento de presas en el lugar.

Entre los procesos y agentes post-depositacionales, los depósitos de manganeso y carbonato son los que han sido determinados en mayor frecuencia y que han afectado en mayor medida al Componente Inferior (Capas 6 y 4/5). Mientras que el principal agente post-depositacional en la Capa 2 fue la acción de raíces y el drenaje deficiente del suelo que se registra a partir de la superficie ondulada de su techo (Figura 8.3b).

En cuanto a las formas de uso del espacio del sitio, tanto el conjunto de la Capa 6 como el de la Capa 4/5 de AEP-1 corresponden al primera etapa del poblamiento registrada en el área, la Fase de Colonización (Miotti y Salemme 1999). El conjunto de Capa 6 es el más antiguo de la secuencia ocupacional (entre ca. 12.000 y 10.500 años AP). Para este momento en el sitio se habrían desarrollado actividades relacionadas principalmente al procesamiento de megamamíferos (Hippidion saldiasi y Mylodon sp.), rheidos y camélidos (guanaco y L. gracilis). La distribución de huesos y de las modificaciones de las superficies óseas de los camélidos permiten proponer dos áreas principales de actividades. Una de ellas localizada en el sector de las cuadrículas L y F, allí se habrían depositado restos óseos que resultan de actividades vinculadas al procesamiento primario y secundario de los camélidos. El otro sector individualizado se centra fundamentalmente en la cuadrícula $\mathrm{B}$, allí se concentró la mayor cantidad de restos óseos quemados y por lo tanto se presenta como una probable área de fogón. Esta distribución de los restos óseos y modificaciones, sumados a la amplitud de los fechados radiocarbónicos obtenidos para este conjunto (ca. 2000 años) nos abre dos posibilidades para su interpretación. Una sería que todo el conjunto es resultado de un mismo evento de ocupación del alero, durante el cual existió una estructuración del espacio interior del sitio: un área destinada al procesamiento de las presas y otra donde pudo existir un pequeño fogón; siendo posible que esta ocupación del alero haya sido relativamente breve. La otra alternativa es considerar que el conjunto pudo ser resultado de más de un evento ocupacional. Durante estas ocupaciones, también breves, se habrían desarrollado actividades específicas relacionadas al procesamiento de las presas. Estas posibilidades deberán ser evaluadas a la luz de nuevas evidencias y profundización de algunos de los 
análisis aquí realizados.

De esta manera, el conjunto de la Capa 6 se ajusta a la expectativa del modelo de poblamiento del área que propone para esta etapa inicial, la existencia de grupos humanos pequeños con una estrategia económica generalista centrada en la caza del guanaco y complementada por un amplio rango de recursos (Borrero 1994-95; Miotti 1998; Miotti y Salemme 1999). De esta misma forma, la información presentada brinda soporte a las hipótesis propuestas para el sitio acerca de su funcionamiento como un locus de actividades limitadas vinculado al procesamiento primario de presas cazadas en la cercanía del sitio (Miotti y Salemme 2005; Miotti et al. 1999). A partir de los resultados aquí presentados, se propone además, la hipótesis de un procesamiento secundario ocasional de los camélidos en relación a un esporádico consumo de médula ósea. Asimismo, se formula la idea de la existencia de dos áreas de actividad que bien podrían haber funcionado de forma simultánea: una como un área de procesamiento y la otra alrededor de un fogón, aunque cabe la posibilidad de que hayan sido usadas diacrónicamente.

Por otro lado, el conjunto de la Capa 4/5 cuyos fechados radiocarbónicos (ca. 10.400- 9200 años AP) lo ubican durante la misma etapa de poblamiento que la Capa 6 (transición Pleistoceno-Holoceno al Holoceno temprano ver Capítulo 2). En este caso, la evidencia presentada también avala la hipótesis previa (Miotti y Salemme 2005; Miotti et al. 1999) que sugiere que, al igual que Capa 6, corresponde a un locus de actividades limitadas relacionadas casi exclusivamente al procesamiento primario y en parte secundario de los guanacos. Las unidades anatómicas representadas de estos ungulados reflejan una estrategia de transporte de partes con alto rendimiento económico. Sin embargo, la presencia en el sitio de todos los elementos anatómicos de los guanacos (Tabla 8.5), sugiere que habrían sido transportados enteros, lo que implicaría que los guanacos habrían sido cazados cerca del sitio. Claramente la presencia de partes del esqueleto articuladas o en asociación primaria estaría indicando que muchas de las actividades estuvieron relacionadas a un procesamiento primario de los guanacos, cosa que también se ve sustentada por la gran cantidad de elementos del esqueleto apendicular enteros, la presencia de partes de alto peso (cintura pélvica) y la baja frecuencia de marcas de procesamiento.

A diferencia de lo que ocurre en la Capa 6, el conjunto de la Capa 4/5 no estaría evidenciando una estrategia generalista como suponen los modelos de poblamiento propuestos para el área (Borrero 1994-95; Miotti 1998; Miotti y Salemme 1999). Que el 
guanaco alcance el 80\% de representación en el conjunto, seguido por los rheidos (5\%), sugiere que la estrategia desarrollada para este momento se asemeja más a la esperada para el Holoceno medio que para la etapa anterior. Esta estrategia se caracterizaría por estar centrada en el recurso guanaco (Miotti y Salemme 1999) y en AEP-1 comenzaría a evidenciarse hacia ca. 10.000 años AP.

El conjunto de la Capa 2 (ca. 7700-7400 años AP) corresponde a la segunda etapa de poblamiento planteada para el área; los modelos propuestos (Miotti y Salemme 1999) sugieren un cambio de estrategia respecto de la desarrollada en la transición PleistocenoHoloceno y el Holoceno temprano. Aquí la estrategia se habría focalizado en la caza de guanacos, y los rheidos habrían jugado un papel complementario de estos ungulados.

El conjunto de Capa 2 parece responder a un sitio donde se realizaron actividades principalmente vinculadas al procesamiento más bien secundario de los guanacos y donde se observa un aprovechamiento integral de los mismos. Esto podría traducirse en una estrategia de especificación (Bettinger 1991; Koyama y Uchiyama 2006) y potenciación (Miotti 1998; 2012) del recurso guanaco. Este aprovechamiento incluiría consumo de médula y manufactura de artefactos. El uso del espacio del sitio estaría indicando un área principal de actividades bajo el alero (cuadrículas H, I y J) y un área menor en la cuadrícula B. 


\section{CAPÍTULO 9}

\section{DISCUSIÓN DE LA VARIABILIDAD ZOOARQUEOLÓGICA Y TAFONÓMICA}

En este capítulo se compara, discute e interpreta la variabilidad tafonómica y zooarqueológica de la cuenca de los Zanjones Rojo y Blanco (Meseta Central de la provincia de Santa Cruz), a partir de los resultados obtenidos del estudio de los sitios Alero el Puesto 1(AEP-1) de Piedra Museo y Cueva Maripe (MA) de La Primavera. El primero de estos sitios está ubicado en el sector bajo de la cuenca del Zanjón Rojo, el segundo en el sector de cabecera del Zanjón Blanco (ver Capítulo 2). La base de la información que aquí se compara proviene de los resultados presentados en los Capítulos 7 y 8 de esta tesis y las discusiones se realizan considerando la información generada para el área de estudio a partir de otras investigaciones y sintetizada en los Capítulos 2, 3, 4 y 5.

Ambos sitios corresponden a contextos estratigráficos dentro de abrigos rocosos y registran amplias secuencias ocupacionales que van desde la transición PleistocenoHoloceno al Holoceno tardío (Tablas 7.1 y 8.1).

Con el objetivo de comparar la variabilidad zooarqueológica y tafonómica en los distintos sectores de la cuenca, los mismos criterios metodológicos y técnicos se aplicaron en el análisis de las arqueofaunas de ambos sitios. Se compararon los resultados entre los conjuntos con cronologías similares, para ello se consideraron las propuestas realizadas para Patagonia acerca de las distintas etapas del poblamiento del área (Borrero 1989-90, 1994-95; Miotti y Salemme 1999, 2004).

\subsection{DIVERSIDAD Y RIQUEZA TAXONÓMICA. IMPLICANCIA EN LA UTILIZACIÓN DE LA FAUNA}

En total se analizaron 12.561 especímenes óseos correspondientes a los 10 conjuntos zooarqueológicos. Los rangos cronológicos a los que corresponden cada uno 
de estos conjuntos muestran que los distintos sectores de la cuenca (baja y alta) estuvieron ocupados desde la transición Pleistoceno-Holoceno hasta el Holoceno tardío. Sobre la base de la cronología obtenida en los dos sitios analizados, el área correspondiente a la cuenca baja y donde se emplaza AEP-1, es el que presenta evidencias de las ocupaciones más tempranas. Luego, aunque también para momentos tempranos, se registran las ocupaciones en el sector de cabeceras, Cueva Maripe, donde continúan incluso hasta momentos del Holoceno tardío (Figura 9.1).

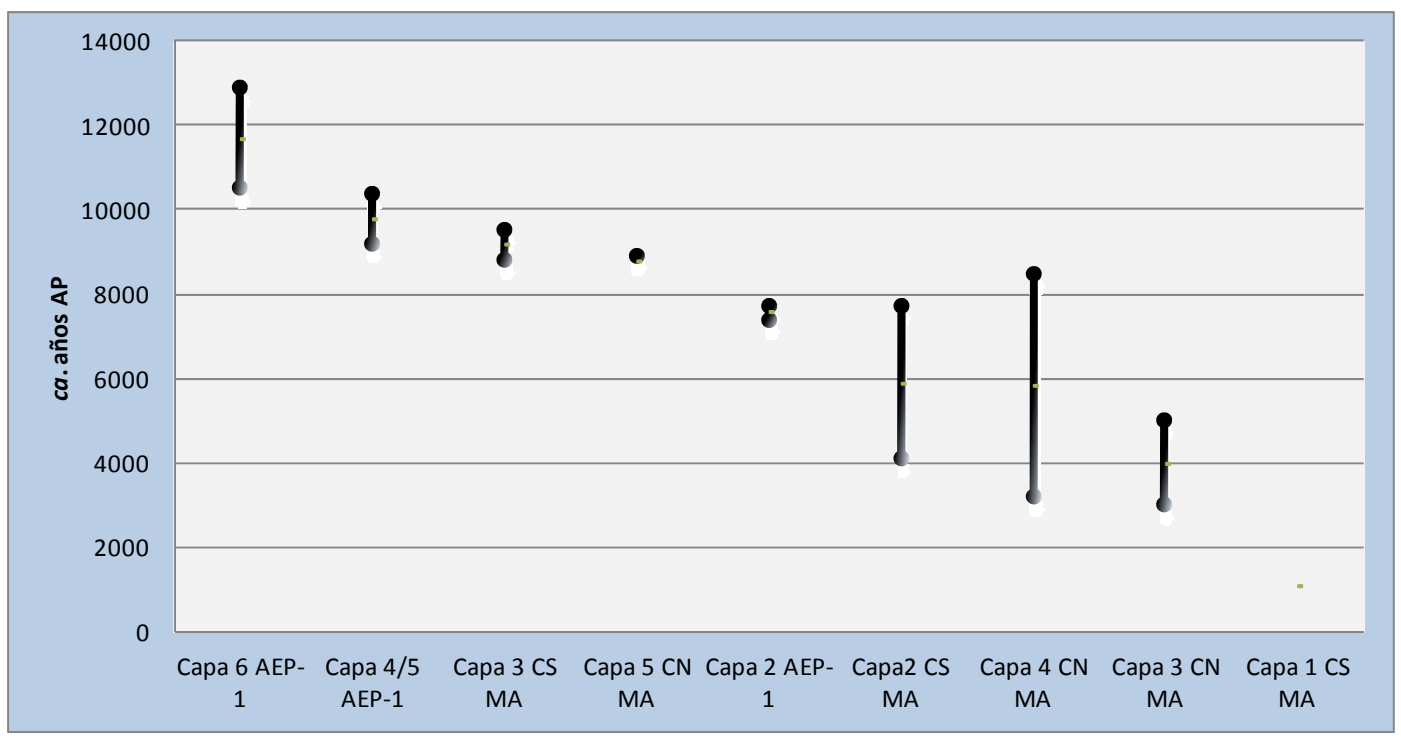

Figura 9.1. Rango cronológico de los conjuntos de AEP-1 y MA.

Los resultados obtenidos (ver Capítulo 7 y 8) muestran que en los dos contextos estudiados (AEP-1 y MA) el guanaco fue el recurso más abundante para los distintos momentos de ocupación en la cuenca estudiada (Figura 9.2). Esta tendencia concuerda con lo observado por otros investigadores en distintos sitios de Patagonia (Aguerre y Pagano 2003; Borrero 1986, 1990a; De Nigris 2004; De Nigris y Mengoni Goñalons 2004; Mengoni Goñalons 1999; Miotti 1998; Miotti et al. 1999, 2007; Rindel 2009 y bibliografía citada en el Capítulo 3) y Pampa (Martínez y Gutiérrez 2004 y bibliografía allí citada).

El registro de marcas de procesamiento, alteración térmica y presencia de artefactos óseos en los distintos conjuntos estudiados, indica que además de los guanacos, otros recursos fueron utilizados por los cazadores-recolectores. Entre ellos, y para los momentos tempranos del poblamiento del área, encontramos evidencias de aprovechamiento de fauna pleistocénica extinguida. Por otro lado, los rheidos, las aves de 
tamaño mediano y los cánidos muestran evidencias de uso a lo largo de toda la ocupación de la cuenca. Otras especies identificadas en los sitios como el zorrino, los roedores y pequeños reptiles, se encuentran escasamente representados y carecen de indicadores que sugieran su incorporación al registro por decisiones antrópicas. Lo mismo ocurre con los restos de puma y dasipódidos, aunque de estos últimos se recuperaron placas dérmicas quemadas. Sin embargo, debido a que las crónicas etnográficas y etnohistóricas destacan la importancia de estos recursos (puma y dasipódidos) para los grupos humanos del pasado, por el momento decidimos considerarlos recursos potencialmente aprovechados. Los nuevos materiales que están siendo procesados, contribuirán a comprender el rol de estos recursos en el pasado de las poblaciones que habitaron el área.

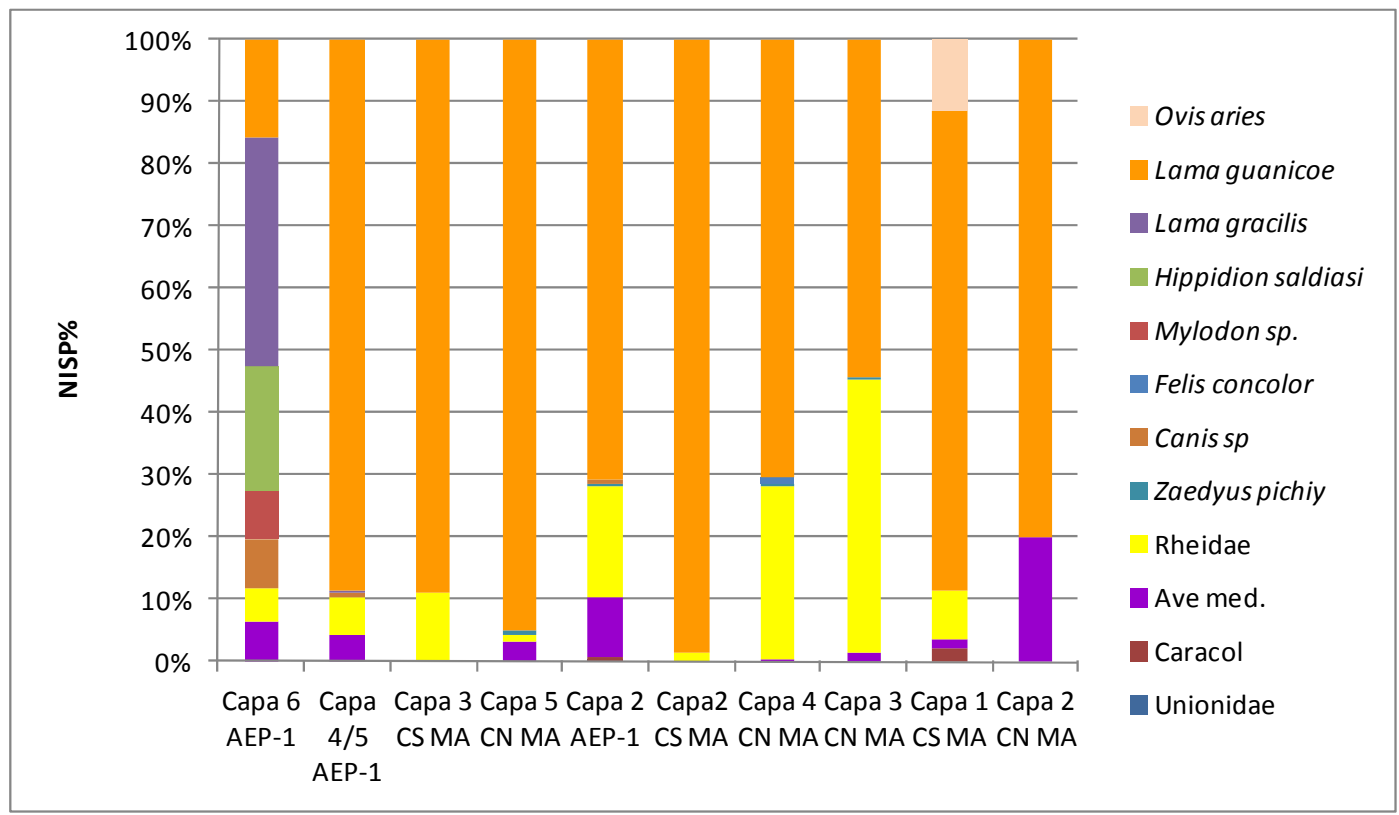

Figura 9.2. Diversidad taxonómica de especies utilizadas por los cazadores-recolectores en la Cuenca de los Zanjones Blanco y Rojo en la Meseta Central de Santa Cruz.

De todos los conjuntos, el correspondiente a la Capa 6 de AEP-1 (ca. 12.80010.500 años AP) es el que presenta la mayor diversidad de taxa utilizados por los cazadores-recolectores (Figura 9.2). Luego de este período, la tendencia general que se observa en la cuenca muestra una focalización en el recurso guanaco y una reducción de la diversidad de especies utilizadas. Desde los inicios de la ocupación de la cuenca el interés estuvo puesto en especies de alto retorno como son los megaherbívoros pleistocénicos y los camélidos. Hacia fines del Holoceno tardío se registra un aumento en 
la diversidad de especies utilizadas en CS de MA, este incremento estaría vinculado a la ocupación post-hispánica que se registra en la cueva ya que corresponde con la utilización de Ovis aries y la incorporación de fragmentos de caracoles. El registro de rheidos se observa en todos los conjuntos con excepción de los correspondientes del Holoceno tardío. Esto indicaría que estas aves estuvieron disponibles y fueron utilizadas por los habitantes de la cuenca desde los inicios de su poblamiento. Sin embargo, y aunque no podemos descartar que esté relacionado a una cuestión de preservación del registro, la presencia de fragmentos de cáscaras de huevo solamente se registra para momentos finales del Holoceno temprano (Capa 4 de $\mathrm{CN}$ ) y durante el Holoceno medio (Capa 3 y 4 de CN en MA y Capa 2 de AEP-1). Desconocemos si el registro de estos fragmentos está vinculado al consumo de los huevos, o si eran incorporados al registro con otros fines como puede ser su utilización como contenedores. Sin embargo, su presencia en estos momentos estaría indicando una utilización de esta especie distinta a la que se registra en momentos previos. Los rheidos han sido utilizados como un recurso adicional en los distintos momentos de ocupación de la cuenca. Esta observación, realizada en distintos sitios de Patagonia (Aschero 1981-82; Frank 2011; Miotti 1998; Paunero 2009; Paunero et al. 2007; Miotti y Salemme 1999; Silveira 1979; Tambussi y Tonni 1985) es la que les brinda un rol complementario en los modelos de poblamiento del área (Borrero 1989-90; Miotti y Salemme 1999, 2005; entre muchos otros). La presencia de cáscaras de huevo, además, nos plantea la posibilidad de que algunas de estas ocupaciones puedan haberse desarrollado en primavera- verano, lo que coincide con la época de reproducción de estas aves. Sin embargo, hasta el momento no disponemos de otros indicadores de estacionalidad por lo que esta observación solo constituye un supuesto que deberá ser evaluado a partir de la búsqueda de nuevas evidencias. No obstante, la elevada frecuencia de restos óseos de rheidos en los tres momentos de ocupación del alero AEP-1, muestran una diferencia con lo que se observa en MA. Mientra que en AEP-1 el registro de restos óseos es abundante, en MA es escaso, ya que, los mayores valores de NISP para estas aves se obtuvieron a partir de fragmentos de cáscara de huevo. Por otro lado, mientras que en MA solamente se recuperaron elementos del esqueleto apendicular de los rheidos, en AEP-1 se encontraron elementos axiales como vértebras, con claras huellas de corte. Estas diferencias pueden estar relacionadas con distintas causa como la disponibilidad del recurso en cada sector de la cuenca, las estrategias de caza y consumo de los grupos, entre otras, más difícilmente creemos se deba a problemas de preservación del registro. De todas formas, la frecuencia de huesos de rheidos de AEP-1 no concuerda 
con lo recurrentemente registrado en el área patagónica, por el contrario, en este sitio las frecuencias son muy elevadas, diferenciándose por lo tanto, del perfil taxonómico macroregional. Esta evidencia plantea nuevos interrogantes ya que existen muchos contextos zooarqueológicos en secuencias estratigráficas dentro de abrigos rocosos. De algún modo, estas condiciones particulares de reparo en el ámbito de la Patagonia extra-andina permitiría esperar similares frecuencias del taxón en ellos. Sin embargo, en la información presentada fundamentalmente en el capítulo 3, se observa que la frecuencia de estas aves en esos sitios es inferior a 15 especímenes en cada uno (ver Paunero et al. 2007). Entonces, si esta diferencia numérica, entre AEP-1 con los demás sitios no responde a preservación diferencial microambiental, tendríamos que esperar decisiones humanas diferentes en el aprovechamiento de este recurso. Esta pregunta sólo podrá ser respondida a medida que se genere información cuantitativa similar a la producida en esta tesis para evaluar la hipótesis.

La disminución de la diversidad de especies utilizadas que se registra en los conjuntos zooarqueológicos ca. 10.000 años AP coincide, como señalan varios autores (Borrero 1989-90, 2009; Miotti 1998; Miotti y Salemme 1999) con el momento en que las poblaciones de fauna Pleistocénica ya reducidas se extinguen (ca. 9500 años AP). Seguramente, por ese motivo, es que en las ocupaciones de la cuenca posteriores a los 10.000 años AP no se registran estos grandes herbívoros, observándose una tendencia de especificación (Bettinger 1991; Koyama y Uchiyama 2006) hacia el guanaco y que continúa durante el Holoceno medio tanto en la cuenca baja como en el sector de cabeceras. Esta focalización en el recurso guanaco fue propuesta tanto para la región patagónica como para la región pampeana como resultado de una estrategia de caza especializada en estos ungulados (Borrero 1994-95; Martínez y Gutiérrez 2004; Miotti 1998; Miotti y Salemme 1999). En el caso de la cuenca de los Zanjones Rojo y Blanco creemos que ya hacia el ca. 10.000 años AP el registro indica tal especialización por parte de los grupos cazadores-recolectores que la habitaron. En otras localidades de la región, como Casa del Minero 1 (Paunero et al. 2007), Cerro Tres Tetas (Frank 2011) y Cueva 3 de Los Toldos (Miotti 1998), hacia esta misma fecha también se evidencia la importancia del guanaco como principal recurso económico.

El registro de $L$. gracilis en la cuenca llega hasta momentos más tardíos que los de Hippidion saldiasi y Mylodon sp.. Sin embargo, su presencia corresponde a escasos especímenes en la Capa 4/5 de AEP-1 con antigüedades de entre ca. 10.400- 9200 años AP. Si bien los fechados obtenidos en la Capa 3 de CS de MA (ca. 9500 años AP) se 
solapan con los de Capa 4/5 de AEP-1, en MA hasta el momento no se han registrado restos de estos camélidos. Posiblemente estos registros de AEP-1 estén relacionados a los fechados más tempranos de esta capa, sin embargo, no descartamos la posibilidad de que la ausencia de registro en MA pueda estar vinculada con características etológicas o de distribución de esta especie y que por tratarse de una especie extinguida solo pueden ser inferidas. Se destaca que escasos ejemplares de L. gracilis, Hemiauchenia sp. e Hippidion sp. fueron registrados solo en las localidades de Los Toldos, El Ceibo (Miotti 1998), y en sitios de La María (Frank 2011; Paunero 2003a, 2003b). Esta distribución geográfica, más allá de la funcionalidad que puedan haber tenido los sitios, y de la diferencia temporal entre ellos (entre 12 ka y 9 ka AP), indica que el uso indiscutido de camélidos y équidos del Pleistoceno se dio en la Meseta Central, mientras que en sitios de pie de cordillera y sitios costeros no hay registros de fauna extinguida. Por otro lado, el rango temporal de ocupación parece haber comenzado en la Meseta Central mientras que en la cordillera las ocupaciones muestran una tendencia ocupacional más tardía (Salemme y Miotti 2008). Esta información ya marca una tendencia regional que estaría indicando las mayores chances de aprovechamiento de los últimos individuos de poblaciones pleistocénicas en el este (Macizo del Deseado), a diferencia del sector andino cuando el poblamiento parece haber sido logrado en momentos en que esta fauna ya no estaba disponible. Otro enclave particular con evidencias de uso de fauna extinguida se daría en la cuenca magallánica (Borrero 2009; Salemme y Miotti 2008). El estudio de estas discontinuidades forma parte de nuestra agenda de investigación.

Las aves indeterminadas corresponden a aves de tamaño mediano tipo anátido, cuya frecuencia se incrementa hacia el Holoceno tardío aunque se las encuentra en ambos sitios en los distintos momentos en que fueron ocupados (Figura 9.2). Las marcas de procesamiento son muy escasas en este grupo, siendo los cilindros óseos decorados en MA las piezas más destacables de acción humana (Figura 7.27). Por otro lado, la caza de aves podría haberse dado para el aprovisionamiento de plumas. En componentes del Holoceno medio de la Cueva 3 de Los Toldos y de Cueva Grande de Arroyo Feo se registran plumas de ñandú así como escasos restos óseos de esas aves (Miotti 1998; Silveira 1979). Plumas de falcónidos también fueron recuperadas en Cerro Casa de Piedra 5 (Aschero 1981-82); en tal sentido podríamos suponer que el uso de las plumas no haya implicado el consumo alimenticio de algunas aves, y que su uso estuvo dirigido a la manufactura de ornamentos. En dicho caso, las chances de encontrar huesos de aves con marcas serían bajísimas, pero debido a la recurrencia de restos de aves en casi todos 
los sitios y a la oferta de materia prima específica es que consideramos a estos recursos como potencialmente importantes.

Otro agente que podría haber incorporado las aves de tamaño mediano a los sitios son los carnívoros como los zorros y los pumas, sin embargo, y sobre la base de los resultados obtenidos en PM y MA (Capítulos 7 y 8), la frecuencia de marcas es muy baja, y además, sólo se registran en especímenes de mamíferos. Por tales motivos, consideramos que estos restos de aves de tamaño mediano fueron incorporados al registro por acción humana.

De todas formas, la presencia de restos de estas aves en el registro estaría indicando su disponibilidad en la cuenca, cuya presencia se vincula a la existencia de cuerpos de agua.

Los cánidos fueron utilizados por los cazadores-recolectores desde el Pleistoceno final. Tanto la presencia de artefactos confeccionados sobre huesos largos como la alteración térmica de algunos de sus elementos, sugieren el interés de los grupos que habitaron la cuenca sobre este taxón. Desconocemos hasta el momento si los cánidos formaron parte de la dieta de estos cazadores pero su presencia en ambos sitios indica que al menos fueron utilizados como materia prima en la producción de artefactos. Casos similares se documentaron entre cazadores-recolectores de la Amazonía colombiana para el uso de huesos, pieles y dientes de jaguares (Panthera onca). Sin embargo, etnoarqueológicamente se demuestra que estos grupos de la floresta tropical no cazan ni consumen carne de jaguares, sino que el uso de las partes arriba mencionadas resulta de la apropiación de animales muertos (Politis y Saunders 2002).

Si bien los restos de Felis concolor (puma) son escasos y sólo fueron recuperados en CN de MA (Figura 9.2), las crónicas indican que los cazadores los consumían y utilizaban sus cueros (Claraz 1988; Musters 1964). Por tal motivo y a la espera de nueva evidencia que está siendo procesada, es que también los consideramos con chances de haber sido aprovechado por estos grupos humanos.

La presencia de dasipódidos es recurrente en casi todos los sitios de la meseta y a lo largo del Holoceno; sin embargo, las partes esqueletarias de estos edentados son escasas apoyando la tendencia de un uso restringido u ocasional de los mismos. Este registro arqueológico es contradictorio con el relato de crónicas y la información etnográfica en las que se pone de manifiesto el aprecio que por su carne y grasa, al menos en momentos del Holoceno tardío, tenían las poblaciones patagónicas por estos recursos. Una de las formas más estandarizada y que recurrentemente aparece en estos documentos es la 
cocción de estos animales directamente sobre las brasas; la coraza actuaba a modo de contenedor y por tal motivo las placas quedaban quemadas. Si bien la evidencia en los sitios estudiados es muy escasa, la presencia de placas quemadas estaría en concordancia con la idea de cocción de esta fauna.

Se estimó la riqueza relativa de especies para los distintos conjuntos estudiados y sus resultados se ordenaron con diferentes criterios que permitieron evaluar las posibles causas de tal variación (Figuras 9.3a y 9.3b). Se observa que la riqueza relativa de especies estimada a partir de los conjuntos estudiados en la cuenca no guarda relación con la variable cronológica (Figura 9.3a). Sin embargo, cuando esa información es ordenada siguiendo un criterio decreciente de la abundancia taxonómica relativa (Figura 9.3b), se observa que estos valores varían en relación con el lugar de procedencia del conjunto estudiado. De esta manera se reconoce la mayor riqueza taxonómica para los conjuntos que provienen de AEP-1. Probablemente esto pueda estar relacionado a las características del emplazamiento de cada uno de los sitios y que seguramente guarde relación con la mayor biodiversidad de microambientes lénticos y de humedales (Willig 1991). Mientras que AEP-1 se localiza a orillas de un paleolago, en un ambiente abierto y que seguramente funcionó como atractor de diferentes especies, MA se encuentra en un cañadón profundo y encajonado por altos farallones de meseta y con un extenso mallín en la base. Si bien el recurso agua actualmente se encuentra altamente disponible a partir de la presencia de manantiales, aguadas y mallines en esta localidad (Magnin 2010). La topografía más accidentada y cerrada que caracteriza a la cuenca alta respecto del nivel de base (ver Capítulo 2), posiblemente haya influido diferencialmente en la biodiversidad disponible en cada uno de los sectores de la cuenca. De tal manera, creemos que la mayor riqueza taxonómica que se registra en los conjuntos de AEP-1 pudo estar vinculada a una mayor oferta de recursos del ambiente de la cuenca baja, y a las probabilidades de que los mismos hayan constituido recursos de acceso inmediato, disponibles en las inmediaciones del paleolago. En la cuenca alta (MA), si bien el atractor agua está presente, su acceso presenta condiciones de riesgo mayores para las potenciales presas ya que las vías de escape de depredadores son más restringidas debido a las abruptas pendientes y al gran desnivel entre la base del mallín y las planicies de la meseta alta adyacente. El sitio MA, como se dijo en el Capítulo 7, se encuentra al borde del mallín y a unos $540 \mathrm{msnm}$, mientras que el borde de la meseta en este sector se encuentra arriba de los $650 \mathrm{msnm}$. AEP-1 se encuentra unos $140 \mathrm{msnm}$, el alero enfrenta al paleolago, el cual tiene una amplitud de ca. 2,5 km circundado por zonas de playas 
bajas que ofrecen vías de escape rápidas, y el campo visual desde estos aleros es de amplias panorámicas (Magnin 2010).

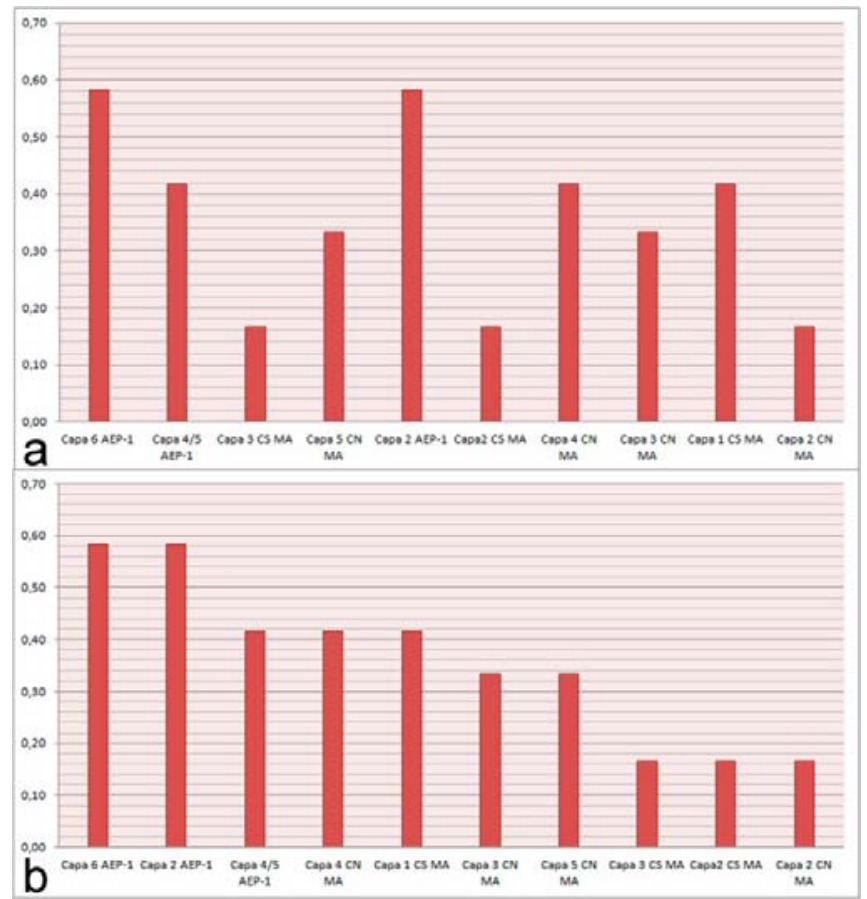

Figura 9.3. Riqueza relativa de especies utilizadas en los sitios AEP-1 y MA (cuenca de los Zanjones Blanco y Rojo, Meseta Central de Santa Cruz): a) Frecuencias ordenadas según la cronología de los conjuntos. b) Frecuencias ordenadas en forma decreciente. Valores expresados en frecuencia relativa de NTaxa (Grayson 1991).

\subsection{COMPARACIÓN DE LA VARIABILIDAD ZOOARQUEOLÓGICA Y TAFONÓMICA REGISTRADA EN LA CUENCA}

La exploración de las características tafonómicas en las diferentes unidades de análisis se basó en la comparación de las mismas variables taxonómicas, anatómicas y tafonómicas representadas de forma estandarizada entre todos los conjuntos. 


\begin{tabular}{|c|c|c|}
\hline VARIABLES & DESCRIPCIÓN & ESCALA \\
\hline NSP & Frecuencia absoluta de especímenes óseos & $0-3000$ \\
\hline NISP & $\begin{array}{l}\text { Frecuencia absoluta de especímenes óseo determinados anatómica o } \\
\text { taxonómicamente }\end{array}$ & $0-3000$ \\
\hline NISP\% Ave med. & Frecuencia relativa de especímenes de ave tamaño anátido & $0-100$ \\
\hline NISP\% Rheidos* & $\begin{array}{l}\text { Frecuencia relativa de especímenes correspondientes a Rheidae (óseos y } \\
\text { cáscaras de huevo) }\end{array}$ & $0-100$ \\
\hline NISP\% Zaedyus Pichiy & Frecuencia relativa de especímenes de Zaedyus Pichiy & $0-100$ \\
\hline NISP\% Canis sp. & Frecuencia relativa de especímenes de cánido & $0-100$ \\
\hline NISP\% Felis concolor & Frecuencia relativa de especímenes de Puma & $0-100$ \\
\hline NISP\% SP. Extiguidas & $\begin{array}{l}\text { Frecuencia relativa de especímenes correspondientes a fauna extinguida: } \\
\text { Hippidion saldiasi, Mylodon sp., Lama gracilis }\end{array}$ & $0-100$ \\
\hline NISP\% Guanaco & Frecuencia relativa de especímenes de Guanaco & $0-100$ \\
\hline MNI Guanacos & Número mínimo de individuos guanacos identificados en el conjunto & $0-20$ \\
\hline Perfil etario $^{* *}$ & $\begin{array}{l}\text { Frecuencia porcentual de especímenes de hueso largo correspondientes a } \\
\text { individuos cría o juveniles }\end{array}$ & $0-100$ \\
\hline Axial/ Apendicular (NISP) *** & $\begin{array}{l}\text { Relación que indica qué representación de especímenes axiales existe en el } \\
\text { conjunto respecto de los apendiculares }\end{array}$ & $0-2$ \\
\hline Axial/ Apendicular (MNE) ${ }^{* * * *}$ & $\begin{array}{l}\text { Relación que indica qué representación de elementos axiales existe en el } \\
\text { conjunto respecto de los apendiculares }\end{array}$ & $0-2$ \\
\hline Fragmentación (MNE/NISP) & Índice de fragmentación MNE/NISP & $0-1$ \\
\hline Huellas de corte & $\begin{array}{l}\text { Frecuencia porcentual de especímenes óseos (axiales y apendiculares) con } \\
\text { presencia de huellas de corte }\end{array}$ & $0-100$ \\
\hline Marcas de machacado & $\begin{array}{l}\text { Frecuencia porcentual de especímenes óseos (axiales y apendiculares) con } \\
\text { presencia de marcas de machacado }\end{array}$ & $0-100$ \\
\hline Puntos de impacto ${ }^{* * * *}$ & $\begin{array}{l}\text { Frecuencia porcentual de especímenes de hueso largo con presencia de } \\
\text { puntos de impacto }\end{array}$ & $0-100$ \\
\hline Marcas de percusión ${ }^{* * * *}$ & $\begin{array}{l}\text { Frecuencia porcentual de especímenes de hueso largo con presencia de } \\
\text { marcas de percusión }\end{array}$ & $0-100$ \\
\hline Marcas de raspado ${ }^{* * * * *}$ & $\begin{array}{l}\text { Frecuencia porcentual de especímenes de hueso largo con presencia de } \\
\text { marcas de raspado }\end{array}$ & $0-100$ \\
\hline Surco perimetral ${ }^{* * * * *}$ & $\begin{array}{l}\text { Frecuencia porcentual de especímenes de hueso largo con presencia de } \\
\text { fractura transversal por surco perimetral }\end{array}$ & $0-100$ \\
\hline Fracturas antrópicas ${ }^{* * * * *}$ & $\begin{array}{l}\text { Frecuencia porcentual de fracturas antrópicas identificadas en especímenes } \\
\text { de hueso largo }\end{array}$ & $0-100$ \\
\hline Instrumentos/adornos & Cantidad de artefactos óseos formatizados & $0-10$ \\
\hline Alteración térmica & $\begin{array}{l}\text { Frecuencia porcentual de especímenes óseos (axiales y apendiculares) con } \\
\text { signos de alteración térmica }\end{array}$ & $0-100$ \\
\hline Meteorización > 2 & $\begin{array}{l}\text { Frecuencia porcentual de especímenes óseos con meteorización mayor al } \\
\text { estadio } 2\end{array}$ & $0-100$ \\
\hline Roedores & $\begin{array}{l}\text { Frecuencia porcentual de especímenes óseos (axiales y apendiculares) con } \\
\text { marcas de roedores }\end{array}$ & $0-100$ \\
\hline Carnívoros & $\begin{array}{l}\text { Frecuencia porcentual de especímenes óseos (axiales y apendiculares) con } \\
\text { marcas de carnívoros }\end{array}$ & $0-100$ \\
\hline Raíces & $\begin{array}{l}\text { Frecuencia porcentual de especímenes óseos (axiales y apendiculares) con } \\
\text { improntas de raíces }\end{array}$ & $0-100$ \\
\hline Manganeso & $\begin{array}{l}\text { Frecuencia porcentual de especímenes óseos (axiales y apendiculares) con } \\
\text { manchas de manganeso }\end{array}$ & $0-100$ \\
\hline Carbonatos & $\begin{array}{l}\text { Frecuencia porcentual de especímenes óseos (axiales y apendiculares) con } \\
\text { manchas depósitos de carbonato }\end{array}$ & $0-100$ \\
\hline Disolución química & $\begin{array}{l}\text { Frecuencia porcentual de especímenes óseos (axiales y apendiculares) con } \\
\text { signos de disolución química }\end{array}$ & $0-100$ \\
\hline Abrasión & $\begin{array}{l}\text { Frecuencia porcentual de especímenes óseos (axiales y apendiculares) con } \\
\text { signos de abrasión }\end{array}$ & $0-100$ \\
\hline Pisoteo & $\begin{array}{l}\text { Frecuencia porcentual de especímenes óseos (axiales y apendiculares) con } \\
\text { marcas de pisoteo }\end{array}$ & $0-100$ \\
\hline Teñido & $\begin{array}{l}\text { Frecuencia porcentual de especímenes óseos (axiales y apendiculares) } \\
\text { ennegrecidos y cuyo agente causal no pudo ser identificado }\end{array}$ & $0-100$ \\
\hline \multicolumn{3}{|c|}{${ }^{*}$ Las frecuencias de NISP de rheidos incluyen los fragmentos de cáscara de huevo. } \\
\hline \multicolumn{3}{|c|}{$\begin{array}{l}\text { **Perfil etario: se estimó como el porcentaje de huesos largos sin fusionar en el conjunto (Mengoni Goñalons 1999). Está basado en el MNE y se } \\
\text { estima sobre el total de huesos largos, falanges px y calcáneo. Como elementos sin fusionar solo fueron considerados los que fusionan antes de los } \\
24 \text { meses y nos podrían indicar la presencia de individuos cría o juveniles en el conjunto (Kaufmann 2009). }\end{array}$} \\
\hline ***En la estimación de esta relación se & excluyeron los dientes sueltos (Mengoni Goñalons 1999) & \\
\hline
\end{tabular}

Tabla 9.1. Variables y escalas consideradas en la construcción de los arqueotafogramas. 
La comparación se realizó a través de una técnica gráfica diseñada originalmente por Behrensmeyer (1991) y a la cual Lyman (1994) hace referencia con el nombre de "arqueotafograma". Los arqueotafogramas son herramientas usadas para realizar comparaciones estandarizadas de diferentes acumulaciones óseas a partir de atributos tafonómicos seleccionados como variables que pueden presentar diferentes estados o valores, permitiendo esta técnica, utilizar datos nominales, ordinales y escalas de intervalos (Lyman 1994; Mengoni Goñalons 1999).

Los arqueotafogramas resumen la información tafonómica de cada conjunto mostrando cómo se comporta cada variable de forma individual y en relación a las otras. El análisis comparativo se realizó sobre la base de 33 variables, la escala definida para cada variable fue la misma en los distintos conjuntos (Tabla 9.1).

\subsubsection{Transición Pleistoceno/Holoceno-Holoceno Temprano}

Se comparan los conjuntos de Capa 6 y Capa 4/5 de AEP-1 y de Capa 3 de CS de MA y Capa 5 de CN de MA que según sus cronologías (Figura 9.1) corresponden a los registros generados por los primeros grupos de cazadores-recolectores que habitaron esta cuenca.

Tres de los cuatro conjuntos muestran una tendencia similar en cuanto a tamaño del conjunto (NSP) y frecuencias de especímenes determinados (NISP) a alguna categoría taxonómica (Figura 9.4). Esta tendencia se diferencia de lo que se observa en el conjunto de Capa 4/5 de AEP-1 tanto porque presenta un número de especímenes muy elevado como por una muy buena resolución taxonómica.

La representación de especies que se registra permite observar que el conjunto de Capa 6 de AEP-1 se diferencia de los restantes debido a que, como se mencionó anteriormente, es donde se registra la mayor frecuencia de especímenes de fauna pleistocénica con claras marcas de procesamiento (Figura 9.4). Si bien creemos que las estrategias uso de los camélidos y los caballos se diferencian de la practicada con los milodontinos, su lugar como recursos económicos explotados por las sociedades cazadoras-recolectoras en el sector de base de la cuenca y durante los primeros años de colonización del área es evidente. Luego, y seguramente vinculado con la extinción de 
estos grandes herbívoros, el foco se habría trasladado a la captura de guanacos. De todas formas, existió un claro interés en el aprovechamiento de recursos de alto retorno económico.

Los guanacos, si bien están presentes en todos los conjuntos, en el de Capa 6 de AEP-1 adquieren una frecuencia relativa menor en relación a la mayor representación que alcanzan las especies extinguidas. De todas formas, para estos momentos se observa que los guanacos habrían sido el recurso económico base desde los inicios del poblamiento de la cuenca (Figura 9.4). Los rheidos y las aves de tamaño mediano se muestran como recursos complementarios desde los inicios de la ocupación de la cuenca. En la cuenca baja (AEP-1), para estas instancias del poblamiento los cánidos fueron utilizados, desconocemos si han sido consumidos, sin embargo la presencia de huesos quemados e instrumentos óseos sobre hueso largo indican su importancia en el pasado.

El conjunto de Capa 4/5 de AEP-1 es el que presentan la mayor cantidad de especímenes óseos y un alto MNI de guanacos en relación a lo observado en los otros conjuntos de este lapso temporal. Estas diferencias podrían estar indicando una ocupación más recurrente del lugar.

Los perfiles de edad a partir del estado de fusión de los huesos largos, indican que para este momento solamente en la CS de MA se habría registrado la presencia de individuos cría o juveniles (Figura 9.4), mientras que en los otros contextos no se identificaron individuos cría y/o individuos menores a 24 meses.

En cuanto a los patrones de representación de partes anatómicas del guanaco, la tendencia en la cuenca para estos momentos indica una mayor incidencia de partes del esqueleto apendicular de los guanacos. Esta representación podría estar influida por la fragmentación de los conjuntos ya que la alta diferencia numérica entre partes del esqueleto axial y apendicular representados en Capa 6 de AEP-1, en Capa 5 de CN y Capa 3 de CS de MA (Figura 9.4), marcaría un uso preferencial de aquellas unidades del esqueleto apendicular. Esto estaría mediado por la mayor tendencia de fragmentación en el esqueleto axial y además por el sesgo muestral de CS de MA que estaría sobredimensionando las partes del esqueleto axial (Figura 9.4). Sin embargo, los índices indican que esa fragmentación ha sido baja en todos los conjuntos. Entre ambos sitios, los conjuntos menos fragmentados corresponden a los de AEP-1.

La presencia de marcas vinculadas a la fragmentación intencional de los huesos como los puntos de impacto y las marcas de percusión y raspado, se registran en frecuencias más elevadas en los conjuntos de MA, lo que es concordante con el mayor 
procesamiento de las presas en estos conjuntos (Figura 9.4).

La presencia de huellas de corte, fracturas antrópicas y alteración térmica de los especímenes se registra en todos los conjuntos de la cuenca para este lapso temporal (Figura 9.4). Sin embargo, los conjuntos de MA presentan una mayor variedad y cantidad de marcas, esto podría estar indicando diferencias en las actividades culturales desarrolladas en cada sector de la cuenca. Lo compartido de estas prácticas de procesamiento estaría dado por el alto porcentaje de fracturas antrópicas para el acceso a la médula ósea en los conjuntos de ambos sitios. Estas marcas de procesamiento podrían estar indicando el desarrollo de actividades distintas en cada localidad. La mayor frecuencia y variedad de marcas de procesamiento en MA sugiere, con claridad, actividades de procesamiento primario, secundario y probablemente consumo de los guanacos en el sitio, avalado también por una mayor frecuencia de restos óseos quemados asociados a áreas de fogones. Mientras que para los conjuntos de AEP-1 se infieren actividades de procesamiento primario y un ocasional procesamiento secundario que se relaciona con el acceso a la médula de los huesos largos por medio de la fracturación intencional de los huesos. En el conjunto de Capa 6, estas actividades de procesamiento habrían involucrado a la fauna extinguida y a los rheidos registrados en el conjunto y con claras evidencias de aprovechamiento, siendo más difuso en cánidos y dasipódidos.

La presencia de escasos instrumentos óseos en dos de los cuatro conjuntos (Figura 9.4) sugiere que desde fines del Pleistoceno las sociedades cazadoras-recolectoras que habitaron la cuenca conocían la materia prima ósea y su potencial para la manufactura de artefactos (Miotti y Marchionni 2010). Otros sitios tempranos del área como los de la localidad de Los Toldos (Miotti 1998), La María y Cerro Tres Tetas (Paunero et al. 2010) también tienen registros de estas tecnologías óseas aunque, hasta el momento, su definición sobre cadenas operativas es poco detallada.

La comparación de las distintas variables que se refieren a la acción de procesos o agentes naturales, indica que en AEP-1 se registra la mayor incidencia de los mismos (Figura 9.4). Ninguna de las modificaciones registradas en ambos sitios estaría indicando problemas de integridad en los conjuntos.

En general, la tendencia a la meteorización es baja siendo el conjunto de Capa 6 de AEP-1 donde se registra la menor preservación. Sin embargo, esta diferencia puede estar vinculada a que es el conjunto más antiguo y más afectado por la variación del nivel freático, junto con los procesos de presión sedimentaria, y aun también a las 
consecuencias de la pedogénesis.

AEP-1: Capa 6

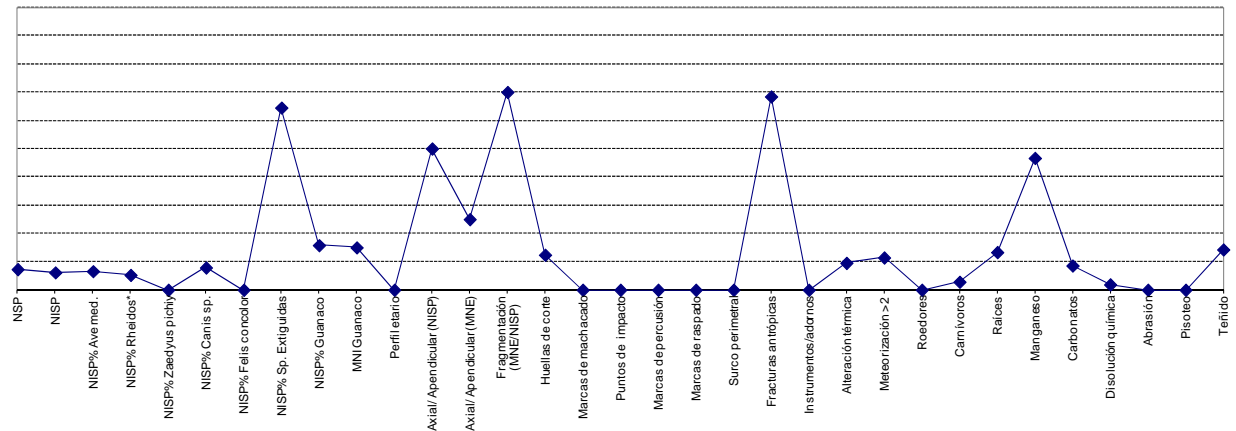

AEP-1: Capa 4/5

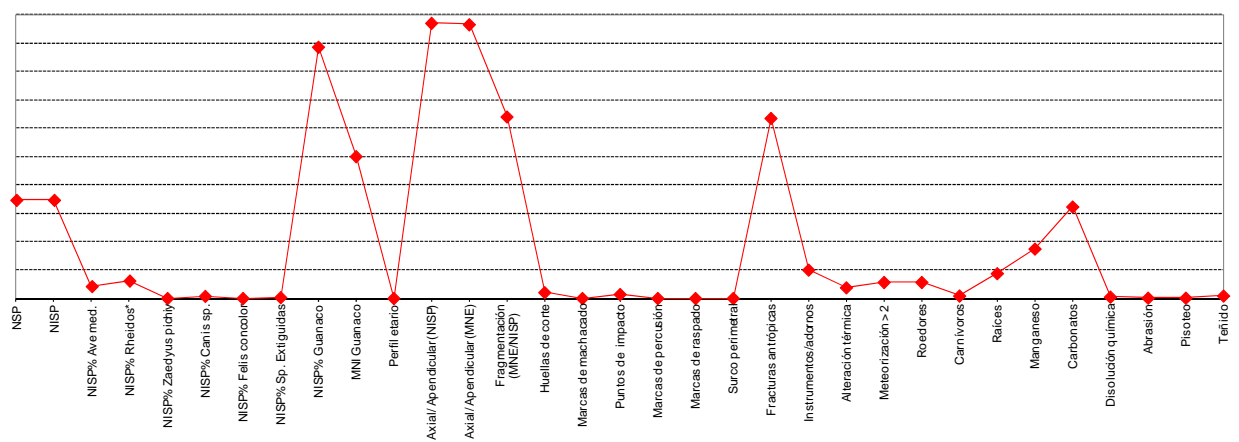

MA: Capa 5 CN

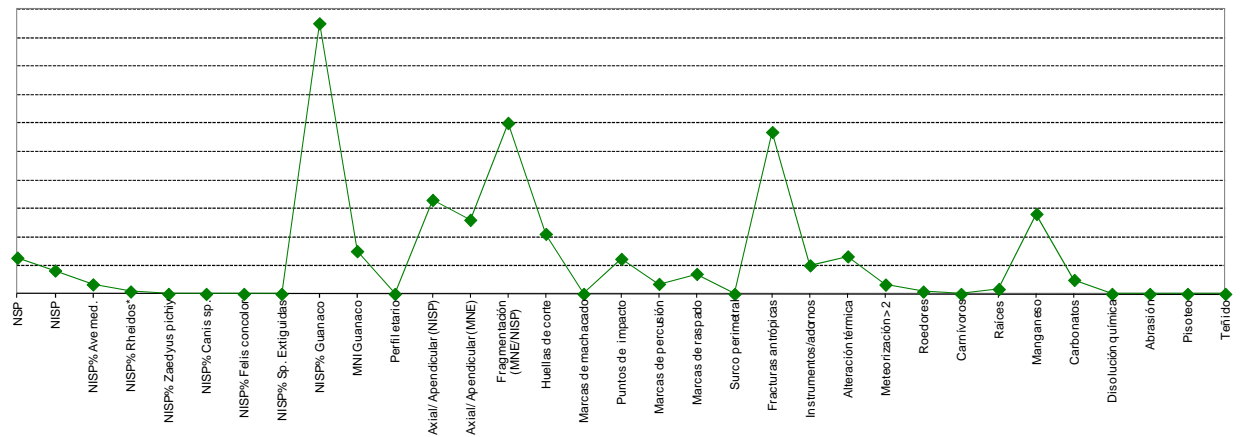

MA: Capa 3 CS

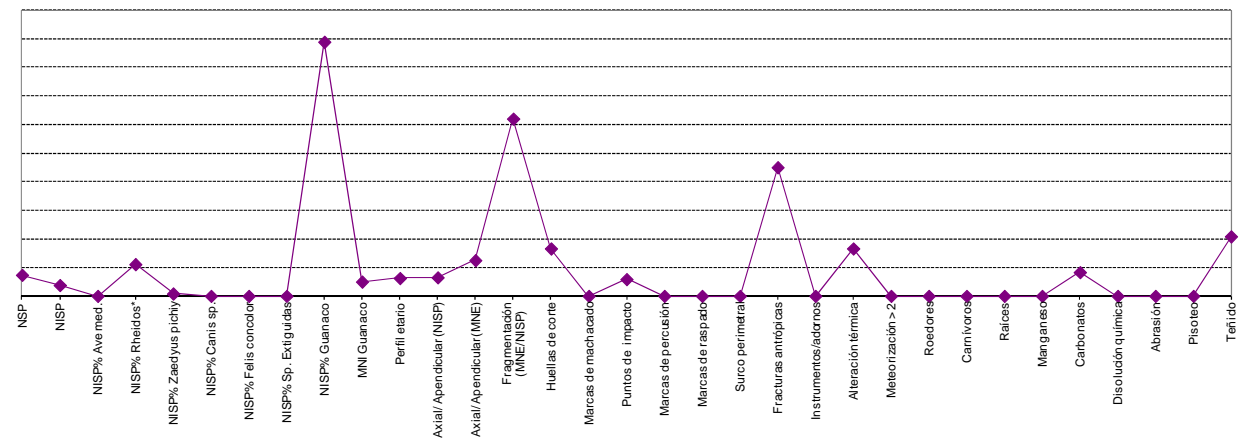

Figura: 9.4. Arqueotafogramas para los conjuntos del Pleistoceno final y Holoceno temprano en la Cuenca de los Zanjones Rojo y Blanco, Meseta Central de Santa Cruz. 
Entre las modificaciones naturales, las manchas de manganeso y los depósitos de carbonato son las que adquieren frecuencias más representativas (Figura 9.49). En términos generales, esto nos estaría indicando que en ambos sitios los conjuntos más antiguos estuvieron expuestos a mayores condiciones de humedad. Sin embargo, la incidencia de estas modificaciones ha sido mayor sobre los conjuntos de AEP-1 que los de MA. Ambos depósitos pudieron haber obliterado las modificaciones de las superficies óseas, ocultando tanto las marcas antrópicas como las de agentes naturales. El conjunto de Capa 4/5 es el que tiene más chances de que la baja frecuencia de marcas esté vinculada a la elevada presencia de depósitos espesos de carbonato. Sin embargo, huellas de corte claras han sido identificadas en todos los conjuntos.

La frecuencia de marcas de carnívoros y roedores muestra una baja tendencia porcentual fundamentalmente en los conjuntos de AEP-1 (Figura 9.4). Su presencia, siempre escasa, avala la buena integridad propuesta para ambos contextos. Lo mismo sucede respecto de la presencia de improntas de pequeñas raíces, si bien se registran en frecuencias bajas, en AEP-1 es donde alcanzan la mayor representación.

Con esta comparación observamos que la mayor cantidad y frecuencia de modificaciones naturales se ha registrado en AEP-1, lo que indicaría en términos relativos, una menor integridad arqueológica que los conjuntos de MA. Si bien la mayor cantidad y variedad de modificaciones antrópicas se cuantificaron en los conjuntos de MA, no podemos descartar la posibilidad que en AEP-1 la elevada frecuencia de depósitos de carbonato y manganeso sobre los huesos y una meteorización levemente superior a la observada en MA, hayan condicionado la preservación de mayor cantidad de marcas antrópicas. Sin embargo, nos inclinamos por proponer que la mayor diferencia registrada en la historia formacional de ambos depósitos está más relacionada a las actividades humanas desarrolladas en ambos lugares y a las características de emplazamiento de cada uno, más que a una supervivencia diferencial de los conjuntos. Es probable, además, que las actividades desarrolladas hayan estado influidas por el entorno inmediato al sitio. En este sentido, la mayor diversidad de especies registradas en AEP-1 nos permite suponer que en ese sector de la cuenca de los zanjones hubo una mayor biodiversidad disponible para los cazadores, con lo que se sostendríamos la hipótesis de que su emplazamiento podría haber correspondido a una "trampa topográfica" con óptimas condiciones para el desarrollo de actividades de acecho, cacerías y procesamiento primario de los animales. Esta idea es acorde con la idea de "Yamnagoo 
Pleistocénico” planteado en trabajos previos (Miotti et al. 1999).

En suma, entre ca. 12.800 y 11.000 años AP la zona del paleolago de Piedra Museo habría estado centrada en las actividades cinegéticas con énfasis en el aprovechamiento de dos camélidos (guanco y L. gracilis), megahervívoros (caballos y perezosos), rheidos y aves de tamaño mediano. Entre ca. 11.000 y 9200 años AP el foco en los guanacos como recurso principal ya se perfila en AEP-1 y ésta es la tendencia que se observa en MA entre ca. 9500 y 8300 años AP. Las diferencias que se identifican conducen a avalar la hipótesis que en AEP-1 se desarrollaron actividades relacionada a la captura y procesamiento primario de estas presas. Es probable que los guanacos hayan sido ingresados enteros al sitio, se haya extraído la carne y descartado, prácticamente enteros los elementos esqueletales, y en algunos casos, partes del esqueleto articulado, en especial aquellas de mayor peso. La baja frecuencia de elementos distales de los miembros sugiere, debido a que son elementos masivos y con alta DO, que los mismos no habrían ingresado al sitio. Este uso del alero difiere de lo que observamos en MA para estos momentos del Pleistoceno final y el Holoceno temprano. En MA la representación casi exclusiva del guanaco, sumado al mayor procesamiento de los restos óseos con áreas de descarte asociadas a los sectores de fogones, indica un sitio de actividades domésticas. Las diferencias en el uso del espacio en MA observadas en el Capítulo 7 indican que en CN se habrían realizados actividades más específicas de procesamiento secundario (trozamiento, cocción y producción de instrumentos y adornos) mientras que la CS parece estar más relacionada a actividades de descarte y consumo.

Posiblemente la mayor incidencia de procesos depositacionales y postdepositacionales en AEP-1 también guarde relación con las características pedológicas de su depósito y con su localización en el nivel de base de la cuenca. Por esos motivos es esperable que algunos procesos como la oxido-reducción, la disolución de la roca carbonática del alero, y las variaciones del nivel freático, estén marcando una diferencia importante respecto de la formación del depósito en MA.

\subsubsection{Holoceno medio}

Se comparan los resultados obtenidos para el conjunto de Capa 2 de AEP-1, y los conjuntos de Capa 3 y 4 de CN y Capa 2 de CS de MA. Los conjuntos de AEP-1 y Capa 
4 de $\mathrm{CN}$ son los de mayor abundancia de especímenes (NSP y NISP) (Figura 9.5). De la cantidad total de restos óseos, en los conjuntos de MA es donde se determinó una menor proporción de los restos óseos. Esa dificultad por asignar una mayor frecuencia de especímenes a alguna categoría taxonómica o anatómica, se relaciona con la fragmentación moderada a alta que registran. Debido a que una alta proporción de las fracturas en diáfisis de huesos largos, coinciden con claros patrones de tipo antrópico, inferimos que el mayor astillamiento de los conjuntos de MA se relaciona con un mayor procesamiento de las presas en este sitio (Figura 9.5).

La utilización de especies durante el Holocenos medio en la cuenca de los Zanjones Rojo y Blanco muestra una tendencia que caracteriza al período a partir de la focalización en el aprovechamiento del guanaco como recurso principal y complementado por rheidos (Figura 9.5). La frecuencia relativa de estas aves se ve incrementada, respecto del período anterior, por la recurrente presencia de fragmentos de cáscaras de huevo. De esta manera, creemos que la mayor abundancia de cáscaras de huevos marca un uso más integral de los rheidos respecto del Holoceno temprano, esta evidencia es suficiente para proponer un posible uso estacional (primavera-verano) de estos recursos en los sitios de la cuenca. En tal sentido, la búsqueda de nuevos indicadores que nos permitan abordar independientemente esta discusión forma parte de la agenda futura de esta tesis.

Las aves de tamaño mediano, aunque en bajos porcentajes, se encuentran representadas tanto en AEP-1 como en MA, alcanzando la mayor frecuencia en el primero de esos sitios (Figura 9.5). Si bien, como se mencionó anteriormente, no sabemos si han sido utilizadas como alimento en primera instancia, la producción de artefactos sobre sus huesos indica la importancia de este recurso como materia prima ósea para la confección de instrumentos y adornos. En otros sitios del área como en los contrafuertes cordilleranos (CCP5) y la meseta (Los Toldos, cueva 3), con fechados para este mismo período, se han documentado plumas tanto de rheidos como de falcónidos (Aschero 1981-82; Miotti 1998; Silveira 1979) que indican el interés de los cazadoresrecolectores por este producto. Sin embargo, en los sitios estudiados en la cuenca no se recuperaron plumas, lo que podría estar indicando que de haber sido ingresadas a los sitios no se habrían preservado en el registro. 


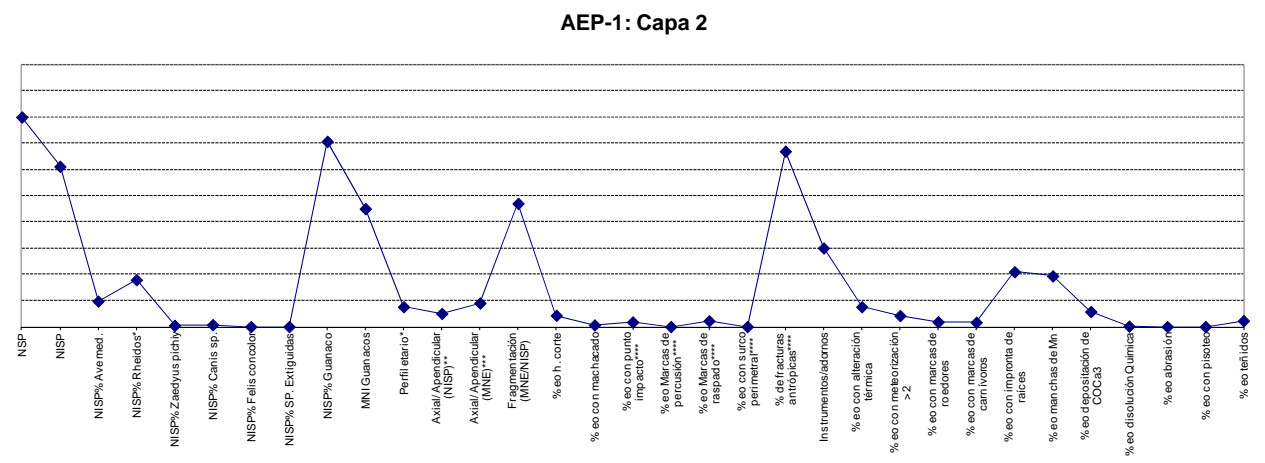

MA: Capa 4 CN

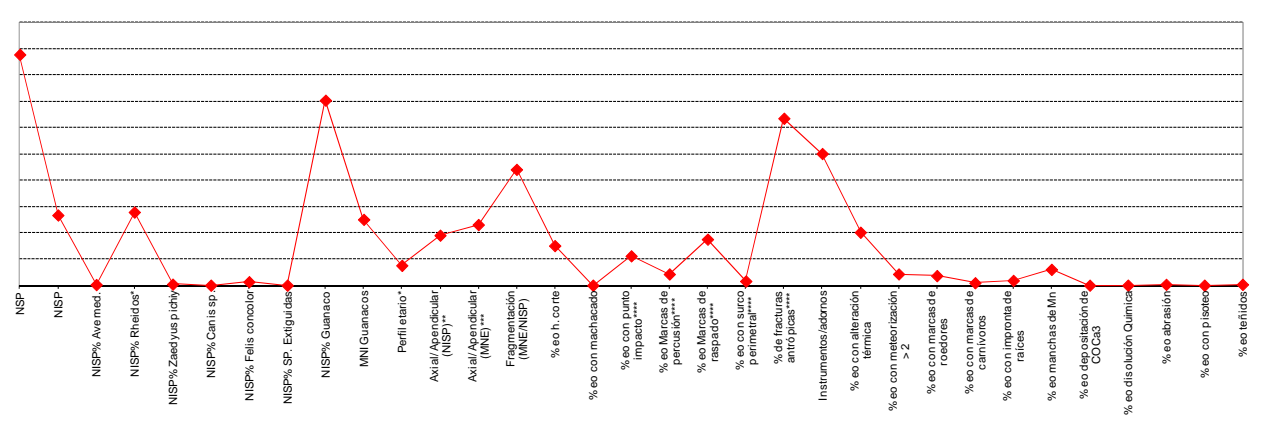

MA: Capa 3 CN
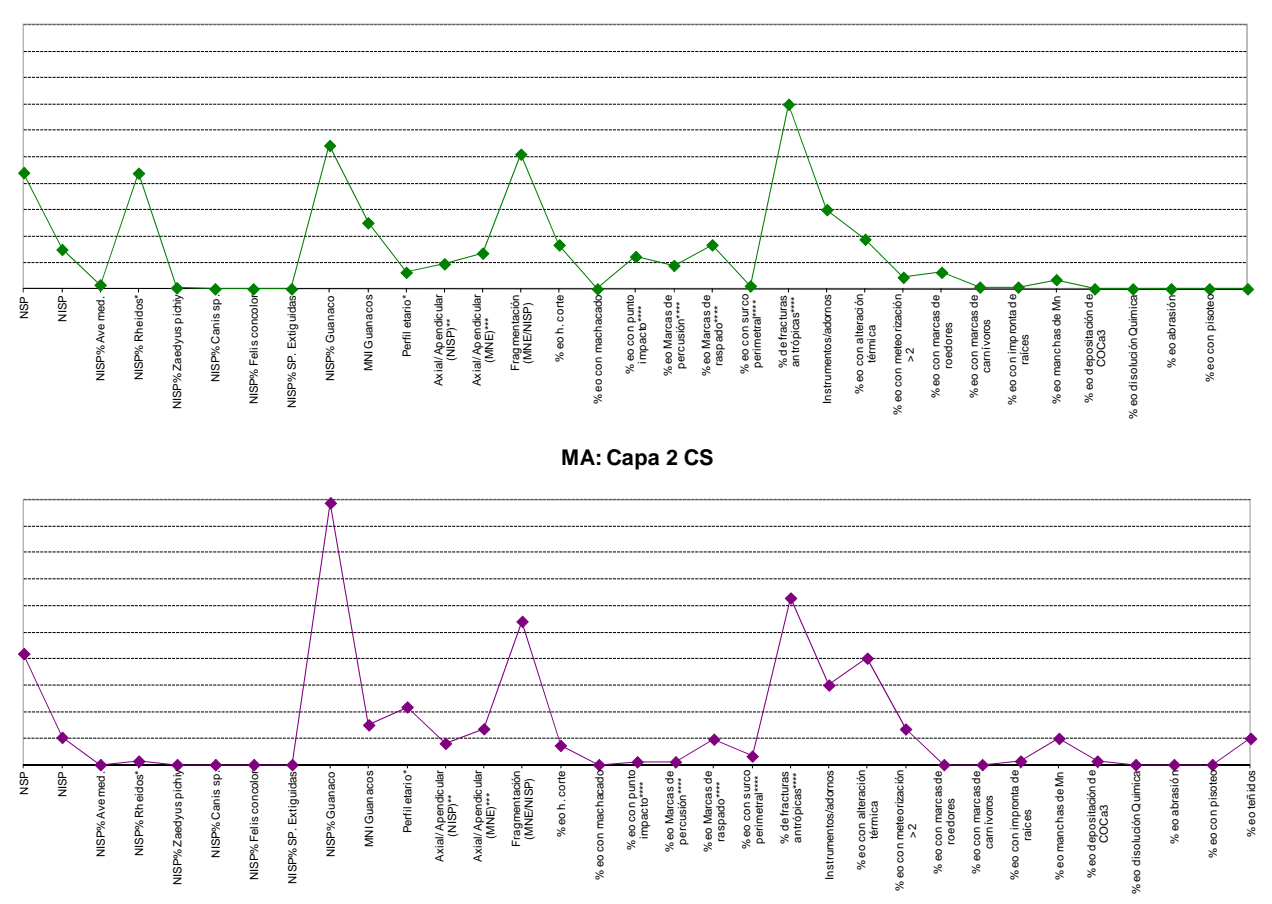

Figura 9.5. Arqueotafogramas para los conjuntos del Holoceno medio en la cuenca de los Zanjones Rojo y Blanco en la Meseta Central de Santa Cruz.

En la Capa 2 de AEP-1 se registra el MNI máximo de guanacos en la cuenca (Figura 9.5), lo que quizá puede estar indicando una mayor recurrencia en el uso que la 
registrada en el sector de cabeceras. Todos los conjuntos para estos momentos registran una frecuencia relativamente baja de elementos de guanaco sin fusionar, que indicarían la presencia de individuos menores a 24 meses (Figura 9.5). A excepción del conjunto de Capa 2 de CS que presenta el mayor de estos porcentajes, no se observa una selección de presas en relación a la edad de las mismas. Si hubiese existido alguna preferencia hacia la captura de individuos inmaduros, las poblaciones que habitaron el Holoceno medio de CS son las que tienen más probabilidad de haber efectuado tal selección. De todas formas, la frecuencia es muy baja y no evidencia un claro patrón de selección de caza. Sin embargo, y como fue discutido en los capítulos 7 y 8 , algunos procesos como la DO y la meteorización, pueden afectar diferencialmente aquellos elementos con menor madurez osteológica (Gutiérrez et al. 2010; Massigoge et al. 2010). En este sentido, y debido a que el conjunto de la CS de MA registra la mayor meteorización relativa entre los conjuntos (Figura 9.5), creemos necesario para el futuro, profundizar sobre estas preguntas y evaluar el sesgo que puede existir en la representación anatómica de los guanacos en relación a estos problemas de preservación diferencial de partes. No obstante estos estudios tafonómicos, que nos hacen prestar atención a los procesos destructivos en los materiales óseos de guanacos crías y juveniles, es importante destacar que esta evidencia, aunque con señal baja en ambos sitios de la cuenca, es una vía independiente que estaría avalando la hipótesis de que al menos, en momentos de primavera-verano, los grupos humanos estaban cazando guanacos en ambos sectores (valles altos y lagunas bajas) de la cuenca.

Los cuatro conjuntos reflejan una mayor representación de especímenes y elementos del esqueleto apendicular sobre el esqueleto axial (Figura 9.5). La diferencia que registran en la relación axial/apendicular entre los valores de NISP y MNE, evidencia una mayor fragmentación de los elementos del esqueleto apendicular en los cuatro conjuntos (Figura 9.5). Esa tendencia es coherente con la relación entre el MNE/NISP que indica una fragmentación moderada a alta en los cuatro conjuntos, siendo un poco más elevada la observada en Capa 2 de AEP-1 y Capa 4 de CN.

El registro de modificaciones en los cuatro conjuntos muestra que la mayor incidencia corresponde a las vinculadas al agente antrópico, y lo tanto al principal responsable de la generación de estos conjuntos. Encontramos que la tendencia en la representación de marcas de procesamiento es similar en los cuatro conjuntos (Figura 9.5), indicando actividades específicas de procesamiento primario y secundario de los guanacos y siendo el conjunto de $\mathrm{CN}$ de $\mathrm{MA}$ el que registra la mayor variedad y 
frecuencia de las mismas. La gran variedad de marcas relacionadas a la fracturación intencional de los huesos como las marcas de raspado y los surcos perimetrales, evidencian la búsqueda de un patrón de fractura controlado - e.g., transversal recto-. Este patrón podría indicar un acceso a la médula ósea para consumo (Bourlot et al. 2009; Muñoz y Belardi 1998), pero además, es una señal clara de la búsqueda de formas base para la manufactura de artefactos óseos, intención que fue manifestada por diferentes autores (Belardi et al. 2010; Hajduck y Lezcano 2005; Miotti 1998; Muñoz y Belardi 1998; Santiago 2010). En algunos casos el uso de estos artefactos está relacionado a la tarea de machacar (Hajduck y Lezcano 2005; Santiago 2010) y en otros casos como enmangues de artefactos de piedra (Miotti 1998). En estos términos, habrá que continuar explorando la hipótesis de si fueron instrumentos en si mismos, o formaron parte de instrumentos compuestos. Sin embargo, la gran cantidad de instrumentos óseos recuperados en estos dos niveles, y que podrían estar relacionados a actividades específicas de talla lítica como las observadas por Hermo (2008), avalaría su inclusión en la cadena de producción de instrumental. A esta evidencia se suma la presencia de huesos con manchas de pigmento rojo, probablemente relacionado a la producción de pinturas rupestres (Carden 2009) o corporales, y que también indican el desarrollo de actividades específicas en ese sector del sitio (Figura 7.28).

El conjunto de CS y de AEP-1, si bien también registra una fragmentación moderada con alta representación de fracturas antrópicas, la frecuencia de marcas que indican la preparación de la superficie ósea previa a la fracturación es menor (Figura 9.5). En el caso de CS, esta información, sumada a la elevada frecuencia de especímenes quemados con distribución acorde a las áreas de fogón, nos permite proponer que funcionó, dentro del ámbito doméstico de MA, como un sector relacionado a actividades de consumo y descarte. De esta manera, para el Holoceno medio de MA se propone que en el sitio se realizaron actividades múltiples cuya distribución de restos y marcas sugiere una estructuración del espacio con la realización de actividades distintas en cada cámara de la cueva.

Es este sentido, el conjunto de Capa 2 de AEP-1, si bien muestra una tendencia similar a la observada en MA respecto de la representación de marcas de procesamiento y alteración térmica, creemos que allí la estructuración del espacio discutida en el Capítulo 8, indica actividades relacionadas a un elevado procesamiento de los guanacos con áreas de consumo y descarte dentro del sitio.

La variada representación de las distintas modificaciones antrópicas en todos los 
conjuntos del Holoceno medio de la cuenca permite proponer que todos ellos corresponden a sitios de actividades múltiples o domésticas. Lo que estaría indicando para estos momentos, la presencia de grupos familiares tanto en el nivel de base como de cabecera.

El registro de modificaciones naturales de las superficies óseas muestra una tendencia hacia una baja meteorización en todos los conjuntos, siendo el de CS, como se mencionó anteriormente, el que registra la menor preservación de restos óseos (Figura 9.5).

La tendencia observada para estos momentos indica que tanto en la cuenca baja como en la alta, la mayor incidencia de procesos y agentes depositacionales y postdepositacionales durante el contexto enterrado se encuentra principalmente relacionada a la presencia de manganeso (Figura 9.5). Estos depósitos, cuya mayor frecuencia se presenta en AEP-1, podrían haber ocultado, al menos en parte, marcas tanto de procesamiento como de otros agentes naturales (carnívoros y roedores). Los conjuntos de CS de MA y AEP-1 con mayor meteorización y mayor frecuencia de especímenes con depósitos de manganeso (Figura 9.5), son los que tienen más posibilidades de que distintas marcas no estén pudiendo ser registradas. En el caso de AEP-1, la ausencia de estas marcas además podría estar acentuada por la mayor cantidad de huesos con depósitos de carbonato (Figura 9.5). De todas maneras, los depósitos observados en este nivel, y a diferencia de los del nivel subyacente del sitio, son poco espesos y se encuentran localizados en rugosidades de los huesos.

Modificaciones producidas por finas raíces se registraron en todos los conjuntos del Holoceno medio, sin embargo, su mayor representación corresponde al sector bajo de la cuenca (Figura 9.5), donde posiblemente las condiciones fueron más favorables para el desarrollo de una cubierta vegetal.

La baja presencia de marcas de carnívoros y roedores en los conjuntos de la cuenca evidencia que estos agentes no habrían tenido una influencia considerable sobre los conjuntos (Figura 9.5). El escaso daño producido por roedores en los conjuntos de CN de MA probablemente haya sido post-entierro ya que fue registrada la presencia de galerías durante las excavaciones. La baja representación de estas marcas en relación a las vinculadas a acción humanas, avala el origen cultural de los conjuntos.

La tendencia general que se observa sobre la incidencia que los distintos procesos y agentes tafonómicos tuvieron en la formación de los conjuntos del Holoceno medio en la cuenca indica una buena preservación e integridad de todos ellos. En términos 
comparativos, la $\mathrm{CN}$ de MA es la que registra la mejor integridad y preservación de los conjuntos.

\subsubsection{Holoceno tardío}

Para este lapso temporal se comparan los conjuntos de Capa 2 de CN y Capa 1 de CS de MA, siendo el de esta última cámara el que presenta la mayor cantidad de restos óseos (Figura 9.6).

Para estos momentos, y al igual que lo que se observa para ocupaciones anteriores en la cuenca, los guanacos corresponden a la principal especie utilizada por los grupos cazadores, con representación similar en cada conjunto (Figura 9.6). Se registra una diferencia entre las cámaras respecto a la representación que alcanzan las aves y otros recursos complementarios. Mientras que en $\mathrm{CN}$ las aves de tamaño mediano alcanzan una mayor importancia, en CS lo hacen los rheidos. Esta diferencia podría reflejar el desarrollo de actividades o usos diferentes de la cueva.

La presencia de restos de oveja quemados en CS de MA, indica además, que estos artiodáctilos habrían formado parte de la dieta en las poblaciones post-hispánicas que tuvieron lugar en la cueva y de las que otros materiales como fragmentos de vidrio y botellas han sido recuperados.

El perfil etario de los guanacos indica en ambos conjuntos la presencia de individuos inmaduros (Figura 9.6). Si bien su representación deberá ser evaluada, como se mencionó anteriormente, en términos de la supervivencia diferencial que estos especímenes presentan, hasta el momento no estamos en condiciones de afirmar que ese registro pueda reflejar un patrón de selección de los guanacos cazados.

La representación de partes de guanaco en ambos conjuntos muestra un patrón similar, y se asemeja a lo observado para momentos previos de la ocupación de la cuenca, con una mayor representación del esqueleto apendicular sobre el axial (Figura 9.6).

La fragmentación que se registra es más elevada en el conjunto de la CS aunque en ambos casos las diferencias observadas entre el NISP y el MNE, indican que el esqueleto apendicular es el más afectado por este proceso (Figura 9.6). Si bien los mayores porcentajes de fracturas se atribuyen a causas antrópicas, esa proporción (antrópicas/tafonómicas) es menor en el conjunto de CS. Esto seguramente se encuentre 
relacionado a que el conjunto de CS es el que registra mayor frecuencia de especímenes quemados y meteorizados (Figura 9.6).

MA: Capa 2 CN

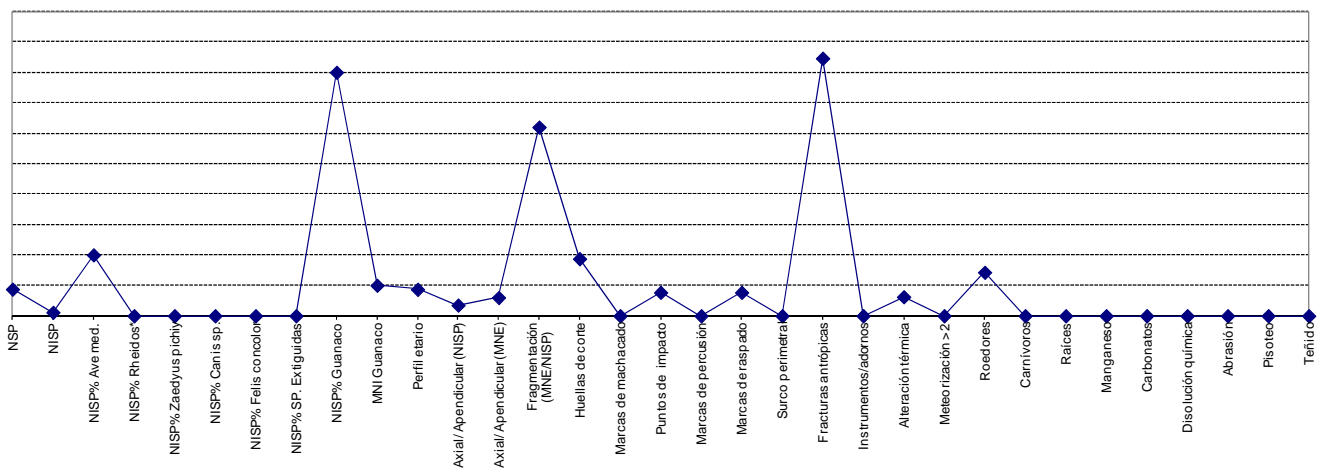

MA: Capa 1

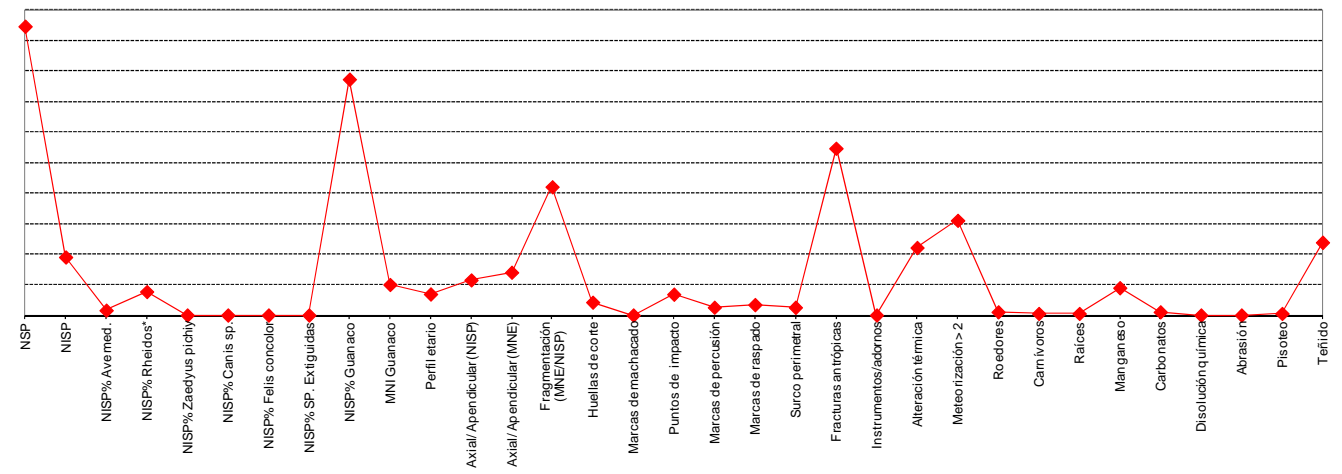

Figura 9.6. Arqueotafogramas para los conjuntos del Holoceno tardío en la cuenca de los Zanjones Rojo y Blanco en la Meseta Central de Santa Cruz.

La frecuencia de modificaciones antrópicas vinculadas con actividades de procesamiento si bien muestran una tendencia similar en ambos conjuntos, las frecuencias relativas son más elevadas en CN (Figura 9.6). De todas formas, la presencia de huellas de corte, puntos de impacto, marcas de raspado y percusión, estaría indicando en ambos sectores de la cueva actividades relacionadas a las distintas etapas del procesamiento de las presas y la obtención de fracturas controladas. La ausencia de instrumentos óseos en estos momentos tardíos en el sitio sugiere que las fracturas pudieron estar relacionadas al consumo de médula ósea. Sin embargo, la presencia escasa de fracturas transversales por marcado perimetral en CS (Figura 9.6) nos permite considerar que, como se observó en los conjuntos del Holoceno medio, la fracturación controlada de los huesos largos a partir del preparado de las superficies óseas, puede 
estar vinculada a la obtención de formas base o instrumentos.

La incidencia de los procesos tafonómicos habría afectado más al conjunto de CS que al de $\mathrm{CN}$, esto se considera ya que es donde se registra una mayor meteorización y presencia de depósitos de manganeso. Las modificaciones producidas por roedores sobre los conjuntos se observan en frecuencias mayores en CN (Figura 9.6). De todas formas, la baja meteorización de este conjunto y la ausencia de otras modificaciones indican que el conjunto de $\mathrm{CN}$ presenta la mayor integridad para estos momentos.

Durante el Holoceno tardío, la CS de MA parece haber sido más utilizada que la CN. La presencia de materiales europeos solamente en CS, evidencia un uso diferente de ambos sectores de la cueva ya que, hasta el momento, ninguno de estos materiales (ni fauna introducida, ni vidrio, ni metales) han sido recuperados en el sector norte de la cueva.

De todas formas, entendemos que la baja frecuencia de especímenes óseos en el conjunto de $\mathrm{CN}$ respecto del de CS, puede estar sobredimensionando algunas de las frecuencias discutidas anteriormente. Por tal motivo consideramos que la nueva evidencia recuperada en MA durante las últimas excavaciones, y que aún está siendo procesada, constituye una fuente importante de información para esclarecer muchas de las preguntas acerca del uso de los recursos y del espacio interior del sitio, generadas en esta tesis. Por ello, la agenda propone considerar esa nueva evidencia en la discusión de las hipótesis aquí formuladas. 


\section{CAPÍTULO 10}

\section{CONCLUSIONES}

A lo largo de esta tesis se abordó el estudio del registro zooraqueológico de la Meseta Central de Santa Cruz, desde dos perspectivas, la tafonómica, que nos brinda una exploración más profunda y detallada de los procesos de formación de sitios, y la que compete estrictamente a las interpretaciones sobre las decisiones humanas respecto del manejo y relación con las faunas en el pasado. Aquí se aplicaron los estándares de la anatomía económica para poder inferir qué recurso pudo haber tenido más relevancia sobre otro, o de qué modo fueron seleccionadas, compartidas, consumidas y descartadas las distintas presas. En suma, se trata de dar cuenta del uso de las arqueofaunas luego de la evaluación de la integridad y preservación de cada conjunto analizado.

El análisis de los distintos conjuntos arqueofaunísticos de Cueva Maripe y Alero El Puesto 1, provenientes de dos zonas diferentes de la cuenca (sector de cabecera y nivel de base respectivamente), aportó información valiosa para comprender la formación de cada depósito y estudiar la variabilidad zooarqueológica y tafonómica de la cuenca.

Si bien en trabajos previos se realizaron los primeros esfuerzos por conocer la historia de formación de sitios arqueológicos como Piedra Museo (Giardina et al. 2000; Miotti et al. 1999; Miotti y Marchionni 2011), esta línea de investigación se pudo continuar consolidando a partir de este trabajo de tesis. Fuera del énfasis que esta línea de investigación tiene dentro del equipo de arqueología regional del que formo parte, es escaso, en otros sectores de la meseta el interés puesto en el tema. A diferencia del amplio desarrollo que estas investigaciones han tenido en áreas vecinas como la cuenca magallánica y el sector cordillerano (Capítulo 3), la falta de información tafonómica de los sitios arqueológicos estudiados en la Meseta Central es evidente. En ese sentido, los estudios aquí realizados intentan continuar de modo sistemático el desarrollo de una investigación tafonómica dentro del área de estudio que brinde información genuina y comparativa para alcanzar una mejor comprensión de: a) las dinámicas de los procesos de formación de sitios en los distintos microambientes de las áreas de estudio, b) los distintos agentes acumuladores y dispersores de los materiales zooarqueológicos, y c) contribuya a una mejor comprensión de los aspectos relacionados con la economía de los 
grupos cazadores-recolectores que habitaron el Macizo del Deseado.

Los análisis cuantitativos y cualitativos de los 10 conjuntos zooarqueológicos aquí estudiados nos permitieron evaluar la acción y la intensidad de los distintos agentes y procesos acumuladores y dispersores (naturales y culturales) de los materiales en los dos sectores de la cuenca. De esta manera fue posible a partir de marcos de referencia más adecuados, inferir los procesos de formación de sitios y el uso de los recursos faunísticos por parte de los grupos humanos en el pasado.

La elaboración, análisis e interpretación de los arqueotafogramas construidos para cada conjunto, a partir de la estandarización de las unidades analíticas (conjuntos arqueofaunísticos), y de la definición y cuantificación de variables tafonómicas (33 variables, ver Capítulo 6 y 9, y Figuras 9.4, 9.5 y 9.6), nos permitió comparar las distintas historias tafonómicas de los contextos. De esta forma pudimos alcanzar los distintos objetivos propuestos al comienzo de esta tesis y ver cómo cada microrregión se comportaba respecto de la apropiación de recursos faunísticos por parte de los cazadoresrecolectores. Esta comparación comprendió además la dinámica temporal, por lo tanto, sobre la base de la información generada y discutida en el capítulo previo, se presentan a continuación las conclusiones más generales a las que se ha podido arribar.

Si bien era esperable sobre la base de los modelos generales presentados en el Capítulo 4, que existiera un uso jerárquico de los recursos dentro de la misma cuenca, principalmente debido a las diferencias microambientales de emplazamiento de los sitios, las cuales estarían relacionadas a cuestiones ecológicas, de visibilidad y características distintas de cada sector de la cuenca, se encontró que la variabilidad zooarqueológica lleva intrínsecamente impresa una variabilidad tafonómica mayor que la esperada. Dicha variabilidad tafonómica se debe en parte a que el contexto de AEP-1 está contenido en un perfil de paleosuelo, mientras que el depósito de Cueva Maripe corresponde a una matriz de sedimento eólico y parental de la misma cueva, sin proceso de edafización.

El depósito del Alero AEP-1 es un suelo local el cual desaparece ni bien se sale de los límites de la cuenca del paleolago, este límite estaría dado por el pedimento más antiguo identificado por Zárate en 1999 (Zárate et al. 2000). Estos suelos locales se caracterizan por generar condiciones micro-locales de depositación diferente a los sectores circundantes y extra-cuencales. Su desarrollo es puntual debido a que aún en momentos de extrema aridez la cuenca pudo mantener condiciones de mayor humedad efectiva y por lo tanto producir una estabilidad que favoreció el desarrollo de un suelo. De este modo, la mayor frecuencia de factores naturales que actuaron en estos conjuntos 
zooarqueológicos es producto del retrabajo pedogenético a posteriori del depósito y enterramiento de los materiales. En la parte alta o de cabeceras de la cuenca, los materiales no proceden de depósitos re-trabajados por edafización, con lo cual, aquellos agentes como las raíces, los manganesos y la carbonatación tienen una menor incidencia que en el sector de la cuenca baja. Sin embargo, las características carbonáticas de la roca en la que abre el alero de AEP-1 y las variaciones que pudo tener el nivel freático en ese sector de la cuenca, sumado a un drenaje deficiente que se infiere a partir de las características onduladas del techo de la Capa 2 y que indica ciclos de encharcamiento, sin duda contribuyeron a una mayor representación de estas modificaciones. En el caso de Cueva Maripe, la mayor incidencia de los procesos tafonómicos en la Cámara Sur guardaría relación con una menor tasa de sedimentación que Cámara Norte y la presencia de una secuencia estratigráfica comprimida.

En cuanto a la preservación de los conjuntos, los resultados indican una buena integridad arqueológica en ambos contextos. En términos relativos de comparación entre los distintos conjuntos, la tendencia marca que la mejor integridad corresponde a los conjuntos de Cámara Norte de Cueva Maripe.

Respecto de la incidencia de los agentes naturales sobre los conjuntos, es destacable que en ambas muestras los materiales no presentan modificaciones de la acción de carnívoros ni roedores. Por lo tanto, si bien ambos depósitos se encuentran en cuevas, las cuales, alternativamente pueden ser ocupadas por roedores y carnívoros, la acción de los mismos no fue significativa. De todos modos no se descarta la posibilidad de que algunos huesos hayan podido ingresar al sitio por la acción de algún carnívoro sin que hayan quedado marcas visibles de su acción en los especímenes analizados. Por otro lado, y respecto de la presencia de cuevas y galerías identificadas en Cueva Maripe durante las excavaciones, no se registraron señales de perturbación o desplazamiento de materiales por fuera de esos sectores. De esta manera, y como se mencionó en el Capítulo 6, para los materiales y sedimentos asociados a dichos rasgos y que fueron separados del conjunto arqueológico se prevé un tratamiento especial que contempla un test de congruencia con los otros huesos de áreas no impactadas por la acción de animales fosoriales para evaluar con mayor profundidad la acción de estos animales en el sitio.

La gran variedad de modificaciones culturales registradas en todos los conjuntos nos permiten considerar que el principal agente acumulador de los mismos fue el antrópico. Sin embargo, las diferentes frecuencias de especies aprovechadas, la 
representación de unidades anatómicas del guanaco, los tipos de marcas de procesamiento, la presencia de instrumentos óseos, y la distribución de los materiales y áreas de fogones indican diferencias en el aprovechamiento de los recursos faunísticos y las actividades culturales desarrolladas en cada sitio.

De esta manera, los resultados obtenidos por un lado avalan las distintas hipótesis que se pusieron a prueba durante esta investigación, por otro lado, el desarrollo de esta investigación aporta nueva información para la cuenca, de esta manera se propone:

La mayor diversidad y riqueza taxonómica de especies aprovechadas se registran en los conjuntos que provienen de AEP-1. Esta diferencia pudo estar vinculada a una mayor oferta de recursos del ambiente de la cuenca baja, y a las probabilidades de que los mismos hayan constituido recursos de acceso inmediato, disponibles en las inmediaciones del paleolago. Mientras que en la cuenca alta (Cueva Maripe), si bien el atractor agua está presente, su acceso implica condiciones de riesgo mayores para las potenciales presas ya que las vías de escape de depredadores son más restringidas debido a las abruptas pendientes y al gran desnivel entre la base del mallín y las planicies de la meseta alta adyacente.

La estrategia económica de los grupos que habitaron la cuenca estuvo centrada en el recurso guanaco (Lama guanicoe) y complementada por rheidos. Se considera un uso ocasional de aves de tamaño mediano, cánidos, pumas y dasipódidos. El abundante registro de cáscaras de huevo de ñandú que se observa hacia el Holoceno medio en ambas localidades, sugiere un aprovechamiento diferente de estos rheidos respecto al de momentos previos. En los niveles inferiores de AEP-1 los megaherbívoros pleistocénicos, y a diferencia de lo que ocurre en Cueva Maripe, también habrían sido recursos importantes explotados por los cazadores-recolectores. El nuevo registro de huellas de corte en Mylodon sp. sugiere que esta especie habría sido explotada de forma ocasional entre ca. 12.800 y 11.000 años AP. Sobre la base de la nueva información aportada por Borrero y Martin (2012) acerca de la utilización antrópica de milodontinos en FuegoPatagonia, consideramos que su presencia en AEP-1 puede estar indicando actividades de carroñeo.

Se confirma la hipótesis formulada previamente de que el componente inferior de AEP-1 (Capas 6 y 4/5) habría funcionado como un sitio de matanza y procesamiento primario de las presas (Miotti et al. 1999), se propone además, la existencia de un consumo ocasional de médula ósea en el sitio con una mayor recurrencia ocupacional del alero para los momentos entre ca. 10.400 y 9200 años AP (Capa 4/5). 
Se propone además, que en la Capa $4 / 5$ se identifica una tendencia a una estrategia de focalización y especialización en el guanaco que se confirma hacia el Holoceno medio en el conjunto de Capa 2. Por su parte, el componente superior de AEP-1 (Capa 2) habría funcionado como un sitio de actividades múltiples. Para este momento también se propone un uso integral del guanaco, el cual podría ser comprendido como una estrategia de potenciación del recurso. Para estos momentos además se propone el desarrollo de actividades domésticas con áreas de descarte y consumo.

En cuanto a lo que corresponde a Cueva Maripe y a diferencia de lo que se propone para AEP-1, desde los inicios de las ocupaciones en la cueva ca. 9500 años AP y hasta los últimos registros de su uso y correspondientes a momentos post-hispánicos, los guanacos fueron el principal recurso económico aprovechado, el sitio habría funcionado como un locus de actividades domésticas con un uso diferencial del espacio interior. En la Cámara Sur se habrían realizado actividades relacionadas al consumo y descarte, la Cámara Norte por su parte, refleja un uso vinculado al desarrollo de actividades específicas vinculadas a la producción y uso de instrumentos óseos y posiblemente de pigmentos naturales. No se descarta que en la Cámara Norte además, se hayan realizado actividades de consumo. El uso diferencial que se registra en Cueva Maripe en los distintos momentos en que fue habitada podría estar relacionado a las diferencias microambientales que caracterizan a cada sector.

La elevada frecuencia de unidades anatómicas de guanaco con bajo rendimiento económico tanto en los conjuntos de Cueva Maripe como en la Capa 2 de AEP-1 sugiere decisiones de selección y transporte, ya sea por la calidad de sus grasa medular, o porque son elementos masivos de interés para la producción de instrumental.

Agenda futura:

- Los estudios desarrollados en esta tesis constituyen una primera aproximación al estudio de la variabilidad zooarqueológica y tafonómica de la cuenca de los Zanjones Rojo y Blanco, en el Macizo del Deseado. Para continuar y profundizar el desarrollo de esta línea de investigación en el área de estudio y poner a prueba los resultados hasta aquí alcanzados, a continuación se mencionan las principales actividades y tareas a desarrollar: 
- La realización de nuevos fechados radiocarbónicos para ambos conjuntos permitirá alcanzar mejores niveles de resolución temporal. Actualmente, nuevas muestras de carbón y hueso del sitio Cueva Maripe están siendo procesadas con esta intención.

- La aplicación de nuevas técnicas o metodologías que permitan mejorar las determinaciones taxonómicas de los especímenes fragmentados de ambos sitios permitirá contribuir a un mejor entendimiento acerca de las formas de utilización de los distintos recursos faunísticos por parte de estas sociedades.

- El estudio de las astillas óseas como posibles desechos de consumo aportará información discutir las distintas estrategias desarrolladas por los grupos cazadores-recolectores durante la preparación y consumo de alimentos y la obtención de grasa ósea.

- Profundizar en el análisis de los distintos indicadores tafonómicos considerados.

- Afinar los perfiles etarios de los conjuntos zooarqueológicos estudiados para evaluar cómo ellos inciden sobre la DO y la meteorización de los conjuntos.

- Evaluar el posible uso estacional de AEP-1 y Cueva Maripe durante el Holoceno medio a partir de la búsqueda de nuevos indicadores.

- Incorporar nuevas muestras zooarqueológicos para el análisis de la variabilidad. En este sentido, consideramos además de la inclusión de nuevos conjuntos en cuevas localizados en otros sectores de la cuenca, como la cuenca media, y la incorporación de muestras procedentes de sitios a cielo abierto. De esta manera sería posible evaluar cómo se comporta esta variabilidad en otros microambientes del área y sitios no estratificados.

- Se prevé además, la elaboración de diseños actualísticos del estudio sistemático de conjuntos de carcasas y restos esqueletarios en diferentes grados de desarticulación y fracturación. Este abordaje es analíticamente importante para poder identificar dentro del área de la meseta, los distintos procesos y agentes pueden actuar sobre los conjuntos, el tipo de modificación resultante y la intensidad de la misma. La integración de resultados actualísticos y zooarqueológicos enriquecerá las interpretaciones sobre las formas del uso de los recursos fáunicos y de los espacios de las sociedades cazadoras-recolectoras en Patagonia. 


\section{BIBLIOGRAFÍA}

\section{Capítulo 1}

Barberena, R.

2008. Arqueología y biogeografía humana en Patagonia Meridional. Sociedad Argentina de Antropología, Buenos Aires.

Behrensmeyer, A. K.

1991. Terrestrial vertebrate accumulations. En P. Allison y D. Briggs (Eds.) Taphonomy: releasing the data locked in the fossil record, Topics in Geobiology 9: 291-335.

Belardi, J.B.

2005. Paisajes Arqueológicos: un estudio comparativo de diferentes ambientes patagónicos. Archaeopress, Oxford.

Belardi, J. B.; T. J. Bourlot y D. Rindel

2010. Representación diferencial de diáfisis y epífisis de huesos largos de guanaco (Lama guanicoe) en contextos arqueológicos de médanos en Patagonia austral: el sitio Río Meseta 1 (lago Tar, provincia de Santa Cruz). En M. A. Gutiérrez; M De Nigris; P. Fernández; M. Giardina; A. Gil; A. Izeta; G. Neme y H. Yacobaccio (Eds.), Zooarqueología a principios del siglo XXI: aportes teóricos, metodológicos y casos de estudio, pp. 119-131. Ediciones del Espinillo, Buenos Aires.

Binford, L.

1978. Nunamiut ethnoarchaeology. Academic Press, New York.

1981. Bones: ancient men and modern myths. Academia Press, NewYork.

Blanco, R. V. y V. Lynch

2011. Experimentos replicativos de gravados en piedra. Implicancias en el arte rupestre de la colcalidad Arqueologica de Piedra Museo (Santa Cruz, Argentina). 
Boletín del Museo Chileno de Arte Precolombino. Vol. 16, N 1, pp 9-21, Santiago de Chile.

\section{Borrero, L. A.}

1986. La economía prehistórica de los habitantes del Norte de la Isla Grande de Tierra del Fuego. Tesis doctoral inédita de la Facultad de Filosofía y LetrasUniversidad Nacional de Buenos Aires, Buenos Aires.

1988. Tafonomía regional. En N. Ratto y A. Haber (Eds.), De Procesos, contextos y otros huesos, pp. 9-15. Facultad de Filosofía y Letras- Universidad Nacional de Buenos Aires, Buenos Aires.

1990. Taphonomy of guanaco bones in Tierra del Fuego. Quaternary Research 34: 361-371

1993. Site formagtion processes in Patagonia: Depositional rates and the properties of the archaeological record. En: Explotacion de Recursos Faunísticos en Sistemas Adaptativos Americanos. Lanata, J. L. (Comps). Arqueología Contemporánea N4: 107-121.

1994-95. Arqueología de la Patagonia. Palimpsesto 4: 9-69.

2001. Cambios, continuidades, discontinuidades: discusiones sobre arqueología Fuego Patagónica. En E. Berberián y A. Nielsen (eds), Historia Argentina Prehispánica, Tomo II, pp. 815-838. Editorial Brujas, Córdoba.

2007. Longitudinal taphonomic studies in Tierra del Fuego, Argentina. En M. Gutiérrez; L. Miotti; G. Barrientos; G. Mengoni Goñalons y M. Salemme (Eds.), Taphonomy and Zooarchaeology in Argentina, pp. 219-233. BAR Series- Archaeopress, Oxford.

2011. La Función Transdisciplinaria de la Arqueozoología en el siglo XXI: restos animales y más allá. Antípodas N¹3, pp 267-274. Bogotá, Colombia.

Borrero, L. A. y F. Martin

2012. Ground sloths and humans in southern Fuego-Patagonia: taphonomy and archaeology. Word Archeology. Vol 44 (1):102-117.

Borrero, L. A., F. M. Martin y J. Vargas

2005. Tafonomía de la interacción entre pumas y guanacos en el Parque Nacional Torres del Paine, Chile. Magallania 33 (1): 95-114. 
Borrero, L. A.; N. Franco; J. L. Lanata y J. B. Belardi

1991. Distribuciones arqueológicas y tafonomicas en la margen norte del Lago Argentino (Santa Cruz, Argentina). Actas del XII Congreso Nacional de Arqueología Chilena. Tomo 1. Pp 23-31.

Carden, N.

2009. Imágenes a través del tiempo: arte rupestre y construcción social del paisaje en la meseta central de Santa Cruz. Sociedad Argentina de Antropología, Buenos Aires.

De Nigris, $\mathrm{M}$.

2004. El consumo en cazadores-recolectores. Un ejemplo zooarqueológico de Patagonia meridional. Sociedad Argentina de Antropología, Buenos Aires.

Durán, V.

1991. Estudios de perturbación por roedores del género Ctenomys en un sitio arqueológico experimental. Revista de Estudios Regionales CEIDER 7: 7-31.

Farrand, W. R.

1985. Rockshelter and cave sediments. En J .K Stein y W. R. Farrand (Eds.), Archaeological sediments in context, pp. 21-40. Center for the Study of Early ManInstitute for Quaternary Studies- University of Maine, Orono.

Gifford-Gonzales, D. V.

1989a Overview Modern analogues: developing and interpretative framework. Bone Modification. Bonnichsen, R. \& Sorg, M. (eds.) Pp.43-52, Peopling of Americas publications edited volume series, Center for the study of the first Americans, University of Maine, Orono.

1989b Etnographic analogues for interpreting modified bones: some cases from Africa. Bone Modification. Bonnichsen, R. \& Sorg, M. (eds.) Pp.179-246, Peopling of Americas publications edited volume series, Center for the study of the first Americans, University of Maine, Orono.

1991. Bones are not enough: analogues, knowledge and interpretative strategies in 
zooarchaelogy. Journal of Anthropological Archaeology 10: 215-254.

1993 Gaps in Zooarchaeological Analyses of Butchery: Is Gender an Issue? En: Interpretation of Faunal Remains, editado por J. Hudson, pp. 181-199. Center for Archaeological Investigations, Ocassional Paper 21. Southern Illinois University at Carbonale.

\section{Grayson D.}

1984 Quantitative Zooarchaeology. Academic Press, New York.

\section{Gutiérrez, M. A.}

2009. “Tafonomía: ¿Tiranía o multivocalidad?” En Perspectivas actuales em Arqueología Argentina, Eds. R. Barberena, K. Borrazzo y L. A. Borrero, pp. 57-87. Buenos Aires, CONICET-IMHICIHU.

Hermo, D.

2008. Los cambios en la circulación de las materias primas líticas en ambientes mesetarios de Patagonia. Una aproximación para la construcción de los paisajes arqueológicos de las sociedades cazadoras-recolectoras. Tesis doctoral inédita de la Facultad de Ciencias Naturales y Museo-Universidad Nacional de La Plata, La Plata.

\section{Johnson, E.}

1985. Current developments in bone technology. En M. B. Schiffer (Ed.), Advances in Archaeological Method and Theory 8: 157-235.

Kornfeldm, M.; S. Vasil' ev y L. Miotti

2008. On shelter's ledge histories, theories and methods of rockshelter. British Archaeological Reports. Vol. 14.

Lyman, R. L.

1994. Vertebrate Taphonomy. Cambridge Manuals in Archaeology. Cambridge University Press. Cambridge. 
Lynch, V.

2012. Analisis morfologico-funcional de raspadores líticos del sitio Cueva Maripe (Santa Cruz, Argentina). En F. Zangrando; R. Barberena; A. Gil; G. Neme; M. Giardina; L. Luna; C. Otaola; S. Paulides; L. Salgán y A. Tivoli, Tendencias teórico-metodológicas y casos de estudio en la arqueología de Patagonia. Sociedad Argentina de Antropología- Instituto Nacional de Antropología y Pensamiento Latinoamericano- Museo de Historia Natural de San Rafael. En Prensa.

Magnin, L.

2010. Distribuciones arqueológicas en la meseta central de Santa Cruz: Implicancias para los estudios de uso del espacio y movilidad de sociedades cazadoras recolectoras. Tesis doctoral inédita de la Facultad de Ciencias NaturalesUniversidad Nacional de La Plata, La Plata.

Marean, C. W.

1995. Of taphonomy and zooarchaeology. Evolutionary Anthropology 4 (2), 64-72.

Marchionni, L.; L. Miotti y B. Mosquera

2010. El uso de la fauna entre el Pleistoceno final y el Holoceno medio en la Patagonia extra-andina. En M. Gutiérrez; M. De Nigris; P. Fernández; M. Giardina; A. Gil; A. Izeta; G. Neme y H. Yacobacio (Eds.), Zooarqueología a principios del siglo XXI: Aportes Teórico, metodológicos y casos de estudio, pp. 259-272. Ediciones del Espinillo, Buenos Aires.

Martin, F.

2008. Tafonomía y paleoecología de la transición Pleistoceno-Holoceno en FuegoPatagonia: Interacción entre poblaciones humanas y de carnívoros y su importancia como agentes en la formación del registro fósil. Tesis doctoral inédita de la Facultad de Ciencias Naturales- Universidad Nacional de La Plata. La Plata.

Mengoni Goñalons, G.

1988. El Estudio de huellas en arqueofaunas. Una vía para reconstruir situaciones interactivas en contextos arqueológicos. Aspectos teóricos-metodológicos y técnicas 
de análisis. In: Haber, A., Ratto, N (Eds.), De procesos, contextos y otros huesos. Facultad de Filosofía y Letras, Universidad de Buenos Aires, pp. 17-28.

1999. Cazadores de guanacos de la estepa patagónica. Sociedad Argentina de Antropología, Buenos Aires.

2010. Zooarqueología en la práctica: algunos temas metodológicos. Xama 19-23: 83-113.

Miotti, L.

1992. Paleoindian occupation at Piedra Museo Locality, Patagonian Region, Argentina. Current Research in the Pleistocene 9: 30-32.

1998. Zooarqueología de la Meseta Central y Costa de Santa Cruz: Un enfoque de las estrategias adaptativas aborígenes y los paleoambientes. Imprenta del Museo de Ciencias Naturales de San Rafael, San Rafael.

2003. South America. A paradox for building images of the colonization of the New World. En L. Miotti y M. Salemme (Eds.). South America, long and winding roads for the First Americans at the Pleistocene/Holocene Transition, 109-110: 147-173.

2008. Household and sacred landscapes among Holocene hunter-gatherers of Patagonia's Central Plateau. Before Farming 2008/3: 5-44.

2012. La potenciación de los recursos entre los cazadores-recolectores de Patagonia. Factores, Procesos e implicancias arqueológicas. Archaeofauna 21: 137160 .

Miotti, L y M. Salemme

1999. Biodiversity, Taxonomic Richness and Generalist-Specialists economical systems in Pampa and Patagonia Regions, Southern South America. Quaternary International 53-54: $53-68$.

2005. Hunting and butchering events at the Pleistocene/Holocene transition in Piedra Museo: An example of adaptation strategies of the first colonizers of Patagonia. En R. Bonnichsen, B. Leppers, D. Stanford y M. Waters (Eds.), Paleoamerican origins: Beyond Clovis, pp. 209-220. Texas A\&M University Press, Texas.

Miotti, L.; M. Vázquez y D. Hermo

1999. Piedra Museo: Un Yamnagoo pleistocénico en la colonización de la meseta de Santa Cruz. El estudio de la arqueofauna. En R. Goñi (Ed.), Soplando en el Viento, pp. 113-136. 
Universidad Nacional del Comahue- Instituto Nacional de Antropología y Pensamiento Latinoamericano, Neuquén-Buenos Aires.

Mosquera, B.

2012. Analisis geoarqueologicos del sitio Cueva Maripe: primeros resultados. Libro de Resumenes IX Jornadas de Jovenes Investigadores. INAPL. Buenos Aires.

Muñoz, A. S.

2008. El procesamietno de los camélidos fueguinos en el pasado. Aspectos metodológicos y resultados alcanzados para el sector atlántico de Tierra del Fuego. En A. Acosta; D. Loponte y L. Mucciolo (Comps.), Estudios tafonómicos y zooarqueológicos I, pp. 77-98. INAPL-AINA, Buenos Aires.

Panza, J. L.

2001. Hoja Geológica 4769-IV Monumento Natural Bosques Petrificados, Provincia de Santa Cruz. Boletín del SEGEMAR 258. Instituto de Geología y Recursos Minerales, Buenos Aires.

Rindel, D.

2009. Arqueología de momentos tardíos en el noroeste de la Provincia de Santa Cruz (Argentina): una perspectiva faunística. Tesis doctoral inédita de la Facultad de Filosofía y Letras- Universidad de Buenos Aires, Buenos Aires.

Salemme, M. y L. Miotti

1987. Zooarchaeology and paleoenvironments: some examples from the Patagonian and Pampean Regions (Argentina). Quaternary of South America and Antarctic Peninsula 5: 24-47. 


\section{Capítulo 2}

Alberdi, M. T. y J. L. Prado

1993. Review of the genus Hippidion Owen, 1869 (Mammalia: Perissodactyla) from the Pleistocene of South America. Zoological Journal of Linnean Society 108: 1-22.

Alberdi, M.; L. Miotti y J. Prado

2001. Hippidion saldiasi Roth, 1899 (Equidae, Perissodactyla), at the Piedra Museo Site (Santa Cruz, Argentina): Its Implication for the Regional Economy and Environmental Reconstruction. Journal of Archaeological Science 28: 411-419.

Borrero, L. A.

2001. Cambios, continuidades, discontinuidades: discusiones sobre arqueología Fuego Patagónica. En E. Berberián y A. Nielsen (Eds.), Historia Argentina Prehispánica, Tomo II, pp. 815-838. Ediciones Brujas, Córdoba.

Borromei, A. M.

2003. Palinology at Piedra Museo Locality, Santa Cruz Province, Argentina. En L. Miotti; M.Salemme y N. Flegenheimer (Eds.), Where the South Winds Blow: Ancient Evidence of Paleo South Americans, pp. 113-120. Center for the Studies of the First Americans- Texas A\&M University Press, Texas.

Cabrera, A. L.

1976. Fitogeografía de la República Argentina. Boletín de la Serie Botánica 14 (1-2): 1-42.

Cabrera, A. L. y A. Willink

1980. Biogeografía de América latina. Programa regional de desarrollo científico y tecnológico-OEA, Washington.

Cabrera, A. y J. Yepes

1960. Mamíferos sudamericanos. EDIAR Editores, Buenos Aires.

Cardich, A. y L. Miotti

1983. Recursos faunisticos en la economia de los cazadores de Los Toldos (Santa Cruz, Argentina). Relaciones de la Sociedad Argentina de Antropología XV: 145- 157. 
Cardich, A.; L. Cardich y A. Hadjuk

1973. Secuencia arqueológica y cronología radiocarbónica de la cueva 3 de Los Toldos (Santa Cruz, Argentina). Relaciones de la Sociedad Argentina de Antropología VII: 85-123.

Delcourt, H. R. y P. A. Delcourt

1988. Quaternary landscape ecology: Relevant scales in space and time. Landscape Ecology 2 (1): $23-44$.

De Aparicio, F.

1933-35. Viaje preliminar de exploración en el territorio de Santa Cruz. Publicaciones del Museo Antropológico y Etnográfico de la Facultad de Filosofía y Letras. Serie A. III: 71-92.

De Giusto, J.; C. Di Persia y E. Pezzi

1980. Nesocratón del Deseado. En J. C. M. Turner (Coord.), Segundo Simposio de Geología Regional Argentina II: 1390-1430. Academia Nacional de Ciencias, Córdoba.

De Porras, M. E.

2010. Dinámica de la vegetación de la Meseta Central de Santa Cruz durante los últimos 11.000 años a partir del análisis polínico: forzantes bióticos y abióticos. Tesis doctoral inédita de la Facultad de Ciencias Exactas y Naturales- Universidad Nacional de Mar Del Plata, Mar del Plata.

Frank, A.

2011. Tratamiento térmico y manejo del fuego en sociedades cazadoras-recolectoras de la Meseta Central de Santa Cruz. Tesis doctoral inédita de La Facultad de Ciencias Naturales y Museo-Universidad Nacional de La Plata, La Plata.

Gradin, C. J.

1980. Secuencias radiocarbónicas del sur de la Patagonia Argentina. Relaciones de la Sociedad Argentina de Antropología XI: 177-194.

Hermo, D.

2008. Los cambios en la circulación de las materias primas líticas en ambientes mesetarios de Patagonia. Una aproximación para la construcción de los paisajes arqueológicos de las sociedades cazadoras-recolectoras. Tesis doctoral inédita de la Facultad de Ciencias Naturales y Museo-Universidad Nacional de La Plata, La Plata. 
Horovitz, I.

2003. Restos faunísticos de La Martita y nuevo registro biogeográfico de Lestodelphys halli (Didelphidae, Mammalia). En A. Aguerre (Comp.), Arqueología y Paleoambiente en la Patagonia Santacruceña Argentina, pp. 87-91. Nuevo Offset, Buenos Aires.

Jobbágy, E. G.; J. M. Paruelo y R. León

1995. Estimación del régimen de precipitación a partir de la distancia a la cordillera en el noroeste de la Patagonia. Ecología Austral 5: 47-53.

Magnin, L.

2010. Distribuciones arqueológicas en la Meseta Central de Santa Cruz. Implicancias para los estudios de uso del espacio y movilidad de sociedades Cazadoras recolectoras. Tesis doctoral inédita de la Facultad de Ciencias Naturales-Universidad Nacional de La Plata, La Plata.

Mancini, M.

1998. Vegetational changes during the Holocene in Extra-Andean Patagonia, Santa Cruz Province, Argentina. Palaeogeography, Palaeoclimatology, Palaeoecology 138 207-219.

Mancini, M. V. y M. E. Trivi de Mandri

1994. Vegetación en el área del Río Pinturas. Análisis polínico del alero Cárdenas. En C. Gradin y A. Aguerre (Eds.), Contribución a la arqueología del Río Pinturas, Provincia de Santa Cruz, Argentina, pp. 48-62. Búsqueda de Ayllú, Concepción del Uruguay.

\section{Martínez, G. y M. Gutiérrez}

2004. Tendencias en la explotación humana de la fauna durante el Pleistoceno finalHoloceno en la Región Pampeana (Argentina). En G. L. Mengoni Goñalons (Ed.), Zooarchaeology of South America, pp. 81-98. BAR International Series, Oxford.

Mengoni Goñalons, G. L.

1976-80. Los materiales óseos de la Cueva II de Los Toldos (Expedición Menghin) y una aproximación a la metodología de análisis de restos faunísticos. RUNA XIII (1-2): 59-68.

1999. Cazadores de guanacos de la estepa patagónica. Sociedad Argentina de Antropología, Buenos Aires. 
Miotti, L.

1996. Piedra Museo (Santa Cruz): nuevos datos para el debate de la ocupación Pleistocénica en Patagonia. En J. Gómez Otero (Ed.), Arqueología, sólo Patagonia, pp. 2738. Publicación Secretaría de Cultura De Chubut-CONICET, Puerto Madryn.

1998. Zooarqueología de la Meseta Central y Costa de Santa Cruz: Un enfoque de las estrategias adaptativas aborígenes y los paleoambientes. Imprenta del Museo de Ciencias Naturales de San Rafael, San Rafael.

2000. Capítulo 4: Localidad Arqueológica Piedra Museo, Introducción. En L. Miotti; R. Paunero; M. Salemme y R. Cattáneo (Eds.), Guía de Campo de la visita a las localidades arqueológicas. Taller Internacional "La Colonización del Sur de América durante la Transición Pleistoceno/Holoceno”, pp. 55-56. Servicoop, La Plata.

Miotti, L. y D. Hermo 2000. Áreas de Estudio. En L. Miotti; R. Paunero; M. Salemme y R. Cattáneo (Eds.). Guía de Campo de la visita a las localidades arqueológicas. Taller Internacional "La Colonización del Sur de América durante la Transición Pleistoceno/Holoceno”, pp. 13-25. Servicoop, La Plata.

Miotti, L. y M. Salemme

1999. Biodiversity, Taxonomic Richness and Generalist-Specialists economical systems in Pampa and Patagonia Regions, Southern South America. Quaternary International 53-54: 53-68.

2004. Poblamiento, movilidad y territorios entre las sociedades cazadoras-recolectoras de Patagonia. Complutum 15: 177-206.

2005. Hunting and butchering events at the Pleistocene/Holocene transition in Piedra Museo: An example of adaptation strategies of the first colonizers of Patagonia. En R. Bonnichsen, B. Leppers, D. Stanford y M. Waters (Eds.), Paleoamerican origins: Beyond Clovis, pp. 209-220. Texas A\&M University Press, Texas.

Miotti, L.; M. Salemme y A. Menegaz

1988. El manejo de los recursos faunísticos durante el Pleistoceno final y Holoceno temprano en Pampa y Patagonia. Precirculados del IX Congreso Nacional de Arqueología Argentina, pp. 102-118. Instituto de Ciencias Antropológicas- Facultad de Filosofía y Letras- UBA, Buenos Aires. 
Miotti, L.; M. Vázquez y D. Hermo

1999. Piedra Museo: Un Yamnagoo pleistocénico en la colonización de la meseta de Santa Cruz. El estudio de la arqueofauna. En R. Goñi (Ed.), Soplando en el Viento, pp. 113-136. Universidad Nacional del Comahue- Instituto Nacional de Antropología y Pensamiento Latinoamericano, Neuquén-Buenos Aires.

Miotti, L.; D. Hermo; L. Magnin; N. Carden; L. Marchionni; A. Alcaraz; B. Mosquera; E. Terranova y M. Salemme 2007. Resolución arqueológica en la Cueva Maripe (Santa Cruz, Argentina). En F. Morello; M. Martinic; A. Prieto y G. Bahamonde (Eds.), Arqueología de FuegoPatagonia: Levantando piedras, desenterrando huesos...y develando arcanos, pp. 555-568. Ediciones CEQUA, Punta Arenas.

Páez, M. M.; A. R. Prieto y M. V. Mancini

1999. Fossil pollen from Los Toldos locality: a record of the Late-Glacial transition in the Extra-Andean Patagonia. Quaternary International 53-54: 69-76.

Panza, J. L.

1982. Descripción geológica de las Hojas 53e "Gobernador Moyano" y 54e "Cerro Vanguardia", provincia de Santa Cruz. Informe inédito presentado al Servicio Geológico Nacional, Buenos Aires.

2001. Hoja Geológica 4769-IV Monumento Natural Bosques Petrificados, Provincia de Santa Cruz. Boletín del SEGEMAR 258. Instituto de Geología y Recursos Minerales, Buenos Aires.

Paruelo, J.; R. Golluscio; E. Jobbágy; M. Canevarki y M. Aguiar 2005. Situación ambiental en la estepa patagónica. En A. Brown; U. Martínez Ortiz; M. Acerbi y J. Corcuera (Eds.), La situación ambiental argentina, pp. 303-313. Fundación Vida Silvestre Argentina, Buenos Aires.

Paunero, R.

2003. The presence of a Pleistocene Colonizing Culture in La Maria archaeological locality, Casa del Minero 1. En L. Miotti; M. Salemme y N. Flegenheimer (Eds.), Where the South Winds Blow: Ancient Evidence of Paleo South Americans, pp. 127-132. Center for the Study of the First Americans-Texas A\&M University Press, Texas. 
2009. La colonización humana de la meseta central de Santa Cruz durante el pleistoceno final: indicadores arqueológicos, referentes estratigráficos y nuevas evidencias. En M. Salemme; F. Santiago; M. Álvarez; E. Piana; M. Vázquez y M. Mansur (Eds.), Arqueología de la Patagonia. Una mirada desde el último confín, Tomo 1, pp. 85-100. Editorial Utopias, Ushuaia.

2010. La extinción de Hippidion saldiasi y su relación con el paleoambiente y los grupos humanos que colonizaron Patagonia. Nuevos datos provenientes de Cerro Bombero, Santa Cruz. En M. Gutiérrez; M. De Nigris; P. Fernández; M. Giardina; A. Gil; A. Izeta; G. Neme y H. Yacobacio (Eds.), Zooarqueología a principios del siglo XXI: Aportes Teórico, metodológicos y casos de estúdio, pp. 297-306. Ediciones del Espinillo, Buenos Aires.

Paunero, R. S., P. Albertengo, M. Cueto, A. Dávila, A. Frank, A. Olivera y C. Piva 2007. Sitio Casa del Minero 1, localidad arqueológica La María: nuevas evidencias sobre ocupación humana pleistocénica en Santa Cruz. En F. Oliva, N. de Grandis y J. Rodríguez (Comps.), Arqueología Argentina en los inicios de un nuevo siglo, pp. 337-344. Laborde Editor, Rosario.

Paunero, R. S., G. Rosales y M. Alberdi 2008. Cerro Bombero: registro de Hippidion saldiasi Roth, 1899 (Equidae, Perissodactyla) en el Holoceno temprano de Patagonia (Santa Cruz, Argentina). Revista Estudios Geológicos 64 (1): 89-98.

Prieto, A. R.; M. V Mancini y M. M. Páez 2002. Análisis polínico de la localidad de Los Toldos: armando rompecabezas. Trabajo presentado en las VJornadas de Arqueología de la Patagonia, Buenos Aires.

Rabassa, J.

1987. The Holocene of Argentina: a review. Quaternary of South America and Antarctic Peninsula 5: 269-290.

Rabassa, J.; C. Heusser y N. Rutter

1989. Late Glacial and Holocene of Tierra del Fuego. Quaternary of South America and Antarctic Peninsula 7: 327-351.

Raedecke, K.

1978. El guanaco de Magallanes, Chile. Su distribución y biología. Corporación Nacional Forestal. Publicación Técnica N ${ }^{\circ}$ 4. Ministerio de Agricultura, Chile. 
Ricciardi, A. y E. Rolleri

1980. Cordillera Patagónica austral. En J. C. M. Turner (Coord.), Segundo Simposio de Geología Regional Argentina II: 1173-1306. Academia Nacional de Ciencias, Córdoba.

Rindel, D.

2009. Arqueología de momentos tardíos en el noroeste de la Provincia de Santa Cruz (Argentina): una perspectiva faunística. Tesis doctoral inédita de la Facultad de Filosofía y Letras- Universidad de Buenos Aires, Buenos Aires.

Salemme, M. y L. Miotti

1987. Zooarchaeology and paleoenvironments: some examples from the Patagonian and Pampean Regions (Argentina). Quaternary of South America and Antarctic Peninsula 5: 24-47.

Sruoga, P; A. Busteros; R. Giacosa; H. Martínez; L. Kleiman; S. Japas; A. Maloberti y M. R. Gayone

2008. Análisis litofacial y estructural del complejo volcánico Bahía Laura en el área El Dorado-Montserrat, Provincia de Santa Cruz. Revista de la Asociación Geológica Argentina 63 (4): 653-664.

Tambussi, C. y E. Tonni

1985. Aves del sitio arqueológico Los Toldos, Cañadón de las Cuevas. Provincia de Santa Cruz (República Argentina). Ameghiniana 22 (1-2): 69-74.

Tonni, E. P.

1992. Mamíferos del holoceno en la Provincia de Buenos Aires. En M. Iriondo (Ed.), El Holoceno en la Argentina, pp. 64-78. CADINQUA, Buenos Aires.

Zárate, M., A. Blasi, y J. Rabassa

2000. Geoarqueología de la localidad Piedra Museo. En L. Miotti, R. Paunero, M. Salemme y G. R. Cattáneo (Eds.), Guía de Campo de la visita a las localidades arqueológicas. Taller Internacional "La Colonización del Sur de América durante la Transición Pleistoceno/Holoceno”, pp. 56.64. Servicoop, La Plata. 


\section{$\underline{\text { Capítulo } 3}$}

Aguerre, A.

1979. Observaciones sobre la Industria Toldense. Sapiens 3: 35-54.

1981-82. Los niveles inferiores de la Cueva Grande (Arroyo Feo), Área Río Pinturas. Provincia de Santa Cruz. Relaciones de la Sociedad Argentina de Antropología XIV (2): 211-239.

1982. Informe preliminar de las excavaciones de la Cueva 4 de La Martita, Departamento de Magallanes, Provincia de Santa Cruz. Trabajo presentado al VII Congreso de Arqueología Argentina, San Luis.

1987. Investigaciones arqueológicas en el área de La Martita, Dto. Magallanes, Provincia de Santa Cruz. En Comunicaciones del las Primeras Jornadas de Arqueología de la Patagonia, pp. 11-16. Gobierno de la Provincia de ChubutDirección de Impresiones Oficiales, Rawson.

1994. Restos óseos guanaco del Alero Charcamata. En C. Gradin y A. Aguerre (Eds.), Contribución a la Arqueología del Río Pinturas, provincia de Santa Cruz, Pp. 229- 243. Búsqueda de Ayllu, Concepción del Uruguay.

1997. Replanteo de la Industria Toldense. Arqueología de la Patagonia CentroMeridional. Tesis doctoral inédita de Facultad de Filosofía y Letras- Universidad Nacional de Buenos Aires, Buenos Aires.

2003. La Martita: ocupaciones de 8.000 años en la Cueva 4. En A. Aguerre (Comp.), Arqueología y Paleoambiente en la Patagonia Santacruceña Argentina, pp. 27-61. Nuevo Offset, Buenos Aires.

Aguerre, A. y C. Gradin 1994. Excavación del Alero Charcamata. En C. Gradin y A. Aguerre (Eds.), Contribución a la Arqueología del Río Pinturas, provincia de Santa Cruz, pp. 178188. Búsqueda de Ayllú, Concepción del Uruguay.

Aguerre A. M. y M. I. Pagano

1991. Análisis faunístico de la capa 3 del Alero Cárdenas. Arqueología 1: 226- 238. 
2003. Fauna de las ocupaciones de 8.000 años de la cueva de La Martita: Guanaco. En A. Aguerre (Comp.) Arqueología y Paleoambiente en la Patagonia Santacruceña Argentina, pp. 71-85. Nuevo Offset, Buenos Aires.

Aguerre, A.; M. I. Pagano y M. I. Scarafoni 1994 a. Material óseo de fauna guanaco, capa 2 del Alero Cárdenas. En A. Aguerre (Comp.) Arqueología y Paleoambiente en la Patagonia Santacruceña Argentina, pp. 100-109. Búsqueda de Ayllú, Concepción del Uruguay.

1994 b. Fauna Guanaco: capa 4 y 5 del Alero Cárdenas. En A. Aguerre (Comp.) Arqueología y Paleoambiente en la Patagonia Santacruceña Argentina, pp. 121-128. Búsqueda de Ayllú, Concepción del Uruguay.

Alberdi, M. T.; L. Miotti y J. L. Prado 2001. Hippidion saldiasi Roth, 1899 (Equidae, Perissodactyla), at the Piedra Museo Site (Santa Cruz, Argentina): Its implication for the regional economy and environmental reconstruction. Journal of Archaeological Science 28: 411-419.

Alonso, F.; C. Gradin; C. Aschero y A. Aguerre 1984-85. Algunas consideraciones sobre recientes dataciones radiocarbónicas para el Área del Río Pinturas, provincia de Santa Cruz. Relaciones de la Sociedad Argentina de Antropología XVI: 275-285.

Aschero, C.

1975. Ensayo para una clasificación morfológica de artefactos líticos aplicada a estudios tipológicos comparativos. Informe inédito presentado al CONICET, Buenos Aires.

1987. Tradiciones culturales en la Patagonia Central: una perspectiva arqueológica. En: Comunicaciones del las Primeras Jornadas de Arqueología de la Patagonia, pp. 17-33. Gobierno de la Provincia de Chubut- Dirección de Impresiones Oficiales, Rawson.

Aschero, C.; C. Pérez de Micou; M. Onetto; C. Bellelli; .L. Nacuzzi y A. Fisher 1988. Arqueología del Chubut. El valle de Piedra Parada. Gobierno de la Provincia del Chubut-Dirección Provincial de Cultura, Serie Humanidades, Rawson. 
Bayardo García, R.

1983. Dentición y estimación de edad en restos arqueológicos de guanaco -Cueva 4 de La Martita- Santa Cruz. Relaciones de la Sociedad Argentina de Antropología $\mathrm{XV}: 159-172$.

Barberena, R.

2008. Arqueología y biogeografía humana en Patagonia Meridional. Sociedad Argentina de Antropología, Buenos Aires.

Behrensmeyer, A. K.

1978. Taphonomic and ecologic information from bone weathering. Paleobiology 4: $150-162$.

Belardi, J. B.

1999. Hay choiques en la terraza. Información tafonómica y primeras implicaciones arqueofaunísticas para Patagonia. Arqueología 9: 163-185.

Borella, F.

2002. Tafonomía regional y estudios arqueofaunísticos de cetáceos en Tierra del Fuego y Patagonia meridional. Tesis doctoral inédita de Facultad de Filosofía y Letras- Universidad Nacional de Buenos Aires, Buenos Aires.

\section{Borrero, L. A.}

1976-80. La fauna de Las Buitreras: su significado en un marco sudamericano. RUNA XIII (1-2): 21- 30 .

1977. La extinción de la megafauna: su explicación por factores concurrentes. Anales del Instituto de La Patagonia 8: 81-93.

1984. The archaeology of continental Patagonia. Trabajo presentado al 4Sth Annual Meeting of the Soviety for American Archaeology, Portland.

1986. La economía prehistórica de los habitantes del Norte de la Isla Grande de Tierra del Fuego. Tesis doctoral inédita de la Facultad de Filosofía y LetrasUniversidad Nacional de Buenos Aires, Buenos Aires. 
1988. Tafonomía regional. En N. Ratto y A. Haber (Eds.), De Procesos, contextos y otros huesos, pp. 9-15. Facultad de Filosofía y Letras- Universidad Nacional de Buenos Aires, Buenos Aires.

1996. The Pleistocene-Holocene transition in Southern South America. En Straus, L., Eriksen, B., Erlanson, J. y D. Yesner (eds.), Humans at the End of the Ice Age. Plenum Press, New York, London, pppp. 339-354.

2000. Ten years after: esquema para una tafonomía regional de la Patagonia meridional y norte de Tierra del Fuego. En Desde el país de los Gigantes. Perspectivas arqueológicas en Patagonia. Tomo I, pp. 183-193. Universidad Nacional de la Patagonia, Río Gallegos.

2001. Cambios, continuidades, discontinuidades: discusiones sobre arqueología Fuego Patagónica. En E. Berberián y A. Nielsen (eds), Historia Argentina Prehispánica, Tomo II, pp. 815-838. Ediciones Brujas, Córdoba.

Bourlot, T.

2010. Zooarqueología de sitios a cielo abierto en el lago Cardiel, Provincia de Santa Cruz: fragmentación ósea y consumo de grasa animal en grupos cazadoresrecolectores del Holoceno tardío. Tesis doctoral inédita de la Facultad de Filosofía y Letras-Universidad Nacional de Buenos Aires, Buenos Aires.

Carden, N.

2009. Imágenes a través del tiempo: arte rupestre y construcción social del paisaje en la meseta central de Santa Cruz. Sociedad Argentina de Antropología, Buenos Aires.

Cardich, A.

1977. Las culturas Pleistocénicas y post-pleistocénicas de Los Toldos y un bosquejo de la Prehistoria de Sudamérica. Obra del Centenario del Museo de la Plata II: 149-172.

1979. A propósito de un motivo sobresaliente en las pinturas rupestres de "El Ceibo" (Provincia de Santa Cruz, Argentina). Relaciones de la Sociedad Argentina de Antropología XIII: 163-182.

1984. Paleoambientes y la más antigua presencia del hombre. En Las culturas de América en la época del Descubrimiento, pp. 1-36. Cultura Hispánica, Madrid. 
1987. Arqueología de Los Toldos y El Ceibo (Prov. de Santa Cruz, Argentina). Estudios Atacameños 8: 95-113.

Cardich, A. y N. Flegenheimer

1978. Descripción y tipología de las industrias líticas más antiguas de Los Toldos. Relaciones de la Sociedad Argentina de Antropología XII: 225-242.

Cardich, A. y A. Laguens

1984. Fractura intencional y posterior utilización del material óseo arqueológico de la Cueva 3 de Los Toldos, provincia de Santa Cruz, Argentina. (Contribución metodológica al estudio del material óseo fracturado recuperado en excavaciones arqueológicas). Revista Museo de La Plata VIII, Serie Antropología 63: 329-384.

Cardich, A. y L. Miotti

1983. Recursos faunísticos en la economía de los cazadores-recolectores de Los Toldos (provincia de Santa Cruz, Argentina). Relaciones de la Sociedad Argentina de Antropología XV: 145-157.

1988. Procesamiento de los recursos faunísticos de la Cueva 13 de Los Toldos, durante el Holoceno medio. Trabajo presentado al IV Congreso Nacional de Arqueología Argentina. Universidad de Buenos Aires, Buenos Aires.

Cardich, A. y R. Paunero 2000. Localidad Arqueológica La María. Introducción: Informe 1994. En L. Miotti; R. Paunero; M. Salemme y R. Cattáneo (Eds.), Guía de Campo de la visita a las Localidades arqueológicas. Taller Internacional "La colonización del Sur de América durante la transición Pleistoceno/Holoceno”, pp. 101-103. Servicoop, La Plata.

Cardich, A.; L. Cardich, y A. Hadjuk

1973. Secuencia arqueológica y cronología radiocarbónica de la cueva 3 de Los Toldos (Santa Cruz, Argentina). Revista Relaciones de la Sociedad Argentina de Antropología VII: 85-123. 
Cardich, A.; E. Tonni y N. Kriskautzky

1977. Presencia de Canis Familiaris en restos arqueológicos de Los Toldos (Provincia de Santa Cruz, Argentina. Relaciones de la Sociedad Argentina de Antropología XI: 115-119.

Cardich, A.; E. Mansur- Franchomme; M. Giesso y V. Durán

1981-82. Arqueología de las Cuevas de "El Ceibo" (Provincia de Santa CruzArgentina). Relaciones de la Sociedad Argentina de Antropología XIV (2): 173209.

Cattáneo, R.

2002. Una Aproximación a la Organización de la Tecnología Lítica entre los Cazadores-Recolectores del Holoceno Medio/Pleistoceno Final en la Patagonia Austral (Argentina). Tesis doctoral inédita de la Facultad de Ciencias NaturalesUniversidad Nacional de La Plata, La Plata.

Caviglia, S. E.

1976-80. La presencia de Dusicyon avus (Burmeister) 1864 en la Capa VIII de la Cueva "Las Buitreras" (Patagonia, Argentina): Su relación con otros hallazgos en Patagonia Meridional. RUNA XIII (1-2): 31-33.

Caviglia, S. y M. J. Figuerero Torres

1976. Material faunístico de Las Buitreras. Relaciones de la Sociedad Argentina de Antropología X: 315-319.

Caviglia, S.; H. Yacobaccio y L. A. Borrero

1986. Buitreras: convivencia del hombre con fauna extinguida en Patagonia meridional. En A. Bryan (ed.), New evidence of the Pleistocene peopling of the America, pp. 295-317. Center for the Study of Early Man- University of Maine, Orono.

Civalero, M. T. y C. Aschero 2003. Early occupations at Cerro Casa de Piedra 7, Santa Cruz Province, Patagonia, Argentina. En L. Miotti; M. Salemme y N. Flegenheimer, (Eds.), Ancient Evidence 
for Paleo South Americans: From Where the South Winds Blow, pp. 141-148. Center for the Study of First Americans and Texas A\&M University Press, Texas.

Cruz, I.

2003. Paisajes tafonómicos de restos de Aves en el sur de Patagonia continental. Aportes para la interpretación de conjuntos avifaunísticos en registros arqueológicos del Holoceno. Tesis doctoral inédita de Facultad de Filosofía y Letras- Universidad Nacional de Buenos Aires, Buenos Aires

Cueto, M. y A. Castro

2012. Technological and functional analysis of Pleistocene components from La Maria Locality, Santa Cruz, Argentina. En L. Miotti; M. Salemme; N. Flegenheimer y T. Goebel (Eds.), Southbound: Late Pleistocene Peopling of Latin America, pp. 149154. Center for the Study of the First Americans, Texas.

De Aparicio, F.

1933-35. Viaje preliminar de exploración en el territorio de Santa Cruz. Publicaciones Museo Antropológico y Etnográfico de la Facultad de Filosofía y Letras. Serie A. III: 71-92.

De Giusto, J. M.; C. A. Di Persia y E. Pezzi. 1980. Nesocratón del Deseado. En J. C. M. Turner (coord.), Segundo Simposio de Geología Regional Argentina II: 1390-1430. Academia Nacional de Ciencias, Córdoba.

De Nigris, $M$.

2004. El consumo en cazadores-recolectores. Un ejemplo zooarqueológico de Patagonia meridional. Sociedad Argentina de Antropología, Buenos Aires.

Durán, V.

1983-85. El arte rupestre de los cazadores patagónicos en El Verano, área de Departamento de Magallanes, Provincia de Santa Cruz (II). Anales de Arqueología y Etnología 38-40: 43-75. 
1986-87. Estudio Tecno-tipológico de los raspadores del sitio El Verano-Cueva I (Área de La Martita). Prov. de Santa Cruz. Anales de Arqueología y Etnología 4142: 129-163.

1988. Arqueología de El Verano. Santa Cruz. Precirculados del IX Congreso Nacional de Arqueología Argentina, pp. 71. Instituto de Ciencias AntropológicasFacultad de Filosofía y Letras- UBA, Buenos Aires.

1991. Estudios de perturbación por roedores del género Ctenomys en un sitio arqueológico experimental. Revista de Estudios Regionales CEIDER 7: 7-31.

Durán, V.; A. Gil; G. Neme y A. Gasco

2003. El Verano: Ocupaciones de 8.900 años en la Cueva 1 (Santa Cruz, Argentina). En A. Aguerre (comp.), Arqueología y Paleoambiente en Patagonia Santacruceña Argentina, pp. 93- 120. Nuevo Offset, Buenos Aires.

Etchichury, M. C.

1976. Sedimentología de la Cueva de Las Manos, Estancia Alto Río Pinturas (provincia de Santa Cruz). Relaciones de la Sociedad Argentina de Antropología X: 251-260.

Fernández, J.

1982. Historia de la arqueología argentina. Anales de Arqueología y Etnología 3435: $1-100$.

Franchomme, J. M.

1987. L'art Rupestre de Patagonie: quelques sites Prehistoriques du Plateau Central, Province de Santa Cruz, Argentine. Tesis doctoral inédita de la Universidad de París X. Nanterre.

Frank, A.

2011. Tratamiento térmico y manejo del fuego en sociedades cazadorasrecolectoras de la Meseta Central de Santa Cruz. Tesis doctoral inédita de la Facultad de Ciencias Naturales- Universidad Nacional de La Plata, La Plata. 
Frenguelli, J.

1933. Situación estratigráfica y edad de la "zona con araucaria" al sur del curso inferior del río Deseado. Apuntes de Geología Patagónica. Boletín de Informaciones Petrolíferas 112: 843-900.

Giardina, M.; D. Hermo; L. Miotti y M. Vázquez

2000. Capítulo. 4.5. Resolución e integridad arqueológica del Componente inferior de Piedra Museo. En L. Miotti; R. Paunero; M. Salemme y R. Cattáneo (Eds.). Guía de Campo de la visita a las Localidades arqueológicas. Taller Internacional "La colonización del Sur de América durante la transición Pleistoceno/Holoceno", pp. 79-83. Servicoop, La Plata.

Gradin, C.

1971. A propósito del arte rupestre de Patagonia Meridional. Anales de Arqueología y Etnología XXVI: 111-116.

1980. Secuencias radiocarbónicas del sur de la Patagonia Argentina. Relaciones de la Sociedad Argentina de Antropología XIV: 177-194.

1994. El alero Cárdenas. En C. Gradin y A. Aguerre (Eds.), Contribución a la Arqueología del Río Pinturas. Provincia de Santa Cruz, pp. 29-43. Búsqueda de Ayllú, Concepción del Uruguay.

Gradin, C. y A. Aguerre

1994. Contribución a la arqueología del Río Pinturas, Provincia de Santa Cruz. Colección "Estudios arqueológicos”. Búsqueda de Ayllú, Concepción del Uruguay.

Gradin, C.; C. Aschero y A. Aguerre

1976. Investigaciones arqueológicas en la Cueva de Las Manos, Estancia Alto Río Pinturas (Provincia de Santa Cruz). Relaciones de la Sociedad Argentina de Antropología X: 201-250.

1979. Arqueología del Área Rio pinturas. Provincia de Santa Cruz. Relaciones de la Sociedad Argentina de Antropología XIII: 183-227. 


\section{Hermo, D.}

2008. Los cambios en la circulación de las materias primas líticas en ambientes mesetarios de Patagonia. Una aproximación para la construcción de los paisajes arqueológicos de las sociedades cazadoras-recolectoras. Tesis doctoral inédita de la Facultad de Ciencias Naturales- Universidad Nacional de La Plata, La Plata.

Hermo, D. y L. Magnin

2012. Blade and bifacial technology in Mid-Holocene occupations at Deseado Massif, Santa Cruz province, Argentina. Quaternary International 256: 71-77.

\section{Horovitz, I.}

1991. Análisis del material faunístico (no guanaco) de la capa 3 del Alero Cárdenas. Arqueología I: 238-243.

1994. Restos Faunísticos no guanaco del alero Cárdenas, Parte II. En C. Gradin. y A. Aguerre (Eds.), Contribución a la Arqueología del Río Pinturas, provincia de Santa Cruz, pp. 63-72. Búsqueda de Ayllu, Concepción del Uruguay.

2003. Restos faunísticos de La Martita y nuevo registro biogeográfico de Lestodelphys halli (Didelphide, Mammalia). En A. Aguerre (Comp.), Arqueología y Paleoambiente en la Patagonia Santacruceña Argentina, pp. 87-91. Nuevo Offset, Buenos Aires.

Leanza, A. F.

1958. Geología regional Argentina. En La Argentina: Suma de Geografía, 1 (3): 217-349. Editorial Peuser, Buenos Aires.

\section{L’Heureux, L. y L. A. Borrero}

2002. Pautas para el reconocimiento de conjuntos óseos antrópico y no-antrópicos de guanaco en Patagonia. Intersecciones en Antropología 3:29-40.

\section{Magnin, L.}

2010. Distribuciones arqueológicas en la meseta central de Santa Cruz: Implicancias para los estudios de uso del espacio y movilidad de sociedades cazadoras recolectoras. Tesis doctoral inédita de la Facultad de Ciencias NaturalesUniversidad Nacional de La Plata, La Plata. 
Mansur-Franchomme, E.

1983. Traces d'utilisation et technologie lithique: exemples de la Patagonie. Tesis doctoral inédita de la Universidad de Bordeaux I, Bordeaux.

1987. El análisis funcional de artefactos líticos. Cuadernos Serie Técnica 1:1-87.

Marchionni, L.; L. Miotti y B. Mosquera

2010. El uso de la fauna entre el Pleistoceno final y el Holoceno medio en la Patagonia extra-andina. En M. Gutiérrez; M. De Nigris; P. Fernández; M. Giardina;

A. Gil; A. Izeta; G. Neme y H. Yacobacio (Eds.), Zooarqueología a principios del siglo XXI: Aportes Teórico, metodológicos y casos de estudio, pp. 259-272. Ediciones del Espinillo, Buenos Aires.

Martin, F.

2008. Tafonomía y paleoecología de la transición Pleistoceno-Holoceno en FuegoPatagonia: Interacción entre poblaciones humanas y de carnívoros y su importancia como agentes en la formación del registro fósil. Tesis doctoral inédita de la Facultad de Ciencias Naturales- Universidad Nacional de La Plata. La Plata.

Martin, F. y L. A. Borrero

1997. A Puma lair in southern Patagonia: implications for the archaeological record. Current anthropology 38(3): 453-461.

Menghin, O. F. A.

1952 a. Fundamentos Cronológicos de la Prehistoria de Patagonia. RUNA V: 2343.

1952 b. Las pinturas rupestres de Patagonia. RUNA V: 5-22.

1957. Estilos de Arte rupestre en Patagonia. Acta Praehistorica I: 57-87.

Mengoni Goñalons, G. L.

1976-80. Los materiales óseos de la Cueva 2 de Los Toldos (Expedición Menghin), y una aproximación a la metodología de análisis de Restos Faunísticos. RUNA XIII (1-2): 59-68. 
1999. Cazadores de guanacos de la estepa patagónica. Sociedad Argentina de Antropología, Buenos Aires.

2007. Archaeofaunal studies in Argentina: a historical overview. En M. Gutiérrez; L.

Miotti; G. Barrientos; G. L. Mengoni Goñalons y M. Salemme (Eds.), Taphonomy and zooarchaeology in Argentina, pp. 13-34. BAR International Series no 1601, Manchester.

Mengoni Goñalons, G. L. y M. Silveira

1976. Análisis e interpretación de los restos faunísticos de la cueva de las Manos Estancia Alto Río Pinturas (Provincia de Santa Cruz). Relaciones de la Sociedad Argentina de Antropología X: 261-270.

Miotti, L.

1992. Paleoindian occupation at Piedra Museo Locality, Patagonian Region, Argentina. Current Research in the Pleistocene 9: 30-32.

1995. Piedra Museo Locality: a special place in the New World. Current Research in the Pleistocene 12: 37-40.

1996. Piedra Museo (Santa Cruz): nuevos datos para el debate de la ocupación Pleistocénica en Patagonia. En J. Gómez Otero Ed.), Arqueología, sólo Patagonia, pp. 27-38. Publicación Secretaría de Cultura de Chubut- CONICET, Puerto Madryn.

1998. Zooarqueología de la Meseta Central y Costa de la Prov. de Santa Cruz: Un enfoque de las estrategias adaptativas aborígenes y los paleoambientes. Imprenta del Museo de Ciencias Naturales de San Rafael, San Rafael.

2003. South America. A paradox for building images of the colonization of the New World. En L. Miotti y M. Salemme (Eds.). South America, long and winding roads for the First Americans at the Pleistocene/Holocene Transition, 109-110: 147-173. 2006. Paisajes domésticos y sagrados desde la arqueología de los cazadoresrecolectores en el macizo del Deseado, provincia de Santa Cruz. Cazadores Recolectores Del Cono Sur. Revista De Arqueología 1: 13-42.

2011. La potenciación de los recursos entre los cazadores-recolectores de Patagonia. Factores, procesos e implicancia arqueológica. En Libro de Resúmenes del Segundo Congreso Argentino de Zooarqueología, pp. 62. Facultad de Ciencias Sociales- UNCPBA, Olavarría. 


\section{Miotti, L. y N. Carden}

2007. The relationships between rock art and archaeofaunas in the Central Patagonian Plateau. En M. Gutiérrez; L. Miotti; G. Barrientos; G. Mengoni Goñalons y M. Salemme (Eds.), Taphonomy and Archaeology in Argentina, pp. 203-218. BAR International Series, Manchester.

Miotti, L. y R. Cattáneo

1997. Bifacial technology at 13,000 years ago in Southern Patagonia. Current Research in the Pleistocene 14: 65-68.

Miotti, L. y L. Marchionni

2009. Procesando huesos: entre la Etnografía y la Arqueología. En M. Salemme, F. Santiago, M. Álvarez, E. Piana, M. Vázquez y M. Mansur (Eds.), Arqueología de la Patagonia. Una mirada desde el confín del mundo, pp. 787-799. Editorial Utopía, Ushuaia.

\section{Miotti, L. y M. Salemme}

1999. Biodiversity, taxonomic richness and generalist-specialists economical systems in Pampa and Patagonia regions, Southern South America. Quaternary International 53-54: 53-68.

2004. Poblamiento, movilidad y territorios entre las sociedades cazadorasrecolectoras de Patagonia: cambios desde la transición Pleistoceno/Holoceno al Holoceno medio. Complutum 15: 177-206.

2005. Hunting and butchering events at the Pleistocene/Holocene transition in Piedra Museo: An example of adaptation strategies of the first colonizers of Patagonia. En R. Bonnichsen, B. Leppers, D. Stanford y M. Waters (Eds.), Paleoamerican origins: Beyond Clovis, pp. 209-220. Texas A\&M University Press, Texas.

\section{Miotti, L.; N. Carden y M. J. Canosa} 1999 a. Paisajes arqueológicos de Cazadores-recolectores, Arte rupestre y Lagunas. En C. Díez Marín (Ed.), Actas del XII Congreso Nacional de Arqueología Argentina, tomo III: 54-63. Facultad de Ciencias Naturales y Museo, La Plata. 


\section{Miotti, L.; N. Carden y L. Magnin}

2007 b. Tendencia central, dispersión y orientación en el paisaje regional. Estudios de distribución del arte rupestre en la meseta central de Santa Cruz, Argentina. En: F. Morello, M. Martinic, A. Prieto y G. Bahamonde (Eds). Arqueología de FuegoPatagonia. Levantando piedras, desenterrando huesos...y develando arcanos, pp. 601-612. Ediciones CEQUA, Punta Arenas.

Miotti, L.; M. Salemme y A. Menegaz

1988. El manejo de los recursos faunísticos durante el Pleistoceno final y Holoceno temprano en Pampa y Patagonia. Actas del IX Congreso Nacional de Arqueología Argentina, pp. 102-118. Instituto de Ciencias Antropológicas- Facultad de Filosofía y Letras- UBA, Buenos Aires.

Miotti, L.; M. Vázquez, y D. Hermo

1999 b. Piedra Museo un Yamnagoo Pleistocénico en la colonización de la meseta de Santa Cruz. El estudio de la arqueofauna. En R. Goñi (ed.), Soplando en el Viento, pp.113-136. Universidad Nacional del Comahue- Instituto Nacional de Antropología y Pensamiento Latinoamericano. Neuquén- Buenos Aires.

Miotti, L.; D. Hermo, M. Salemme, L. Magnin y L. Marchionni

2009. Cueva Maripe y su excavación. Implicancias en los Estudios Regionales del Macizo del Deseado. En A. Austral y Tamagnini (comps.), Problemática de arqueología contemporánea, Tomo III. Pp. 1031-1035. Universidad Nacional de Río Cuarto, Río Cuarto.

Miotti, L.; D. Hermo; L. Magnin; N. Carden; L. Marchionni; A. Alcaraz; B. Mosquera; E. Terranova y M. Salemme 2007 a. Resolución arqueológica en la Cueva Maripe (Santa Cruz, Argentina). En F. Morello; M. Martinic; A. Prieto y G. Bahamonde (Eds.), Arqueología de FuegoPatagonia: Levantando piedras, desenterrando huesos...y develando arcanos, pp.555-568. Ediciones CEQUA, Punta Arenas. 
Miotti, L.; M. Salemme; D. Hermo; M. Vázquez; N. Carden; M. Giardina y L. Magnin 2005. Aguada del Cuero, un nuevo escalón en la arqueología de la Meseta Central de Santa Cruz. En E. Berberián (ed.), Actas XIII Congreso Nacional de Arqueología Argentina 4: 55-62. Universidad Nacional de Córdoba, Córdoba.

Miotti, L; L. Marchionni; B. Mosquera; D. Hermo y M. Fernández 2011. Aportes metodológicos para el ajuste temporal de las ocupaciones humanas de la Cueva Maripe, Santa Cruz, Argentina. En A. F. Zangrando; R. Barberena; A. Gil y G. Neme (Eds.), Libro de resúmenes de las VIII Jornadas de Arqueología de la Patagonia, p. 54. Centro de Convenciones y Exposiciones Thesaurus, Museo de Historia Natural de San Rafael, Malargüe.

Outes, F.

1905. La edad de la piedra en Patagonia. Estudio de Arqueología comparada. Anales del Museo Nacional de Buenos Aires XII: 203-575.

Pagano, M. I.

1996. Determinación de edad en mandíbulas de guanaco arqueológicas -cueva 4 La Martita- Santa Cruz. En J. Gómez Otero (ed.), Actas Segundas Jornadas de Arqueología en la Patagonia, pp. 279-292. Publicación Secretaria de Cultura De Chubut- CONICET, Puerto Madryn.

Pagano, M. I. y A. Aguerre

2001. Desgaste dentario y determinación de edad en guanacos arqueológicos: una puesta al día. En G. Mengoni Goñalons; D. Olivera y H.Yacobaccio (Eds.), El uso de los camélidos a través del tiempo, pp. 203-220. Editorial Tridente, Buenos Aires.

Paunero, R.

1994. El sitio Cueva 1 de la Localidad Arqueológica Cerro Tres Tetas (Estancia San Rafael, provincia de Santa Cruz, Argentina). Anales de Arqueología y Etnología 48/49: 73-90.

1996. Noticia sobre nuevas fechas radiocarbónicas del sitio Cueva 1, C3T, Santa Cruz, Argentina. Anales de Arqueología y Etnología 50-51: 189-199. 
2000 a. Relevamiento, arte rupestre y sectorización de la localidad La María. En L. Miotti; R. Paunero; M. Salemme y R. Cattáneo (Eds.). Guía de Campo de la visita a las Localidades arqueológicas. Taller Internacional "La colonización del Sur de América durante la transición Pleistoceno/Holoceno”, pp. 104-108. Servicoop, La Plata.

2000 b. Cueva de la Mesada de La María Quebrada. En L. Miotti; R. Paunero; M. Salemme y R. Cattáneo (Eds.). Guía de Campo de la visita a las Localidades arqueológicas. Taller Internacional "La colonización del Sur de América durante la transición Pleistoceno/Holoceno”, pp. 109-113. Servicoop, La Plata.

2000 c. Cañadón de La Mina: Sitio Casa del Minero 1. En L. Miotti; R. Paunero; M. Salemme y R. Cattáneo (Eds.). Guía de Campo de la visita a las Localidades arqueológicas. Taller Internacional "La colonización del Sur de América durante la transición Pleistoceno/Holoceno”, pp. 118-120. Servicoop, La Plata.

2000 d. Estratigrafía de sitio Cueva de la Ventana. En L. Miotti; R. Paunero; M. Salemme y R. Cattáneo (Eds.), Guía de Campo de la visita a las Localidades arqueológicas. Taller Internacional "La colonización del Sur de América durante la transición Pleistoceno/Holoceno”, pp. 113-116. Servicoop, La Plata. 2000 e. Localidad arqueológica Cerro Tres Tetas. En L. Miotti; R. Paunero; M. Salemme y R. Cattáneo (Eds.), Guía de Campo de la visita a las Localidades arqueológicas. Taller Internacional "La colonización del Sur de América durante la transición Pleistoceno/Holoceno”, pp. 89-100. Servicoop, La Plata.

2003 a. The Cerro Tres Tetas (C3T) locality in the Central Plateau of Santa Cruz, Argentina. En L. Miotti, M. Salemme y N. Flegenheimer (Eds.), Where the South Winds Blow: Ancient Evidence of Paleo South Americans, pp. 33-40. Center for the Studies of the First Americans-Texas A \& M University Press, Texas.

2003 b. The presence of a Pleistocene colonizing culture in La Maria archaeological locality, Casa del Minero 1. En L. Miotti, M. Salemme y N. Flegenheimer (Eds.), Where the South Winds Blow: Ancient Evidence of Paleo South Americans, pp. 127-132. Center for the Study of the First Americans- Texas A\&M University Press, Texas.

2009 a. Fogones, conjuntos líticos y funcionalidad en el componente pleistocénico del sitio Cueva 1 de Cerro Tres Tetas, provincia de Santa Cruz. En F. Oliva, N. de Grandis y J. Rodríguez (Eds.), Arqueología Argentina en los inicios de un nuevo siglo, Tomo 2, pp. 419-428. Universidad Nacional de Rosario, Rosario. 
2009 b. La colonización humana de la Meseta Central de Santa Cruz durante el pleistoceno final: indicadores arqueológicos, referentes estratigráficos y nuevas evidencias. En M. Salemme, F. Santiago, M. Álvarez, E. Piana, M. Vázquez y M. Mansur (Eds.), Arqueología de la Patagonia. Una mirada desde el último confín. Tomo 1, pp. 85-100. Editorial Utopías, Ushuaia.

Paunero, R. S. y A. Castro

2001. Análisis lítico y funcionalidad del componente inferior del sitio Cueva 1, localidad arqueológica Cerro Tres Tetas, provincia de Santa Cruz, Argentina. Anales del Instituto de la Patagonia (Serie Ciencias Sociales) 29: 189-206.

Paunero, R. S.; M. E. Cueto; A. Frank; G. Rosales; F. Skarbun; M. F. Paunero y G. Zapata

2004. Localidad Arqueológica La María en la Meseta Central de Santa Cruz: estado actual de nuestra investigación. Trabajo presentado $X V$ Congreso Nacional de Arqueología Argentina. Universidad Nacional de Río Cuarto, Río Cuarto.

Paunero, R. S.; A. Frank; F. Skarbun; G. Rosales; G. Zapata; M. Cueto; M. F. Paunero; D. G. Martínez; R. López; N. Lunazzi y M. Del Giorgio 2005. Arte rupestre en Estancia La María, Meseta Central de Santa Cruz: sectorización y contextos arqueológicos. Relaciones de la Sociedad Argentina de Antropología XXX: 147-168.

Paunero, R.; A. Frank; F.Skarbun; G. Rosales; M. Cueto; G. Zapata; M. Paunero; N. Lunazzi y M. Del Giorgio

2007 a. Investigaciones arqueológicas en sitio Casa del Minero 1, Estancia La María, Meseta Central de Santa Cruz. En F. Morello; M. Martinic; A. Prieto y G. Bahamonde (Eds.), Arqueología de Fuego-Patagonia. Levantando piedras, desenterrando huesos... y develando arcanos, pp. 577-588. Ediciones CEQUA, Punta Arena. 
Paunero, R. S.; A. Frank; F. Skarbun; M. F. Paunero; M. Cueto; G. Rosales; N. Lunazzi y D. Martínez

2007 b. Componente pleistocénico del sitio Cueva Túnel de la María Quebrada: fauna extinta y artefactos asociados. Trabajo presentado en el XVII Congreso Nacional de Arqueología Argentina. San Salvador de Jujuy.

Paunero, R. S.; M. F. Paunero y D. Ramos

2010. Artefactos óseos en componentes del Pleistoceno final de las Localidades La María y Cerro Tres Tetas, Santa Cruz, Argentina. En M. Gutiérrez, M. De Nigris, P. Fernández, M. Giardina, A. Gil, A. Izeta, G. Neme y H. Yacobaccio (Eds.), Zooarqueología a principios del siglo XXI. Aportes teóricos, metodológicos y casos de estudio, pp. 459-466. Ediciones del Espinillo, Buenos Aires.

Pereda, I.

1994. Restos óseos no guanaco del Alero Charcamata. En C. Gradin y A. Aguerre (Eds.), Contribución a la Arqueología del Río Pinturas, provincia de Santa Cruz, pp. 244-246. Búsqueda de Ayllu, Concepción del Uruguay.

Podestá, M.; R. S. Paunero y D. Rolandi 2005. El Arte Rupestre de Argentina Indígena: Patagonia. Academia Nacional de la Historia- Union Academique Internacional, Buenos Aires.

Politis, G.

1984. Arqueología del área Interserrana Bonaerense. Tesis doctoral inédita de la Facultad de Ciencias Naturales- Universidad Nacional de La Plata, La Plata.

Politis, G.

1992. Politica nacional, arqueologia y universidad en Argentina. Arqueología en América latina hoy. Ed. G. Politis, Bogotá, Banco Popular, pp. 70-87.

Ramos, V.

1999. Las provincias geológicas argentinas. En R. Caminos (Ed.), Geología Argentina, pp. 41-97. SEGEMAR, Buenos Aires. 
Ramos, D. y M. F. Paunero

2009. Estudio preliminar de los elementos óseos de un sitio componente pleistocénico: sitio Cueva Túnel, localidad La María, Provincia de Santa Cruz. Libro de resúmenes VIII Jornadas de Jóvenes Investigadores en Ciencias Antropológicas, pp. 32. INAPL, Buenos Aires.

Rindel, D.

2009. Arqueología de momentos tardíos en el noroeste de la Provincia de Santa Cruz (Argentina): una perspectiva faunística. Tesis doctoral inédita de la Facultad de Filosofía y Letras- Universidad de Buenos Aires, Buenos Aires.

Salemme, M. y L. Miotti

2008. Archaeological hunter-gatherer landscapes since the latest Pleistocene in Fuego-Patagonia. En J. Rabassa (Ed.), Late Cenozoic of Patagonia and Tierra Del Fuego, pp. 437-483. Elsevier, Nueva York

Sanguinetti de Bórmida, M. A. y L. A. Borrero

1977. Los niveles con fauna extinta de la cueva de las Buitreras. Relaciones de la Sociedad Argentina de Antropología XI: 167-175.

Silveira, M.

1979. Análisis e interpretación de los restos faunísticos de la Cueva Grande del Arroyo Feo (provincia de Santa Cruz). Relaciones de la Sociedad Argentina de Antropología XIII: 229-253.

Skarbun, F.

2009. La organización tecnológica en grupos cazadores recolectores desde las ocupaciones del Pleistoceno final al Holoceno tardío, en la Meseta Central de Santa Cruz. Tesis doctoral inédita de la Facultad de Ciencias Naturales- Universidad Nacional de La Plata. La Plata.

Skarbun, F.; A. Frank; M. Paunero; M. Cueto y G. Rosales 2007. Análisis de la tecnología lítica del Sitio Casa del Minero 1, Meseta Central de Santa Cruz. En F. Morello; M. Martinic; A. Prieto y G. Bahamonde (Eds.), 
Arqueología de Fuego-Patagonia. Levantando piedras, desenterrando huesos... y develando arcanos, pp. 589-600. Ediciones CEQUA, Punta Arena.

Vignati, M. A.

1950. Estudios antropológicos en la zona Militar de Comodoro Rivadavia, I Relación. Anales del Museo de La Plata, Antropología, I: 1-18.

\section{$\underline{\text { Capítulo } 4}$}

Aguerre, A. M.

2000. Las vidas de Pati en la toldería Tehuelche del Río Pinturas y después. Universidad Nacional de Buenos Aires.

Álvarez, M. C; M. González; A. Massigoge; C. Kaufmann y M. A. Gutiérrez. 2010. La densidad mineral ósea y la variabilidad ontogénica en guanaco (Lama guanicoe). Implicancias para la construcción de marcos de referencia en Zooarqueología. En M. Gutiérrez; M. De Nigris; P. Fernández; M. Giardina; A. Gil; A. Izeta; G. Neme y H. Yacobacio (Eds.), Zooarqueología a principios del siglo XXI: Aportes Teórico, metodológicos y casos de estudio, pp. 95-106. Ediciones del Espinillo, Buenos Aires.

Barberena, R.

2008. Arqueología y biogeografía humana en Patagonia Meridional. Sociedad Argentina de Antropología, Buenos Aires.

Bartram, L. E.

1993. Perspectives on Skeletal part profiles and utility curves from Eastern Kalahari ethnoarchaeology. En From bones to behavior: ethnoarchaeology and experimental contributions to the interpretation of faunal remains, editado por J Hudson, pp. 115-137. Occasional Paper, 21. Carbondale: Center for Archaeological Investigations, Southern Illinois University. 
Behrensmeyer, A. K.

1975. The taphonomy and paleoecology of plio-pleistocene vertebrate assemblages east of Lake Rudolf, kenya. Bulletin of the Museum of Comparative Zoology 146(10): 473-578.

Behrensmeyer, A. K. y S. M. Kidwell.

1985. Taphonomy's contribution to paleobiology. Paleobiology 11: 105-119.

Behrensmeyer, A. K.; K. D. Gordon y G. Yanagi

1989. Nonhuman bone modification in Miocene fossil from Pakistan. En R. Bonnichen, y M. Sorg (Eds.), Bone Modification. Peopling of Americas, pp. 99-120. Center for the Study of the First Americans- University of Maine, Orono.

Belardi, J.B.

2005. Paisajes Arqueológicos: un estudio comparativo de diferentes ambientes patagónicos. Archaeopress, Oxford.

Binford, L.

1978 Nunamiut Ethnoarchaeology. University of New Mexico, Academic Press, Albuquerque.

1980 Willow smoke and dogs' tails: hunter-gatherers settlement systems and archaeological site formation. Working at archaeology. Pp. 337-356, Academic Press.

1981. Bones: Ancient Men and Modern Myths. Academic Press. New York.

Binford, L. y J. B. Bertram

1977. Bone Frequencies and Attritional Processes. En: For Theory Building in Archaeology, editado por L. R. Binford, pp. 77-153. Academic Press, Nueva York.

\section{Belardi, J. B. y J. Gomez Otero.}

1998. Anatomía Económica del Huemul (Hippocamelus bisulcus): una contribución a la interpretación de las evidencias arqueológicas de su aprovechamiento en Patagonia. Anales del instituto de la Patagonia 26: 195-207. 
Bettinger, R. L.

1991 Hunter- Gatherers: Archaeological and Evolutionary Theory. University of California. Plenum Press, New York/ London: Plenum Press.

Borrero, L. A.

1986. La economía prehistórica de los habitantes del Norte de la Isla Grande de Tierra del Fuego. Tesis doctoral inédita de la Facultad de Filosofía y LetrasUniversidad Nacional de Buenos Aires, Buenos Aires.

1988. Tafonomía Regional. De Procesos, Contextos y Otros Huesos. Editado por Ratto N. y A. Haber, 9-15. ICA. Sección Prehistoria. FFyL. UBA. Buenos Aires.

1990. Taphonomy of guanaco bones in Tierra del Fuego. Quaternary Research 34: $361-371$

1994-95. Arqueología de la Patagonia. Palimpsesto 4: 9-69.

1998. Tafonomía regional. En Ratto, N.; Haber (Comps). De procesos, contextos y otros huesos. FFyL-UBA. Pp 9-15.

2001 Regional Taphonomy: The Scales of Application to the Archaeological Record. Animals and Man in the Past. Essay in honour of Dr. A. T. Clason emeritus professor of archaeozoology Rijksuuniversiteit Groningen, the Netherlands. Editado por H. Buitenhuis y W. Prummel, pp. 17-20, ARCPublicatie 41, Groningen, Holanda

2009. The elusive evidence: The archaeological record of the South American extinct megafauna. En American Megafaunal Extinctions at the end of the Pleistocene, editado por G. Haynes, pp. 145-168. Springer Science.

2011. La Función Transdisciplinaria de la Arqueozoología en el siglo XXI: restos animales y más allá. Antípodas N¹3, pp 267-274. Bogotá, Colombia.

Blumeschine, R. J. y C. W. Marean

1993. A carnivore's view of archaeological bone assemblage. En: From bones to behavior, editado por J. Hudson, pp. 273-300. Center for Archaeological Investigation, Southern Illinois University, Carbondale.

Bourlot, T.

2010. Zooarqueología de sitios a cielo abierto en el lago Cardiel, Provincia de Santa Cruz: fragmentación ósea y consumo de grasa animal en grupos cazadores- 
recolectores del Holoceno tardío. Tesis doctoral inédita de la Facultad de Filosofía y Letras-Universidad Nacional de Buenos Aires, Buenos Aires.

Brain, C. K.

1969. The contribution of Namib Desert Hottentots to an understanding of Australopithecine bone accumulations, Scientific Papers of the Namib Desert Research Station 39: 13-22.

1976. Some principles in the interpretation of bone accumulations associated with man. En G. L. Isaac y E. R. McCown (Eds.). Human origins: Luis Leakey and the East African evidence, pp. 97-116. Menlo Park: W. A. Benjamin, Inc.

1981. The Hunters or the Hunted? An introduction to African Cave Taphonomy. The University of Chicago Press, Chicago.

Bridges, $\mathrm{T}$.

1952. El último confín de la Tierra. Emecé Editores, Buenos Aires.

Brink, J. W. y B. Dawe

1989. Final report of the 1985 and 1986 field season at Head-Smashed-In buffalo jump, Alberta. Archaeological Survey of Alberta Manuscript Series $\mathrm{N}^{\circ} 16$. Edmonton.

Bunn, H. T.

1993. Bone assemblages at base camps: a further consideration of carcass transport and bone destruction by the Hadza. En From bones to behavior: ethnoarchaeology and experimental contributions to the interpretation of faunal remains, editado por J Hudson, pp. 158-168. Occasional Paper, 21. Carbondale: Center for Archaeological Investigations, Southern Illinois University.

Chambers, A. L

1992. Seal bone mineral density: its effect on specimen survival in arcjaeological sites. Tesis Doctoral inédita. Departament of Anthropology, University of Misouri, Columbia. 
Claraz, J.

1988. Diario de viaje de exploración al Chubut 1865-1866. Marymar, Buenos Aires.

De Nigris, M.

2004. El consumo en cazadores-recolectores. Un ejemplo zooarqueológico de Patagonia meridional. Editorial Sociedad Argentina de Antropología, Buenos Aires. 2008. Modelos de transporte etnoarqueológicos: sobre su aplicabilidad y pertinencia en el interior de Patagonia. En A. Acosta; D. Loponte y L. Mucciolo (Comps.), Estudios tafonómicos y zooarqueológicos I, pp. 37-55. INAPL-AINA, Buenos Aires.

De Nigris, M. y G. Mengoni Goñalons

2004. El guanaco como fuente de carne y grasas en Patagonia. En T. Civalero; P. Fernández y A. G. Guráieb (Eds.), Contra viento y marea. Arqueología de Patagonia, pp. 469-476. Instituto Nacional de Antropología y Pensamiento Latinoamericano, Buenos Aires.

Durán, V.; A. Gil; G. Neme y A. Gasco 2003. El Verano: Ocupaciones de 8.900 años en la Cueva 1 (Santa Cruz, Argentina). En A. Aguerre (comp.), Arqueología y Paleoambiente en Patagonia Santacruceña Argentina, pp. 93-120. Nuevo Offset, Buenos Aires.

Elkin, D. C.

1995. Volume density of South American camelids skeletal parts. International Journal of Osteoarchaeology 5: 29-37.

Elkin, D. C. y J. Zanchetta.

1991. Densitometría ósea de camélidos- aplicaciones arqueológicas. Actas del X Congreso Nacional de Arqueología Argentina Tomo 3, pp. 195-204. Catamarca. 


\section{Emerson, A. M.}

1993. The Role of Body Part Utility in Small-scale Hunting under Two Strategies of Carcass Recovery. En: From Bone To Behaviour, Ethnoarchaeological and Experimental Contributions to the Interpretation of Faunal Remanis, editado por J. Hudson. Center for Archaeological Investigations, Southern Illinois University at Carbondale.

Favier-Dubois, C.

1997. Indicadores de tasas de depositación relativas en el registro arqueológico, su aplicación en sitios de Fuego Patagonia, Arqueología (7) pp. 51-75.

Farrand, W. R.

1985. Rockshelter and cave sediments. En J .K Stein y W. R. Farrand (Eds.), Archaeological sediments in context, pp. 21-40. Center for the Study of Early ManInstitute for Quaternary Studies- University of Maine, Orono.

1993. Discontinuity in the stratigraphic record: snapshots from Franchti cave. En: Goldberg, P., Nash, D.T., Petraglia, M.D. (Eds.), Formation Processes in Archaeological Context. Monographs in World Archaeology $\mathrm{N}^{\circ}$ 17. Prehistory Press, Madison, Wisconsin, pp. 85-96.

Fernandez, P.

2010. Cazadores y presas: 3500 años de interacción entre seres humanos y animales en el Noroeste de Chubut. Buenos Aires: Fundación de Historia Natural Félix de Azara.

Ferring, C. R.

1986. Rates of Fluvial Sedimentation: Implications for Archaeological Variability. Geoarchaeology: An International journal, Vol. 1, N³ pp. 259-274.

Frontini, R.

2012. El Aprovechamiento de animales en valles fluviales y lagunas del sur bonaerense durante el Holoceno. Tesis doctoral inédita de la Facultad de Filosofía y Letras- Universidad Nacional de Buenos Aires, Buenos Aires. 
Gallardo, C. R.

1910. Los Onas. Cabaut y Cia. Editores. Buenos Aires.

Gándara, M.

2006 La inferencia por analogía: más allá de la analogía etnográfica. Etnoarqueología de la prehistoria: más allá de la analogía. Consejo Superior de Investigaciones Científicas (CSIC). Pp. 13-23, Madrid.

Giardina, M. A

2006. Anatomía económica de Rheidae. Intersecciones en Antropología 7.

Gifford-Gonzalez, D. P.

1989a Overview Modern analogues: developing and interpretative framework. Bone Modification. Bonnichsen, R. \& Sorg, M. (eds.) Pp.43-52, Peopling of Americas publications edited volume series, Center for the study of the first Americans, University of Maine, Orono.

1989b Etnographic analogues for interpreting modified bones: some cases from Africa. Bone Modification. Bonnichsen, R. \& Sorg, M. (eds.) Pp.179-246, Peopling of Americas publications edited volume series, Center for the study of the first Americans, University of Maine, Orono.

1991 Bones are not enough: analogues, knowledge, and interpretive strategies in zooarchaeology. Journal of Anthropological Archaeology 10:215-254

1993 Gaps in Zooarchaeological Analyses of Butchery: Is Gender an Issue? En: Interpretation of Faunal Remains, editado por J. Hudson, pp. 181-199. Center for Archaeological Investigations, Ocassional Paper 21. Southern Illinois University at Carbonale.

2008. Toughts on a Method for Zooarchaeologcal Study of Quotidian Life, en Interpreting Household Practices. En: Engendering Social Dynamics: The Archaeology of Maintenance Activities. Montón-Subías, S. y M. Sánchez-Romero (Editores) BAR. Pp. 15-23.

\section{Grayson D.}

1984 Quantitative Zooarchaeology. Academic Press, New York. 
Gutiérrez, M. A.

2004. Análisis tafonómicos en el Área Interserrana, provincia de Buenos Aires. Tesis doctoral inédita de Facultad de Ciencias Naturales- Universidad Nacional de La Plata, La Plata.

Gutiérrez M. y C. Kaufmann.

2007. Criteria for the identificationof formation processes in guanaco (Lama guanicoe) bone assemblages in fluvial-lacustrine environments. Journal of Taphonomy 5 (4): 151-176.

Gutiérrez, M. A.; C. Kaufmann; M. González; A. Massigoge y M. C. Álvarez 2010. Intrataxonomic variability in metapodial and femur bone density related to age in guanaco (Lama guanicoe). Zooarchaeological and taphonomical implications. Journal of Archaeological Science 37 (12): 3226-3238.

Grayson D.

1984 Quantitative Zooarchaeology. Academic Press, New York.

Haynes, G.

1980. Evidence of carnivore gnawing on Pleistocene and recent mammalian bones. Paleobiology 6 (3): 341-351.

Ioannidou, E. 2003. Taphonomy of Animal Bones: Species, Sex, Age and Breed Variability of Sheep, Cattle and Pig Bone Density, Journal of Archaeological Science 30: 355365.

Johnson, E.

1985. Current developments in bone technology. En M. B. Schiffer (Ed.), Advances in Archaeological Method and Theory 8: 157-235. 
Kelly, R.

1995. The Foraging Spectrum: diversity in hunter-gatherer lifeways. Smithsonian Institution Press, Washington.

Kent, S.

1993. Variability in faunal Assemblages: the influence of hunting skill, sharing, dogs, and mode of cooking on faunal remains at a sedentary Kalahari community. Journal of Anthropological Archaeology 12 (4): 323-385.

Kreutzer, L. A.

1992. Bison and deer bone mineral densities: comparisons and implications for the interpretation of archaeological faunas. Journal of Archaeological Science 19: 271294.

Kornfeldm, M.; S. Vasil'ev y L. Miotti

2008. On shelter's ledge histories, theories and methods of rockshelter. British Archaeological Reports. Vol. 14.

Lam, Y. M y O. M. Pearson

2004. The Fallibility of Bone Density Values and Their Use in Archaeological Analyses. Journal of Taphonomy 2(2): 99-112.

2005. Bone density studies and the interpretation of the faunal record. Evolutionary Anthropology 14: 99-108.

Lam, Y. M; O. M. Pearson; C. W. Marean y X. Chen

2003. Bone Density Studies in Zooarchaeology. Journal of Archaeological Science 30: 1701-1708.

Lyman, R. L.

1982. a. Archaeofaunas and subsistence studies. In (M. B. Schiffer. Ed.) Advances in archaeological method an Theory vol. 5, pp. 331- 393. New York: Academic Press. 
1982 b. The taphonomy of vertebrate archaeofaunas: bone density and differential survivorship of fossil classes. Ph. D. dissertation, University of Washington, Seattle. Ann Arbor: University Microfilms International.

1984. Bone density and differential survivorship of fossil clases. Journal of Antrhopological Archaeology 3: 259-299.

1992. Anatomical considerations of utility curves in zooarchaeology. Journal of Archaeological Science 19: 7-22.

1994. Vertebrate Taphonomy. Cambridge Manuals in Archaeology. Cambridge University Press. Cambridge.

Lyman, R. L., L. E. Houghton y A. L. Chambers. 1992. The effect of structural density on marmot skeletal part representation in archaeological sites. Journal of Archaeological Science 19: 557-573.

Lupo, K. D.

1998. Experimentally Derived Extraction Rates for Marrow: Implications for Body Part Exploitation Strategies of Plio-Pleistocene Hominid Scavengers. Journal of Archaeological Science 25: 657-675.

2007. Evolutionary foraging models in zooarchaeological analysis: recent applications and future challenges. Journal of Archaeological Research 15: 143-189.

Lupo, K. D y.D. N Schmitt

2005 Small prey hunting technology and zooarchaeological measures of taxonomic diversity and abundance: Ethnoarchaeological evidence from Central African forest foragers. Journal of Anthropological Archaeology. Vol. 14: 335-353.

Madrigal, T. C y J. Z. Holt.

2002. White-tailed deer meat and marrow return rates and their application to Eastern Woodlands archaeology. American Antiquity 67: 745-759.

Marani, H.

2011. Anatomía económica de Mara (Dolichotis patagonum) y su aplicación en la evaluación de restos zooarqueológicos recuperados en la costa norpatagonica (Río Negro, Argentina). Magallania Vol. 39(2): 267-278. Chile. 


\section{Marean, C. W.}

1995. Of taphonomy and zooarchaeology. Evolutionary Anthropology 4 (2), 64-72.

Marean, C. W. y L. M. Spencer

1991. Impact of carnivore ravaging on zooarchaeological measures of element abundance. American Antiquity 56(4): 645-658.

Martínez, G.

1999. Tecnología, Subsistencia y Asentamiento en el Curso Medio del Río Quequén Grande: Un Enfoque Arqueológico. Tesis doctoral inédita, Facultad de Ciencias Naturales y Museo, Universidad Nacional de La Plata.

Massigoge, A.

2010. Arqueología de los Cazadores-Recolectores del Sudeste de la Región Pampeana: Una Perspectiva Tafonómica. Tesis doctoral inédita, Facultad de Ciencias Naturales y Museo, Universidad Nacional de La Plata.

Massigoge, A.; M. González; C. Kaufmann y M. Gutiérrez,

2010. Observaciones actualísticas sobre meteorización ósea en restos esqueletales de guanaco. En M. Berón; D. Luna; M. Bonomo; C. Montalvo; C. Aranda y M. Carrera Aizpitarte (Eds.), Mamül Mapu. Pasado y presente desde la arqueología pampeana, Tomo I, pp. 309-322. Libros del Espinillo, Buenos Aires.

Marshall, F

1993 Food Sharing and the Faunal Record. En: From Bones to Behavior: Ethnoarchaeological and Experimental Contributions to the Interpretation of Faunal Remains. Editado por J. Hudson, pp. 228-46. Center for Archaeological Investigations, Occasional Paper 21. Southern Illinois University at Carbondale.

Mengoni Goñalons, G. L.

1988. El Estudio de huellas en arqueofaunas. Una vía para reconstruir situaciones interactivas en contextos arqueológicos. Aspectos teóricos-metodológicos y técnicas de análisis. In: Haber, A., Ratto, N (Eds.), De procesos, contextos y otros huesos. Facultad de Filosofía y Letras, Universidad de Buenos Aires, pp. 17-28. 
1991. La llama y sus productos primarios. Arqueología. Revista de la Sección Prehistoria 1: 179-196.

1996. La domesticación de los camélidos sudamericanos y su anatomía económica.

En D. C. Elkin y C. M. Madero, Zooarqueología de camélidos 2: 33-46.

1999. Cazadores de guanacos de la estepa patagónica. Sociedad Argentina de Antropología, Buenos Aires.

2007. Archaeofaunal studies in Argentina: a historical overview. In: Gutiérrez, M.A., Miotti, L., Barrientos, G., Mengoni Goñalons, G., Salemme, M. (Eds.), Taphonomy and Zooarchaeology in Argentina, Vol. 1601. British Archaeological Research International Series, Oxford, pp. 13-34.

2010. Zooarqueología en la práctica: algunos temas metodológicos. Xama 19-23: 83-113.

Messineo, P. G

2008. Investigaciones arqueológicas en la cuenca superior del Arroyo Tapalqué (Partidos de Olavarría y Benito juárez, Provincia de Buenos Aires). Tesis doctoral inédita, Facultad de Ciencias Naturales y Museo, Universidad Nacional de La Plata.

Metcalfe, D. y K. T. Jones.

1988. A reconsideration of animal body part utility índices. American Antiquity 53: 486-504.

Miotti, L.

1998 Zooarqueología de la meseta central y la costa de la provincia de Santa Cruz. Un enfoque de las estrategias adaptativas y los paleoambientes. Tesis Doctoral FCNyM. Univ. Nac. La Plata. Pp. 1-564., Museo de Historia Natural de San Rafael.

2008. Household and sacred landscapes among Holocene hunter-gatherers of Patagonia's Central Plateau. Before Farming 2008/3: 5-44

2010. Cuevas y abrigos rocosos: nudos de las redes sociales entre los cazadoresrecolectores del Macizo del Deseado, Patagonia extra-andina. En J. C. Jiménez; C. Serrano; A. González y F. Aguilar (Eds.), III Simposio Internacional (2008) El Hombre Temprano en América, pp. 147-174. UNAM-Instituto de Investigaciones Antropológicas-INAH, México. 
Miotti, L. y L. Marchionni

2012. Autopodios de guanacos: un caso de equifinalidad entre lo palatable y lo preservado del registro zooarqueológico. Libro de Resúmenes II Encuentro Latinoamericano de Arqueozoología, pp. 39. Santiago de Chile.

Miotti, L; Vázquez, M. y Hermo, D.

1999. Piedra Museo, un Yammago pleistocénico de los colonizadores de la meseta de santa cruz. El estudio de la arqueofauna. En: Soplando en el Viento. Actas de las Terceras Jornadas de Arqueología de la Patagonia, pp.113- 136.

Miotti, L.; Hermo, D.; Salemme M.; Magnín, L.; Cárden, N.; Marchionni, L.; Alcaraz, A.; Mosquera, B.; Terranova, E. y Salemme, M.

2007 Resolución e Integridad Arqueológica de la Cueva Maripe (Santa Cruz Argentina). En: Arqueología de Fuego-Patagonia. Levantando piedras, desenterrando huesos... y develando arcanos. Ediciones CEQUA. Punta Arenas, Chile. Pp 555-568

Mondini, M.

2002. Formación del registro arqueofaunístico en abrigos rocosos de la Puna argentina. Tafonomía de carnívoros. Ph.D. Universidad de Buenos Aires. Buenos Aires. Argentina

Montón Subías, S.

2002 Cooking in Zooarchaeology: Is This Issue Still Raw? Consuming passions and patterns of consumtion. Ed. Preston Miracle and Nicky Milner. McMonald Institute Monografhs. Cap 2. Pp7-15

Morín, E.

2007 Fat composition, skeletal part selection, and Nunamiut decision- making. Journal of Archaeological Science 34: 69-82

Muñoz, A.S.

2002. La explotación de mamíferos por cazadores- recolectores terrestres de Tierra del Fuego. Unpublished PhD, Universidad de Buenos Aires. Argentina. 
Musters, G. C.

1964. Vida entre los Patagones. Un año de excursiones por tierras no frecuentadas desde el Estrecho de Magallanes hasta el Río Negro. Ediciones Solar- Hachette, Buenos Aires.

Nash, D. T. y M. D. Petraglia.

1987. Natural Formation Processes and the Archaeological Record: Present Problems and Future Requisites. En: Natural Formation Process and the Archaeological Record, editado por D. T. Nash y M. D. Petraglia. BAR Internacional Series 352: 186-204

O’Connell, J. F.

1995 Etnoarchaeology needs a general theory of behavior. Journal of Archaeological Research 3: 205-255.

O’Connell, J. F.; K. Hawkes y N. B. Jones. 1990. Reanalysis of large mammal body part transport among the Hadza. Journal of Archaeological Science 17: 301-316.

O'Connor, T.

2000. The Archaeology of Animal Bones. Sutton Publishing. Great Britain

\section{Oliver, J. S.}

1993. Carcass Processing by the Hadza: Bone Breakage from Butchery to Consumption. En From Bones to Behavior: Ethnoarchaeological and Experimental Contributions to the Interpretation of Faunal Remains, editado por J. Hudson, pp. 200-227, Center for Archaeological Investigations, University at Carbondale, Southern Illinois

Olivera, D. E.

2001. Perfil etario y rendimiento económico de Lama Glama. En: El uso de los camélidos a través del tiempo, editado por G. L. Mengoni Goñalons, D. E. Olivera y H. D. Yacobaccio, pp. 179-202. Ediciones del Tridente, Buenos Aires. 
Outram, A.

2004. Applied Models and Indices vs. High-Resolution, Observed Data: Detailed Fracture and Fragmentation Analyses for the investigation of skeletal Part Abundance Patters. Journal of Taphonomy 2(3): 167-184.

Outram, A. y P. Rowley-Conwy.

1998. Meat and marrow utility índices for horse (Eqqus). Journal of Archaeological Science 25: 839-849.

Perkins, D. y P. Daly

1968. A hunter's village in Neolithic Turkey. Scientific American 219(5): 96-106.

Politis, G.

1984. Arqueología del área Interserrana Bonaerense. Tesis doctoral inédita de la Facultad de Ciencias Naturales- Universidad Nacional de La Plata, La Plata.

2007. Nukak: Ethnoarchaeology of an Amazonian People. UCL institute of Archaeology Series. Left Coast Press, California EEUU.

Politis, G. y Martinez, G.

1996. La Cacería, el procesamiento y los tabúes alimenticios. En Nukak, editado por G. Politits, pp.231-280. Instituto Amazónico de Investigaciones Científicas, SINCHI, Bogotá.

Politis, G. y N. J. Saunders

2002. Archaeological correlates of ideological activity: food taboos and spiritanimals in an Amazonian hunter-gatherer society. En P. Miracle y N. Milner (Eds.), Consuming passions and patterns of consumption, pp. 113-130. McDonald Institute Monographs- University of Cambridge, Cambridge.

Rindel, D.

2009. Arqueología de momentos tardíos en el noroeste de la Provincia de Santa Cruz: Una perspectiva faunística. Tesis doctoral inédita de la Facultad de Filosofía y Letras-Universidad de Buenos Aires, Buenos Aires. 
Salemme, M.

1987 Paleoetnozoología del Sector Bonaerense de la Región Pampeana, con Especial Atención a los Mamíferos. Tesis doctoral inédita de la Facultad de Ciencias Naturales y Museo-Universidad Nacional de La Plata, La Plata.

\section{Salemme, M. y L. Miotti}

1987. Zooarchaeology and paleoenvironments: some examples from the Patagonian and Pampean Regions (Argentina). Quaternary of South America and Antarctic Peninsula 5: 24-47.

Santiago, F.

2010. La ocupación humana en el norte de Tierra del Fuego durante el Holoceno Medio y Tardío. Su vinculación con el paisaje. Tesis Doctoral inédita. Facultad de Ciencias SocialesUNCEN, Olavarría, Argentina

\section{Stein, J. K.; J. N. Deo y L. S. Phillips}

2003. Big Sites Short Time: Accumulation Rates in Archaeological Sites. Journal of Archaeological Science, 30, 297-316.

Stahl, P. W.

1999. Structural density of domesticated South American camelid skeletal elements and the archaeological invetigation of prehistoric Andean ch'arki. Journal of Archaeological Science 26: 1347-1368.

Stiner, M. C.

1993. The Place of Hominids among Predators: Interspecific Comparisons of Food Procurement and Transport. En: From Bone T Behaviour, Ethnoarchaeological and Experimental Contributions to the Interpretation of Faunal Remains, editado por J. Hudson. Center for Archaeological Investigations, Southern Illinois University at Carbondale.

Symmons, R.

2005a. Bone density variation between similar animals in early life: implications for future Taponomic analysis. En: Biosphere to Lithosphere, editado por T. O'Connor, pp. 86-93. Oxbow, Oxford. 
2005b.New density data for ungused and fused sheep bones, and a preliminary discussion on the modellng of taphonomic bias in archaeofaunal age profiles. Journal of Archaeological Science 32(11): 1691-1698.

Tivoli, A. M. y A. F. Pérez

2009 Rendimiento económico del cauquén común (Chloephaga picta, Familia: Anatidae).

En M. Salemme; F. Santiago; M. Álvarez; E. Piana; M. Vázquez y M. Mansur (Eds.), Arqueología de la Patagonia. Una mirada desde el último confín, Tomo 2, pp. 853-864. Editorial Utopias, Ushuaia.

Waters, M. R.

1992. Principles of geoarchaeology. The University of Arizona Press. Tucson and London.

White, T. E.

1953. Observations on the butchering technique of some aboriginal peoples: $n^{\circ} 2$. American Antiquity 19: 160-164.

Yellen, J. E.

1977. Cultural patterning in faunal remains: evidence from the !Kung Bushmen. En D. Ingresoll; J. E. Yellen y W. MacDonal (Eds.), Experimental Archaeology, pp. 271-331. Columbia University Press, New York.

\section{Capítulo 5.}

\section{Binford, L.}

1980. Willow smoke and dog tail's: hunter-gatherer settlement systems and archaeological site formation. American Antiquity 45 (1):4-20.

\section{Borrero, L. A.}

1984. The archaeology of continental Patagonia. Trabajo presentado al 45th Annual Meeting of the Soviety for American Archaeology, Portland.

1986. La economía prehistórica de los habitantes del Norte de la Isla Grande de Tierra del Fuego. Tesis doctoral inédita de la Facultad de Filosofía y LetrasUniversidad Nacional de Buenos Aires, Buenos Aires. 
1989. Replanteo de la arqueología patagónica. Interciencia XIV (3): 127-135.

1989-90. Evolución cultural divergente en la Patagonia Austral. Anales del Instituto de la Patagonia (Serie Ciencias Sociales) 19: 133-140.

1994-95. Arqueología de la Patagonia. Palimpsesto 4: 9-69.

2009. The elusive evidence: The archaeological record of the South American extinct megafauna. En American Megafaunal Extinctions at the end of the Pleistocene, editado por G. Haynes, pp. 145-168. Springer Science.

Cardich, A. y L. Miotti

1983. Recursos faunisticos en la economia de los cazadores de Los Toldos (Santa Cruz, Argentina). Relaciones de la Sociedad Argentina de Antropología XV: 145157.

Claraz, J.

1988. Diario de viaje de exploración al Chubut 1865-1866. Marymar, Buenos Aires.

Goñi, R.

2010. Cambio climático y poblamiento humano durante el Holoceno tardío en Patagonia meridional. Una perspectiva arqueológica. Tesis doctoral inédita de la Facultad de Filosofía y Letras-Universidad de Buenos Aires, Buenos Aires.

Gutiérrez M. y G, Martínez

2008. Trends in the faunal human exploitation during the late Pleistocene and early Holocene in the Pampean region (Argentina). Quaternary International 191: 53-68.

Martínez, G. y M. Gutiérrez

2004. Tendencias en la explotación humana de la fauna durante el Pleistoceno finalHoloceno en la Región Pampeana (Argentina). En G. L. Mengoni Goñalons (Ed.), Zooarchaeology of South America, pp. 81-98. BAR International Series, Oxford.

Mengoni Goñalons, G. L.

1983. Prehistoric utilisation of faunal resources in arid Argentina. En J. Clutton-Brock y C. Grigson (Eds.), Animals and Archaeology: I. Hunter and their prey, pp. 325-335. BAR International Series, Oxford. 
1988. Análisis de materiales faunísticos de sitios arqueológicos. Xama 1: 71-120

\section{Miotti, L.}

1995 Piedra Museo Locality: an Special Place in he New World. Current Research in the Pleistocene, vol. 12: 37-40 (Edit. Bradley Lepper).

1998. Zooarqueología de la Meseta Central y Costa de la Prov. de Santa Cruz: Un enfoque de las estrategias adaptativas aborígenes y los paleoambientes. Imprenta del Museo de Ciencias Naturales de San Rafael, San Rafael.

2003. South America. A paradox for building images of the colonization of the New World. En L. Miotti y M. Salemme (Eds.), South America, long and winding roads for the First Americans at the Pleistocene/Holocene Transition, Quaternary International 109-110: 147-173.

2008. Household and sacred landscapes among Holocene hunter-gatherers of Patagonia's Central Plateau. Before Farming 2008/3: 5-44.

2012. La potenciación de los recursos entre los cazadores-recolectores de Patagonia. Factores, Procesos e implicancias arqueológicas. Archaeofauna 21: 137160 .

Miotti, L. y M. Salemme

1999. Biodiversity, taxonomic richness and generalist-specialists economical systems in Pampa and Patagonia regions, Southern South America. Quaternary International 53-54: 53-68.

2004. Poblamiento, movilidad y territorios entre las sociedades cazadorasrecolectoras de Patagonia: cambios desde la transición Pleistoceno/Holoceno al Holoceno medio. Complutum 15: 177-206.

\section{Miotti, L.; M. Salemme y A. Menegaz}

1988. El manejo de los recursos faunísticos durante el Pleistoceno final y Holoceno temprano en Pampa y Patagonia. Actas del IX Congreso Nacional de Arqueología Argentina, pp. 102-118. Instituto de Ciencias Antropológicas- Facultad de Filosofía y Letras- UBA, Buenos Aires. 


\section{Musters, G. C.}

1964. Vida entre los Patagones. Un año de excursiones por tierras no frecuentadas desde el Estrecho de Magallanes hasta el Río Negro. Ediciones Solar- Hachette, Buenos Aires.

\section{Politis, G.}

1984. Arqueología del área Interserrana Bonaerense. Tesis doctoral inédita de la Facultad de Ciencias Naturales-Universidad Nacional de La Plata, La Plata.

Politis, G y P. G. Messineo

2008. The Campo Laborde site: New evidence for the Holocene survival of Pleistocene megafauna in the Argentine Pampas. Cuaternary International 191(1): 98-114.

Salemme, M. y L. Miotti

2008. Archaeological hunter-gatherer landscapes since the latest Pleistocene in FuegoPatagonia. En J. Rabassa (Ed.), Late Cenozoic of Patagonia and Tierra Del Fuego, pp. 437483. Elsevier, Nueva York

\section{Capítulo 6.}

Alcántara García, V.; R. Barba Egido; J. Maroa Barral de Pinto; A. B. Crespo Euiz; A. Eiriz Vidal; A. Falquina Aparicio; S. Herrero Calleja; A. Ibarra Jiménez; M. Megoeas González; M. Pérez Tello; J. Rolland Calvo; J. Yravedra Sainz de los Terrenos; A. Vidal y M. DomínguezRodrigo

2006. Determinación de procesos de fracturación como discriminador de agentes bióticos. Trabajos de Prehistoria 63: 37-45.

Andrews, P. y J. Cook

1985. Natural modifications to bone in a temperate setting. Man 20 (4): 675-691

Behrensmeyer, A. K.

1978. Taphonomic and ecology information from bone weathering. Paleobiology 4, 150162.

1991. Terrestrial vertebrate accumulations. En: P. A. Allison y D. E. G. Briggs (Eds.), Taphonomy: releasing the data locked in the fossil record, pp. 291-335. Plenum Press, New York. 
Behrensmeyer, A. K.; K. D. Gordon y G. Yanagi

1986. Trampling as a cause of bone surface damage and pseudo-cutmarks. Nature 319: $768-771$.

1989. Nonhuman bone modification in Miocene fossil from Pakistan. En R. Bonnichen, y M. Sorg (Eds.), Bone Modification. Peopling of Americas, pp. 99-120. Center for the Study of the First Americans- University of Maine, Orono.

Belardi, J. B.; T. J. Bourlot y D. Rindel

2010. Representación diferencial de diáfisis y epífisis de huesos largos de guanaco (Lama guanicoe) en contextos arqueológicos de médanos en Patagonia austral: el sitio Río Meseta 1 (lago Tar, provincia de Santa Cruz). En M. A. Gutiérrez; M De Nigris; P. Fernández; M. Giardina; A. Gil; A. Izeta; G. Neme y H. Yacobaccio (Eds.), Zooarqueología a principios del siglo XXI: aportes teóricos, metodológicos y casos de estudio, pp. 119-131. Ediciones del Espinillo, Buenos Aires.

Bennet, J. L.

1999. Thermal alteration of buried bone. Journal of Archaeology Science 26: 1-8.

Binford, L.

1978. Nunamiut ethnoarchaeology. Academic Press, New York.

1981. Bones: ancient men and modern myths. Academia Press, NewYork.

1984. Faunal remains from Klasies River Mouth. Academic Press, Orlando.

Blumenschine, R. L.

1986. Carcass consumption sequences and the archaeological distinction of scavenging and hunting. Journal of Human Evolution 15: 639-659.

1995. Percussion Marks, tooth marks, and experimental determinations of the timing of hominid and carnivore access to long bone at FLK Zinjanthropus, Olduvai Gorge, Tanzania. Journal of Archaeological Science 25: 1605-1618.

Blumenschine J. R. y C.W. Marean

1993. A carnivore's view of archaeological bone assemblage. En J. Hudson (Ed.), Form bones to behavior, pp. 273-300 Center for Archaeological Investigation- Southern Illinois University, Carbondale. 
Blumenschine, J. R. y M. M. Selvaggio

1988. Percussion marks on bone surfaces as a new diagnostic of hominid behavior. Nature 333: 763-765.

Blumenschine, J. R.; C. W. Marean y S. C. Capaldo

1996. Blind test of inter-analyst correspondence and accuracy in the identification of cut marks, percussion marks, and carnivore tooth marks on bone surfaces. Journal of Archaeological Science 23: 493-507.

Blumenschine, J. R; K. A. Passack, C. D. Kreger y M. C. Pante

2007. Carnivore tooth-marks, microbial bioerosion, and the invalidation of the test of Oldowan hominid scavenging behavior. Journal of Human Evolution 53: 420-426.

Bocek, B.

1986. Rodent ecology and burrowing behavior: predicted effects on archaeological site formation. American Antiquity 51(3): 589-603.

Bonnichsen, R.

1979. Pleistocene bone technology in the Beringian refugium. National Museum of ManArchaeological Survey of Canada, Ottawa.

Borrero, L. A.

1990. Taphonomy of guanaco bones in Tierra del Fuego. Quaternary Research 34: 361371.

2001. Cambios, continuidades, discontinuidades: discusiones sobre arqueología Fuego Patagónica. En E. Berberián y A. Nielsen (Eds.), Historia Argentina Prehispánica, Tomo II, pp. 815-838. Ediciones Brujas, Córdoba.

2007. Longitudinal taphonomy studies in Tierra del Fuego, Argentina. En M. A. Gutierrez; L. Miotti; G. Barrientos; G. Mengoni Goñalons y M. Salemme (Eds.), Taphonomy and Zooarchaeology in Argentina, pp. 219-233. BAR International Series Oxford.

2011. La Función Transdisciplinaria de la Arqueozoología en el siglo XXI: restos animales y más allá. Antípodas №13, pp 267-274. Bogotá, Colombia.

Borrero, L. A., F. M. Martin y J. Vargas

2005. Tafonomía de la interacción entre pumas y guanacos en el Parque Nacional Torres del Paine, Chile. Magallania 33 (1): 95-114. 
Brain, C. K.

1967. Bone weathering and the problem of bone pseudo-tools. South African Journal of Science 63:97-99.

1981. The Hunters or the Hunted? An introduction to African Cave Taphonomy. The University of Chicago Press, Chicago.

Buikstra, J. E. y M. Swegle

1989. Bone modification due to burning: experimental evidence. En R. Bonnichsen y M. Sorg (Eds.), Bone Modification. Peopling of Americas, pp. 247-257. Center for the Study of the First Americans- University of Maine, Orono.

Bunn, H. T.

1983. Evidence on the diet and subsistence patterns of Plio-Pleistocene hominids at Koobi Fora, Kenya and Olduvai Gorge, Tanzania. En J. Clutton-Brock y C. Grigson (Eds.), Animals and archaeology: 1, hunters and their prey, pp. 21-30. BAR Intenational Series, Oxford.

1989. Diagnosing Plio-Pleistocene hominid activity with bone fracture evidence. En R. Bonnichsen y M. H. Sorg (Eds.), Bone Modification. Peopling of Americas, pp. 299-316. Center for the Study of the First Americans- University of Maine, Orono.

Cain, C. R.

2005. Using burned animal bone to look at Middle Stone Age occupation and behavior. Journal of Archaeological Science 32: 873-884.

Cardich, A. y L. Miotti

1983. Recursos faunísticos en la economía de los cazadores-recolectores de Los Toldos (provincia de Santa Cruz, Argentina). Relaciones de la Sociedad Argentina de Antropología XV: 145-157.

Church, R. T. y R. L. Lyman

2003. Small fragments make small differences in efficiency when rendering grease from fractured artiodactyl bones by boiling. Journal of Archaeological Science 30: 1077-1084.

Cleghorn, N. y C. W. Marean

2007. The destruction of human-discarded bone by carnivores: The growth of a general model for bone survival and destruction in zooarchaeological assemblages. En T. R. 
Pickering, N. Toth y K. Schick (Eds.), African taphonomy: A tribute to the career of $C . K$. "Bob" Brain Bloomington, pp. 13-42. Stone Age Press, Bloomington.

Cook, J.

1986. The application of scanning electron microscopy to taphonomic and archaeological problems. En D. A. Roe (Ed.), Studies in the Upper Paleolithic of Britain and Northwest Europe, pp. 143-163. BAR International Series, Oxford.

Costamagno, S., I. Théry-Parisot, J. P. Brugal y R. Guibert

2005. Taphonomic consequences of the use of bones as fuel. Experimental data and archaeological applications. En T. O' Connor (Ed.), Biosphere to Lithosphere. New studies in vertebrate taphonomy, pp. 51-62. Oxbow Books, Oxford.

Courty, M. A.; P.Goldberg y R. I. Macphail

1989. Soils and Micromorphology in Archaeology. Cambridge University Press, Cambridge.

David, B.

1990. How was this bone burnt? En S. Solomon; I. Davidson y D. Watson (Eds.), Problem Solving in Taphonomy: Archaeological and paleontological studies from Europe, Africa and Oceania, pp. 65-79. University of Queensland, Queensland.

Denys, C.

2002. Taphonomy and Experimentation. Archaeometry 44 (3): 469-484.

\section{De Nigris, M.}

2004. El consumo en grupos cazadores recolectores. Un ejemplo zooarqueológico de Patagonia meridional. Sociedad Argentina de Antropología, Buenos Aires.

Durán, V.

1991. Estudios de perturbación por roedores del género Ctenomys en un sitio arqueológico experimental. Revista de Estudios Regionales (CEIDER) 7: 7-31

Egeland, C. P.

2003. Carcass processing intensity and cutmark creation: an experimental approach. Plains Anthropologist 48: 39-51. 
Elkin, D. C.

1995. Volume density of South American camelids skeletal parts. International Journal of Osteoarchaeology 5: 29-37.

Enloe, J. G.

1993. Ethnoarchaeology of marrow cracking: implications for the recognition of prehistoric subsistence organization. En J. Hudson (Ed.), From bones to behavior: ethnoarchaeological and experimental contributions to the interpretation of faunal remains, pp. 82-97. Center for Archaeological Investigations, Southern Illinois University at Carbondale, Illinois.

Fernández-Jalvo, Y. y C. Perales Piquer

1990. Análisis macroscópico de huesos quemados experimentalmente. Comunicaciones de la Reunión de Tafonomía y Fosilización, pp. 105-114. Departamento de PaleontologíaInstituto de Geología Económica- Museo Nacional de Ciencias Naturales, Madrid.

Fernández-Jalvo, Y.; B. Sánchez-Chillón, P. Andrews, S. Fernández-López y L. Alcalá Martínez 2002. Morphological taphonomic transformations of fossils bones in continental environments, and repercussions on their chemical composition. Archaeometry 44(3): 353361.

Fiorillo, A. R.

1989. An experimental study of trampling: implications for the fossil record. En R. Bonnichsen y M. H. Sorg (Eds.), Bone Modification, Peopling of Americas, pp. 61-71. Center for the study of the first Americans- University of Maine, Orono.

Fisher, J. W. Jr.

1995. Bone surface modifications in zooarchaeology. Journal of Archaeological Method and Theory 2 (1): 7-68.

Frank, A.

2011. Tratamiento térmico y manejo del fuego en sociedades cazadoras-recolectoras de la Meseta Central de Santa Cruz. Tesis doctoral inédita de la Facultad de Ciencias Naturales y Museo- Universidad Nacional de La Plata, La Plata. 
Frontini, R.

2012. El Aprovechamiento de animales en valles fluviales y lagunas del sur bonaerense durante el Holoceno. Tesis doctoral inédita de la Facultad de Filosofía y LetrasUniversidad Nacional de Buenos Aires, Buenos Aires.

Frontini, R. y C. M. Deschamps

2007. La actividad de Chaetophractus villosus en sitios arqueológicos. El Guanaco como caso de estudio. En C. Bayón, A. Pupio, M. I. González, N. Flegenhimer y M. Frére (Eds.), Arqueología en las pampas, Tomo 1, pp. 439-454. Sociedad Argentina de Antropología, Buenos Aires.

Gavrilov, K.

1959. Curso de Anatomia y Fisiologia Comparadas. Universidad Nacional de Tucuman. Escuela Universitaria de Ciencias Naturales. Ms.

Gifford-González, D. P.

1981. Taphonomy and Paleoecology: A critical Review of Archaeology's Sister Disciplines. Advances in Archaeological Method and Theory 4: 365-438.

1989. Ethnographic analogues for interpreting modified bones: Some cases from East Africa. En R. Bonnichsen y M. Sorg (Eds.), Bone Modification, Peopling of Americas. pp. 179-246. Center for the study of the first Americans- University of Maine, Orono.

1991. Bone are not enough: analogues, knowledge, and interpretative strategies in zooarchaelogy. Journal of Anthropological Archaeology 10, 215-254.

1993. Gaps in Zooarchaeological Analyses of Butchery: Is Gender an Issue? En: Interpretation of Faunal Remains, editado por J. Hudson, pp. 181-199. Center for Archaeological Investigations, Ocassional Paper 21. Southern Illinois University at Carbonale.

Gifford-González, D. P., D. B. Damrosch, D. R. Damrosch, J. Pryor y R. L. Thunen

1985. The third dimension in site structure: an experiment in trampling and vertical dispersal. American Antiquity 50(4): 803-818.

Grayson, D.

1984. Quantitative Zooarchaeology. Academic Press, New York

1988. Danger Cave, Last Supper Cave and Hanging Rock Shelter: the faunas. American Museum of Natural History Anthropological Papers 66 (1): 1-130. 
1989. Bone Transport, Vone Destruction, and Recerse Utility Curves. Journal of Archaeological Science 16: 643-652.

1991. Alpine faunas from the White Mountains, California: adaptative change in the late prehistoric Great Basin. Journal of Archaeological Science 18: 483-506.

Gutiérrez, M. A.

2004. Análisis tafonómicos en el Área Interserrana, provincia de Buenos Aires. Tesis doctoral inédita de Facultad de Ciencias Naturales- Universidad Nacional de La Plata, La Plata.

Hanson, M. y C. R. Cain

2007. Examining histology to identify burned bone. Journal of Archaeological Science 34: 1902-1913.

Haynes, G.

1983. Frequencies of spiral and green-bone fractures on ungulate limb bones in modern surface assemblages. American Antiquity 48: 102-114.

1986. A review of some attacks on the overkill hypothesis, with special attention to misrepresentations and doubletalk. Quaternary International 169-170: 84-94.

1991. Mammoths, mastodonts and elephants: biology, behavior, and the fossil record. Cambridge University Press, Cambridge.

Hedges, R. E. M.

2002. Bone diagenesis: an overview of processes. Archaeometry 44(3): 319-328.

Hill, A.

1979. Butchery and natural disarticulation: an investigatory technique. American Antiquity 44: 739-744.

Johnson, E.

1985. Current developments in bone technology. En M. B. Schiffer (Ed.), Advances in Archaeological Method and Theory 8: 157-235.

1989. Human modified bones from Early Southern Plain sites. En R. Bonnichsen y M. Sorg (Eds.), Bone Modification. Peopling of Americas, pp. 431-471. Center for the Study of the First Americans- University of Maine, Orono. 
Joly, D.; R. J. March y G. Martínez

2005. Les os brulés de Paso Otero 5: un témoignage posible de l'utilisation de l'os comme combustible par des chasseurs-cuielleurs de la fin du Pléistoce en Argentine. ArcheoSciences 29: 83-93.

Kaufman, C. A.

2009. Estructura de edad y sexo en guanaco: estudios actualísticos y arqueologicos en Pampa y Patamgonia. Buenos Aires. Sociedad Argentina de Antropología.

Klein, R. y K. Cruz Uribe

1984. The analysis of animal bones from archaeological sites. The University of Chicago Press, Chicago.

Langiano, M. C.

2006. Alteración térmica y experiencias de cocción de cerámica con material óseo. En P. P. Funari y E. R. Britez (comp.), Arqueología Histórica en América Latina: Temas y discusiones recientes, pp. 191-217. Ediciones Suárez, Mar del Plata.

López-González, F.; A. Grandal-d`Anglade y J. R. Vidal-Romani

2006. Deciphering bone dopositational sequences in caves trought the study of manganese coatings. Journal of Archaeological Science 33: 707-717.

Lupo, K. D. y D. N. Schmitt

1997. Experiments in bone boiling: nutritional returns and archaeological reflections. Anthropozoologica 25/26: 137-144.

Lyman, R. L.

1992. Anatomical considerations of utility curves in zooarchaeology. Journal of Archaeological Science 19: 7-22.

1994 a. Vertebrate Taphonomy. Cambridge University Press, Cambridge.

1994 b. Quantitative units and terminology in zooarchaeology. American Antiquity 59(1): 36-71.

2003. The influence of time averaging and space averaging on the application of foraging theory in zooarchaeology. Journal of Archaeological Science 30: 595-610.

2008. Quantitative Paleozoology. Cambridge University Press, New York. 
Marean, C. W.

1995. Of taphonomy and zooarchaeology. Evolutionary Anthropology 4 (2), 64-72.

Marean, C. W. y L. M. Spencer

1991. Impact of carnivore ravaging on zooarchaeological measures of element abundance. American Antiquity 56(4): 645-658.

1995. Of taphonomy and zooarchaeology. Evolutionary Anthropology 4 (2), 64-72.

Marín Arroyo, A. B.; M. D. Landete Ruiz; G. Vidal Bernabeu; R. Seva Román; M. R. González Morales y L. G. Straus

2008. Archaeological implications of human-derived manganese coatings: a study of blackened bones in El Mirón Cave, Cantabrian Spain. Journal of Archaeological Science 35: 801-813.

Marshall, L. G.

1989. Bone modification and "the laws of burial." En R. Bonnichsen y M. H. Sorg (Eds.), Bone modification. Peopling of Americas, pp. 7-24. Center for the study of the first Americans- University of Maine, Orono.

Martin, F. M.

2008. Tafonomía y Paleoecología de la transición Pleistoceno-Holoceno en FuegoPatagonia. Interacción entre poblaciones humanas y de carnívoros y su importancia como agentes en la formación del registro fósil. Tesis doctoral inédita de la Facultad de Ciencias Naturales- Universidad Nacional de La Plata, La Plata.

Mello Araujo, A. G. y J. C. Marcellino

2003. The role of Armadillos in the movement of archaeological materials: an experimental approach. Geoarchaeology: An International Journal 18(4): 433-460.

Mengoni Goñalons, G. L.

1982. Notas zooarqueológicas I: fracturas en hueso. Resúmenes del VII Congreso Nacional de Arqueología, pp. 87-91, Montevideo.

1988. Análisis de materiales faunísticos de sitios arqueológicos. Xama 1:71-120.

1996. La domesticación de los camélidos sudamericanos y su anatomía económica. En D.

C. Elkin y C. M. Madero, Zooarqueología de camélidos 2: 33-46.

1999. Cazadores de guanaco de la estepa patagónica. Sociedad Argentina de Antropología, Buenos Aires, Argentina. 
2007. Archaeofaunal studies in Argentina: a historical overview. En M. Gutiérrez; L. Miotti; G. Barrientos; G. L. Mengoni Gonalons y M. Salemme (Eds.), Taphonomy and zooarchaeology in Argentina, pp. 13-34. BAR International Series no 1601, Manchester. 2010. Zooarqueología en la práctica: algunos temas metodológicos. Xama 19-23: 83-113.

Merlo, J.

2006. Investigaciones actualísticas experimentales para la interpretación del registro arqueofaunístico en sitios fortificados del siglo XIX. En P.P Funari y F. R. Brittez (Eds.), Arqueología Histórica en America Latina. Temas y discusiones recientes, pp. 219-243. Ediciones Suárez, Mar del Plata.

Miotti, L.

1992. La experimentación simulativa de fracturas y marcas óseas y sus implicancias arqueológicas. Arqueología Contemporánea 3: 39-61.

1998. Zooarqueología de la meseta central y la costa de la Provincia de Santa cruz. Un enfoque de las estrategias adaptativas y paleoambientales. Imprenta del Museo Municipal de Historia Natural de San Rafael, San Rafael.

Miotti, L. y M. Salemme.

1999. Biodiversity, Taxonomic Richness and Generalist-Specialists economical systems in Pampa and Patagonia Regions, Southern South America. Quaternary International 53-54: 53-68.

2004. Poblamiento, movilidad y territorios entre las sociedades cazadorasrecolectoras de Patagonia. Complutum 15: 177-206.

\section{Miotti, L.; M. Vázquez y D. Hermo}

1999. Piedra Museo un Yamnagoo Pleistocénico en la colonización de la meseta de Santa Cruz. El estudio de la arqueofauna. En R. Goñi (ed.), Soplando en el Viento, pp.113-136. Universidad Nacional del Comahue- Instituto Nacional de Antropología y Pensamiento Latinoamericano. Neuquén- Buenos Aires.

Miotti, L.; M. Salemme y J. Rabassa

2003. Radiocarbon chronology at Piedra Museo Locality. En L. Miotti; M Salemme y N. Flegenheimer (Eds.), Where the South Winds Blow: Ancient Evidence of Paleo South 
Americans, pp. 99-104. Center for the Studies of the First Americans-Texas A \& M University Press, Texas.

Miotti, L.; D. Hermo; L. Magnin; N. Carden; L. Marchionni; A. Alcaraz; B. Mosquera; E. Terranova y M. Salemme 2007. Resolución arqueológica en la Cueva Maripe (Santa Cruz, Argentina). En F. Morello; M. Martinic; A. Prieto y G. Bahamonde (Eds.), Arqueología de FuegoPatagonia: Levantando piedras, desenterrando huesos...y develando arcanos, pp. 555-568. Ediciones CEQUA, Punta Arenas.

Miotti, L.; D. Hermo, M. Salemme, L. Magnin y L. Marchionni 2009. Cueva Maripe y su excavación. Implicancias en los Estudios Regionales del Macizo del Deseado. En A. Austral y Tamagnini (comps.), Problemática de arqueología contemporánea, Tomo III. Pp. 1031-1035. Universidad Nacional de Río Cuarto, Río Cuarto.

Mondini, M.

1995. Artiodactyle prey transport by foxes in Puna rockshelters. Current Anthropology 36: 520-525.

2002. Formación del registro arqueofaunístico en abrigos rocosos de la Puna argentina. Tafonomía de carnívoros. Tesis doctoral inédita de la Facultad de Filosofía y LetrasUniversidad de Buenos Aires, Buenos Aires.

Montalvo, C. I.

2002. Root traces in fossil bones from Huayquerian (Late Miocene) faunal assemblage of Telén, La Pampa, Argentina. Acta Geológica Hispánica 37 (1): 37-42.

Morlan, R. E.

1980. Taphonomy and archaeology in the upper Pleistocene of the northern Yukon Territory: a glimpse of the peopling of the New World. National Museum of ManArchaeological Survey of Canada, Ottawa.

1994. Bison bone fragmentation and survivorship: a comparative method. Journal of Archaeological Science 21: 797-807. 


\section{Muñoz, A. S.}

2008. El procesamietno de los camélidos fueguinos en el pasado. Aspectos metodológicos y resultados alcanzados para el sector atlántico de Tierra del Fuego. En A. Acosta; D. Loponte y L. Mucciolo (Comps.), Estudios tafonómicos y zooarqueológicos I, pp. 77-98. INAPL-AINA, Buenos Aires.

Nicholson, R. A.

1996. Bone degradation, burial medium and species representation: debunking the myths, an experiment-based approach. Journal of Archaeological Science 23: 513-533.

Nilssen, P. J.

2000. An actualistic butchery study in South Africa and its implications for reconstructing hominid strategies of carcass adquisition and butchery in the Upper Pleistocene and PlioPleistocene. Tesis doctoral inédita de la University of Cape Town, Cape Town.

Olsen, S.

1988. The identification of stone and metal tool marks on bone artifacts. En S. Olsen (Ed.), Scanning Electron Microscopy, pp. 337-360. BAR International Series, Londres.

Olsen, S. L. y P. Shipman

1988. Surface modification on bone: trampling versus butchery. Journal of Archaeological Science 15: 535-553.

Outram, A. K.

2002. Bone fracture and within-bone nutrients: an experimentally based method for investigating levels of marrow extraction. En P. Miracle y N. Milner (Eds.), Consuming passions and patterns of consumption, pp. 51-64. McDonald Institute for Archaeological Research, Cambridge.

O’Brien M. J. y R. L. Lyman 2002. The epistemological nature of archaeological units. Anthropological Theory 2(1): 3756 .

Payne, S.

1975. Partial recovery and sample bias. En A. T. Clason (ed.), Archaezoological Studies, pp. 7-17. North Holland, Amsterdam. 
Pickering, T. R. y C. P. Egeland

2006. Experimental patterns of hammerstone percussion damage on bones: implications for inferences of carcass processing by humans. Journal of Archaeological Science 33: 459469.

Politis, G.

1999. La estructura del debate sobre el poblamiento de América. Boletín de Arqueología 14 (2): $25-52$.

Politis, G. y Martinez, G.

1996. La Cacería, el procesamiento y los tabúes alimenticios. En Nukak, editado por G. Politits, pp.231-280. Instituto Amazónico de Investigaciones Científicas, SINCHI, Bogotá.

Politis, G. G. y N. J. Saunders

2002. Archaeological correlates of ideological activity: food taboos and spiritanimals in an Amazonian hunter-gatherer society. En P. Miracle y N. Milner (Eds.), Consuming passions and patterns of consumption, pp. 113-130. McDonald Institute Monographs- University of Cambridge, Cambridge.

Potts, R. y P. Shipman

1981. Cutmarks made by stone tools on bones from Olduvai Gorge, Tanzania. Nature 291: 577-580.

Rindel, D.

2009. Arqueología de momentos tardíos en el noroeste de la Provincia de Santa Cruz: Una perspectiva faunística. Tesis doctoral inédita de la Facultad de Filosofía y LetrasUniversidad de Buenos Aires, Buenos Aires.

Salemme, M. y L. Miotti

1987. Zooarchaeology and paleoenvironments: some examples from the Patagonian and Pampean Regions (Argentina). Quaternary of South America and Antarctic Peninsula 5: 24-47 
Salemme, M.; L. Miotti y E. Tonni

1988. La determinación sistemática de los mamíferos en el análisis arqueofaunístico. En R. Ratto y A. F. Haber (Eds.), De Procesos, Contextos y otros Huesos, pp. 65-75. Facultad de Filosofía y Letras- Universidad Nacional de Buenos Aires, Buenos Aires.

Salemme, M., P. Escosteguy y R. Frontini

2011. La fauna menor en sitios arqueológicos pampeanos. Recursos económicos vs. Agentes disturbadores. Libro de resúmenes del II Congreso de Zooaqueología Argentina, pp. 75. Facultad de Ciencias Sociales- UNCPBA, Olavarría.

Shahack-Gross, R.; O. Bar-Yosef y S. Weiner

1997. Black-coloured bones in Hayonin Cave, Israel: differentiation between burning and oxide staining. Journal of Archaeological Science 24: 439-446.

Shipman, P.

1981. Applications of scanning electron microscopy to taphonomic

problems. En A. M. Cantwell; J. B. Griffin y N. Rotschild (Eds.), The Research Potential of Anthropological Museum Collections. Annals of de New York Academy of Science, 276: 357-385.

1983. Early hominid lifestyles: hunting and gathering or foraging and scavenging? En J. Clutton-Brock y C. Grigson (Eds.), Animals and archaeology: 1. Hunters and their prey. pp. 31-49. BAR International Series, Manchester.

1986 a. Scavenging or hunting in early hominids: theoretical fraamework and test. American Anthropologist 88:27-43.

1986 b. Studies of hominid- faunal interactions at Olduvai Gorge. Journal of Human Evolution 15: 691-706.

Shipman, P. y J. J. Rose

1983 a. Evidence of butchery and hominid activities at Torralba and Ambrona; An evaluation using microscopic techniques. Journal of Archaeological Science 10: 465-474.

1983 b. Early hominid hunting, butchery, and carcass-processing behaviors: approaches to the fossil record. Journal and Anthropological Archaeology 2:57-98.

1984. Cutmark mimics on modern and fossil bovid bones. Current Anthropology 25(1): 116-117. 
Shipman, P.; G. Foster y M. Schoeninger

1984. Burnt bones and theet: an experimental study of color, morphology, crystal structure and shrinkage. Journal of Archaeological Science 11: 307-325.

Stallibrans, $\mathrm{S}$.

1984. The distinction between the effects of small carnivores and humans on post-glacial faunal assemblages. A case study using scavenging of sheep carcasses by foxes. En C. Grigson y J. Clutton-Brock (Eds.), Animals and Archaeology 4. Husbandry in Europe, pp. 259-269. BAR International Series, Oxford.

Stiner, M. C.; S. L. Jung; S. Weiner y O. Bar-Josef

1995. Differential burning, recrystallization, and fragmentation of archaeological bone. Journal of Archaeological Science 22:223-237.

Taylor, R. E.; P. E. Hare y T. D. White

1995. Geochemical criteria for thermal alteration of bone. Journal of Archaeological Science 22:115-119.

\section{Théry-Parisot, I.}

2002. Fuel management (bone and wood) during the Lower Aurignacian in the Pataud Rock Shelter (Lower Paleolithic, Les Eyzies de Tayac, Dordogne, France): contribution of experimentation. Journal of archaeological Science 29: 1415-1421.

Wandsnider, L.

1997. The roasted and the boiled: food composition and heat treatment with special emphasis on pit-hearth cooking. Journal of Anthropological Archaeology 16:1-48.

White, T. E.

1953. A method of calculating the dietary percentage of various food animals utilized by aboriginal peoples. American Antiquity 19: 396-398.

1992. Prehistoric Cannibalism at Mancos 5MTUMR-2346. Princeton University Press, Oxford.

Yellen, J. E.

1977. Cultural patterning in faunal remains: evidence from the !Kung Bushmen. En D. Ingresoll; J. E. Yellen y W. MacDonal (Eds.), Experimental Archaeology, pp. 271-331. Columbia University Press, New York. 
1991. Small mammals: post-discard patterning of !Kung San faunal remains. Journal of Anthropological Archaeology 10: 1-26.

Zárate, M., A. Blasi, y J. Rabassa 2000. Geoarqueología de la localidad Piedra Museo. En L. Miotti, R. Paunero, M. Salemme y G. R. Cattáneo (Eds.), Guía de Campo de la visita a las localidades arqueológicas. Taller Internacional "La Colonización del Sur de América durante la Transición Pleistoceno/Holoceno", pp. 56.64. Servicoop, La Plata.

\section{Capítulo 7}

Aguerre, A. M.

1994. Restos óseos guanaco del Alero Charcamata. En C. Gradin y A. Aguerre (Eds.), Contribución a la Arqueología del Río Pinturas, provincia de Santa Cruz, Pp. 229-243. Búsqueda de Ayllu, Concepción del Uruguay.

Aguerre, A. M. y M. I. Pagano

2003. Fauna de las ocupaciones de 8.000 años de la cueva de La Martita: Guanaco. En A. Aguerre (Comp.), Arqueología y Paleoambiente en la Patagonia Santacruceña Argentina, pp. 71-85. Nuevo Offset, Buenos Aires.

Aguerre, A.; M. I. Pagano y M. I. Scarafoni

1994 a. Material óseo de fauna guanaco, capa 2 del Alero Cárdenas. En A. Aguerre (Comp.) Arqueología y Paleoambiente en la Patagonia Santacruceña Argentina, pp. 100-109. Búsqueda de Ayllú, Concepción del Uruguay.

1994 b. Fauna Guanaco: capa 4 y 5 del Alero Cárdenas. En A. Aguerre (Comp.) Arqueología y Paleoambiente en la Patagonia Santacruceña Argentina, pp. 121-128. Búsqueda de Ayllú, Concepción del Uruguay.

Behrensmeyer, A. K.

1978. Taphonomic and ecologic information from bone weathering. Paleobiology 4: 150162. 


\section{Belardi, J. B.; T. J. Bourlot y D. Rindel}

2010. Representación diferencial de diáfisis y epífisis de huesos largos de guanaco (Lama guanicoe) en contextos arqueológicos de médanos en Patagonia austral: el sitio Río Meseta 1 (lago Tar, provincia de Santa Cruz). En M. A. Gutiérrez; M De Nigris; P. Fernández; M. Giardina; A. Gil; A. Izeta; G. Neme y H. Yacobaccio (Eds.), Zooarqueología a principios del siglo XXI: aportes teóricos, metodológicos y casos de estudio, pp. 119-131. Ediciones del Espinillo, Buenos Aires.

Binford, L. 1978. Nunamiut Ethnoarchaeology. New York, Academic Press 1981. Bones: ancient men and modern myths. Academia Press, NewYork.

\section{Borrero, L. A.}

1989. Replanteo de la arqueología patagónica. Interciencia XIV (3): 127-135. 1990. Fuego-Patagonia bone assemblages and the problem of comunal guanaco hunting. En L. Davis y B. Reeves (Eds.), Hunters of the recent past, pp. 373-406. Unwin Hyman, Londres.

1994-95. Arqueología de la Patagonia. Palimpsesto 4: 9-69.

2007. Longitudinal taphonomic studies in Tierra del Fuego, Argentina. En M. Gutiérrez; L. Miotti; G. Barrientos; G. Mengoni Goñalons y M. Salemme (Eds.), Taphonomy and Zooarchaeology in Argentina, pp. 219-233. BAR Series- Archaeopress, Oxford.

2009. Arqueología y evolución: comentarios y digresiones. En G. López y M. Cardillo (Eds.), Arqueología y evolución. Teoría, metodología y casos de estudio, pp. 7-21. Editorial SB, Buenos Aires.

Borrero, L. A. y F. Martin

1996. Tafonomía de carnívoros: un enfoque regional. En J. Gómez Otero (ed.), Arqueología. Sólo Patagonia, pp. 189-206. Publicación Secretaría de Cultura De ChubutCONICET, Puerto Madryn.

Borrero, L. A., F. M. Martin y J. Vargas

2005. Tafonomía de la interacción entre pumas y guanacos en el Parque Nacional Torres del Paine, Chile. Magallania 33 (1): 95-114. 
Bourlot, T.

2010. Zooarqueología de sitios a cielo abierto en el lago Cardiel, Provincia de Santa Cruz: fragmentación ósea y consumo de grasa animal en grupos cazadores-recolectores del Holoceno tardío. Tesis doctoral inédita de la Facultad de Filosofía y Letras-Universidad Nacional de Buenos Aires, Buenos Aires.

Brain, C. K.

1981. The Hunters or the Hunted? An introduction to African Cave Taphonomy. The University of Chicago Press, Chicago.

Cardich, A. y L. Miotti

1983. Recursos faunísticos en la economía de los cazadores-recolectores de Los Toldos (provincia de Santa Cruz, Argentina). Relaciones de la Sociedad Argentina de Antropología XV: 145-157.

Civalero, M. T. y C. Aschero

2003. Early occupations at Cerro Casa de Piedra 7, Santa Cruz Province, Patagonia, Argentina. En L. Miotti; M. Salemme y N. Flegenheimer, (Eds.), Ancient Evidence for Paleo South Americans: From Where the South Winds Blow, pp. 141-148. Center for the Study of First Americans and Texas A\&M University Press, Texas.

Ceraso, A.

2011. SIG y estadística espacial en el contexto arqueológico de Cueva Maripe (Santa Cruz). Informe inédito de Beca de Experiencia Laboral para Graduados, FCNyM- UNLP.

Carden, N.

2009. Imágenes a través del tiempo: arte rupestre y construcción social del paisaje en la meseta central de Santa Cruz. Sociedad Argentina de Antropología, Buenos Aires.

Claraz, J.

1988. Diario de viaje de exploración al Chubut 1865-1866. Marymar, Buenos Aires. 
Courty, M. A.; P. Goldberg y R. Macphail

1989. Soils and Micromorphology in Archaeology. Cambridge University Press, Cambridge.

\section{De Nigris, $M$.}

2004. El consumo en cazadores-recolectores. Un ejemplo zooarqueológico de Patagonia meridional. Sociedad Argentina de Antropología, Buenos Aires.

2008. Modelos de transporte etnoarqueológicos: sobre su aplicabilidad y pertinencia en el interior de Patagonia. En A. Acosta; D. Loponte y L. Mucciolo (Comps.), Estudios tafonómicos y zooarqueológicos I, pp. 37-55. INAPL-AINA, Buenos Aires.

Durán, V.; A. Gil; G. Neme y A. Gasco 2003. El Verano: Ocupaciones de 8.900 años en la Cueva 1 (Santa Cruz, Argentina). En A. Aguerre (comp.), Arqueología y Paleoambiente en Patagonia Santacruceña Argentina, pp. 93-120. Nuevo Offset, Buenos Aires.

Elkin, D. C.

1995. Volume density of South American camelids skeletal parts. International Journal of Osteoarchaeology 5: 29-37.

Elkin, D. y J. Zanchetta

1991. Densitometría ósea de camélidos- aplicaciones arqueológicas. Actas del X Congreso Nacional de Arqueología Argentina Tomo 3, pp. 195-204. Catamarca.

Farrand, W. R.

1985. Rockshelter and cave sediments. En J .K Stein y W. R. Farrand (Eds.), Archaeological sediments in context, pp. 21-40. Center for the Study of Early ManInstitute for Quaternary Studies- University of Maine, Orono.

Franco, N. y L. A. Borrero

2003. Chorrillo Malo 2: Initial peopling of the Upper Santa Cruz Basin. En L. Miotti; M. Salemme y N. Flegenheimer (Eds.), Where the South Winds Blow: Ancient Evidence of Paleo South Americans, pp. 149-152. Center for the Studies of the First Americans- Texas A\&M University Press, Texas pp. 
Frank, A.

2011. Tratamiento térmico y manejo del fuego en sociedades cazadoras-recolectoras de la Meseta Central de Santa Cruz. Tesis doctoral inédita de la Facultad de Ciencias NaturalesUniversidad Nacional de La Plata, La Plata.

\section{Gifford-González, D. P.}

1993. Gaps in zooarchaeological analyses of butchery: is gender an issue? En J. Hudson (Ed.), Bones to Behavior, pp. 181-199. Southern Illinois University Press, Carbondale.

\section{Gutiérrez, M. A.}

2004. Análisis tafonómicos en el Área Interserrana, provincia de Buenos Aires. Tesis doctoral inédita de la Facultad de Ciencias Naturales- Universidad Nacional de La Plata, La Plata.

\section{Gutiérrez M. y C. Kaufmann}

2007. Criteria for the identificationof formation processes in guanaco (Lama guanicoe) bone assemblages in fluvial-lacustrine environments. Journal of Taphonomy 5 (4): 151-176.

Gutiérrez, M. A.; C. Kaufmann; M. González; A. Massigoge y M. C. Álvarez

2010. Intrataxonomic variability in metapodial and femur bone density related to age in guanaco (Lama guanicoe). Zooarchaeological and taphonomical implications. Journal of Archaeological Science 37(12): 3226-3238.

\section{Hermo, D.}

2008. Los cambios en la circulación de las materias primas líticas en ambientes mesetarios de Patagonia. Una aproximación para la construcción de los paisajes arqueológicos de las sociedades cazadoras-recolectoras. Tesis doctoral inédita de la Facultad de Ciencias Naturales- Universidad Nacional de La Plata, La Plata.

Hermo, D.; V. Lynch y A. Ceraso

2012. Tendencias temproales en la tecnología lítica del sitio Cueva Maripe (Santa Cruz, Argentina). Latin American Antiquity. 66 pp. En evaluación 
Haynes, G.

1980. Evidence of carnivore gnawing on Pleistocene and recent mammalian bones. Paleobiology 6 (3): 341-351.

Kelly, R.

1995. The Foraging Spectrum: diversity in hunter-gatherer lifeways. Smithsonian Institution Press, Washington.

Kreutzer, L. A.

1992. Bison and deer bone mineral densities: comparisons and implications for the interpretation of archaeological faunas. Journal of Archaeological Science 19: 271-294.

López- González, N.; J. Borrego; J. A. Morales y B. Carro.

2006. Variación estacional de los contenidos en carbono orgánico, inorgánico y azufre en los sedimentos del estuario de los ríos Tinto y Odiel (SO España). Geogaceta 40: 295-298.

\section{Lyman, R. L.}

1992. Anatomical considerations of utility curves in zooarchaeology. Journal of Archaeological Science 19: 7-22.

1994. Vertebrate Taphonomy. Cambridge University Press, New York.

\section{Lynch, V.}

2012. Analisis morfologico-funcional de raspadores líticos del sitio Cueva Maripe (Santa Cruz, Argentina). En F. Zangrando; R. Barberena; A. Gil; G. Neme; M. Giardina; L. Luna; C. Otaola; S. Paulides; L. Salgán y A. Tivoli, Tendencias teórico-metodológicas y casos de estudio en la arqueología de Patagonia, Sociedad Argentina de Antropología- Instituto Nacional de Antropología y Pensamiento Latinoamericano- Museo de Historia Natural de San Rafael. En Prensa.

\section{Lynch, V. y D. Hermo}

2011. ¿Es posible la detección de huellas de enmangue? Evidencias macro y microscópicas en instrumentos líticos experimentales. Magallania 39 (1): 241-252. 
Magnin, L.

2010. Distribuciones arqueológicas en la meseta central de Santa Cruz: Implicancias para los estudios de uso del espacio y movilidad de sociedades cazadoras recolectoras. Tesis doctoral inédita de la Facultad de Ciencias NaturalesUniversidad Nacional de La Plata, La Plata.

Marean, C. W. y N. Cleghorn

2003. Large mammal skeletal element transport: apllying foraging theory in a complex taphonomic system. Journal of Taphonomy 1 (1): 15-42.

Marín Arroyo, A. B.; M. D. Landete Ruiz; G. Vidal Bernabeu; R. Seva Román; M. R. González Morales y L. G. Straus

2008. Archaeological implications of human-derived manganese coatings: a study of blackened bones in El Mirón Cave, Cantabrian Spain. Journal of Archaeological Science 35 (3), 801-813.

Martin, F.

2008. Tafonomía y paleoecología de la transición Pleistoceno-Holoceno en FuegoPatagonia: Interacción entre poblaciones humanas y de carnívoros y su importancia como agentes en la formación del registro fósil. Tesis doctoral inédita de la Facultad de Ciencias Naturales- Universidad Nacional de La Plata. La Plata.

Martínez, G. y M. Gutiérrez

2004. Tendencias en la explotación humana de la fauna durante el Pleistoceno finalHoloceno en la Región Pampeana (Argentina). En G. L. Mengoni Goñalons (Ed.), Zooarchaeology of South America, pp. 81-98. BAR International Series, Oxford.

Massigoge A.; M. González; C. Kaufmann y M. Gutiérrez

2010. Observaciones actualísticas sobre meteorización ósea en restos esqueletales de guanaco. En M. Berón; D. Luna; M. Bonomo; C. Montalvo; C. Aranda y M. Carrera Aizpitarte (Eds.), Mamül Mapu. Pasado y presente desde la arqueología pampeana, Tomo I, pp. 309-322. Libros del Espinillo, Buenos Aires. 
Mengoni Goñalons, G. L.

1999. Cazadores de guanacos de la estepa patagónica. Sociedad Argentina de Antropología, Buenos Aires.

Mengoni Goñalons, G. L. y M. Silveira

1976. Análisis e interpretación de los restos faunísticos de la cueva de las Manos Estancia Alto Río Pinturas (Provincia de Santa Cruz). Relaciones de la Sociedad Argentina de Antropología X: 261-270.

Miotti, L.

1996. Piedra Museo (Santa Cruz): nuevos datos para el debate de la ocupación pleistocénica en Patagonia. En J. Gómez Otero (Ed.), Arqueología, sólo Patagonia, pp. 27-38. Publicación Secretaría de Cultura De Chubut- CONICET, Puerto Madryn.

1998. Zooarqueología de la meseta central y costa de la provincia de Santa Cruz: Un enfoque de las estrategias adaptativas aborígenes y los paleoambientes. Imprenta del Museo Municipal de Historia Natural de San Rafael, San Rafael.

2008. Household and sacred landscapes among Holocene hunter-gatherers of Patagonia's Central Plateau. Before Farming 2008/3: 5-44.

2010. Cuevas y abrigos rocosos: nudos de las redes sociales entre los cazadoresrecolectores del Macizo del Deseado, Patagonia extra-andina. En J. C. Jiménez; C. Serrano; A. González y F. Aguilar (Eds.), III Simposio Internacional (2008) EI Hombre Temprano en América, pp. 147-174. UNAM- Instituto de Investigaciones Antropológicas-INAH, México.

2012. La potenciación de los recursos entre los cazadores-recolectores de Patagonia. Factores, Procesos e implicancias arqueológicas. Archaeofauna 21: 137160.

Miotti, L. y L. Marchionni 2009. Procesando huesos: entre la Etnografía y la Arqueología. En M. Salemme, F. Santiago, M. Álvarez, E. Piana, M. Vázquez y M. Mansur (Eds.), Arqueología de la Patagonia. Una mirada desde el confín del mundo, pp. 787-799. Editorial Utopía, Ushuaia. 
2011. Beyond tools: bone as raw material for tools in Central Plateau of Santa Cruz, Argentinian Patagonia. En A. Choyke; S. O’Connor y C. Vercoutère (Eds.), Raw and work osseous materials, pp. 20. Oxbow, Londres. En prensa.

2012. Autopodios de guanacos: un caso de equifinalidad entre lo palatable y lo preservado del registro zooarqueológico. Libro de Resúmenes II Encuentro Latinoamericano de Arqueozoología, pp. 39. Santiago de Chile.

Miotti, L. y M. Salemme

1999. Biodiversity, taxonomic richness and generalist-specialists economical systems in Pampa and Patagonia regions, Southern South America. Quaternary International 53-54: 53-68.

2004. Poblamiento, movilidad y territorios entre las sociedades cazadorasrecolectoras de Patagonia: cambios desde la transición Pleistoceno/Holoceno al Holoceno medio. Complutum 15: 177-206.

Miotti, L.; M. Vázquez y D. Hermo

1999. Piedra Museo un Yamnagoo Pleistocénico en la colonización de la meseta de Santa Cruz. El estudio de la arqueofauna. En R. Goñi (Ed.), Soplando en el Viento, pp.113-136. Universidad Nacional del Comahue- Instituto Nacional de Antropología y Pensamiento Latinoamericano, Neuquén- Buenos Aires.

Miotti, L.; D. Hermo, M. Salemme, L. Magnin y L. Marchionni 2009. Cueva Maripe y su excavación. Implicancias en los Estudios Regionales del Macizo del Deseado. En A. Austral y Tamagnini (comps.), Problemática de arqueología contemporánea, Tomo III. Pp. 1031-1035. Universidad Nacional de Río Cuarto, Río Cuarto.

Miotti, L.; D. Hermo; L. Magnin; N. Carden; L. Marchionni; A. Alcaraz; B. Mosquera; E. Terranova y M. Salemme 2007. Resolución arqueológica en la Cueva Maripe (Santa Cruz, Argentina). En F. Morello; M. Martinic; A. Prieto y G. Bahamonde (Eds.), Arqueología de FuegoPatagonia: Levantando piedras, desenterrando huesos...y develando arcanos, pp. 555-568. Ediciones CEQUA, Punta Arenas.

Miotti, L; L. Marchionni; B. Mosquera; D. Hermo y M. Fernández 
2011. Aportes metodológicos para el ajuste temporal de las ocupaciones humanas de la Cueva Maripe, Santa Cruz, Argentina. En A. F. Zangrando, R. Barberena, A. Gil and G. Neme (Eds.), Libro de resúmenes de las VIII Jornadas de Arqueología de la Patagonia, p. 54. Centro de Convenciones y Exposiciones Thesaurus, Museo de Historia Natural de San Rafael, Malargüe.

Miotti L. L., M. Osterrieth; L. Marchionni; R. Blanco; J. Rabassa 2008. "First contributions of phytolithic studies to the paleoenvironmental reconstruction of the Maripe Cave site, Santa Cruz”. Libro de resúmenes del 7th: VII International Meeting On Phytolith Research and IV Southamerican Meeting On Phytolith Research. Mar del Plata

Mondini, M.

2002. Formación del registro arqueofaunístico en abrigos rocosos de la Puna argentina. Tafonomía de carnívoros. Tesis doctoral inédita de la Facultad de Filosofía y LetrasUniversidad de Buenos Aires, Buenos Aires.

Montalvo, C. I.

2002. Root traces in fossil bones from Huayquerian (Late Miocene) faunal assemblage of Telén, La Pampa, Argentina. Acta Geológica Hispánica 37 (1): 3742.

Morín, E.

2007. Fat composition, skeletal part selection and Nunamiut decision-making. Journal of Archaeological Science 34: 69-82.

Musters, G. C.

1964. Vida entre los Patagones. Un año de excursiones por tierras no frecuentadas desde el Estrecho de Magallanes hasta el Río Negro. Ediciones Solar-Hachette, Buenos Aires. 
Paunero, R.; A. Frank; F.Skarbun; G. Rosales; M. Cueto; G. Zapata; M. Paunero; N. Lunazzi y M. Del Giorgio

2007 . Investigaciones arqueológicas en sitio Casa del Minero 1, Estancia La María, Meseta Central de Santa Cruz. En F. Morello; M. Martinic; A. Prieto y G. Bahamonde (Eds.), Arqueología de Fuego-Patagonia. Levantando piedras, desenterrando huesos... y develando arcanos, pp. 577-588. Ediciones CEQUA, Punta Arena.

Rabassa, J.; L. Miotti; L. Marchionni; R. V. Blanco y M. Salemme 2007. Informe de campaña arqueológica 2007. Excavación y geoarqueología del sitio Cueva Maripe. Informe de campaña inédito en posesión de los autores.

Rindel, D.

2009. Arqueología de momentos tardíos en el noroeste de la provincia de Santa Cruz (Argentina): una perspectiva faunística. Tesis doctoral inédita de la Facultad de Filosofía y Letras- Universidad Nacional de Buenos Aires, Buenos Aires.

Salemme, M. y L. Miotti

1987. Zooarchaeology and paleoenvironments: some examples from the Patagonian and Pampean Regions (Argentina). Quaternary of South America and Antarctic Peninsula 5: 24-47.

2008. Archaeological hunter-gatherer landscapes since the latest Pleistocene in FuegoPatagonia. En J. Rabassa (Ed.), Late Cenozoic of Patagonia and Tierra Del Fuego, pp. 437483. Elsevier, Nueva York

Shahack-Gross, R.; O. Bar-Yosef y S. Weiner

1997. Black-coloured bones in Hayonim Cave, Israel: diferentiating between burning and oxide staining. Journal of Archaeological Science 24 (5): 439-446.

Silveira, M.

1979. análisis e interpretación de los restos faunísticos de la Cueva Grande del Arroyo Feo (provincia de Santa Cruz). Relaciones de la Sociedad Argentina de Antropología XIII: 229253. 
Tambussi, C. y E. Tonni

1985. Aves del sitio arqueológico Los Toldos, Cañadón de las Cuevas. Provincia de Santa Cruz (República Argentina). Ameghiniana 22 (1-2): 69-74.

\section{Capítulo 8}

Aguerre, A. M.

1994. Restos óseos guanaco del Alero Charcamata. En C. Gradin y A. Aguerre (Eds.), Contribución a la Arqueología del Río Pinturas, provincia de Santa Cruz, Pp. 229- 243. Búsqueda de Ayllu, Concepción del Uruguay.

\section{Aguerre A. M. y M. I. Pagano}

2003. Fauna de las ocupaciones de 8.000 años de la cueva de La Martita: Guanaco. En A. Aguerre (Comp.) Arqueología y Paleoambiente en la Patagonia Santacruceña Argentina, pp. 71-85. Nuevo Offset, Buenos Aires.

Alberdi, M. T.; L. Miotti y J. L. Prado 2001. Hippidion saldiasi Roth, 1899 (Equidae, Perissodactyla), at the Piedra Museo Site (Santa Cruz, Argentina): Its Implication for the Regional Economy and Environmental Reconstruction. Journal of Archaeological Science 28: 411-419.

Barba, R. y M. Domínguez-Rodrigo

2005. The taphonomic relevance of the analysis of long limb bone shaft features and their application to implement element identification: study of bone thickness and the morphology of the medullary cavity. Journal of Taphonomy 3: 111-124.

Barberena, R.

2008. Arqueología y biogeografía humana en Patagonia Meridional. Sociedad Argentina de Antropología, Buenos Aires. 
Behrensmeyer, A. K.

1978. Taphonomic and ecologic information from bone weathering. Paleobiology 4: 150-162.

Belardi, J. B.

1999. Hay choiques en la terraza. Información tafonómica y primeras implicaciones arqueofaunísticas para Patagonia. Arqueología 9: 163-185.

Bettinger, R. L.

1991. Hunters-gatherers. Archaeological and evolutionary theory. Plenum, Nueva York.

Binford, L.

1978. Nunamiut Ethnoarchaeology. New York, Academic Press

1980 Willow smoke and dogs' tails: hunter-gatherers settlement systems and archaeological site formation. Working at archaeology. Pp. 337-356, Academic 1981. Bones: ancient men and modern myths. Academia Press, NewYork.

Blasi, A.; J. Rabassa; L. Miotti y R. Cattáneo

1997. Investigación geoarqueológica en la localidad Piedra Museo. Resúmenes del XII Congreso Nacional de Arqueología Argentina, pp. 9. Universidad Nacional de La Plata, La Plata.

Borella, F.

2002. Tafonomía regional y estudios arqueofaunísticos de cetáceos en Tierra del Fuego y Patagonia meridional. Tesis doctoral inédita de Facultad de Filosofía y Letras- Universidad Nacional de Buenos Aires, Buenos Aires.

Borrero, L. A.

1984. The archaeology of continental Patagonia. Trabajo presentado al 45th Annual Meeting of the Soviety for American Archaeology, Portland. 
1988. Tafonomía regional. En N. Ratto y A. Haber (Eds.), De Procesos, contextos y otros huesos, pp. 9-15. Facultad de Filosofía y Letras- Universidad Nacional de Buenos Aires, Buenos Aires.

1989-90. Evolución cultural divergente en la Patagonia Austral. Anales del Instituto de la Patagonia (Serie Ciencias Sociales) 19: 133-140.

1990. Fuego-Patagonia bone assemblages and the problem of comunal guanaco hunting. En L. Davis y B. Reeves (Eds.), Hunters of the recent past, pp. 373-406. Unwin Hyman, Londres.

1994-95. Arqueología de la Patagonia. Palimpsesto 4: 9-69.

2000. Ten years after: esquema para una tafonomía regional de la Patagonia meridional y norte de Tierra del Fuego. En Desde el país de los Gigantes. Perspectivas arqueológicas en Patagonia. Tomo I, pp. 183-193. Universidad Nacional de la Patagonia, Río Gallegos.

2001. Cambios, continuidades, discontinuidades: discusiones sobre arqueología Fuego Patagónica. En E. Berberián y A. Nielsen (eds), Historia Argentina Prehispánica, Tomo II, pp. 815-838. Editorial Brujas, Córdoba.

2005. The Archaeology of the Patagonian Deserts: Hunter-Gatherers in a Cold Desert. En P. Veth; M. Smith y P. Hiscock (Eds.), Desert Peoples. Archaeological Perspectives, pp. 142-158. Blackwell, Oxford.

2007. Longitudinal taphonomic studies in Tierra del Fuego, Argentina. En M. Gutiérrez; L. Miotti; G. Barrientos; G. Mengoni Goñalons y M. Salemme (Eds.), Taphonomy and Zooarchaeology in Argentina, pp. 219-233. BAR Series- Archaeopress, Oxford.

2009. Arqueología y evolución: comentarios y digresiones. En G. López y M. Cardillo (Eds.), Arqueología y evolución. Teoría, metodología y casos de estudio, pp. 7-21. Editorial SB, Buenos Aires.

\section{Borrero, L. A y N. Franco}

1997. Early Patagonian hunter-gatherers: subsistence and technology. Journal of Anthropological Research 53: 219-239.

Borrero, L. A. y F. Martin

1996. Tafonomía de carnívoros: un enfoque regional. En J. Gómez Otero (ed.), Arqueología. Sólo Patagonia, pp. 189-206. Publicación Secretaría de Cultura De ChubutCONICET, Puerto Madryn.

2012. Ground sloths and humans in southern Fuego-Patagonia: taphonomy and archaeology. Word Archeology. Vol 44 (1):102-117. 
Borromei, A. M.

2000 Análisis Polínico de la localidad arqueológica Piedra Museo. En L. Miotti, R. Paunero, M. Salemme, and G. R. Cattáneo (Eds.), Guía de Campo de la visita a las localidades arqueológicas, pp. 65-67.Taller Internacional del INQUA "La Colonización del Sur de América durante la Transición Pleistoceno/Holoceno” La Plata-Santa Cruz.

2003. Palynology at Piedra Museo Locality, Santa Cruz Province, Argentina. En L. Miotti; M. Salemme y N. Flegenheimer (Eds.), Where the South Winds Blow: Ancient Evidence of Paleo South Americans, pp. 113-120. Center for the Studies of the First AmericansTexas A\&M University Press, Texas.

Brain, C. K.

1981. The Hunters or the Hunted? An introduction to African Cave Taphonomy. The University of Chicago Press, Chicago.

Buikstra, J. E. y M. Swegle

1989. Bone modification due to burning: experimental evidence. En R. Bonnichsen y M. Sorg (Eds.), Bone Modification. Peopling of Americas, pp. 247-257. Center for the Study of the First Americans- University of Maine, Orono.

Cain, C.

2005. Using burned animal bone to look at the Middle Stone Age occupation and behavior. Journal of Archaeological Science 32: 873-884.

Cardich, A. y L. Miotti

1983. Recursos faunísticos en la economía de los cazadores-recolectores de Los Toldos (provincia de Santa Cruz, Argentina). Relaciones de la Sociedad Argentina de Antropología XV: 145-157.

Cattáneo, R.

2002. Una aproximación a la organización de la tecnología lítica entre los cazadoresrecolectores del Holoceno medio/Pleistoceno final en la Patagonia austral (Argentina). Tesis doctoral inédita de la Facultad de Ciencias Naturales-Universidad Nacional de La Plata, La Plata. 
2005. Tecnología lítica en la localidad arqueológica Piedra Museo (Santa Cruz, Argentina) Relaciones de la Sociedad Argentina de Antropología XXX p. 79-103. Buenos Aires.

Claraz, J.

1988. Diario de viaje de exploración al Chubut 1865-1866. Marymar, Buenos Aires.

Courty, M. A.; P. Goldberg y R. Macphail

1989. Soils and Micromorphology in Archaeology. Cambridge University Press, Cambridge.

Cruz, I.

2003. Paisajes tafonómicos de restos de Aves en el sur de Patagonia continental. Aportes para la interpretación de conjuntos avifaunísticos en registros arqueológicos del Holoceno. Tesis doctoral inédita de Facultad de Filosofía y Letras- Universidad Nacional de Buenos Aires, Buenos Aires

\section{De Nigris, M.}

2004. El consumo en cazadores-recolectores. Un ejemplo zooarqueológico de Patagonia meridional. Sociedad Argentina de Antropología, Buenos Aires. 2008. Modelos de transporte etnoarqueológicos: sobre su aplicabilidad y pertinencia en el interior de Patagonia. En A. Acosta; D. Loponte y L. Mucciolo (Comps.), Estudios tafonómicos y zooarqueológicos I, pp. 37-55- INAPL-AINA, Buenos Aires.

Durán, V.; A. Gil; G. Neme y A. Gasco 2003. El Verano: Ocupaciones de 8.900 años en la Cueva 1 (Santa Cruz, Argentina). En A. Aguerre (comp.), Arqueología y Paleoambiente en Patagonia Santacruceña Argentina, pp. 93- 120. Nuevo Offset, Buenos Aires.

Fernández Jalvo, Y. y C. Perales Piquer 1990. Análisis macroscópico de huesos quemados experimentalmente. Comunicaciones de la Reunión de Tafonomía y Fosilisación, pp. 105-114. Madrid. 
Frank, A.

2011. Tratamiento térmico y manejo del fuego en sociedades cazadorasrecolectoras de la Meseta Central de Santa Cruz. Tesis doctoral inédita de la Facultad de Ciencias Naturales- Universidad Nacional de La Plata, La Plata.

\section{Giardina, M.; D. Hermo; L. Miotti y M. Vázquez}

2000. Capítulo. 4.5. Resolución e integridad arqueológica del Componente inferior de Piedra Museo. En L. Miotti; R. Paunero; M. Salemme y R. Cattáneo (Eds.). Guía de Campo de la visita a las Localidades arqueológicas. Taller Internacional "La colonización del Sur de América durante la transición Pleistoceno/Holoceno", pp. 79-83. Servicoop, La Plata.

\section{Goñi, R.}

2010. Cambio climático y poblamiento humano durante el Holoceno tardío en Patagonia meridional. Una perspectiva arqueológica. Tesis doctoral inédita de la Facultad de Filosofía y Letras-Universidad de Buenos Aires, Buenos Aires.

Grayson, D.

1984. Quantitative Zooarchaeology: topics in the analysis of archaeological faunas. Academics Press, Orlando.

\section{Gutiérrez, M. A.}

2004. Análisis tafonómicos en el Área Interserrana, provincia de Buenos Aires. Tesis doctoral inédita de la Facultad de Ciencias Naturales- Universidad Nacional de La Plata, La Plata.

Gutiérrez, M. A. y G. Martínez

2008. Trends in the faunal human exploitation during the late Pleistocene and early Holocene in the Pampean region (Argentina). Quaternary International 191: 53-68.

Gutiérrez, M. A.; C. Kaufmann; M. González; A. Massigoge y M. C. Álvarez 2010. Intrataxonomic variability in metapodial and femur bone density related to age in guanaco (Lama guanicoe). Zooarchaeological and taphonomical implications. Journal of Archaeological Science 37(12): 3226-3238. 
Izeta, A. D.

2004. Zooarqueología del sur de los valles Calchaquíes. Estudio de conjuntos faunísticos del Período Formativo. Tesis doctoral inédita de la Facultad de Ciencias NaturalesUniversidad Nacional de La Plata, La Plata.

Koyama, S. y J. Uchiyama

2006. Why "beyond affluent foragers"? Looking back at the original affluent foragers concept. En C. Grier, J. Kim y J. Uchiyama (Eds.), Beyond Affluent Foragers: rethinking hunter-gatherer complexity. Proceedings of the 9th Conference of the International Council of Archaeozoology-Durham, pp. 1-3. Oxbow Books, Oxford.

\section{L’Heureux, L. y L. A. Borrero}

2002. Pautas para el reconocimiento de conjuntos óseos antrópico y no-antrópicos de guanaco en Patagonia. Intersecciones en Antropología 3:29-40.

López- González, N.; J. Borrego; J. A. Morales y B. Carro

2006. Variación estacional de los contenidos en carbono orgánico, inorgánico y azufre en los sedimentos del estuario de los ríos Tinto y Odiel (SO España). Geogaceta 40: 295-298.

\section{Lyman, R. L.}

1992. Anatomical considerations of utility curves in zooarchaeology. Journal of Archaeological Science 19: 7-22.

1994. Vertebrate Taphonomy. Cambridge University Press, New York.

Marchionni, L. y M. Vázquez

2012. New data on exploited Pleistocene fauna at Piedra Museo (Central Plateau of Santa Cruz Province, Argentina). En L. Miotti; M. Salemme; N. Flegenheimer y T. Goebel (Eds.), Southbound: Late Pleistocene Peopling of Latin America, pp. 139-142. Center for the Study of the First Americans, Texas.

Marean, C. W. 1995. Of taphonomy and zooarchaeology. Evolutionary Anthropology 4 (2): 64-72. 
Marean, C. W. y N. Cleghorn

2003. Large mammal skeletal element transport: apllying foraging theory in a complex taphonomic system. Journal of Taphonomy 1 (1): 15-42.

Marín Arroyo, A. B.; M. D. Landete Ruiz; G. Vidal Bernabeu; R. Seva Román; M. R. González Morales y L. G. Straus

2008. Archaeological implications of human-derived manganese coatings: a study of blackened bones in El Mirón Cave, Cantabrian Spain. Journal of Archaeological Science 35 (3), 801-813.

Martin, F.

2008. Tafonomía y paleoecología de la transición Pleistoceno-Holoceno en FuegoPatagonia: Interacción entre poblaciones humanas y de carnívoros y su importancia como agentes en la formación del registro fósil. Tesis doctoral inédita de la Facultad de Ciencias Naturales- Universidad Nacional de La Plata. La Plata.

Martin, F. y L. A. Borrero

1997. A Puma lair in southern Patagonia: implications for the archaeological record. Current anthropology 38(3): 453-461.

Martínez, G. y M. Gutiérrez

2004. Tendencias en la explotación humana de la fauna durante el Pleistoceno finalHoloceno en la Región Pampeana (Argentina). En G. L. Mengoni Goñalons (Ed.), Zooarchaeology of South America, pp. 81-98. BAR International Series, Oxford.

Massigoge A.; M. González; C. Kaufmann y M. Gutiérrez 2010. Observaciones actualísticas sobre meteorización ósea en restos esqueletales de guanaco. En M. Berón; D. Luna; M. Bonomo; C. Montalvo; C. Aranda y M. Carrera Aizpitarte (Eds.), Mamül Mapu. Pasado y presente desde la arqueología pampeana, Tomo I, pp. 309-322. Libros del Espinillo, Buenos Aires. 
Mengoni Goñalons, G. L.

1976-80. Los materiales óseos de la Cueva 2 de Los Toldos (Expedición Menghin), y una aproximación a la metodología de análisis de Restos Faunísticos. RUNA XIII (1-2): 59-68.

1983. Prehistoric utilisation of faunal resources in arid Argentina. En J. Clutton-Brock y C. Grigson (Eds.), Animals and Archaeology: I. Hunter and their prey, pp. 325-335. BAR International Series, Oxford.

1988. El estudio de huellas en arqueofaunas: una vía para reconstruir situaciones interactivas en contextos arqueológicos: aspectos teóricos-metodológicos y técnicas de análisis. En R. Ratto y A. F. Haber (Eds.), De Procesos, Contextos y otros Huesos, pp. 1728. Facultad de Filosofía y Letras- Universidad Nacional de Buenos Aires, Buenos Aires. 1999. Cazadores de guanacos de la estepa patagónica. Sociedad Argentina de Antropología, Buenos Aires.

\section{Mengoni Goñalons, G. L. y M. Silveira}

1976. Análisis e interpretación de los restos faunísticos de la cueva de las Manos Estancia Alto Río Pinturas (Provincia de Santa Cruz). Relaciones de la Sociedad Argentina de Antropología X: 261-270.

Meltzer, D.

2003. Lessons in landscape learning. En M. Rockman y J. Steele (Eds.), Colonization of unfamiliar landscapes. The archaeology of adaptation, pp. 222-241. Routledge, Londres.

\section{Miotti, L.}

1992. Paleoindian occupation at Piedra Museo Locality, Patagonian Region, Argentina. Current Research in the Pleistocene 9: 30-32.

1995. Piedra Museo Locality: a special place in the New World. Current Research in the Pleistocene 12: 37-40.

1996. Piedra Museo (Santa Cruz): nuevos datos para el debate de la ocupación pleistocénica en Patagonia. En J. Gómez Otero (Ed.), Arqueología, sólo Patagonia, pp. 27-38. Publicación Secretaría de Cultura De Chubut- CONICET, Puerto Madryn. 
1998. Zooarqueología de la meseta central y costa de la provincia de Santa Cruz: Un enfoque de las estrategias adaptativas aborígenes y los paleoambientes. Imprenta del Museo Municipal de Historia Natural de San Rafael, San Rafael.

2003. South America. A paradox for building images of the colonization of the New World. En L. Miotti y M. Salemme (Eds.), South America, long and winding roads for the First Americans at the Pleistocene/Holocene Transition, Quaternary International 109-110: 147-173.

2004. Quandary: the Clovis phenomenon, the first Americans, and the view from the Patagonia region. En B. Lepper (Ed.), New Perspectives on the First Americans, pp. 31-36. Texas A\&M University Press- Center for the Study of First Americans, Texas.

Miotti, L. y R. Cattáneo. 2003. Pleistocene/Holocene transition at Piedra Museo and surrounding region. En L. Miotti, M. Salemme y N. Flegenheimer (Eds.), Where the south winds blow: ancient evidence of paleo South Americans, pp. 105-113. Center for the Studies of the First Americans- Texas A\&M University Press, Texas.

Miotti, L. y L. Marchionni

2011. Beyond tools: bone as raw material for tools in Central Plateau of Santa Cruz, Argentinian Patagonia. En A. Choyke; S. O'Connor y C. Vercoutère (Eds.), Raw and work osseous materials, pp. 20. Oxbow, Londres. En prensa.

Miotti, L. y M. Salemme

1999. Biodiversity, taxonomic richness and generalist-specialists economical systems in Pampa and Patagonia regions, Southern South America. Quaternary International 53-54: 53-68.

2004. Poblamiento, movilidad y territorios entre las sociedades cazadorasrecolectoras de Patagonia: cambios desde la transición Pleistoceno/Holoceno al Holoceno medio. Complutum 15: 177-206.

2005. Hunting and butchering events at the Pleistocene/Holocene transition in Piedra Museo: An example of adaptation strategies of the first colonizers of Patagonia. En R. Bonnichsen, B. Leppers, D. Stanford y M. Waters (Eds.), 
Paleoamerican origins: Beyond Clovis, pp. 209-220. Texas A\&M University Press, Texas.

Miotti, L. y E. Tonni

1996. Rheidos del sitio arqueológico AEP-1 de Piedra Museo y la meseta central de Santa Cruz y sus implicancias paleoambientales. Póster inédito presentado en las III Jornadas de Arqueología de Patagonia, Bariloche.

Miotti, L.; D. Hermo; L. Magnin; N. Carden; L. Marchionni; A. Alcaraz; B. Mosquera; E. Terranova y M. Salemme 2007. Resolución arqueológica en la Cueva Maripe (Santa Cruz, Argentina). En F. Morello; M. Martinic; A. Prieto y G. Bahamonde (Eds.), Arqueología de FuegoPatagonia: Levantando piedras, desenterrando huesos...y develando arcanos, pp. 555-568. Ediciones CEQUA, Punta Arenas.

Miotti, L.; M. Salemme y A. Menegaz

1988. El manejo de los recursos faunísticos durante el Pleistoceno final y Holoceno temprano en Pampa y Patagonia. Actas del IX Congreso Nacional de Arqueología Argentina, pp. 102-118. Instituto de Ciencias Antropológicas- Facultad de Filosofía y Letras- UBA, Buenos Aires.

Miotti, L., M. Salemme y J. Rabassa

2000. Cronología radiocarbónica. En L. Miotti; R. Paunero; M. Salemme y R. Cattáneo (Eds.). Guía de Campo de la visita a las Localidades arqueológicas. Taller Internacional "La colonización del Sur de América durante la transición Pleistoceno/Holoceno”, pp. 83-85. Servicoop, La Plata.

2003. Radiocarbon chronology at Piedra Museo Locality. En L. Miotti; M Salemme y N. Flegenheimer (Eds.), Where the South Winds Blow: Ancient Evidence of Paleo South Americans, pp. 99-104. Center for the Studies of the First AmericansTexas A \& M University Press, Texas. 


\section{Miotti, L.; M. Vázquez y D. Hermo}

1999. Piedra Museo un Yamnagoo Pleistocénico en la colonización de la meseta de Santa Cruz. El estudio de la arqueofauna. En R. Goñi (ed.), Soplando en el Viento, pp.113-136. Universidad Nacional del Comahue- Instituto Nacional de Antropología y Pensamiento Latinoamericano. Neuquén- Buenos Aires.

Mondini, M.

1995. Artiodactyl prey transport by foxes in Puna rock shelters. Current Anthropology 36(3):520-524.

Montalvo, C. I.

2002. Root traces in fossil bones from Huayquerian (Late Miocene) faunal assemblage of Telén, La Pampa, Argentina. Acta Geológica Hispánica 37 (1): $37-$ 42.

Morín, E. 2007. Fat composition, skeletal part selection and Nunamiut decision- making. Journal of Archaeological Science 34: 69-82.

Musters, G. C.

1964. Vida entre los Patagones. Un año de excursiones por tierras no frecuentadas desde el Estrecho de Magallanes hasta el Río Negro. Ediciones Solar- Hachette, Buenos Aires.

\section{Pagano, M. I. y A. Aguerre}

2001. Desgaste dentario y determinación de edad en guanacos arqueológicos: una puesta al día. En G. Mengoni Goñalons; D. Olivera y H. Yacobaccio (Eds.), El uso de los camélidos a través del tiempo, pp. 203-220. Editorial Tridente, Buenos Aires. 
Panza, J. L.

2001. Hoja Geológica 4769-IV Monumento Natural Bosques Petrificados, Provincia de Santa Cruz. Boletín del SEGEMAR 258. Instituto de Geología y Recursos Minerales, Buenos Aires.

Paunero, R.; A. Frank; F.Skarbun; G. Rosales; M. Cueto; G. Zapata; M. Paunero; N. Lunazzi y M. Del Giorgio

2007. Investigaciones arqueológicas en sitio Casa del Minero 1, Estancia La María, Meseta Central de Santa Cruz. En F. Morello; M. Martinic; A. Prieto y G. Bahamonde (Eds.), Arqueología de Fuego-Patagonia. Levantando piedras, desenterrando huesos... y develando arcanos, pp. 577-588. Ediciones CEQUA, Punta Arena.

Perkins, D. y P. Daly

1968. A hunter's village in Neolithic Turkey. Scientific American 219(5): 96-106.

Politis, G.

1984. Arqueología del área Interserrana Bonaerense. Tesis doctoral inédita de la Facultad de Ciencias Naturales- Universidad Nacional de La Plata, La Plata.

Politis, G. G. y P. G. Messineo

2008. The Campo Laborde site: New evidence for the Holocene survival of Pleistocene megafauna in the Argentine Pampas. Quaternary International 191: 98114.

Rabassa, J.

1997. Geological and stratigraphical observations at AEP-1, Piedra Museo Locality. Informe de Campaña inédito en posesión de los autores.

Rindel, D.

2009. Arqueología de momentos tardíos en el noroeste de la provincia de Santa Cruz (Argentina): una perspectiva faunística. Tesis doctoral inédita de la Facultad de Filosofía y Letras- Universidad Nacional de Buenos Aires, Buenos Aires. 


\section{Rockman, M.}

2003. Knowledge and learning in the archaeology of colonization. En M. Rockman y J. Steele (Eds.), Colonization and unfamiliar landscape. The archaeology of adaptation, pp. 324. Routledge, Londres.

Salemme, M. y L. Miotti

1987. Zooarchaeology and paleoenvironments: some examples from the Patagonian and Pampean Regions (Argentina). Quaternary of South America and Antarctic Peninsula 5: $24-47$.

1998 The status of rheids in Patagonia: environmental approach and economic interpretation at the transition Late Pleistocene/Early Holocene. Resúmenes del 8th International Conference of the International Council for Archaeozoology (ICAZ' 98), pp. 249. Vancouver, Canadá.

Shahack-Gross, R.; O. Bar-Yosef y S. Weiner

1997. Black-coloured bones in Hayonim Cave, Israel: diferentiating between burning and oxide staining. Journal of Archaeological Science 24 (5): 439-446.

\section{Shipman, P.; G. Foster y M. Schoeninger}

1984. Burnt bones and teeth: an experimental study of color, morphology, crystal structure and shrinkage. Journal of Archaeological Science, 11: 307-325.

\section{Silveira, M.}

1979. Análisis e interpretación de los restos faunísticos de la Cueva Grande del Arroyo Feo (provincia de Santa Cruz). Relaciones de la Sociedad Argentina de Antropología XIII: 229253.

Speth, J. D.

1983. Bone kills and bone counts: decision making by ancient hunters. University of Chicago Press, Chicago.

Tambussi, C. y E. Tonni

1985. Aves del sitio arqueológico Los Toldos, Cañadón de las Cuevas. Provincia de Santa Cruz (República Argentina). Ameghiniana 22 (1-2): 69-74. 
Tonni, E. P.

1992. Mamíferos del Holoceno en la provincia de Buenos Aires. En M. Iriondo (Ed.), El Holoceno en la Argentina, pp. 64-78. CADINQUA, Buenos Aires.

Todd, L.

1987. Taphonomy of The Horner II Bone Bed. En G. Frison y L. Todd (Eds.), The Horner Site: The Type Site of the Cody Cultural Complex, pp. 107-199. Academic Press,U.S.A.

Zárate, M., A. Blasi, y J. Rabassa 2000. Geoarqueología de la localidad Piedra Museo. En L. Miotti, R. Paunero, M. Salemme y G. R. Cattáneo (Eds.), Guía de Campo de la visita a las localidades arqueológicas. Taller Internacional "La Colonización del Sur de América durante la Transición Pleistoceno/Holoceno”, pp. 56.64. Servicoop, La Plata.

\section{Capítulo 9.}

Aguerre A. M. y M. I. Pagano

2003. Fauna de las ocupaciones de 8.000 años de la cueva de La Martita: Guanaco. En A. Aguerre (Comp.) Arqueología y Paleoambiente en la Patagonia Santacruceña Argentina, pp. 71-85. Nuevo Offset, Buenos Aires.

Aschero, C.

1981-82. Nuevos datos sobre la arqueología del Cerro Casa de Piedra, sitio CCP 5 (Parque Nacional Perito Moreno; Santa Cruz, Argentina). Relaciones de la Sociedad Argentina de Antropología XIV (2): 267-284.

Behrensmeyer, A. K.

1991. Terrestrial vertebrate accumulations. En P. Allison y D. Briggs (Eds.), Taphonomy: releasing the data locked in the fossil record, Topics in Geobiology 9: 291-335. 


\section{Belardi, J. B.; T. J. Bourlot y D. Rindel}

2010. Representación diferencial de diáfisis y epífisis de huesos largos de guanaco (Lama guanicoe) en contextos arqueológicos de médanos en Patagonia austral: el sitio Río Meseta 1 (lago Tar, provincia de Santa Cruz). En M. A. Gutiérrez; M De Nigris; P. Fernández; M. Giardina; A. Gil; A. Izeta; G. Neme y H. Yacobaccio (Eds.), Zooarqueología a principios del siglo XXI: aportes teóricos, metodológicos y casos de estudio, pp 119-131. Ediciones del Espinillo, Buenos Aires.

Bettinger, R. L.

1991. Hunters-gatherers. Archaeological and evolutionary Theory. Plenum, Nueva York.

Borrero, L. A.

1986. La economía prehistórica de los habitantes del Norte de la Isla Grande de Tierra del Fuego. Tesis doctoral inédita de la Facultad de Filosofía y LetrasUniversidad Nacional de Buenos Aires, Buenos Aires.

1989-90. Evolución cultural divergente en la Patagonia Austral. Anales del Instituto de la Patagonia (Serie Ciencias Sociales) 19: 133-140.

1990. Fuego-Patagonia bone assemblages and the problem of comunal guanaco hunting. En L. Davis y B. Reeves (Eds.), Hunters of the recent past, pp. 373-406. Unwin Hyman, Londres.

1994-95. Arqueología de la Patagonia. Palimpsesto 4: 9-69.

2009. Arqueología y evolución: comentarios y digresiones. En G. López y M. Cardillo (Eds.), Arqueología y evolución. Teoría, metodología y casos de estudio, pp. 7-21. Editorial $\mathrm{SB}$, Buenos Aires.

Boutlot, T.; D. Rindel y A. Aragone

2009. La fractura transversa/marcado perimetral en sitios a cielo abierto durante el holoceno tardío en el noroeste de Santa Cruz. En M. Salemme; F. Santiago; M. Álvarez; E. Piana; M. Vázquez y M. Mansur (Eds.), Arqueología de la Patagonia. Una mirada desde el último confín, Tomo 2, pp. 693-706. Editorial Utopias, Ushuaia. 
Carden, N.

2009. Imágenes a través del tiempo: arte rupestre y construcción social del paisaje en la meseta central de Santa Cruz. Sociedad Argentina de Antropología, Buenos Aires.

Claraz, J.

1988. Diario de viaje de exploración al Chubut 1865- 1866. Marymar, Buenos Aires.

\section{De Nigris, $M$.}

2004. El consumo en cazadores-recolectores. Un ejemplo zooarqueológico de Patagonia meridional. Sociedad Argentina de Antropología, Buenos Aires.

De Nigris, M. y G. Mengoni Goñalons

2004. El guanaco como fuente de carne y grasas en Patagonia. En T. Civalero; P. Fernández y A. G. Guráieb (Eds.), Contra viento y marea. Arqueología de Patagonia, pp. 469-476. Instituto Nacional de Antropología y Pensamiento Latinoamericano, Buenos Aires.

Frank, A.

2011. Tratamiento térmico y manejo del fuego en sociedades cazadorasrecolectoras de la Meseta Central de Santa Cruz. Tesis doctoral inédita de la Facultad de Ciencias Naturales- Universidad Nacional de La Plata, La Plata. Grayson 1991

Gutiérrez, M. A.; C. Kaufmann; M. González; A. Massigoge y M. C. Álvarez. 2010. Intrataxonomic variability in metapodial and femur bone density related to age in guanaco (Lama guanicoe). Zooarchaeological and taphonomical implications. Journal of Archaeological Science 37(12): 3226-3238.

Hajduk, A. y M. Lezcano.

2005. Un "nuevo-viejo" integrante del elenco de instrumentos óseos de Patagonia: los machacadores óseos. Magallania 33 (1): 63-80. 


\section{Hermo, D.}

2008. Los cambios en la circulación de las materias primas líticas en ambientes mesetarios de Patagonia. Una aproximación para la construcción de los paisajes arqueológicos de las sociedades cazadoras-recolectoras. Tesis doctoral inédita de la Facultad de Ciencias Naturales- Universidad Nacional de La Plata, La Plata.

Koyama, S. y J. Uchiyama 2006. Why "beyond affluent foragers"? Looking back at the original affluent foragers concept. En C. Grier; J. Kim y J. Uchiyama (Eds.), Beyond Affluent Foragers: rethinking hunter-gatherer complexity. Proceedings of the 9th Conference of the International Council of Archaeozoology-Durham, pp. 1-3. Oxbow Books, Oxford.

Lyman, R. L.

1994. Vertebrate Taphonomy. Cambridge University Press, New York.

Magnin, L.

2010. Distribuciones arqueológicas en la meseta central de Santa Cruz: Implicancias para los estudios de uso del espacio y movilidad de sociedades cazadoras recolectoras. Tesis doctoral inédita de la Facultad de Ciencias NaturalesUniversidad Nacional de La Plata, La Plata.

\section{Martínez, G. y M. Gutiérrez}

2004. Tendencias en la explotación humana de la fauna durante el Pleistoceno finalHoloceno en la Región Pampeana (Argentina). En G. L. Mengoni Goñalons (Ed.), Zooarchaeology of South America, pp. 81-98. BAR International Series, Oxford.

Massigoge, A.; M. González; C. Kaufmann y M. Gutiérrez, 2010. Observaciones actualísticas sobre meteorización ósea en restos esqueletales de guanaco. En M. Berón; D. Luna; M. Bonomo; C. Montalvo; C. Aranda y M. Carrera Aizpitarte (Eds.), Mamül Mapu. Pasado y presente desde la arqueología pampeana, Tomo I, pp. 309-322. Libros del Espinillo, Buenos Aires. 
Mengoni Goñalons, G. L.

1999. Cazadores de guanacos de la estepa patagónica. Sociedad Argentina de Antropología, Buenos Aires.

Miotti, L.

1998. Zooarqueología de la meseta central y costa de la provincia de Santa Cruz: Un enfoque de las estrategias adaptativas aborígenes y los paleoambientes. Imprenta del Museo Municipal de Historia Natural de San Rafael, San Rafael.

Miotti, L. y L. Marchionni

2011. Beyond tools: bone as raw material for tools in Central Plateau of Santa Cruz, Argentinian Patagonia. En A. Choyke; S. O'Connor y C. Vercoutère (Eds.), Raw and work osseous materials, pp. 20. Oxbow, Londres. En prensa.

Miotti, L. y M. Salemme

1999. Biodiversity, taxonomic richness and generalist-specialists economical systems in Pampa and Patagonia regions, Southern South America. Quaternary International 53-54: 53-68.

2004. Poblamiento, movilidad y territorios entre las sociedades cazadorasrecolectoras de Patagonia: cambios desde la transición Pleistoceno/Holoceno al Holoceno medio. Complutum 15: 177-206.

2005. Hunting and butchering events at the Pleistocene/Holocene transition in Piedra Museo: An example of adaptation strategies of the first colonizers of Patagonia. En R. Bonnichsen, B. Leppers, D. Stanford y M. Waters (Eds.), Paleoamerican origins: Beyond Clovis, pp. 209-220. Texas A\&M University Press, Texas.

Miotti, L.; M. Vázquez y D. Hermo.

1999. Piedra Museo un Yamnagoo Pleistocénico en la colonización de la meseta de Santa Cruz. El estudio de la arqueofauna. En R. Goñi (ed.), Soplando en el Viento, pp.113-136. Universidad Nacional del Comahue- Instituto Nacional de Antropología y Pensamiento Latinoamericano. Neuquén- Buenos Aires. 
Miotti, L.; D. Hermo; L. Magnin; N. Carden; L. Marchionni; A. Alcaraz; B. Mosquera; E. Terranova y M. Salemme 2007. Resolución arqueológica en la Cueva Maripe (Santa Cruz, Argentina). En F. Morello; M. Martinic; A. Prieto y G. Bahamonde (Eds.), Arqueología de FuegoPatagonia: Levantando piedras, desenterrando huesos...y develando arcanos, pp. 555-568. Ediciones CEQUA, Punta Arenas.

Muñoz, A. S. y J. B. Belardi

1998. El marcado perimetral en los huesos largos de guanaco de Cañadon Leona (Colecció Junius Bird): implicaciones arqueofaunísticas para Patagonia Meridional. Anales del Instituto de la Patagonia, Serie Ciencias Sociales 26: 107-118.

Musters, G. C.

1964. Vida entre los Patagones. Un año de excursiones por tierras no frecuentadas desde el Estrecho de Magallanes hasta el Río Negro. Ediciones Solar- Hachette, Buenos Aires.

Paunero, R.

2003 a. The Cerro Tres Tetas (C3T) locality in the Central Plateau of Santa Cruz, Argentina. En L. Miotti, M. Salemme y N. Flegenheimer (Eds.), Where the South Winds Blow: Ancient Evidence of Paleo South Americans, pp. 33-40. Center for the Studies of the First Americans-Texas A \& M University Press, Texas.

2003 b. The presence of a Pleistocene colonizing culture in La Maria archaeological locality, Casa del Minero 1. En L. Miotti, M. Salemme y N. Flegenheimer (Eds.), Where the South Winds Blow: Ancient Evidence of Paleo South Americans, pp. 127-132. Center for the Study of the First Americans- Texas A\&M University Press, Texas.

2009. La colonización humana de la Meseta Central de Santa Cruz durante el Pleistoceno final: indicadores arqueológicos, referentes estratigráficos y nuevas evidencias. En M. Salemme; F. Santiago; M. Álvarez; E. Piana; M. Vázquez y M. Mansur (Eds.), Arqueología de la Patagonia. Una mirada desde el último confín, Tomo 1, pp. 85-100. Editorial Utopias, Ushuaia. 
Paunero, R. S.; M. F. Paunero y D. Ramos.

2010. Artefactos óseos en componentes del Pleistoceno final de las Localidades La María y Cerro Tres Tetas, Santa Cruz, Argentina. En M. Gutiérrez, M. De Nigris, P. Fernández, M. Giardina, A. Gil, A. Izeta, G. Neme y H. Yacobaccio (Eds.), Zooarqueología a principios del siglo XXI. Aportes teóricos, metodológicos y casos de estudio, pp. 459-466. Ediciones del Espinillo, Buenos Aires.

Paunero, R.; A. Frank; F.Skarbun; G. Rosales; M. Cueto; G. Zapata; M. Paunero; N. Lunazzi y M. Del Giorgio

2007. Investigaciones arqueológicas en sitio Casa del Minero 1, Estancia La María, Meseta Central de Santa Cruz. En F. Morello; M. Martinic; A. Prieto y G. Bahamonde (Eds.), Arqueología de Fuego-Patagonia. Levantando piedras, desenterrando huesos... y develando arcanos, pp. 577-588. Ediciones CEQUA, Punta Arena.

Politis, G. G. y N. J. Saunders

2002. Archaeological correlates of ideological activity: food taboos and spiritanimals in an Amazonian hunter-gatherer society. En P. Miracle y N. Milner (Eds.), Consuming passions and patterns of consumption, pp. 113-130. McDonald Institute Monographs- University of Cambridge, Cambridge.

Rindel, D.

2009. Arqueología de momentos tardíos en el noroeste de la provincia de Santa Cruz (Argentina): una perspectiva faunística. Tesis doctoral inédita de la Facultad de Filosofía y Letras- Universidad Nacional de Buenos Aires, Buenos Aires. Salemme y Miotti 2008

Santiago, F.

2010. La ocupación humana en el norte de Tierra del Fuego durante el Holoceno Medio y Tardío. Su vinculación con el paisaje. Tesis Doctoral inédita. Facultad de Ciencias SocialesUNCEN, Olavarría, Argentina 
Scheinsohn, V.

2010. Down to the bone: tracking prehistoric bone technology in Southern Patagonia. En A. Legrand-Pineau, I. Sidera, N. Buc, E. David y V. Scheinsohn (Eds.), Ancient and modern bone artefacts from America to Russia. Cultural, technological and functional signature, pp. 295-302. BAR International Series, Oxford.

Silveira, M.

1979. Análisis e interpretación de los restos faunísticos de la Cueva Grande del Arroyo Feo (provincia de Santa Cruz). Relaciones de la Sociedad Argentina de Antropología XIII: 229253.

Tambussi, C. y E. Tonni

1985. Aves del sitio arqueológico Los Toldos, Cañadón de las Cuevas. Provincia de Santa Cruz (República Argentina). Ameghiniana 22 (1-2): 69-74.

Willig, J.

1991. Clovis Technology and adaptations in far Western North American: Regional pattern and environmental context. En R. Bonichsen y K. Turnmire (Eds.), Clovis: origins and adaptations, 91-118. Center for the Study of the First Americans- Oregon State University, Corvallis.

\section{Capítulo: 10}

\section{Borrero, L. A. y F. Martin}

2012. Ground sloths and humans in southern Fuego-Patagonia: taphonomy and archaeology. Word Archeology. Vol 44 (1):102-117.

\section{Giardina, M.; D. Hermo; L. Miotti y M. Vázquez}

2000. Capítulo. 4.5. Resolución e integridad arqueológica del Componente inferior de Piedra Museo. En L. Miotti; R. Paunero; M. Salemme y R. Cattáneo (Eds.). Guía de Campo de la visita a las Localidades arqueológicas. Taller Internacional "La colonización del Sur de América durante la transición Pleistoceno/Holoceno", pp. 79-83. Servicoop, La Plata. 
Miotti, L.; M. Vázquez y D. Hermo.

1999. Piedra Museo un Yamnagoo Pleistocénico en la colonización de la meseta de Santa Cruz. El estudio de la arqueofauna. En R. Goñi (ed.), Soplando en el Viento, pp.113-136. Universidad Nacional del Comahue. Instituto Nacional de Antropología y Pensamiento Latinoamericano. Neuquén, Buenos Aires.

Miotti, L. y L. Marchionni

2011. The study of Archaeofauna at Middle Holocene in AEP-1 rockshelter, Santa Cruz, Argentina: Taphonomic implications. En Quaternary International Vol. 245. pp 148-158.

Zárate, M., A. Blasi, y J. Rabassa

2000. Geoarqueología de la localidad Piedra Museo. En L. Miotti, R. Paunero, M. Salemme y G. R. Cattáneo (Eds.), Guía de Campo de la visita a las localidades arqueológicas. Taller Internacional "La Colonización del Sur de América durante la Transición Pleistoceno/Holoceno”, pp. 56.64. Servicoop, La Plata. 